Portland State University

PDXScholar

Winter 1-26-2014

\title{
Development of a Steady-State River Hydrodynamic and Temperature Model Based on CE-QUAL-W2
}

Wenwei Xu

Portland State University

Follow this and additional works at: https://pdxscholar.library.pdx.edu/open_access_etds

Part of the Water Resource Management Commons

Let us know how access to this document benefits you.

\section{Recommended Citation}

Xu, Wenwei, "Development of a Steady-State River Hydrodynamic and Temperature Model Based on CEQUAL-W2" (2014). Dissertations and Theses. Paper 1619.

https://doi.org/10.15760/etd.1618

This Thesis is brought to you for free and open access. It has been accepted for inclusion in Dissertations and Theses by an authorized administrator of PDXScholar. Please contact us if we can make this document more accessible: pdxscholar@pdx.edu. 
Development of a Steady-State River Hydrodynamic and Temperature Model

\section{Based on CE-QUAL-W2}

by

Wenwei Xu

A thesis submitted in partial fulfillment of the requirements for the degree of

Master of Science

in

Civil and Environmental Engineering

Thesis Committee:

Scott A. Wells, Chair

Chris J. Berger

Stefan A. Talke

Portland State University

2014 
(C) 2014 Wenwei Xu 


\begin{abstract}
CE-QUAL-W2 is a 2-D hydrodynamic and water quality model that has been applied to reservoirs, lakes, river systems, and estuaries throughout the world. However, when this model is applied for shallow systems, this model requires a long calculation time to maintain numerical stability, compared to applications of reservoirs or deeper river systems.
\end{abstract}

To solve this problem, a new hydrodynamic and temperature model was built based on the framework of CE-QUAL-W2 but that allows for steady-state hydrodynamic computations. By calculating the hydrodynamics at steady-state, the time step for stability is relaxed and simulations can proceed at much higher time steps. The rest of the model framework is still used for water quality state variables, in this case, temperature. The algorithm used for computing the water surface elevation is Manning's equation.

This thesis study is one part of the Willamette Water 2100 project (Santelmann et al., 2012), which examines hydrological, ecological, and human factors affecting water scarcity in the Willamette River Basin. This study included three stages: (1) Convert six existing CE-QUAL-W2 V3.1 models into a newer version: CE-QUAL-W2 V3.7. (2) Develop the steady-state model code in FORTRAN. (3) Test the steady-state model on three river systems in the Willamette River Basin at Year 2001 and 2002.

The result proved that the steady-state model could reduce the computing time by $90 \%$ for river applications, while predicting dynamic river temperature with high accuracy at a two-minute time scale. This new model will be employed to simulate the future of the 
Willamette River System at a decadal or centennial timescales, addressing river temperature concerns and fish habitat issues. 


\section{Table of Contents}

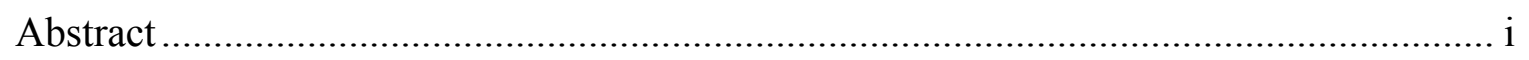

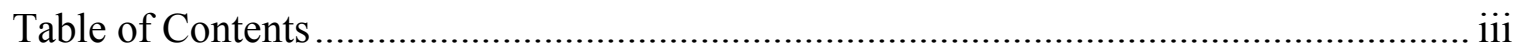

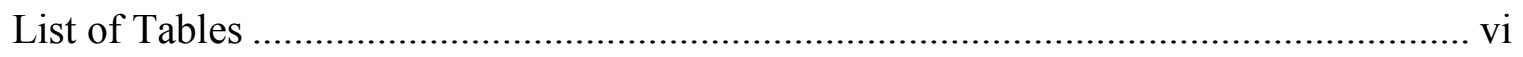

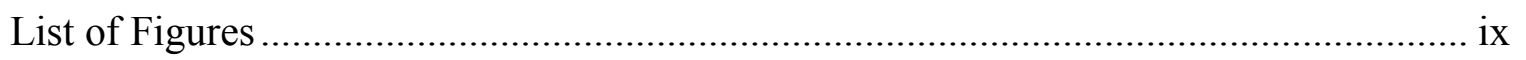

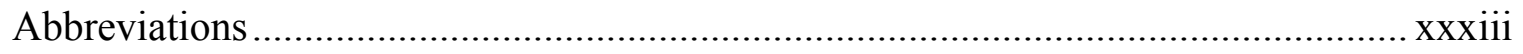

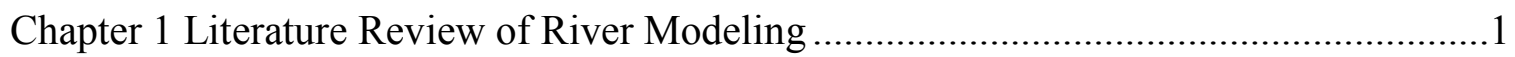

1.1 Hydrodynamic Models and Temperature Models .................................................

1.1.1 The Importance of River Temperature Models .................................................1

1.1.2 River Temperature Models Classification .........................................................

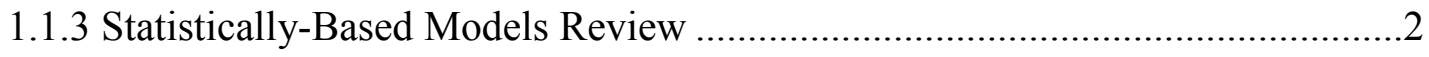

1.1.4 Physically-Based Models Review................................................................

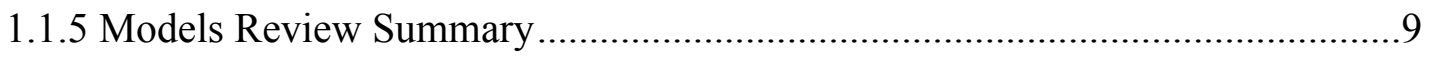

1.2 Willamette Model Using CE-QUAL-W2 V3.1 ..................................................11

Chapter 2 Converting Willamette River Models from V3.1 to V3.7..................................13

2.1 Converting all Willamette Models from V3.1 to V3.7 ……...................................13

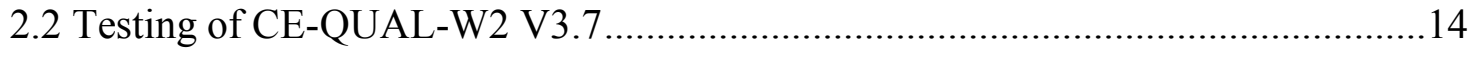


2.2.1 Lower Willamette River / Columbia River

2.2.2 Middle Willamette River

2.2.3 Upper Willamette River .69

2.2.4 Clackamas River. .96

2.2.5 McKenzie River. .111

2.2.6 Long Tom River. 135

2.2.7 Summary and Conclusions

Chapter 3 Development of Steady-State Model for Hydrodynamics

3.1 New Expectation from River Hydrodynamic and Temperature Model. 151

3.2 Model Development Theory 152

3.2.1 CE-QUAL-W2 Version 3.7 as the base model. 153

3.2.2 Coordinate System and Model Grid 153

3.2.3 Steady-State Hydrodynamic Calculation 157

3.2.4 Dynamic Temperature Calculation 161

3.3 Model Development Process 163

3.4 Converting V3.7 models to Steady-state models 165

3.5 Testing of New Steady State Model Codes .165 
3.5.1 Clackamas River

3.5.2 McKenzie River.

3.5.3 Long Tom River.

Chapter 4 Summary and Conclusions ...................................................................215

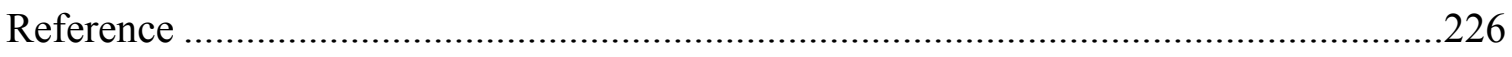

Appendix A: The steady-state model FORTRAN source code..... 230 


\section{List of Tables}

Table 1 Comparison of select river temperature models 8

Table 2: Lower Willamette River / Columbia River hydrodynamic calibration statistics, 2001 17

Table 3: Lower Willamette River hydrodynamic calibration statistics, 2002 21

Table 4: Willamette River continuous water temperature calibration model-data error statistics, 2001 25

Table 5: Willamette River continuous water temperature calibration model-data error statistics, 2002 33

Table 6: Middle Willamette River hydrodynamic calibration statistics, 2001 46

Table 7: Middle Willamette River hydrodynamic calibration statistics, 2002 48

Table 8: Willamette River continuous water temperature calibration model-data error statistics, 2001 50

Table 9: Willamette River continuous water temperature calibration model-data error statistics, 2002 65

Table 10: Upper Willamette River hydrodynamic calibration statistics, 2001 71

Table 11: Upper Willamette River hydrodynamic calibration statistics, 2002 76

Table 12: Upper Willamette River continuous water temperature calibration model-data error statistics, 2001 82

Table 13: Upper Willamette River continuous water temperature calibration model-data

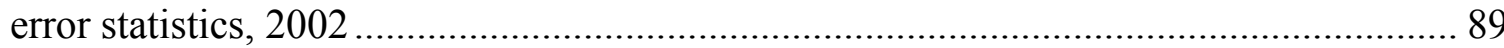

Table 14: Clackamas River hydrodynamic calibration statistics, 2001 ........................ 97

Table 15: Clackamas River hydrodynamic calibration statistics, 2002 ...................... 100 
Table 16: Clackamas River continuous water temperature calibration model-data error statistics, 2001 103

Table 17: Clackamas River continuous water temperature calibration model-data error statistics, 2002 107

Table 18: McKenzie River hydrodynamic calibration model-data error statistics, 2001112 Table 19: McKenzie River hydrodynamic calibration model-data error statistics, 2002116 Table 20: McKenzie River continuous water temperature calibration model-data error statistics, 2001

Table 21: McKenzie River continuous water temperature calibration model-data error statistics, 2002 128

Table 22 Long Tom River hydrodynamic calibration model-data error statistics, 2001136 Table 23 Long Tom River hydrodynamic calibration model-data error statistics, 2002139 Table 24 Long Tom River continuous water temperature calibration model-data error statistics, 2001 142

Table 25 Long Tom River continuous water temperature calibration model-data error statistics, 2002 144 Table 26: Comparison of CE-QUAL-W2 Version 3.1 and Version 3.7 temperature predictions accuracy on six river systems 148

Table 27: CPU runtime of CE-QUAL-W2 Version 3.7 model at six river systems applications in 2001 and 2002 149

Table 28: Clackamas River hydrodynamic calibration statistics, 2001 167

Table 29: Clackamas River hydrodynamic calibration statistics, 2002 170 
Table 30: Clackamas River continuous water temperature calibration model-data error statistics, 2001 173

Table 31: Clackamas River continuous water temperature calibration model-data error statistics, 2002 176

Table 32: McKenzie River hydrodynamic calibration model-data error statistics, 2001180 Table 33: McKenzie River hydrodynamic calibration model-data error statistics, 2002185 Table 34: McKenzie River continuous water temperature calibration model-data error statistics, 2001 190

Table 35: McKenzie River continuous water temperature calibration model-data error statistics, 2002 196

Table 36 Long Tom River hydrodynamic calibration model-data error statistics, 2001203 Table 37 Long Tom River hydrodynamic calibration model-data error statistics, 2002206 Table 38 Long Tom River continuous water temperature calibration model-data error statistics, 2001 209

Table 39 Long Tom River continuous water temperature calibration model-data error statistics, 2002 212 Table 40: Comparison of CE-QUAL-W2 Steady-State Model, CE-QUAL-W2 Version 3.1 and Version 3.7 temperature predictions accuracy on six river systems ..... 216 Table 41: Comparison of CPU runtime of Steady-State Model and CE-QUAL-W2 Version 3.7 model for three river systems applications in 2001 and 2002 ................... 217 Table 42: McKenzie River continuous water temperature calibration model-data error statistics, 2001. From left to right, the compared models are Version 3.7, steady-state model without re-calibration and steady-state model after calibration 221 


\section{List of Figures}

Figure 1: River systems with delineated watersheds in the Willamette River Basin ....... 12

Figure 2: Lower Willamette / Columbia River model grid....................................... 16

Figure 3: Willamette River below the Willamette Falls model-data water level

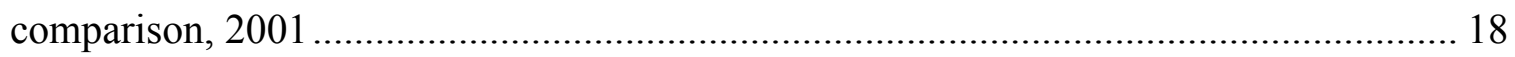

Figure 4: Willamette River at Portland model-data water level comparison, 2001......... 18

Figure 5: Columbia River below Bonneville Dam model-data water level comparison,

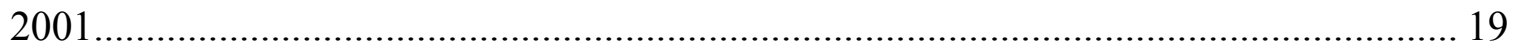

Figure 6 : Columbia River at Vancouver, WA model-data water level comparison, 2001

Figure 7: Columbia River at St. Helens, OR model-data water level comparison, 2001 . 20 Figure 8: Columbia River at Beaver Army Terminal model-data flow comparison, 2001

Figure 9: Willamette River below the Willamette Falls model-data water level

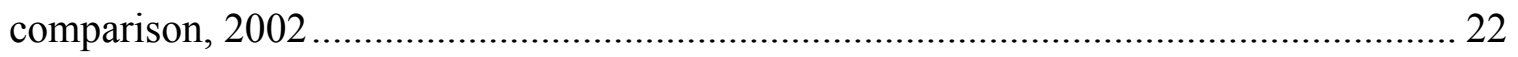

Figure 10: Willamette River at Portland model-data water level comparison, 2002 ....... 22 Figure 11: Columbia River below Bonneville Dam model-data water level comparison, 2002. 23

Figure 12: Columbia River at Vancouver, WA model-data water level comparison, 2002

Figure 13: Columbia River at St. Helens, OR model-data water level comparison, 200224 Figure 14: Columbia River at Beaver Army Terminal model-data flow comparison, 2002 
Figure 15: Willamette River downstream of the Willamette Falls site A model-data

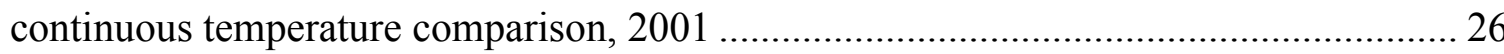

Figure 16: Willamette River downstream of the Willamette Falls site B continuous

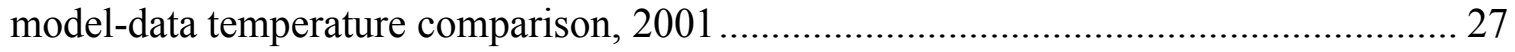

Figure 17: Willamette River at Roehr Waterfront Park (shallow) model-data continuous temperature comparison, 27 Figure 18: Willamette River at Roehr Waterfront Park (deep) model-data continuous

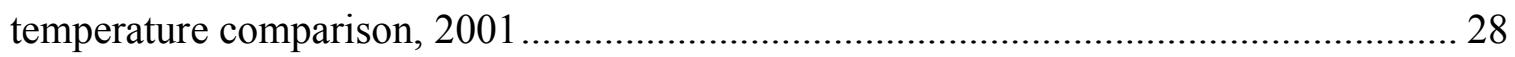
Figure 19: Multnomah Channel downstream of Gilbert River model-data continuous

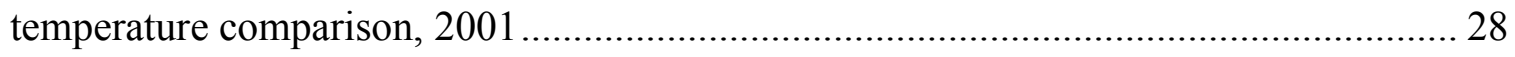

Figure 20: Columbia River Left Bank at Dodson continuous model-data temperature

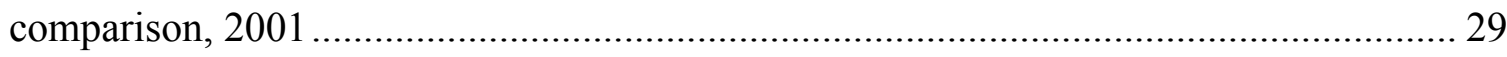

Figure 21: Columbia River Right Bank near Skamania model-data continuous

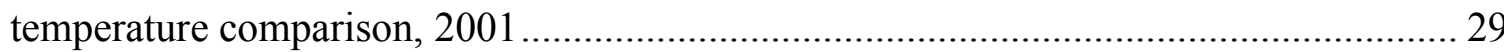

Figure 22: Columbia River at Washougal, WA model-data continuous temperature

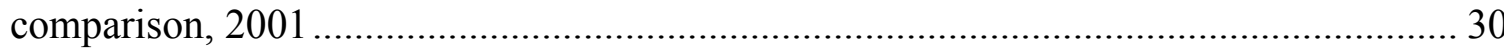

Figure 23: Columbia River at RM 122.5 model-data continuous temperature comparison, 2001 30

Figure 24: Columbia River d/s Multnomah Channel model-data continuous temperature comparison, 2001 31

Figure 25: Columbia River at RM 66.8 model-data continuous temperature comparison, 2001. 31 
Figure 26: Columbia River at Beaver Army Terminal model-data continuous temperature

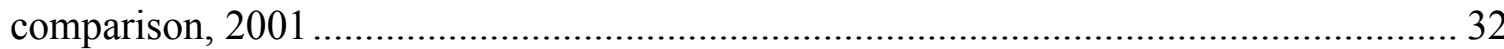

Figure 27: Willamette River at Roehr Waterfront Park (shallow) model-data continuous

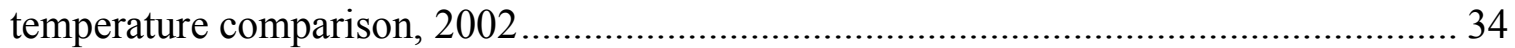

Figure 28: Willamette River at Roehr Waterfront Park (deep) model-data continuous temperature comparison, 2002 34

Figure 29: Willamette River north of Deer Island (shallow) model-data continuous temperature comparison, 2002 35

Figure 30: Willamette River north of Deer Island (deep) model-data continuous

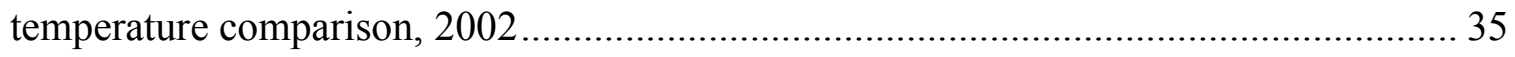

Figure 31: Willamette River upstream of Kellog Creek WWTP outfall (shallow) model-

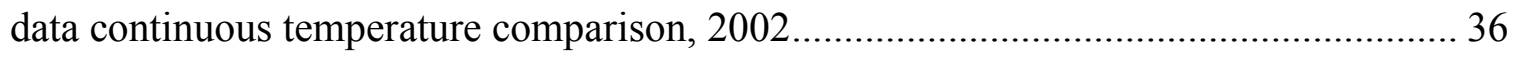

Figure 32: Willamette River upstream of Kellog Creek WWTP outfall (deep) model-data

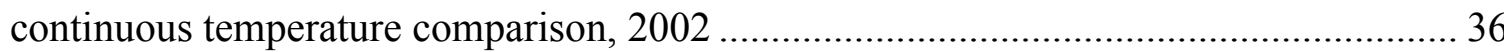

Figure 33: Willamette River downstream of Kellog Creek WWTP outfall (shallow)

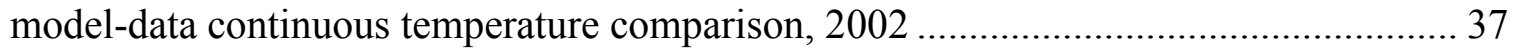

Figure 34: Willamette River downstream of Kellog Creek WWTP outfall (deep) model-

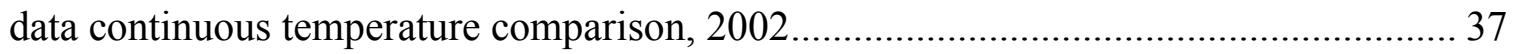
Figure 35: Willamette River at Waverly Country Club model-data continuous

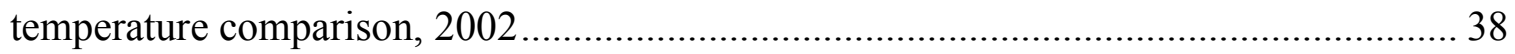
Figure 36: Willamette River at Waverly Country Club (QA data set) model-data

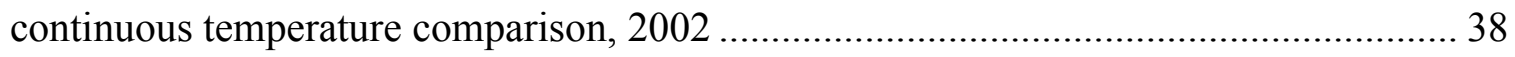


Figure 37 : Willamette River at St. Johns Bridge (deep) model-data continuous

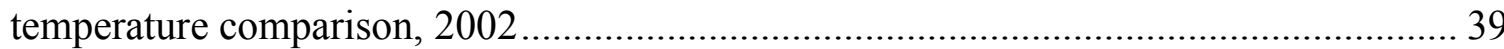

Figure 38: Willamette River at St. Johns Bridge (shallow) model-data continuous temperature comparison, 2002 39

Figure 39: Willamette River upstream of Oregon Steel Mills (shallow) model-data continuous temperature comparison, 2002 40

Figure 40: Willamette River upstream of Oregon Steel Mills (deep) model-data continuous temperature comparison, 40

Figure 41: Columbia River left bank at Dodson, OR model-data continuous temperature comparison, 2002

Figure 42: Columbia River at Washougal, WA model-data continuous temperature comparison, 2002 41

Figure 43: Columbia River downstream of Multnomah Channel (deep) model-data continuous temperature comparison, 2002 42

Figure 44: Columbia River downstream of Multnomah Channel (shallow) model-data continuous temperature comparison, 2002 42 Figure 45: Columbia River at RM 66.8 (deep) model-data continuous temperature comparison, 2002 43

Figure 46: Columbia River at RM 66.8 (shallow) model-data continuous temperature comparison, 2002 43

Figure 47: Columbia River at Beaver Army Terminal model-data continuous temperature comparison, 2002 44

Figure 48: Middle Willamette River Model Grid 45 
Figure 49: Willamette River at Salem model-data flow comparison, 2001 46

Figure 50: Willamette River at Salem model-data water level comparison, 2001 47

Figure 51: Willamette River at the Willamette Falls model-data water level comparison, 2001 47

Figure 52: Willamette River at Salem model-data flow comparison, 2001 ................... 48

Figure 53: Willamette River at Salem model-data water level comparison, 2002 .......... 49

Figure 54: Willamette River at Newberg model-data water level comparison, 2002 ...... 49

Figure 55: Willamette River at the Willamette Falls model-data water level comparison, 2002. 50

Figure 56: Willamette River at Salem model-data continuous temperature comparison, 2001 52

Figure 57: Willamette River at Keizer model-data continuous temperature comparison, 2001 52

Figure 58: Willamette River at Willow Lake Treatment Plant model-data continuous temperature comparison, 2001 53

Figure 59: Willamette River at Wheatland Ferry model-data continuous temperature comparison, 2001 53

Figure 60: Willamette River at Eagle Nest A model-data continuous temperature comparison, 2001 . 54

Figure 61: Willamette River at Eagle Nest B model-data continuous temperature comparison, 2001 54

Figure 62: Willamette River at Coffee Island A model-data continuous temperature comparison, 2001 55 
Figure 63: Willamette River at Coffee Island B model-data continuous temperature

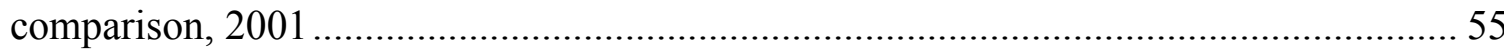

Figure 64: Willamette River at San Salvador A model-data continuous temperature

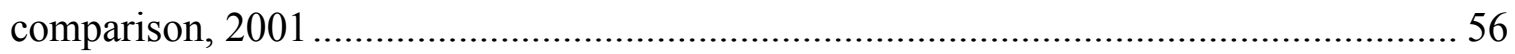

Figure 65: Willamette River at San Salvador B model-data continuous temperature

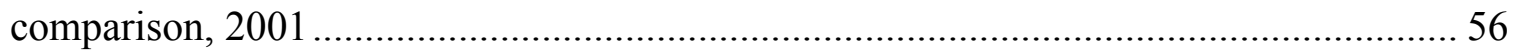
Figure 66: Willamette River above Ash Island A model-data continuous temperature

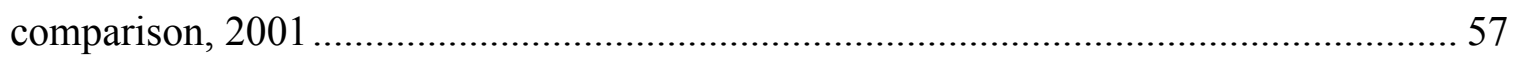
Figure 67: Willamette River above Ash Island B model-data continuous temperature

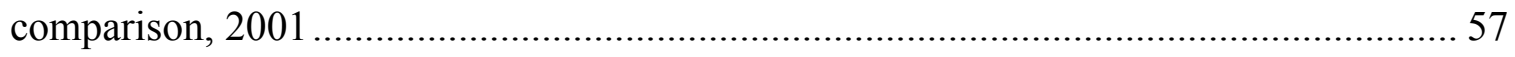

Figure 68: Willamette River at Champoeg Park A model-data continuous temperature

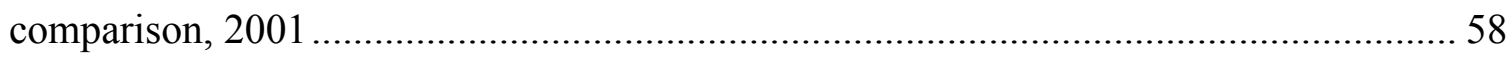

Figure 69: Willamette River at Champoeg Park B model-data continuous temperature

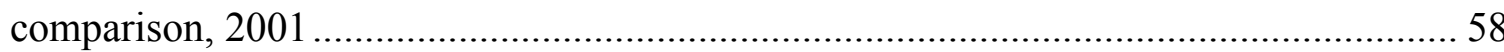

Figure 70: Willamette River at I5 Bridge, Wilsonville model-data continuous temperature

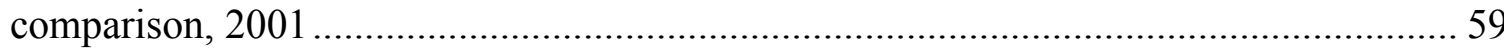

Figure 71: Willamette River upstream of the Molalla River confluence, Power-line A

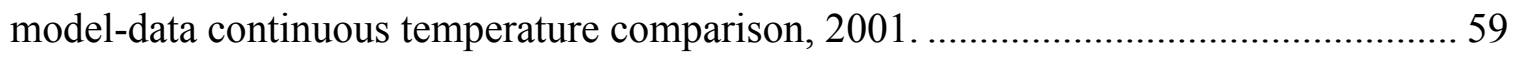
Figure 72: Willamette River upstream of the Molalla River confluence, Power-line B model-data continuous temperature comparison, 2001. 60 Figure 73: Willamette River at Canby Ferry B model-data continuous temperature comparison, 2001. 60 
Figure 74: Willamette River at Powerline A model-data continuous temperature comparison, 2001 61

Figure 75: Willamette River at Powerline A model-data continuous temperature comparison, 2001 61 Figure 76: Willamette River at Tug Dock A model-data continuous temperature comparison, 2001 62

Figure 77: Willamette River at Boathouse A model-data continuous temperature comparison, 2001 62

Figure 78: Willamette River at Forebay B model-data continuous temperature comparison, 2001 63

Figure 79: Willamette River at Log Boom B model-data continuous temperature comparison, 63

Figure 80: Willamette River at Log Boom B model-data continuous temperature comparison, 64

Figure 81: Willamette River at the Willamette Falls model-data continuous temperature comparison, 2001 64 Figure 82: Willamette River at Forebay A model-data continuous temperature comparison, 2001 65 Figure 83: Willamette River at Willow Lake Treatment Plant model-data continuous temperature comparison, 2002 66 Figure 84: Willamette River at Wheatland Ferry model-data continuous temperature comparison, 2002 66 
Figure 85: Willamette River at Coffee Island model-data continuous temperature comparison, 2002

Figure 86: Willamette River upstream of the Yamhill River model-data continuous temperature comparison, 2002 67

Figure 87: Willamette River at Newberg model-data continuous temperature comparison, 2002 68

Figure 88: Willamette River at I5 Bridge, Wilsonville model-data continuous temperature comparison, 2002 68

Figure 89: Willamette River at the Willamette Falls model-data continuous temperature comparison, 2002 69

Figure 90: Upper Willamette River Model Grid. 70

Figure 91: Willamette River at Eugene model-data flow comparison, 2001 ................. 72

Figure 92: Willamette River at Eugene model-data water level comparison, 2001 ......... 73

Figure 93: Willamette River at Harrisburg model-data flow comparison, 2001 ............. 73

Figure 94: Willamette River at Harrisburg model-data water level comparison, 2001 ... 74

Figure 95: Willamette River at Corvallis model-data water level comparison, 2001 ...... 74

Figure 969: Willamette River at Albany model-data flow comparison, 2001 ................ 75

Figure 97: Willamette River at Albany model-data water level comparison, 2001 ........ 75

Figure 98: Willamette River at Salem model-data flow comparison, 2001 (gage is $900 \mathrm{~m}$

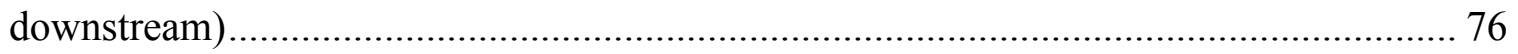

Figure 99: Willamette River at Eugene model-data flow comparison, 2002 ................. 77

Figure 100: Willamette River at Eugene model-data water level comparison, 2002 ...... 78

Figure 101: Willamette River at Harrisburg model-data flow comparison, 2002 ........... 78 
Figure 102: Willamette River at Harrisburg model-data water level comparison, 2002 .. 79 Figure 103: Willamette River at Corvallis model-data flow comparison, 2002 ............. 79 Figure 104: Willamette River at Corvallis model-data water level comparison, 2002 .... 80 Figure 105: Willamette River at Albany model-data flow comparison, 2002 ................. 80 Figure 106: Willamette River at Albany model-data water level comparison, 2002 ...... 81 Figure 107: Willamette River at Salem model-data flow comparison, 2002 (gage is $900 \mathrm{~m}$

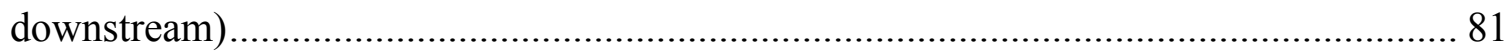

Figure 108: Upper Willamette River near Springfield model-data continuous temperature comparison, 2001 83

Figure 109: Upper Willamette River above McKenzie River model-data continuous temperature comparison, 2001 83 Figure 110: Upper Willamette River at Harrisburg model-data continuous temperature comparison, 2001 84

Figure 111: Upper Willamette River above Long Tom River model-data continuous temperature comparison, 2001 84

Figure 112: Upper Willamette River at RM 147.4 model-data continuous temperature comparison, 2001 85

Figure 113: Upper Willamette River at RM 142.4 model-data continuous temperature comparison, 2001 85

Figure 114: Upper Willamette River at Corvallis model-data continuous temperature comparison, 2001 86 Figure 115: Upper Willamette River at Albany model-data continuous temperature comparison, 2001 86 
Figure 116: Upper Willamette River at Conser Rd model-data continuous temperature comparison, 2001 87

Figure 117: Upper Willamette River at South River Rd model-data continuous temperature comparison, 2001 87

Figure 118: Upper Willamette River above Rickreall Creek model-data continuous temperature comparison, 2001 88 Figure 119: Upper Willamette River at Salem model-data continuous temperature comparison, 2001 88

Figure 120: Upper Willamette River near Springfield model-data continuous temperature comparison, 2002 90

Figure 121: Upper Willamette River above McKenzie River model-data continuous

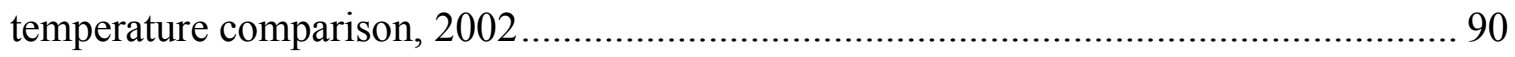

Figure 122: Upper Willamette River at Harrisburg model-data continuous temperature comparison, 2002 91

Figure 123: Upper Willamette River above Long Tom River model-data continuous temperature comparison, 2002 91 Figure 124: Upper Willamette River at RM 147.4 model-data continuous temperature comparison, 2002 92 Figure 125: Upper Willamette River at RM 142.4 model-data continuous temperature comparison, 2002 92 Figure 126: Upper Willamette River at Corvallis model-data continuous temperature comparison, 2002 93 
Figure 127: Upper Willamette River at Albany model-data continuous temperature

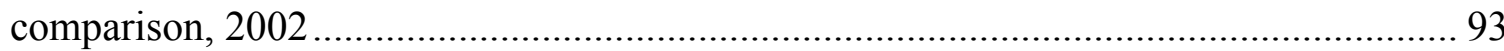

Figure 128: Upper Willamette River at Conser Rd model-data continuous temperature comparison, 2002 94

Figure 129: Upper Willamette River at South River Rd model-data continuous temperature comparison, 2002 94

Figure 130: Upper Willamette River above Rickreall Creek model-data continuous

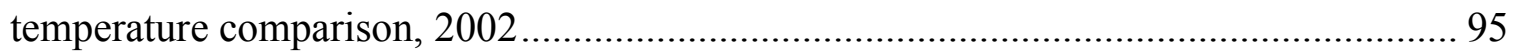

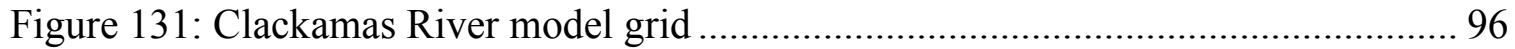

Figure 132: Clackamas River at Estacada model-data flow comparison, 2001 .............. 98

Figure 133: Clackamas River at Estacada model-data water level comparison, 2001 ..... 98

Figure 134: Clackamas River near Oregon City model-data flow comparison, 2001 ..... 99

Figure 135: Clackamas River near Oregon City model-data water level comparison, 2001

Figure 136: Clackamas River at Estacada model-data flow comparison, time step=10s, 2002 101

Figure 137: Clackamas River at Estacada model-data flow comparison, time step $=5 \mathrm{~s}$, 2002 101

Figure 138: Clackamas River at Estacada model-data water level comparison, 2002 ... 102 Figure 139: Clackamas River near Oregon City model-data flow comparison, 2002 ... 102 Figure 140: Clackamas River near Oregon City model-data water level comparison, 2002 
Figure 141: Clackamas River at Estacada model-data continuous temperature comparison, 2001 104

Figure 142 : Clackamas River at McIver Park model-data continuous temperature comparison, 2001 105

Figure 143: Clackamas River upstream of Eagle Creek model-data continuous temperature comparison, 2001 105

Figure 144 : Clackamas River at Barton model-data continuous temperature comparison, 2001 106

Figure 145: Clackamas River at Carver Bridge model-data continuous temperature comparison, 2001 106

Figure 146: Clackamas River at Oregon City model-data continuous temperature comparison, 2001 107

Figure 147: Clackamas River at Estacada model-data continuous temperature comparison, 2002 108

Figure 148 : Clackamas River at Rivermill Tailrace model-data continuous temperature comparison, 2002 108

Figure 149 : Clackamas River upstream of Eagle Creek model-data continuous temperature comparison, 2002 109 Figure 150: Clackamas River upstream of Clear Creek model-data continuous temperature comparison, 2002 109 Figure 151: Clackamas River at Oregon City model-data continuous temperature comparison, 2002 110 
Figure 152: Clackamas River at Oregon City model-data continuous temperature

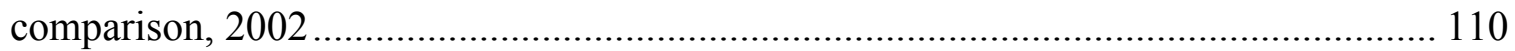

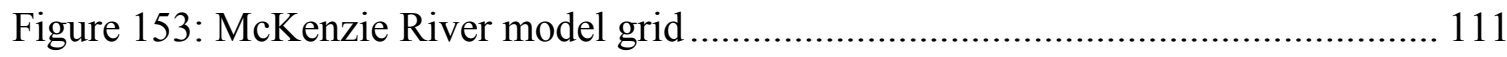

Figure 154: South Fork McKenzie River below Cougar Dam model-data flow

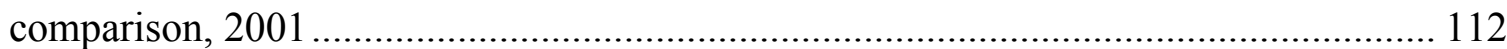

Figure 155: South Fork McKenzie River below Cougar Dam model-data water level

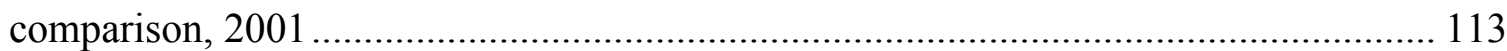

Figure 156: McKenzie River near Vida model-data flow comparison, 2001 ................ 113

Figure 157: McKenzie River near Vida model-data water level comparison, 2001 ...... 114

Figure 158: McKenzie River below Leaburg Dam model-data flow comparison, 2001114

Figure 159: McKenzie River below Leaburg Dam model-data water level comparison, 2001 115

Figure 160: McKenzie River near Walterville model-data flow comparison, 2001...... 115 Figure 161: McKenzie River near Walterville model-data water level comparison, 2001 116

Figure 162: South Fork McKenzie River below Cougar Dam model-data flow comparison, 2002 117

Figure 163: South Fork McKenzie River below Cougar Dam model-data water level

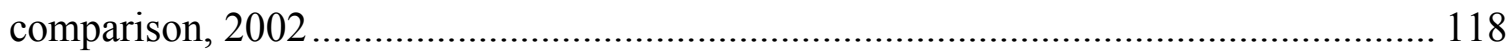

Figure 164: McKenzie River near Vida model-data flow comparison, 2002 ................ 118 Figure 165: McKenzie River near Vida model-data water level comparison, 2002 ...... 119 Figure 166: McKenzie River below Leaburg Dam model-data flow comparison, 2002119 
Figure 167: McKenzie River below Leaburg Dam model-data water level comparison, 2002 120

Figure 168: McKenzie River near Walterville model-data flow comparison, 2002...... 120 Figure 169: McKenzie River near Walterville model-data water level comparison, 2002 121

Figure 170: South Fork McKenzie River below Cougar Dam model-data continuous temperature comparison, 2001 122

Figure 171: McKenzie River below Cougar River model-data continuous temperature comparison, 2001 123

Figure 172: McKenzie River near Vida model-data continuous temperature comparison, 2001 123

Figure 173: McKenzie River below Leaburg Dam model-data continuous temperature comparison, 2001 124

Figure 174: McKenzie River above the Leaburg tailrace model-data continuous temperature comparison, 2001 124

Figure 175: McKenzie River at Deerborn model-data continuous temperature comparison, 2001 125

Figure 176: McKenzie River near Walterville model-data continuous temperature comparison, 2001 125

Figure 177: McKenzie River above Walterville Tailrace model-data continuous temperature comparison, 2001 126 Figure 178: McKenzie River at Bellinger Landing model-data continuous temperature comparison, 2001 126 
Figure 179: Leaburg Canal Intake, upstream end model-data continuous temperature comparison, 2001 127

Figure 180: Leaburg Canal Powerhouse Tailrace, downstream end model-data continuous temperature comparison, 127

Figure 181: South Fork McKenzie below Cougar Dam model-data continuous temperature comparison, 2002 129 Figure 182: McKenzie River below Cougar River model-data continuous temperature comparison, 2002 129 Figure 183: McKenzie River near Vida model-data continuous temperature comparison, 2002 130

Figure 184: McKenzie River at Helfrich boat ramp model-data continuous temperature comparison, 2002 130

Figure 185: McKenzie River below Leaburg Dam model-data continuous temperature comparison, 2002 131

Figure 186: McKenzie River at Deerborn model-data continuous temperature comparison, 2002 131 Figure 187: McKenzie River near Walterville model-data continuous temperature comparison, 2002 132 Figure 188: McKenzie River at Bellinger Landing model-data continuous temperature comparison, 2002 132 Figure 189: McKenzie River above Mohawk River model-data continuous temperature comparison, 2002 133 
Figure 190: McKenzie River at Coburg $\mathrm{Rd}$ model-data continuous temperature

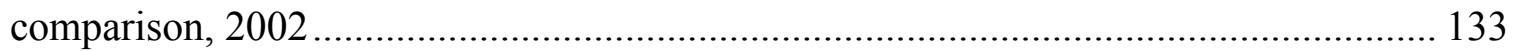

Figure 191: Leaburg Canal Intake, upstream end model-data continuous temperature comparison, 2002 134

Figure 192: Leaburg Canal Powerhouse Tailrace, downstream end model-data continuous temperature comparison, 134

Figure 193: Long Tom River Model Grid 135

Figure 194: Long Tom River near Alvadore model-data flow comparison, 2001 ...... 137

Figure 195: Long Tom River near Alvadore model-data water level comparison, 2001 137

Figure 196: Long Tom River at Monroe model-data flow comparison, 2001 138

Figure 197: Long Tom River at Monroe model-data water level comparison, 2001 .. 138

Figure 198 Long Tom River near Alvadore model-data flow comparison, 2002 140

Figure 199 Long Tom River near Alvadore model-data water level comparison, 2002140 Figure 200 Long Tom River at Monroe model-data flow comparison, 2002. 141

Figure 201 Long Tom River at Monroe model-data water level comparison, 2002 ...... 141 Figure 202 Long Tom River near Alvadore model-data continuous temperature comparison, 2001 142 Figure 203 Long Tom River at RM 19.8 model-data continuous temperature comparison, 2001 143

Figure 204 Long Tom River at RM 12.3 model-data continuous temperature comparison, 2001 143 
Figure 205 Long Tom River at Monroe model-data continuous temperature comparison, 2001 144

Figure 206 Long Tom River near Alvadore model-data continuous temperature comparison, 2002 145

Figure 207 Long Tom River at RM 19.8 model-data continuous temperature comparison, 2002 145

Figure 208 Long Tom River at RM 12.3 model-data continuous temperature comparison, 2002 146

Figure 209 Long Tom River at Monroe model-data continuous temperature comparison, 2002 146

Figure 210 Long Tom River near mouth model-data continuous temperature comparison, 2002

Figure 211: Estimated runtime for one year simulation using CE-QUAL-W2 Version 3.7

Figure 212: Comparison of river top view in the real world (left) and in the steady-steady model (right) 153

Figure 213: Comparison of river cross-section view in the real world (left) and in the steady-steady model (right). 154

Figure 214: Comparison of river side view in the real world (left) and in the steadysteady model (right) 154

Figure 215: Example of a loop branch in the real world and in model 156

Figure 216: Flow distribution at the beginning of loop branch 156

Figure 217: An example of transporting flow between branches 157 
Figure 218: Flow rate calculation in the Steady-state model. 158

Figure 219: Water surface elevation smoothing …………..................................... 160

Figure 220: Longitudinal velocity calculation ........................................................ 161

Figure 221: Vertical velocity calculation....................................................................... 161

Figure 222: Sketch of heat conservation of a cell...................................................... 163

Figure 223: Steady-State Model testing and refining process flow chart....................... 164

Figure 224: Clackamas River at Estacada model-data flow comparison, 2001 ............. 167

Figure 225: Clackamas River at Estacada model-data water level comparison, 2001 ... 168

Figure 226: Clackamas River near Oregon City model-data flow comparison, 2001 .... 168

Figure 227: Clackamas River near Oregon City model-data water level comparison, 2001 169

Figure 228: Clackamas River at Estacada model-data flow comparison, 2002 ............. 170

Figure 229: Clackamas River at Estacada model-data water level comparison, 2002 ... 171

Figure 230: Clackamas River near Oregon City model-data flow comparison, 2002 .... 171

Figure 231: Clackamas River near Oregon City model-data water level comparison, 2002

172

Figure 232: Clackamas River at Estacada model-data continuous temperature

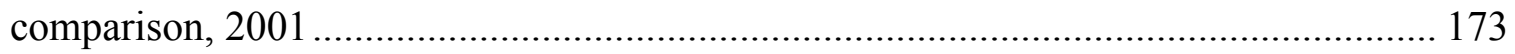

Figure 233: Clackamas River at McIver Park model-data continuous temperature

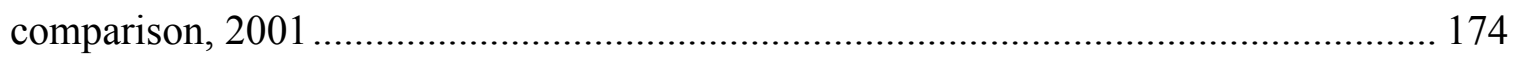

Figure 234: Clackamas River upstream of Eagle Creek model-data continuous

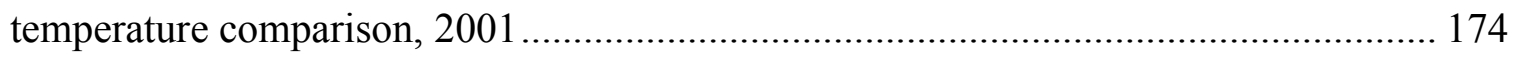


Figure 235: Clackamas River at Barton model-data continuous temperature comparison, 2002 175

Figure 236: Clackamas River at Carver Bridge model-data continuous temperature comparison, 2001 175

Figure 237: Clackamas River at Oregon City model-data continuous temperature comparison, 2001 176

Figure 238: Clackamas River at Estacada model-data continuous temperature comparison, 2002 177

Figure 239: Clackamas River upstream of Eagle Creek model-data continuous temperature comparison, 2002

Figure 240: Clackamas River upstream of Clear Creek model-data continuous

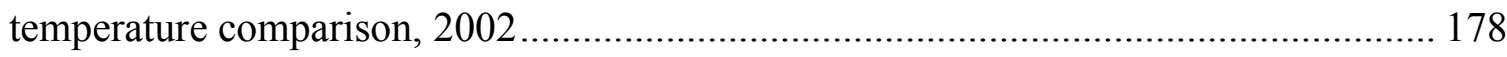

Figure 241: Clackamas River at Oregon City model-data continuous temperature comparison, 2002 178

Figure 242: South Fork McKenzie River below Cougar Dam model-data flow comparison, 2001 180

Figure 243: South Fork McKenzie River below Cougar Dam model-data water level comparison, 2001 181

Figure 244: McKenzie River near Vida model-data flow comparison, 2001 181

Figure 245: McKenzie River near Vida model-data water level comparison, 2001 ...... 182 Figure 246: McKenzie River below Leaburg Dam model-data flow comparison, 2001182 Figure 247: McKenzie River below Leaburg Dam model-data water level comparison, 2001 183 
Figure 248: McKenzie River near Walterville model-data flow comparison, 2001...... 183 Figure 249: McKenzie River near Walterville model-data water level comparison, 2001 184

Figure 250: South Fork McKenzie River below Cougar Dam model-data flow comparison, 2002 185

Figure 251: South Fork McKenzie River below Cougar Dam model-data water level comparison, 2002 186

Figure 252: McKenzie River near Vida model-data flow comparison, 2002 ................ 186 Figure 253: McKenzie River near Vida model-data water level comparison, 2002 ...... 187 Figure 254: McKenzie River below Leaburg Dam model-data flow comparison, 2002188 Figure 255: McKenzie River below Leaburg Dam model-data water level comparison, 2002 188

Figure 256: McKenzie River near Walterville model-data flow comparison, 2002...... 188 Figure 257: McKenzie River near Walterville model-data water level comparison, 2002 189

Figure 258: South Fork McKenzie River below Cougar Dam model-data continuous temperature comparison, 2001 190 Figure 259: McKenzie River below Cougar River model-data continuous temperature comparison, 2001 191

Figure 260: McKenzie River near Vida model-data continuous temperature comparison, 2001 191

Figure 261: McKenzie River below Leaburg Dam model-data continuous temperature comparison, 2001 192 
Figure 262: McKenzie River above the Leaburg tailrace model-data continuous temperature comparison, 2001

192

Figure 263: McKenzie River at Deerborn model-data continuous temperature comparison, 2001 193

Figure 264: McKenzie River near Walterville model-data continuous temperature comparison, 2001 193

Figure 265: McKenzie River above Walterville Tailrace model-data continuous temperature comparison, 2001 194

Figure 266: McKenzie River at Bellinger Landing model-data continuous temperature comparison, 2001

Figure 267: Leaburg Canal Intake, upstream end model-data continuous temperature comparison, 2001 195

Figure 268: South Fork McKenzie below Cougar Dam model-data continuous temperature comparison, 2002 . 196 Figure 269: McKenzie River below Cougar River model-data continuous temperature comparison, 2002 197 Figure 270: McKenzie River near Vida model-data continuous temperature comparison, 2002 197

Figure 271: McKenzie River at Helfrich boat ramp model-data continuous temperature comparison, 2002 198 Figure 272: McKenzie River below Leaburg Dam model-data continuous temperature comparison, 2002 198 
Figure 273: McKenzie River at Deerborn model-data continuous temperature comparison, 2002 199

Figure 274: McKenzie River near Walterville model-data continuous temperature comparison, 2002 199

Figure 275: McKenzie River at Bellinger Landing model-data continuous temperature comparison, 2002 200 Figure 276: McKenzie River above Mohawk River model-data continuous temperature comparison, 2002 200 Figure 277: McKenzie River at Coburg $\mathrm{Rd}$ model-data continuous temperature comparison, 2002 201

Figure 278: Leaburg Canal Intake, upstream end model-data continuous temperature comparison, 2002 201

Figure 279: Leaburg Canal Powerhouse Tailrace, downstream end model-data continuous

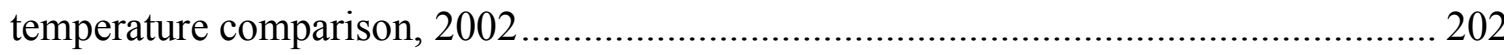

Figure 280 Long Tom River near Alvadore model-data flow comparison, 2001 ......... 204 Figure 281: Long Tom River near Alvadore model-data water level comparison, 2001204 Figure 282: Long Tom River at Monroe model-data flow comparison, 2001............... 205 Figure 283: Long Tom River at Monroe model-data water level comparison, 2001 ..... 205 Figure 284: Long Tom River near Alvadore model-data flow comparison, 2002 ........ 207 Figure 285: Long Tom River near Alvadore model-data water level comparison, 2002207 Figure 286: Long Tom River at Monroe model-data flow comparison, 2002 ............... 207 Figure 287: Long Tom River at Monroe model-data water level comparison, 2002 _.... 208 
Figure 288: Long Tom River near Alvadore model-data continuous temperature comparison, 2001 209

Figure 289: Long Tom River at RM 19.8 model-data continuous temperature comparison, 2001 210

Figure 290: Long Tom River at RM 12.3 model-data continuous temperature comparison, 2001 210

Figure 291: Long Tom River at Monroe model-data continuous temperature comparison, 2001 211

Figure 292: Long Tom River near Alvadore model-data continuous temperature comparison, 2002 212

Figure 293: Long Tom River at RM 19.8 model-data continuous temperature comparison, 2002 213

Figure 294: Long Tom River at RM 12.3 model-data continuous temperature comparison, 2002 213

Figure 295: Long Tom River at Monroe model-data continuous temperature comparison, 2002 214

Figure 296: Long Tom River near mouth model-data continuous temperature comparison, 2002 214

Figure 297: Comparison of estimated runtime for one year simulation using Steady-State Model and CE-QUAL-W2 Version 3.7. 218

Figure 298: Continuous temperature comparison between models (red) VS data (black) at Segment 285 in McKenzie River model, 2001. From top down, the compared models are 
Version 3.7, steady-state model without re-calibration and steady-state model after

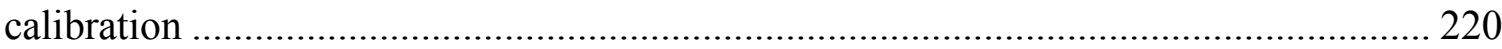

Figure 299: Side view of the example branch with even grid .................................. 222

Figure 300: Side view of the example branch with higher river bed in the middle....... 223

Figure 301: Side view of the example branch with lower river bed in the middle......... 223 
Abbreviations

cfs

Cubic Feet Per Second

MAE

ME

Mean absolute error

SEE

$\mathrm{RM}$

standard error of estimation

RMSE

River Mile

root-mean-square error 


\section{Chapter 1 Literature Review of River Modeling}

\subsection{Hydrodynamic Models and Temperature Models}

\subsubsection{The Importance of River Temperature Models}

River temperature is one of the most important physical properties that influence aquatic ecosystem health (Poole \& Berman, 2001). Most fish species are cold-blooded, and their living is affected by the environmental temperature in a variety of ways. Temperature alters respiration, metabolism, food availability (Metcalfe, 1999), and the ease of mobility. Extreme temperature may result in some species experiencing population decline (Elliott, 1981). With climate change, it is more and more important to know the temperature in rivers, which regulation rules and management decisions depend upon.

Specifically for the Pacific Northwest, this area is a natural habitat for many salmon species, and many of them are listed as endangered species, according to the Endangered Species Act (1993). In the Willamette River Basin, endangered species, Chinook salmon, Coho salmon, and Steelhead, give reason for investigation into river temperature.

There are two ways to estimate river temperature: measurement or model predictions. However, temperature measurements only exist in a few locations, and they are usually located on the main-stem of a river and not on other habitat areas. Also, extensive field temperature measurement can take too much time and money. As a result, river temperature models are often built to predict river temperature, and model results are often used as a basis for river management agencies to make management decisions. 


\subsubsection{River Temperature Models Classification}

Basing on the method of how temperature is predicted, river temperature models can be classified into two groups: statistically-based models and physically-based models.

\subsubsection{Statistically-Based Models Review}

Statistically-based river temperature models are generally built on regression analysis, which relates river temperature to one or more variables in the river systems, for example, air temperature.

Although statistically-based models are easy to build and are not data intensive, they have limitations due to the statistical theories they are based on. First, statistically-based models are generally not able to simulate temperature at a smaller time scale, meaning that they are not able to capture the temperature change dynamics in a day. Instead, generally they can only predict water temperature at a daily or monthly time scale. Second, statistically-based models cannot be adjusted to reflect changes in the system such as new restoration projects or extreme climate changes.

Two statistically-based river temperature models were reviewed for this thesis study. One is in South Africa, where air temperatures data are generally available while river temperature data is not (River-Moore and Lorentz, 2004). River-Moore and Lorentz built a statistically-based model and attempted to simulate hourly water temperature based on hourly air temperature. The model was able to capture the general trend of temperature dynamics in a day, but with MAE up to $\pm 7{ }^{\circ} \mathrm{C}$ for a year-long simulation period. The 
River-Moore and Lorentz study also found that the simulated temperature fit observed data better in the upstream of the rivers, and fit not as well in the downstream.

In the second reviewed study, Sahoo et al. (2009) compared three different methods multiple regression analysis, artificial neutral network and chaos non-linear dynamic method - in simulating daily river temperature, and tested these three methods on four rivers. The Sahoo et al. study found that the chaos non-linear dynamic method produced the best result, with the RMSE ranging from 0.8 to $2.5^{\circ} \mathrm{C}$ for the daily river temperature over a four year simulation.

\subsubsection{Physically-Based Models Review}

Physically-based models use governing equations to represent the mechanism of temperature change in a natural environment.

\subsubsection{Physically-Based Models Classification}

\section{Dimensions}

Water temperature varies with time as well as in the three dimensions of space. As a result, the governing equations in physically-based temperature modeling are secondorder partial differential equations. For river systems, if the variation of temperature in lateral direction is negligible, the governing equations can be simplified to a twodimensional form; if the variation of temperature in vertical direction is also negligible, the governing equations can be further simplified to a one-dimensional form. Depending on the degree of simplification, physically-based temperature models can be classified into 1, 2, and 3-D models. 
For river systems 1-D or 2-D models are applied more frequently, while 3-D models are rarely used. The 3-D models require more detailed boundary conditions, and also require much more time to run. 1-D models are the easiest to build as they require the least input information. However, such models are not able to simulate temperature variation in vertical and lateral directions. On the other hand, 2-D models are somewhere in between 1-D and 3-D models. Decisions on which dimensional models to use should be made based on the hydrodynamic and temperature characteristics of the river system to be modeled.

\section{Steady state vs unsteady state}

Steady state is an equilibrium condition which in mathematical terms means that accumulation of the state variable is zero (Chapra, 1997).

In hydrodynamic modeling, steady state assumes that flow conditions reach equilibrium for every time step, so that momentum and turbulence need not to be calculated. By calculating the hydrodynamics at steady-state, the time step for stability is relaxed and simulations can proceed at much higher time steps. However, unsteady state requires the calculation of momentum and turbulence, and the time steps must be smaller.

\subsubsection{Models Review}

Eight existing river temperature models were reviewed in this study. Models were assessed basing on dimensions, hydrodynamic and water quality modeling theory, and example applications. Model characteristics are summarized in Table 1.

\section{QUAL2K}


QUAL2K (Chapra, et al. 2008) is a 1-D hydrodynamic and water quality model that simulates flow, temperature and water quality. Velocity and in-stream water depth are simulated at steady state. QUAL2K provides two calculation methods: (1) rating curve, and (2) the Manning formula. The rating curve method use the following empirical equations:

Velocity $(\mathrm{m} / \mathrm{s})=\mathrm{aQ}^{\mathbf{b}}$

Depth $(\mathrm{m})$ or width $(\mathrm{m})=\alpha \mathrm{Q}^{\beta}$

Where $\mathrm{Q}=$ flow rate, $\mathrm{m}^{3} / \mathrm{s}$

In the Manning formula, trapezoidal channel shape is used.

Temperature and water quality variables are also simulated at steady state. Although meteorological data and shading data should be input as hourly base, stream temperature result is outputted as daily average temperature, daily maximum temperature and daily minimum temperature.

Von Stackelberg and Neilson (2012) developed a QUAL2K water quality model for Jordan River, Utah. The RMSE of daily average temperature ranges from 0.3 to $1.9^{\circ} \mathrm{C}$.

\section{SNTEMP}

SNTEMP (Theurer et al., 1985) is a 1-D stream temperature model. There is no hydrodynamic component in this model, so flow data should be inputted for every time step of simulation. Generally this model runs on a time step of 1 day, and the output is maximum temperature and mean temperature for each time step.

Norton and Bradford (2009) developed a SNTEMP model for Speed River in Ontario, Canada. The simulation period is from June 9 to October 31 in 2004, and the time step is selected as 1 day. HEC-RAS model was applied for the hydraulic simulation. The MAE 
for daily mean temperature ranged from 0.2 to $1.0^{\circ} \mathrm{C}$, and the MAE for daily maximum temperature ranged from 0.3 to $0.8^{\circ} \mathrm{C}$.

\section{CE-QUAL-RIV 1}

CE-QUAL-RIV 1 (Environmental Laboratory, 1995) is a 1-D hydrodynamic and water quality model that simulates flow, temperature and water quality. Flow condition is simulated dynamically using St. Venant equations. Heat flux terms included are shortwave radiation, long-wave radiation, evaporation, back radiation of the water, and heat exchange with river bottom.

No example was found in the literature using this model for river temperature modeling.

\section{An unnamed model}

Younus et al. (2000) built a 1-D hydrodynamic and stream temperature model specifically for Little Pine Creek in Indiana. Both hydrodynamic and temperature are simulated dynamically. Heat flux terms included are air-water heat exchange, sedimentwater heat exchange, lateral heat inflow/outflow, subsurface inflow/outflow, and the interaction between solar radiation and riparian vegetation. The result showed good agreement between modeled temperature and measured stream temperature for every 15 minutes, with the SEE equal to $0.7^{\circ} \mathrm{C}$ over a 25 -day simulation period.

\section{HEC - RAS}

HEC - RAS (Brunner, 2010) is a 1-D unsteady hydrodynamic and water quality model. Water temperature is calculated using the ultimate quickest numerical scheme. Drake et al. (2010) believed that Hydrologic Simulation Program-FORTRAN (HSPF), CE-QUALW2 and SNTEMP are more accurate and detailed in temperature simulations than HEC- 
RAS, but HEC-RAS can be used in cases where hydraulic simulation is critical in temperature and water quality modeling.

Drake et al. (2010) built a HEC - RAS temperature model for Swan Creek in Ontario, Canada, to test the HEC -RAS temperature simulation capability as well as to investigate groundwater flow contribution. In the two-week long simulation, the ME was found to be $0.4^{\circ} \mathrm{C}$ and $1.0^{\circ} \mathrm{C}$ for two measurement sites.

\section{Mike 11}

Mike 11 (Danish Hydraulics Institute, 1993) is a 1-D hydrodynamic and water quality model. Both hydrodynamic and water quality are simulated dynamically. Temperature is calculated from the difference between solar energy gain and heat radiation (day and night) emission loss. Topographic shading is considered but vegetation shading is not. Parkinson (2002) developed a Mike 11 model for Snake River from Hells Canyon Dam to just upstream of the confluence with the Clearwater River. Water temperature, dissolved oxygen, nitrogen, and total dissolved gas were simulated in 1984 summer and 2000 fall. The result showed good agreement for temperature simulation, with the MAE for different sites ranging from 0.1 to $0.5^{\circ} \mathrm{C}$, and the RMSE ranging from 0.2 to $0.6^{\circ} \mathrm{C}$.

\section{Heat Source}

Heat Source Version 7.0 (Boyd and Kasper, 2003) is a 1-D hydrodynamic and river temperature model. This modeling methodology and program is maintained by Oregon Department of Environmental Quality. Temperature modeling is based on dynamic topographic and vegetation shading.

\section{Mike 21}


Mike 21 (Danish Hydraulics Institute, 1996) is a 2-D hydrodynamic and water quality model. It is a vertical averaged model, and is more suitable for shallow lake systems. The temperature calculation scheme in Mike 21 is similar to the one in Mike 11. Most applications of Mike 21 are found to be water quality models on lake or reservoir systems, or hydrodynamic models on river systems for purposes of flood control.

No example was found in the literature using this model for river temperature modeling.

\section{CE-QUAL-W2 V3.7}

CE-QUAL-W2 V3.7 (Cole and Wells, 2011) is a 2-D, laterally averaged hydrodynamic and water quality model. Both hydrodynamic and temperature are simulated dynamically. Heat flux terms that are included are short/ long wave radiation, air-water heat exchange, sediment-water heat exchange, inflow/outflow, dynamic topographic shading and vegetation shading, and ice cover. As temperature influences water density, and accurate hydrodynamic modeling requires accurate water density, temperature calculation is hooked up with hydrodynamic modeling. CE-QUAL-W2 V3.7 provides various options for different hydraulic structures set up, including spillway, weir, gate, withdraw, dam, pipe, etc. Besides, it can be easily applied for fish habitat volume calculation.

Berger et al. (2004) developed a CE-QUAL-W2 V3.1 model for Clackamas River, Oregon for 2001 and 2002. In 2012, this model was converted into CE-QUAL-W2 V3.7, and the modeled river temperature showed good agreement with measured data at six sites along the Clackamas River, with the ME ranging from \pm 0.01 to $\pm 0.15^{\circ} \mathrm{C}$, MAE ranging from 0.02 to $0.69^{\circ} \mathrm{C}$, and the RMSE ranging from 0.03 to $0.86^{\circ} \mathrm{C}$.

Table 1 Comparison of select river temperature models

\begin{tabular}{|c|c|c|c|c|c|c|c|c|}
\hline $\begin{array}{c}\text { Model } \\
\text { Name }\end{array}$ & $\begin{array}{c}\text { Dimensi } \\
\text { on }\end{array}$ & $\begin{array}{c}\text { Hydrodyna } \\
\text { mic }\end{array}$ & $\begin{array}{c}\text { Dynam } \\
\text { ic }\end{array}$ & $\begin{array}{c}\text { Minimu } \\
\text { m Time }\end{array}$ & $\begin{array}{c}\text { Minimu } \\
\mathrm{m}\end{array}$ & $\begin{array}{c}\text { Example } \\
\text { River }\end{array}$ & $\begin{array}{c}\text { Example } \\
\text { Applicati }\end{array}$ & Reference \\
\hline
\end{tabular}




\begin{tabular}{|c|c|c|c|c|c|c|c|c|}
\hline & & & $\begin{array}{c}\text { Shadin } \\
\mathrm{g}\end{array}$ & Step & $\begin{array}{l}\text { Output } \\
\text { Time } \\
\text { Step }\end{array}$ & $\begin{array}{l}\text { Applicati } \\
\text { on }\end{array}$ & $\begin{array}{l}\text { on Error } \\
\left({ }^{\circ} \mathrm{C}\right)\end{array}$ & \\
\hline $\begin{array}{c}\text { QUAL2 } \\
\mathrm{K}\end{array}$ & $1-\mathrm{D}$ & $\begin{array}{l}\text { Steady } \\
\text { State }\end{array}$ & No & $\begin{array}{l}\text { Less } \\
\text { than } \\
\text { hourly }\end{array}$ & Daily & $\begin{array}{c}\text { Jordan } \\
\text { River, } \\
\text { Utah }\end{array}$ & $\begin{array}{l}\text { RMSE } \\
(0.3-1.9)\end{array}$ & $\begin{array}{c}\text { Chapra, et } \\
\text { al. } 2006\end{array}$ \\
\hline $\begin{array}{c}\text { SNTEM } \\
\mathrm{P}\end{array}$ & $1-\mathrm{D}$ & $\begin{array}{l}\text { Steady } \\
\text { State }\end{array}$ & No & Daily & Daily & $\begin{array}{c}\text { Speed } \\
\text { River, } \\
\text { Ontario, } \\
\text { Canada }\end{array}$ & $\begin{array}{c}\text { MAE } \\
(0.2-1.0)\end{array}$ & $\begin{array}{l}\text { Theurer et } \\
\text { al., } 1985\end{array}$ \\
\hline $\begin{array}{l}\text { CE- } \\
\text { QUAL- } \\
\text { RIV 1 }\end{array}$ & 1-D & $\begin{array}{l}\text { Unsteady } \\
\text { State }\end{array}$ & No & $\begin{array}{l}\text { Less } \\
\text { than } \\
\text { hourly }\end{array}$ & $\begin{array}{l}\text { Less } \\
\text { than } \\
\text { hourly }\end{array}$ & N.A. & N.A. & $\begin{array}{c}\text { Environme } \\
\text { ntal } \\
\text { Laboratory, } \\
1995\end{array}$ \\
\hline $\begin{array}{c}* \text { Unnam } \\
\text { ed }\end{array}$ & $1-\mathrm{D}$ & $\begin{array}{l}\text { Unsteady } \\
\text { State }\end{array}$ & No & $\begin{array}{l}\text { Less } \\
\text { than } \\
\text { hourly }\end{array}$ & $\begin{array}{l}\text { Less } \\
\text { than } \\
\text { hourly }\end{array}$ & $\begin{array}{c}\text { Little } \\
\text { Pine } \\
\text { Creek, } \\
\text { Indiana }\end{array}$ & $\begin{array}{l}\text { SEE } \\
(0.7)\end{array}$ & $\begin{array}{c}\text { Younus et } \\
\text { al., } 2000\end{array}$ \\
\hline $\begin{array}{c}\text { HEC - } \\
\text { RAS }\end{array}$ & $1-\mathrm{D}$ & $\begin{array}{c}\text { Unsteady } \\
\text { State }\end{array}$ & No & $\begin{array}{l}\text { Less } \\
\text { than } 1 \mathrm{~s}\end{array}$ & $\begin{array}{l}\text { Less } \\
\text { than } 1 \mathrm{~s}\end{array}$ & $\begin{array}{c}\text { Swan } \\
\text { Creek, } \\
\text { Ontario, } \\
\text { Canada }\end{array}$ & $\begin{array}{c}\mathrm{ME} \\
(0.4,0.7)\end{array}$ & $\begin{array}{c}\text { Brunner, } \\
2010\end{array}$ \\
\hline $\begin{array}{c}\text { MIKE } \\
11\end{array}$ & 1-D & $\begin{array}{l}\text { Unsteady } \\
\text { State }\end{array}$ & No & $\begin{array}{l}\text { Less } \\
\text { than } 1 \mathrm{~s}\end{array}$ & $\begin{array}{l}\text { Less } \\
\text { than } 1 \mathrm{~s}\end{array}$ & $\begin{array}{l}\text { Snake } \\
\text { River, } \\
\text { Idaho }\end{array}$ & $\begin{array}{c}\text { MAE } \\
(0.1-0.5) \\
\text { RMSE } \\
(0.2-0.6)\end{array}$ & $\begin{array}{c}\text { Danish } \\
\text { Hydraulics } \\
\text { Institute, } \\
1993\end{array}$ \\
\hline $\begin{array}{l}\text { Heat } \\
\text { Source }\end{array}$ & $1-\mathrm{D}$ & Steady state & Yes & $\begin{array}{l}\text { Less } \\
\text { than } 1 \mathrm{~s}\end{array}$ & $\begin{array}{l}\text { Less } \\
\text { than } 1 \mathrm{~s}\end{array}$ & N.A. & N.A. & $\begin{array}{c}\text { Boyd and } \\
\text { Kasper, } \\
2003\end{array}$ \\
\hline $\begin{array}{c}\text { MIKE } \\
21\end{array}$ & $2-\mathrm{D}$ & $\begin{array}{c}\text { Unsteady } \\
\text { State }\end{array}$ & No & $\begin{array}{l}\text { Less } \\
\text { than } 1 \mathrm{~s}\end{array}$ & $\begin{array}{l}\text { Less } \\
\text { than } 1 \mathrm{~s}\end{array}$ & N.A. & N.A. & $\begin{array}{c}\text { Danish } \\
\text { Hydraulics } \\
\text { Institute, } \\
1996\end{array}$ \\
\hline $\begin{array}{c}\text { CE- } \\
\text { QUAL- } \\
\text { W2 } \\
\text { V3.7 }\end{array}$ & $2-\mathrm{D}$ & $\begin{array}{l}\text { Unsteady } \\
\text { State }\end{array}$ & Yes & $\begin{array}{l}\text { Less } \\
\text { than } 1 \mathrm{~s}\end{array}$ & $\begin{array}{l}\text { Less } \\
\text { than } 1 \mathrm{~s}\end{array}$ & $\begin{array}{c}\text { Clackam } \\
\text { as River, } \\
\text { Oregon }\end{array}$ & $\begin{array}{c}\text { ME } \\
( \pm 0.01- \\
\pm 0.15) \\
\text { MAE } \\
(0.02- \\
0.69) \\
\text { RMSE } \\
(0.03- \\
0.86)\end{array}$ & $\begin{array}{c}\text { Cole \& } \\
\text { Wells, } 2011\end{array}$ \\
\hline
\end{tabular}

\subsubsection{Models Review Summary}


Limited by time, this river temperature model review study could not be comprehensive: only a few existing models were reviewed, and only one example application were reviewed for each model. However, this review study still revealed some facts in the river temperature modeling field:

- Statistically-based models are easy to build, but the simulation results are generally not accurate, and models cannot be adjusted to reflect future changes.

- Some of the very popular physically-based models, like QUAL2K, only simulate temperature on daily basis, giving simulation results like daily average temperature, maximum daily temperature. However, continuous temperature is very important for assessing fish species living conditions and making regulation rules.

- 3-D river temperature modeling example could not be found, and 2-D river temperature modeling example could only be found using CE-QUAL-W2.

- According to example applications that were reviewed, both CE-QUAL-W2 model and MIKE 11 model produce accurate continuous temperature simulation. 


\subsection{Willamette Model Using CE-QUAL-W2 V3.1}

In 2004, to assist the Oregon Department of Environmental Quality developing a TMDL for temperature in the Willamette River Basin, river temperature models were built for main stem of Willamette River and all the major tributaries (except Tualatin River where a TMDL already existed). CE-QUAL-W2 Version 3.1 (Cole and Wells, 2002) was chosen as the appropriate model for this system with the following reasons: the ability to model stratified water quality; the ability to model temperature basing on dynamic shading; the ability to various complex hydraulic structures included in the model (Berger et al., 2004); and also very importantly, the fact that many reservoirs within the systems were already modeled with CE-QUAL-W2, which made it easier to prepare input data for river models.

Berger et al. (2004) developed hydrodynamic and water temperature model for Lower Willamette River (including Columbia River from Beaver Army Terminal to Bonneville Dam, and Willamette River from river mouth to RM 26.5), Middle Willamette River (RM 26.5 to RM 85), Upper Willamette River (RM 85 to RM 187), Clackamas River (mouth to RM 26), Long Tom River (mouth to RM 26), McKenzie River (McKenzie River from mouth to RM 56, and South Fork McKenzie River to RM 4), Coast Fork/ Middle Fork River (Middle Fork Willamette from mouth to RM 17, Coast Fork Willamette from mouth to RM 30). Figure 1 shows the location of these river systems in the Willamette River Basin. The simulation period varied between models. All models were at least built for the summer of 2001 and 2002, and some models' simulation period also included the spring and fall of those years. These seven models were able to 
represent the temperature and hydraulic regime of these river systems. The RMSE for temperature for these models were all less than $1{ }^{\circ} \mathrm{C}$.

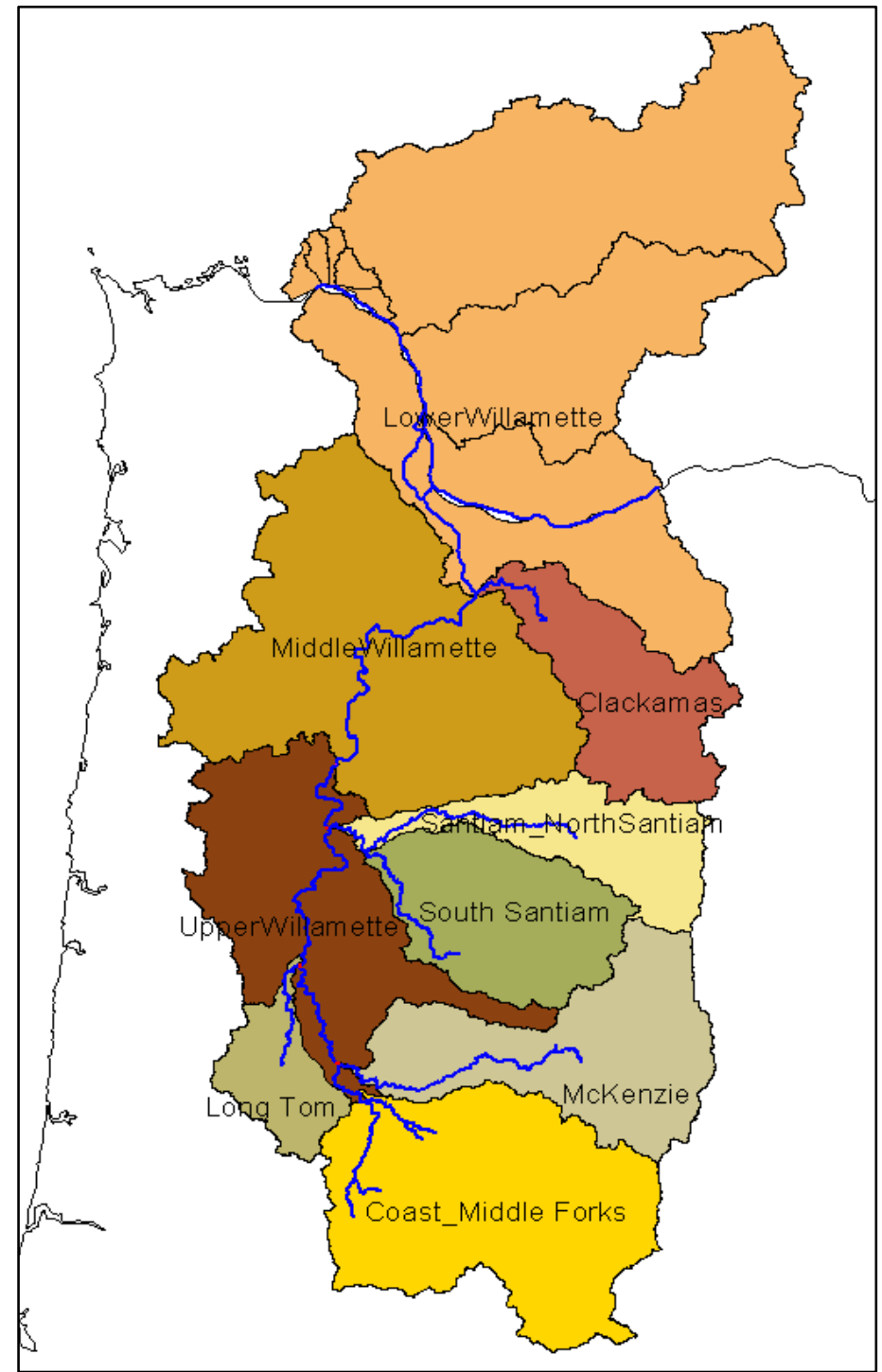

Figure 1: River systems with delineated watersheds in the Willamette River Basin

Sullivan and Rounds (2004) built a hydrodynamic and water temperature model for the North Santiam River and the Santiam River. The RMSE of hourly temperature comparison between simulation results and measured data ranged from $0.50{ }^{\circ} \mathrm{C}$ to $1.16{ }^{\circ} \mathrm{C}$ during the simulation period in 2001 and 2002. 


\title{
Chapter 2 Converting Willamette River Models from V3.1 to
}

\author{
V3.7

\subsection{Converting all Willamette Models from V3.1 to V3.7} \\ CE-QUAL-W2 is a public domain and open source code, and it has been updated over \\ the years. By the year 2012, CE-QUAL-W2 was updated to Version 3.7 from Version 3.1 \\ in year 2002 (Cole and Wells, 2011). There were several major differences between \\ Version 3.1 and Version 3.7. Some of the new features included addition of the following \\ new algorithms:
}

- Suspended solid velocity;

- Zooplankton, macrophyte, and state variables;

- Updated TKE algorithm;

- User-defined roughness height of the water for correction of the vertical velocity wind profile;

- New output format for TECPLOT;

- Updates to NO3, organic decay rate, and CBOD;

- The ability to specify the number of processors;

- The ability of using automatic selective withdrawal, fish habitat volumes, environmental performance criteria, artificial aeration, and initial water surface and velocity computations;

- The ability to control the interpolation of the maximum time step; 
- Slopec as the hydraulic equivalent slope for a river channel;

- The ability to interpolate gate or weir inflow data;

- The ability to specify whether the pipes or pumps are controlled by time series or partially open gate;

- The ability to specify whether the grid is interpreted as rectangular in depth or trapezoidal.

In 2012, six Willamette River System models were converted from CE-QUAL-W2 Version 3.1 to Version 3.7. There were two objectives to convert those models: (1) to test the accuracy and other performance of CE-QUAL-W2 Version 3.7 model; (2) to update and calibrate the Willamette River System models to the current newest version of CEQUAL-W2.

Converting Willamette River System models from V 3.1 to V 3.7 included: (1) changing the control file, graph file and other files to make the models able to run with the new Version 3.7 executable; (2) adjusting model setting to make the models run through the simulation periods; and (3) re-examine the model calibration to make sure the models calibrated to an acceptable degree.

\subsection{Testing of CE-QUAL-W2 V3.7}

Six river models within the Willamette River Basin were tested with CE-QUAL-W2 Version 3.7, they were Lower Willamette River/ Columbia River, Middle Willamette River, Upper Willamette River, Clackamas River, McKenzie River, Long Tom River. Attempts have been made to test CE-QUAL-W2 Version 3.7 on Coast Fork/ Middle Fork 
Willamette River, North Santiam River and South Santiam River, however due to stability issues and the difficulty to calibrate, together with the limited time available, this work was not attempted. Calibration results of applying CE-QUAL-W2 Version 3.7 on each of the six river systems were described in the following sections.

\subsubsection{Lower Willamette River / Columbia River}

\section{Introduction}

Lower Willamette River / Columbia River model domain includes part of Willamette River: from Willamette Falls (RM 26.8) to Willamette River Mouth (RM 0), and part of Columbia River: from Bonneville Dam (RM 145) to Beaver Army Terminal (RM 53.8). Although Willamette River is not directly connected to the ocean, flow characteristics in Lower Willamette River are strongly influenced by the tide. The model grid is shown in Figure 2.

In the CE-QUAL-W2 Version 3.1 model, a water level boundary condition was set up at Beaver Army Terminal to incorporate tidal fluctuations.

Following the setting up of Version 3.1 model, the CE-QUAL-W2 Version 3.7 model was set up as 2 water bodies, including 13 branches, 462 segments and 28 layers. There were 16 tributaries flowing into the system. 


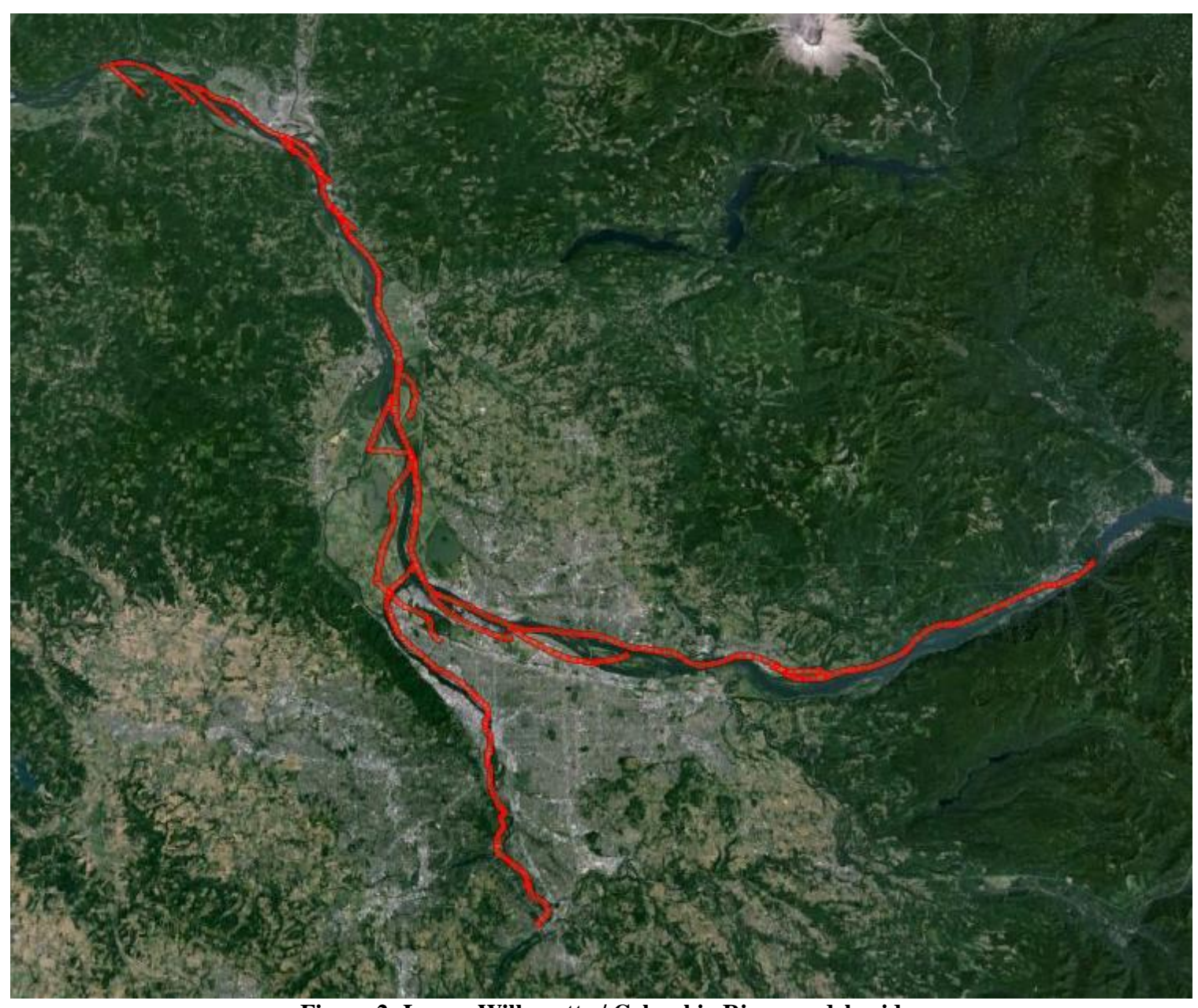

Figure 2: Lower Willamette / Columbia River model grid

\section{Hydrodynamics}

Flow rate and water surface elevation was first tested using the original setting in V3.1 model. As the model showed good agreement with data, no further calibrations were conducted.

\section{Year 2001}

The hydrodynamic calibration period in 2001 was from July to September. Figure 3 through 8 show the water level and flow comparison between model predictions and measured data. Error statistics are summarized in Table 2. Both the flow and water level 
predictions matched well with data at all the sites, and the water level fluctuation due to tidal effect was accurately captured. The root mean square error of flow at Segment 347 was $56.064 \mathrm{~m}^{3} / \mathrm{s}$, which was actually very small compared to the flow rate in river which was about $10,000 \mathrm{~m}^{3} / \mathrm{s}$.

Table 2: Lower Willamette River / Columbia River hydrodynamic calibration statistics, 2001

\begin{tabular}{|c|c|c|c|c|c|c|}
\hline \multicolumn{7}{|c|}{ Flow } \\
\hline Gage ID & $\mathrm{RM}$ & $\begin{array}{c}\text { Model } \\
\text { Segment }\end{array}$ & $\begin{array}{l}\text { Number of } \\
\text { Comparisons }\end{array}$ & $\mathrm{ME}, \mathrm{m}^{3} / \mathrm{s}$ & $\mathrm{AME}, \mathrm{m}^{3} / \mathrm{s}$ & RMSE, $\mathrm{m}^{3} / \mathrm{s}$ \\
\hline USGS 14246900 & 53.00 & 347 & 4208 & -43.34 & 43.439 & 56.064 \\
\hline \multicolumn{7}{|c|}{ Water Level } \\
\hline Gage ID & $\mathrm{RM}$ & $\begin{array}{c}\text { Model } \\
\text { Segment }\end{array}$ & $\begin{array}{c}\text { Number of } \\
\text { Comparisons }\end{array}$ & $\mathrm{ME}, \mathrm{m}$ & AME, $m$ & RMSE, $\mathrm{m}$ \\
\hline USGS 14207770 & 26.48 & 2 & 2976 & 0.051 & 0.128 & 0.192 \\
\hline USGS 14211720 & 12.70 & 66 & 2976 & 0.027 & 0.122 & 0.17 \\
\hline USGS 14128870 & 144.50 & 118 & 5952 & 0.042 & 0.091 & 0.116 \\
\hline USGS 14144700 & 106.50 & 223 & 5952 & 0.039 & 0.13 & 0.169 \\
\hline ACOE SHNO3 & 85.75 & 270 & 7996 & 0.089 & 0.116 & 0.162 \\
\hline
\end{tabular}




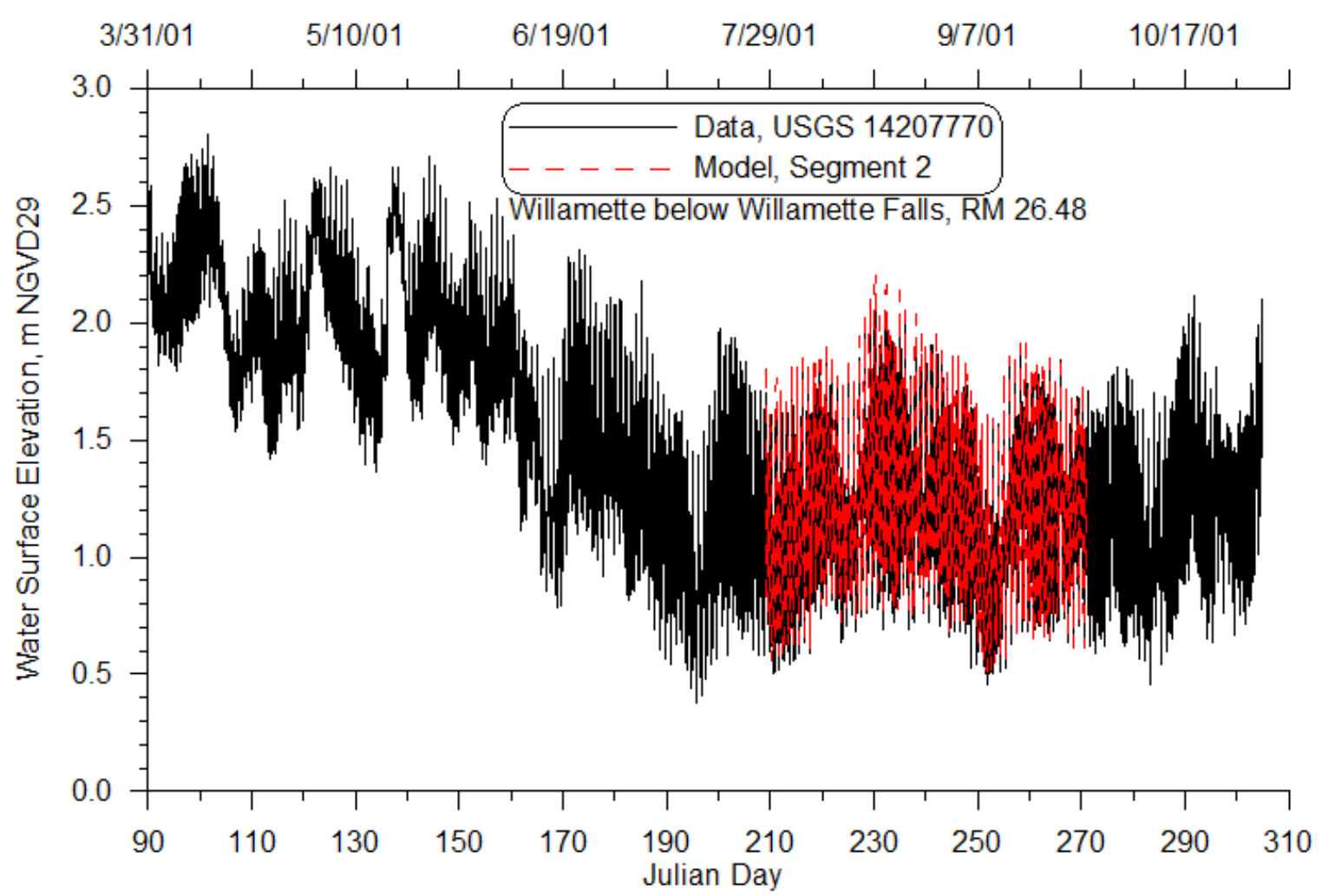

Figure 3: Willamette River below the Willamette Falls model-data water level comparison, 2001

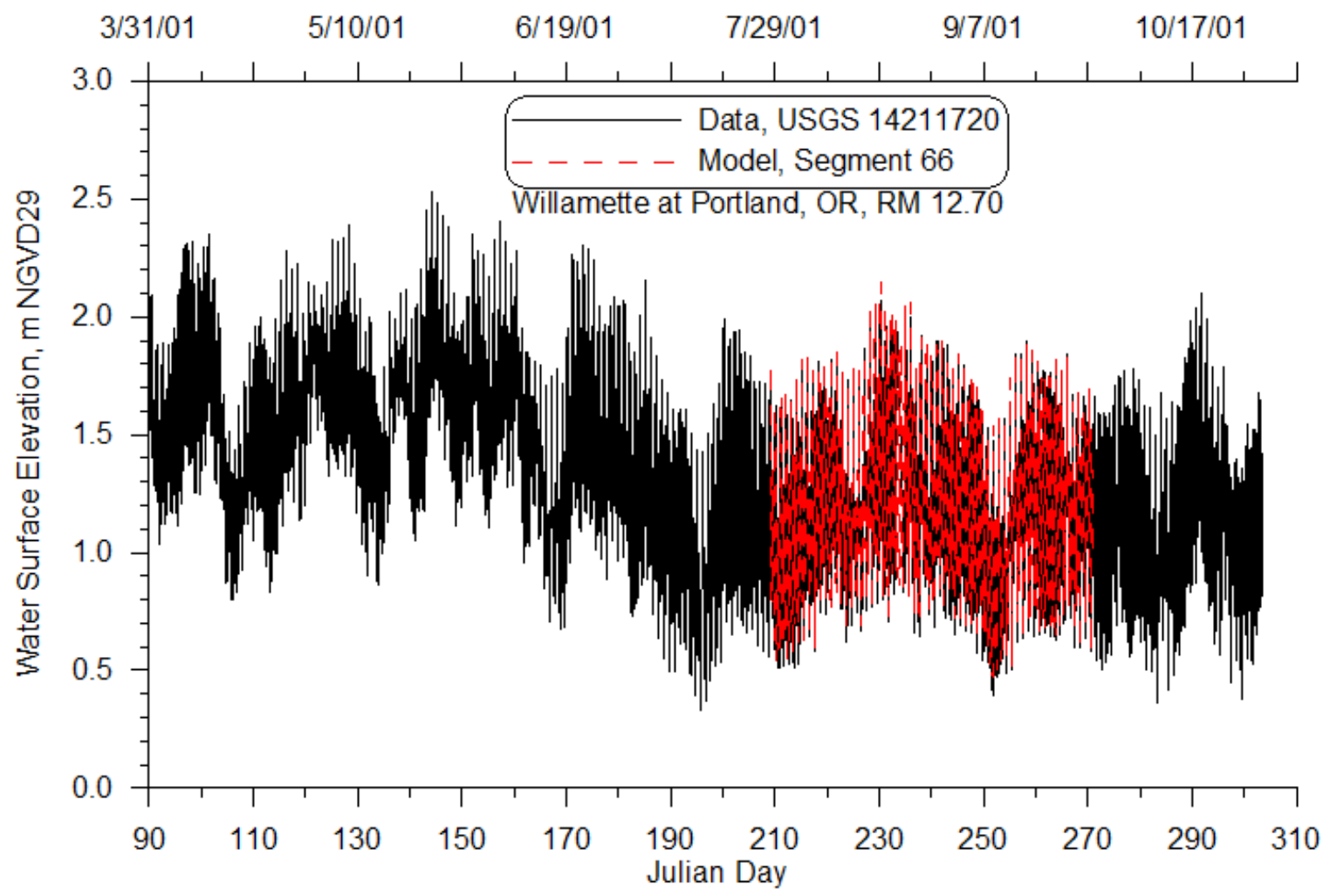

Figure 4: Willamette River at Portland model-data water level comparison, 2001 


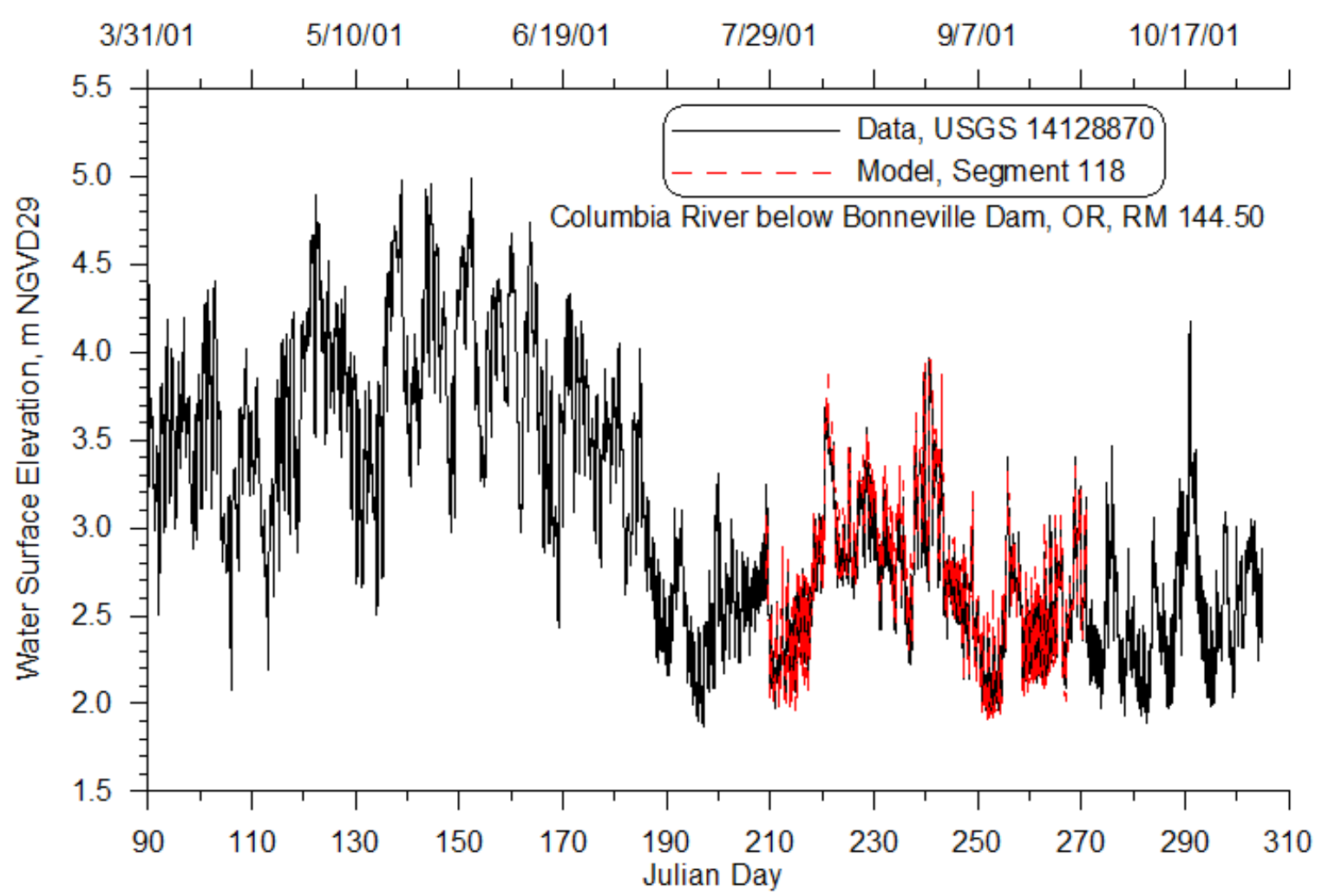

Figure 5: Columbia River below Bonneville Dam model-data water level comparison, 2001

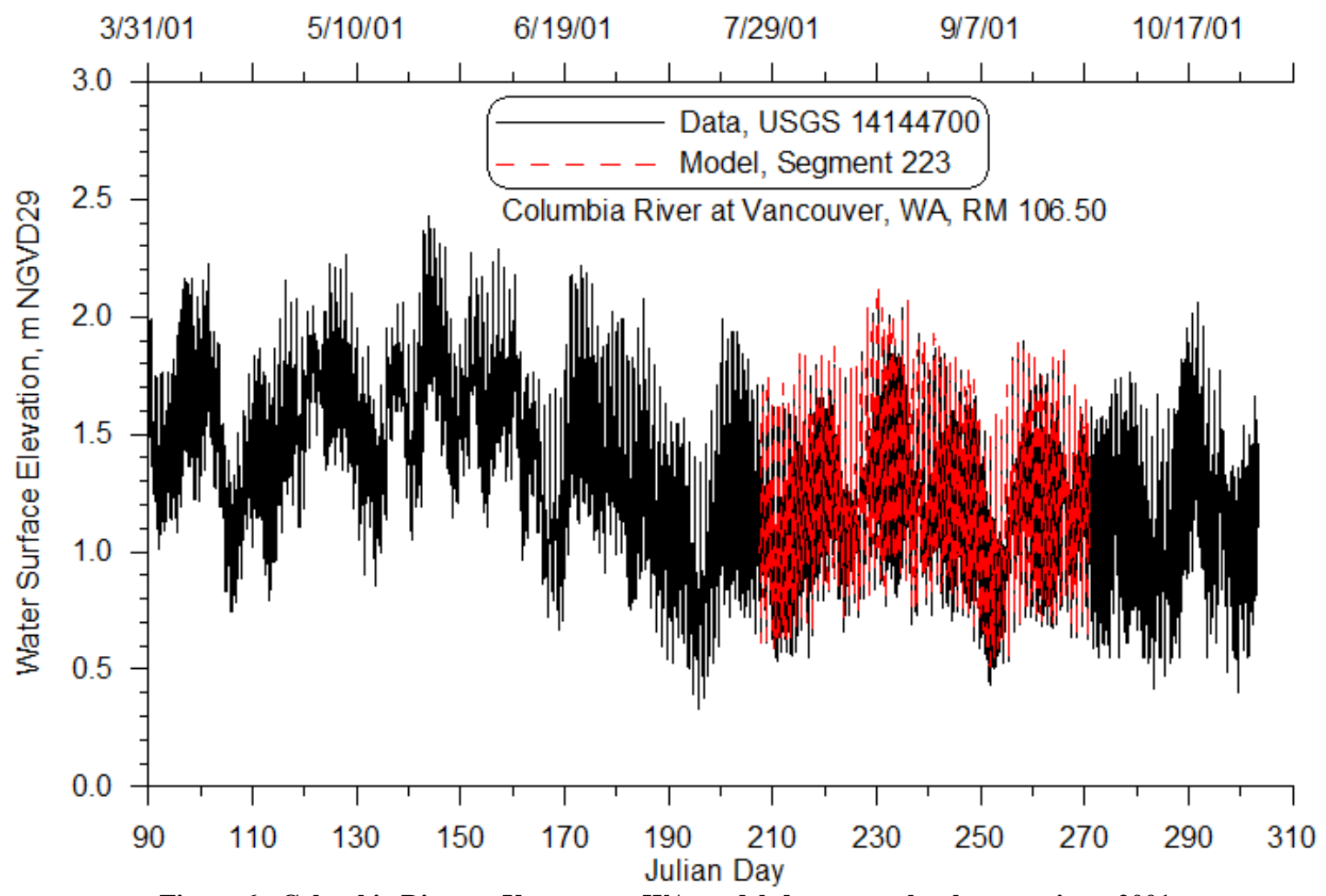

Figure 6 : Columbia River at Vancouver, WA model-data water level comparison, 2001 


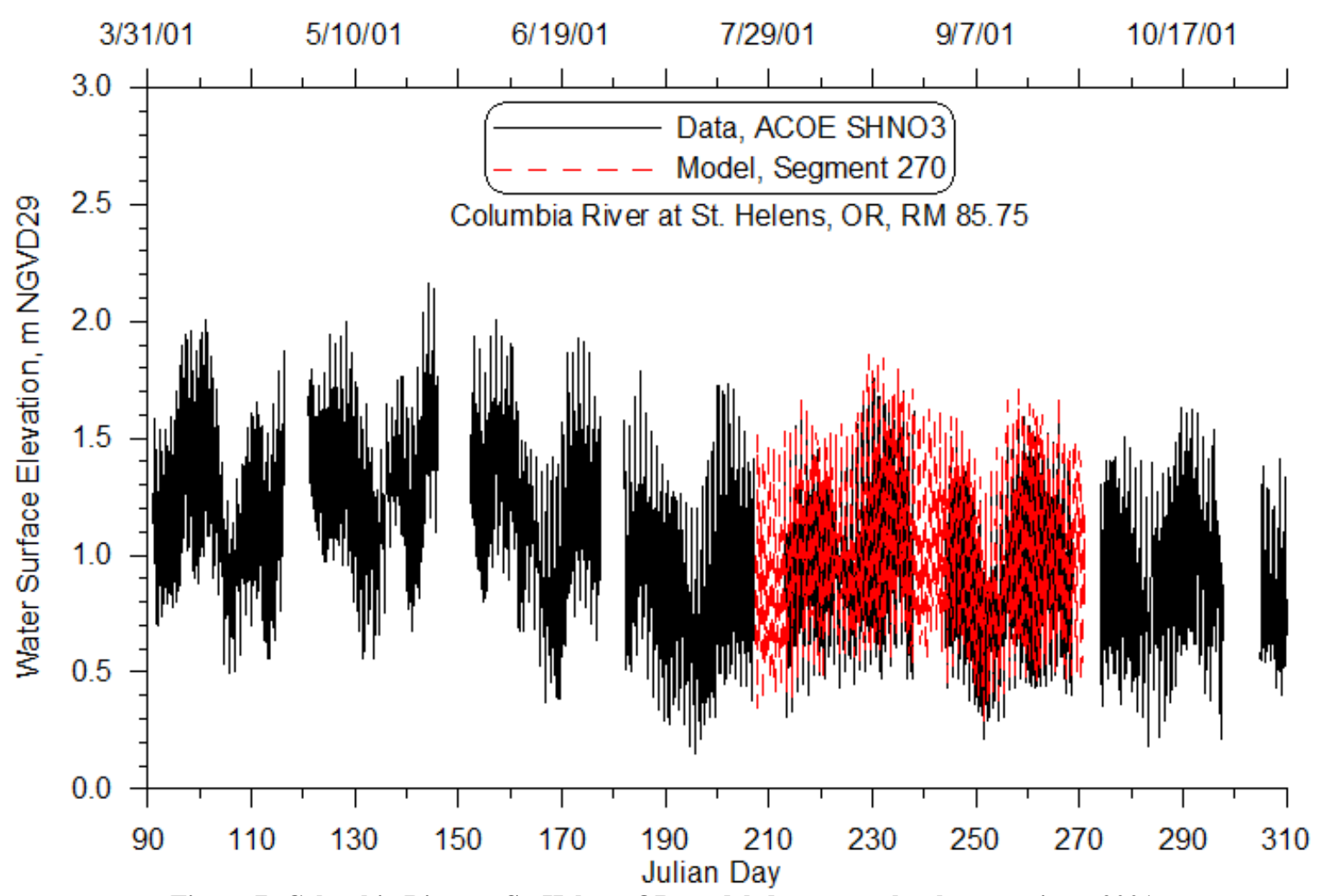

Figure 7: Columbia River at St. Helens, OR model-data water level comparison, 2001

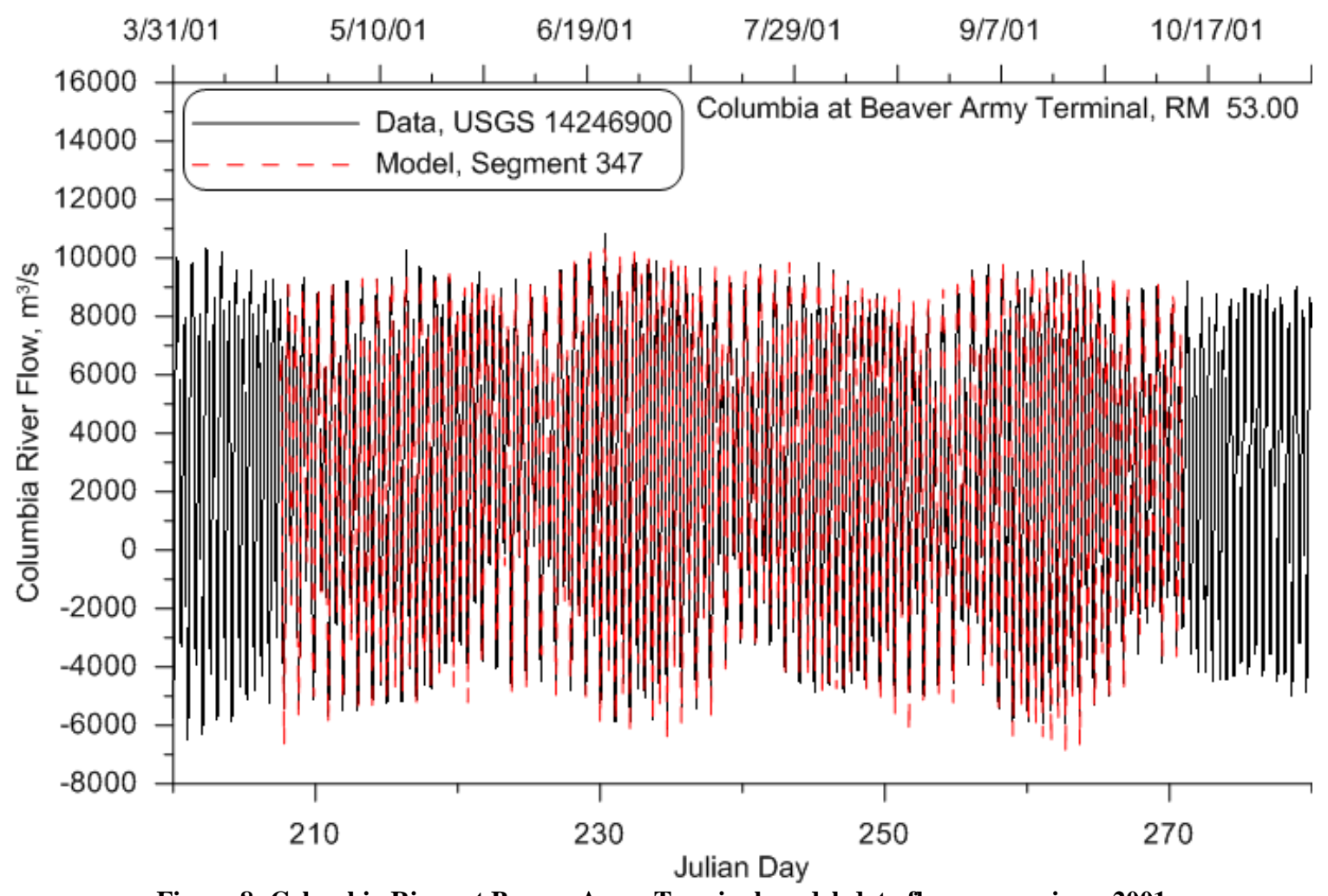

Figure 8: Columbia River at Beaver Army Terminal model-data flow comparison, 2001 


\section{Year 2002}

The hydrodynamic calibration period in 2002 was from April to September. Figure 9 through 14 show the water level and flow comparison between model predictions and measured data. Error statistics are summarized in Table 3. The water level was underestimated at high flow period (Julian Day 95-114) for several segments (Segment 2, $66,223)$. The reason could be inaccurate segment width at high water levels, or special hydrodynamic phenomenon that was unknown at high flow period. However, during summer and fall when river temperature is more critical, the model was better able to predict the water level.

Table 3: Lower Willamette River hydrodynamic calibration statistics, 2002

\begin{tabular}{|c|c|c|c|c|c|c|}
\hline \multicolumn{7}{|c|}{ Flow } \\
\hline Gage ID & $\mathrm{RM}$ & $\begin{array}{c}\text { Model } \\
\text { Segment }\end{array}$ & $\begin{array}{c}\text { Number of } \\
\text { Comparisons }\end{array}$ & $\mathrm{ME}, \mathrm{m}^{3} / \mathrm{s}$ & $\mathrm{AME}, \mathrm{m}^{3} / \mathrm{s}$ & RMSE, $\mathrm{m}^{3} / \mathrm{s}$ \\
\hline USGS 14246900 & 53.00 & 347 & 17446 & -14.525 & 14.874 & 28.392 \\
\hline \multicolumn{7}{|c|}{ Water Level } \\
\hline Gage ID & $\mathrm{RM}$ & $\begin{array}{c}\text { Model } \\
\text { Segment }\end{array}$ & $\begin{array}{c}\text { Number of } \\
\text { Comparisons }\end{array}$ & ME, $m$ & AME, $m$ & RMSE, $\mathrm{m}$ \\
\hline USGS 14207770 & 26.48 & 2 & 8352 & -0.198 & 0.224 & 0.396 \\
\hline USGS 14211720 & 12.70 & 66 & 8352 & -0.12 & 0.141 & 0.201 \\
\hline USGS 14128870 & 144.5 & 118 & 4175 & -0.006 & 0.114 & 0.15 \\
\hline USGS 14144700 & 106.50 & 223 & 16704 & -0.061 & 0.115 & 0.172 \\
\hline ACOE SHNO3 & 85.75 & 270 & 22128 & 0.035 & 0.136 & 0.186 \\
\hline
\end{tabular}




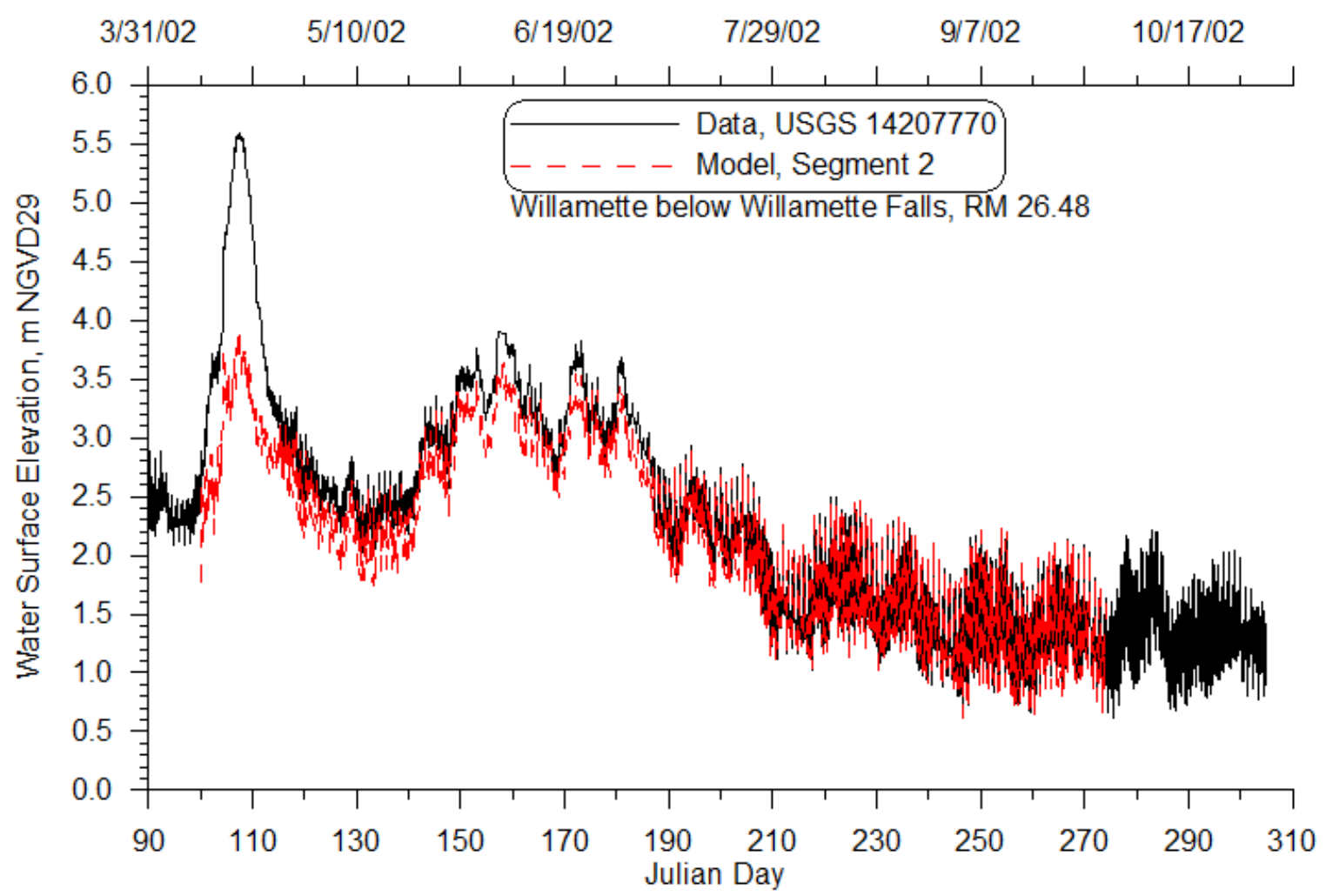

Figure 9: Willamette River below the Willamette Falls model-data water level comparison, 2002

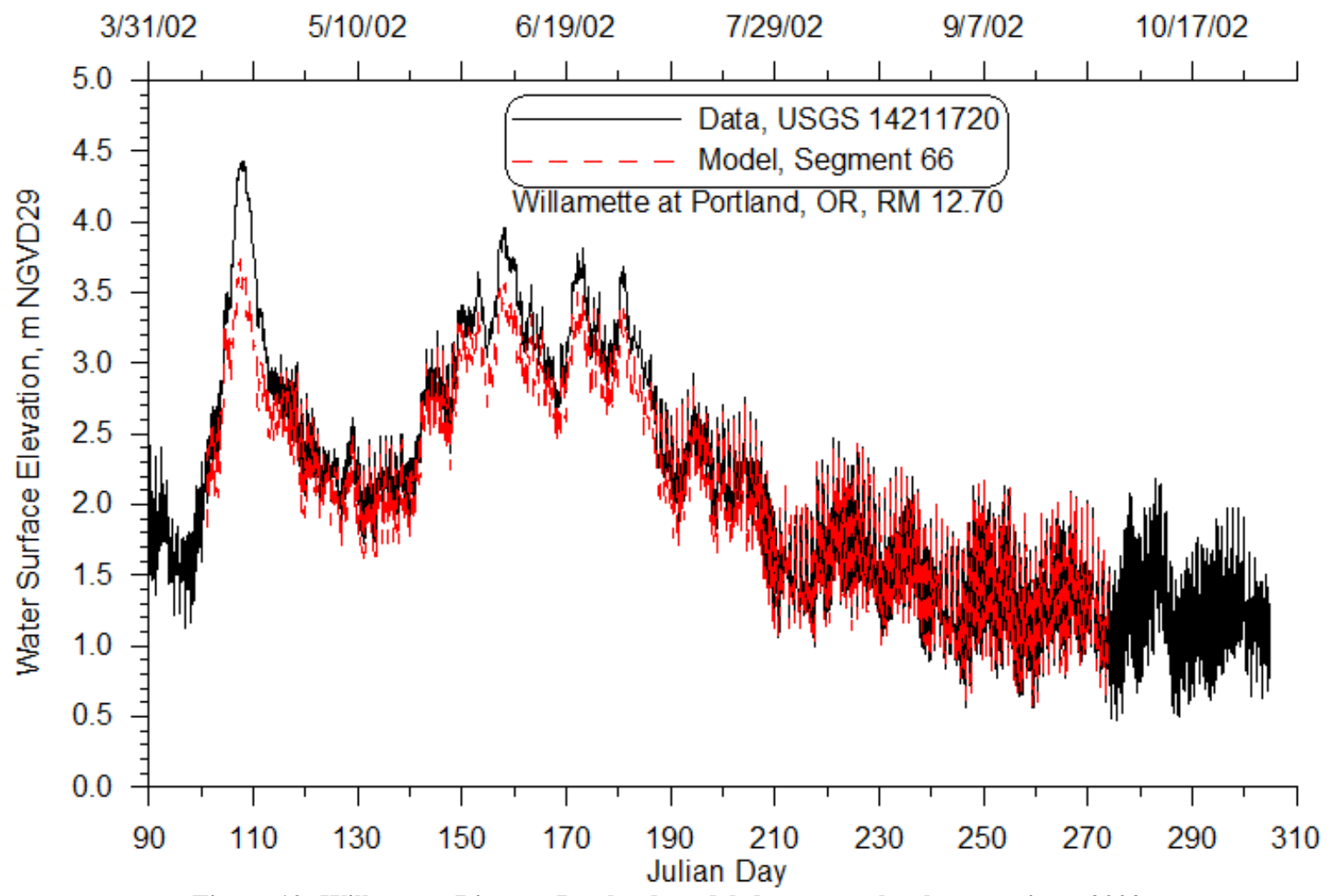

Figure 10: Willamette River at Portland model-data water level comparison, 2002 


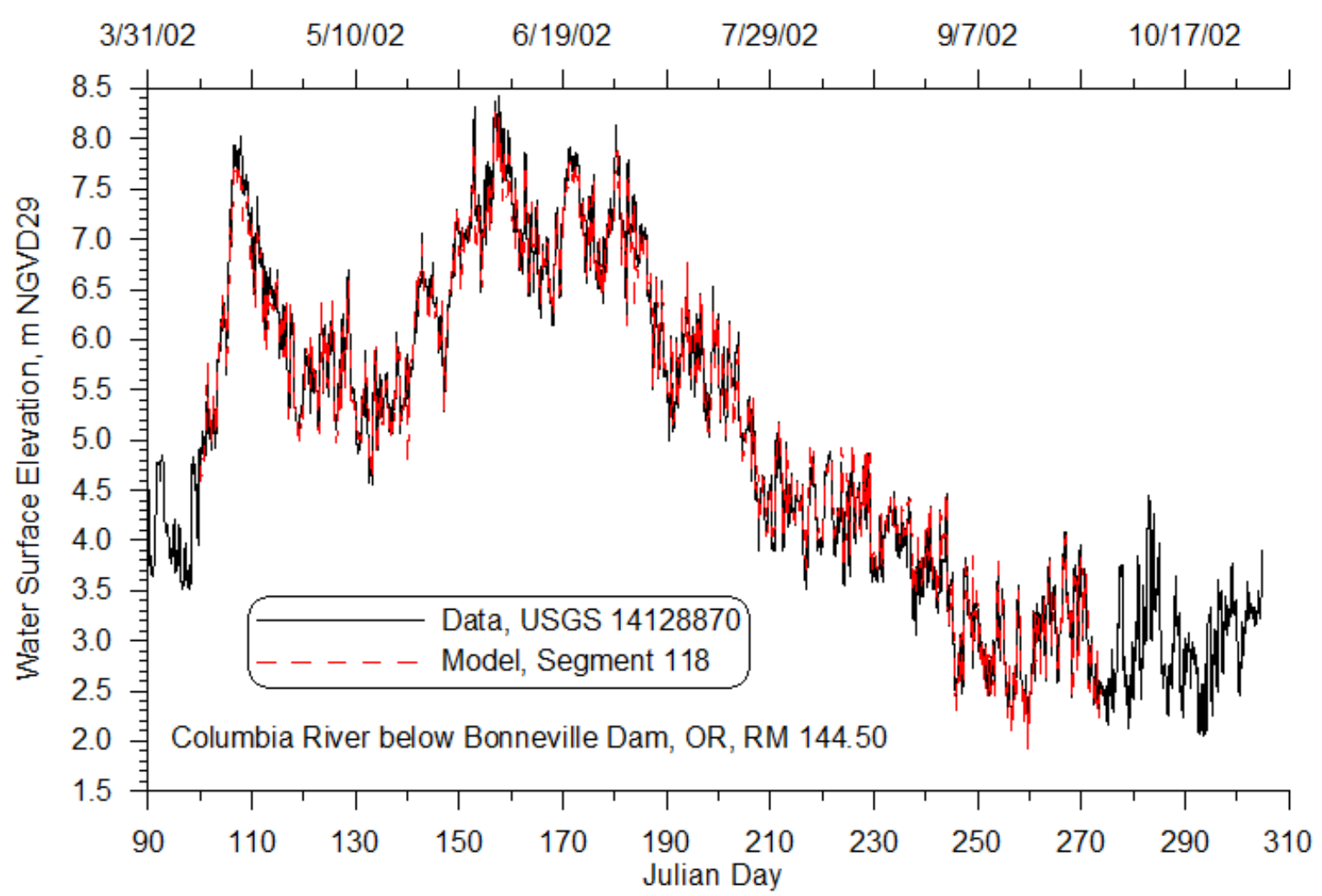

Figure 11: Columbia River below Bonneville Dam model-data water level comparison, 2002

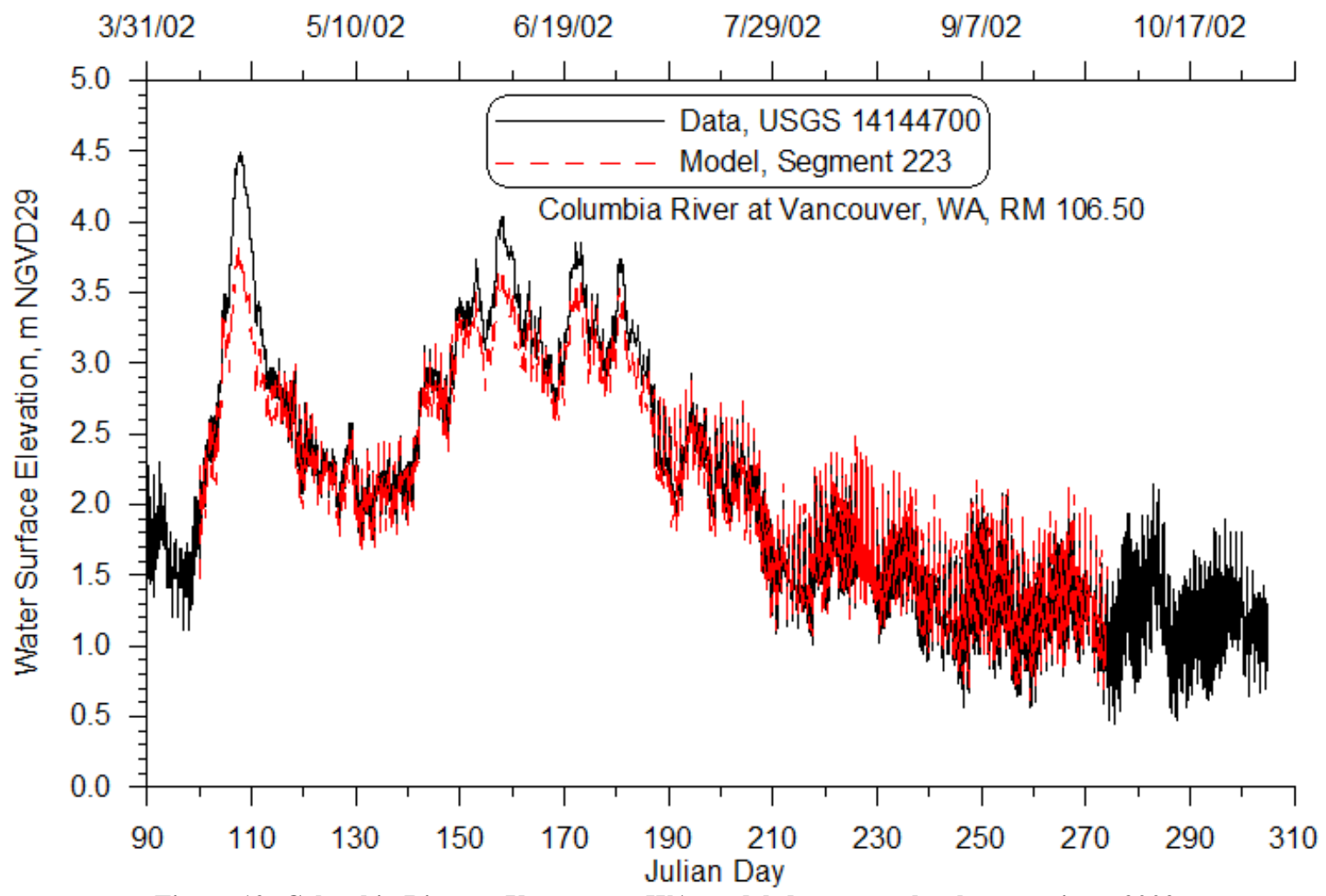

Figure 12: Columbia River at Vancouver, WA model-data water level comparison, 2002 


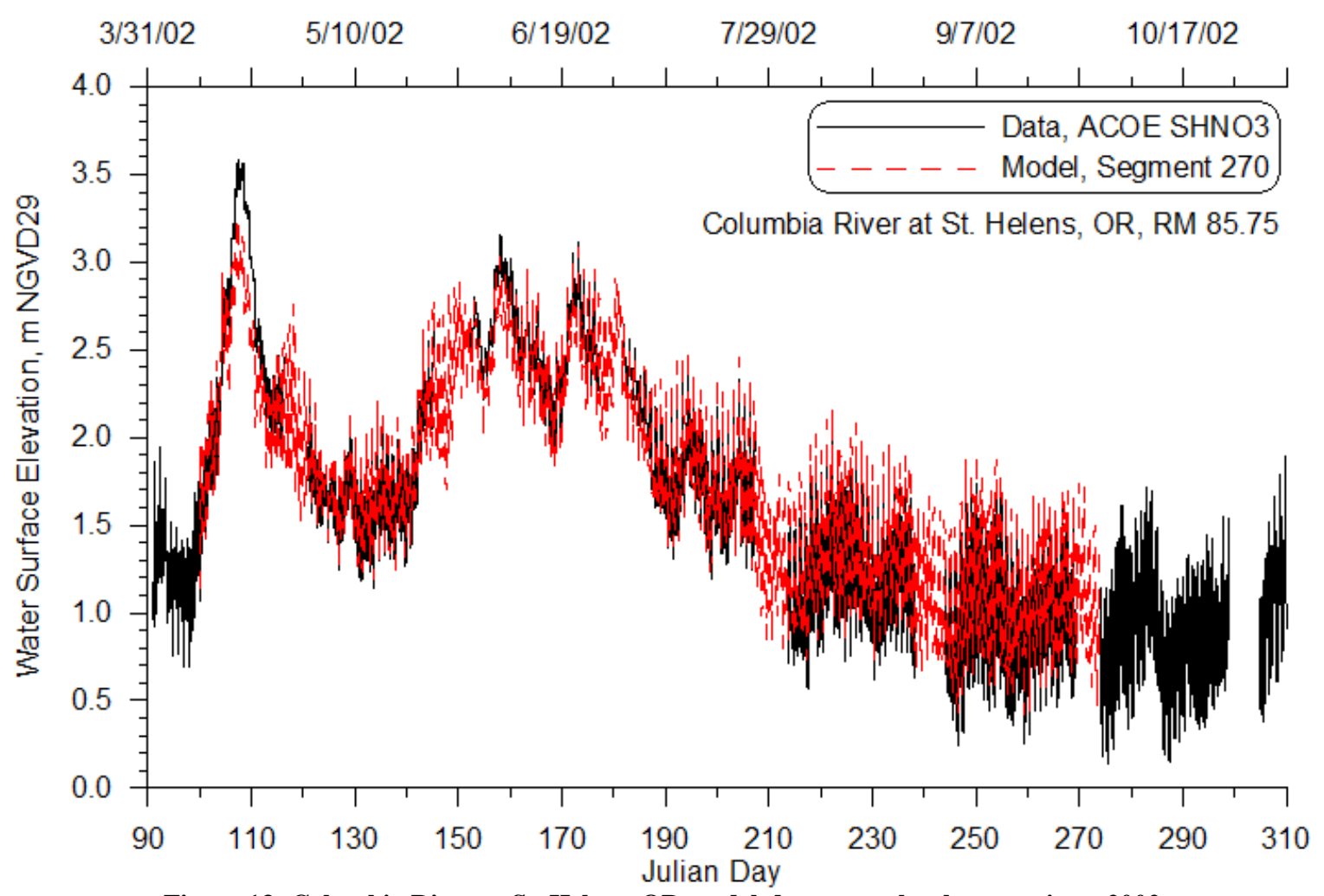

Figure 13: Columbia River at St. Helens, OR model-data water level comparison, 2002

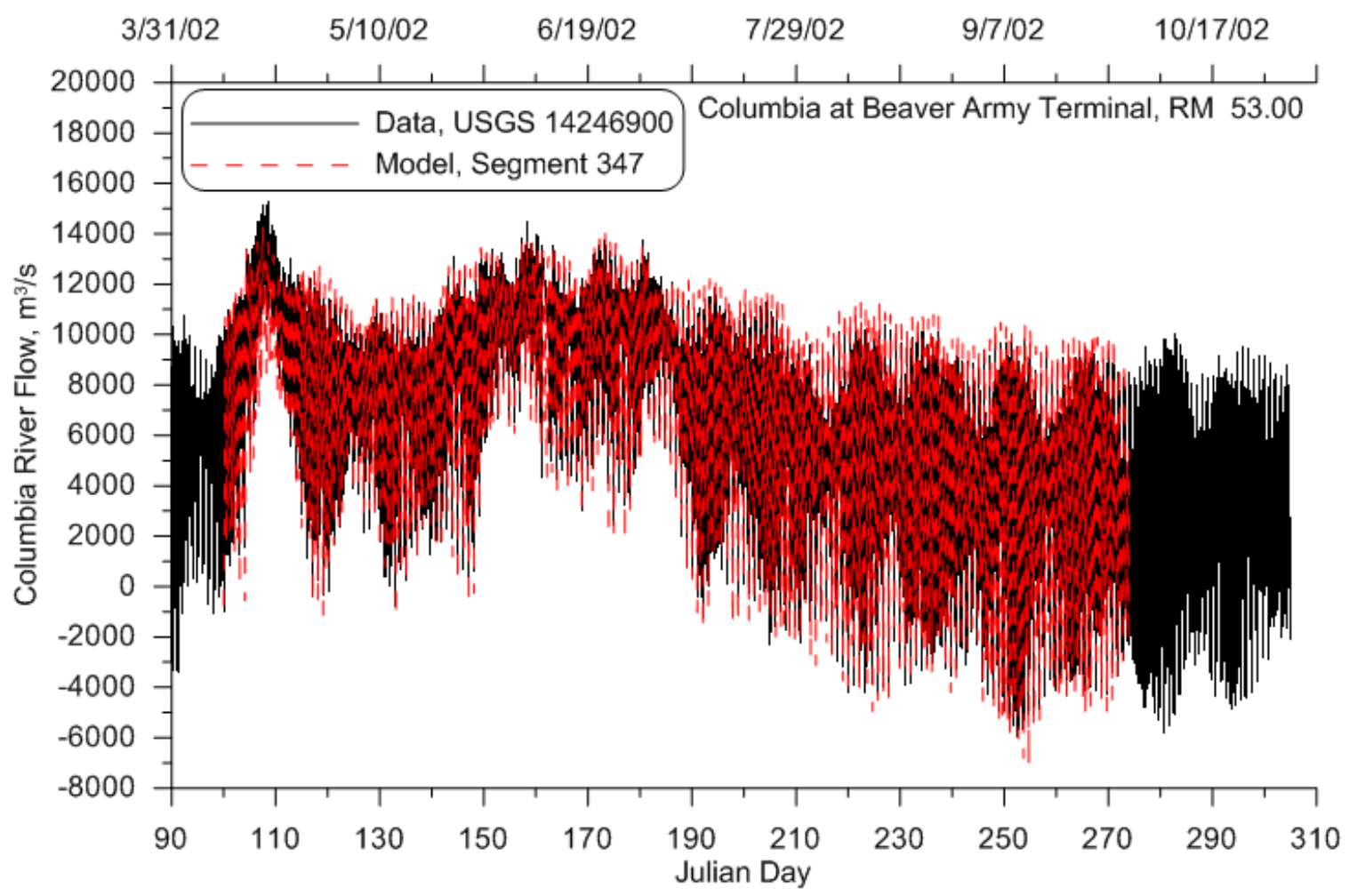

Figure 14: Columbia River at Beaver Army Terminal model-data flow comparison, 2002

\section{Temperature}




\section{Year 2001}

Figure 15 through 26 show the continuous temperature comparison between model predictions and measured data. Error statistics are summarized in Table 4. Predicted temperature matched data very well for all the 12 sites with the RMSEs below $0.64{ }^{\circ} \mathrm{C}$. The simulation results were similar with the V3.1 model results; however there were some small differences, with V3.7 better predicting on some sites, and V3.1 better predicting on other sites.

Table 4: Willamette River continuous water temperature calibration model-data error statistics, 2001

\begin{tabular}{|c|c|c|c|c|c|c|}
\hline \multirow[b]{2}{*}{ Site ID } & \multirow[b]{2}{*}{ RM } & \multirow[b]{2}{*}{$\begin{array}{c}\text { Model } \\
\text { Segmen } \\
\mathrm{t}\end{array}$} & \multicolumn{4}{|c|}{ Continuous Temperature } \\
\hline & & & $\begin{array}{c}\text { Number of } \\
\text { Comparison } \\
\mathrm{s}\end{array}$ & $\mathrm{ME},{ }^{\circ} \mathrm{C}$ & $\mathrm{AME},{ }^{\circ} \mathrm{C}$ & $\mathrm{RMSE},{ }^{\circ} \mathrm{C}$ \\
\hline PGE_2590 A & 26.24 & 2 & 1426 & -0.051 & 0.256 & 0.322 \\
\hline PGE_2590 B & 26.24 & 2 & 1488 & -0.232 & 0.31 & 0.398 \\
\hline LASAR 26745 Shallow & 20.75 & 33 & 1488 & -0.064 & 0.371 & 0.447 \\
\hline LASAR 26745 Deep & 20.75 & 33 & 1488 & -0.011 & 0.386 & 0.466 \\
\hline LASAR 26760 & 11.10 & 107 & 160 & -0.186 & 0.222 & 0.273 \\
\hline $\begin{array}{c}\text { USGS4 } \\
53651122022200\end{array}$ & 140.40 & 134 & 1488 & 0.025 & 0.12 & 0.168 \\
\hline $\begin{array}{c}\text { USGS } \\
453630122021400\end{array}$ & 140.40 & 134 & 1279 & 0.029 & 0.061 & 0.077 \\
\hline $\begin{array}{c}\text { USGS } \\
453439122223900\end{array}$ & 121.75 & 187 & 1284 & -0.058 & 0.137 & 0.169 \\
\hline $\begin{array}{c}\text { USGS } 14129400 \\
\text { LASAR } 26752\end{array}$ & 121.50 & 188 & 2975 & -0.042 & 0.123 & 0.158 \\
\hline LASAR 26747 & 85.50 & 271 & 163 & -0.42 & 0.423 & 0.492 \\
\hline LASAR 26754 & 67.00 & 314 & 989 & 0.463 & 0.499 & 0.608 \\
\hline USGS 14246900 & 53.00 & 347 & 5952 & -0.074 & 0.264 & 0.636 \\
\hline
\end{tabular}




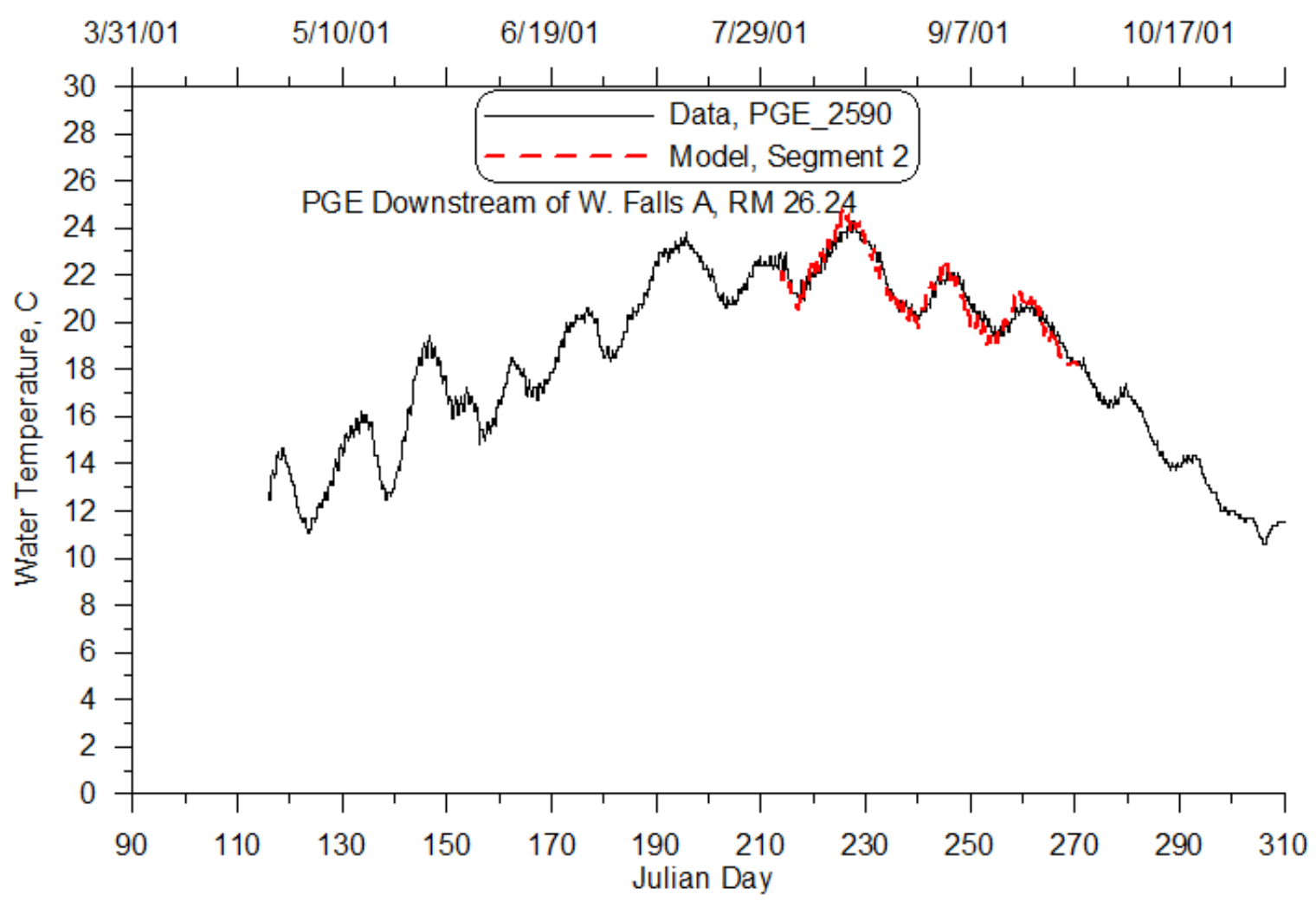

Figure 15: Willamette River downstream of the Willamette Falls site A model-data continuous temperature

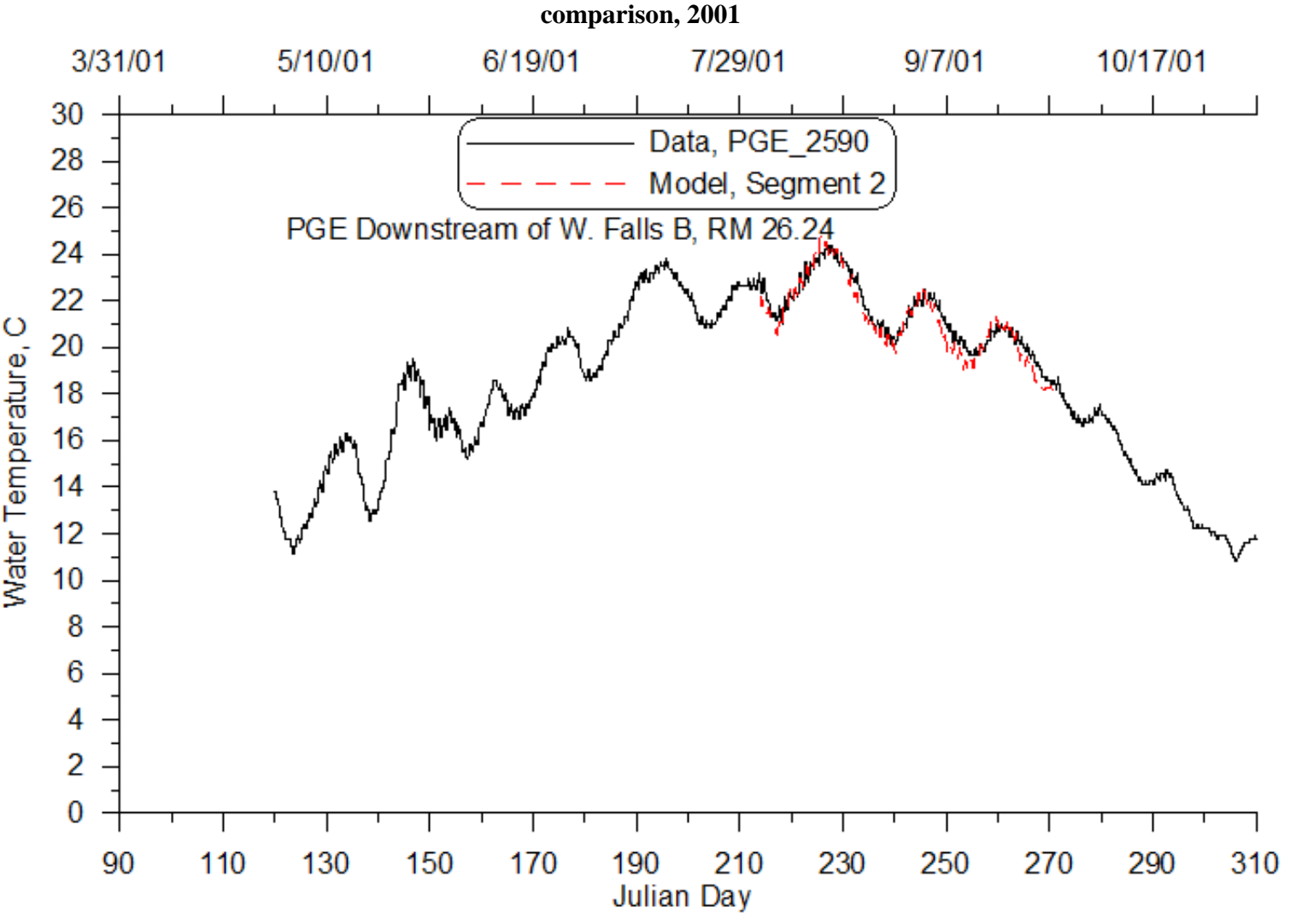


Figure 16: Willamette River downstream of the Willamette Falls site B continuous model-data temperature comparison, 2001

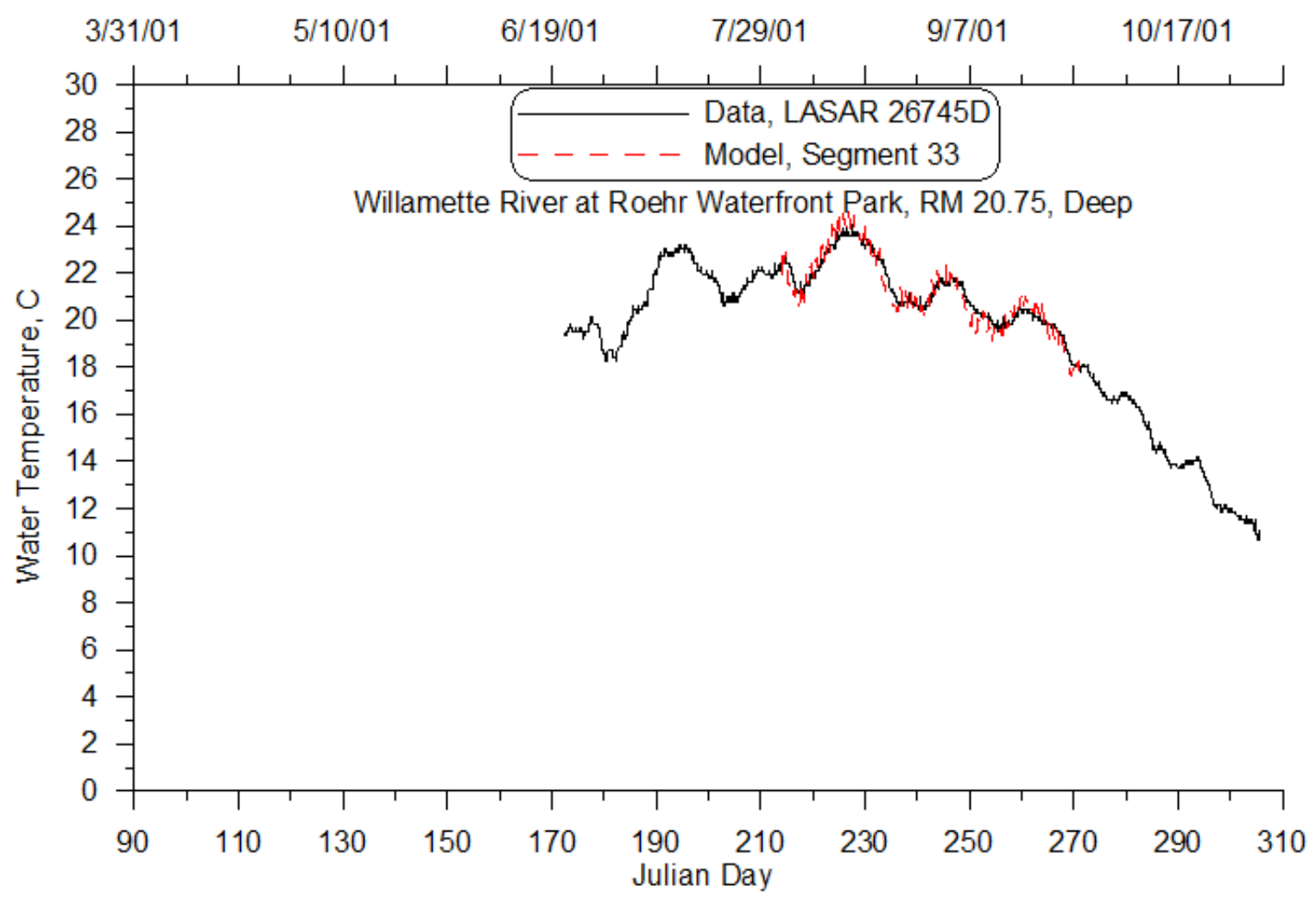

Figure 17: Willamette River at Roehr Waterfront Park (shallow) model-data continuous temperature comparison, 


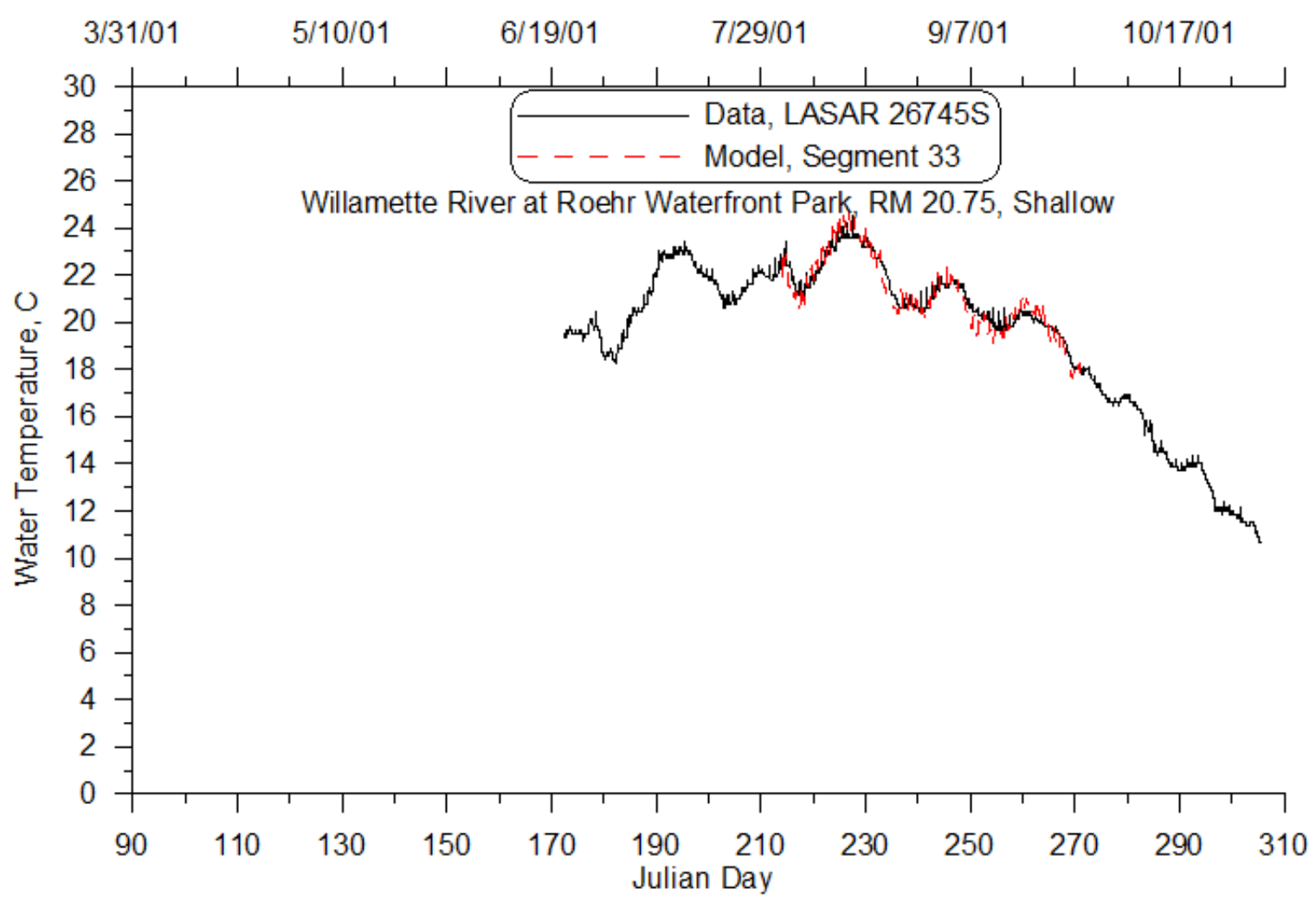

Figure 18: Willamette River at Roehr Waterfront Park (deep) model-data continuous temperature comparison, 2001

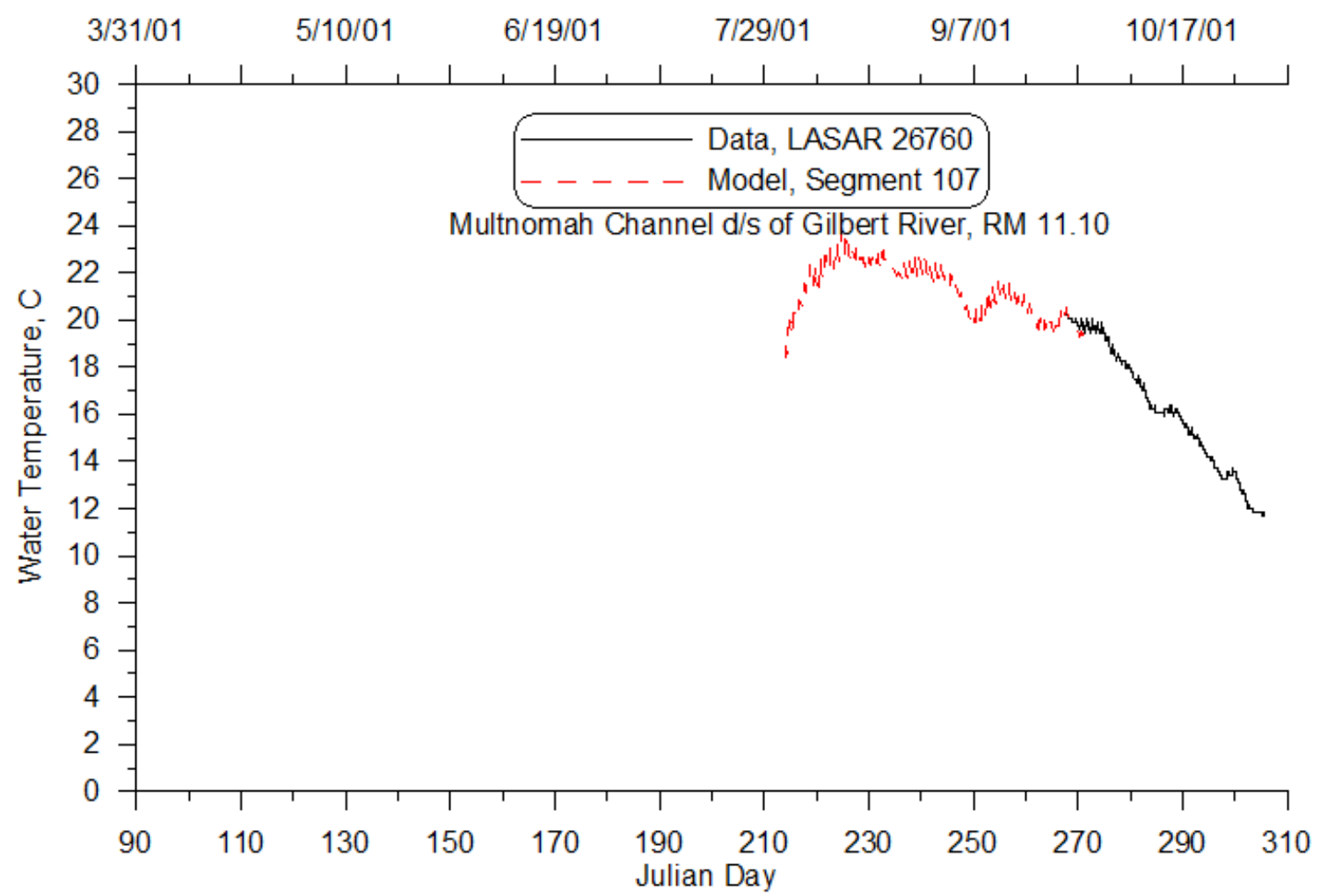

Figure 19: Multnomah Channel downstream of Gilbert River model-data continuous temperature comparison, 2001 


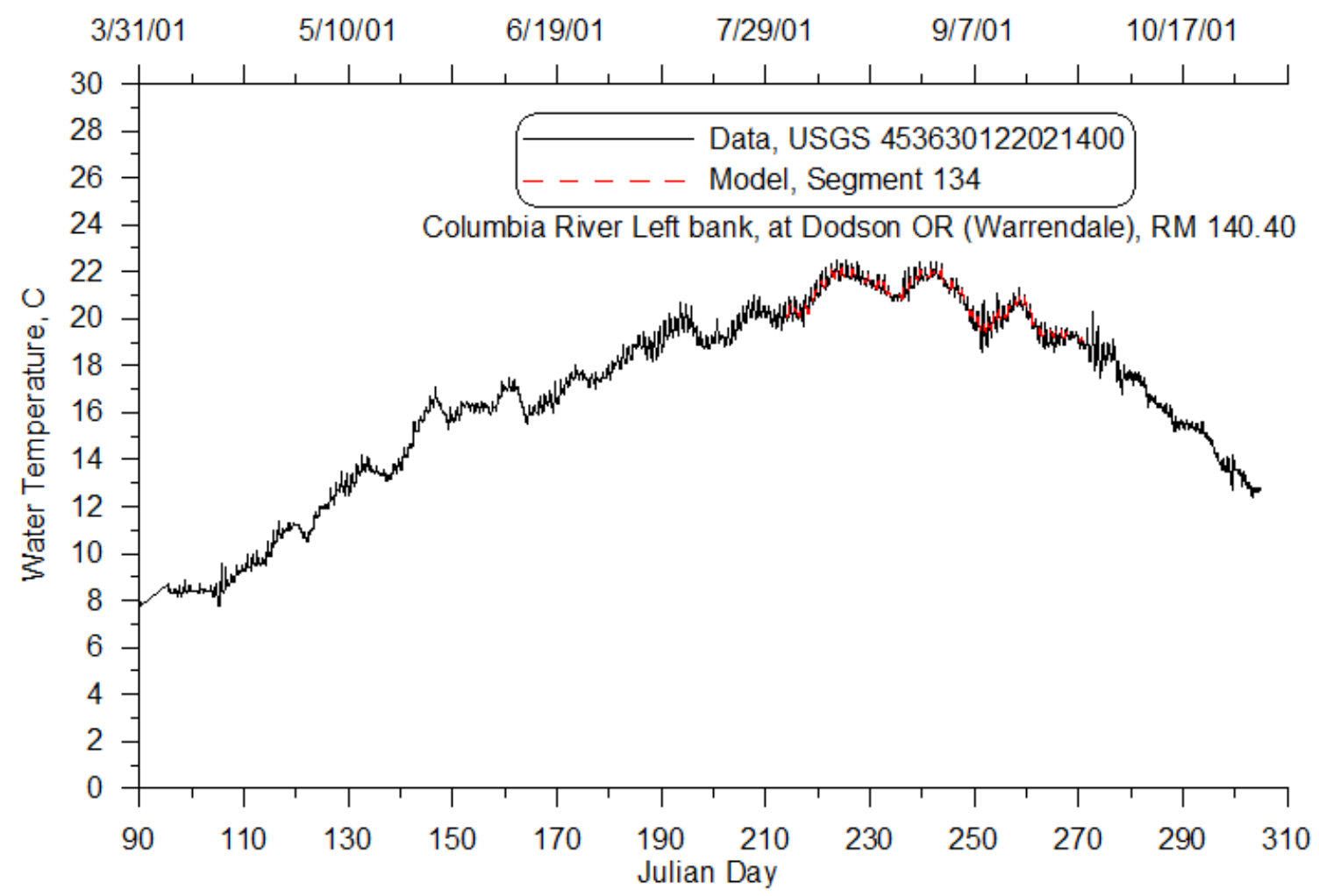

Figure 20: Columbia River Left Bank at Dodson continuous model-data temperature comparison, 2001

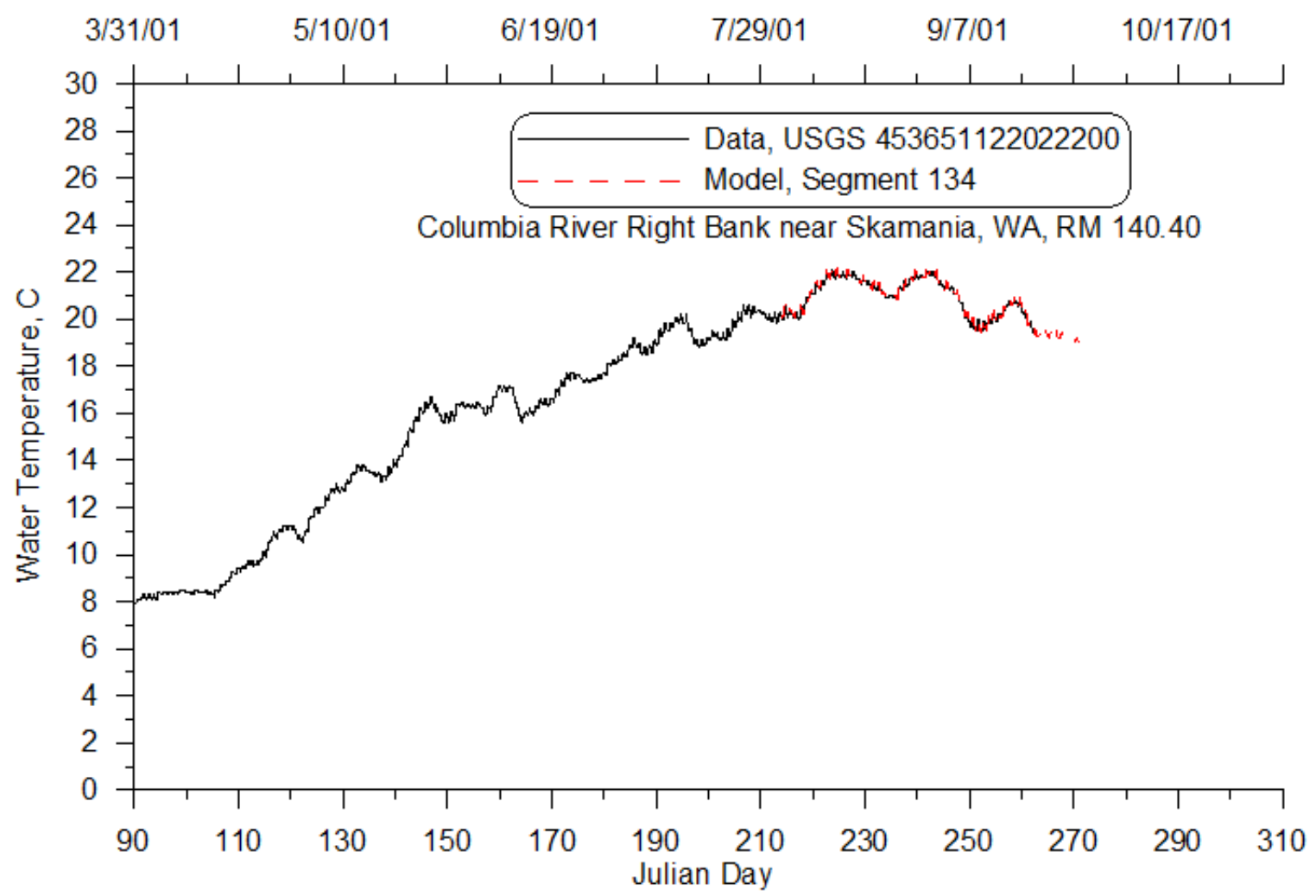

Figure 21: Columbia River Right Bank near Skamania model-data continuous temperature comparison, 2001 


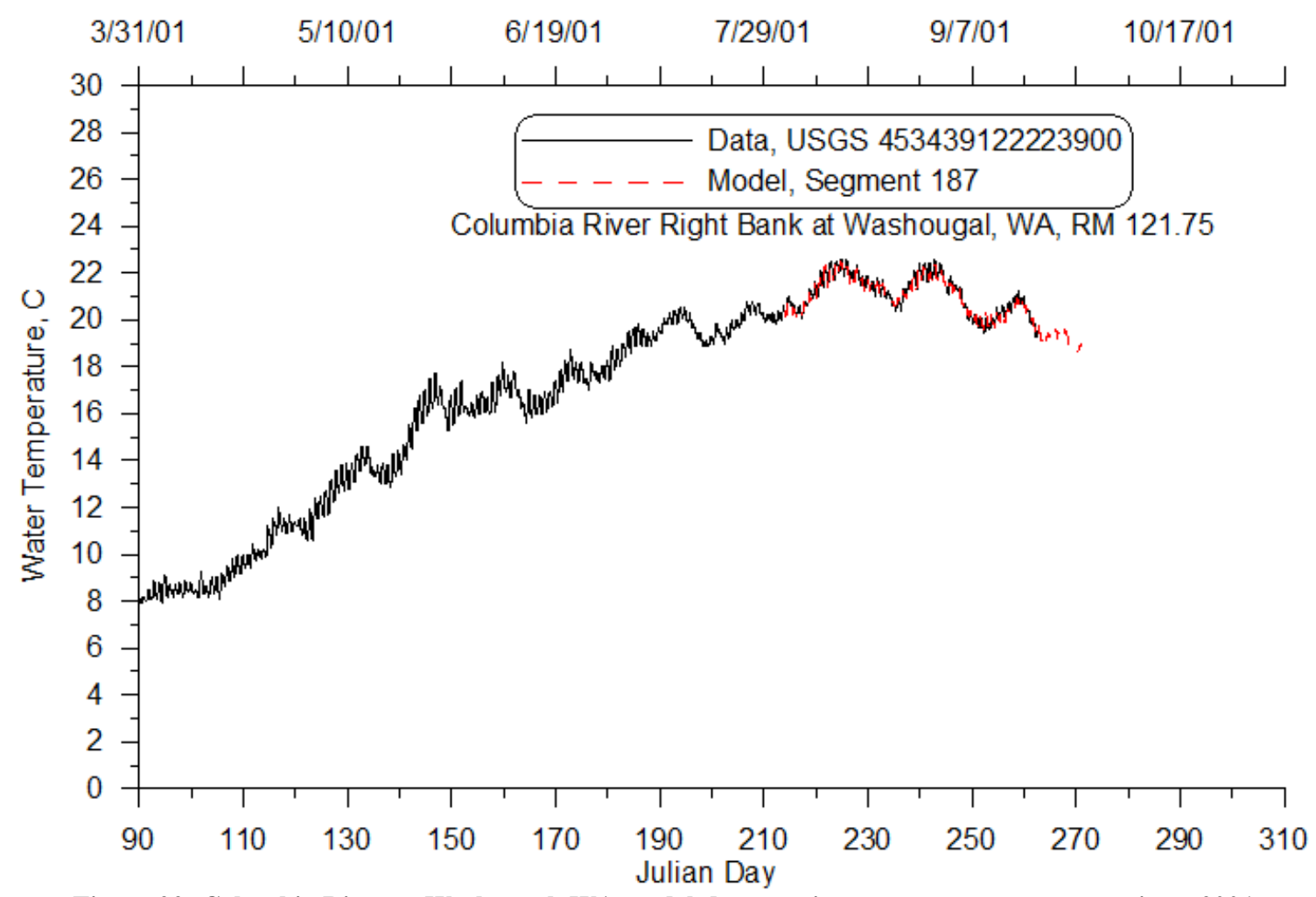

Figure 22: Columbia River at Washougal, WA model-data continuous temperature comparison, 2001

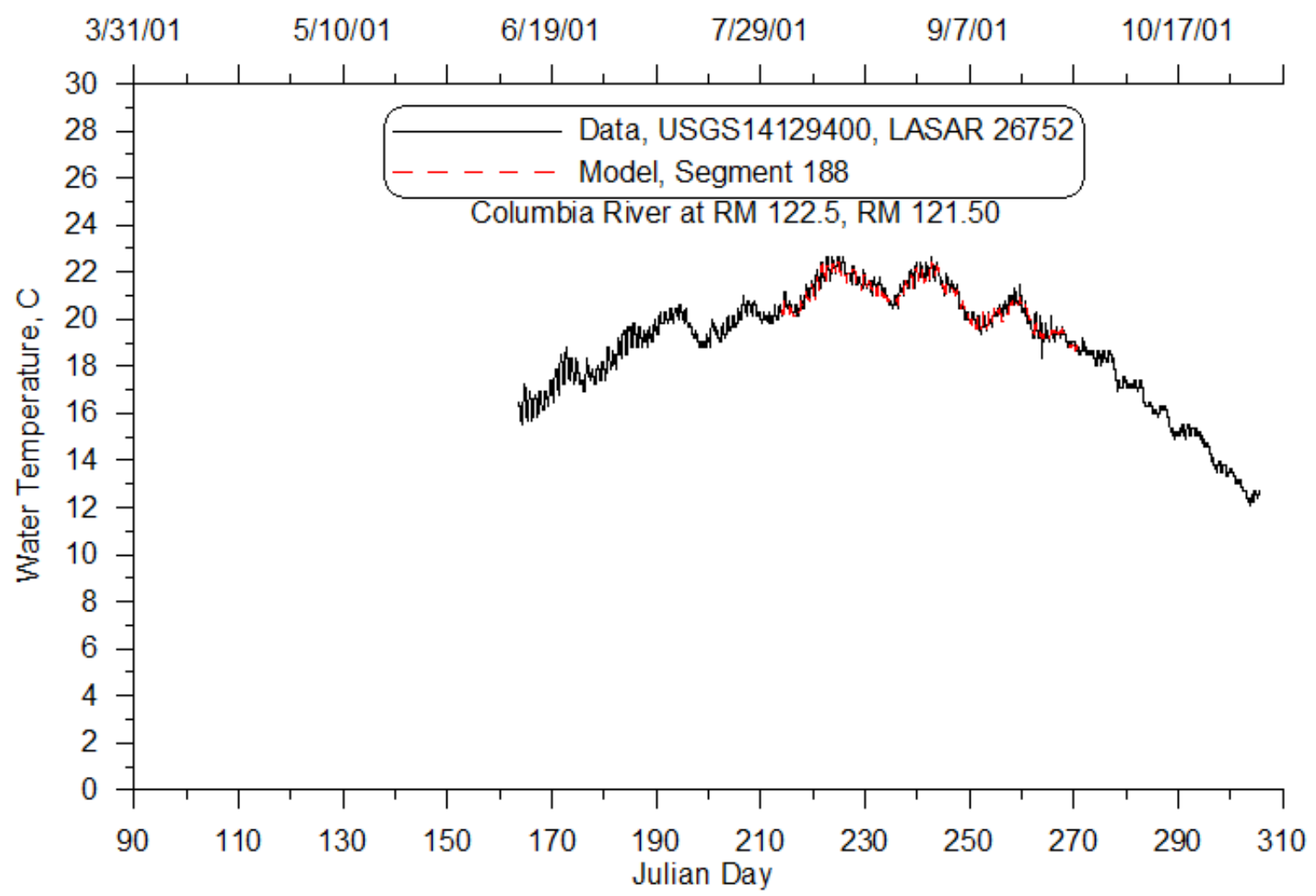

Figure 23: Columbia River at RM 122.5 model-data continuous temperature comparison, 2001 


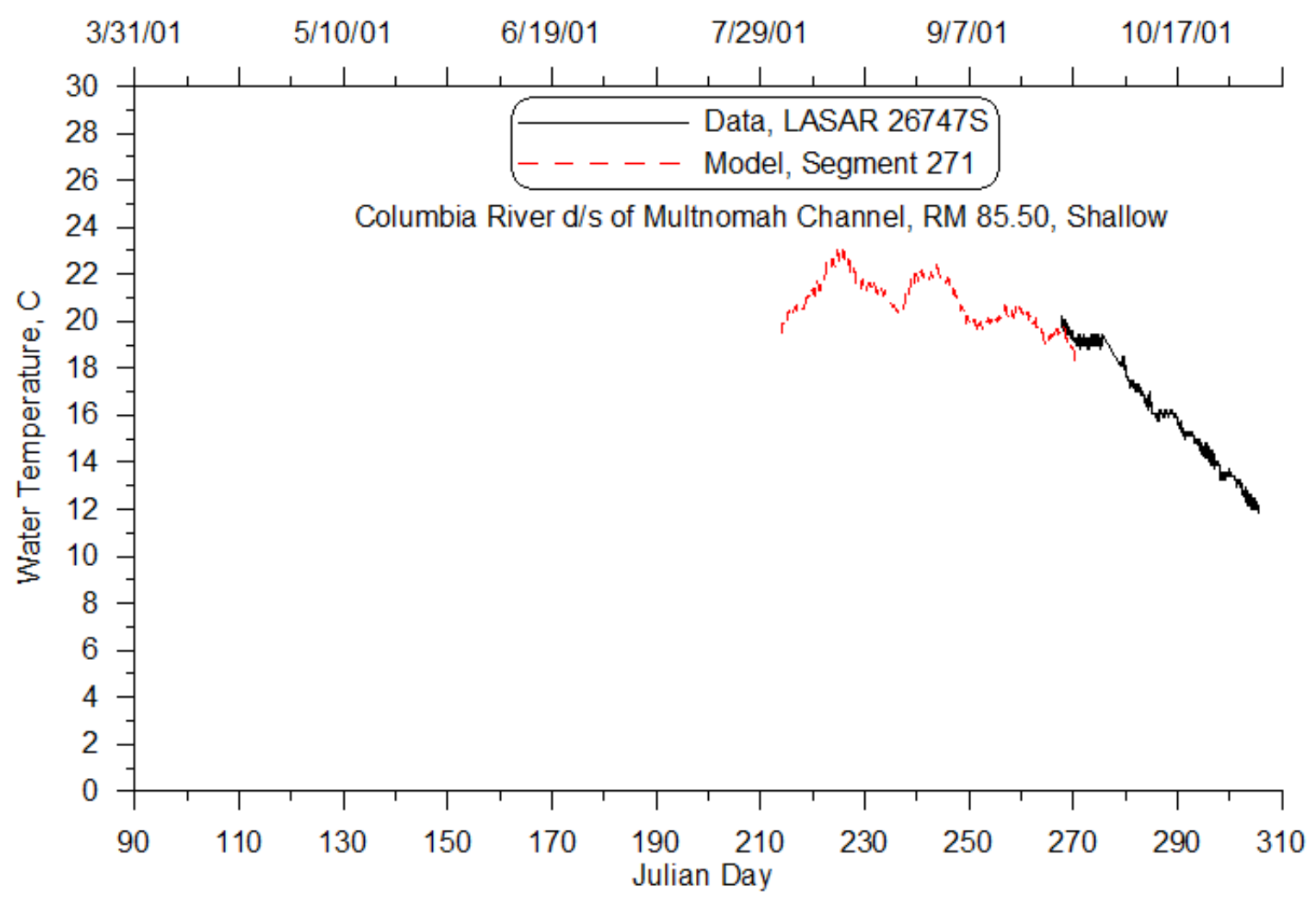

Figure 24: Columbia River d/s Multnomah Channel model-data continuous temperature comparison, 2001

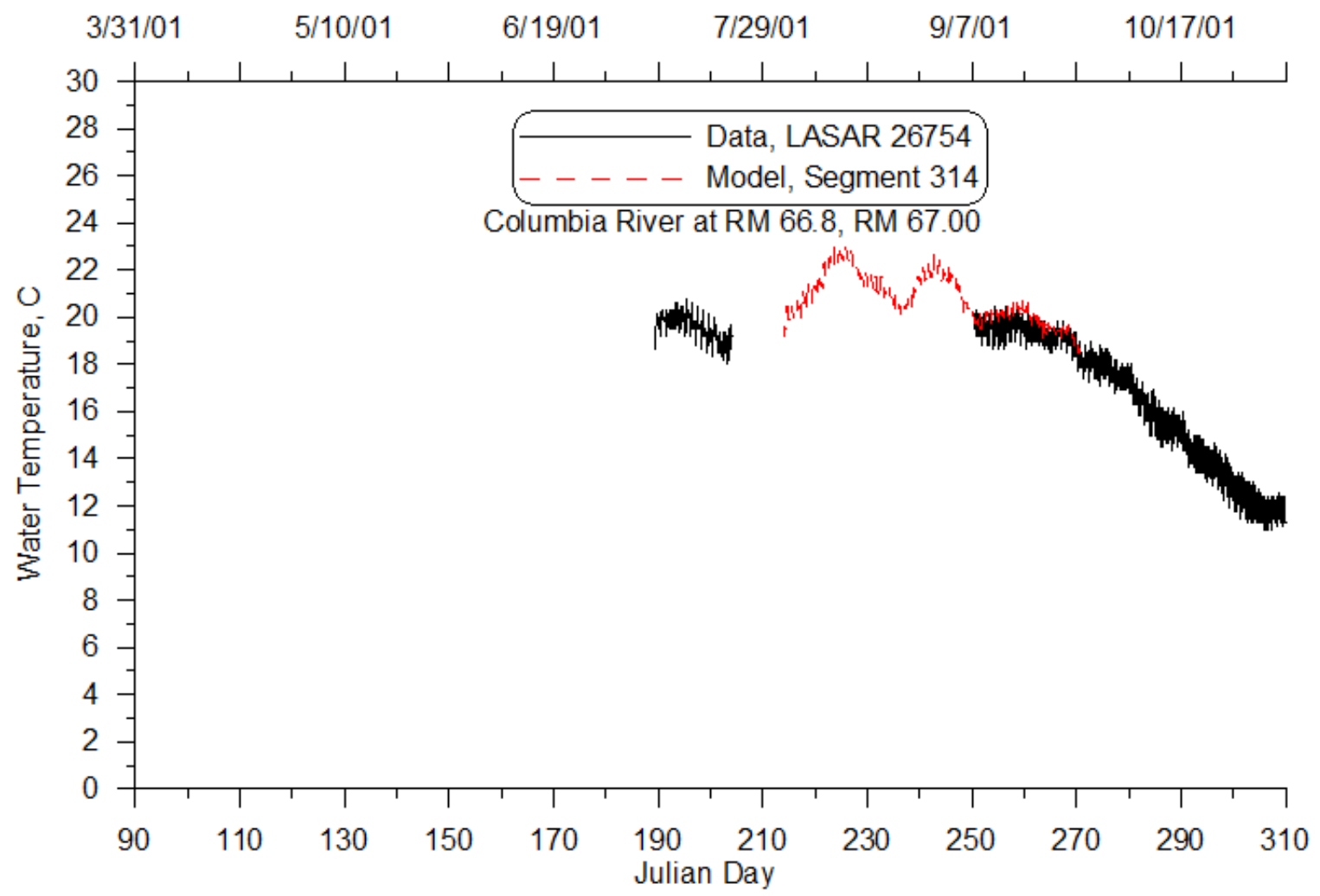

Figure 25: Columbia River at RM 66.8 model-data continuous temperature comparison, 2001 


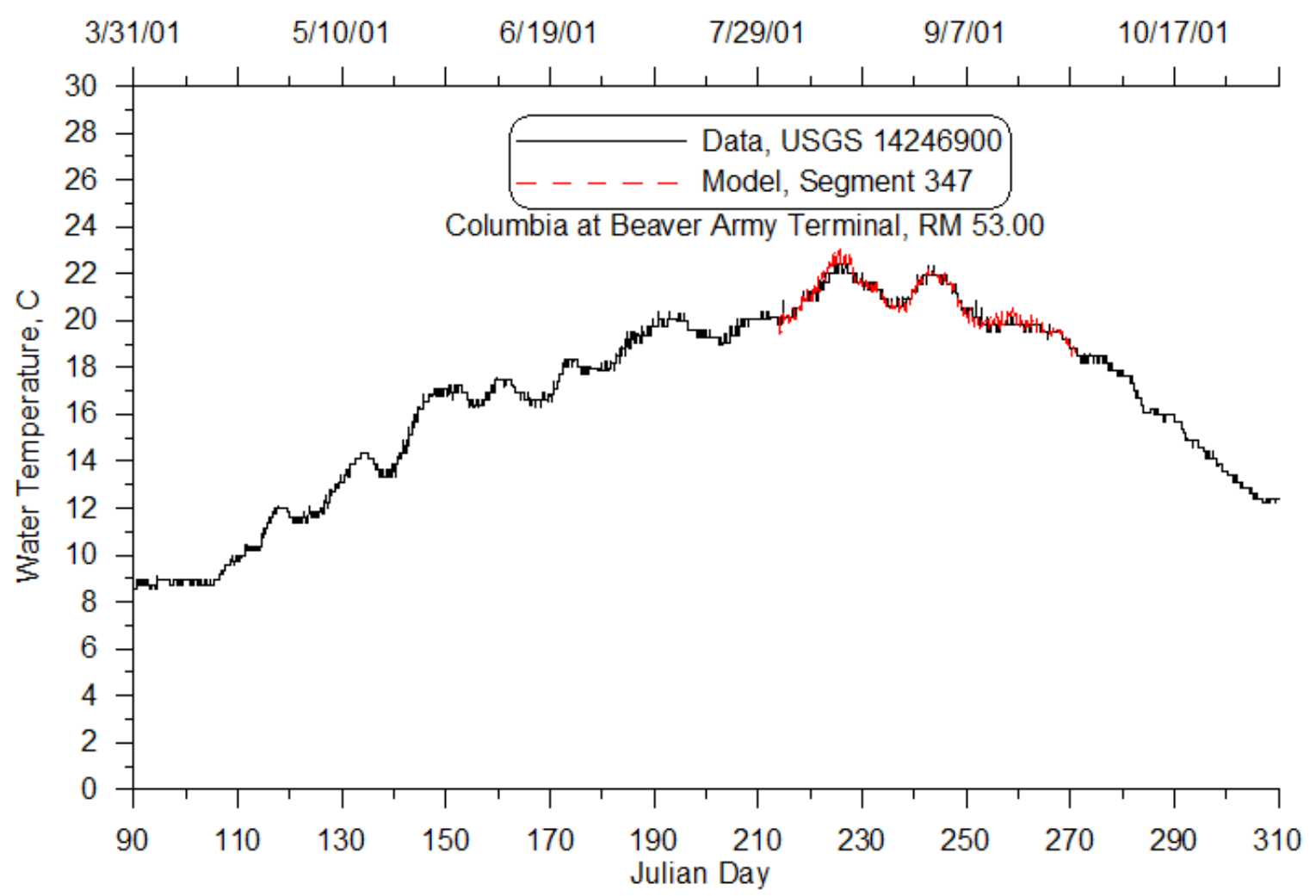

Figure 26: Columbia River at Beaver Army Terminal model-data continuous temperature comparison, 2001

\section{Year 2002}

Figure 27 through 47 show the continuous temperature comparison between model predictions and measured data. Error statistics are summarized in Table 5. Predicted temperature matched data very well for all the 12 sites with the RMSEs below $0.78^{\circ} \mathrm{C}$.

For some sites, there were two series of measured data. These series of data were marked as either "shallow" or "deep", indicating the different depths where water temperature was measured. These measured temperature data were compared with predicted temperature at the according depth. 
The simulation results were similar with the V3.1 model results; however there were some small differences, with V3.7 better predicting on some sites, and V3.1 better predicting on other sites.

Table 5: Willamette River continuous water temperature calibration model-data error statistics, 2002

\begin{tabular}{|c|c|c|c|c|c|c|}
\hline & \multirow{2}{*}{ Site ID } & \multirow{2}{*}{\begin{tabular}{c} 
Model \\
\cline { 4 - 7 }
\end{tabular}} & $\mathrm{RM}$ & \multicolumn{4}{|c|}{ Continuous Temperature } \\
\cline { 5 - 8 } & & $\begin{array}{c}\text { Number of } \\
\text { Comparison } \\
\mathrm{s}\end{array}$ & ME, ${ }^{\circ} \mathrm{C}$ & AME, ${ }^{\circ} \mathrm{C}$ & RMSE, ${ }^{\circ} \mathrm{C}$ \\
\hline LASAR 26745 Shallow & 20.75 & 33 & 3370 & 0.289 & 0.431 & 0.543 \\
\hline LASAR 26745 Deep & 20.75 & 33 & 3370 & 0.23 & 0.378 & 0.474 \\
\hline LASAR 28506 Shallow & 18.83 & 45 & 3351 & 0.319 & 0.43 & 0.525 \\
\hline LASAR 28506 Deep & 18.83 & 45 & 3351 & -0.178 & 0.444 & 0.51 \\
\hline LASAR 28507 Shallow & 18.75 & 46 & 3351 & 0.321 & 0.429 & 0.523 \\
\hline LASAR 28507 Deep & 18.75 & 46 & 3351 & -0.163 & 0.4 & 0.463 \\
\hline LASAR 28508 Shallow & 18.59 & 48 & 3351 & 0.373 & 0.462 & 0.562 \\
\hline LASAR 28508 Deep & 18.59 & 48 & 3351 & -0.073 & 0.377 & 0.431 \\
\hline LASAR 29747 & 17.38 & 52 & 2945 & 0.229 & 0.371 & 0.451 \\
\hline LASAR 29747 QA set & 17.38 & 52 & 1995 & 0.172 & 0.319 & 0.404 \\
\hline USGS 14211720 & 12.70 & 66 & 8352 & 0.152 & 0.361 & 0.463 \\
\hline LASAR 28765 Shallow & 7.14 & 83 & 2402 & -0.127 & 0.273 & 0.341 \\
\hline LASAR 28765 Deep & 7.14 & 83 & 3351 & 0.011 & 0.238 & 0.293 \\
\hline LASAR 29746 Shallow & 3.20 & 91 & 3351 & -0.015 & 0.327 & 0.441 \\
\hline LASAR 29746 Deep & 3.20 & 91 & 3351 & 0.183 & 0.35 & 0.459 \\
\hline USGS & 140.40 & 134 & & & & \\
\hline 453630122021400 & & & 4176 & 0.023 & 0.052 & 0.074 \\
\hline USGS & 121.75 & 187 & & & & \\
\hline 453439122223900 & & & 4176 & -0.036 & 0.134 & 0.183 \\
\hline LASAR 26747 Shallow & 85.50 & 271 & 5296 & -0.656 & 0.667 & 0.774 \\
\hline LASAR 26747 Deep & 85.50 & 271 & 5296 & -0.172 & 0.277 & 0.348 \\
\hline LASAR 26754 Shallow & 67.00 & 314 & 5299 & 0.45 & 0.491 & 0.578 \\
\hline LASAR 26754 Deep & 67.00 & 314 & 5299 & 0.393 & 0.443 & 0.532 \\
\hline USGS 14246900 & 53.00 & 347 & 16702 & 0.01 & 0.15 & 0.193 \\
\hline
\end{tabular}




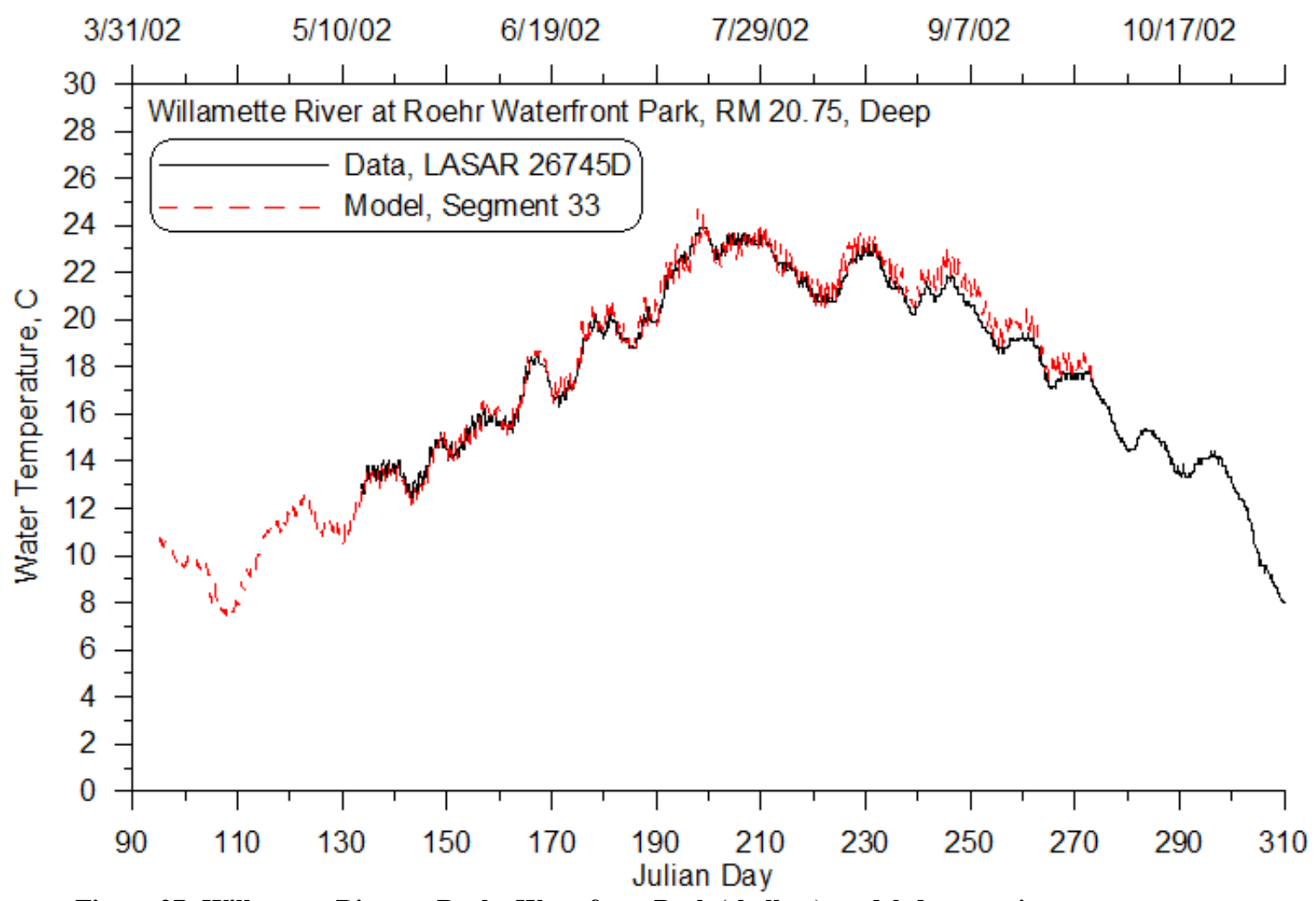

Figure 27: Willamette River at Roehr Waterfront Park (shallow) model-data continuous temperature comparison, 2002

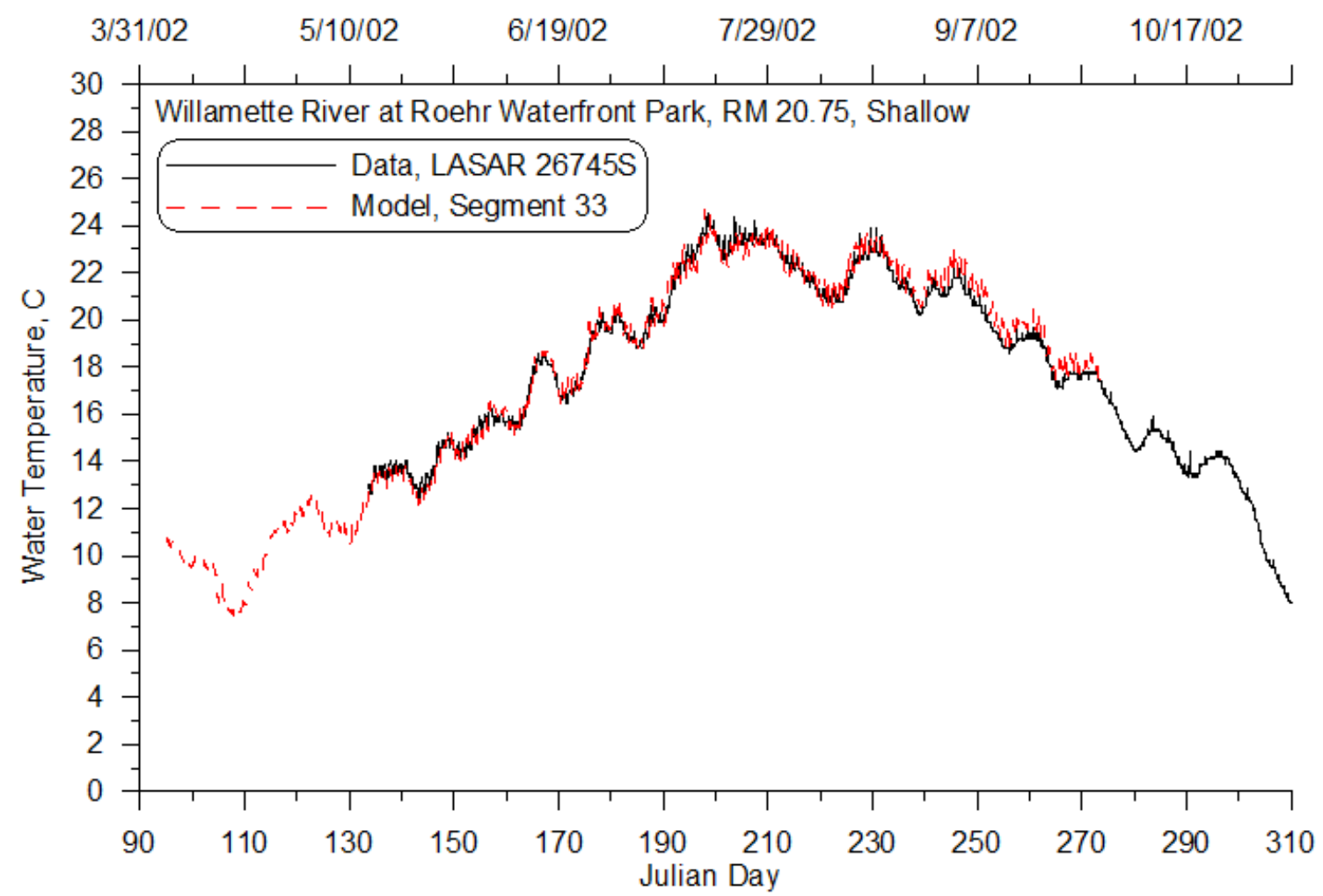

Figure 28: Willamette River at Roehr Waterfront Park (deep) model-data continuous temperature comparison, 2002 


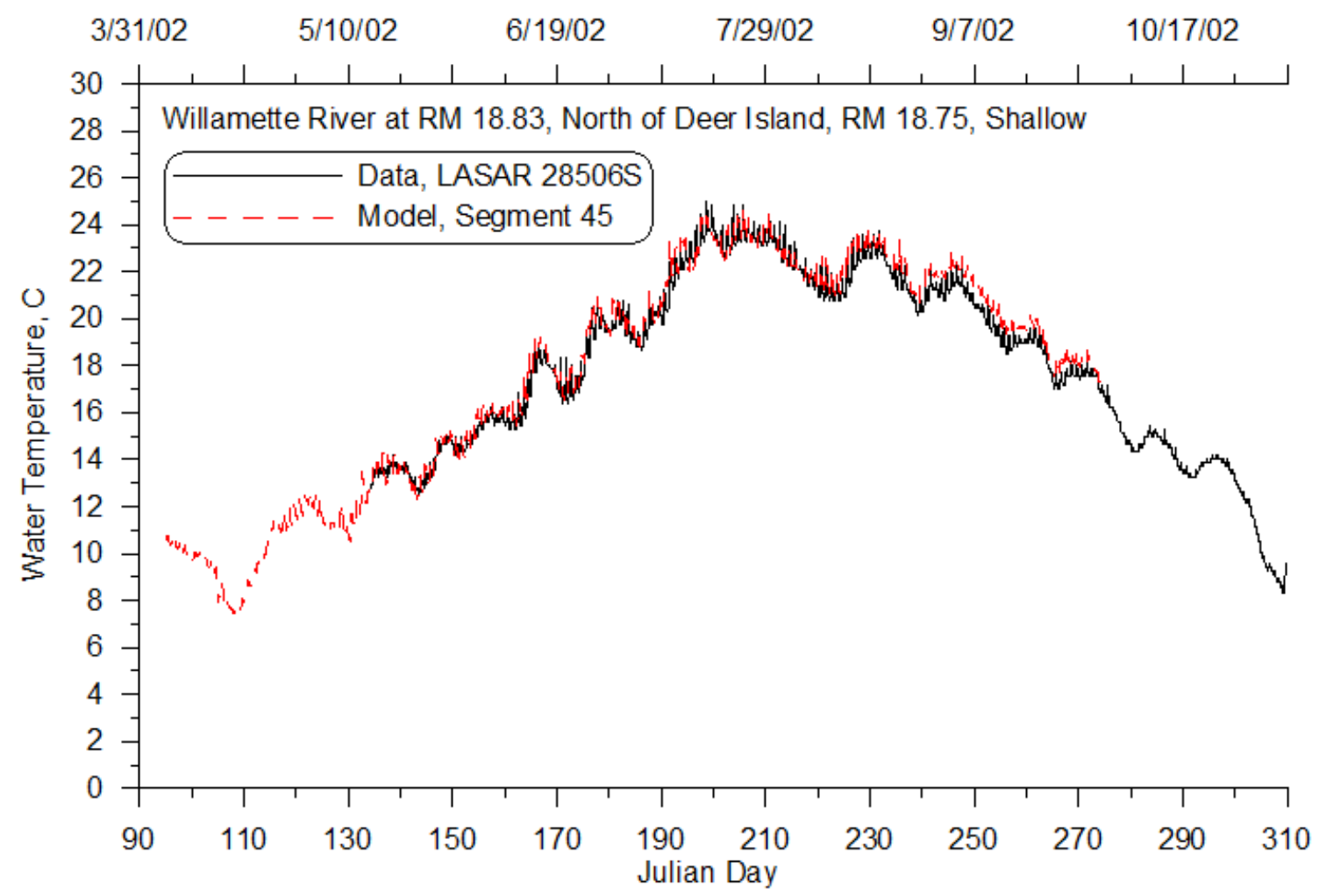

Figure 29: Willamette River north of Deer Island (shallow) model-data continuous temperature comparison,

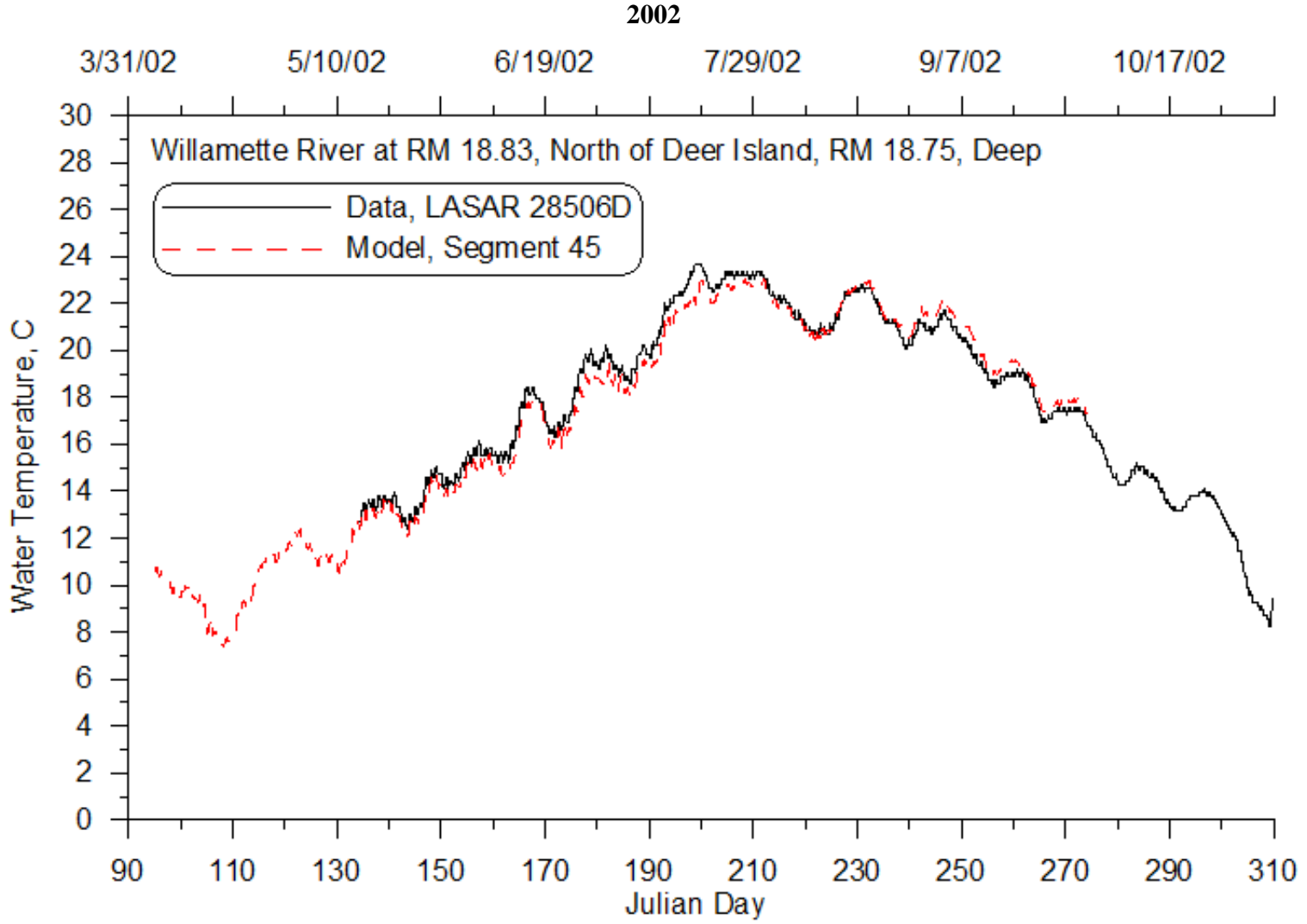

Figure 30: Willamette River north of Deer Island (deep) model-data continuous temperature comparison, 2002 


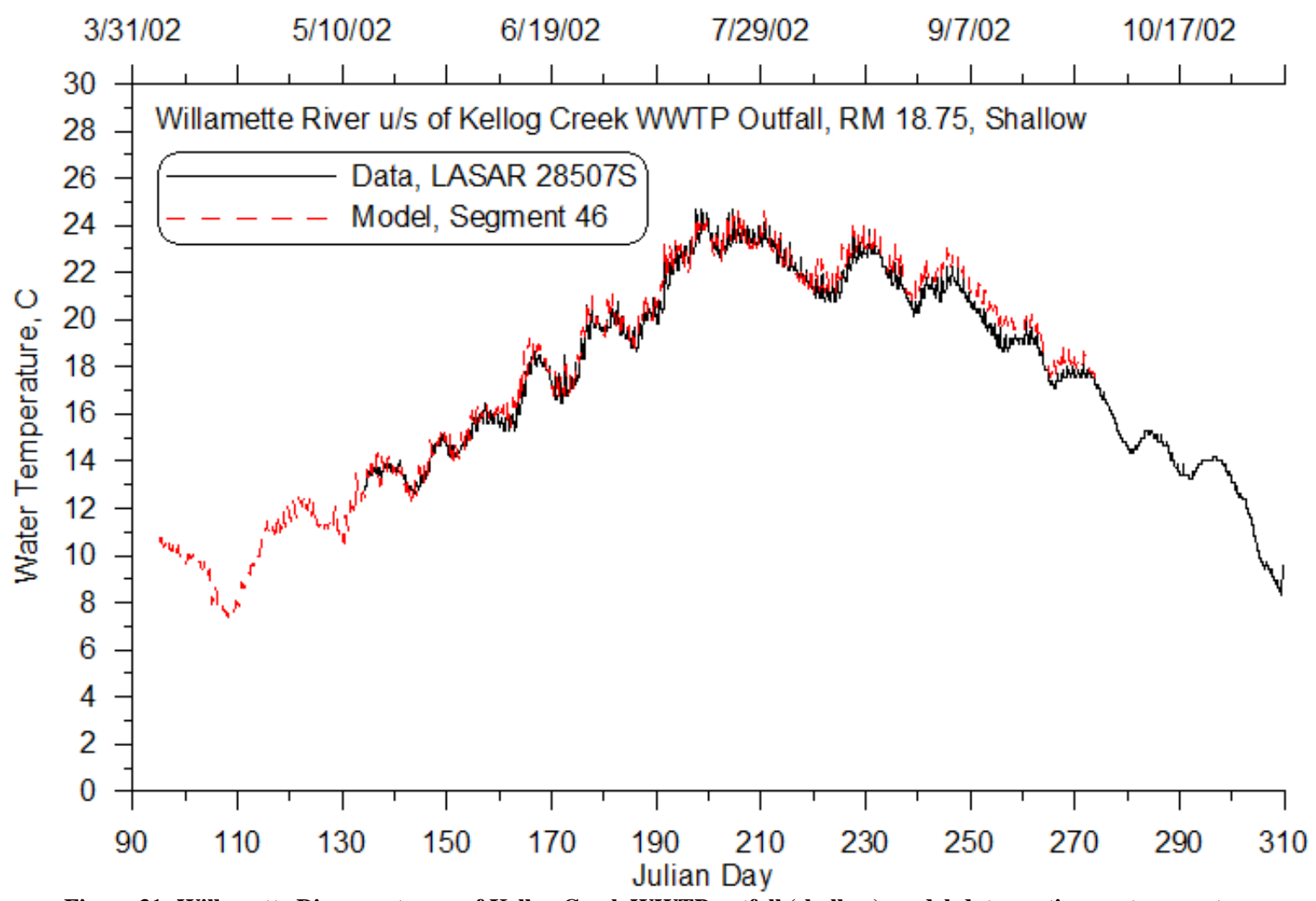

Figure 31: Willamette River upstream of Kellog Creek WWTP outfall (shallow) model-data continuous temperature

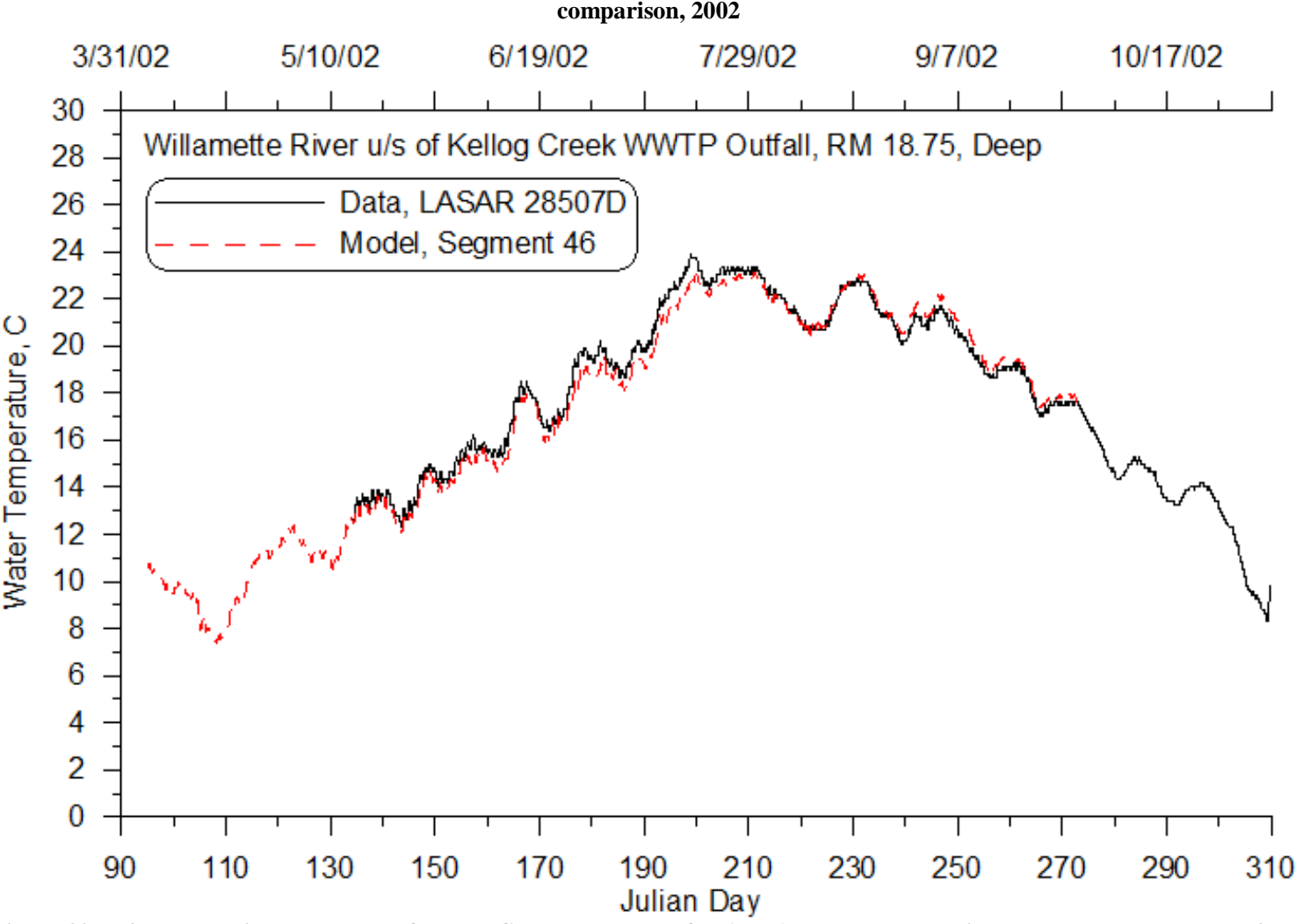

Figure 32: Willamette River upstream of Kellog Creek WWTP outfall (deep) model-data continuous temperature comparison, 2002 


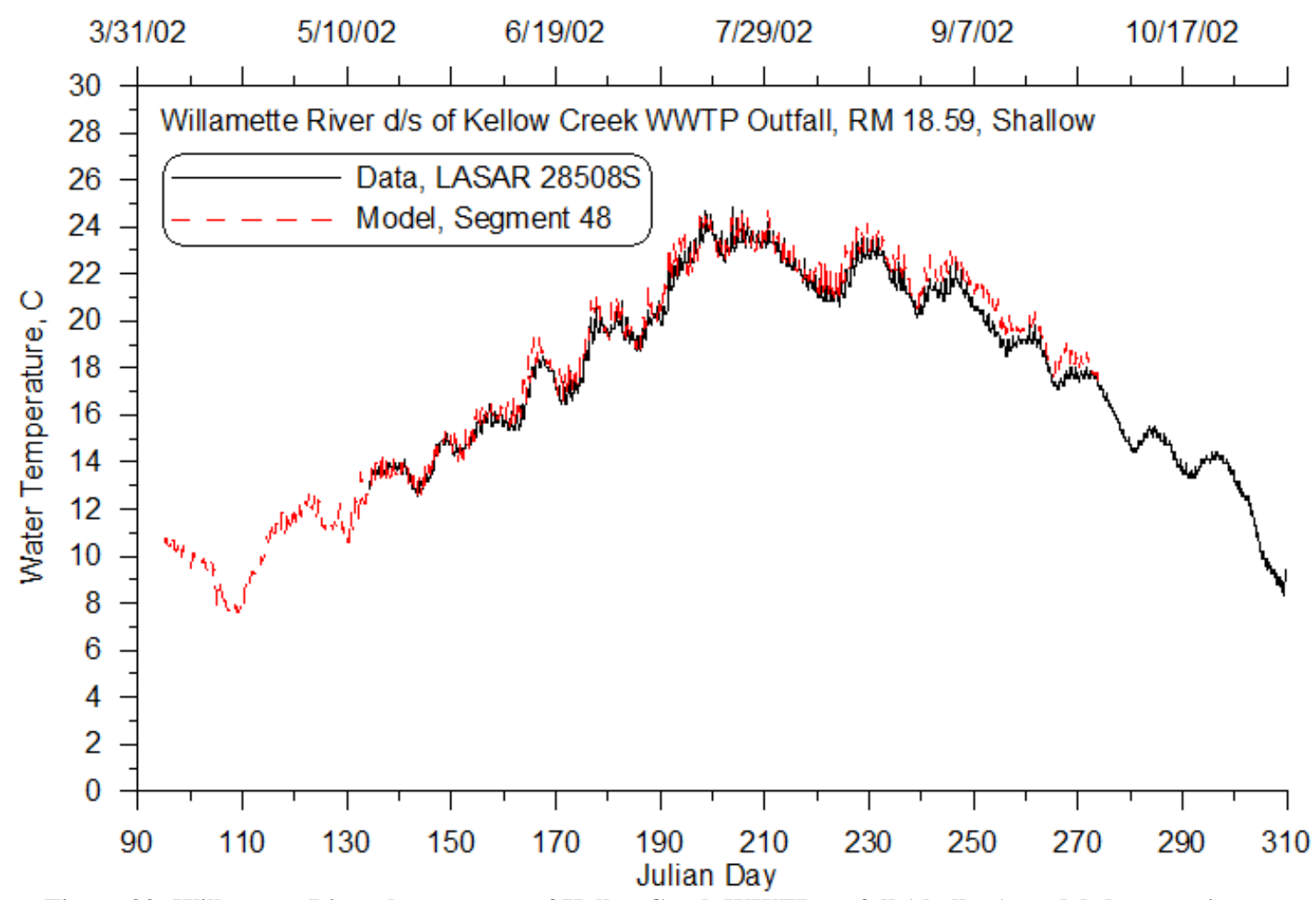

Figure 33: Willamette River downstream of Kellog Creek WWTP outfall (shallow) model-data continuous

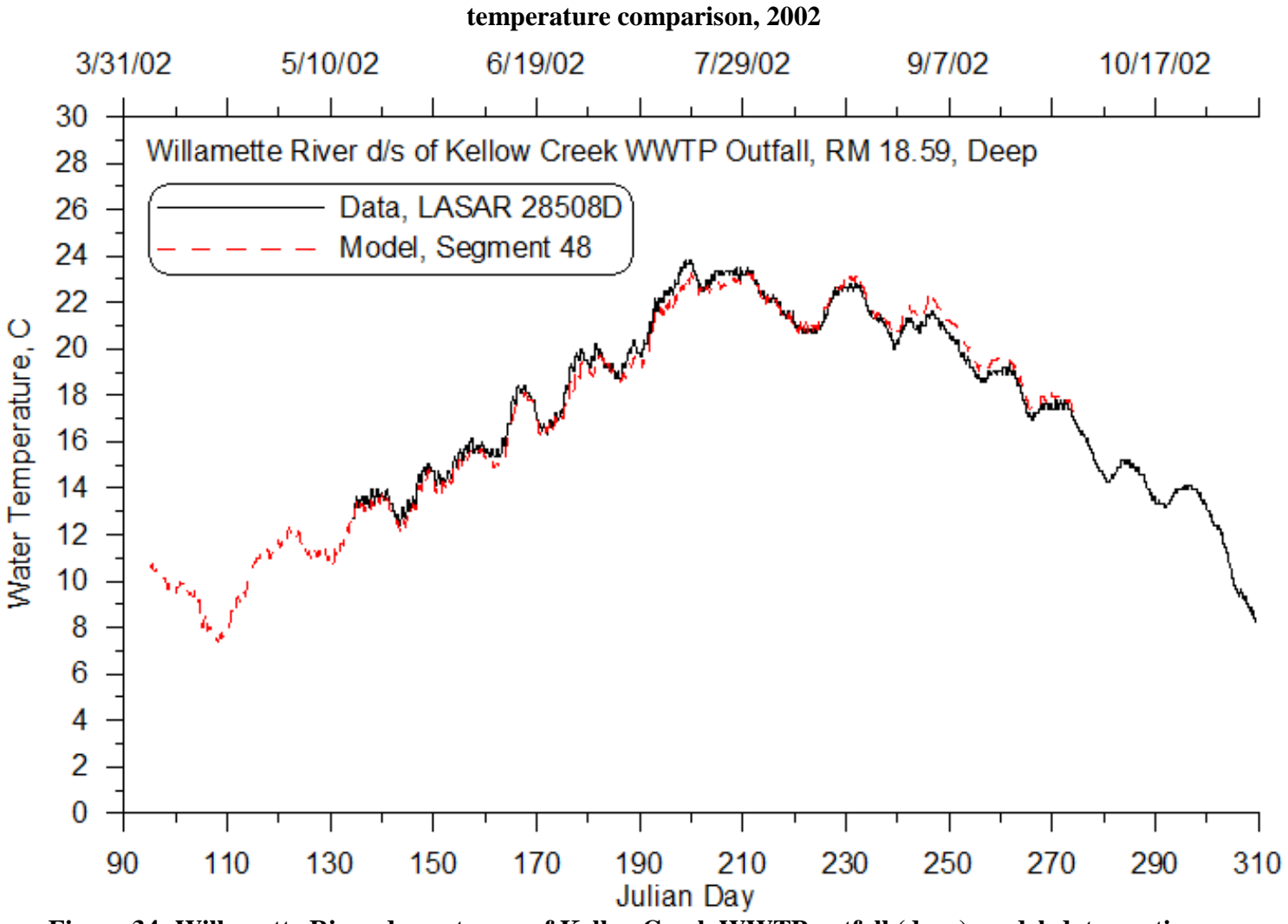

Figure 34: Willamette River downstream of Kellog Creek WWTP outfall (deep) model-data continuous temperature comparison, 2002 


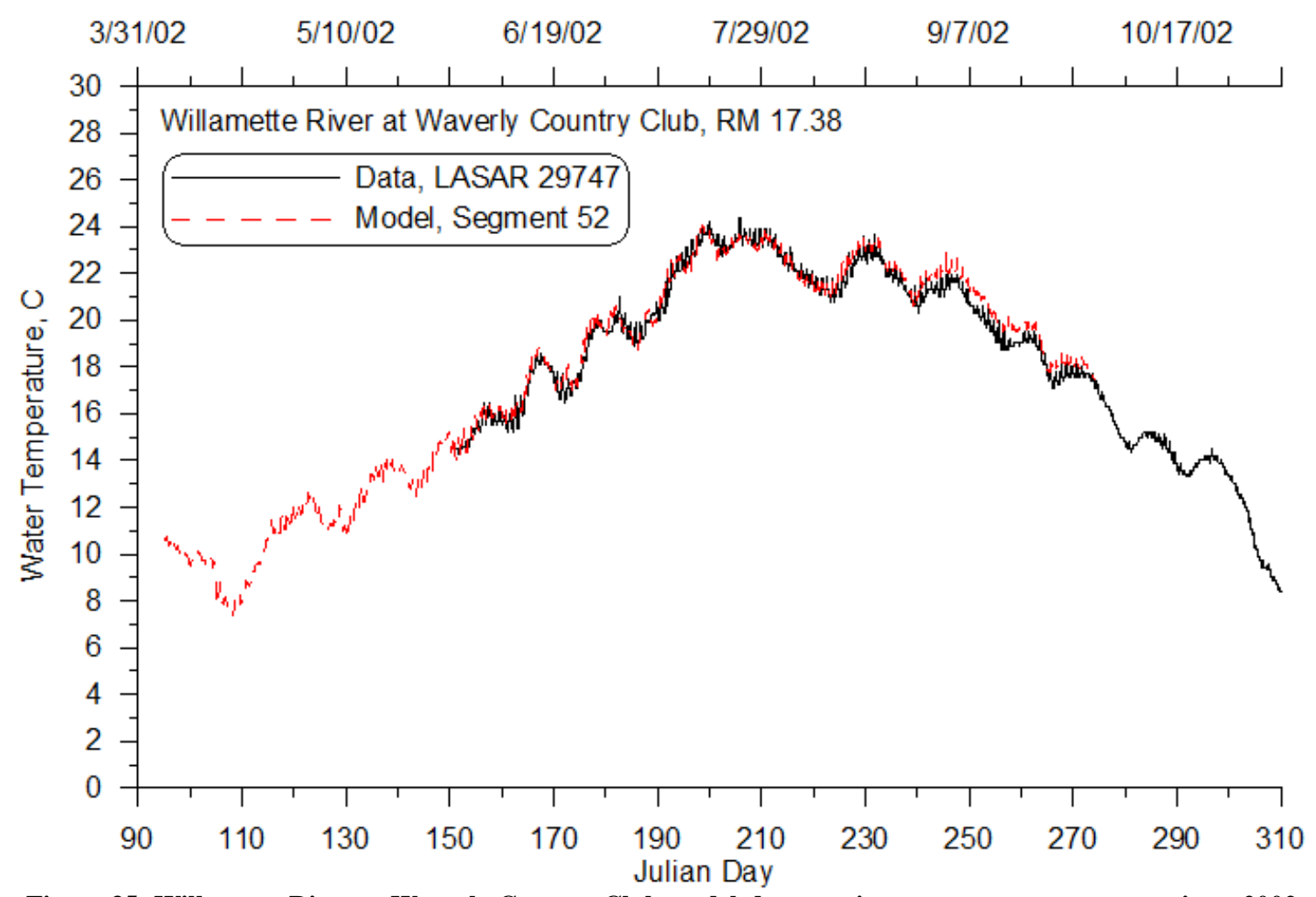

Figure 35: Willamette River at Waverly Country Club model-data continuous temperature comparison, 2002

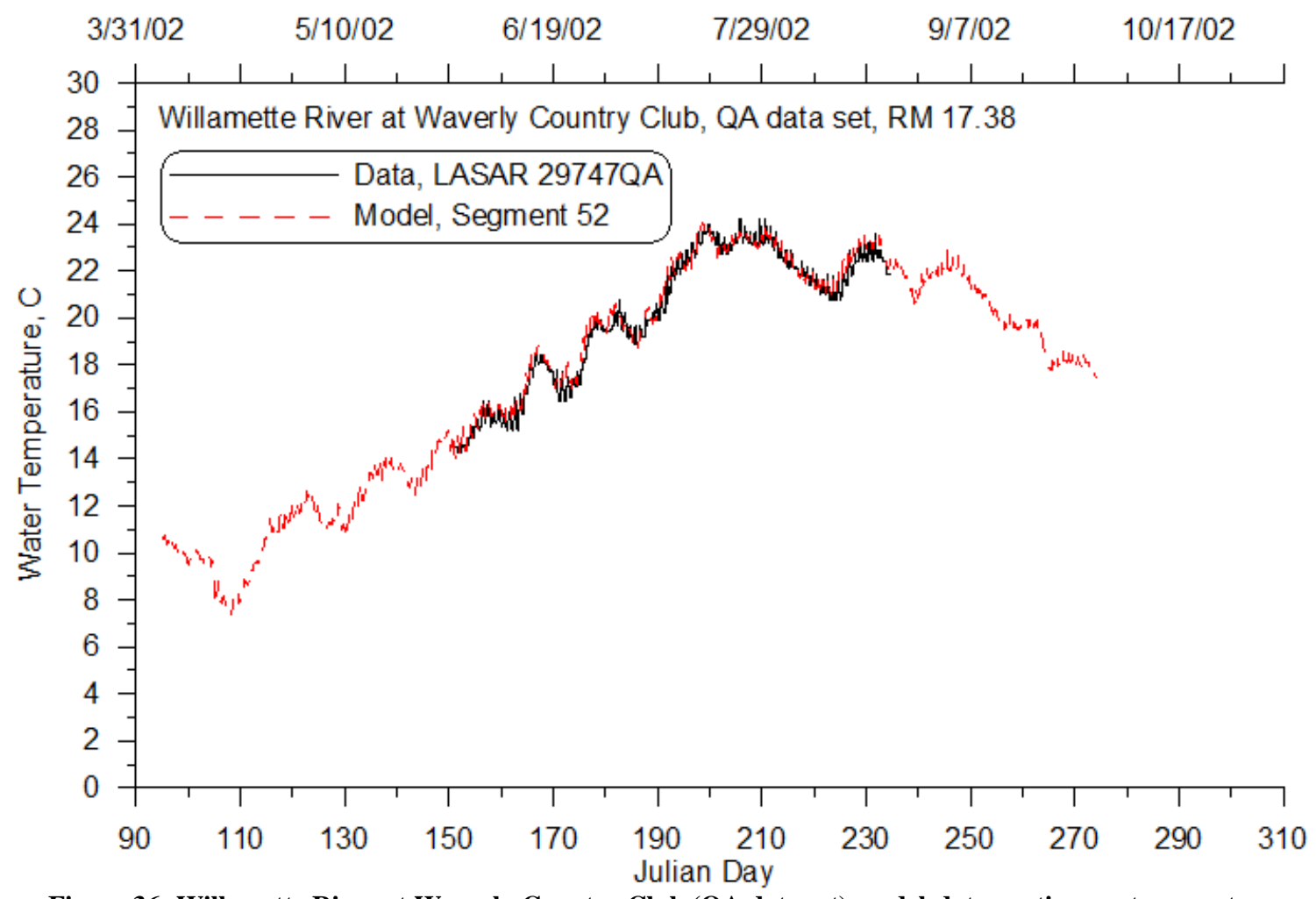

Figure 36: Willamette River at Waverly Country Club (QA data set) model-data continuous temperature comparison, 2002 


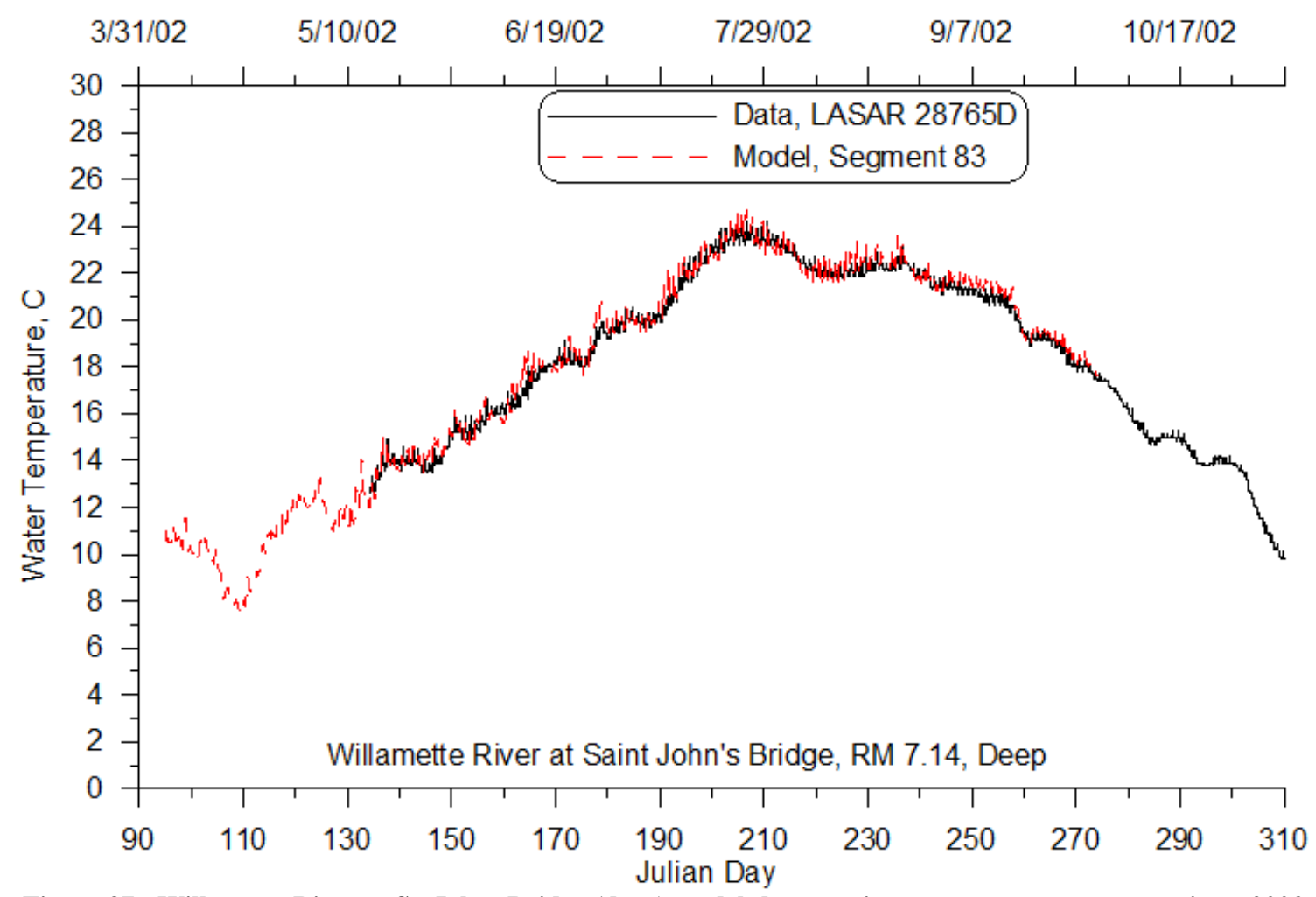

Figure 37 : Willamette River at St. Johns Bridge (deep) model-data continuous temperature comparison, 2002

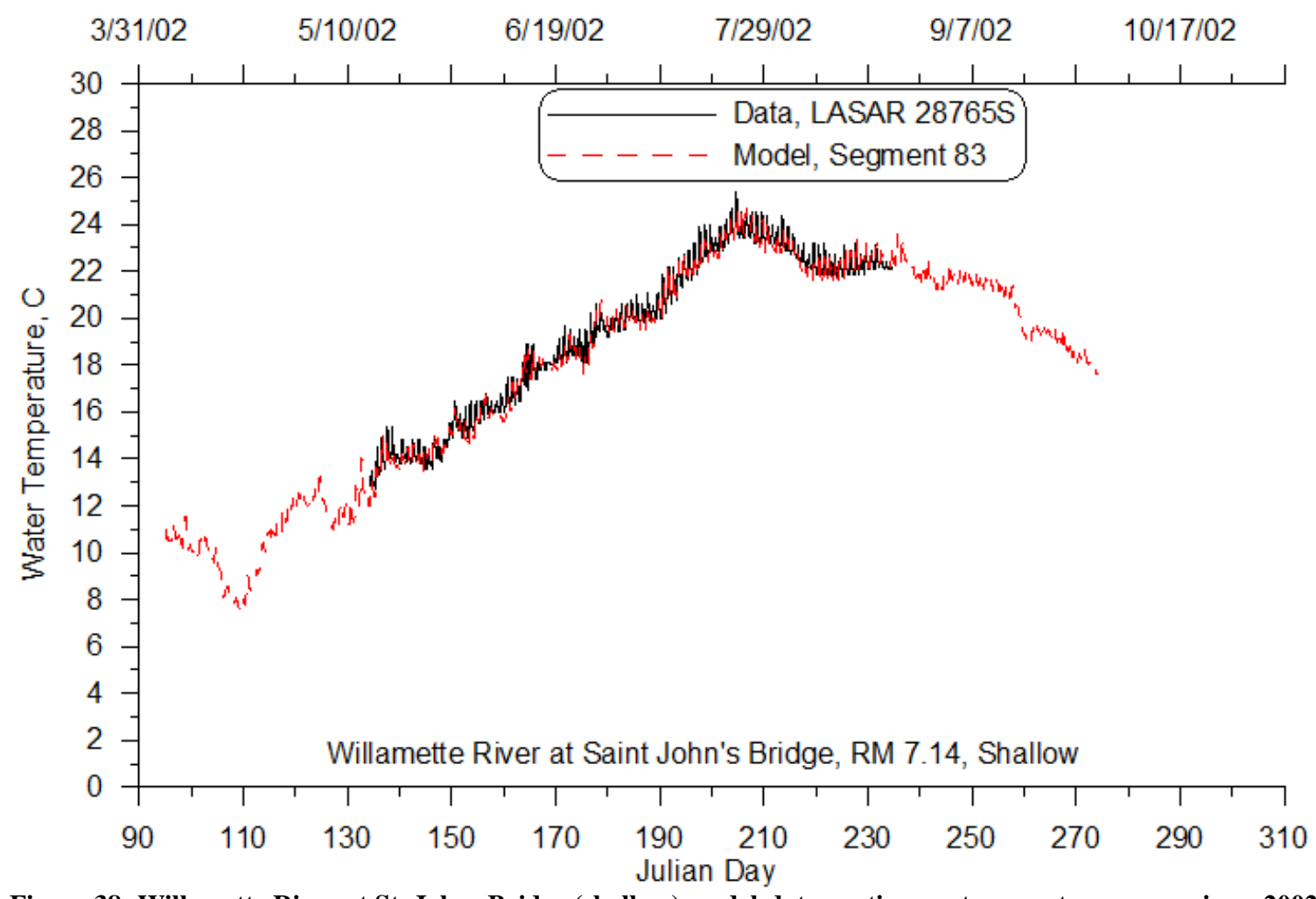

Figure 38: Willamette River at St. Johns Bridge (shallow) model-data continuous temperature comparison, 2002 


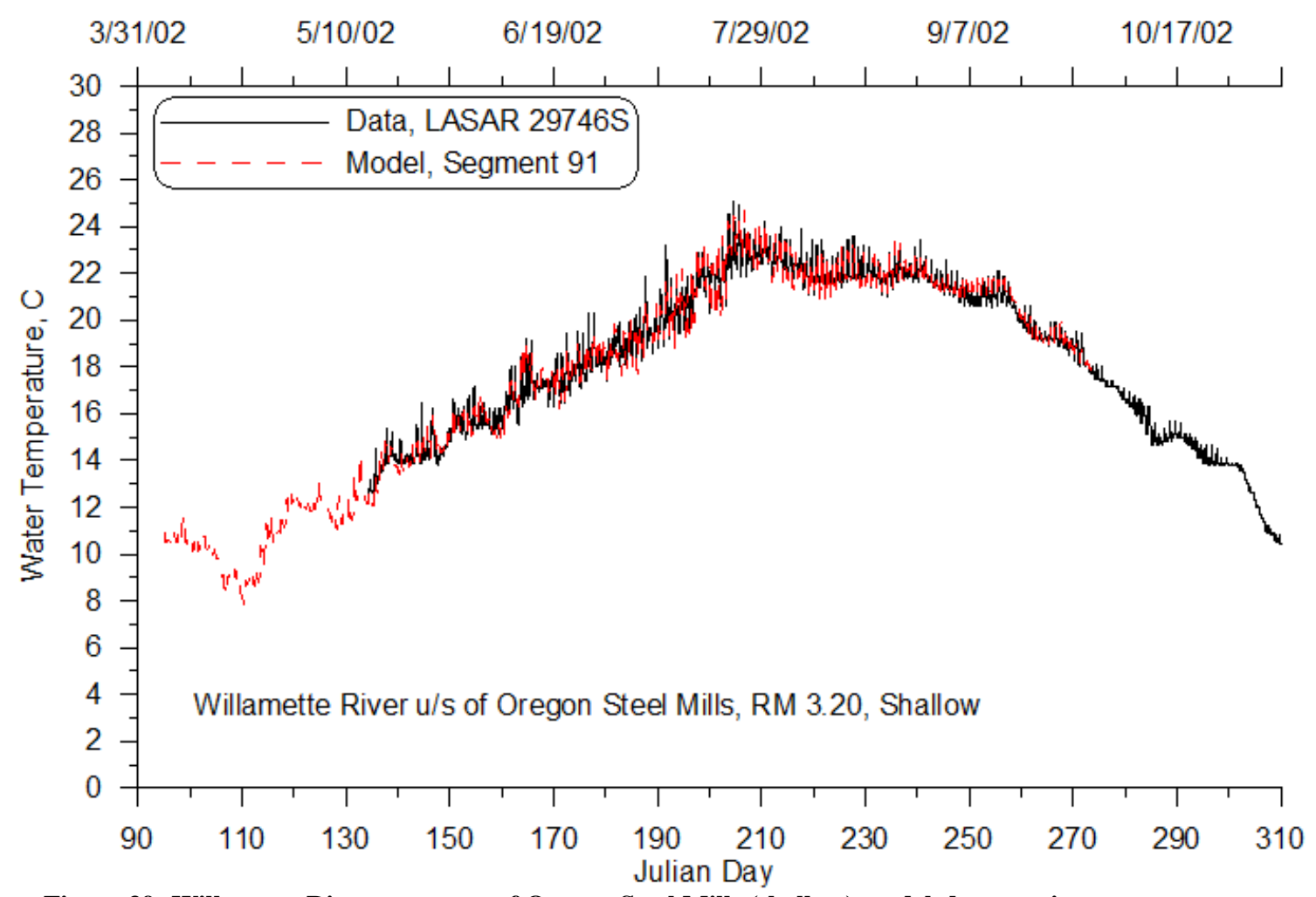

Figure 39: Willamette River upstream of Oregon Steel Mills (shallow) model-data continuous temperature comparison, 2002

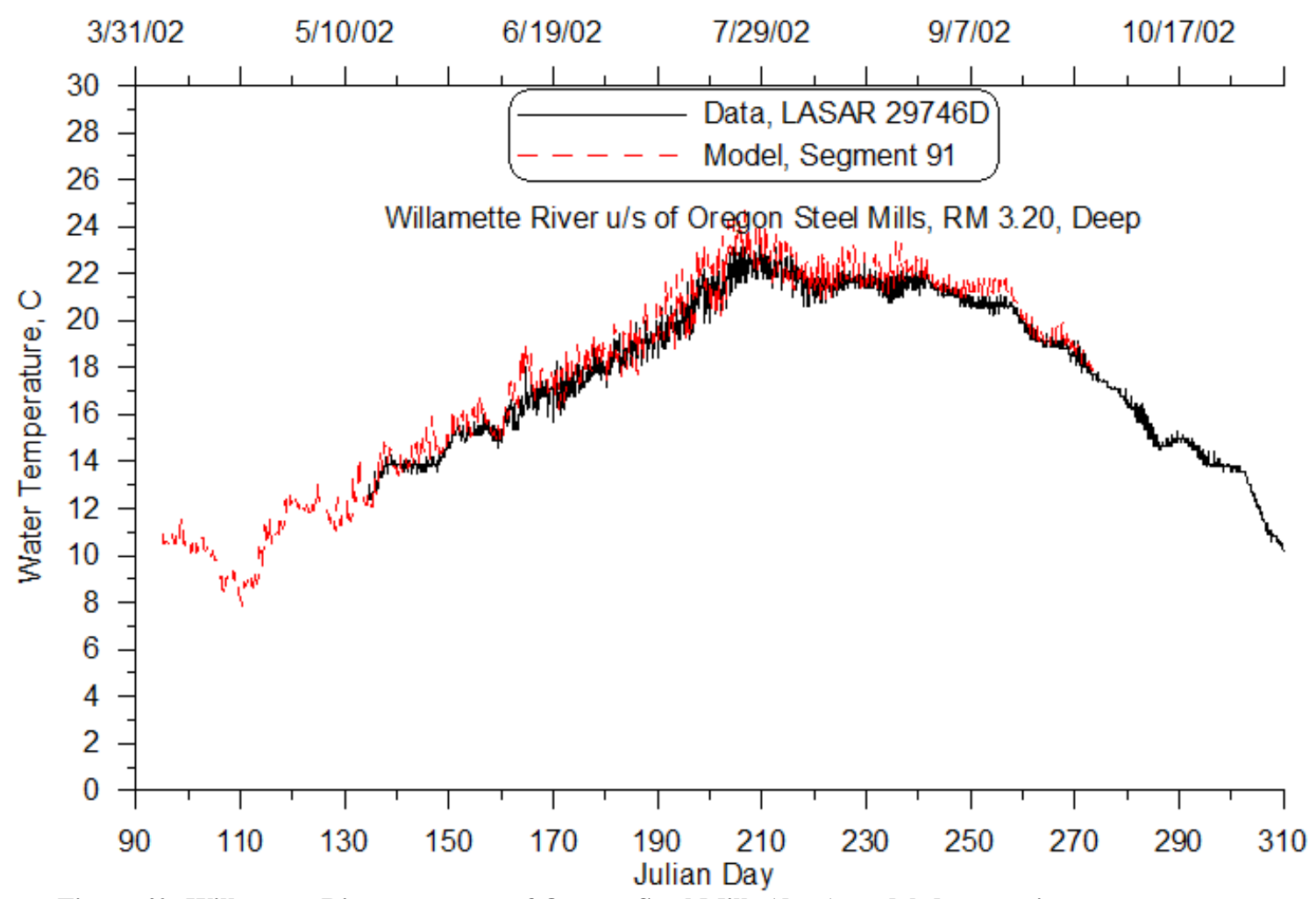

Figure 40: Willamette River upstream of Oregon Steel Mills (deep) model-data continuous temperature comparison, 


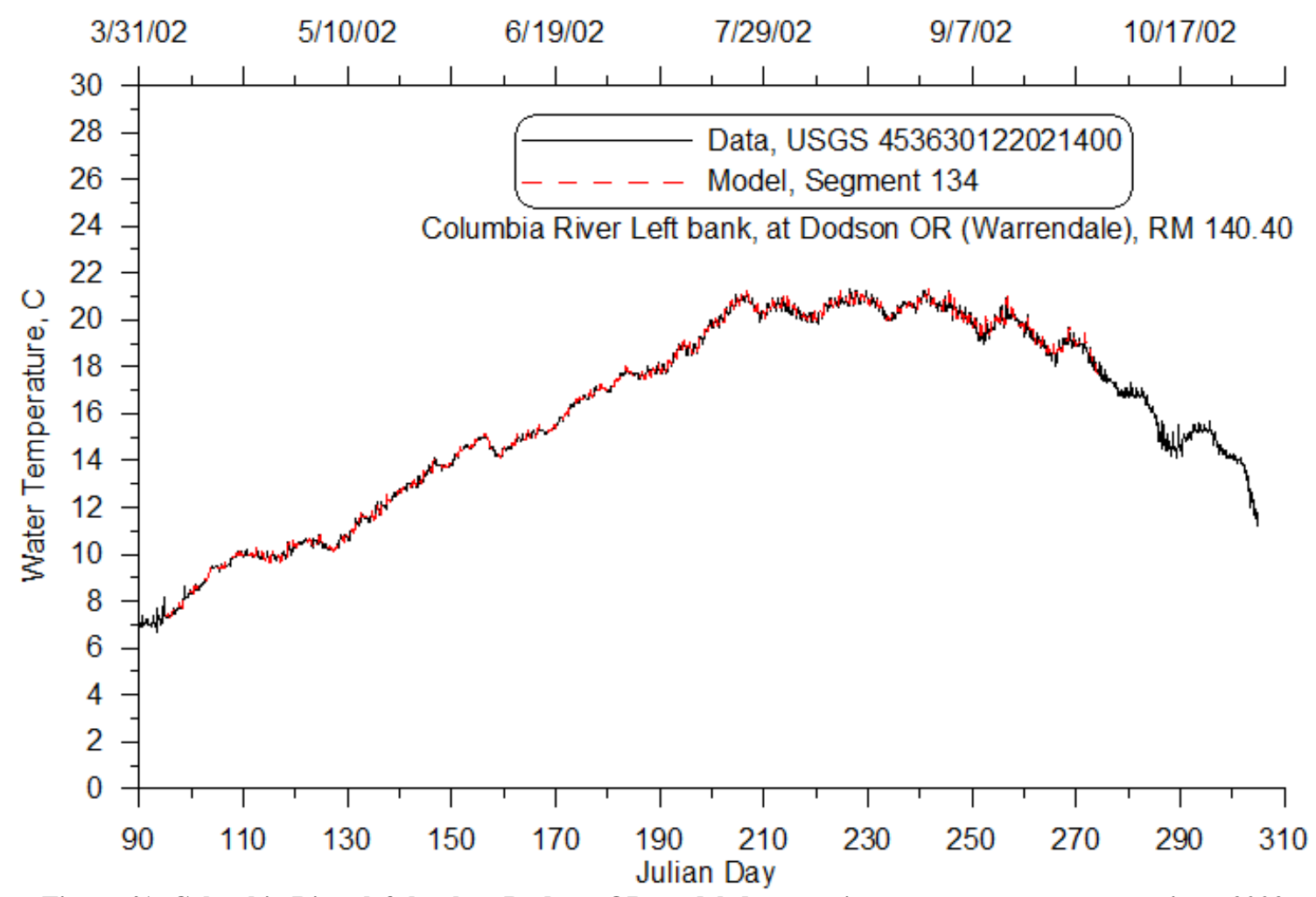

Figure 41: Columbia River left bank at Dodson, OR model-data continuous temperature comparison, 2002

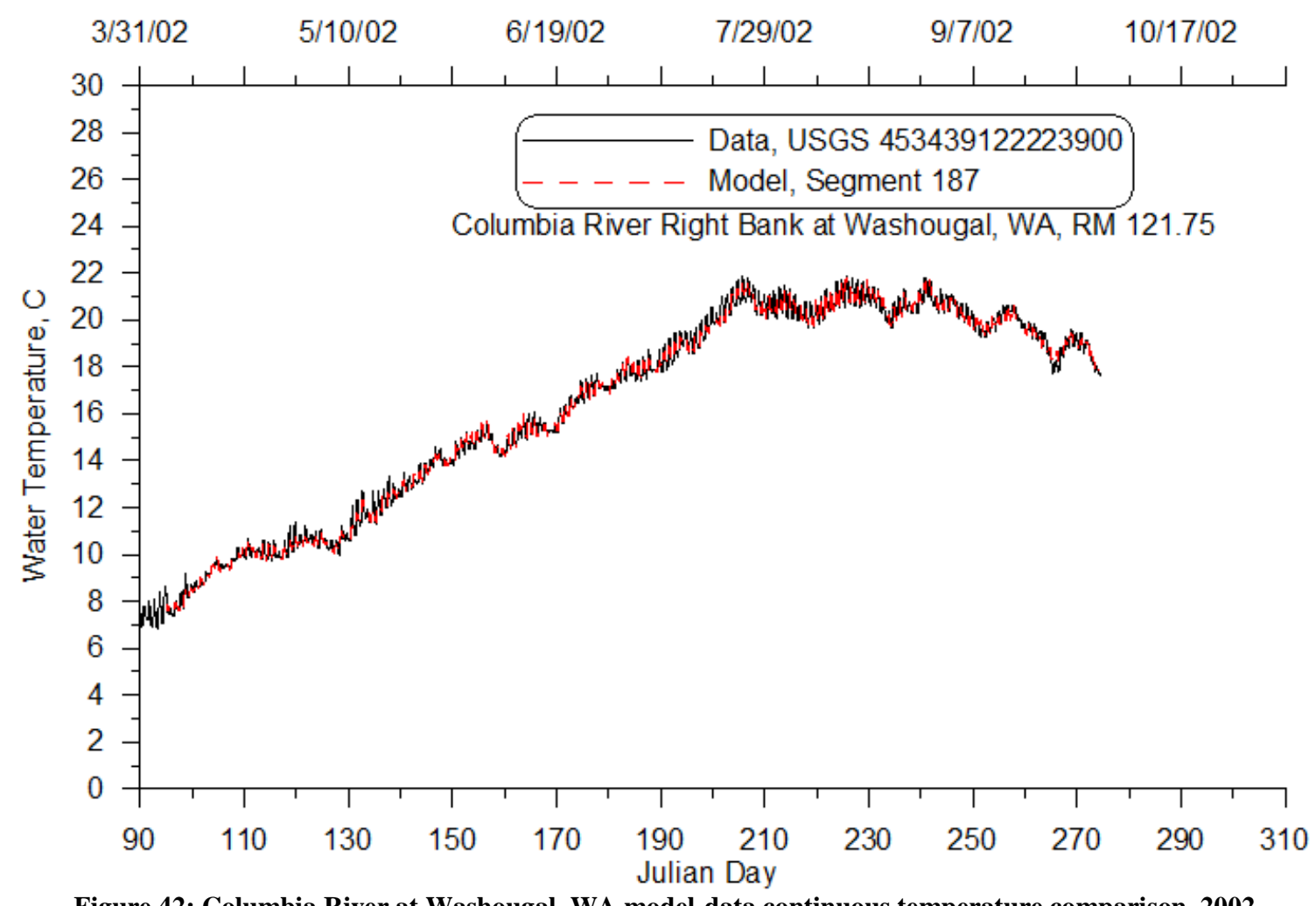

Figure 42: Columbia River at Washougal, WA model-data continuous temperature comparison, 2002 


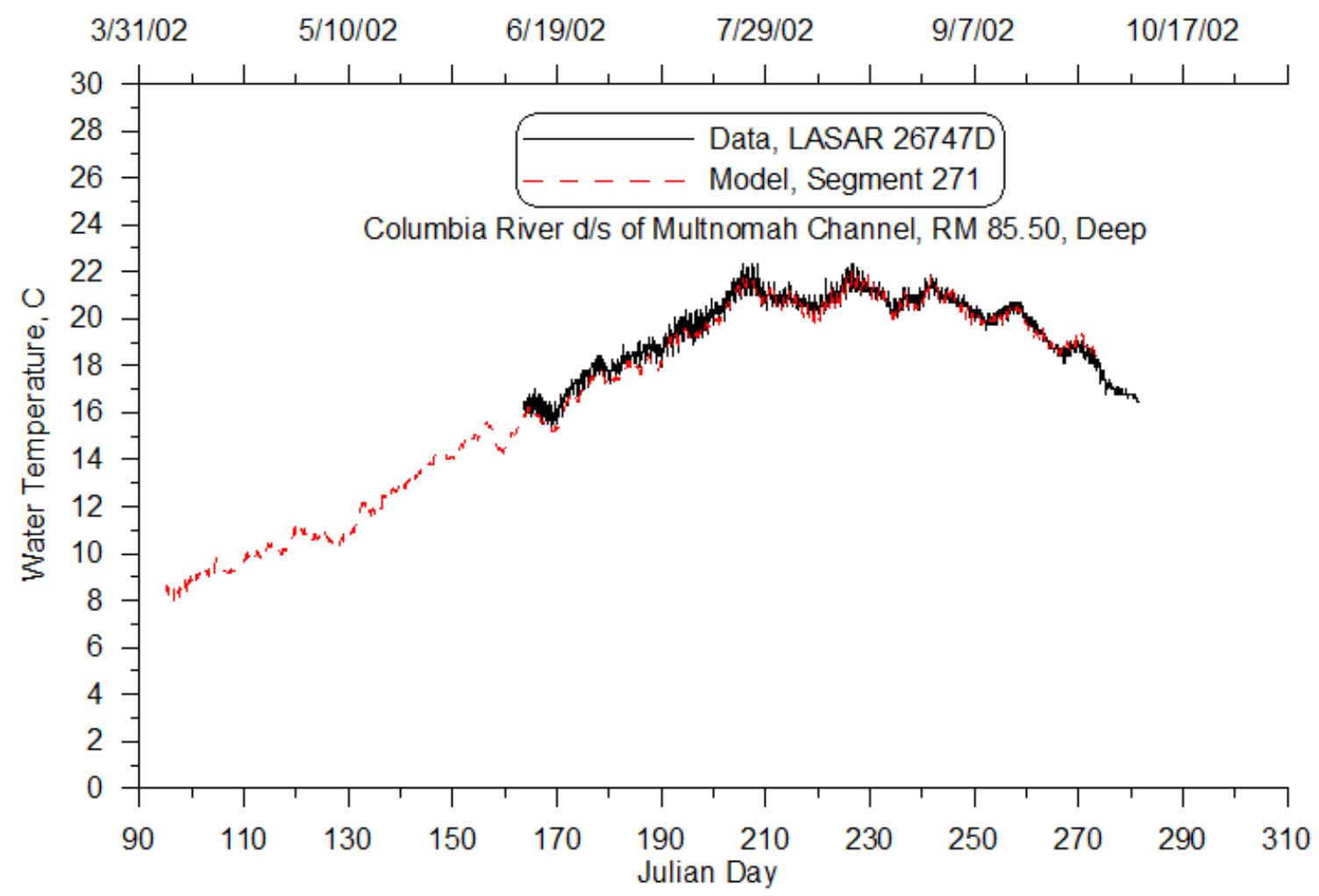

Figure 43: Columbia River downstream of Multnomah Channel (deep) model-data continuous temperature comparison, 2002

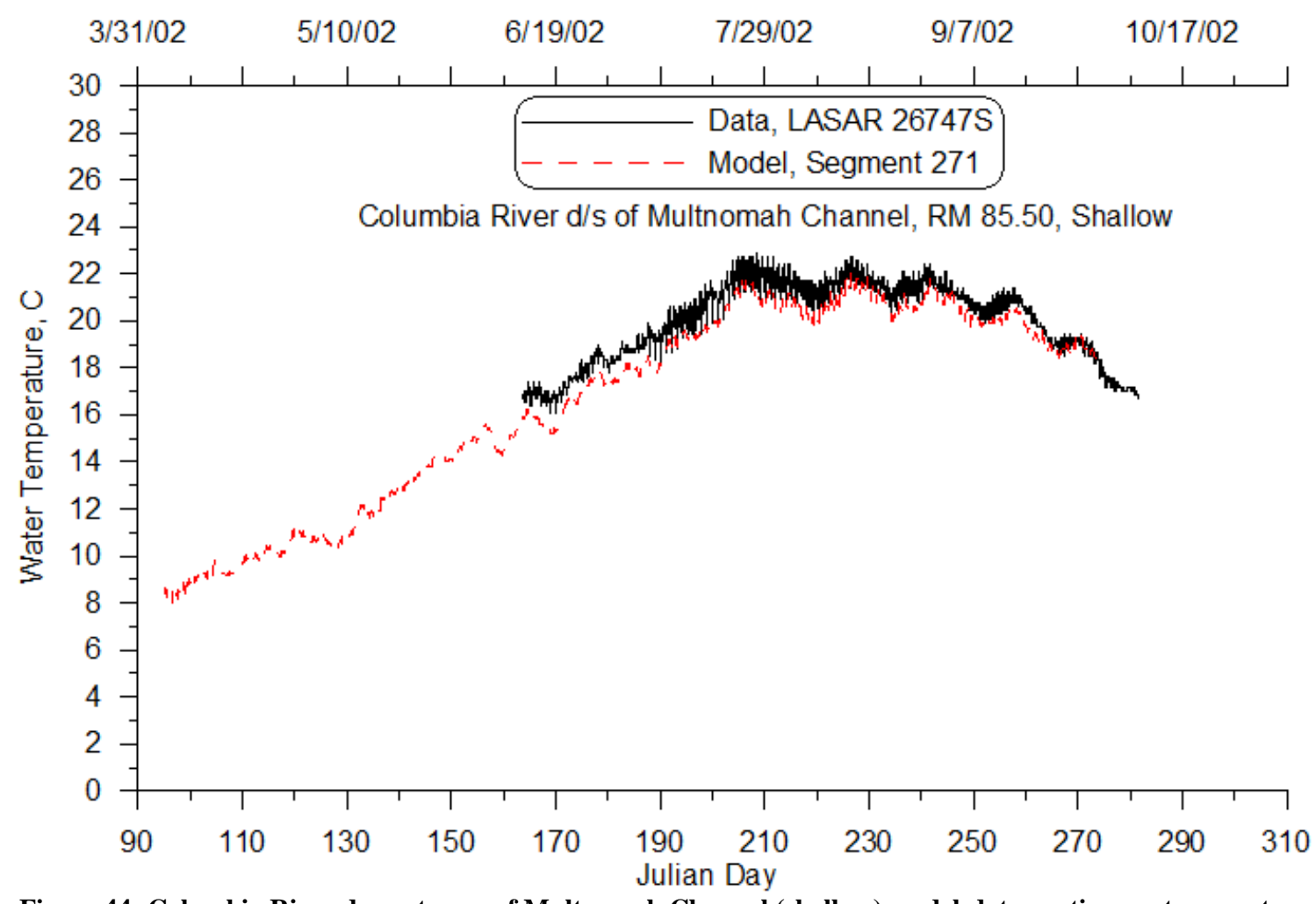

Figure 44: Columbia River downstream of Multnomah Channel (shallow) model-data continuous temperature comparison, 2002 


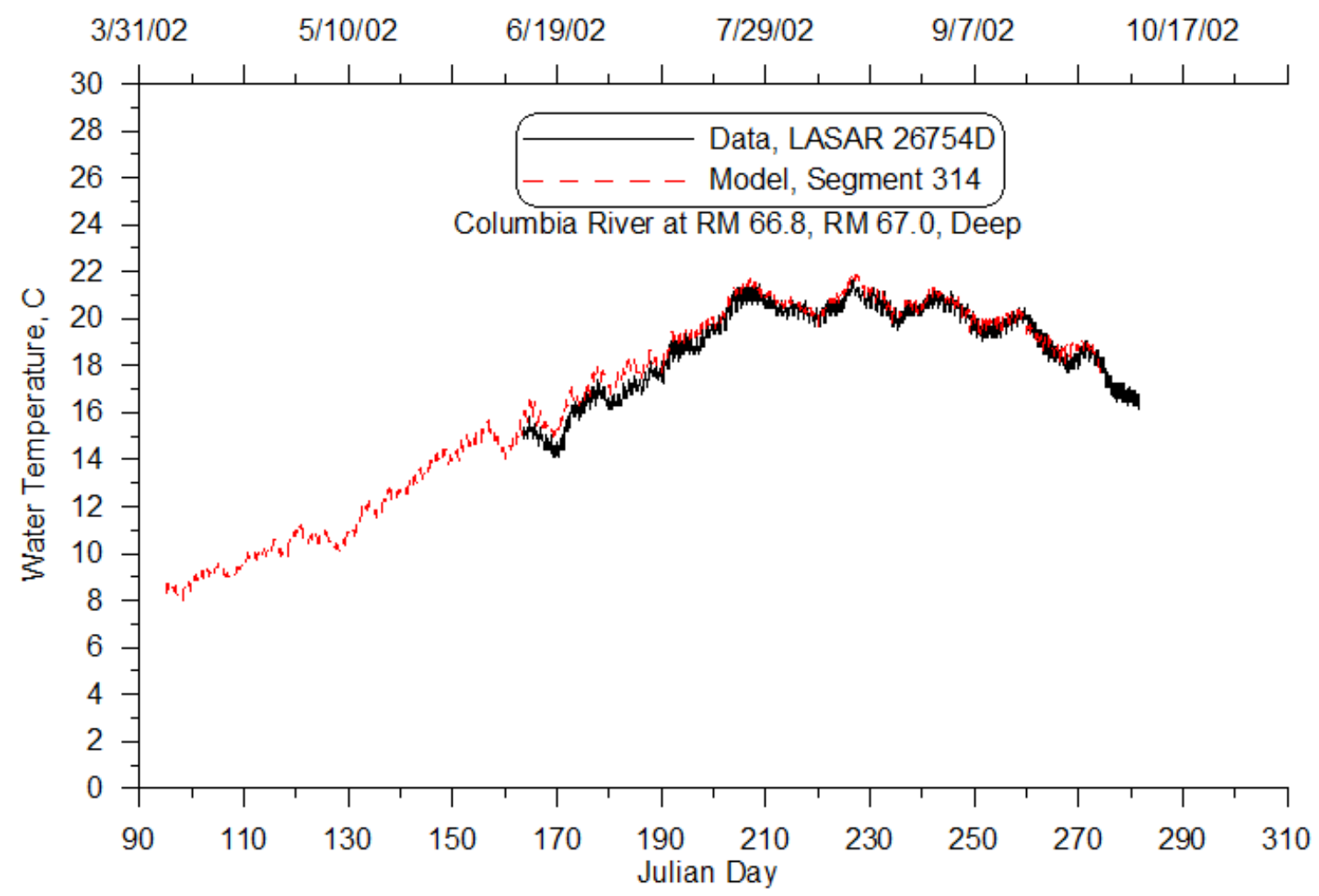

Figure 45: Columbia River at RM 66.8 (deep) model-data continuous temperature comparison, 2002

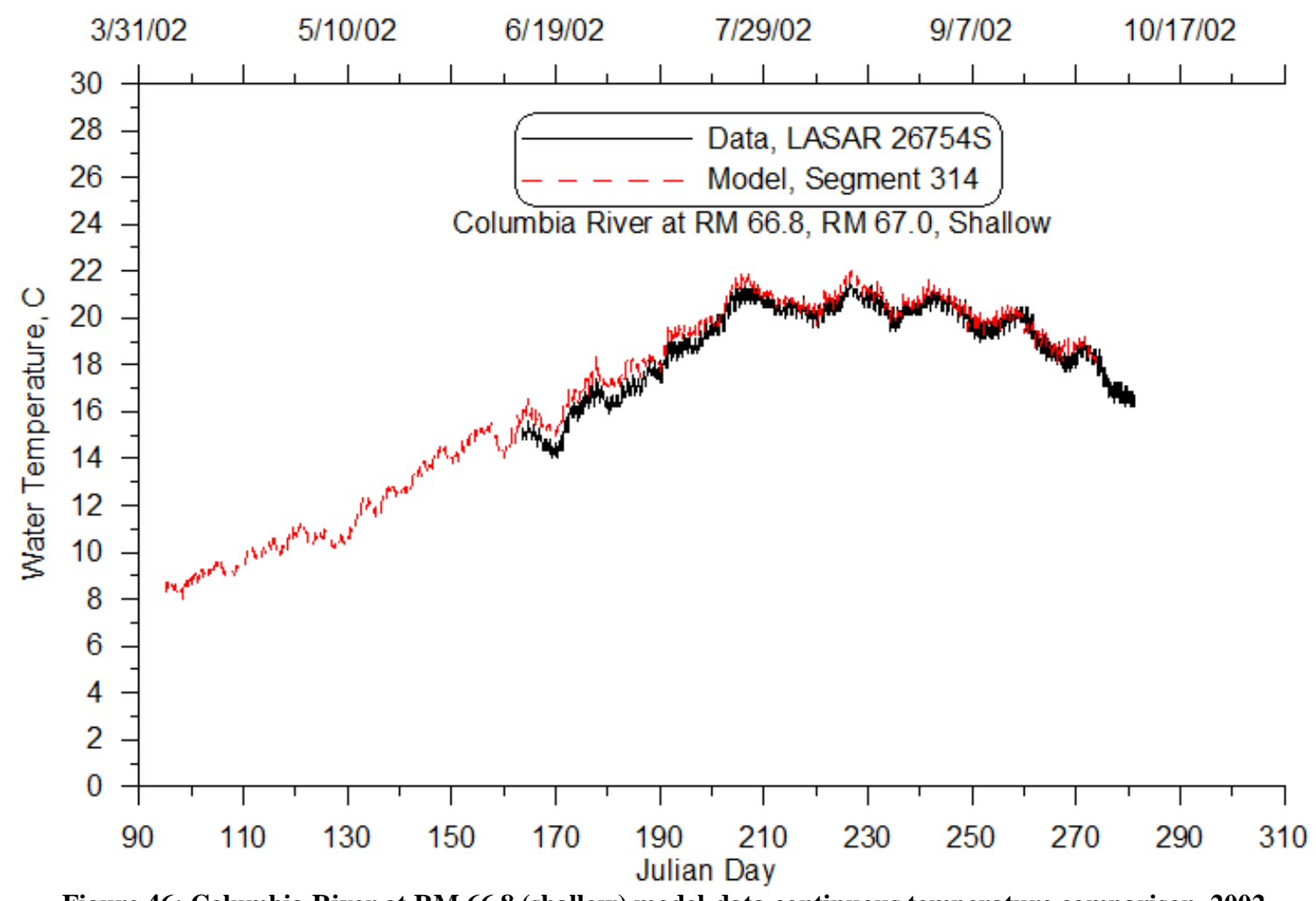

Figure 46: Columbia River at RM 66.8 (shallow) model-data continuous temperature comparison, 2002 


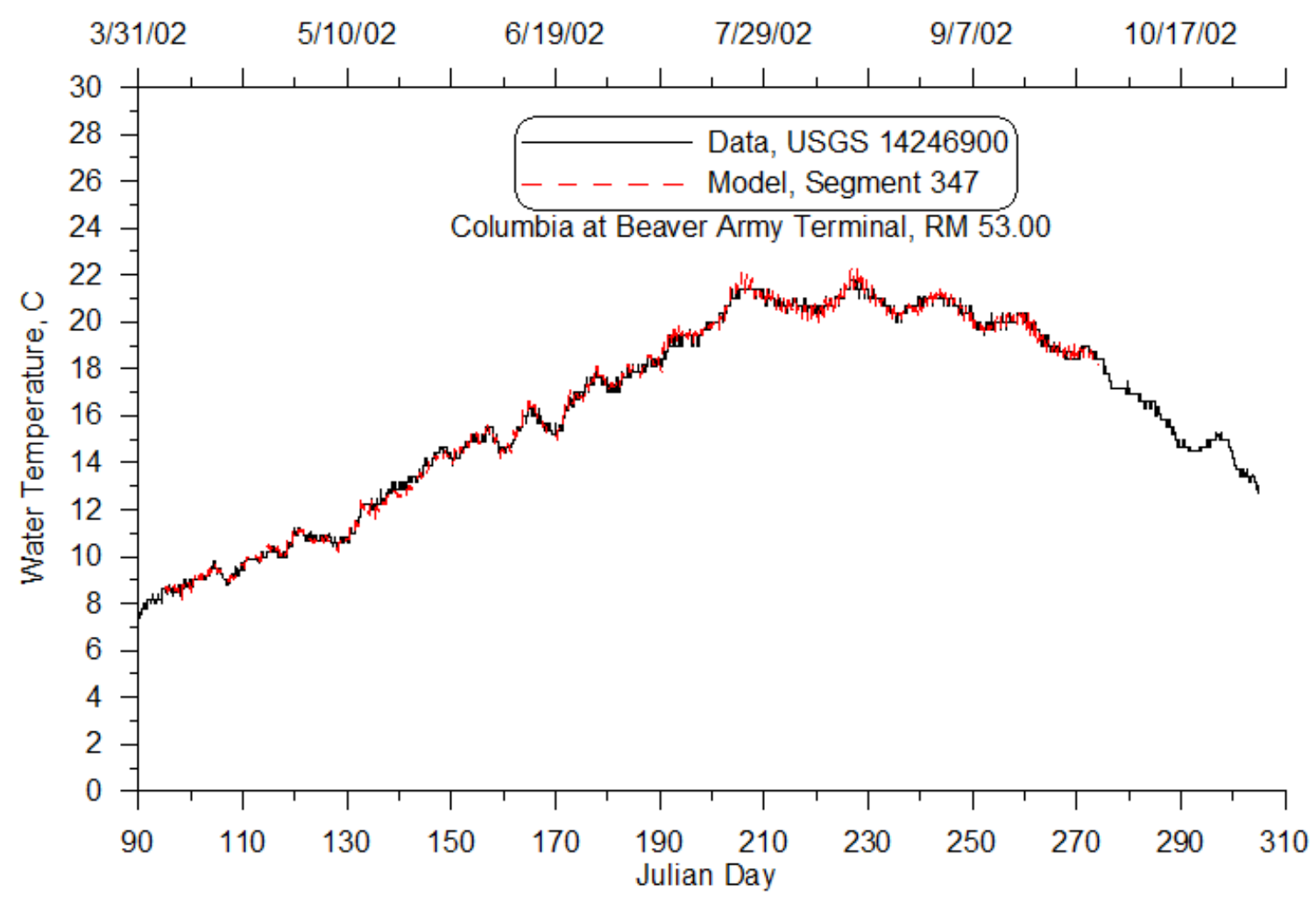

Figure 47: Columbia River at Beaver Army Terminal model-data continuous temperature comparison, 2002

\subsubsection{Middle Willamette River}

\section{Introduction}

The Middle Willamette River model domain starts from Salem (RM 85.4) and ends at Willamette Falls (RM 26.8). The model was set up as 3 water bodies, including 6 branches, 407 segments and 45 layers. There are 10 tributaries flows into the system. Among the 6 branches, there were loop branches, which represented flow around two islands. The model grid is shown in Figure 48. 


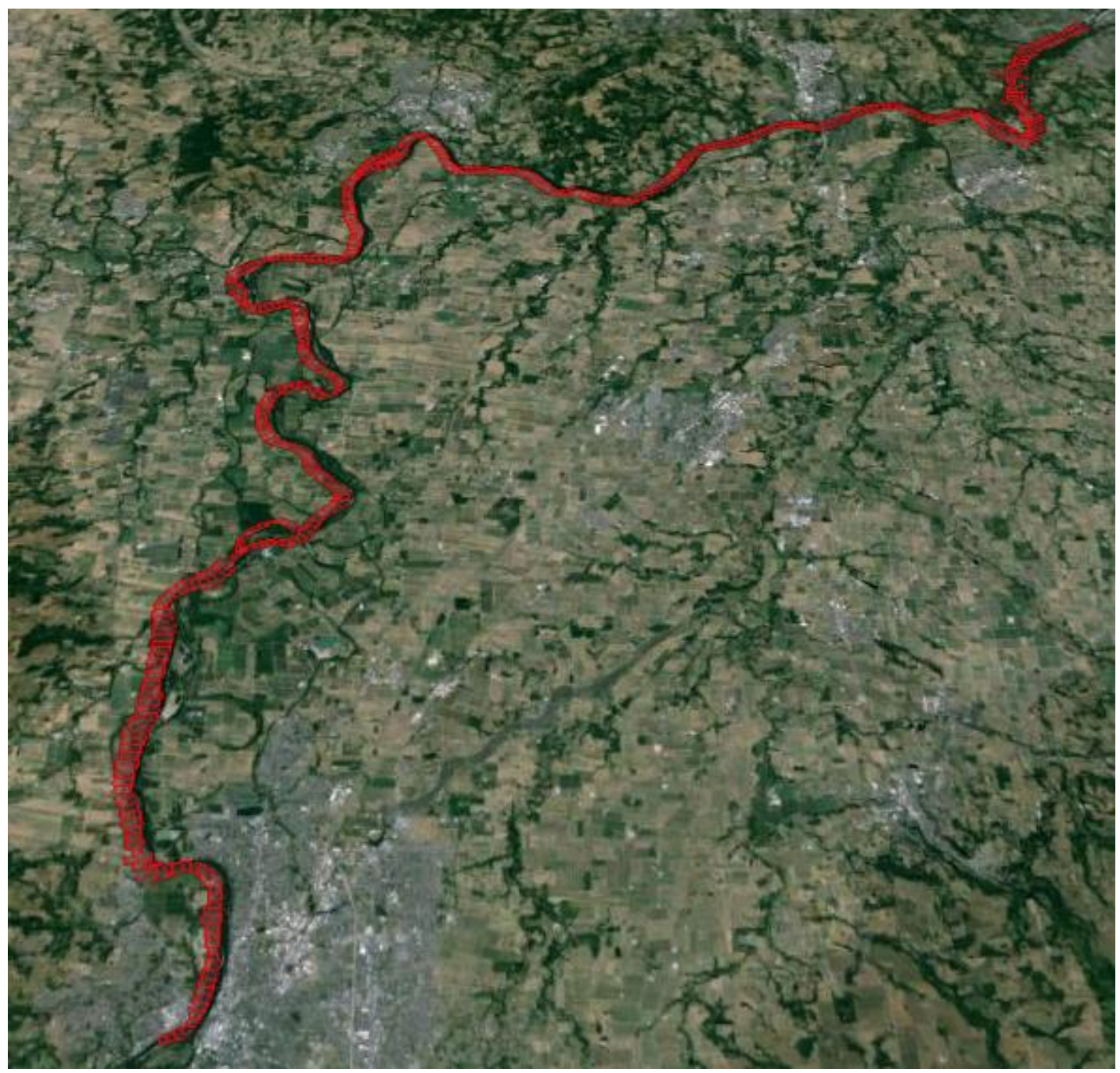

Figure 48: Middle Willamette River Model Grid

\section{Hydrodynamics}

Flow rate and water surface elevation was first tested using the original setting in V3.1 model. As the model showed good agreement with data, no further calibrations were conducted.

Year 2001 
The hydrodynamic calibration period in 2001 was from August to September. Error statistics are summarized in Table 6 . Figure 49 through 51 show the water level and flow comparison between model predictions and measured data. Previous research suspected that the water level measurement at Segment 396 was not accurate (Berger, et al., 2004). Despite that, the flow rate and water level predicted by CE-QUAL-W2 Version 3.7 model showed good consistency with data measured.

Table 6: Middle Willamette River hydrodynamic calibration statistics, 2001

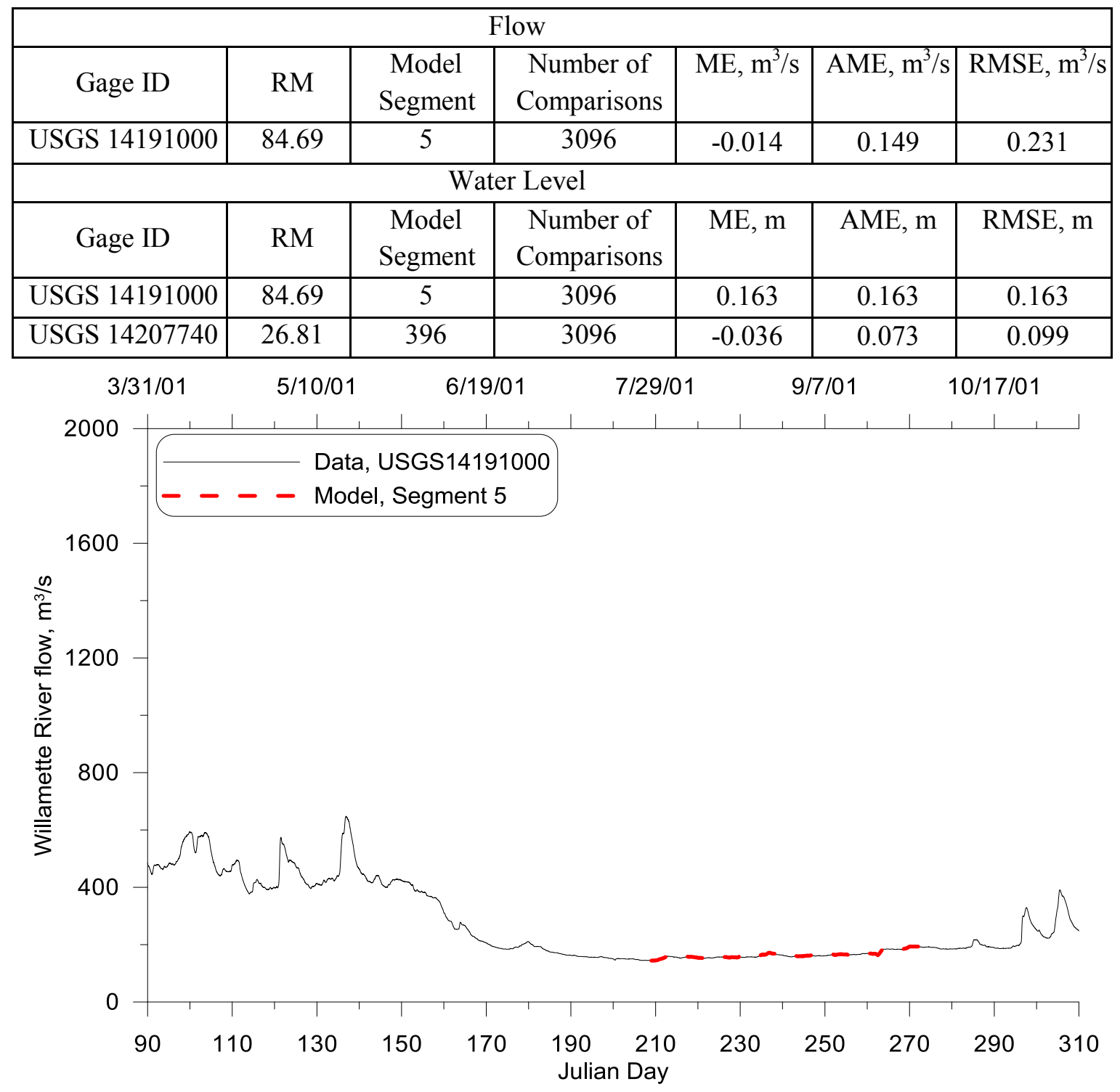

Figure 49: Willamette River at Salem model-data flow comparison, 2001 


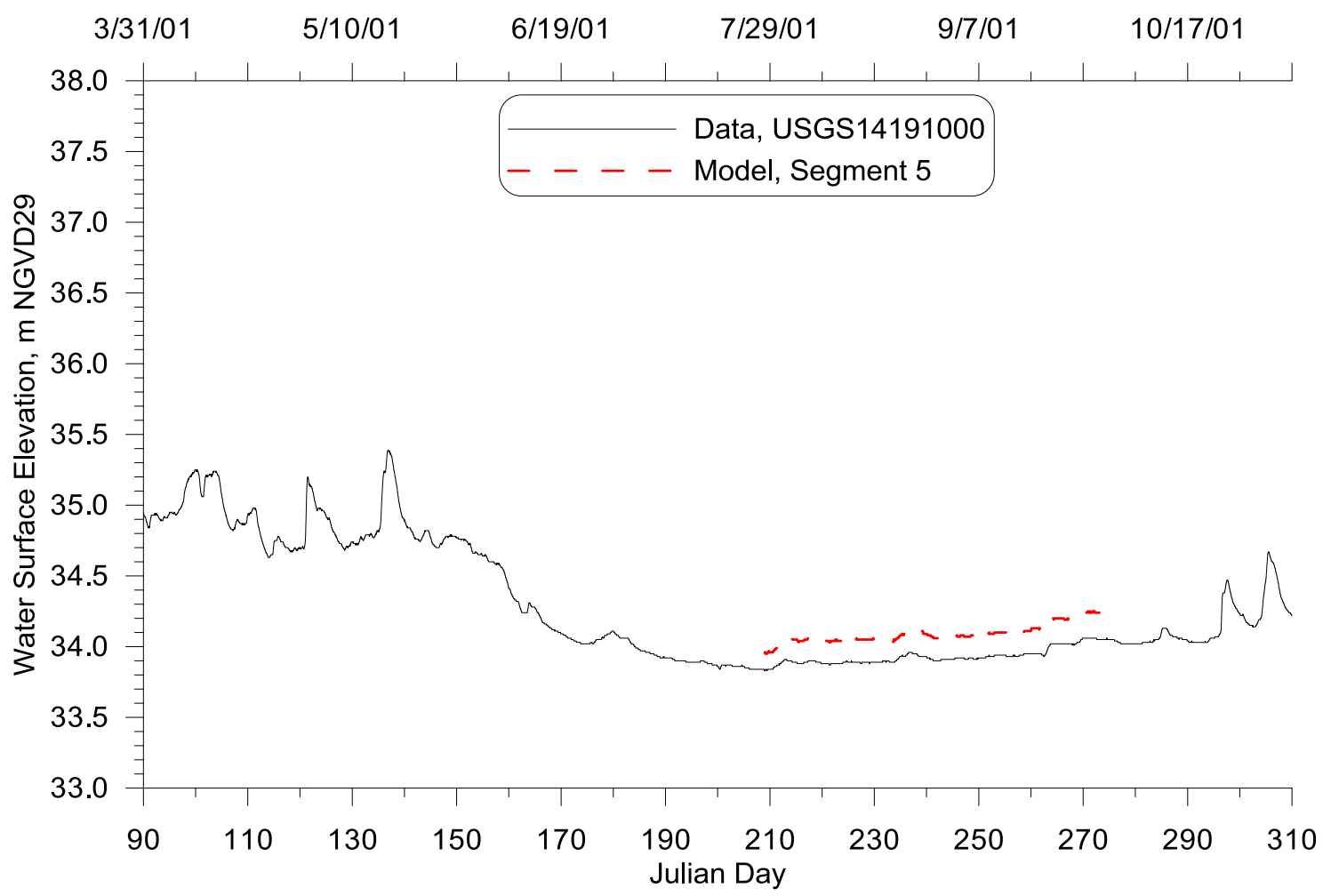

Figure 50: Willamette River at Salem model-data water level comparison, 2001

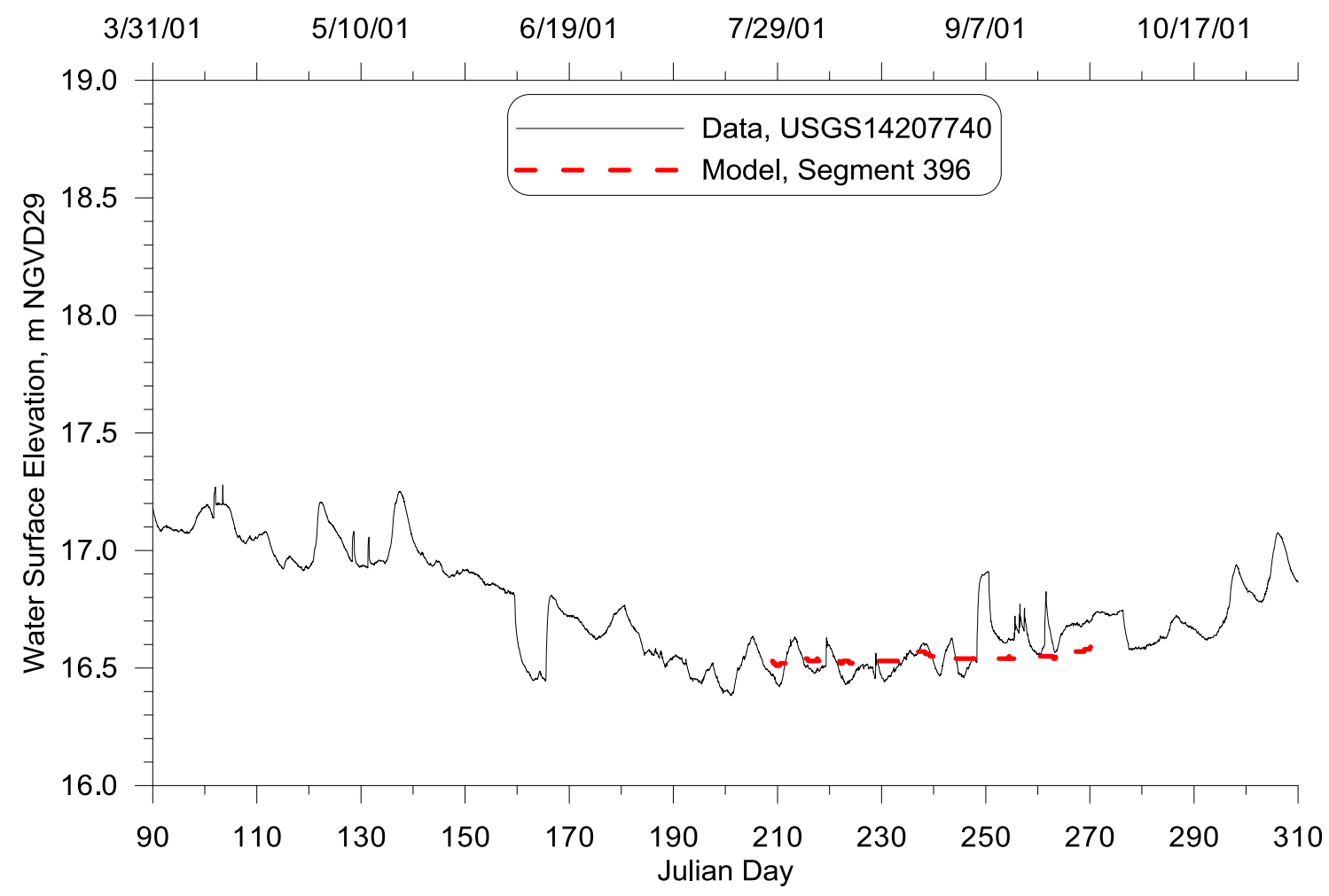

Figure 51: Willamette River at the Willamette Falls model-data water level comparison, 2001 


\section{Year 2002}

The hydrodynamic calibration period in 2002 was from April to September. Figure 52 through 55 show the water level and flow comparison between model predictions and measured data. There were slightly overestimate in water level for several sites. Error statistics are summarized in Table 7.

Table 7: Middle Willamette River hydrodynamic calibration statistics, 2002

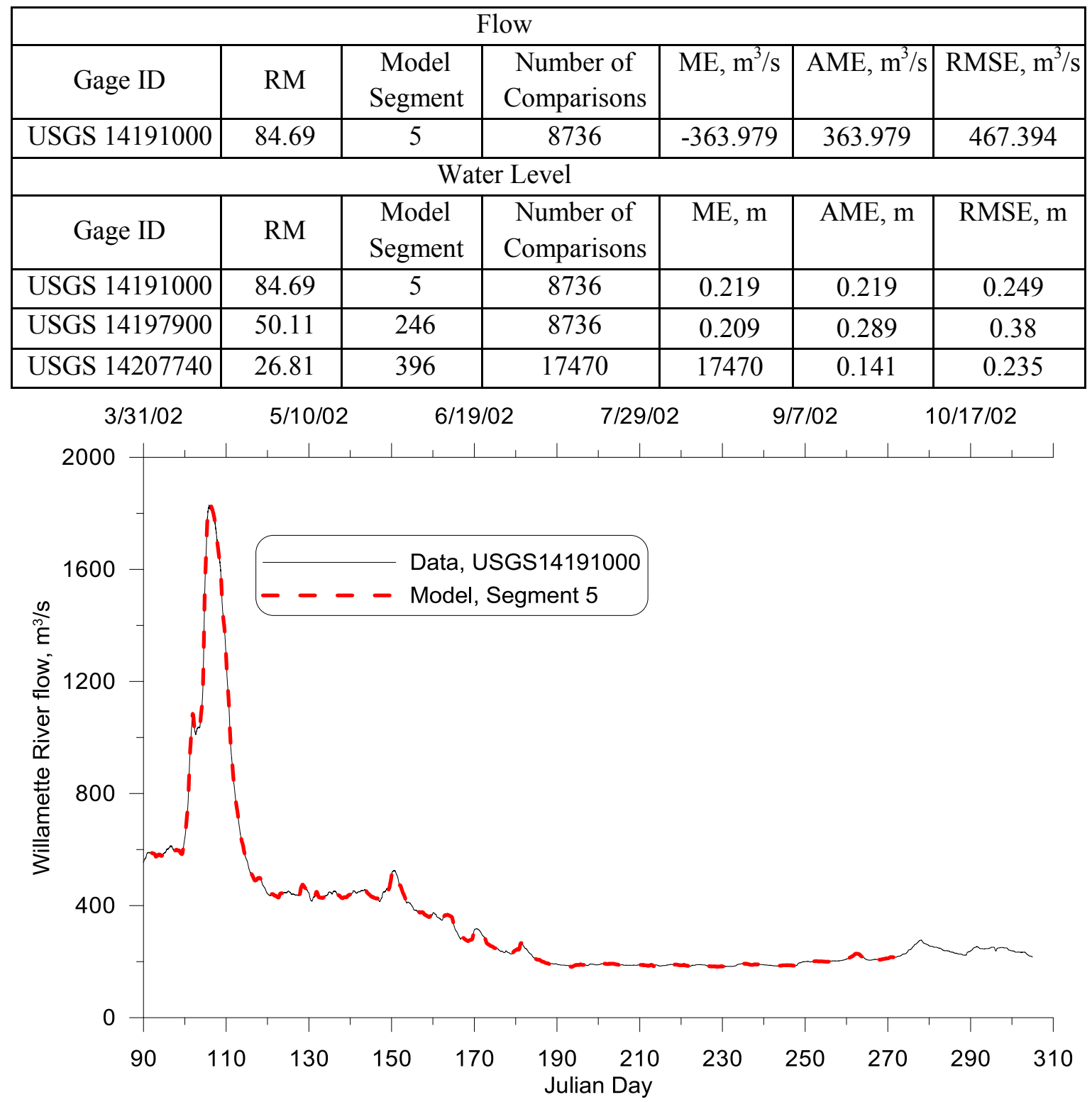

Figure 52: Willamette River at Salem model-data flow comparison, 2001 


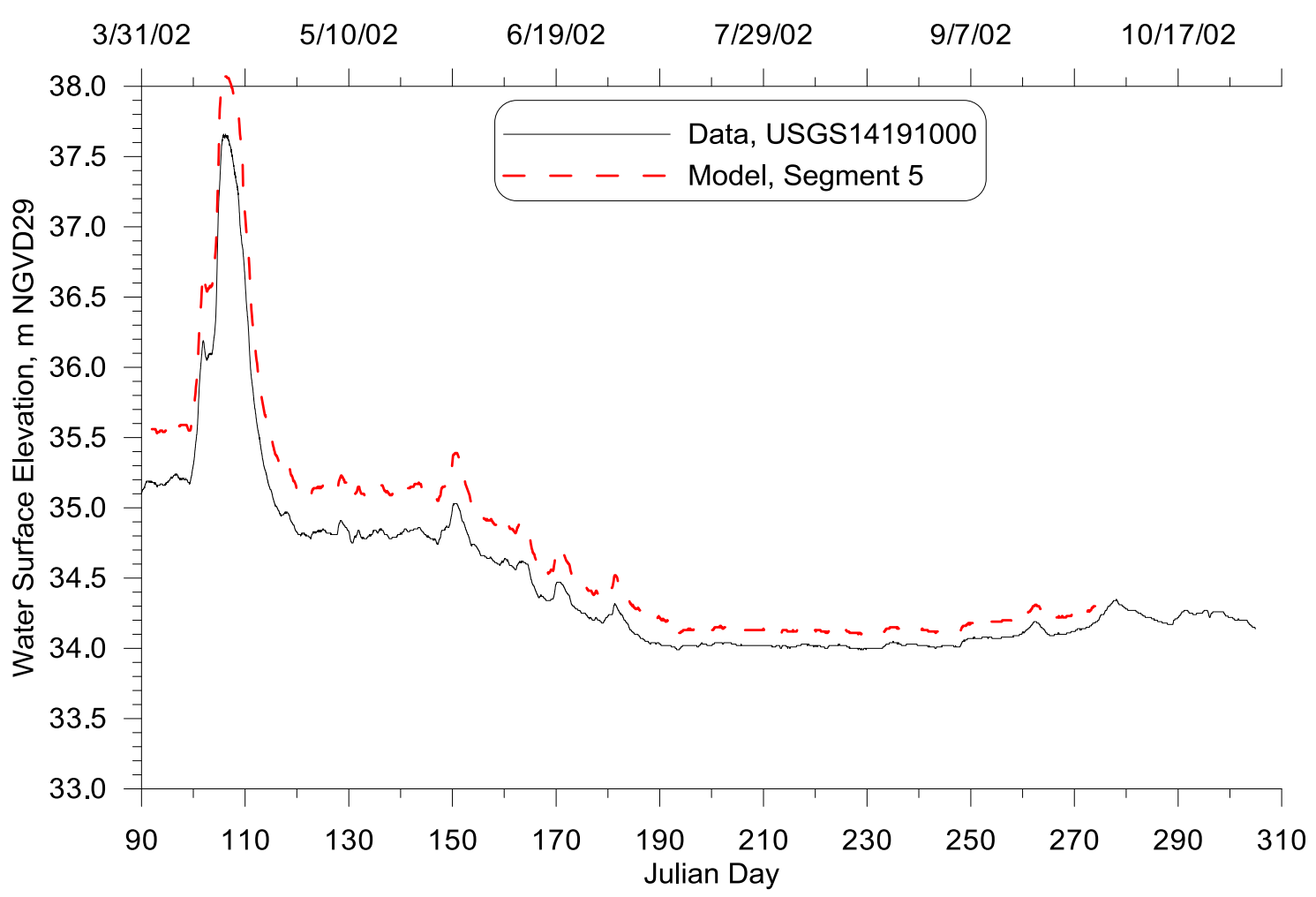

Figure 53: Willamette River at Salem model-data water level comparison, 2002

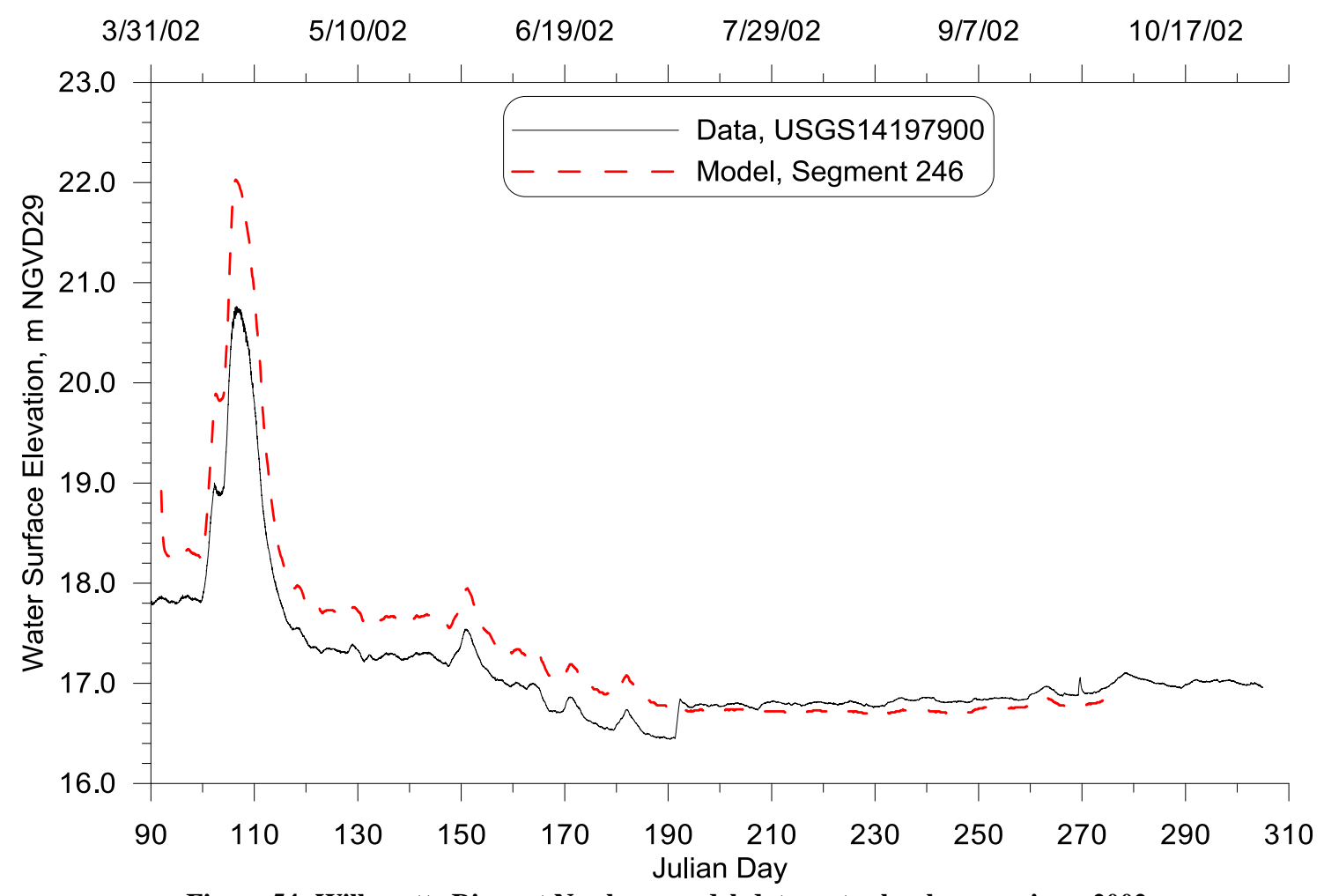

Figure 54: Willamette River at Newberg model-data water level comparison, 2002 


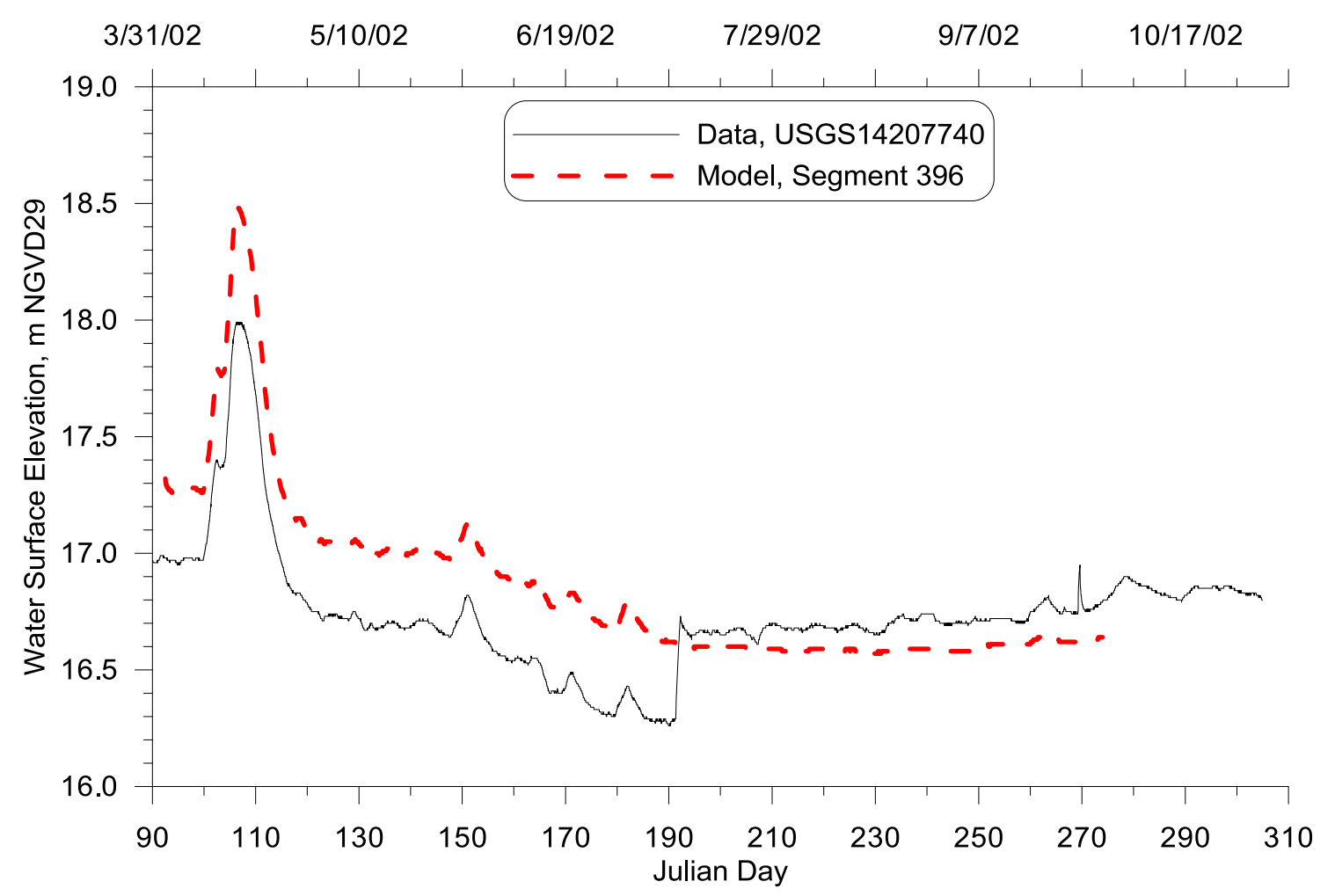

Figure 55: Willamette River at the Willamette Falls model-data water level comparison, 2002

\section{Temperature}

\section{Year 2001}

Figure 56 through 81 show the continuous temperature comparison between model predictions and measured data. Error statistics are summarized in Table 8. Predicted temperature matched data very well for all the 22 sites with the RMSEs below $0.84{ }^{\circ} \mathrm{C}$.

Table 8: Willamette River continuous water temperature calibration model-data error statistics, 2001

\begin{tabular}{|c|c|c|c|c|c|c|}
\hline \multirow[b]{2}{*}{ Site ID } & \multirow[b]{2}{*}{ RM } & \multirow[b]{2}{*}{$\begin{array}{c}\text { Model } \\
\text { Segmen } \\
\mathrm{t}\end{array}$} & \multicolumn{4}{|c|}{ Continuous Temperature } \\
\hline & & & $\begin{array}{c}\text { Number of } \\
\text { Comparison } \\
\mathrm{s}\end{array}$ & $\mathrm{ME},{ }^{\circ} \mathrm{C}$ & $\mathrm{AME},{ }^{\circ} \mathrm{C}$ & $\mathrm{RMSE},{ }^{\circ} \mathrm{C}$ \\
\hline USGS 14191000 & 85.66 & 5 & 253 & 0.008 & 0.053 & 0.069 \\
\hline USGS 14192015 & 82.60 & 18 & 2839 & 0.333 & 0.479 & 0.568 \\
\hline LASAR 28255 & 79.18 & 40 & 2951 & 0.712 & 0.728 & 0.832 \\
\hline LASAR 10344 & 72.63 & 82 & 1596 & 0.632 & 0.675 & 0.762 \\
\hline
\end{tabular}




\begin{tabular}{|c|c|c|c|c|c|c|}
\hline PGE Eagle Nest A & 63.95 & 140 & 1596 & 0.484 & 0.603 & 0.729 \\
\hline PGE Eagle Nest B & 63.95 & 140 & 1596 & 0.436 & 0.576 & 0.698 \\
\hline PGE Coffee Island A & 61.51 & 156 & 1595 & 0.179 & 0.569 & 0.692 \\
\hline PGE Coffee Island B & 61.51 & 156 & 1596 & 0.303 & 0.593 & 0.721 \\
\hline PGE San Salvador A & 55.58 & 196 & 1596 & 0.29 & 0.591 & 0.725 \\
\hline PGE San Salvador B & 55.58 & 196 & 1596 & 0.298 & 0.591 & 0.728 \\
\hline PGE Ash Island A & 52.76 & 228 & 1596 & 0.243 & 0.608 & 0.76 \\
\hline PGE Ash Island B & 52.76 & 228 & 1596 & 0.093 & 0.597 & 0.729 \\
\hline PGE Champoeg Dock & 45.21 & 277 & 1596 & & & \\
A & & & & 0.034 & 0.498 & 0.608 \\
\hline PGE Champoeg Dock & 45.21 & 277 & 1596 & & & \\
B & & & & 0.122 & 0.499 & 0.619 \\
\hline LASAR 10340 & 38.94 & 318 & 3192 & -0.294 & 0.478 & 0.587 \\
\hline PGE US Molalla R. A & 36.17 & 336 & 1577 & -0.171 & 0.478 & 0.577 \\
\hline PGE US Molalla R. B & 36.17 & 336 & 1596 & -0.088 & 0.465 & 0.555 \\
\hline PGE Canby A & 34.32 & 348 & 1596 & 0.13 & 0.47 & 0.555 \\
\hline PGE Canby B & 34.32 & 348 & 1596 & 0.304 & 0.52 & 0.621 \\
\hline PGE Powerline A & 29.37 & 380 & 1548 & 0.102 & 0.465 & 0.562 \\
\hline PGE Powerline B & 29.37 & 380 & 1548 & 0.222 & 0.487 & 0.596 \\
\hline PGE Tug Dock A & 28.61 & 384 & 1548 & 0.33 & 0.493 & 0.603 \\
\hline PGE Tug Dock B & 28.61 & 384 & 1548 & 0.055 & 0.426 & 0.505 \\
\hline PGE Boathouse A & 27.27 & 393 & 1548 & 0.005 & 0.404 & 0.483 \\
\hline PGE Boathouse B & 27.27 & 393 & 1548 & 0.027 & 0.407 & 0.488 \\
\hline PGE Forebay A & 26.81 & 396 & 1516 & 0.219 & 0.478 & 0.594 \\
\hline PGE Forebay B & 26.81 & 396 & 1517 & 0.386 & 0.525 & 0.667 \\
\hline PGE Log Boom A & 26.81 & 396 & 1548 & 0.189 & 0.483 & 0.598 \\
\hline PGE Log Boom B & 26.81 & 396 & 1192 & 0.33 & 0.507 & 0.649 \\
\hline USGS 14207740 & 28.81 & 396 & 2544 & 0.251 & 0.486 & 0.599 \\
\hline
\end{tabular}




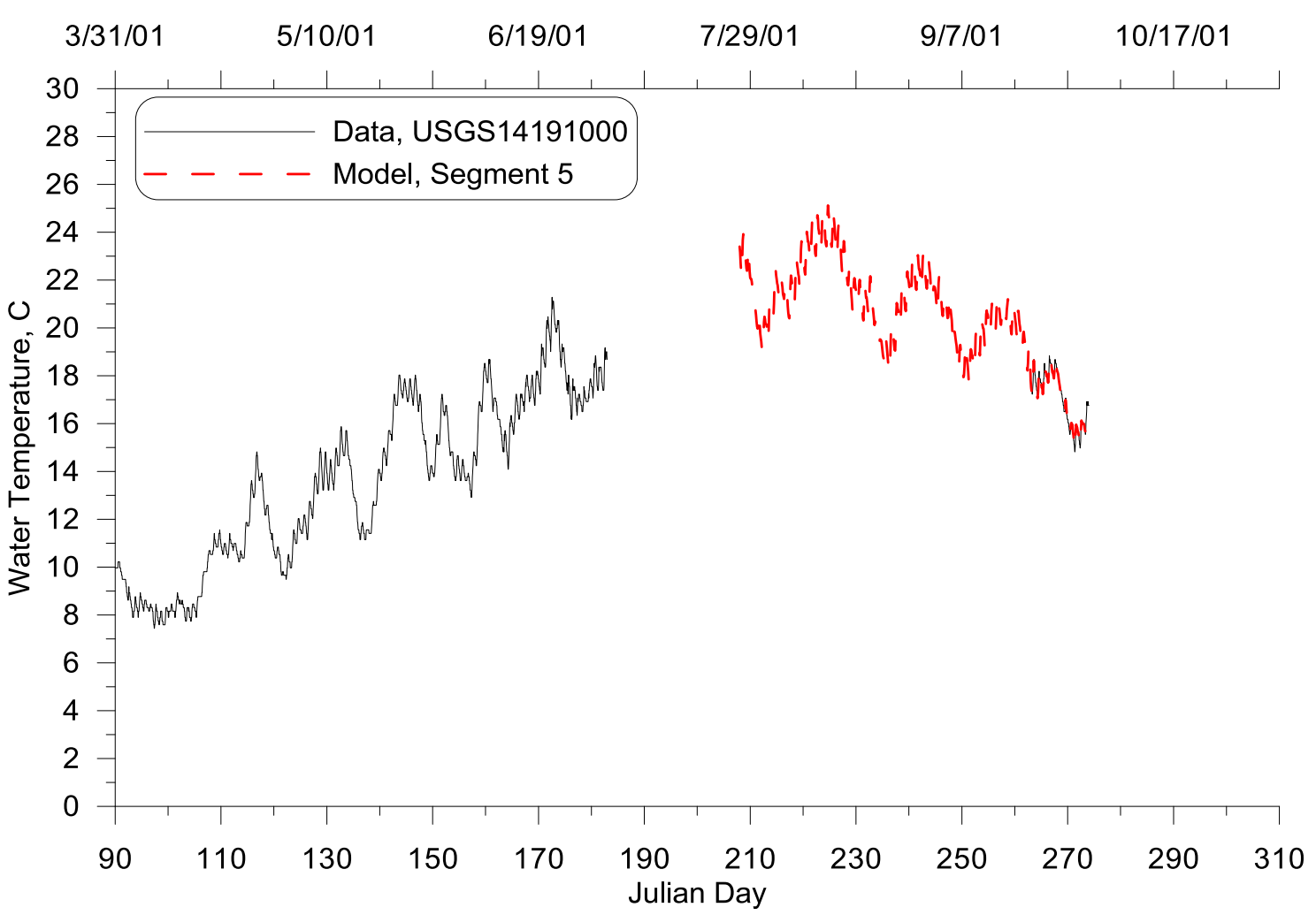

Figure 56: Willamette River at Salem model-data continuous temperature comparison, 2001

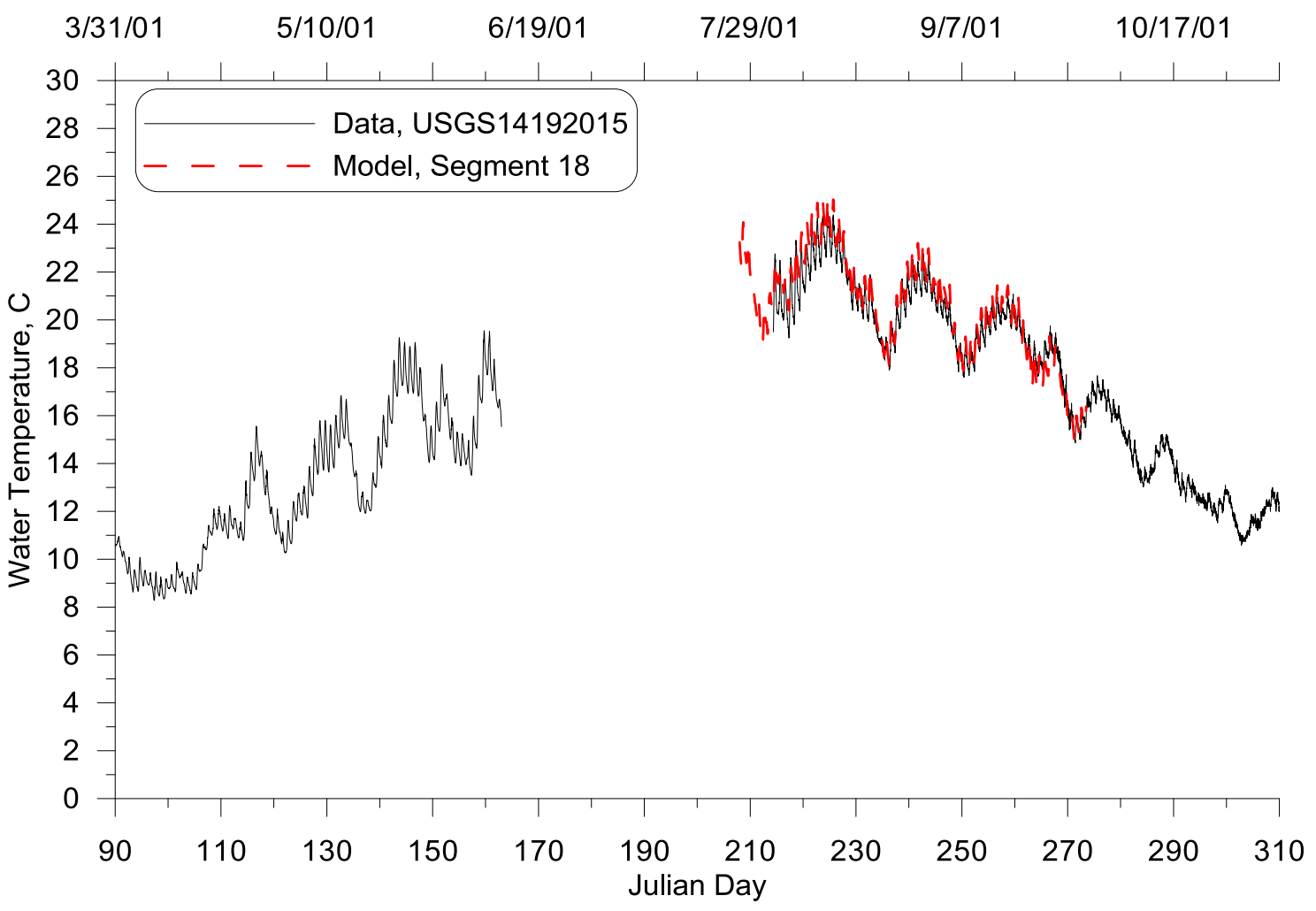

Figure 57: Willamette River at Keizer model-data continuous temperature comparison, 2001 


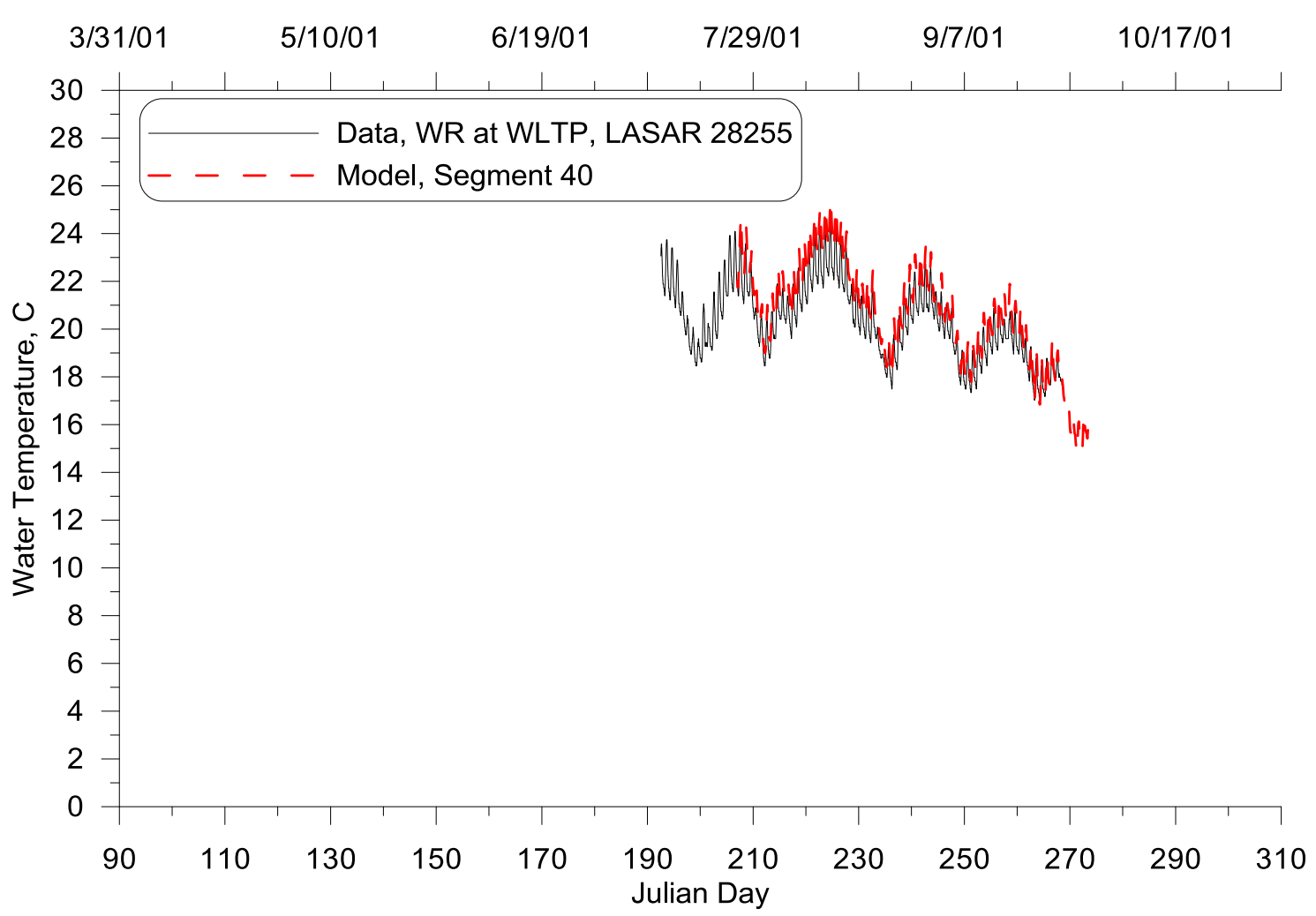

Figure 58: Willamette River at Willow Lake Treatment Plant model-data continuous temperature comparison, 2001

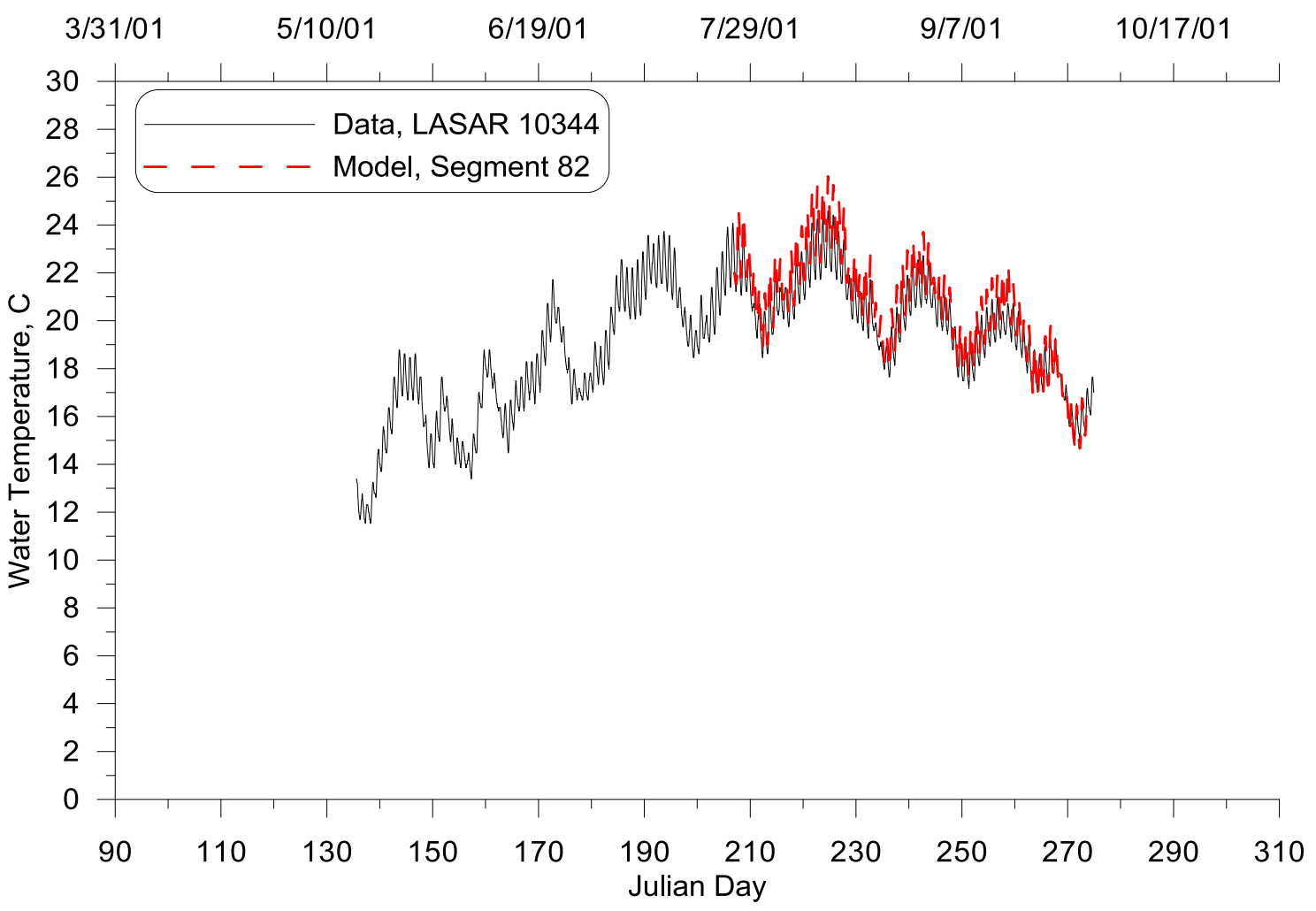

Figure 59: Willamette River at Wheatland Ferry model-data continuous temperature comparison, 2001 


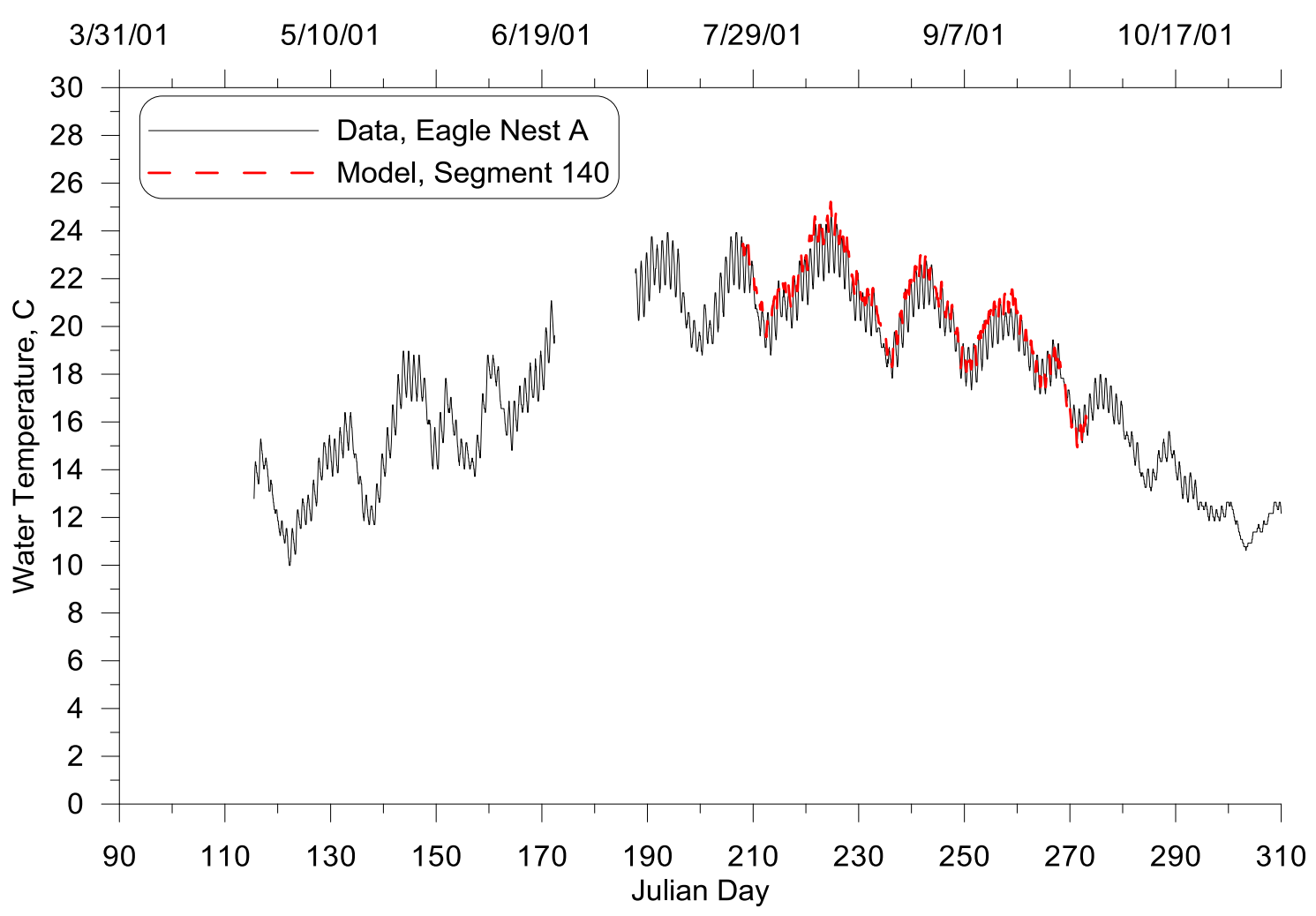

Figure 60: Willamette River at Eagle Nest A model-data continuous temperature comparison, 2001

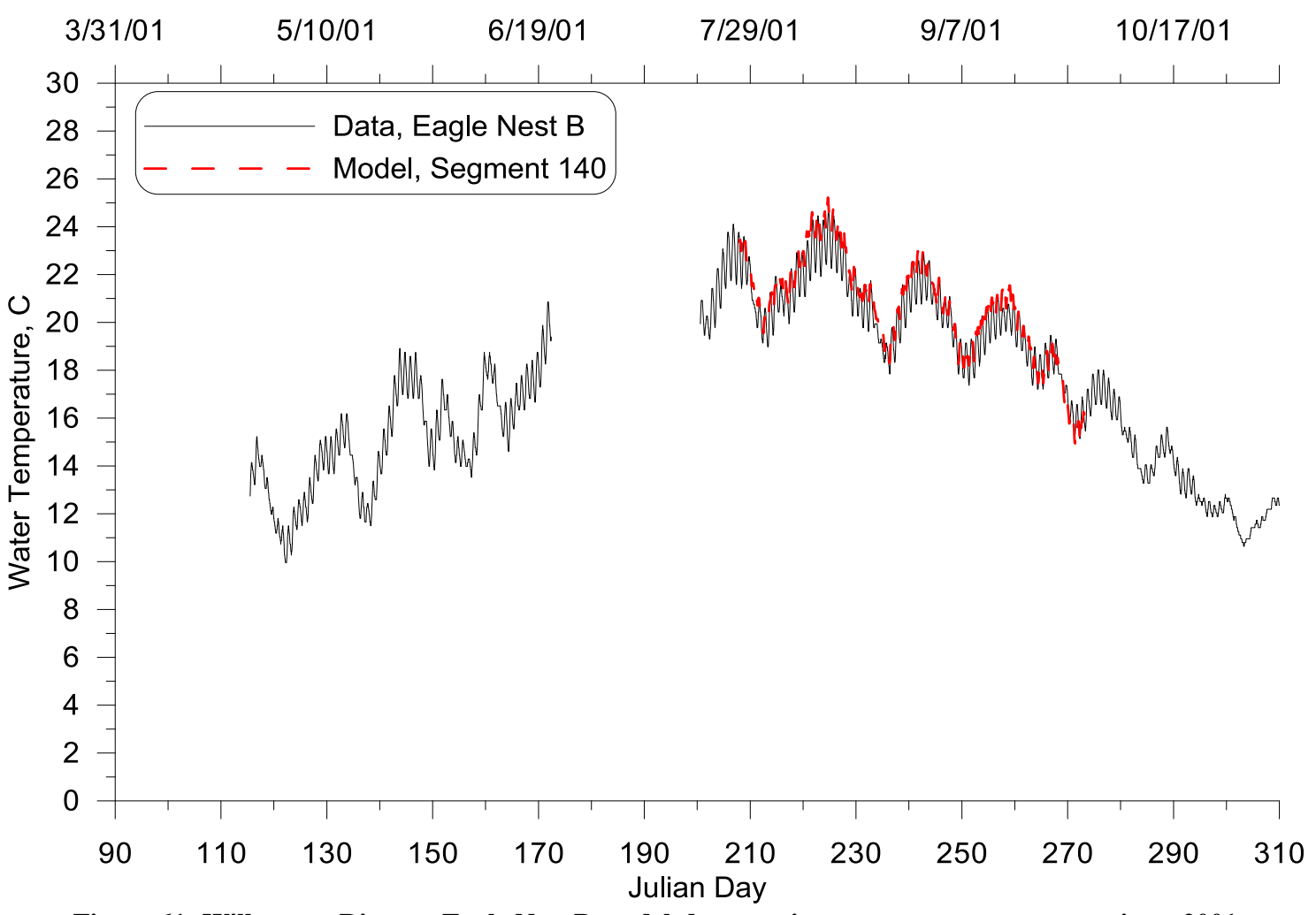

Figure 61: Willamette River at Eagle Nest B model-data continuous temperature comparison, 2001 


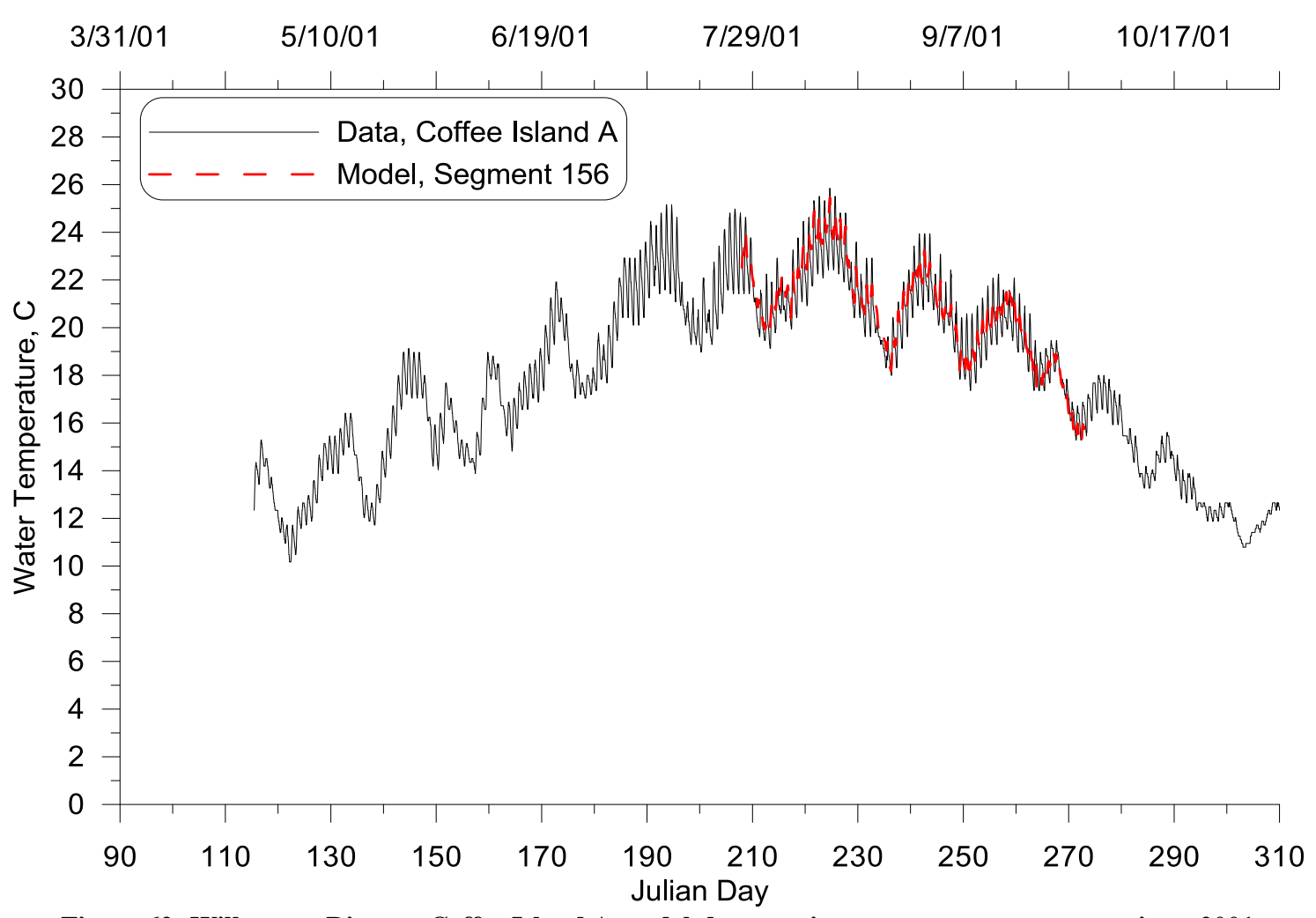

Figure 62: Willamette River at Coffee Island A model-data continuous temperature comparison, 2001

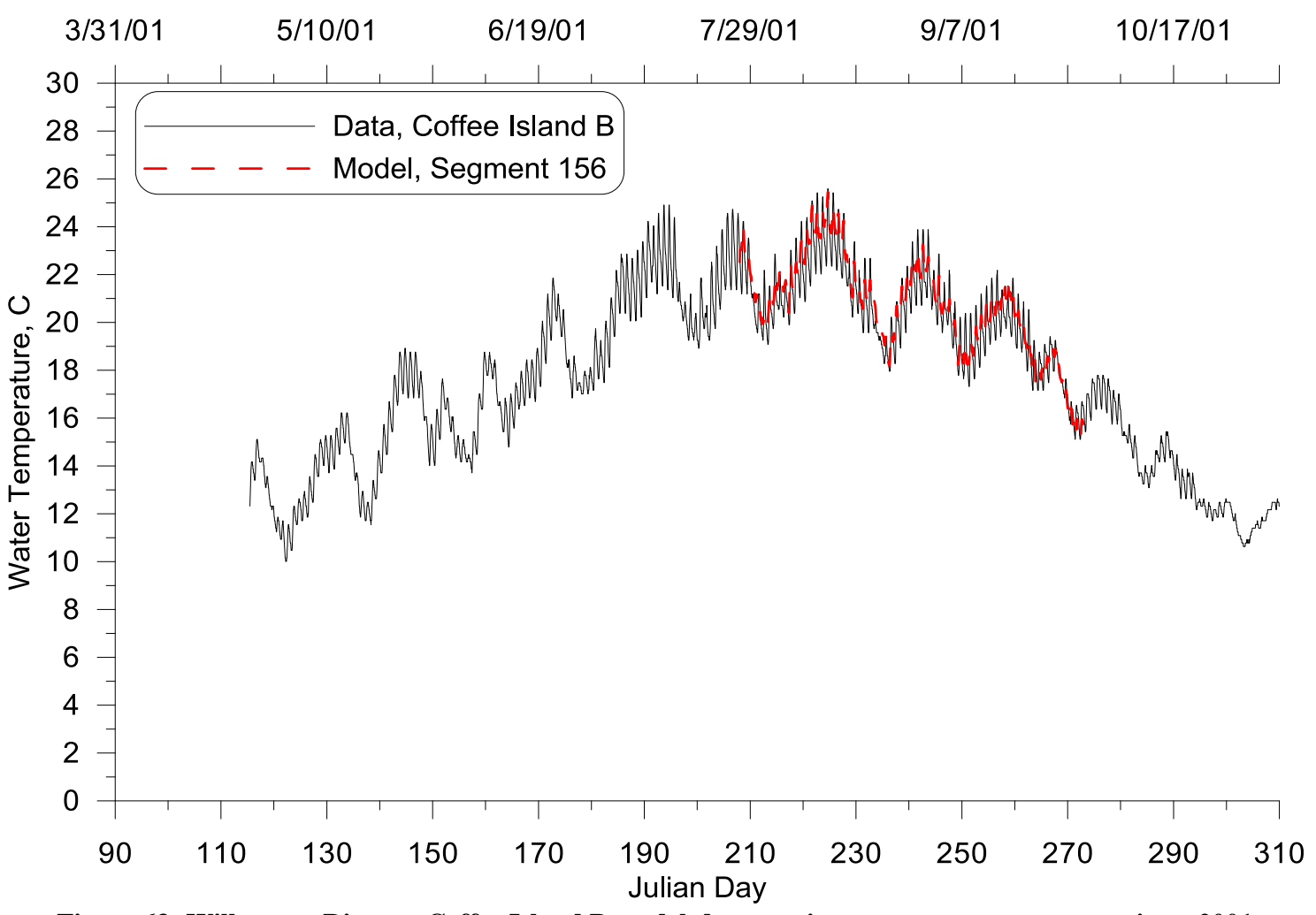

Figure 63: Willamette River at Coffee Island B model-data continuous temperature comparison, 2001 


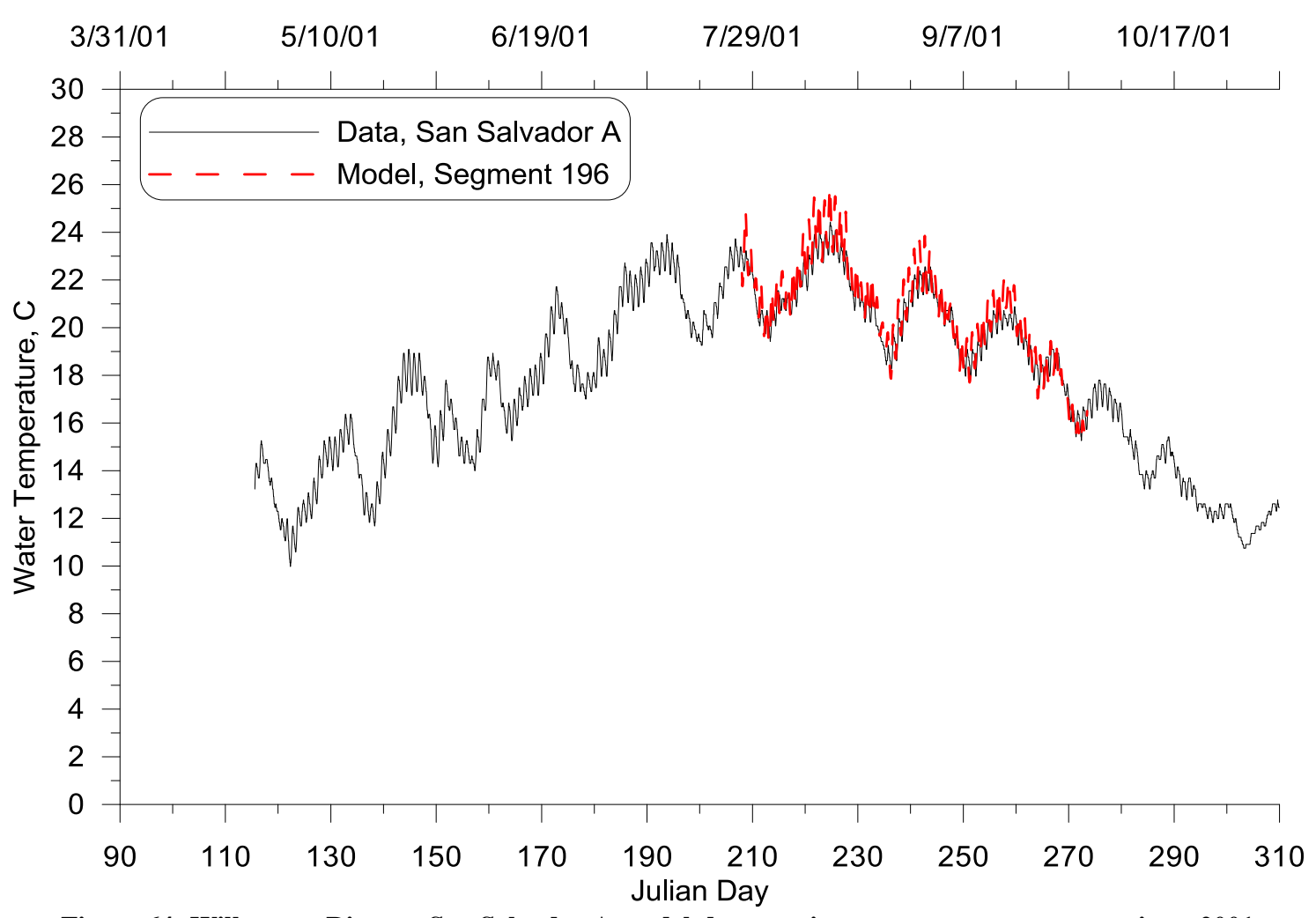

Figure 64: Willamette River at San Salvador A model-data continuous temperature comparison, 2001

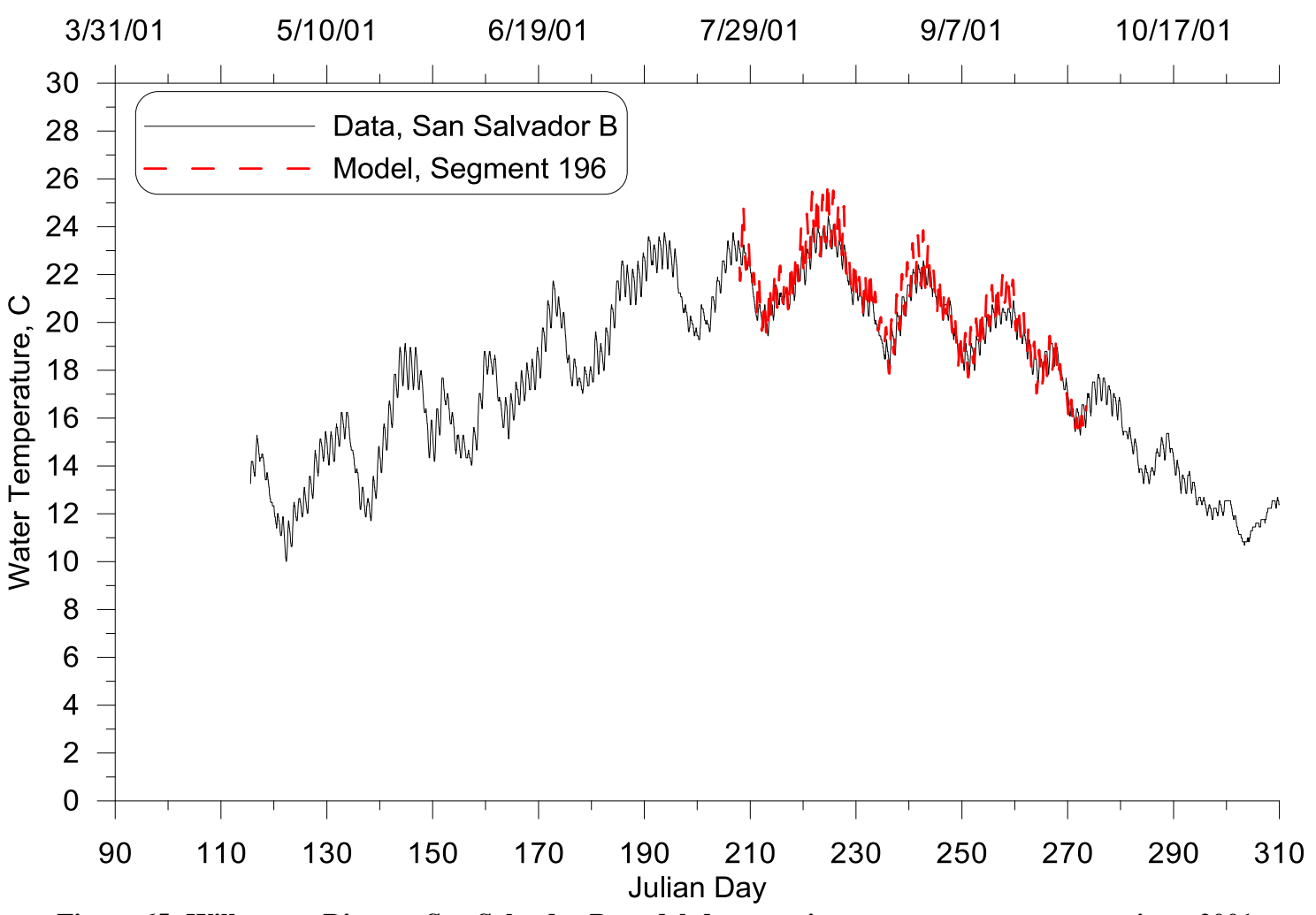

Figure 65: Willamette River at San Salvador B model-data continuous temperature comparison, 2001 


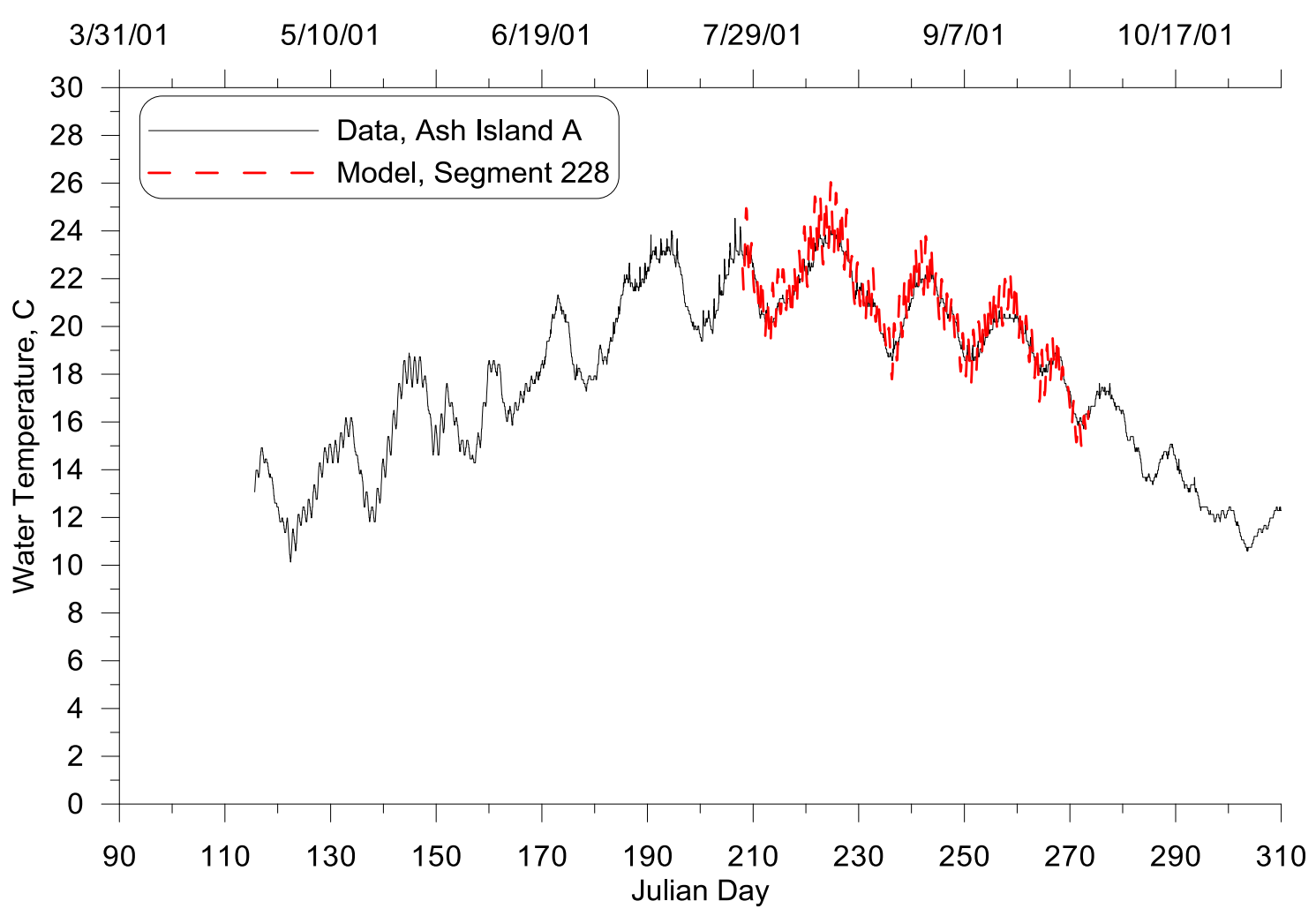

Figure 66: Willamette River above Ash Island A model-data continuous temperature comparison, 2001

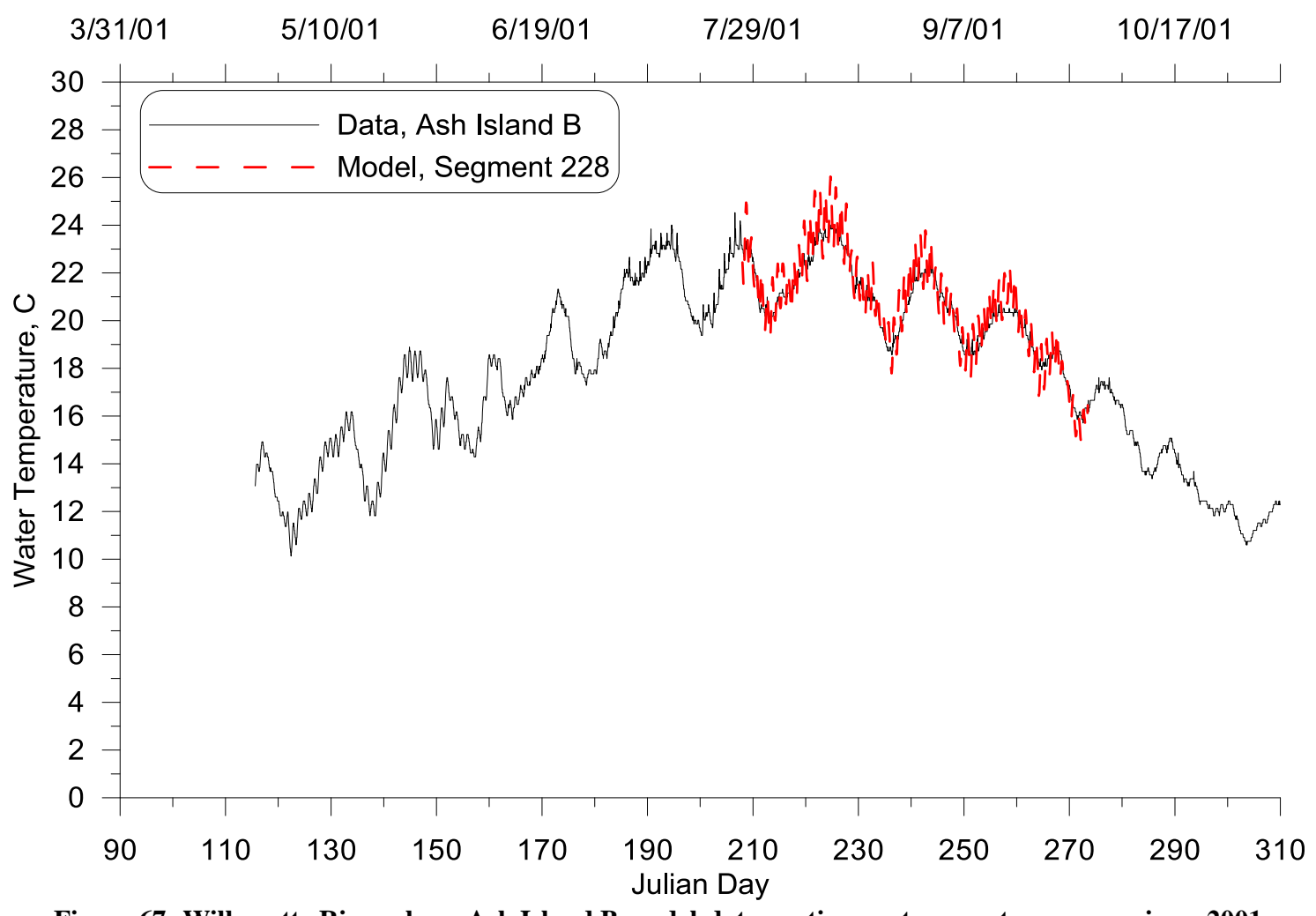

Figure 67: Willamette River above Ash Island B model-data continuous temperature comparison, 2001 


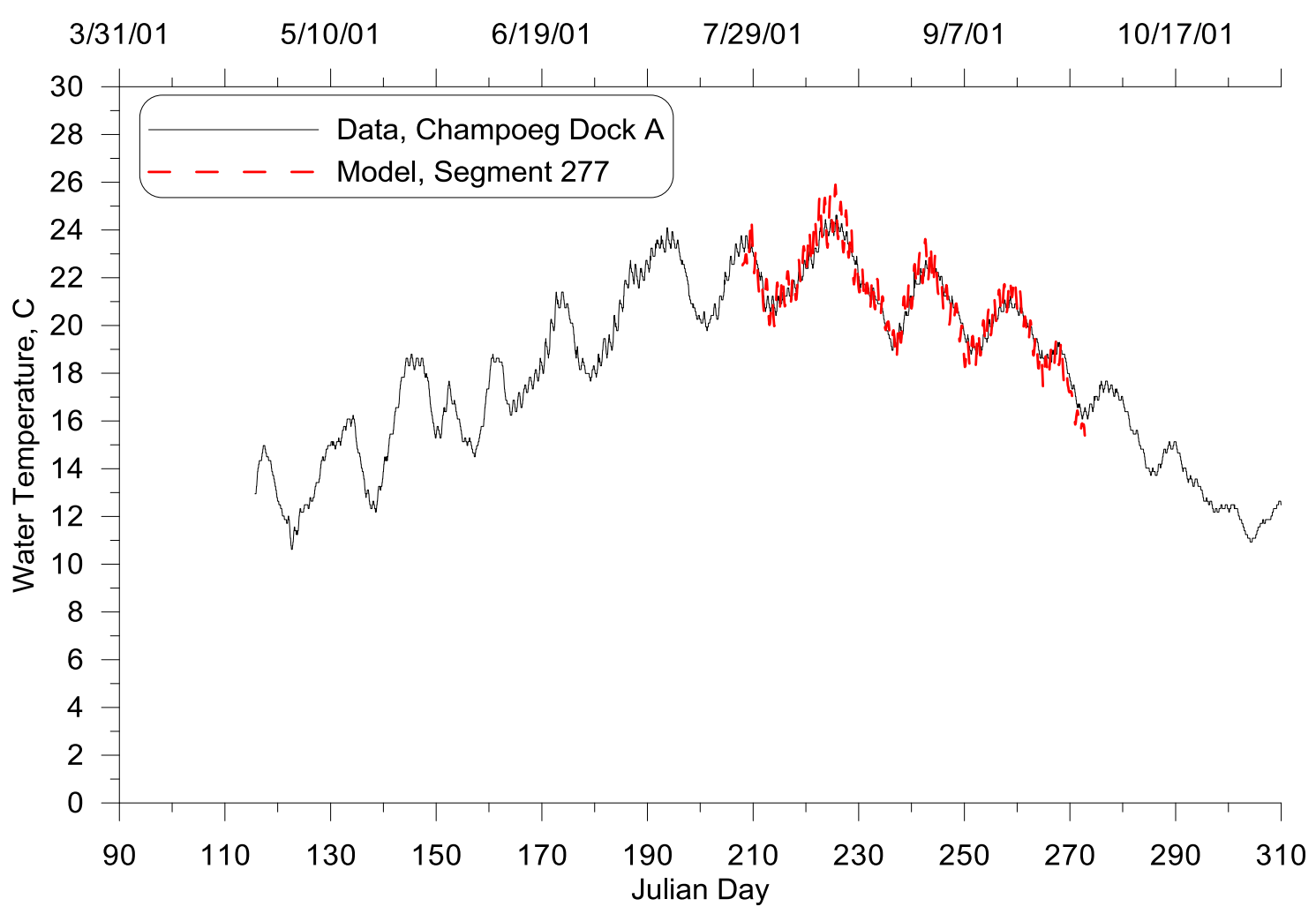

Figure 68: Willamette River at Champoeg Park A model-data continuous temperature comparison, 2001

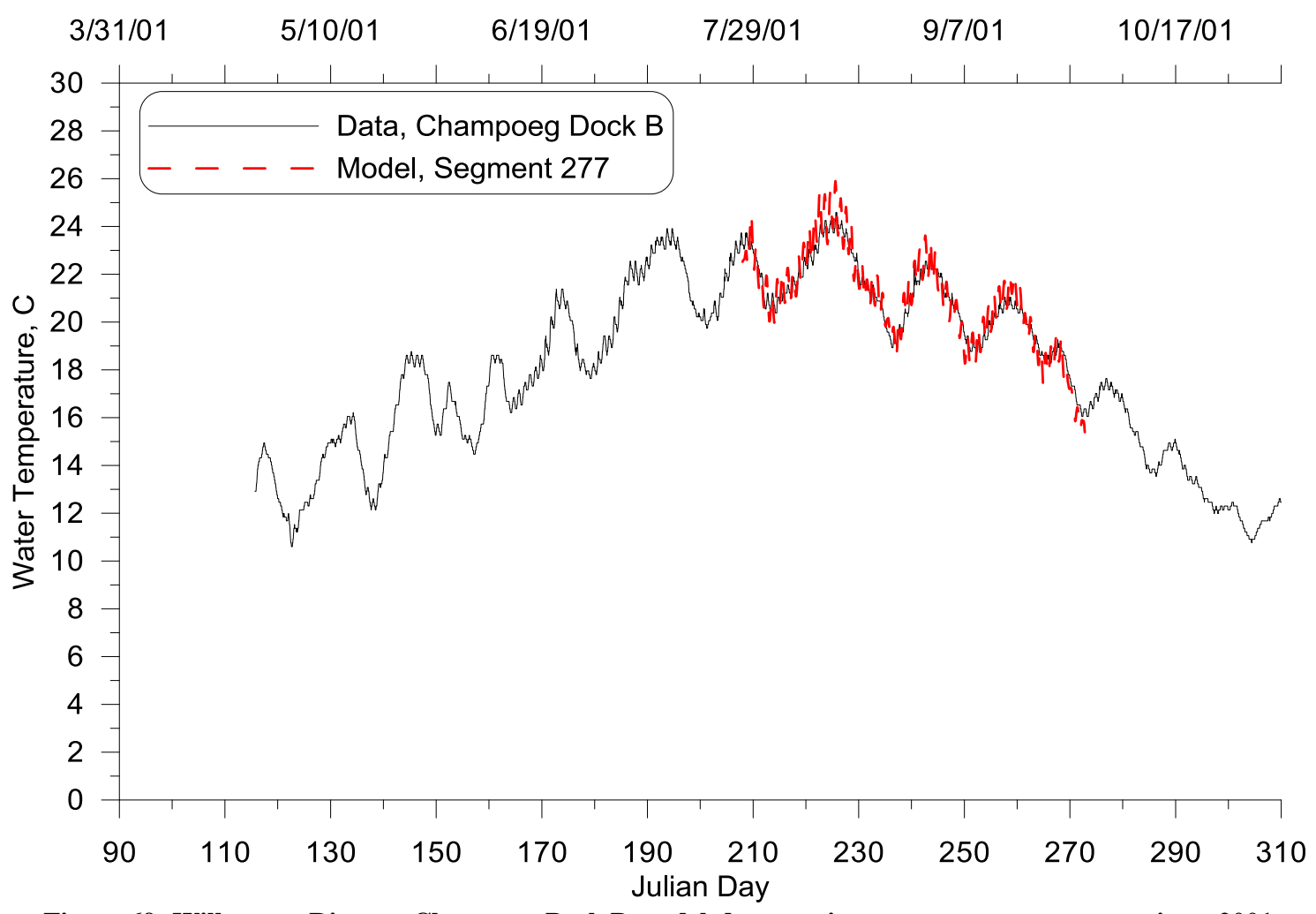

Figure 69: Willamette River at Champoeg Park B model-data continuous temperature comparison, 2001 


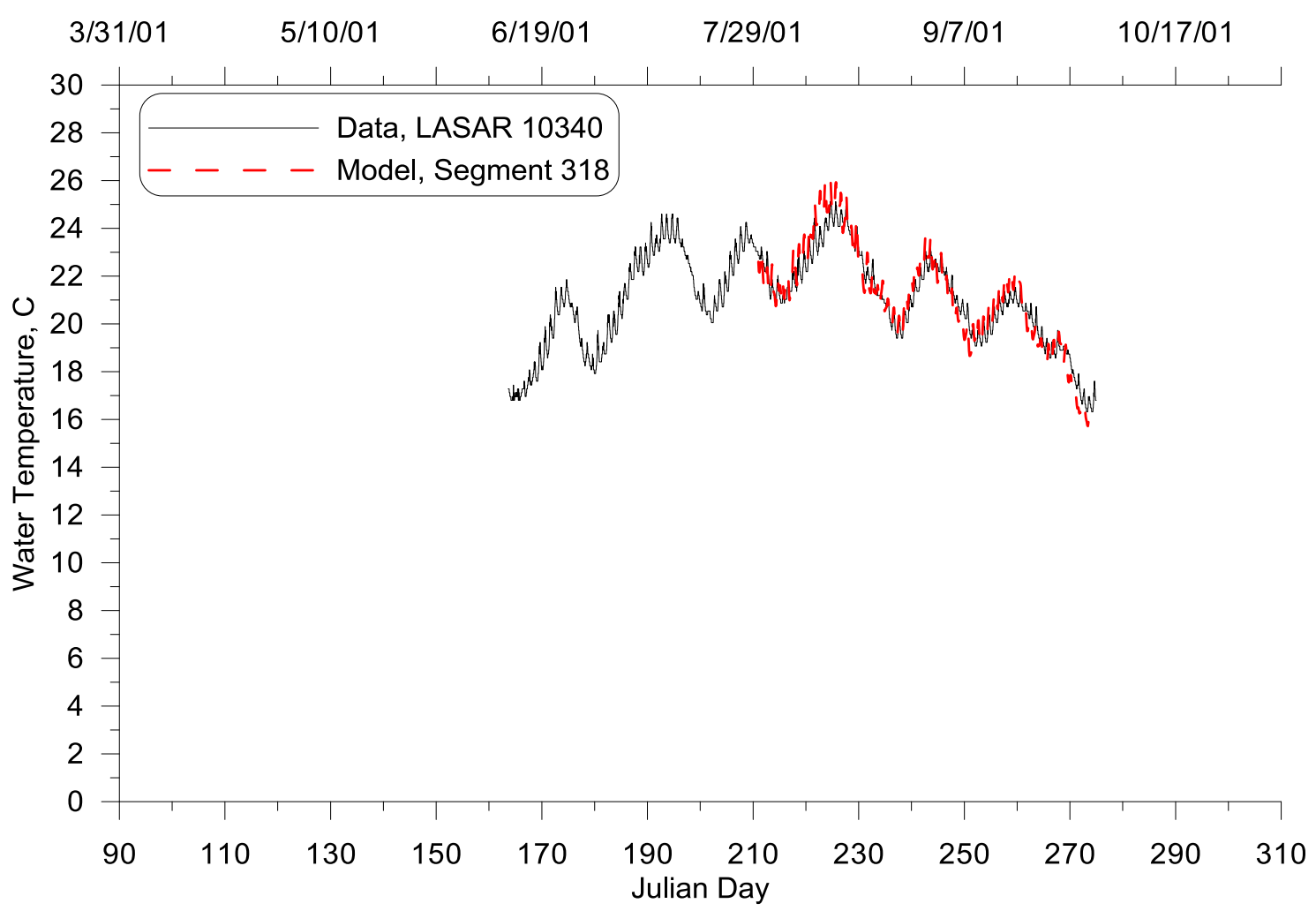

Figure 70: Willamette River at I5 Bridge, Wilsonville model-data continuous temperature comparison, 2001

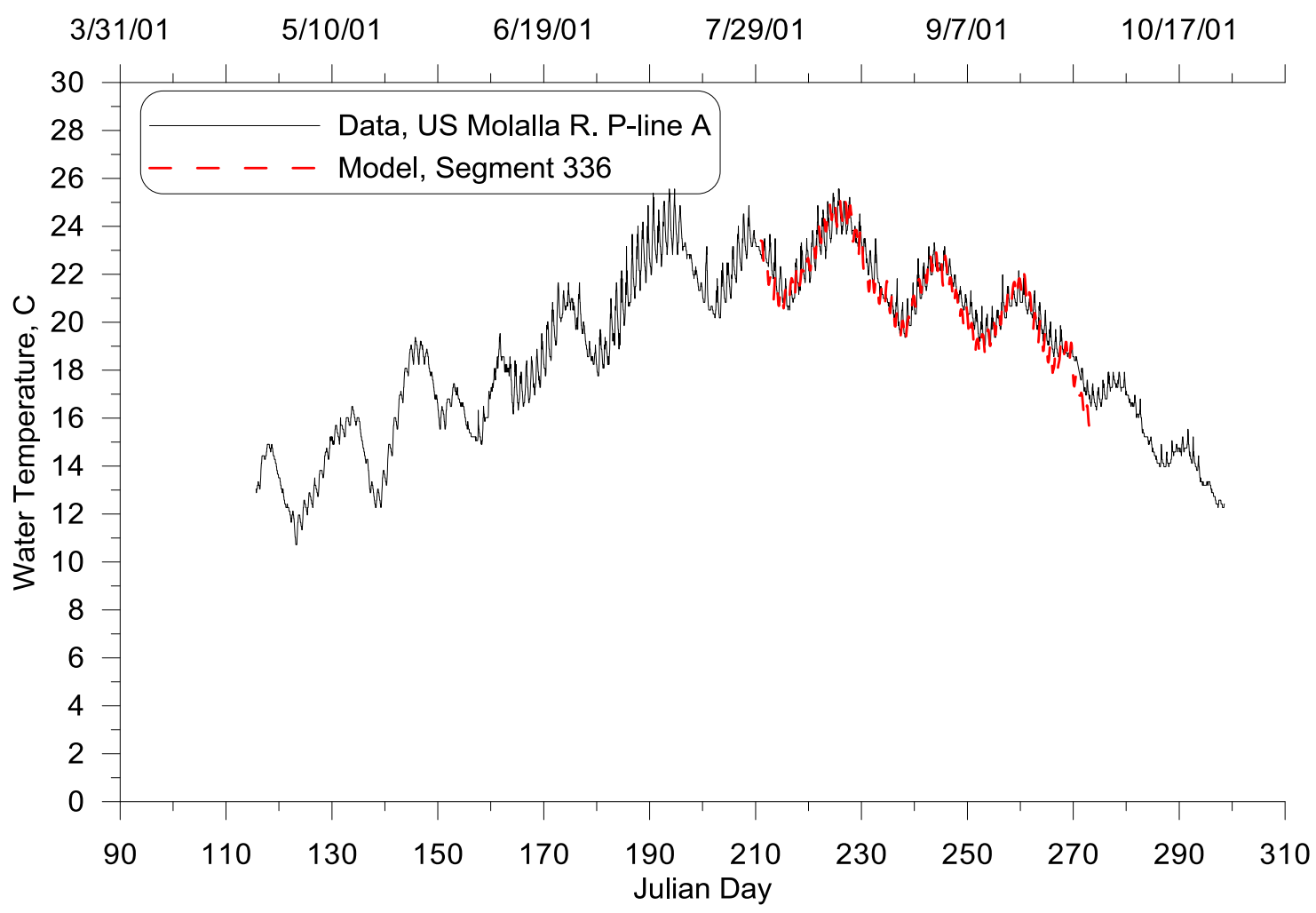

Figure 71: Willamette River upstream of the Molalla River confluence, Power-line A model-data continuous temperature comparison, 2001. 


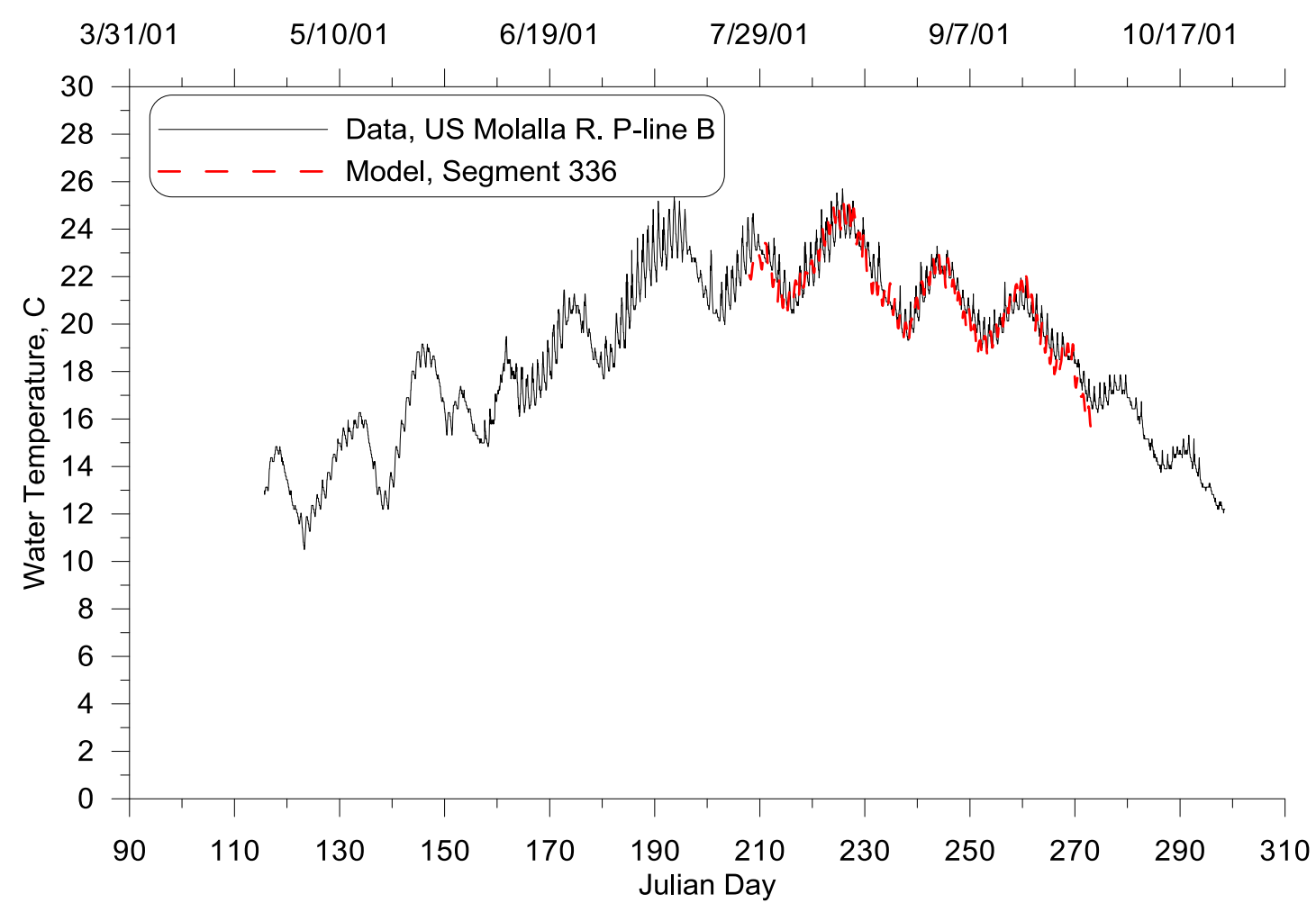

Figure 72: Willamette River upstream of the Molalla River confluence, Power-line B model-data continuous temperature comparison, 2001.

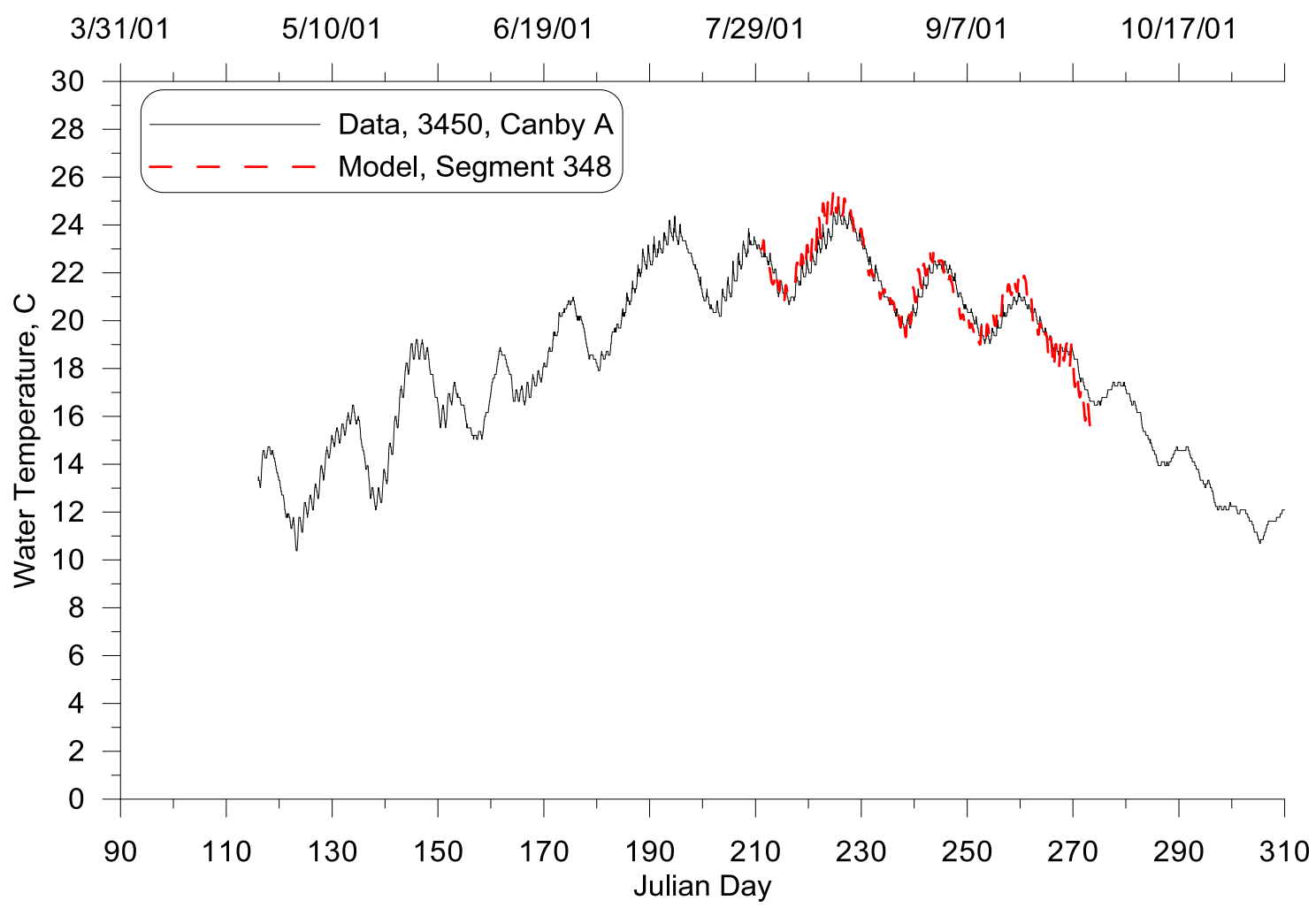

Figure 73: Willamette River at Canby Ferry B model-data continuous temperature comparison, 2001. 


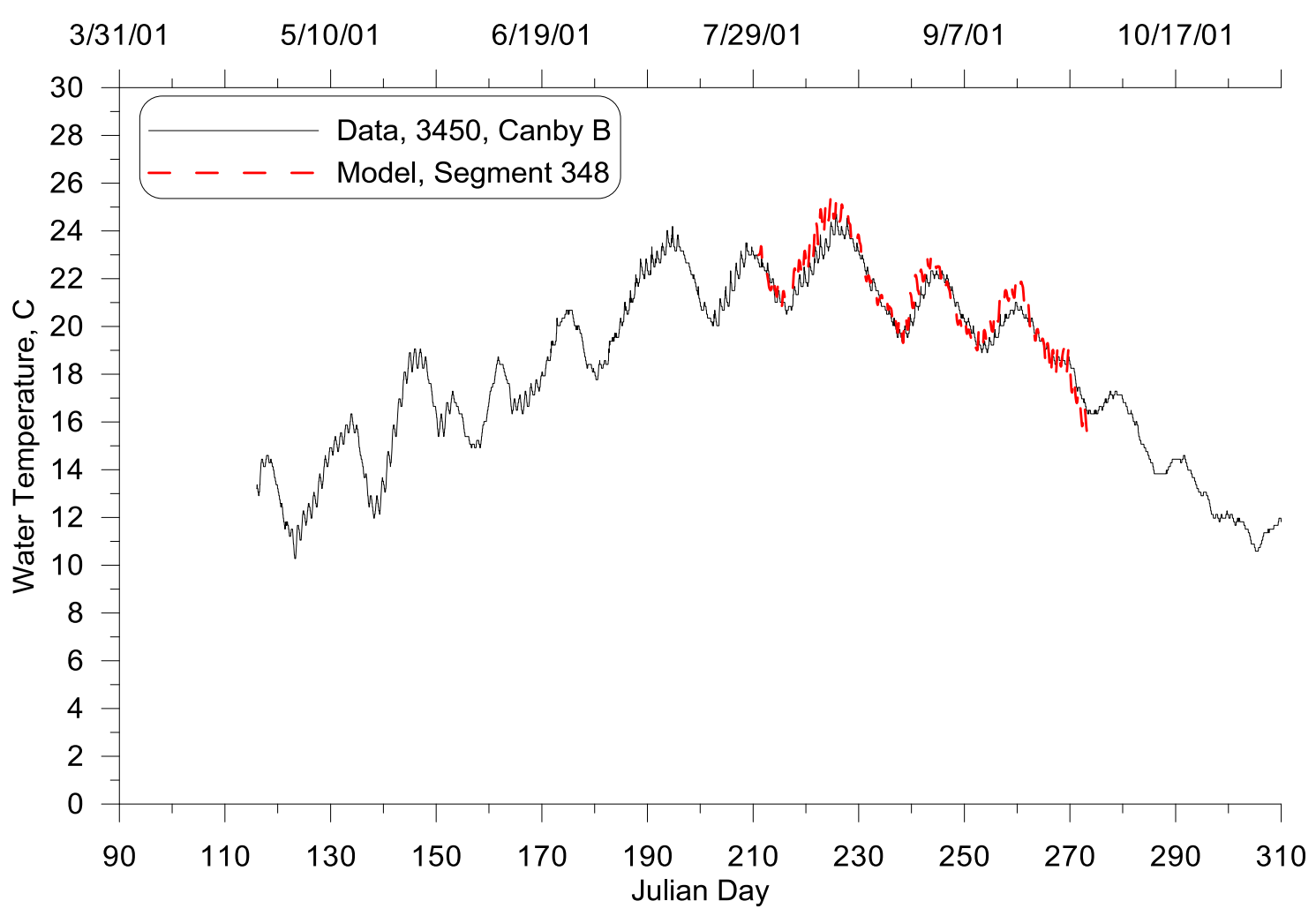

Figure 74: Willamette River at Powerline A model-data continuous temperature comparison, 2001

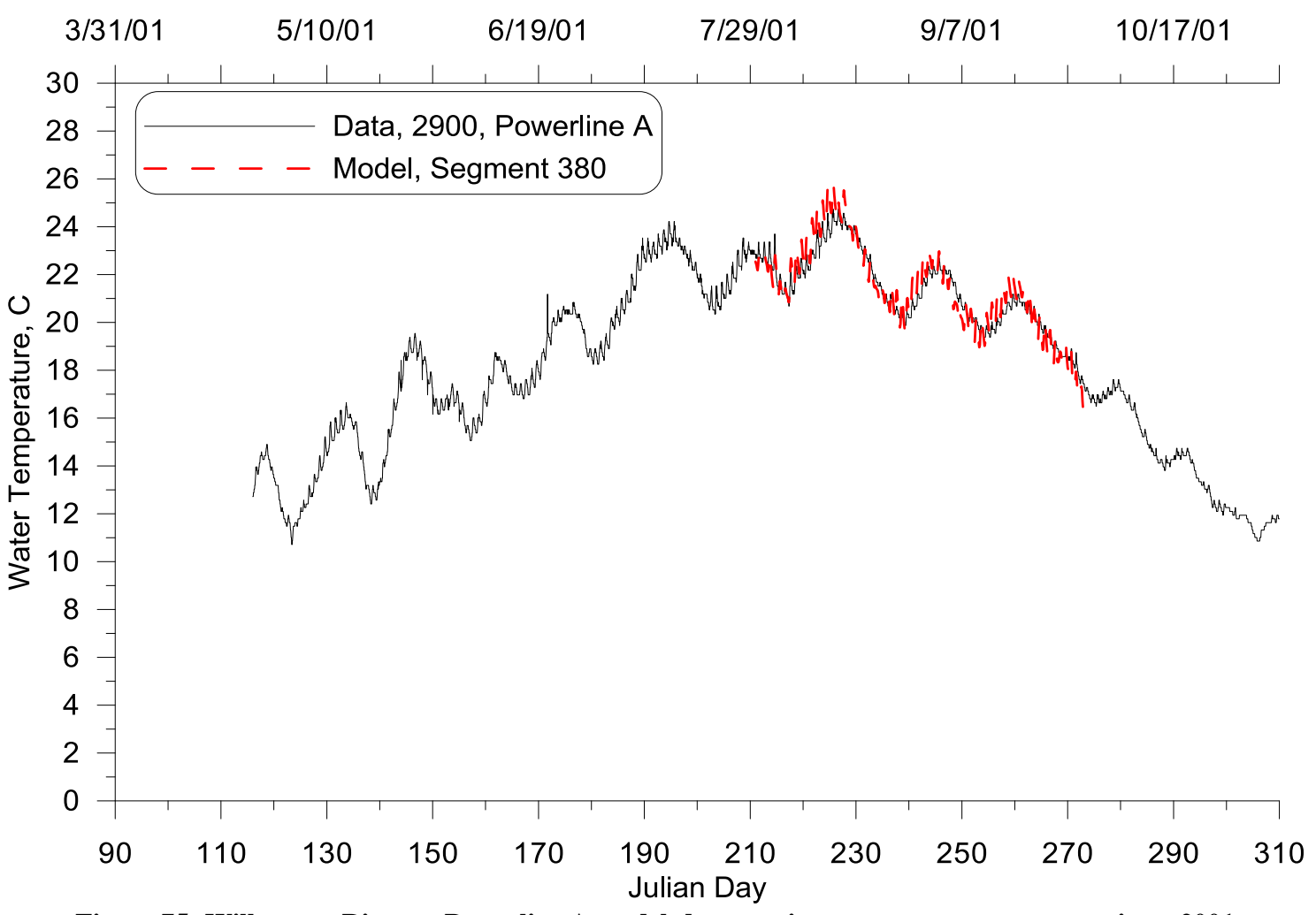

Figure 75: Willamette River at Powerline A model-data continuous temperature comparison, 2001 


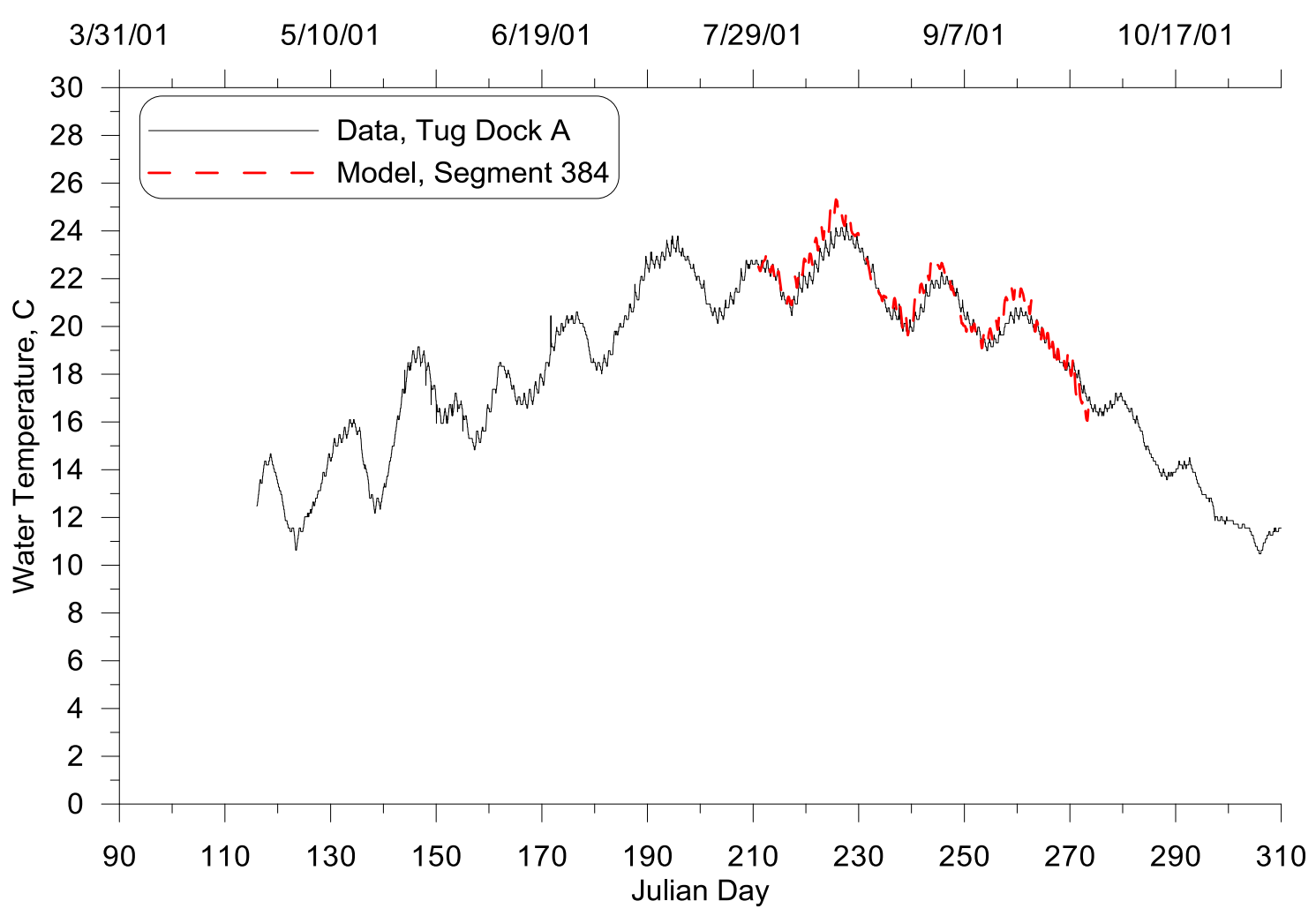

Figure 76: Willamette River at Tug Dock A model-data continuous temperature comparison, 2001

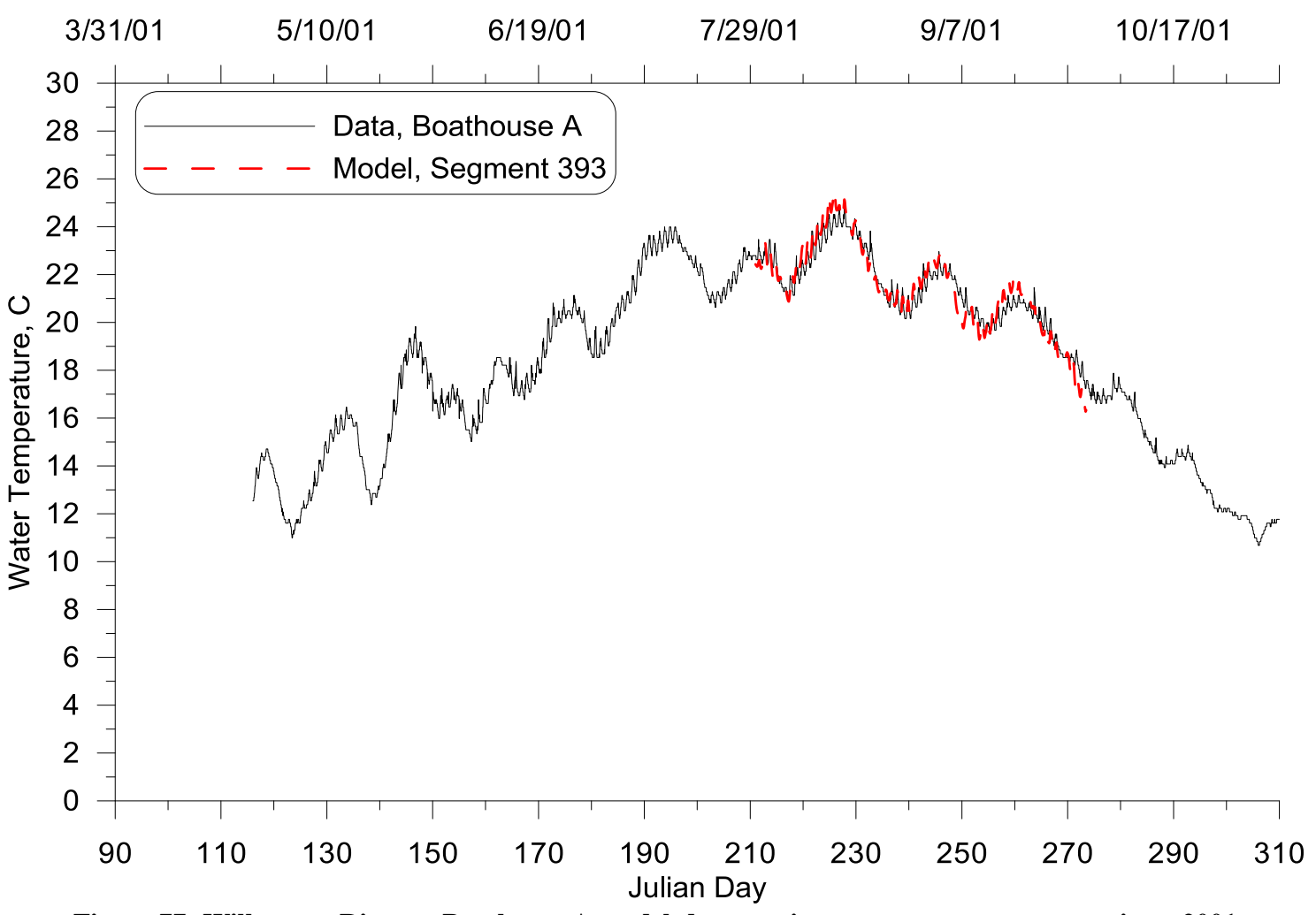

Figure 77: Willamette River at Boathouse A model-data continuous temperature comparison, 2001 


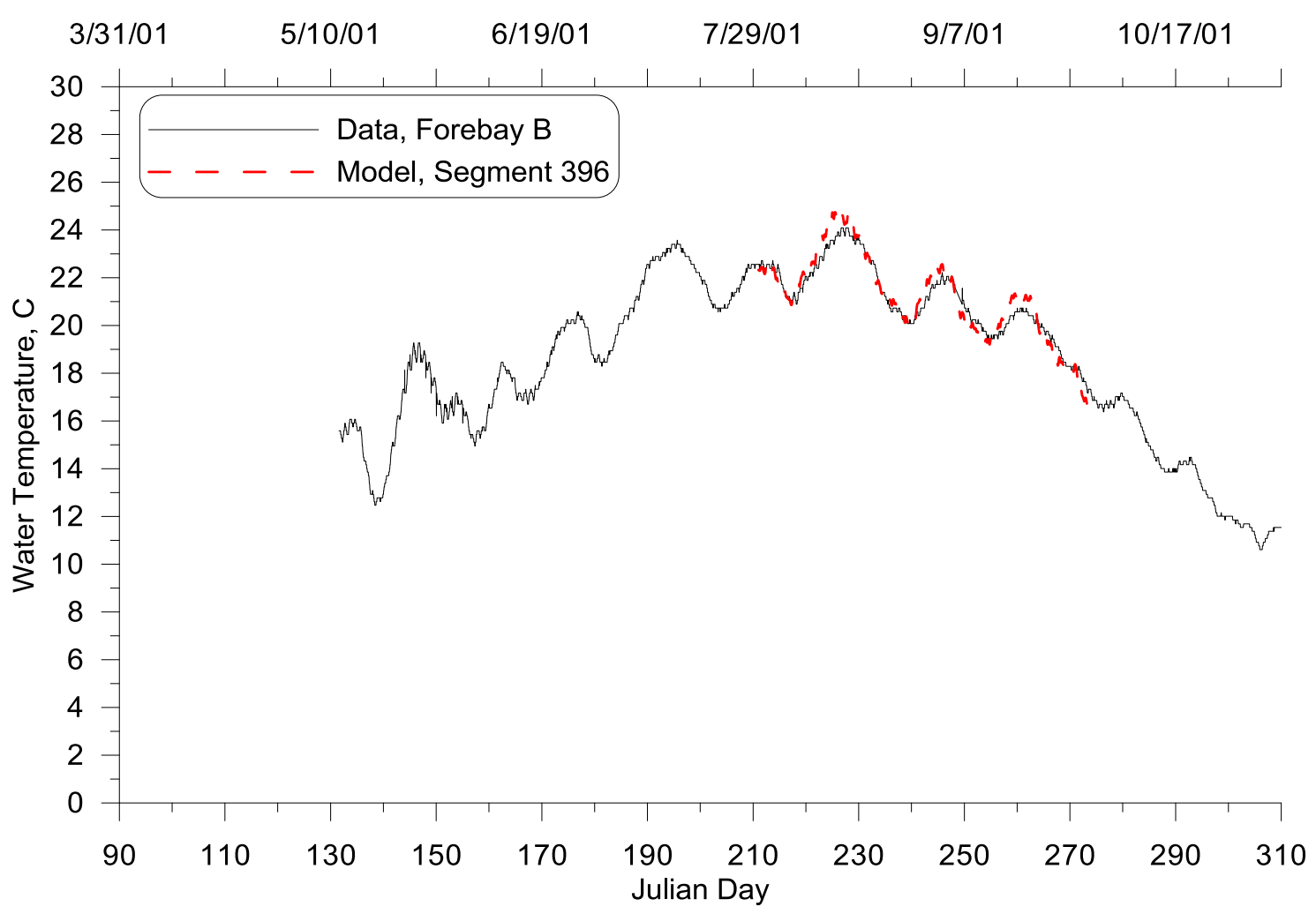

Figure 78: Willamette River at Forebay B model-data continuous temperature comparison, 2001

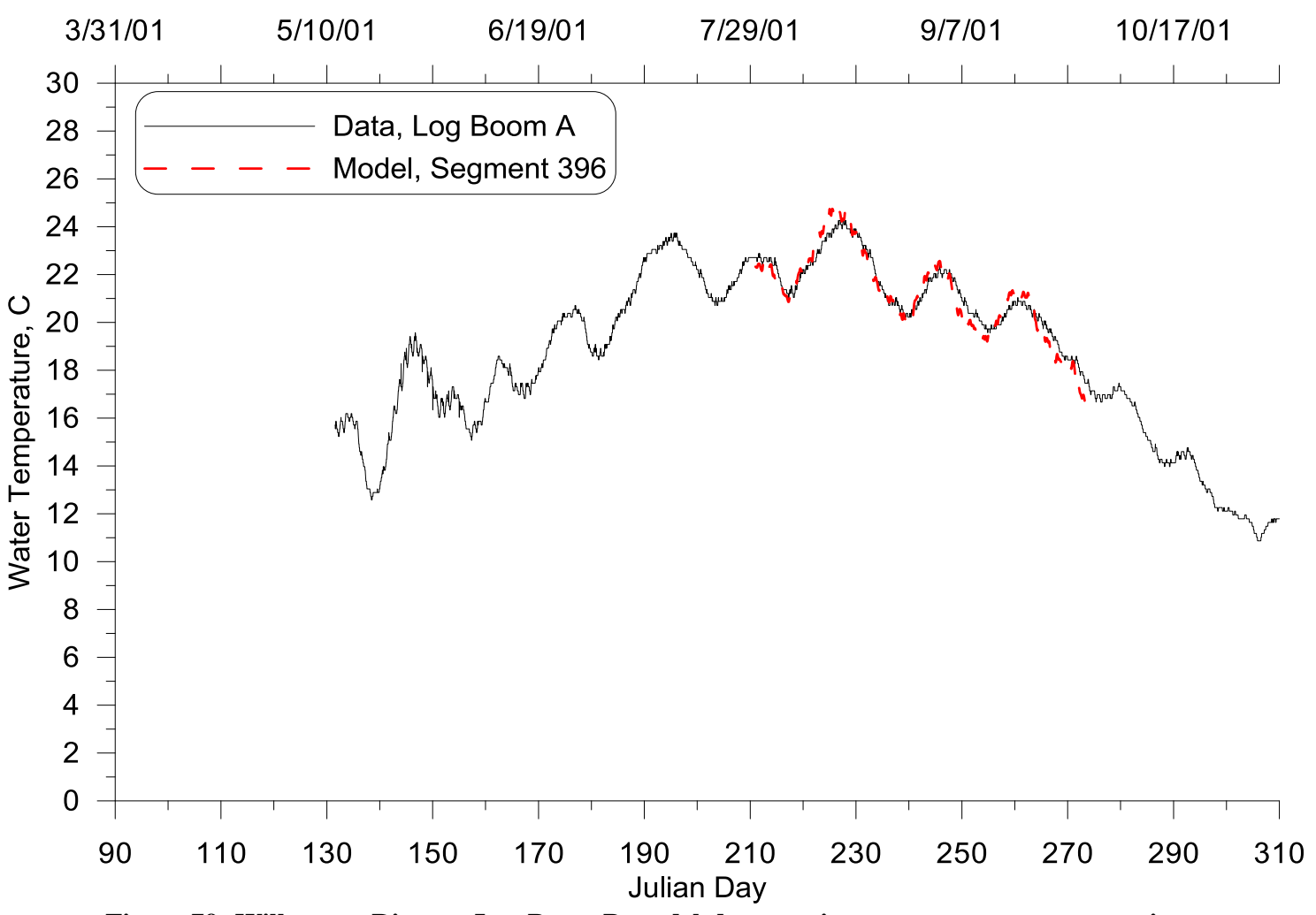

Figure 79: Willamette River at Log Boom B model-data continuous temperature comparison, 


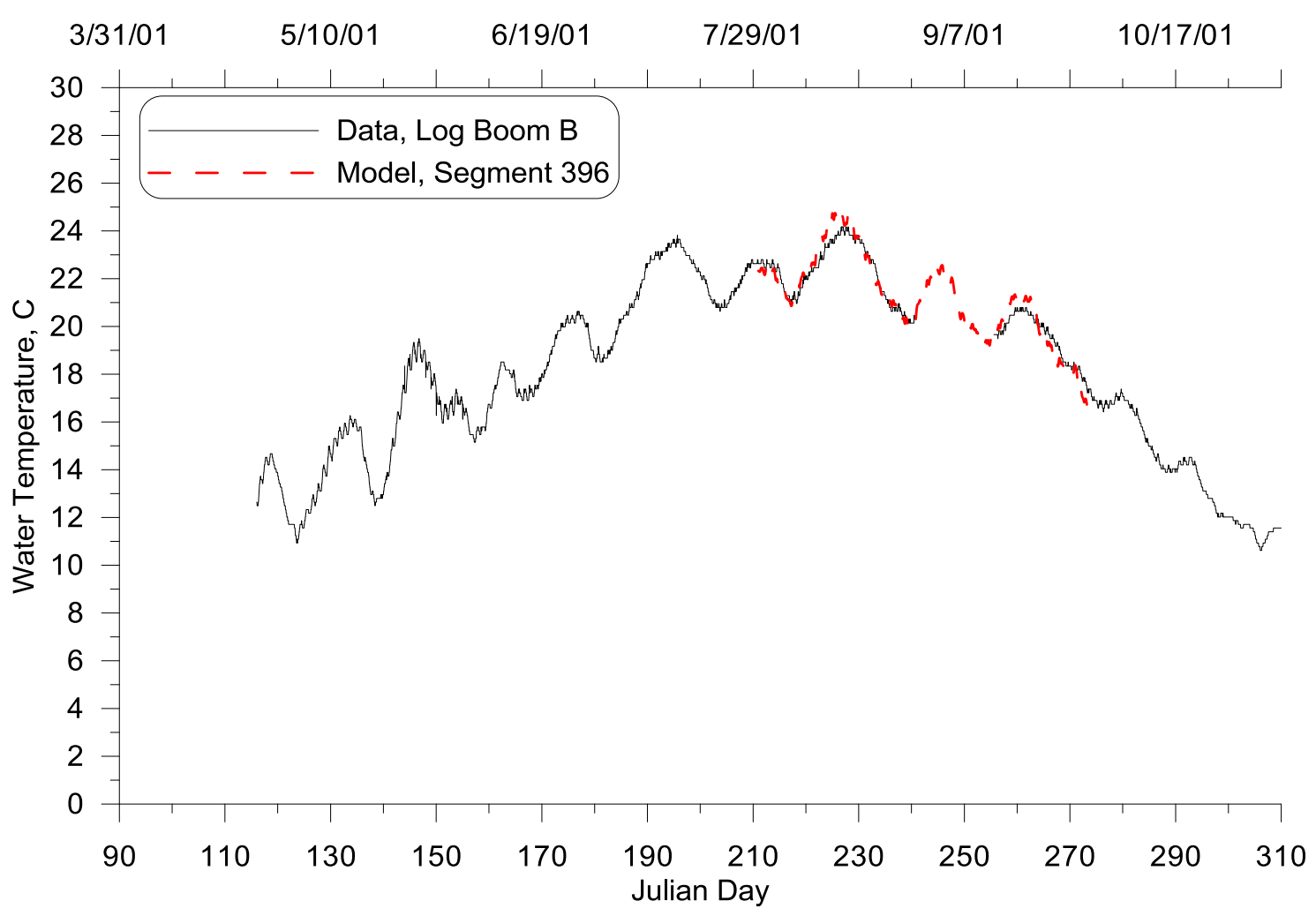

Figure 80: Willamette River at Log Boom B model-data continuous temperature comparison,

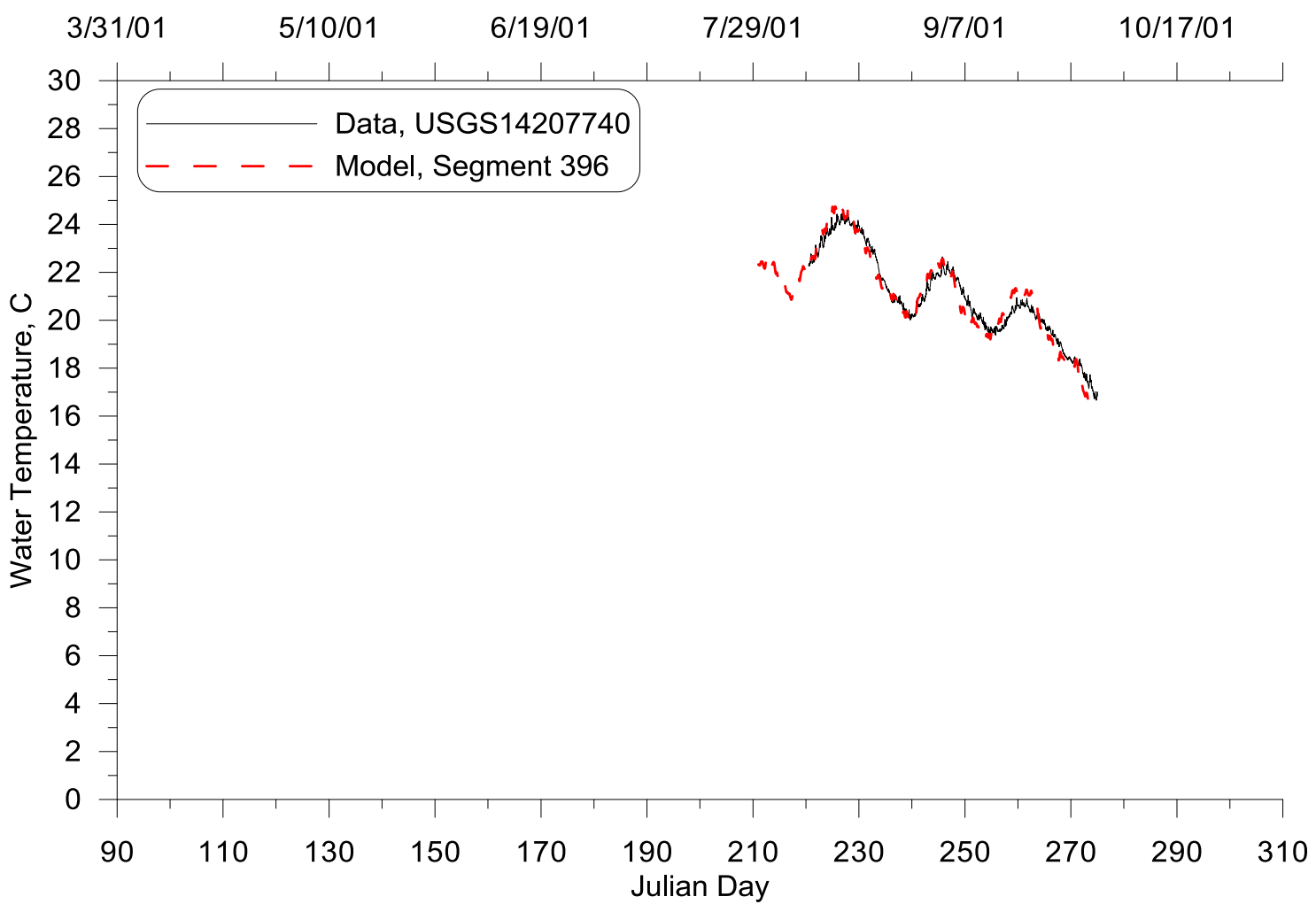

Figure 81: Willamette River at the Willamette Falls model-data continuous temperature comparison, 2001 


\section{Year 2002}

Figure 82 through 89 show the continuous temperature comparison between model predictions and measured data. Error statistics are summarized in Table 9. Predicted temperature matched data very well for all the 8 sites with the RMSEs below $0.93{ }^{\circ} \mathrm{C}$.

Table 9: Willamette River continuous water temperature calibration model-data error statistics, 2002

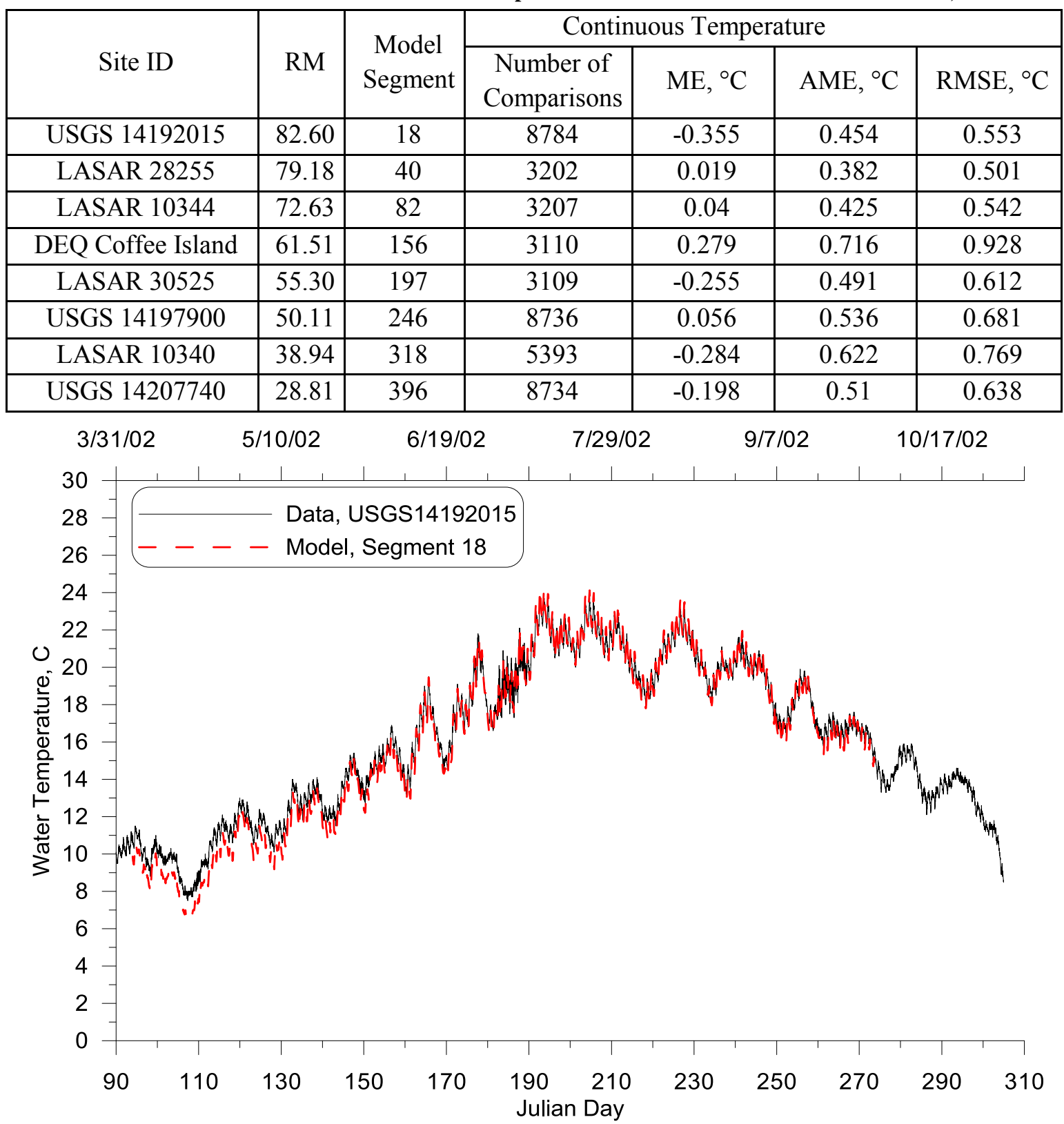

Figure 82: Willamette River at Forebay A model-data continuous temperature comparison, 2001 


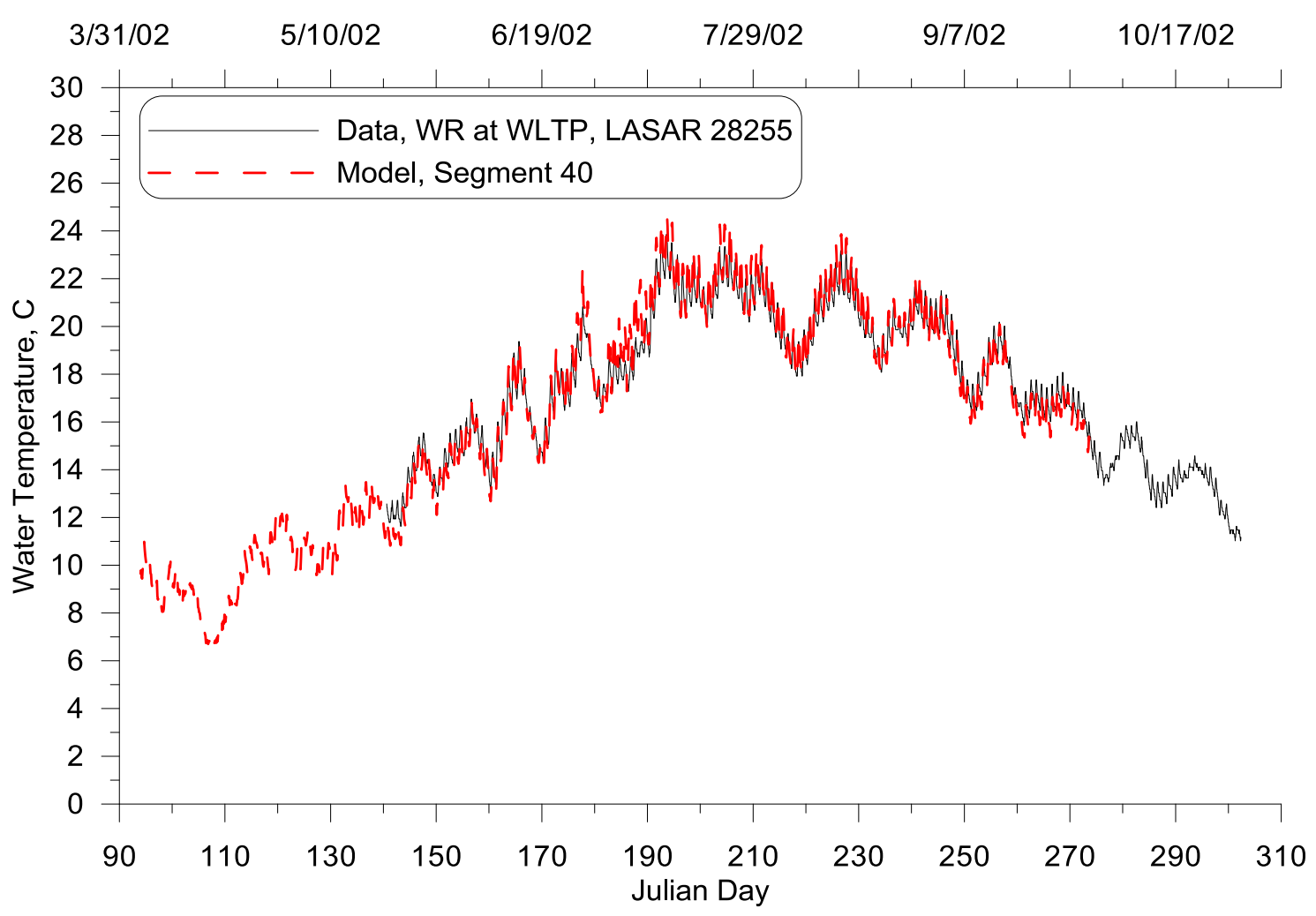

Figure 83: Willamette River at Willow Lake Treatment Plant model-data continuous temperature comparison, 2002

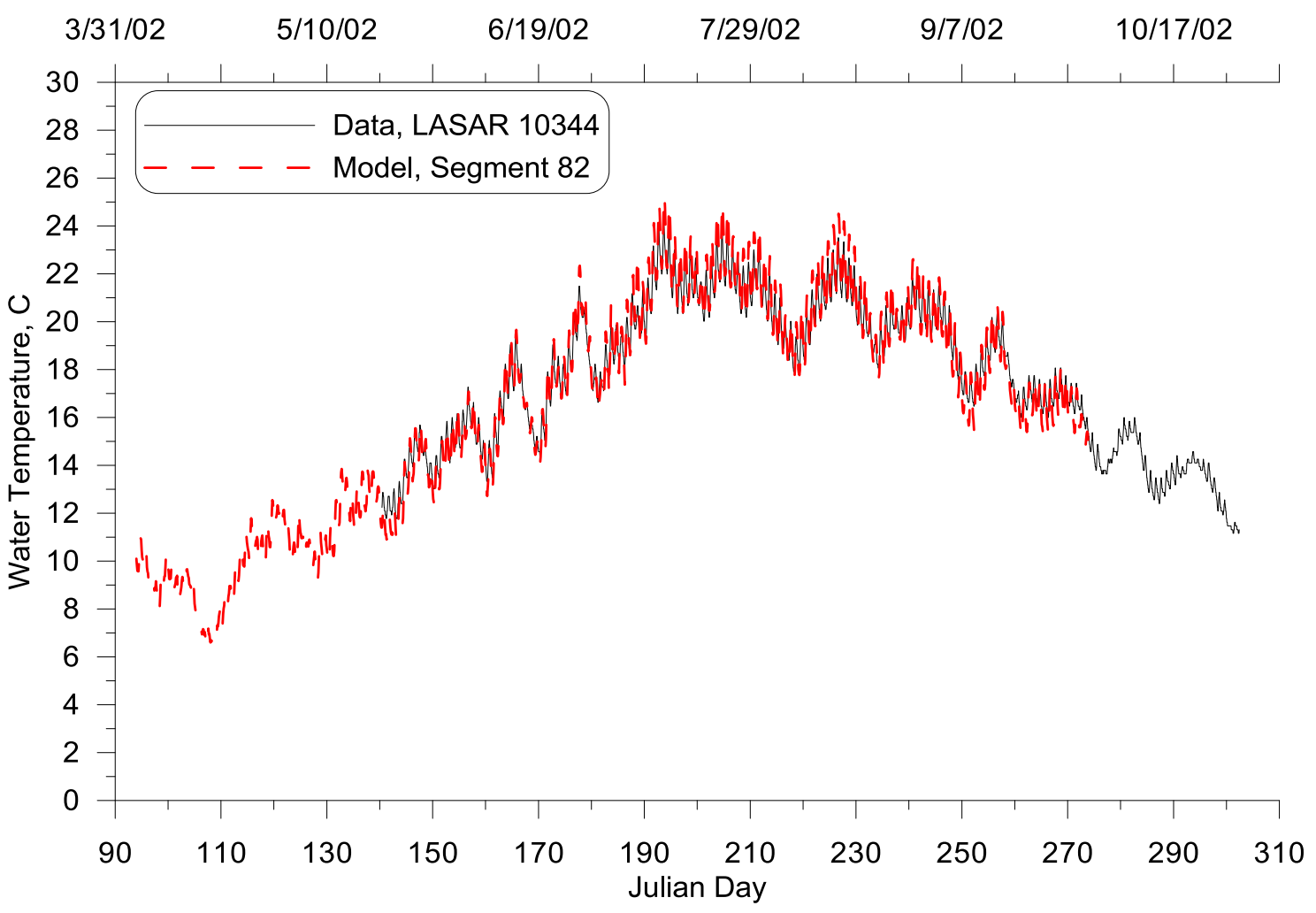

Figure 84: Willamette River at Wheatland Ferry model-data continuous temperature comparison, 2002 


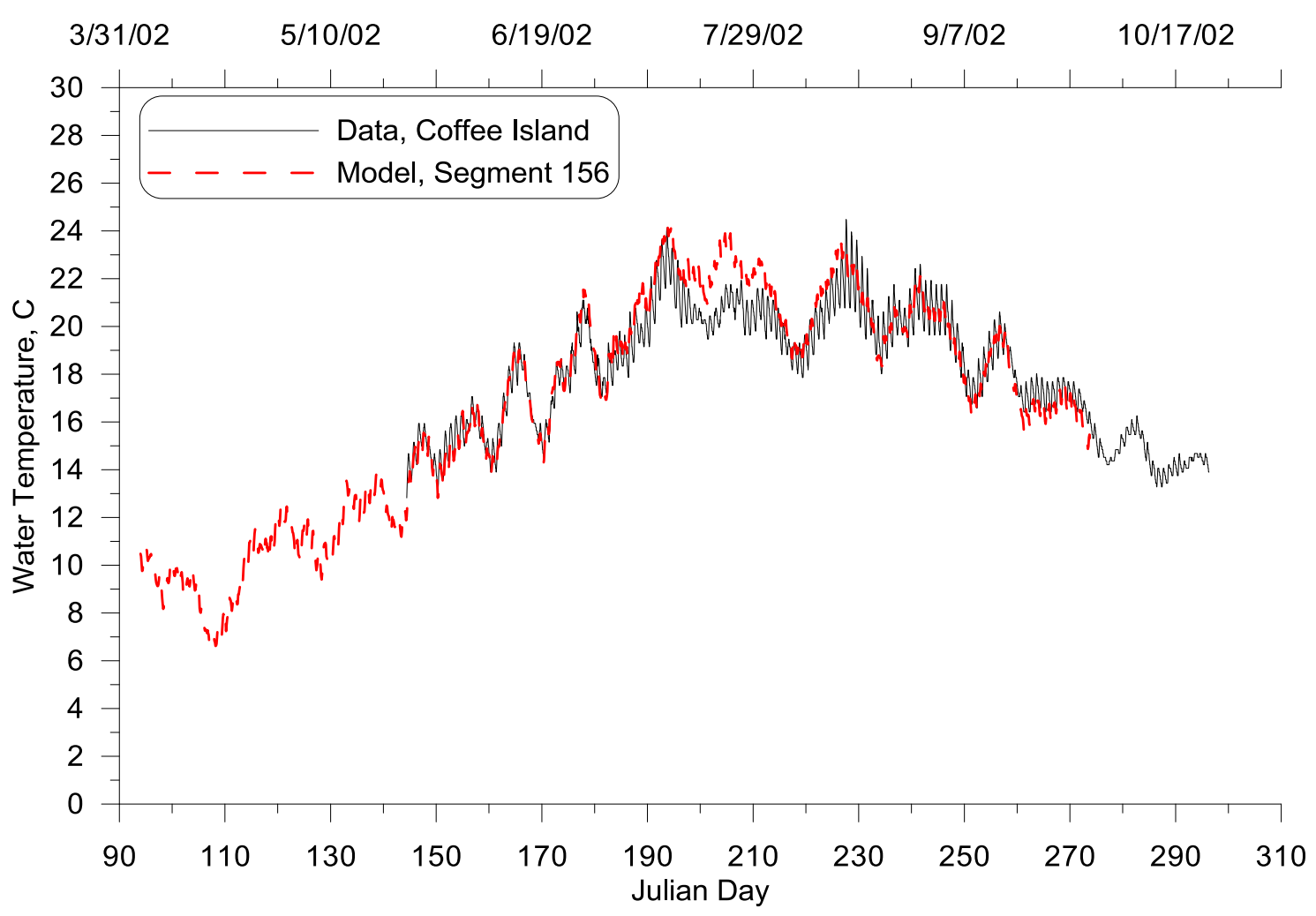

Figure 85: Willamette River at Coffee Island model-data continuous temperature comparison, 2002

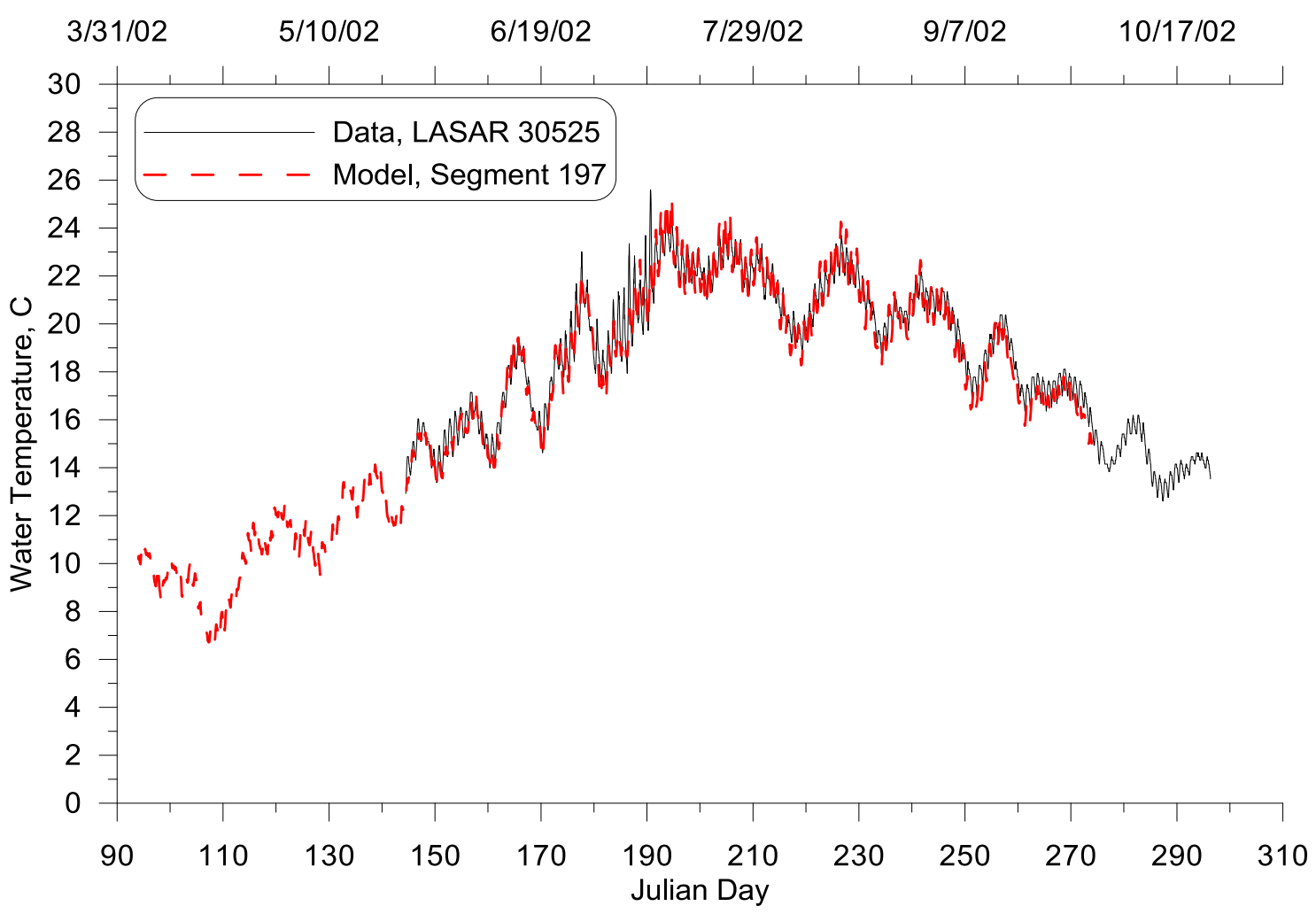

Figure 86: Willamette River upstream of the Yamhill River model-data continuous temperature comparison, 2002 


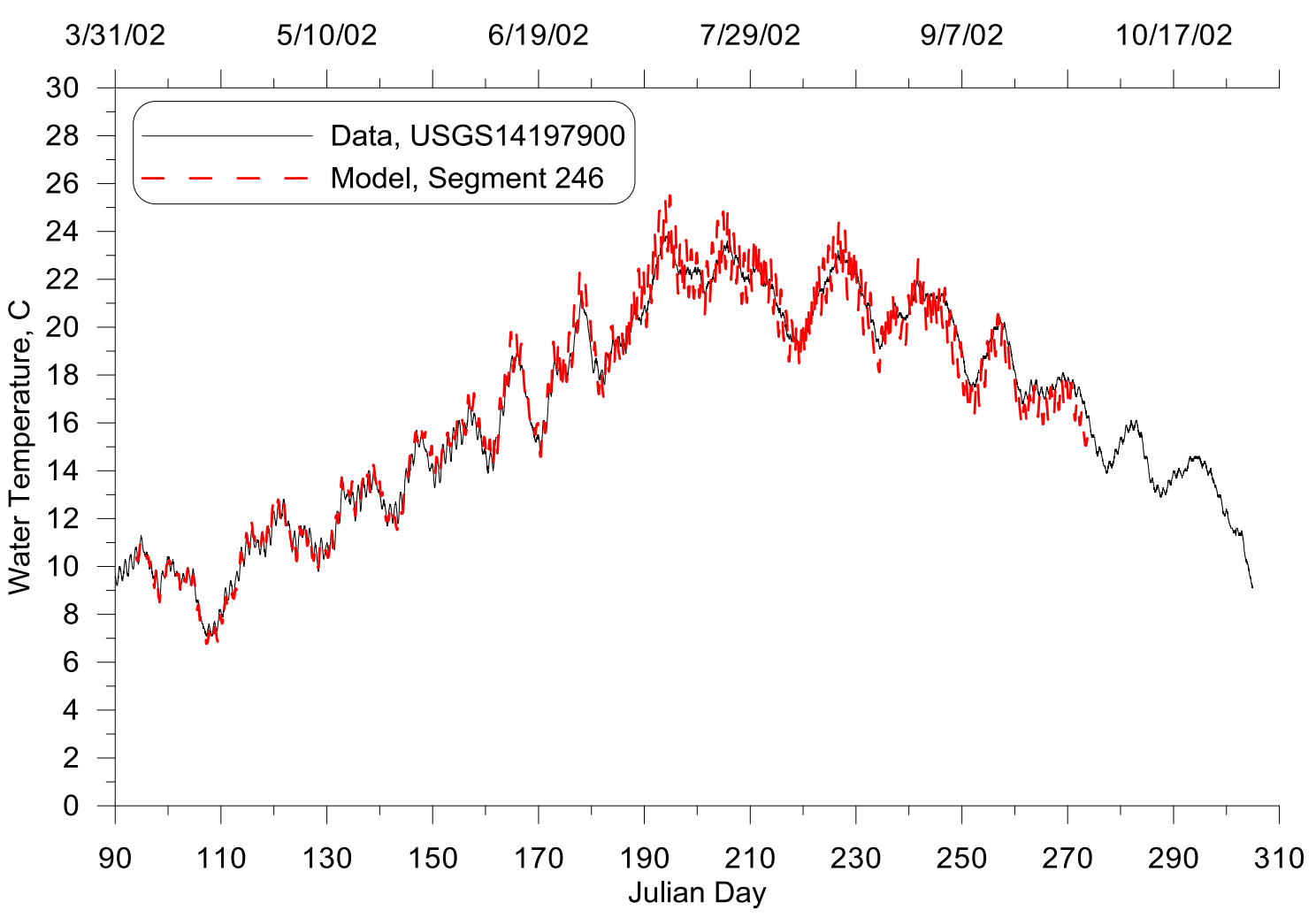

Figure 87: Willamette River at Newberg model-data continuous temperature comparison, 2002

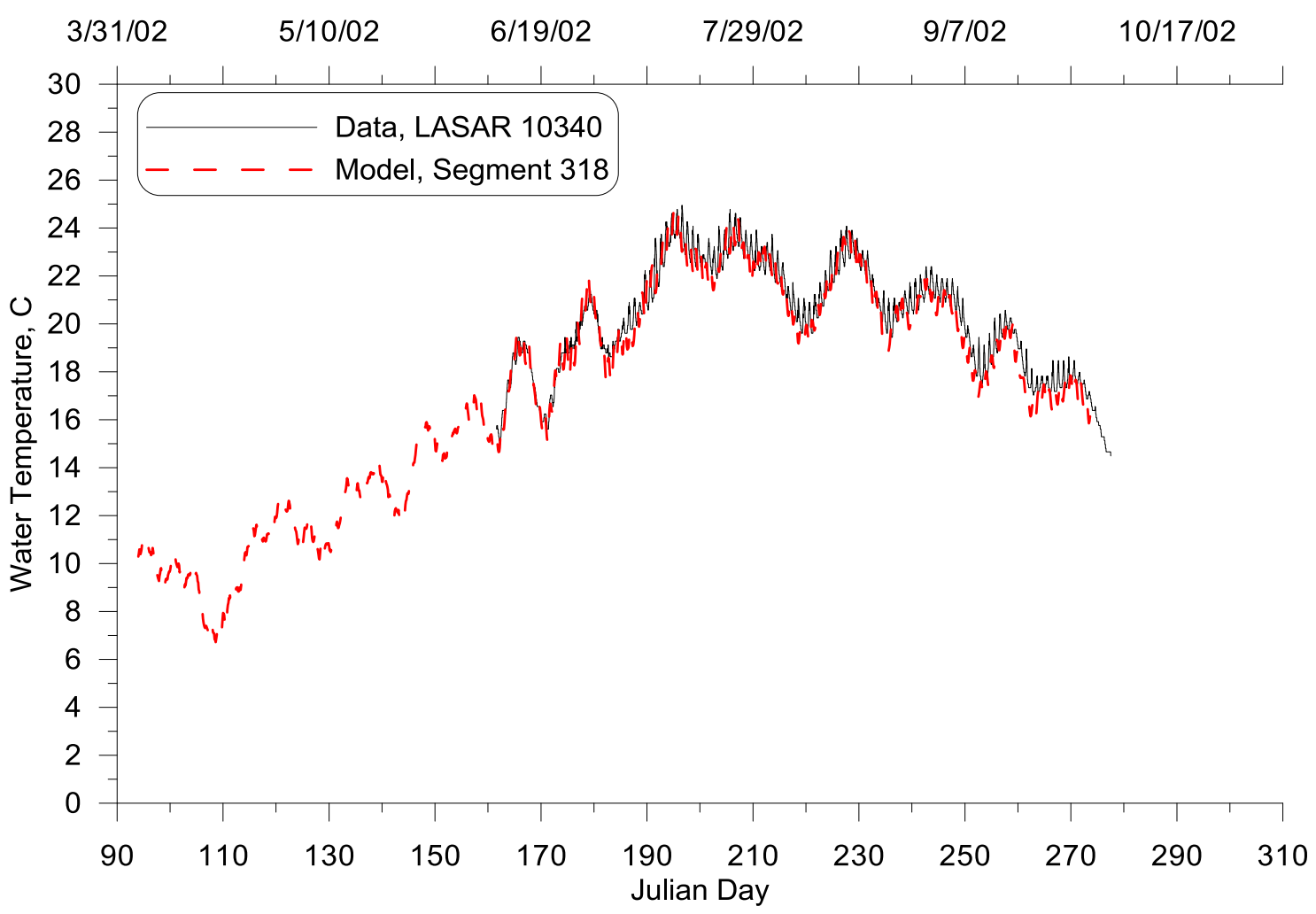

Figure 88: Willamette River at I5 Bridge, Wilsonville model-data continuous temperature comparison, 2002 


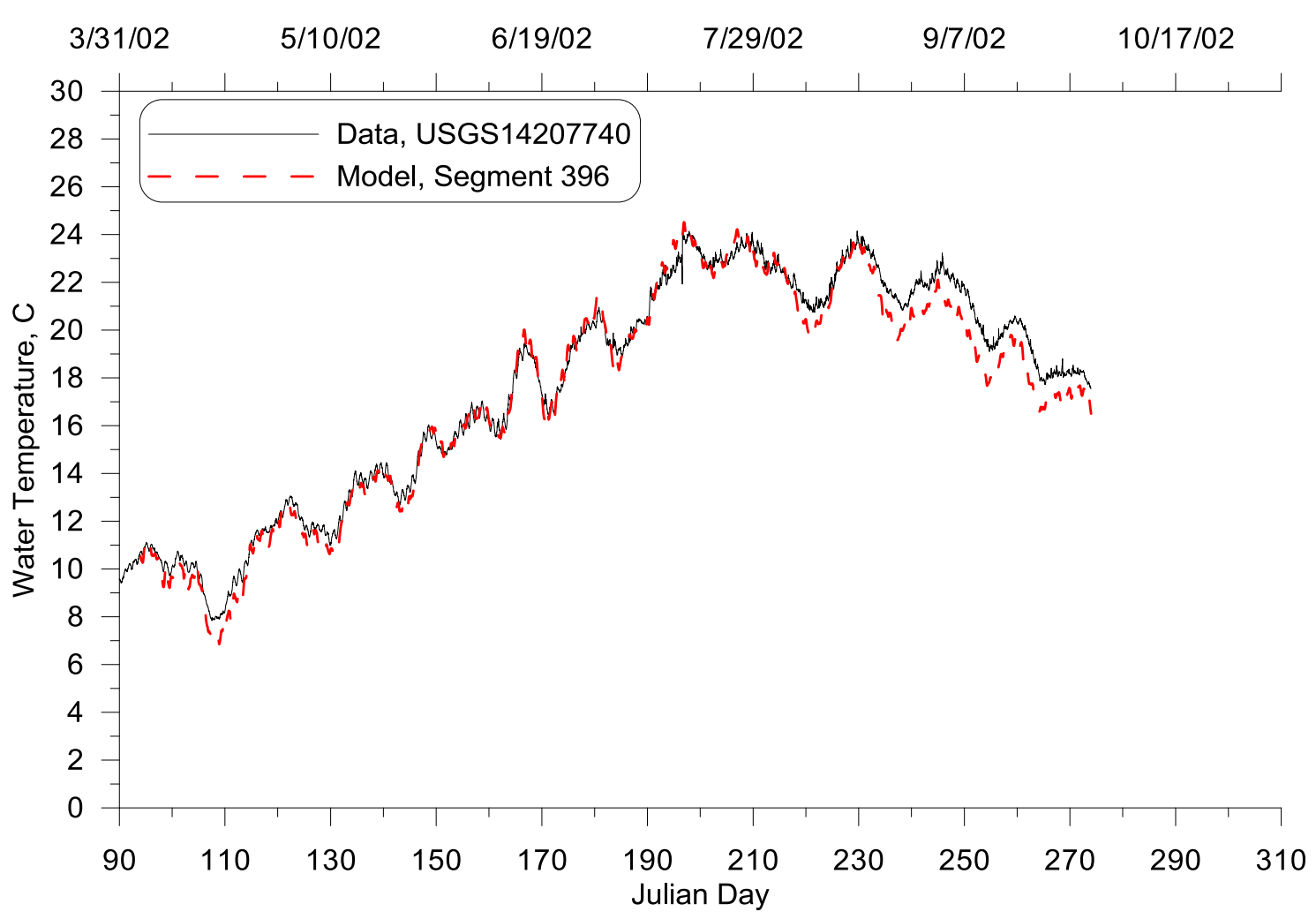

Figure 89: Willamette River at the Willamette Falls model-data continuous temperature comparison, 2002

\subsubsection{Upper Willamette River}

\section{Introduction}

Upper Willamette River model domain includes the upstream part of Willamette River main stem, which starts from RM 185.2 and ends at RM 85.4. The model was set up as 9 water bodies including 13 branches, with 667 segments and 45 layers. There are 14 tributaries flows into the reach. The model grid is shown in Figure 90. 


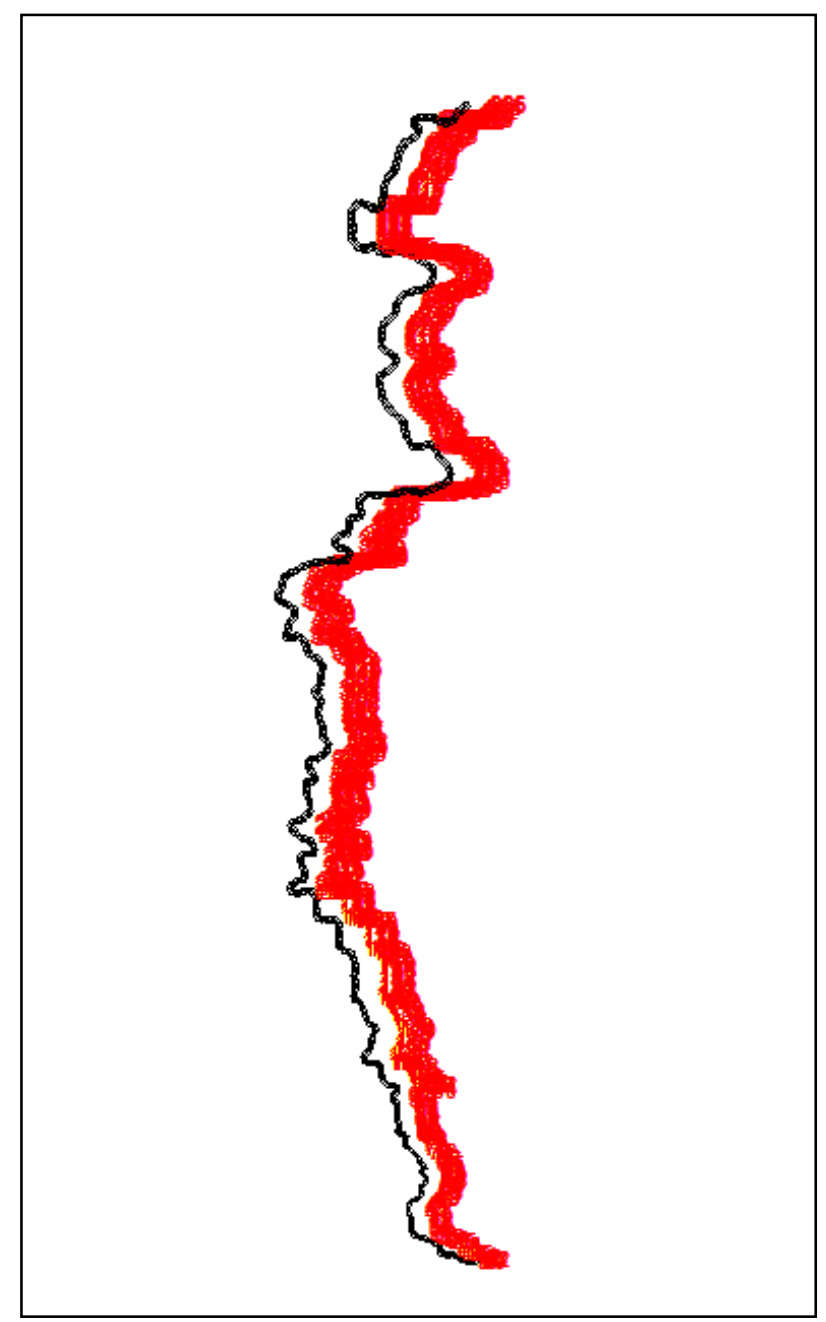

Figure 90: Upper Willamette River Model Grid

\section{Hydrodynamics}

In the original set up in V3.1 model, AX (longitudinal eddy viscosity, $\mathrm{m}^{2} / \mathrm{s}$ ) and DX (longitudinal eddy diffusivity, $\mathrm{m}^{2} / \mathrm{s}$ ) were at the magnitude of 50 , which was derived from dye study. However, the Version 3.7 model suffered stability issues with these parameters being set to so big. These two parameters were assigned to 1.0. Further calibration was conducted by changing manning friction coefficients. The calibrated model showed better hydrodynamic predictions result for year 2001 than year 2002. The reason was that calibration was first conducted for year 2001. Although there was a 
potential for further model improvement, the calibration was conducted until hydrodynamic and temperature results were acceptable.

\section{Year 2001}

The hydrodynamic calibration period in 2001 was from June to September. Figure 91 through 98 show the water level and flow comparison between model predictions and measured data. The figures showed that flow predictions matched well with data. Error statistics are summarized in Table 10.

Overall, model predicted flow rate and water surface elevation showed good agreement with measured data, except for water level predictions at segment 352. However, the measured data indicated the same water level for over 100 days, which raised suspect about the accuracy of this data. As a result, water level calibration for segment 352 was conducted mainly basing on data in Year 2002.

Table 10: Upper Willamette River hydrodynamic calibration statistics, 2001

\begin{tabular}{|c|c|c|c|c|c|c|}
\hline \multicolumn{7}{|c|}{ Flow } \\
\hline Gage ID & $\mathrm{RM}$ & $\begin{array}{c}\text { Model } \\
\text { Segment }\end{array}$ & $\begin{array}{c}\text { Number of } \\
\text { Comparisons }\end{array}$ & $\mathrm{ME}, \mathrm{m}^{3} / \mathrm{s}$ & AME, $\mathrm{m}^{3} / \mathrm{s}$ & $\begin{array}{c}\text { RMSE, } \\
\mathrm{m}^{3} / \mathrm{s}\end{array}$ \\
\hline ACOE EUGO3 & 182.45 & 19 & 4983 & 0.222 & 0.497 & 0.718 \\
\hline USGS 14166000 & 161.98 & 156 & 4992 & -0.241 & 0.501 & 0.7 \\
\hline ACOE CORO3 & 132.32 & 352 & 1728 & \multicolumn{3}{|c|}{ Quality of data is questionable } \\
\hline USGS 14174000 & 120.11 & 434 & 4634 & 0.17 & 0.933 & 1.516 \\
\hline USGS 14191000 & 84.70 & 665 & 4678 & 0.011 & 0.450 & 0.562 \\
\hline \multicolumn{7}{|c|}{ Water Level } \\
\hline Gage ID & RM & $\begin{array}{c}\text { Model } \\
\text { Segment }\end{array}$ & $\begin{array}{c}\text { Number of } \\
\text { Comparisons }\end{array}$ & ME, $\mathrm{m}$ & AME, $\mathrm{m}$ & RMSE, $m$ \\
\hline ACOE EUGO3 & 182.45 & 19 & 4983 & 0.008 & 0.022 & 0.028 \\
\hline USGS 14166000 & 161.98 & 156 & 4992 & 0.007 & 0.007 & 0.012 \\
\hline
\end{tabular}




\begin{tabular}{|c|c|c|c|c|c|c|}
\hline ACOE CORO3 & 132.32 & 352 & \multicolumn{4}{|c|}{ Flow data is not available } \\
\hline USGS 14174000 & 120.11 & 434 & 4634 & -0.004 & 0.013 & 0.021 \\
\hline USGS 14191000 & 84.70 & 665 & 5040 & \multicolumn{2}{|c|}{$\begin{array}{c}\text { Not appropriate comparison, } 1 \mathrm{~km} \\
\text { downstream of model grid }\end{array}$} \\
\hline
\end{tabular}

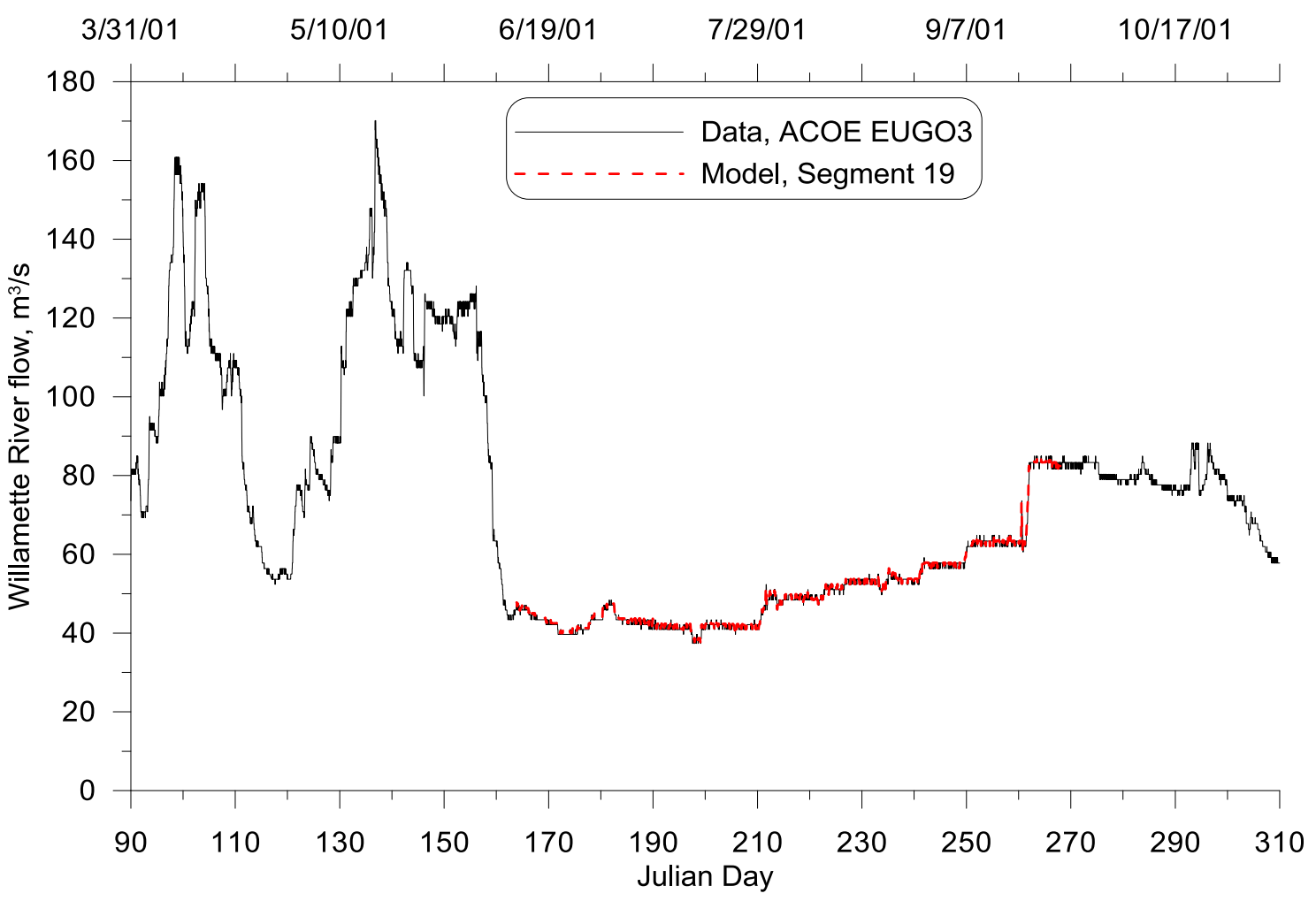

Figure 91: Willamette River at Eugene model-data flow comparison, 2001 


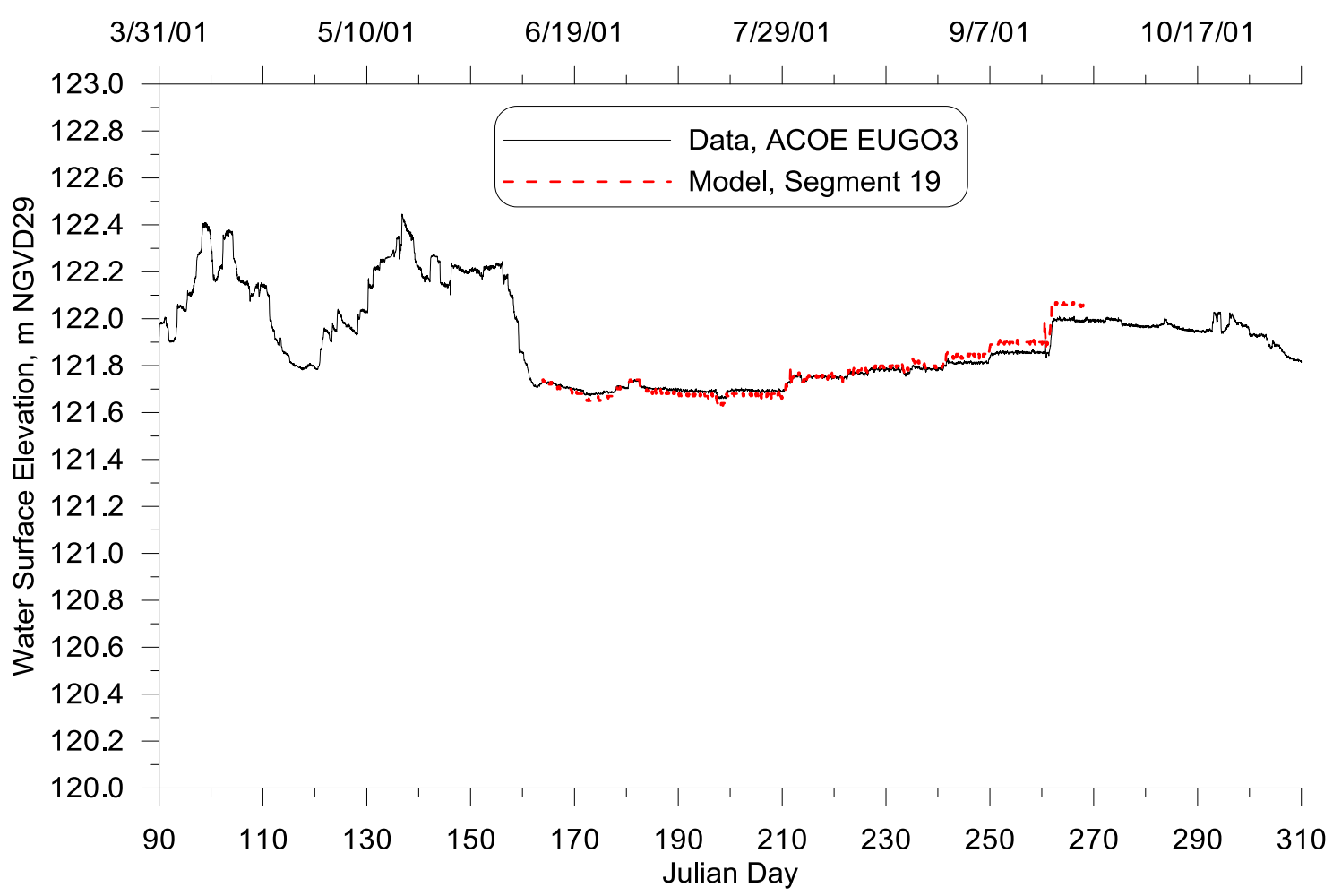

Figure 92: Willamette River at Eugene model-data water level comparison, 2001

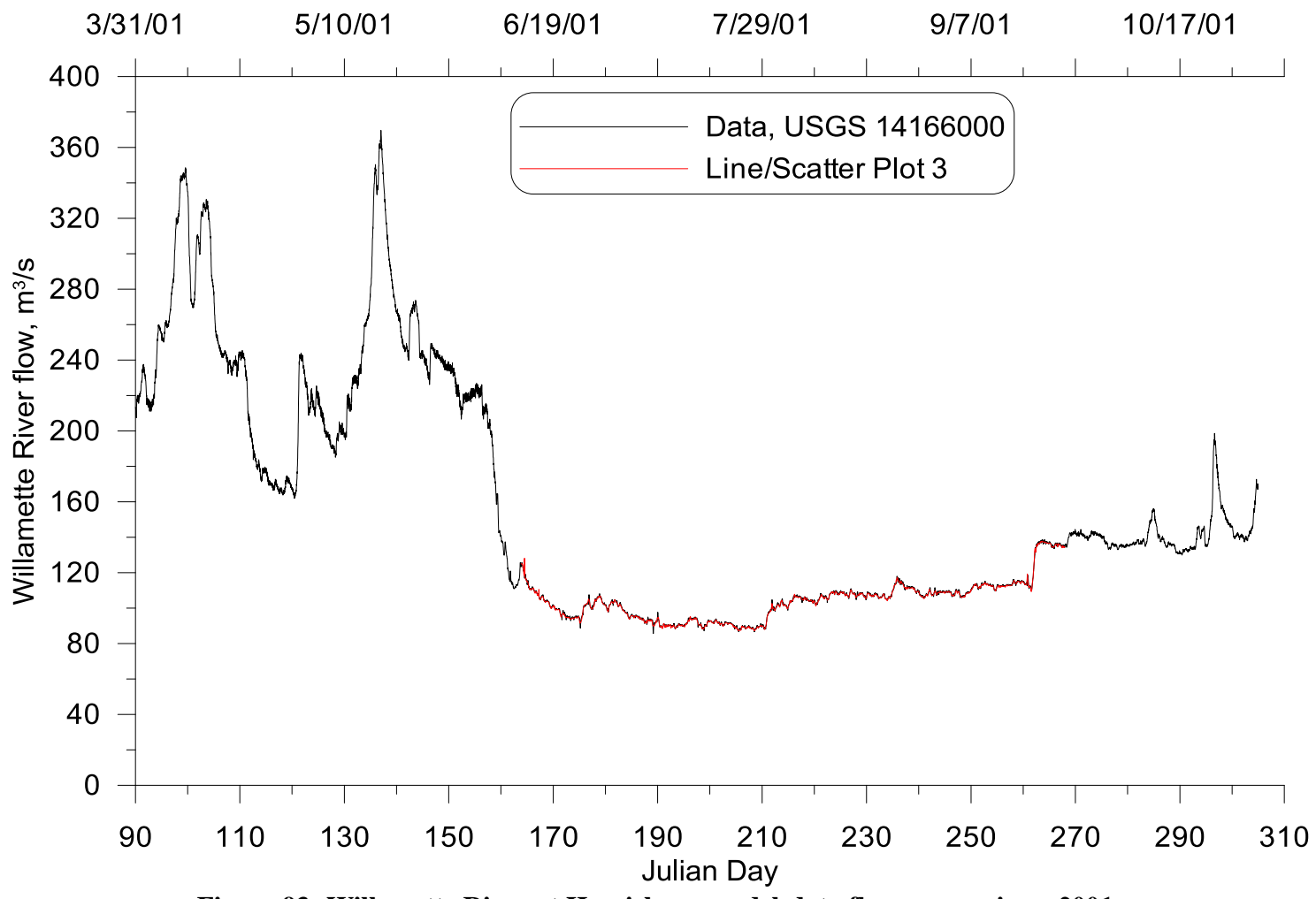

Figure 93: Willamette River at Harrisburg model-data flow comparison, 2001 


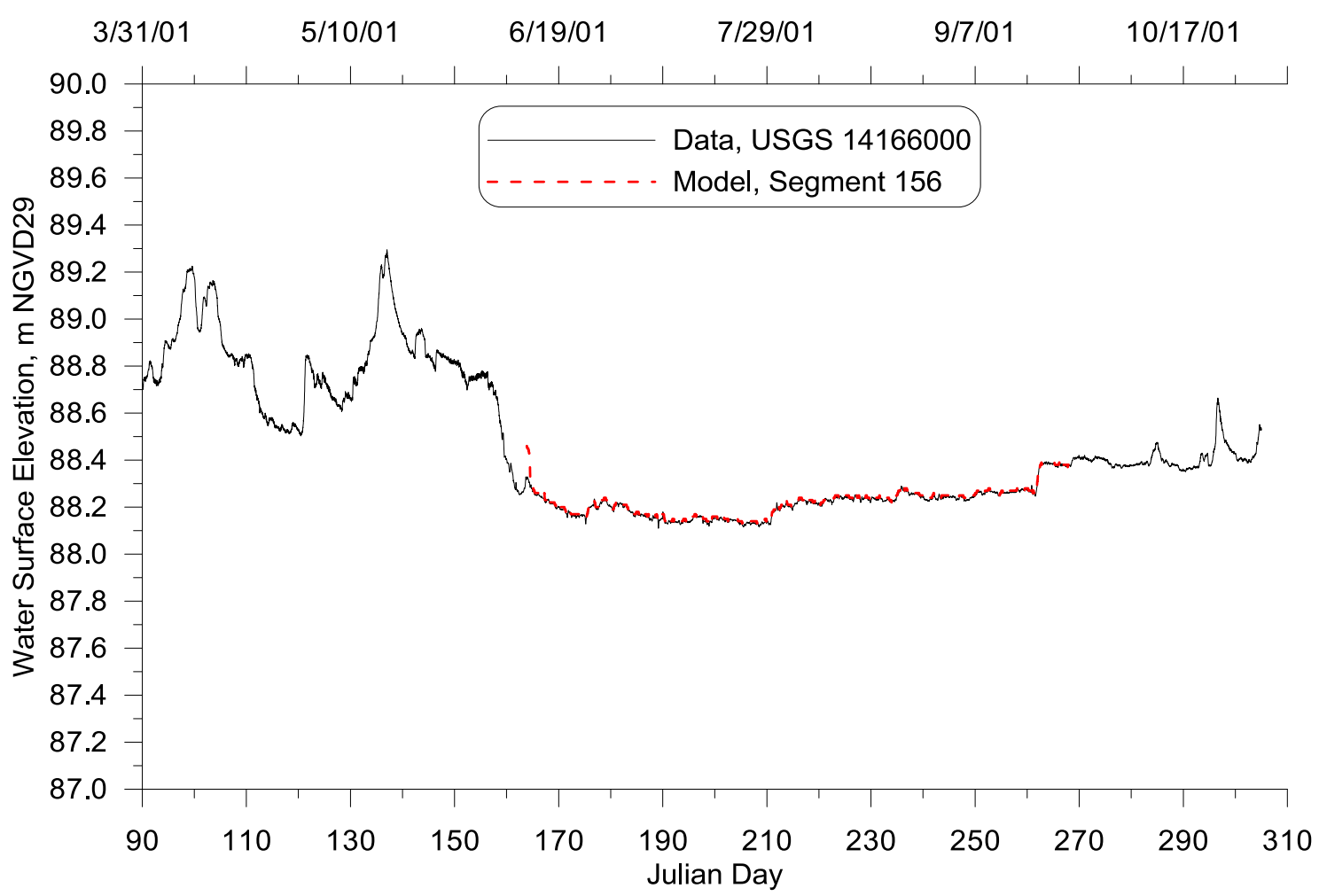

Figure 94: Willamette River at Harrisburg model-data water level comparison, 2001

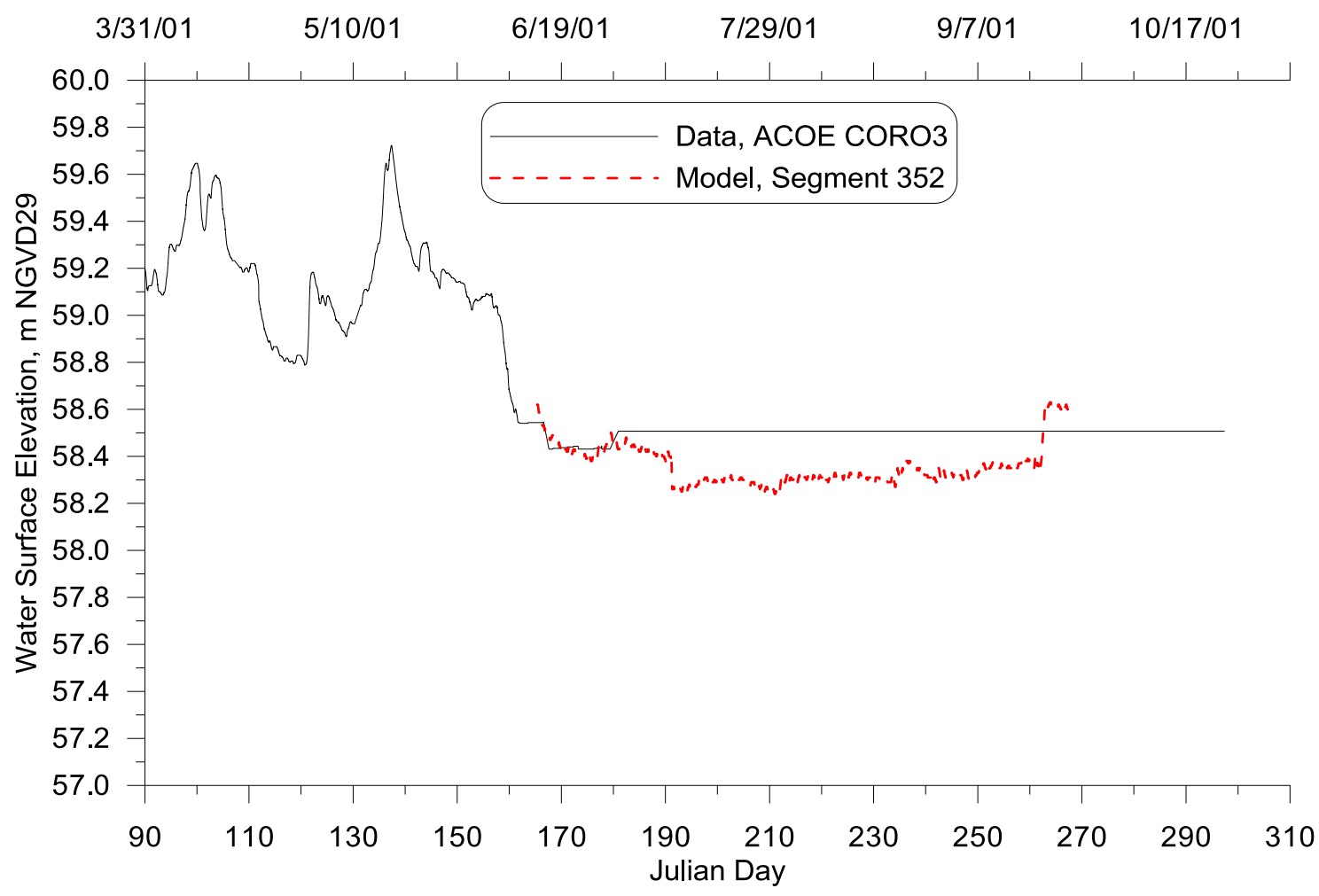

Figure 95: Willamette River at Corvallis model-data water level comparison, 2001 


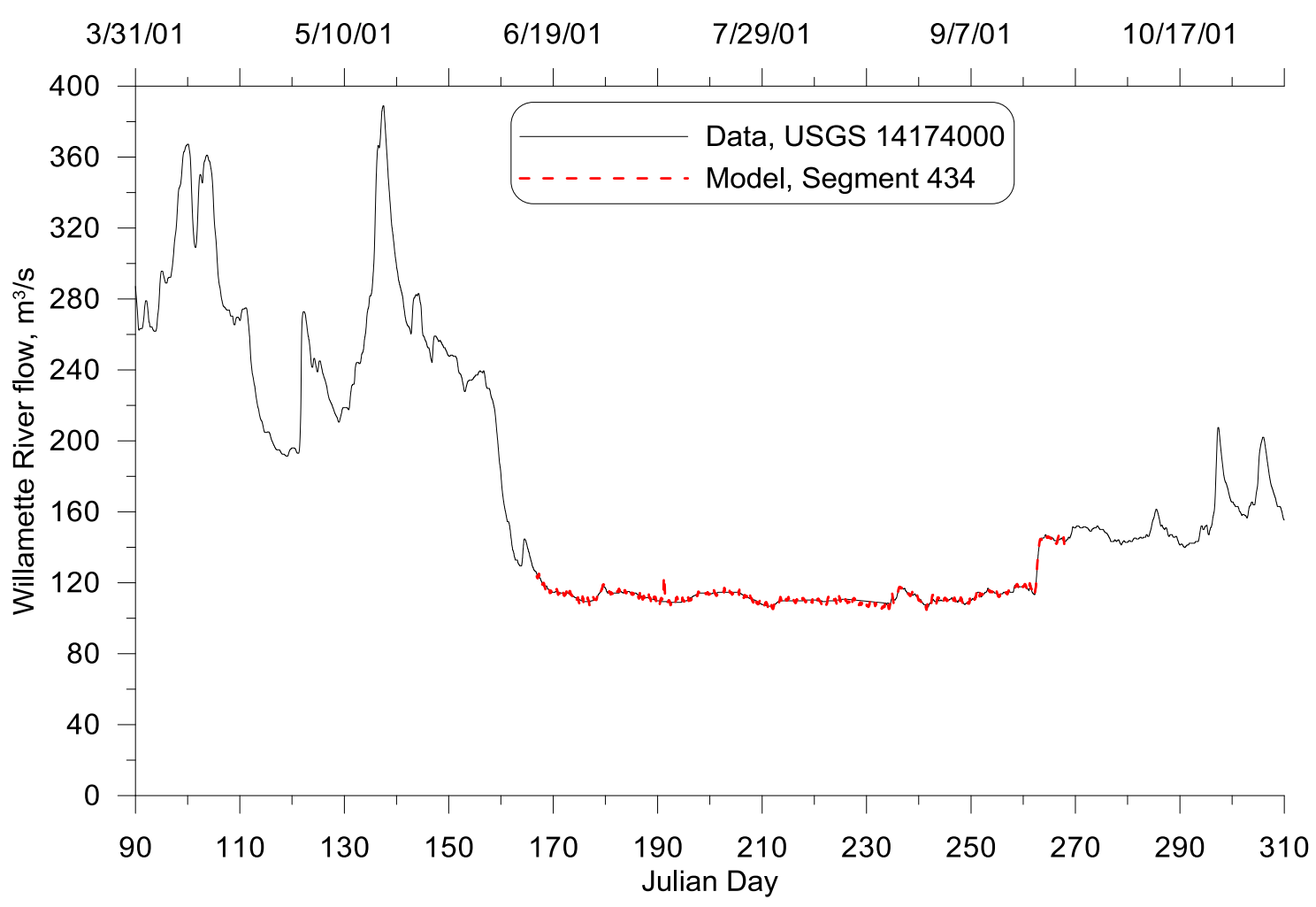

Figure 969: Willamette River at Albany model-data flow comparison, 2001

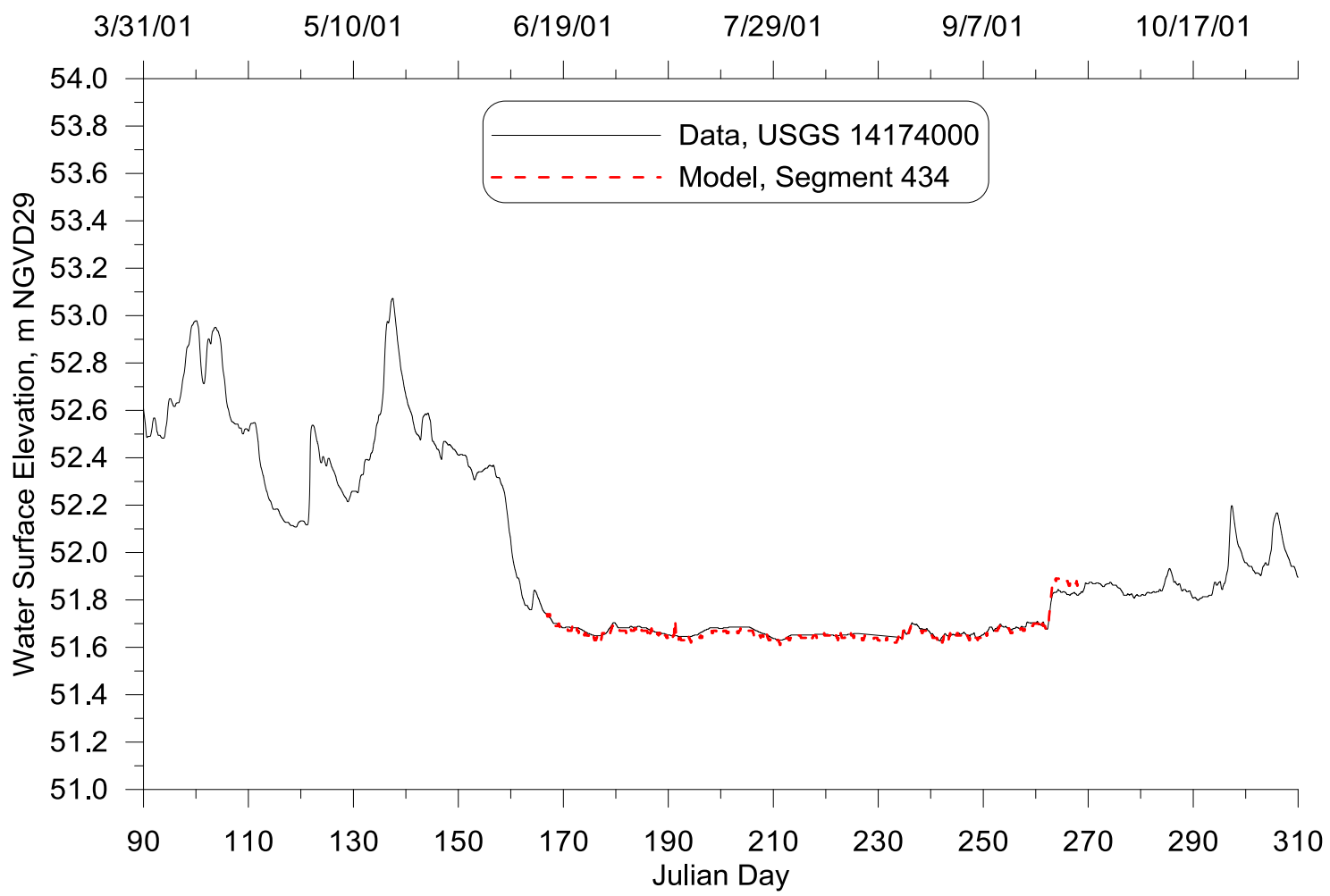

Figure 97: Willamette River at Albany model-data water level comparison, 2001 


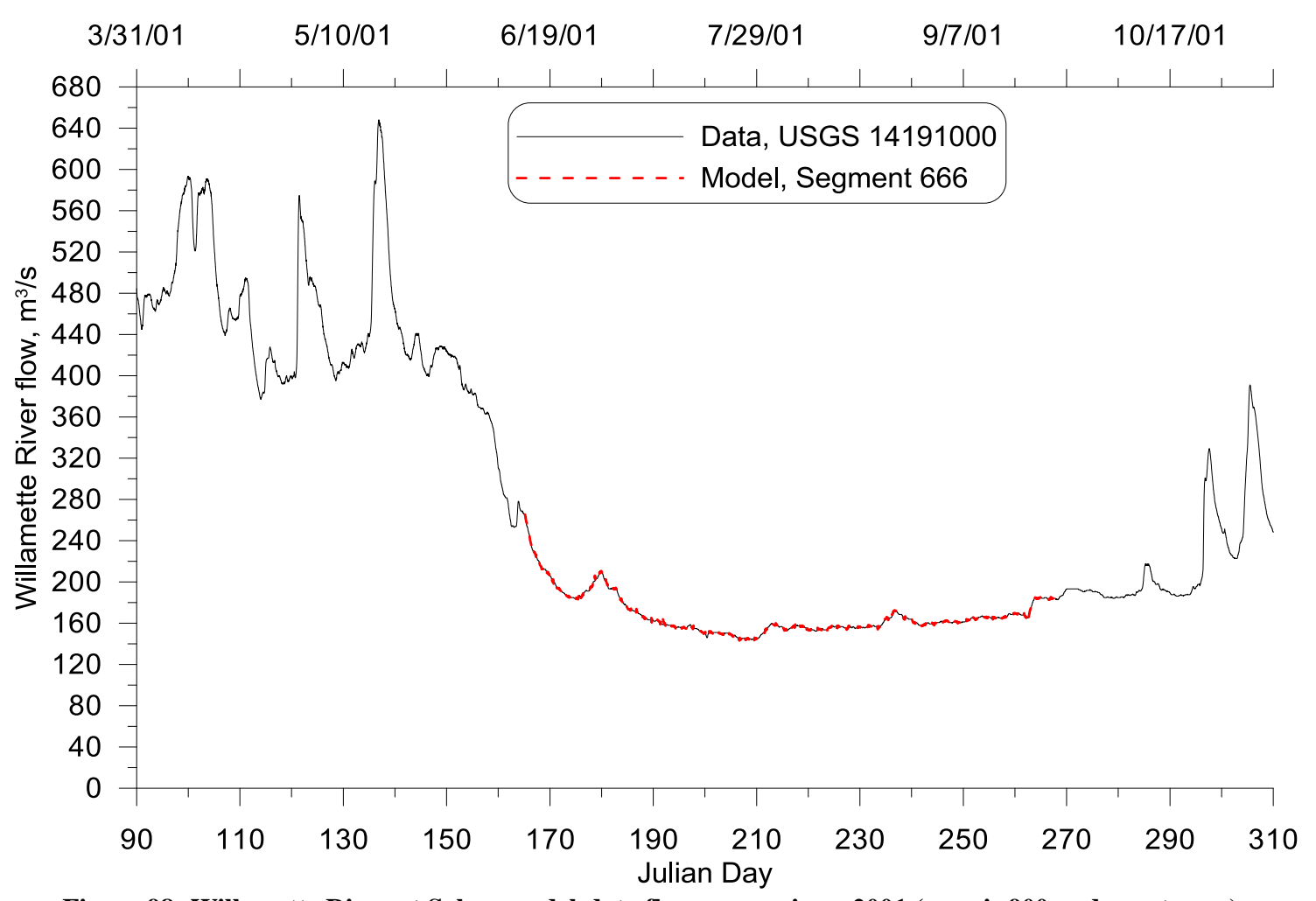

Figure 98: Willamette River at Salem model-data flow comparison, 2001 (gage is $900 \mathrm{~m}$ downstream)

\section{Year 2002}

The hydrodynamic calibration period in 2002 was from May to October. Figure 99 through 107 show the water level and flow comparison between model predictions and measured data. The figures showed that flow predictions matched well with data. Error statistics are summarized in Table 11.

Table 11: Upper Willamette River hydrodynamic calibration statistics, 2002

\begin{tabular}{|c|c|c|c|c|c|c|}
\hline \multicolumn{7}{|c|}{ Flow } \\
\hline Gage ID & RM & $\begin{array}{l}\text { Model } \\
\text { Segment }\end{array}$ & $\begin{array}{c}\text { Number of } \\
\text { Comparisons }\end{array}$ & $\mathrm{ME}, \mathrm{m}^{3} / \mathrm{s}$ & AME, $\mathrm{m}^{3} / \mathrm{s}$ & $\begin{array}{c}\text { RMSE, } \\
\mathrm{m}^{3} / \mathrm{s}\end{array}$ \\
\hline ACOE EUGO3 & 182.45 & 19 & 8289 & 0.266 & 0.586 & 2.649 \\
\hline USGS 14166000 & 161.98 & 156 & 8399 & 0.027 & 1.237 & 6.948 \\
\hline ACOE CORO3 & 132.32 & 352 & 15701 & 0.611 & 1.18 & 10.378 \\
\hline USGS 14174000 & 120.11 & 434 & 8399 & 0.993 & 1.694 & 15.265 \\
\hline USGS 14191000 & 84.70 & $665^{*}$ & 5758 & 0.081 & 0.987 & 1.650 \\
\hline
\end{tabular}




\begin{tabular}{|c|c|c|c|c|c|c|}
\hline \multicolumn{7}{|c|}{ Water Level } \\
\hline Gage ID & RM & $\begin{array}{c}\text { Model } \\
\text { Segment }\end{array}$ & $\begin{array}{c}\text { Number of } \\
\text { Comparisons }\end{array}$ & ME, m & AME, m & RMSE, m \\
\hline ACOE EUGO3 & 182.45 & 19 & 8289 & 0.073 & 0.073 & 0.076 \\
\hline USGS 14166000 & 161.98 & 156 & 8399 & -0.131 & 0.14 & 0.156 \\
\hline ACOE CORO3 & 132.32 & 352 & 15701 & 0.106 & 0.106 & 0.118 \\
\hline USGS 14174000 & 120.11 & 434 & 8399 & 0.026 & 0.028 & 0.075 \\
\hline USGS 14191000 & 84.70 & $665^{*}$ & 5760 & $\begin{array}{c}\text { Not appropriate comparison, } 1 \mathrm{~km} \\
\text { downstream of model grid }\end{array}$ \\
\hline
\end{tabular}

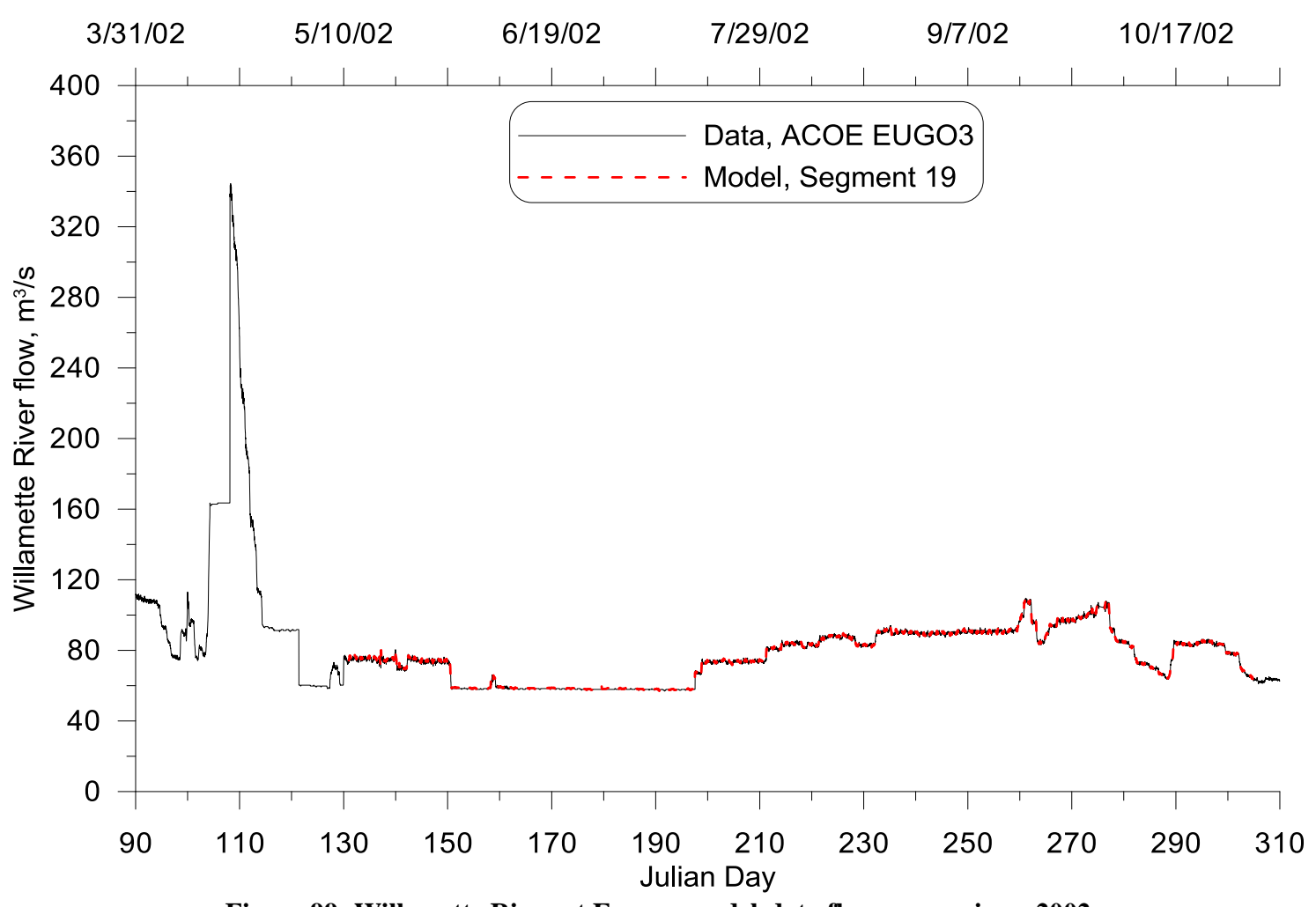

Figure 99: Willamette River at Eugene model-data flow comparison, 2002 


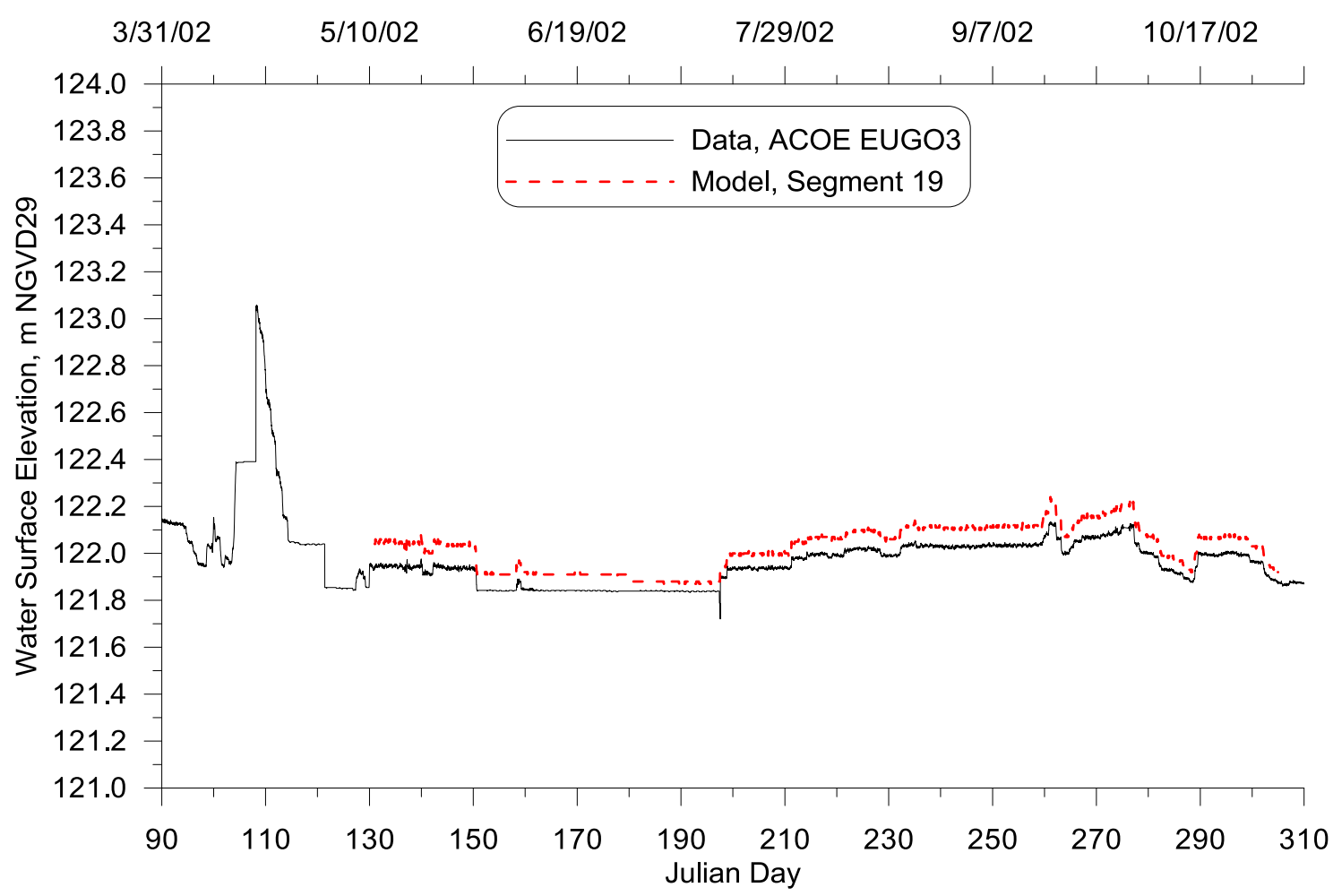

Figure 100: Willamette River at Eugene model-data water level comparison, 2002

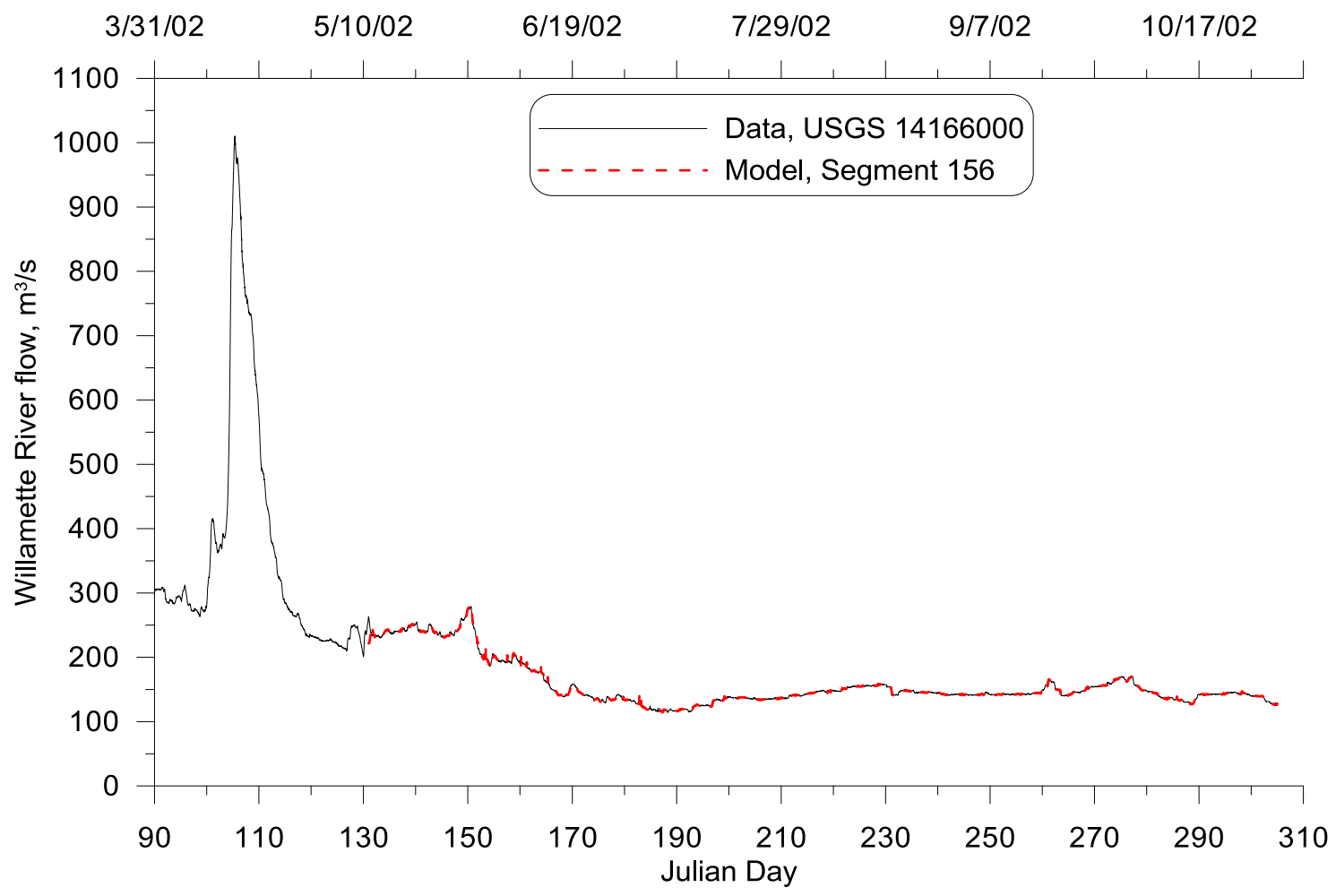

Figure 101: Willamette River at Harrisburg model-data flow comparison, 2002 


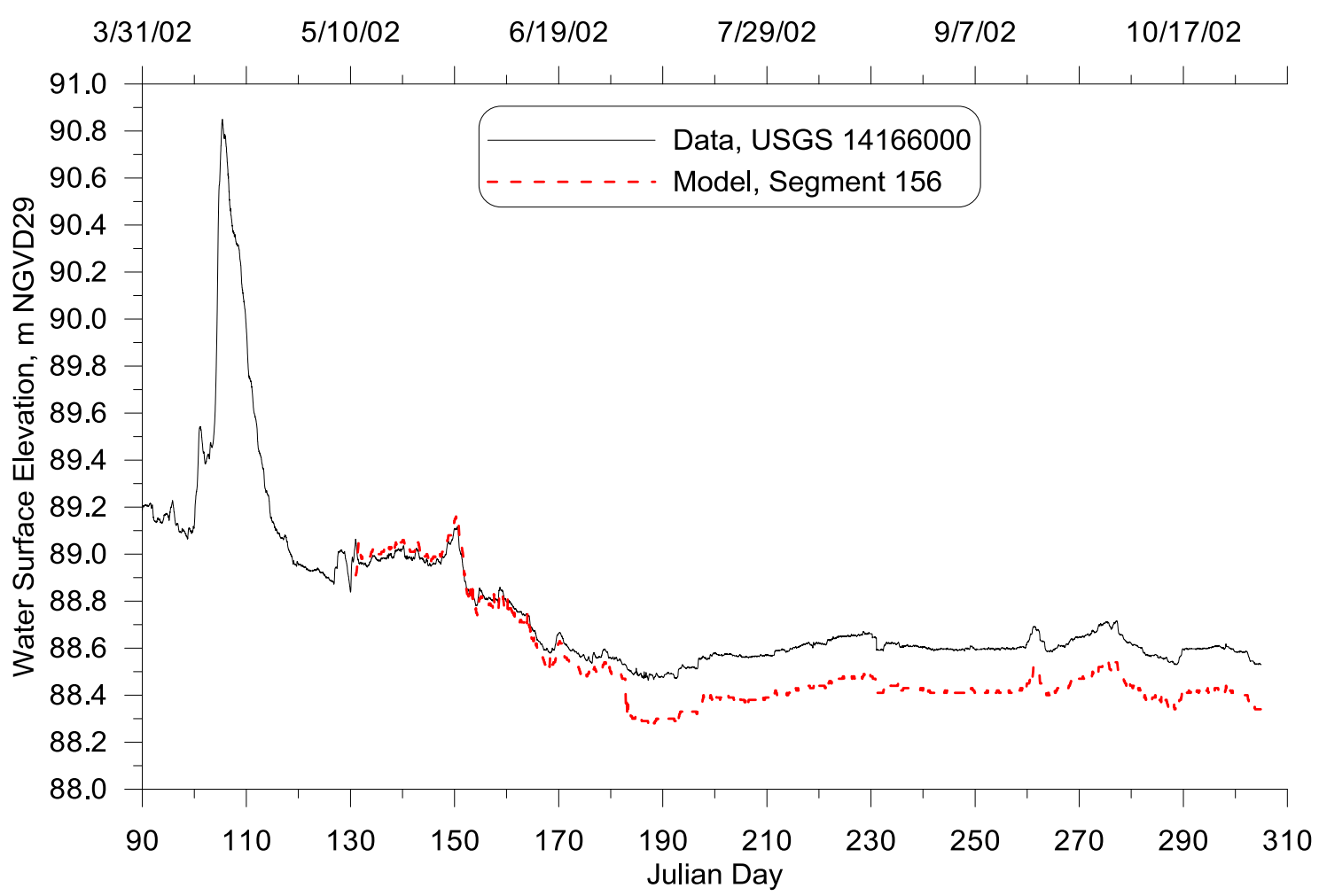

Figure 102: Willamette River at Harrisburg model-data water level comparison, 2002

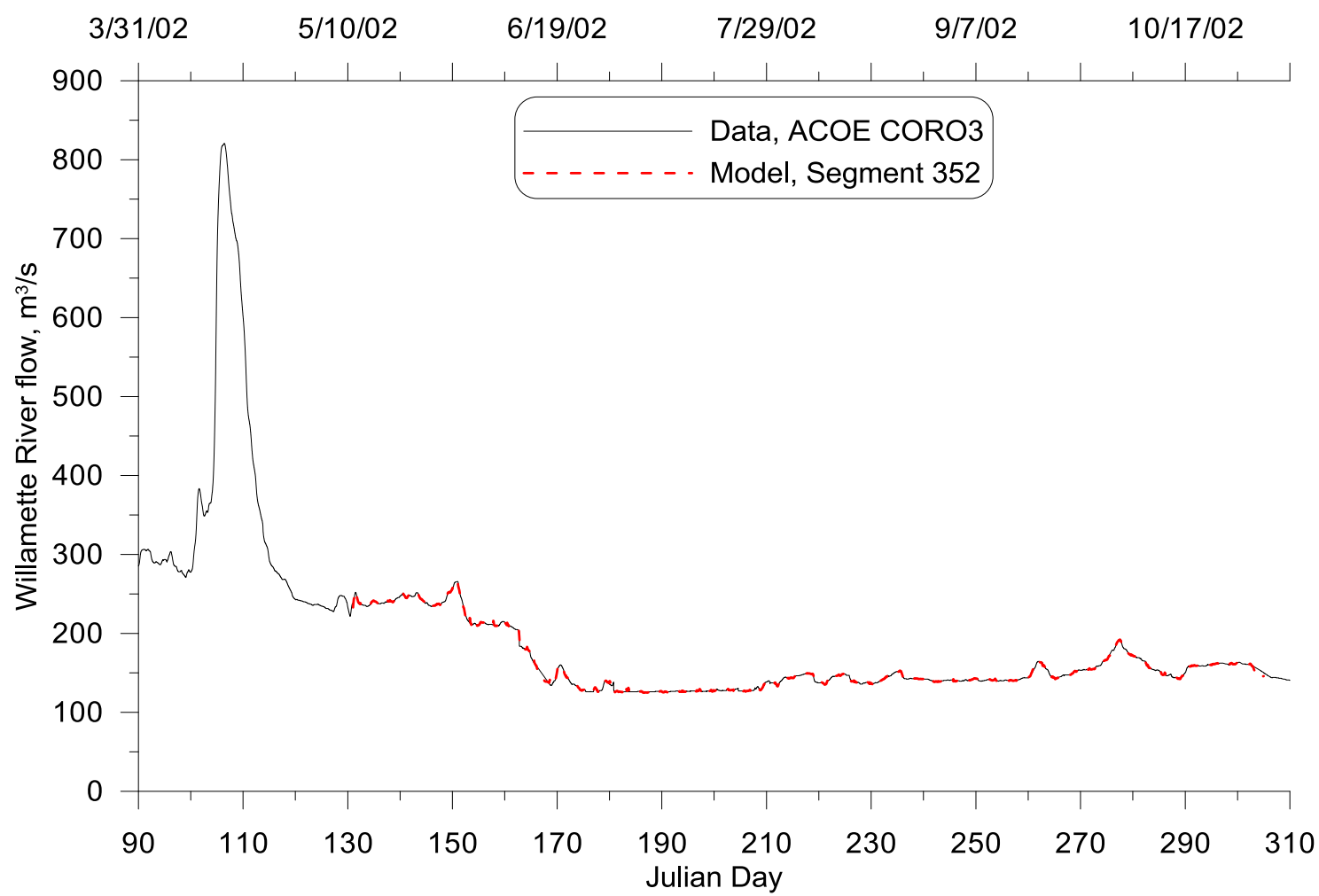

Figure 103: Willamette River at Corvallis model-data flow comparison, 2002 


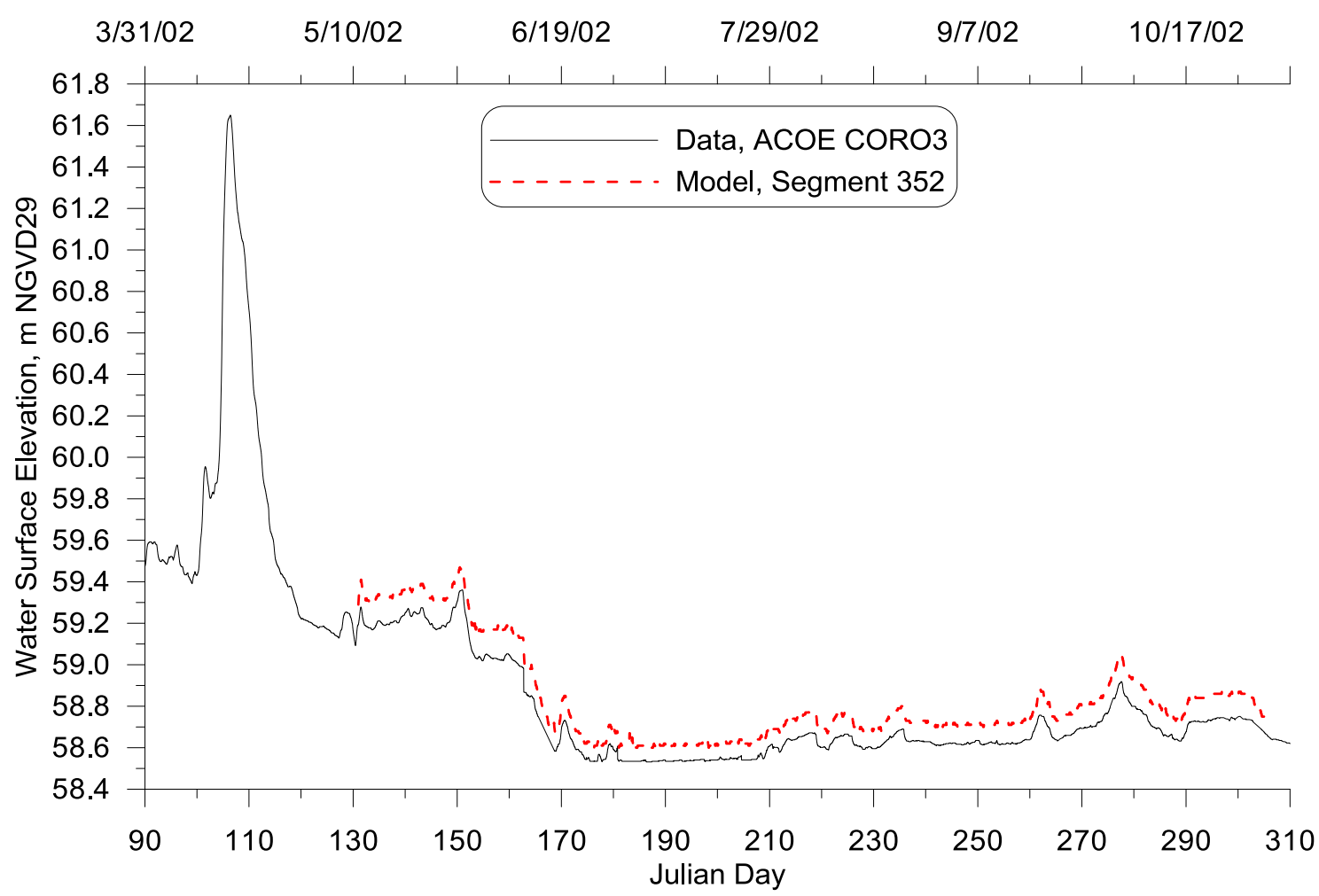

Figure 104: Willamette River at Corvallis model-data water level comparison, 2002

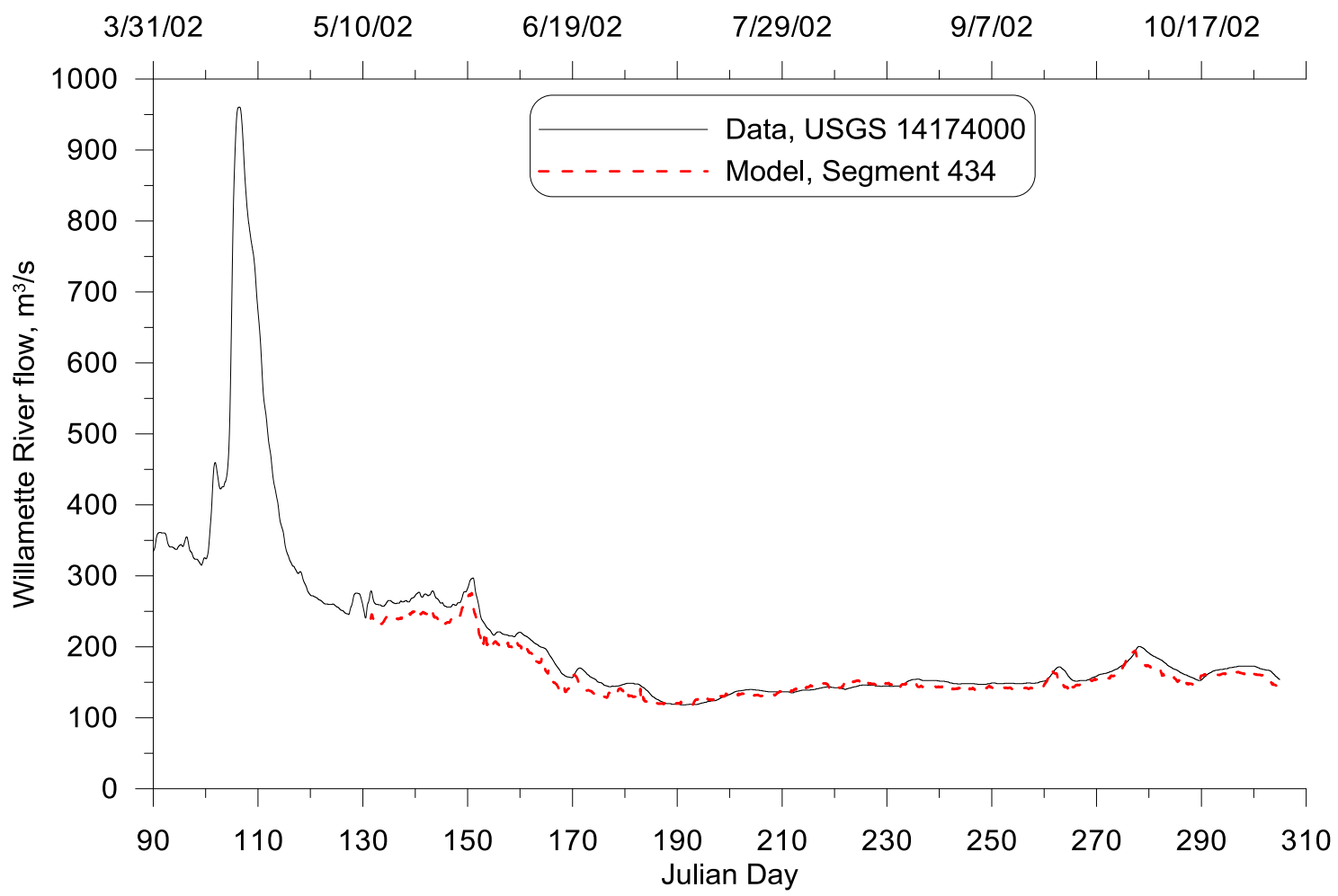

Figure 105: Willamette River at Albany model-data flow comparison, 2002 


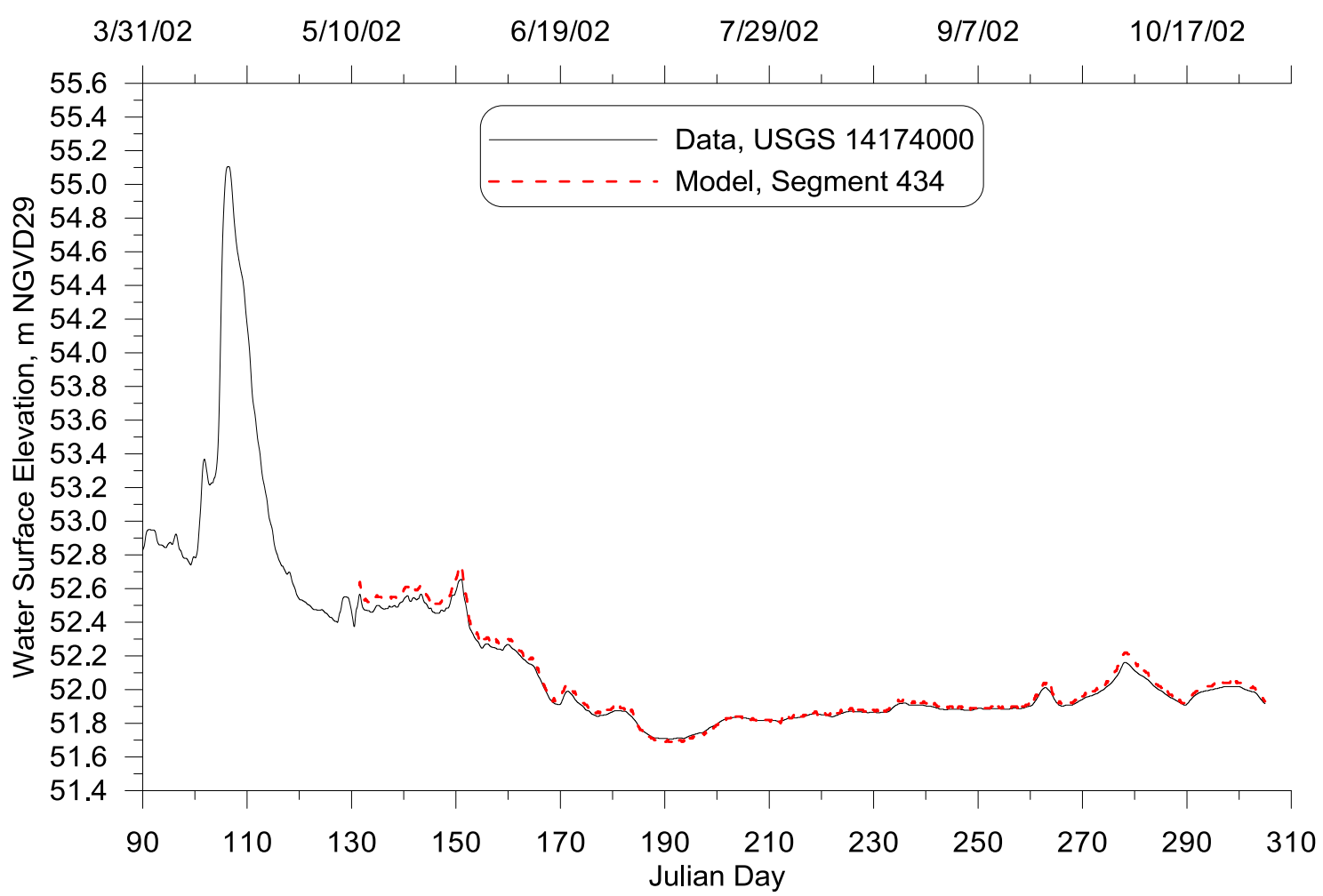

Figure 106: Willamette River at Albany model-data water level comparison, 2002

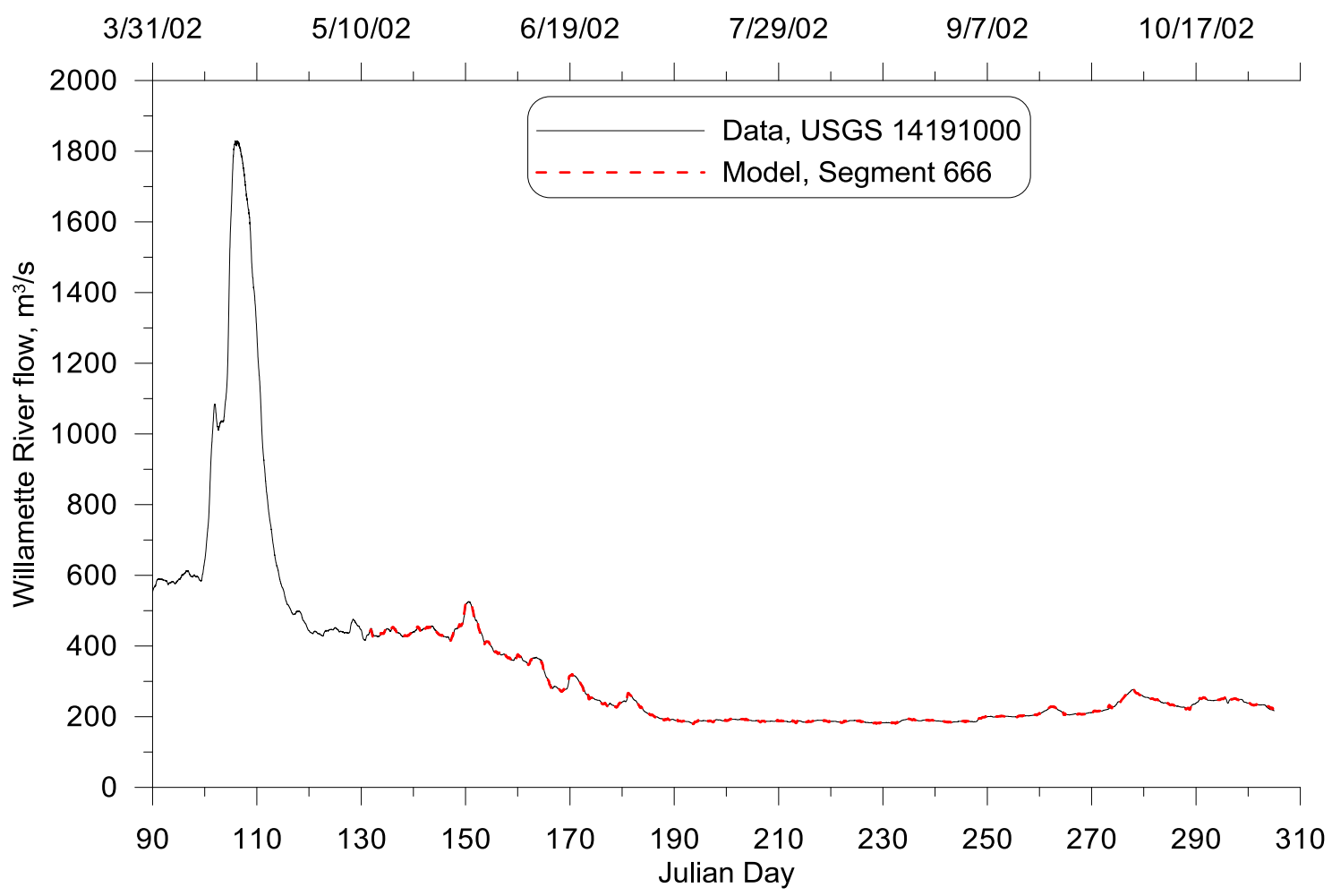

Figure 107: Willamette River at Salem model-data flow comparison, 2002 (gage is $900 \mathrm{~m}$ downstream)

\section{Temperature}




\section{Year 2001}

Figure 108 through 119 show the continuous temperature comparison between model predictions and measured data. Error statistics are summarized in Table 12. Predicted temperature matched data very well for all the 12 sites with the RMSEs below $0.88^{\circ} \mathrm{C}$.

Table 12: Upper Willamette River continuous water temperature calibration model-data error statistics, 2001

\begin{tabular}{|c|c|c|c|c|c|c|}
\hline \multirow[b]{2}{*}{ Site ID } & \multirow[b]{2}{*}{$\mathrm{RM}$} & \multirow{2}{*}{$\begin{array}{c}\text { Model } \\
\text { Segment }\end{array}$} & \multicolumn{3}{|c|}{ Continuous Temperature } & \multirow[b]{2}{*}{$\mathrm{RMSE},{ }^{\circ} \mathrm{C}$} \\
\hline & & & $\begin{array}{c}\text { Number of } \\
\text { Comparisons }\end{array}$ & $\mathrm{ME},{ }^{\circ} \mathrm{C}$ & $\mathrm{AME},{ }^{\circ} \mathrm{C}$ & \\
\hline LASAR 10359 & 185.3 & 2 & 5040 & 0.004 & 0.034 & 0.048 \\
\hline LASAR 28723 & 177.7 & 53 & 2362 & -0.223 & 0.464 & 0.593 \\
\hline USGS 14166000 & 162.0 & 156 & 5040 & 0.135 & 0.659 & 0.782 \\
\hline LASAR 26755 & 151.6 & 227 & 5040 & 0.332 & 0.647 & 0.803 \\
\hline LASAR 26753 & 147.4 & 255 & 5040 & 0.444 & 0.698 & 0.877 \\
\hline LASAR 26772 & 142.4 & 287 & 5040 & 0.317 & 0.708 & 0.861 \\
\hline LASAR 10353 & 135.2 & 334 & 2520 & 0.169 & 0.514 & 0.654 \\
\hline USGS 14174000 & 120.2 & 434 & 2179 & -0.129 & 0.408 & 0.519 \\
\hline LASAR 10349 & 113.9 & 476 & 4967 & -0.005 & 0.498 & 0.638 \\
\hline LASAR 10347 & 96.9 & 589 & 4958 & -0.213 & 0.476 & 0.59 \\
\hline LASAR 28254 & 88.9 & 643 & 2520 & 0.063 & 0.606 & 0.791 \\
\hline USGS 14191000 & 84.7 & 666 & 600 & 0.139 & 0.46 & 0.562 \\
\hline
\end{tabular}




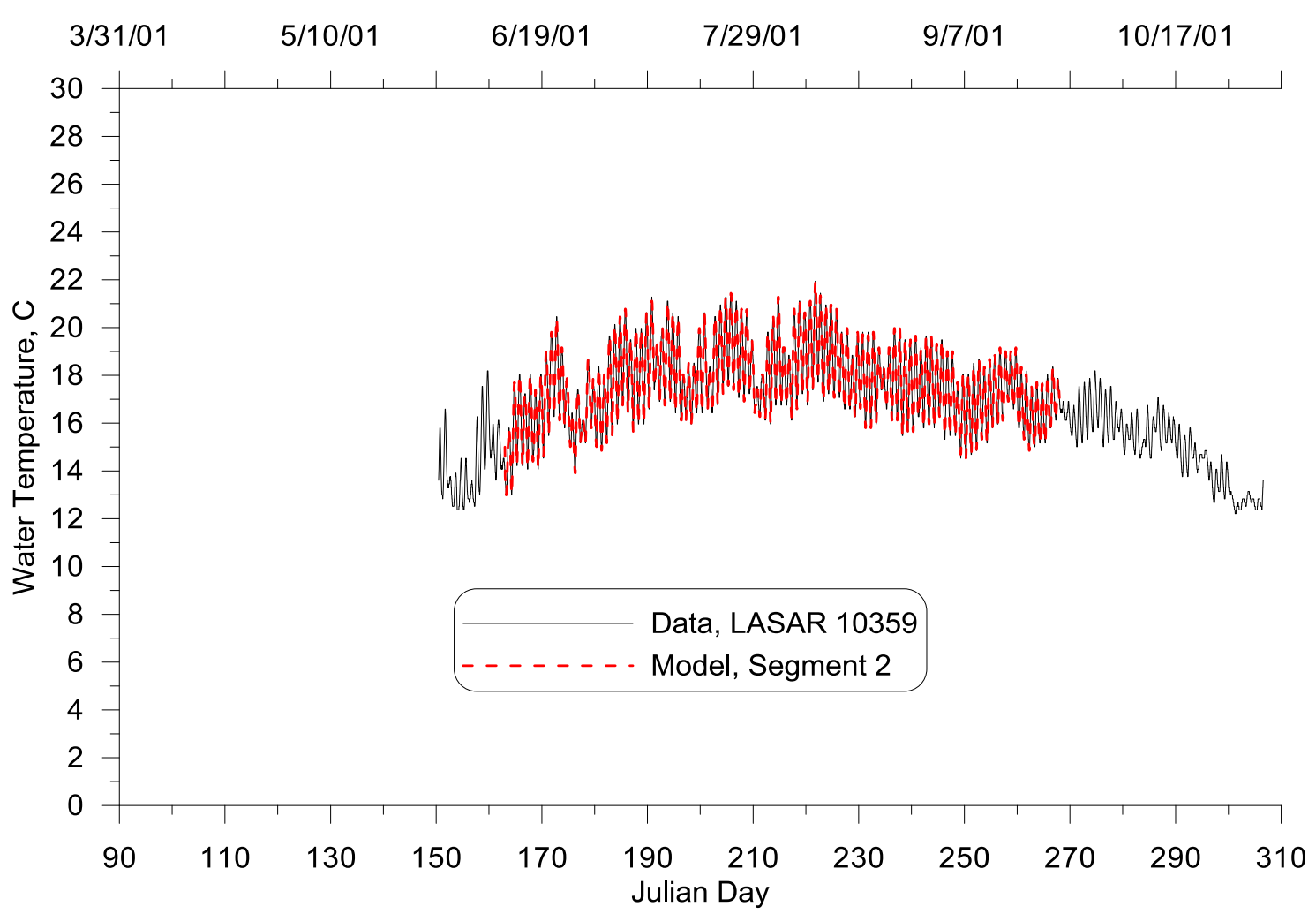

Figure 108: Upper Willamette River near Springfield model-data continuous temperature comparison, 2001

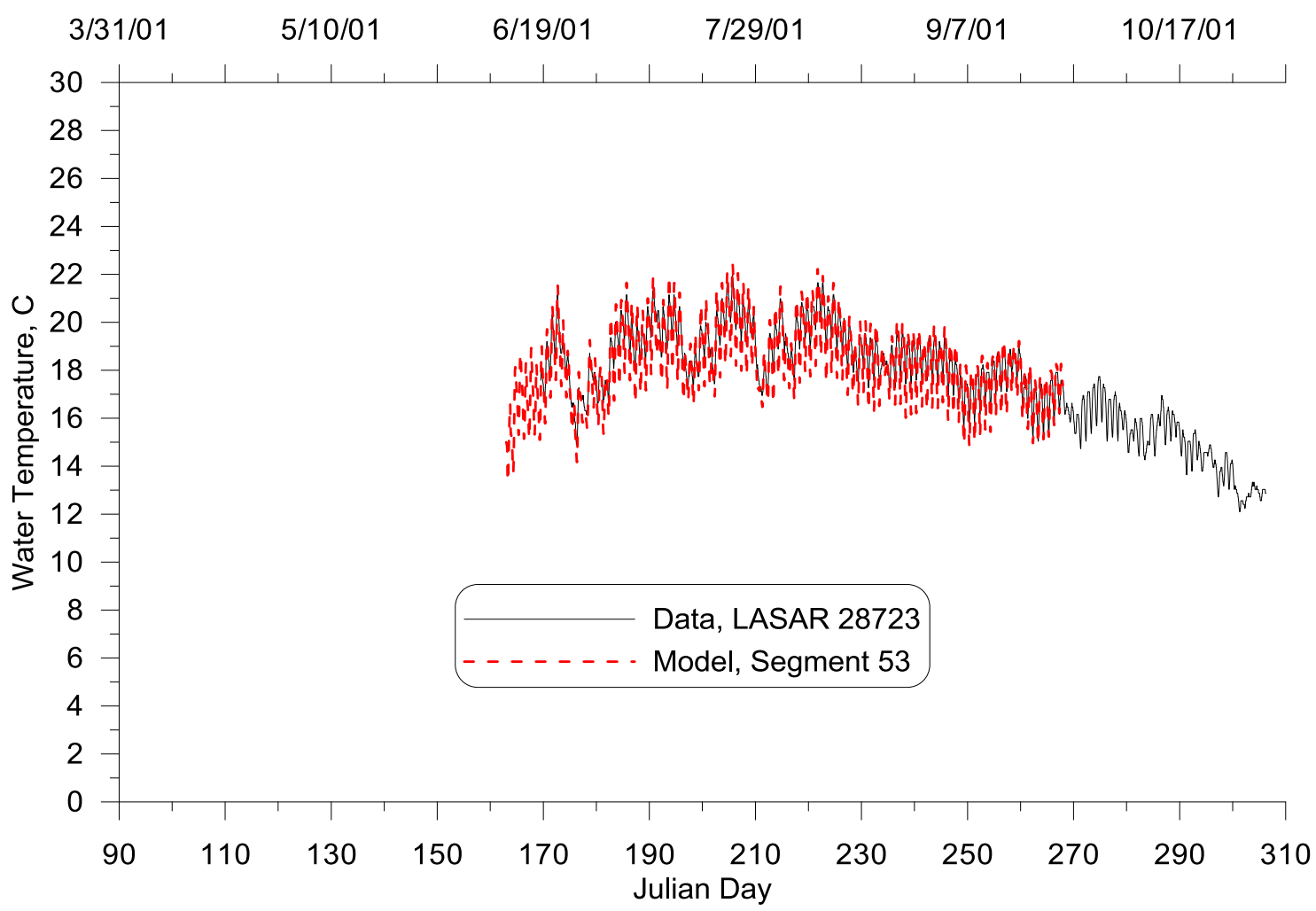

Figure 109: Upper Willamette River above McKenzie River model-data continuous temperature comparison, 2001 


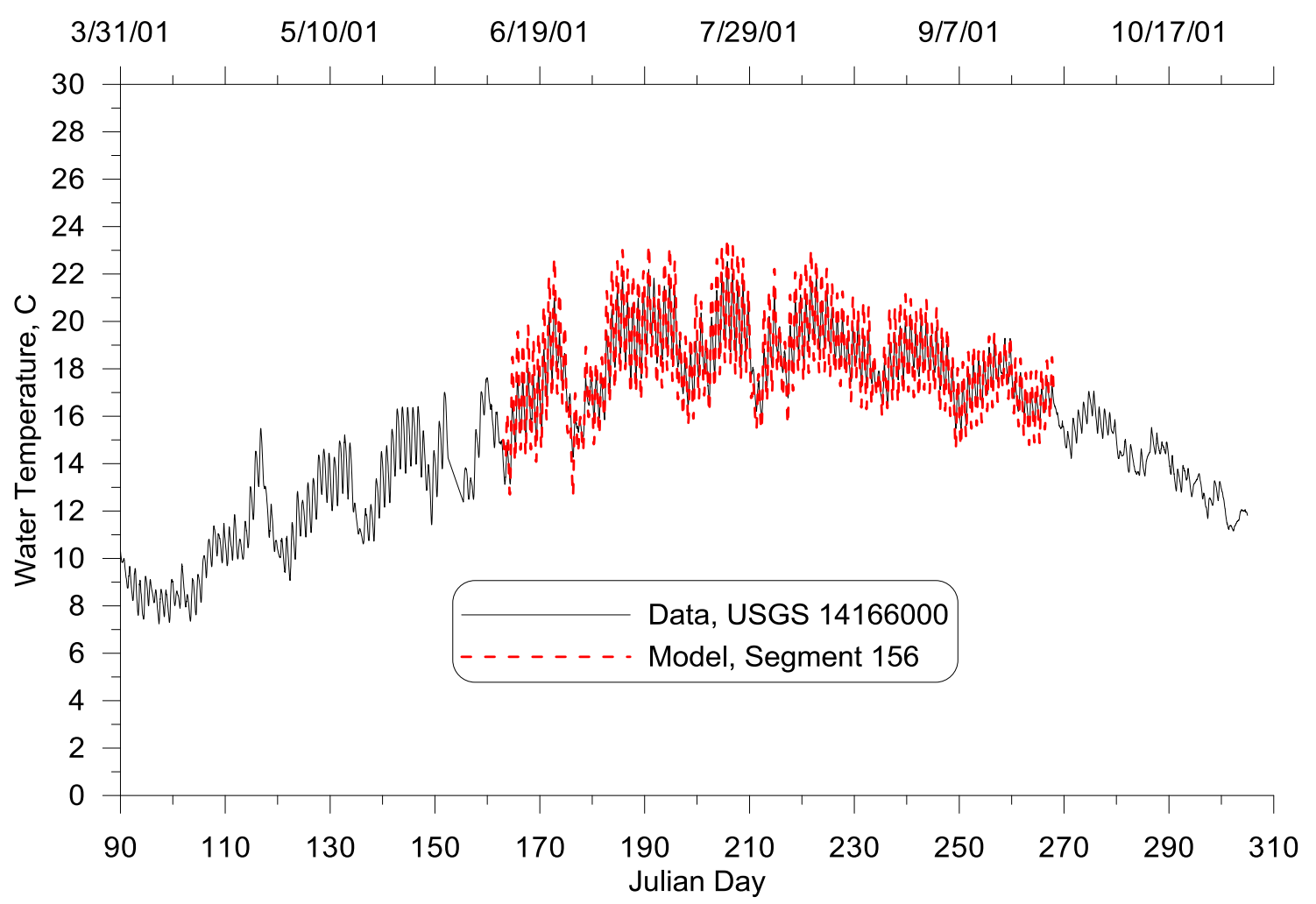

Figure 110: Upper Willamette River at Harrisburg model-data continuous temperature comparison, 2001

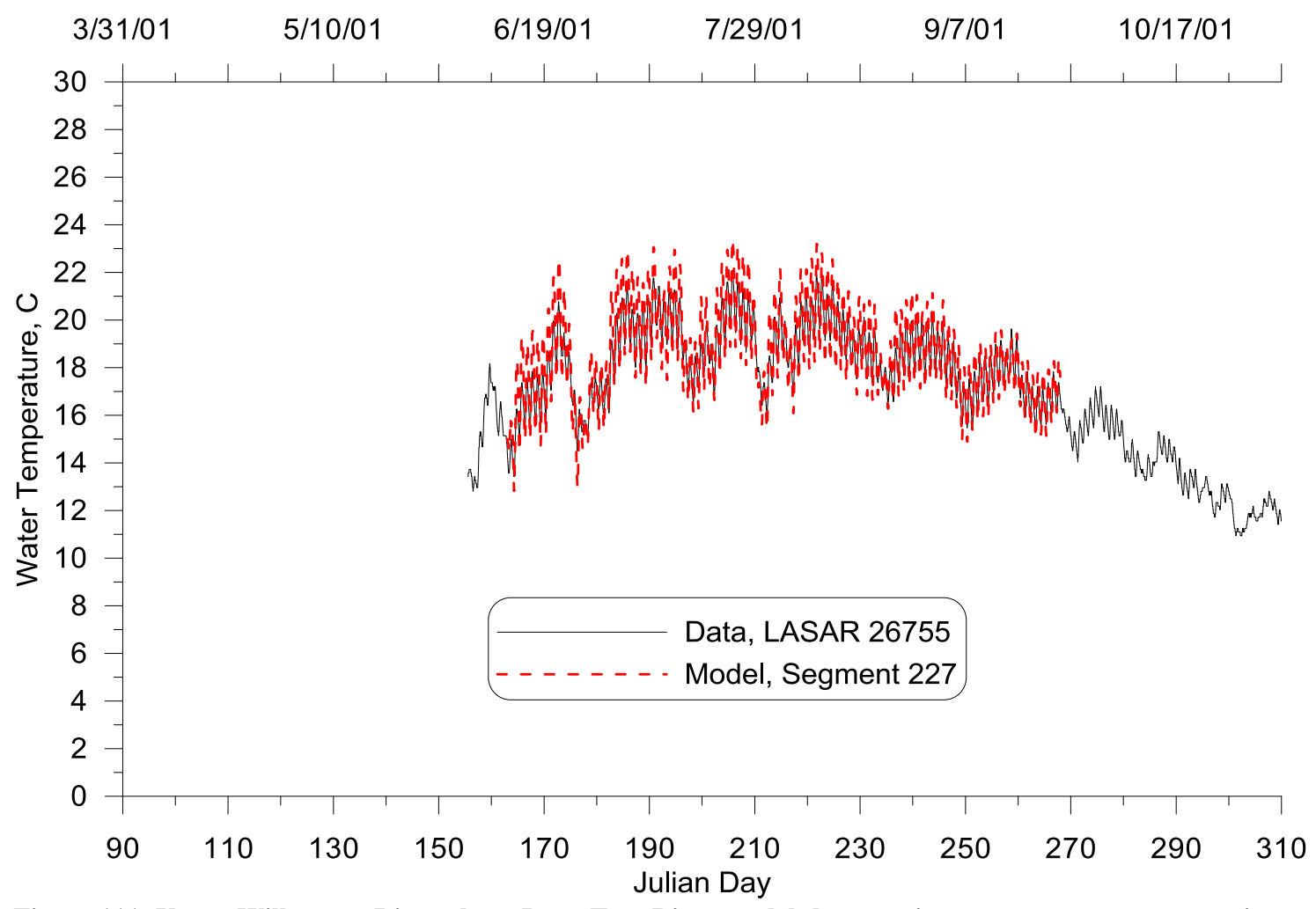

Figure 111: Upper Willamette River above Long Tom River model-data continuous temperature comparison, 2001 


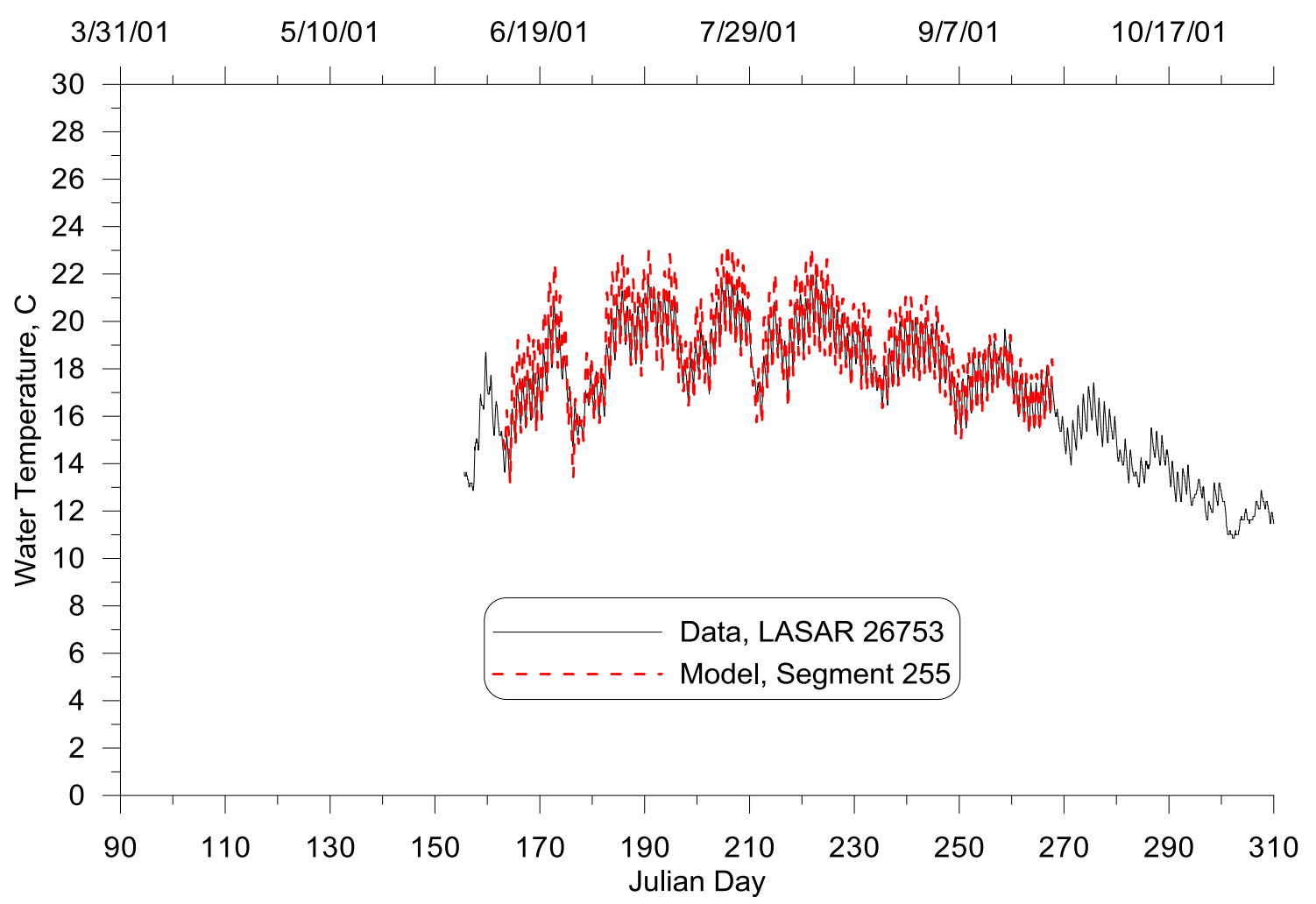

Figure 112: Upper Willamette River at RM 147.4 model-data continuous temperature comparison, 2001

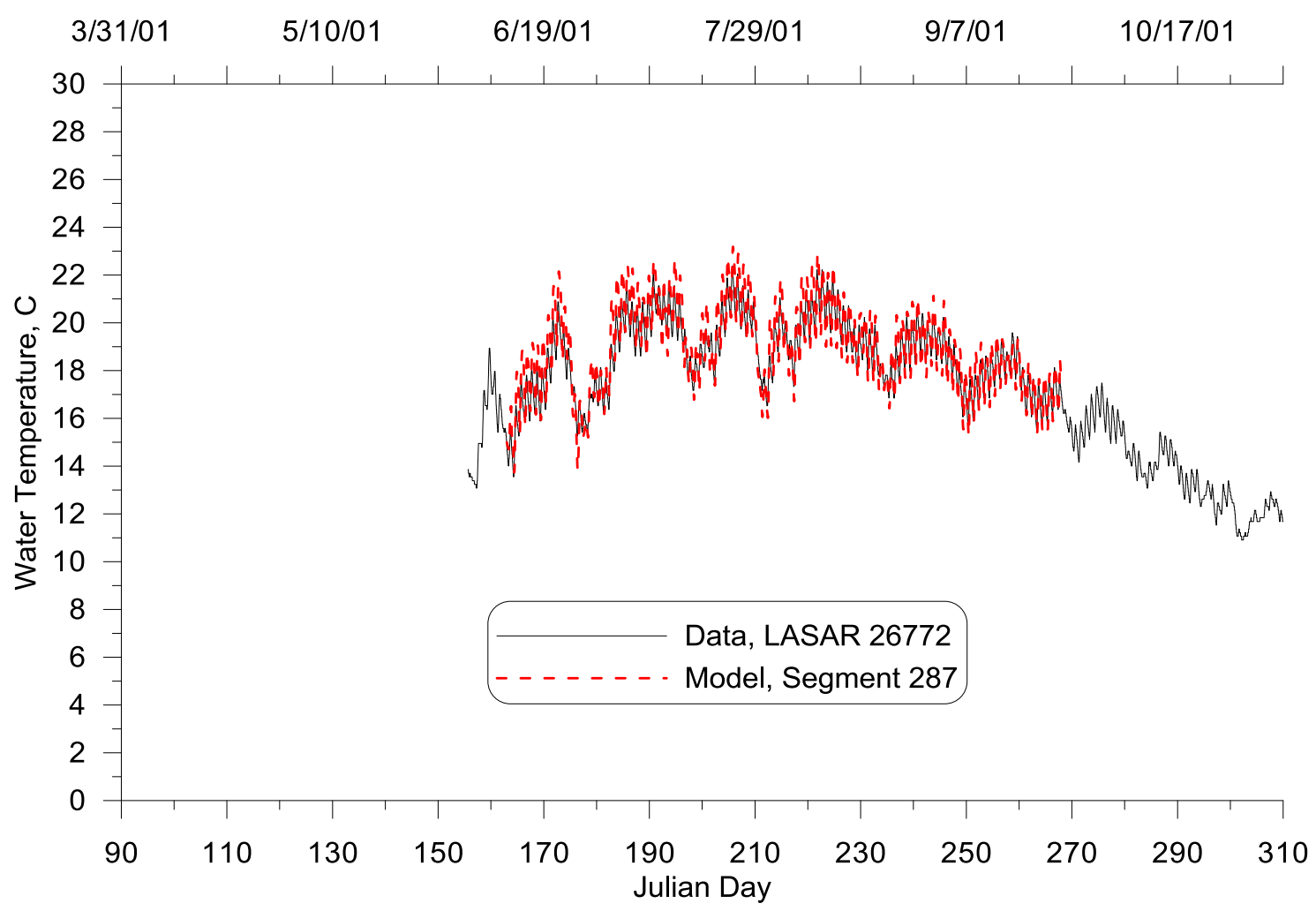

Figure 113: Upper Willamette River at RM 142.4 model-data continuous temperature comparison, 2001 


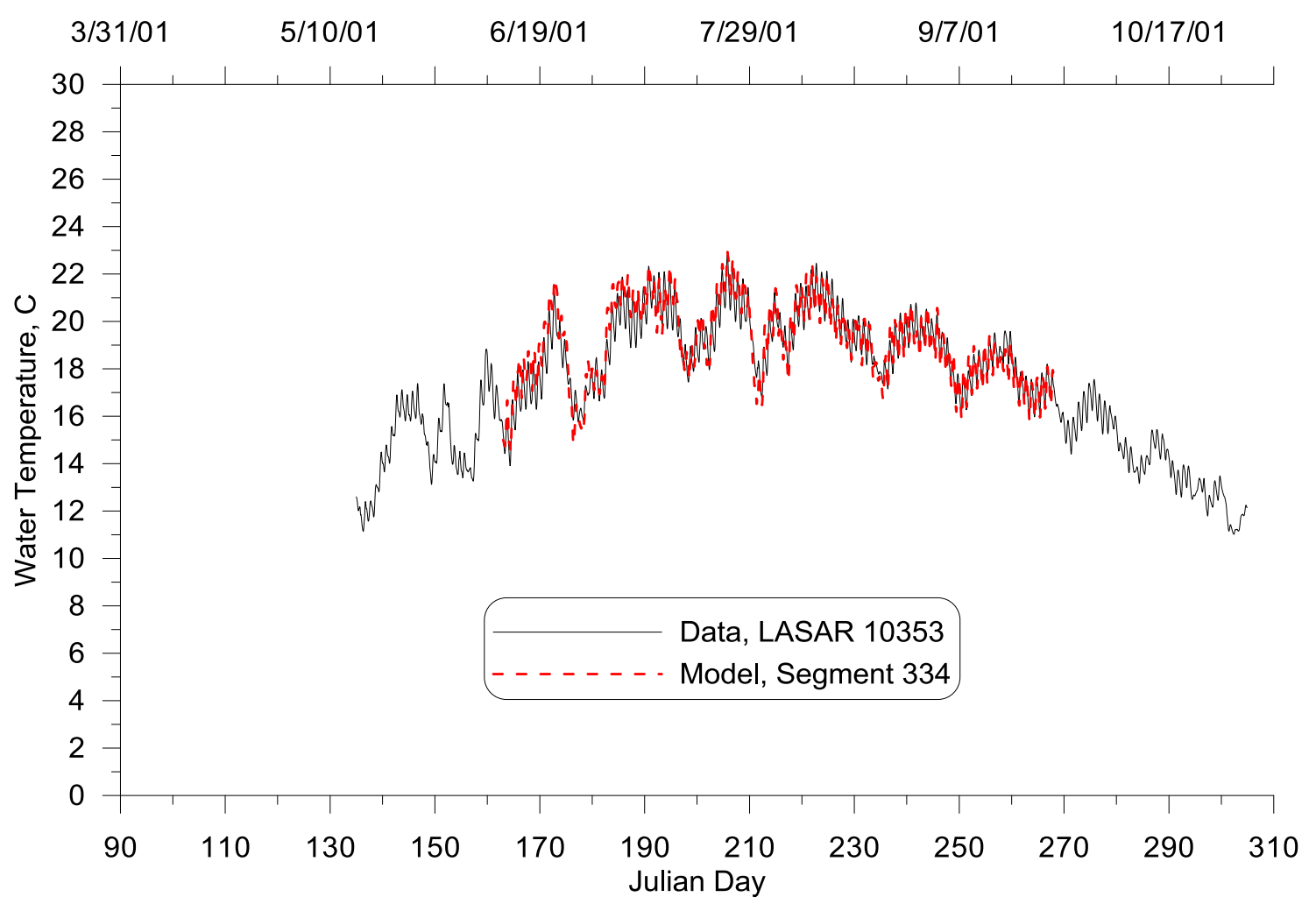

Figure 114: Upper Willamette River at Corvallis model-data continuous temperature comparison, 2001

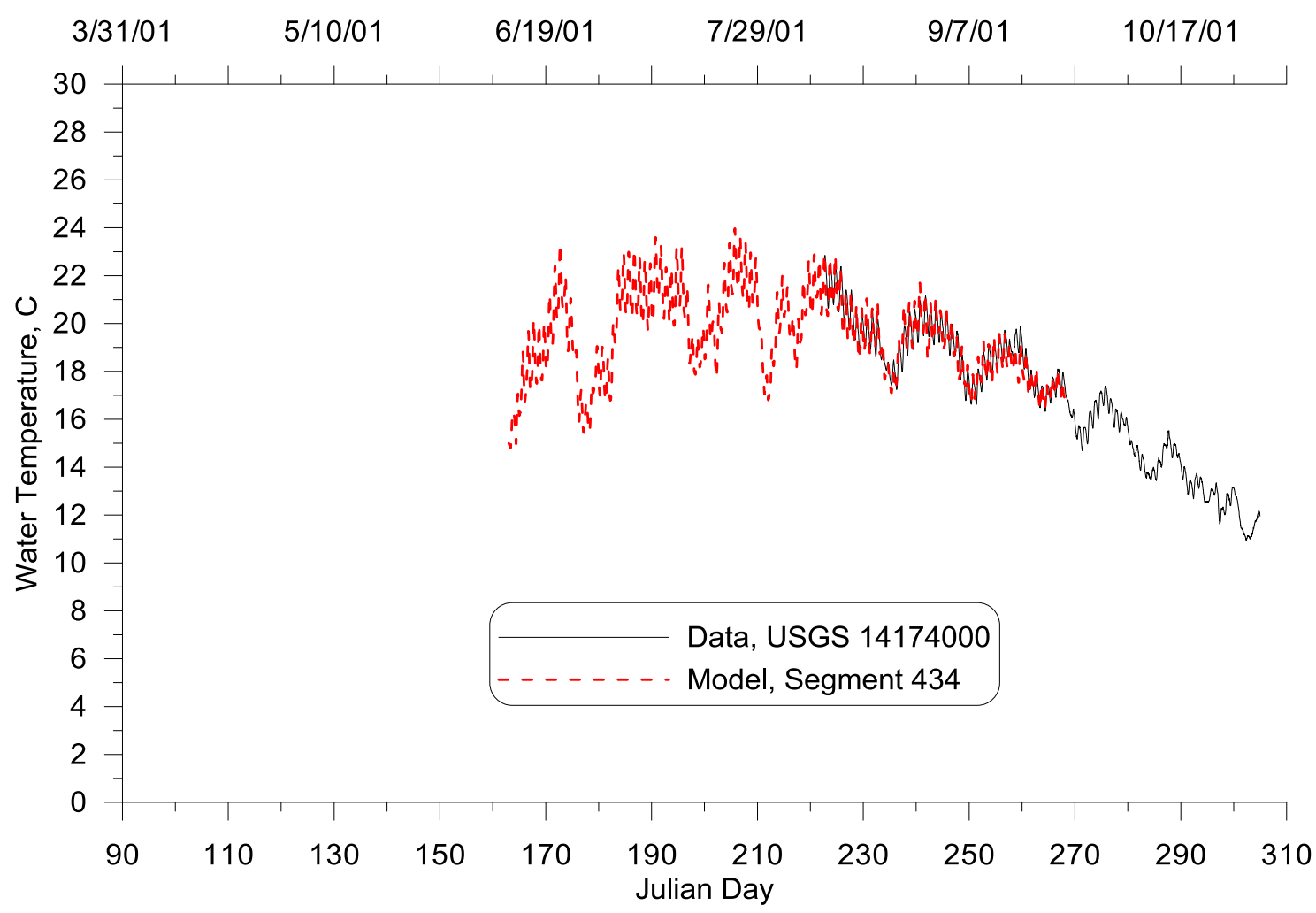

Figure 115: Upper Willamette River at Albany model-data continuous temperature comparison, 2001 


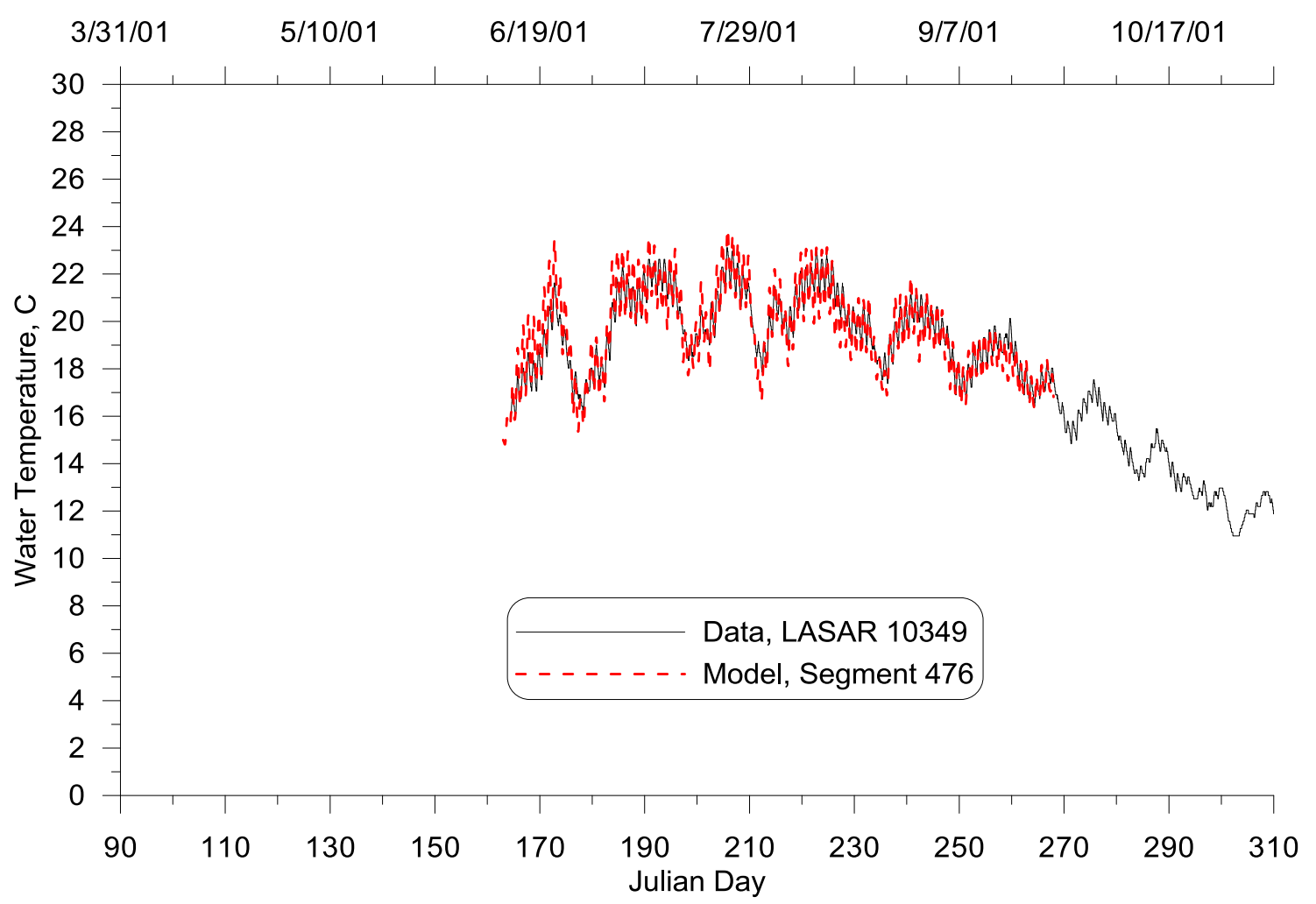

Figure 116: Upper Willamette River at Conser Rd model-data continuous temperature comparison, 2001

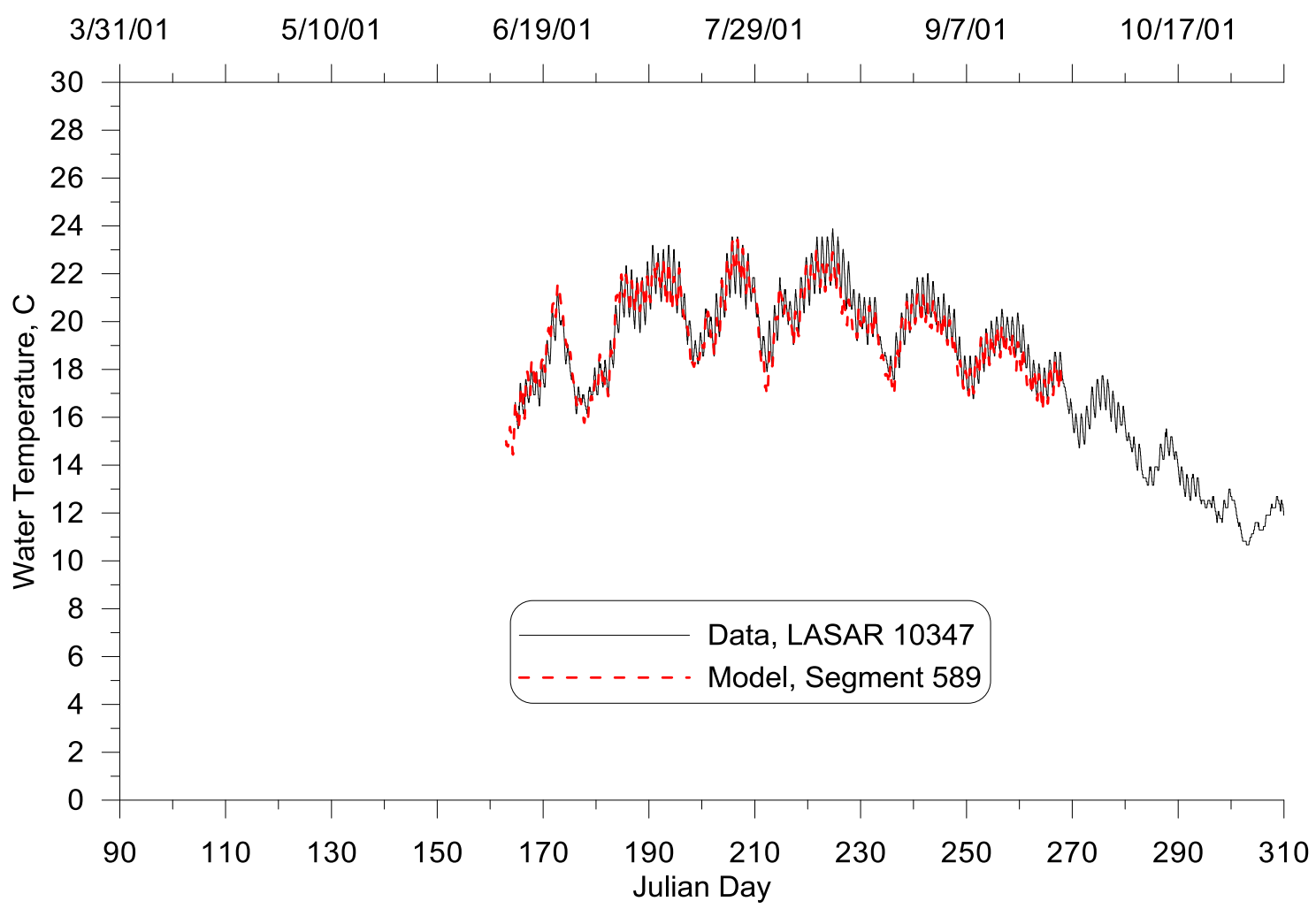

Figure 117: Upper Willamette River at South River Rd model-data continuous temperature comparison, 2001 


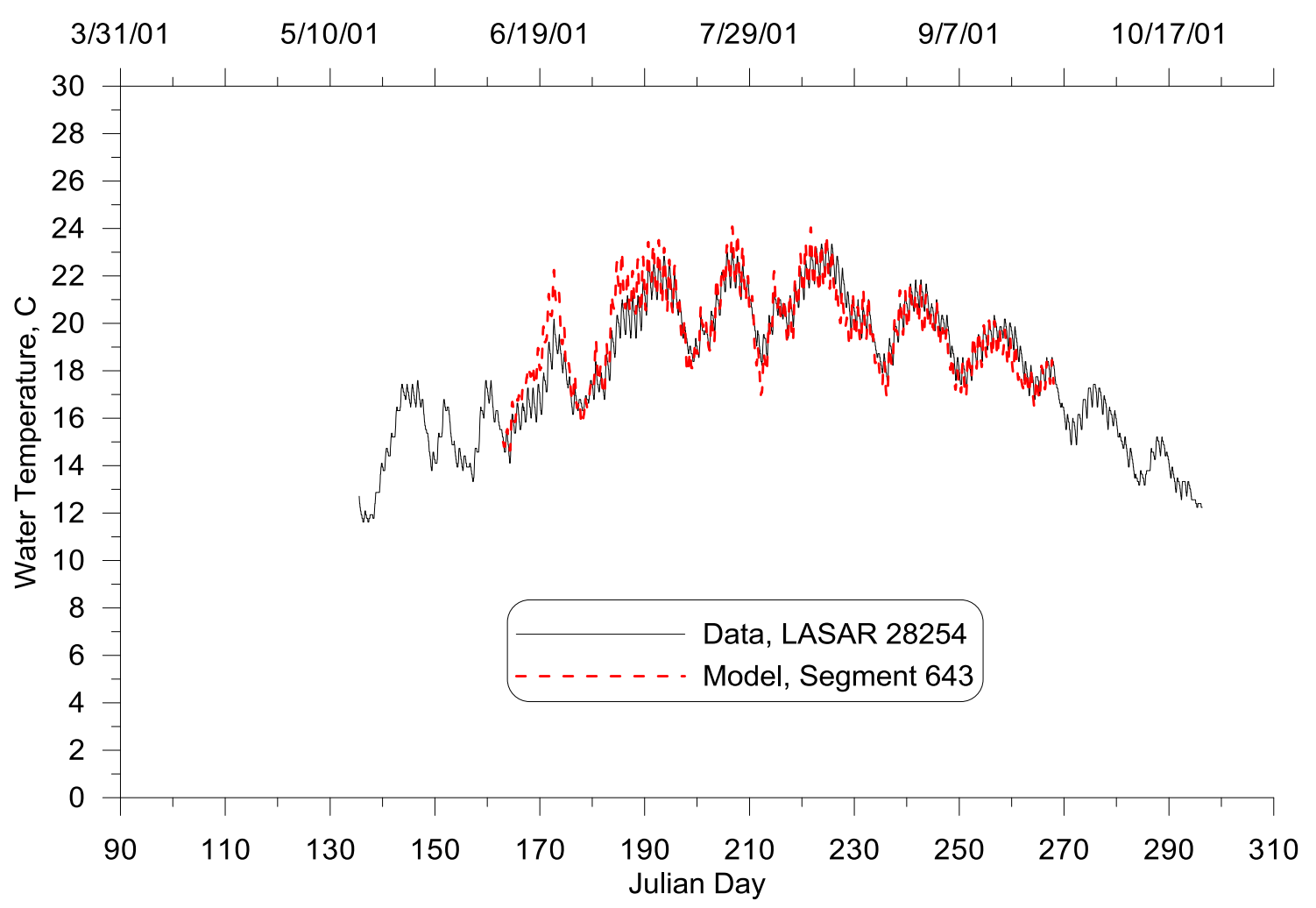

Figure 118: Upper Willamette River above Rickreall Creek model-data continuous temperature comparison, 2001

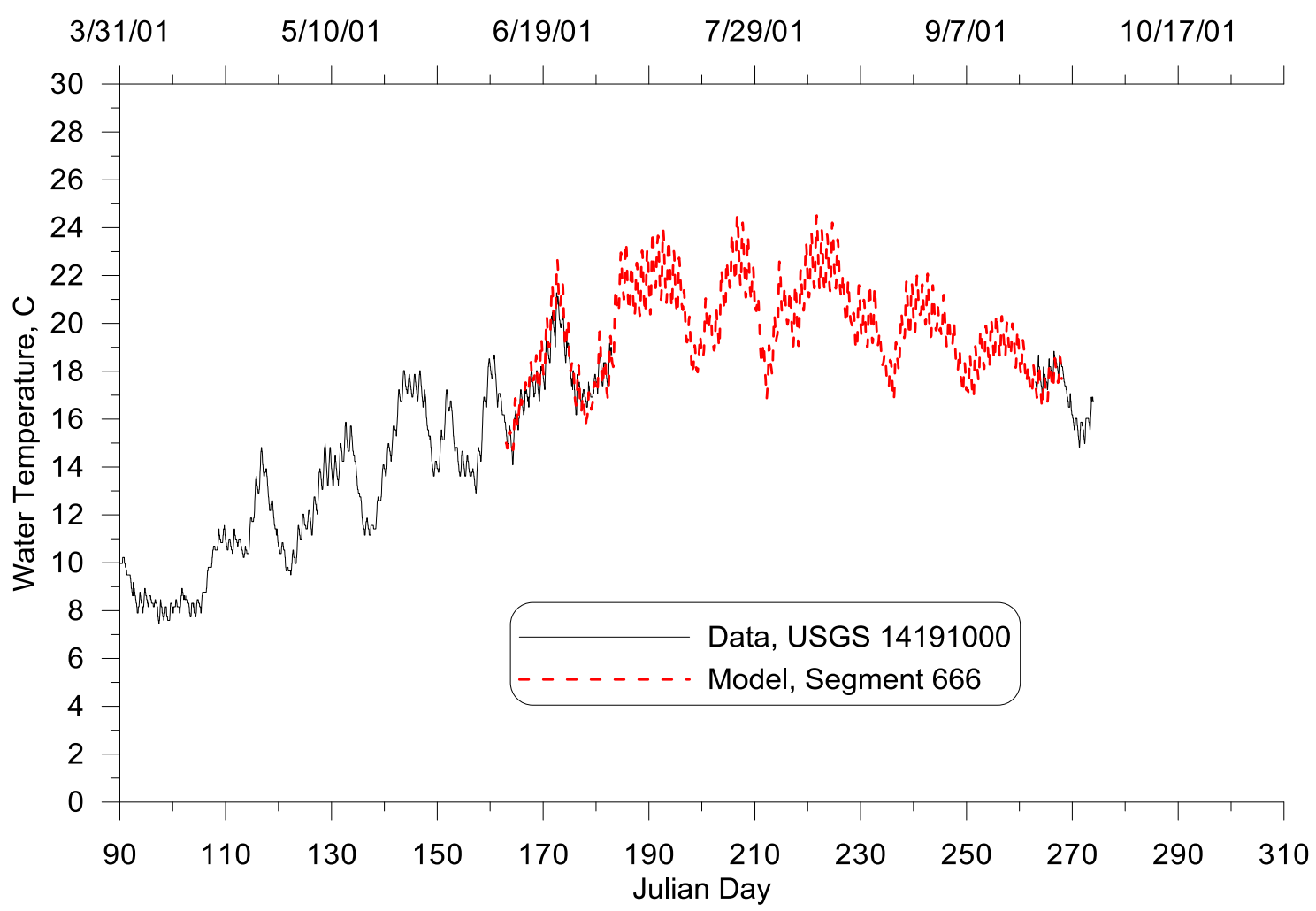

Figure 119: Upper Willamette River at Salem model-data continuous temperature comparison, 2001 


\section{Year 2002}

Figure 120 through 130 show the continuous temperature comparison between model predictions and measured data. Error statistics are summarized in Table 13. Predicted temperature matched data very well for all the 10 sites with the RMSEs below $0.73{ }^{\circ} \mathrm{C}$.

Table 13: Upper Willamette River continuous water temperature calibration model-data error statistics, 2002

\begin{tabular}{|c|c|c|c|c|c|c|}
\hline \multirow{2}{*}{ Site ID } & \multirow{2}{*}{ RM } & \multirow{2}{*}{\begin{tabular}{c} 
Model \\
\cline { 4 - 7 }
\end{tabular}} & & \multicolumn{4}{|c|}{ Continuous Temperature } \\
\cline { 4 - 7 } & & $\begin{array}{c}\text { Number of } \\
\text { Comparisons }\end{array}$ & ME, ${ }^{\circ} \mathrm{C}$ & AME, ${ }^{\circ} \mathrm{C}$ & \multirow{2}{*}{ RMSE, ${ }^{\circ} \mathrm{C}$} \\
\hline LASAR 10359 & 185.3 & 2 & 5761 & 0.009 & 0.141 & 0.17 \\
\hline LASAR 28723 & 177.7 & 53 & 4152 & -0.163 & 0.515 & 0.647 \\
\hline USGS 14166000 & 162.0 & 156 & 8303 & -0.373 & 0.591 & 0.717 \\
\hline LASAR 26755 & 151.6 & 227 & 5959 & -0.403 & 0.485 & 0.601 \\
\hline LASAR 26753 & 147.4 & 255 & 5955 & -0.222 & 0.422 & 0.534 \\
\hline LASAR 26772 & 142.4 & 287 & 4077 & -0.393 & 0.537 & 0.658 \\
\hline LASAR 10353 & 135.2 & 334 & 4063 & -0.317 & 0.469 & 0.581 \\
\hline USGS 14174000 & 120.2 & 434 & 8303 & -0.493 & 0.569 & 0.729 \\
\hline LASAR 10349 & 113.9 & 476 & 5993 & -0.447 & 0.501 & 0.628 \\
\hline LASAR 10347 & 96.9 & 589 & 5665 & -0.401 & 0.439 & 0.536 \\
\hline LASAR 28254 & 88.9 & 643 & 2688 & -0.425 & 0.543 & 0.689 \\
\hline
\end{tabular}




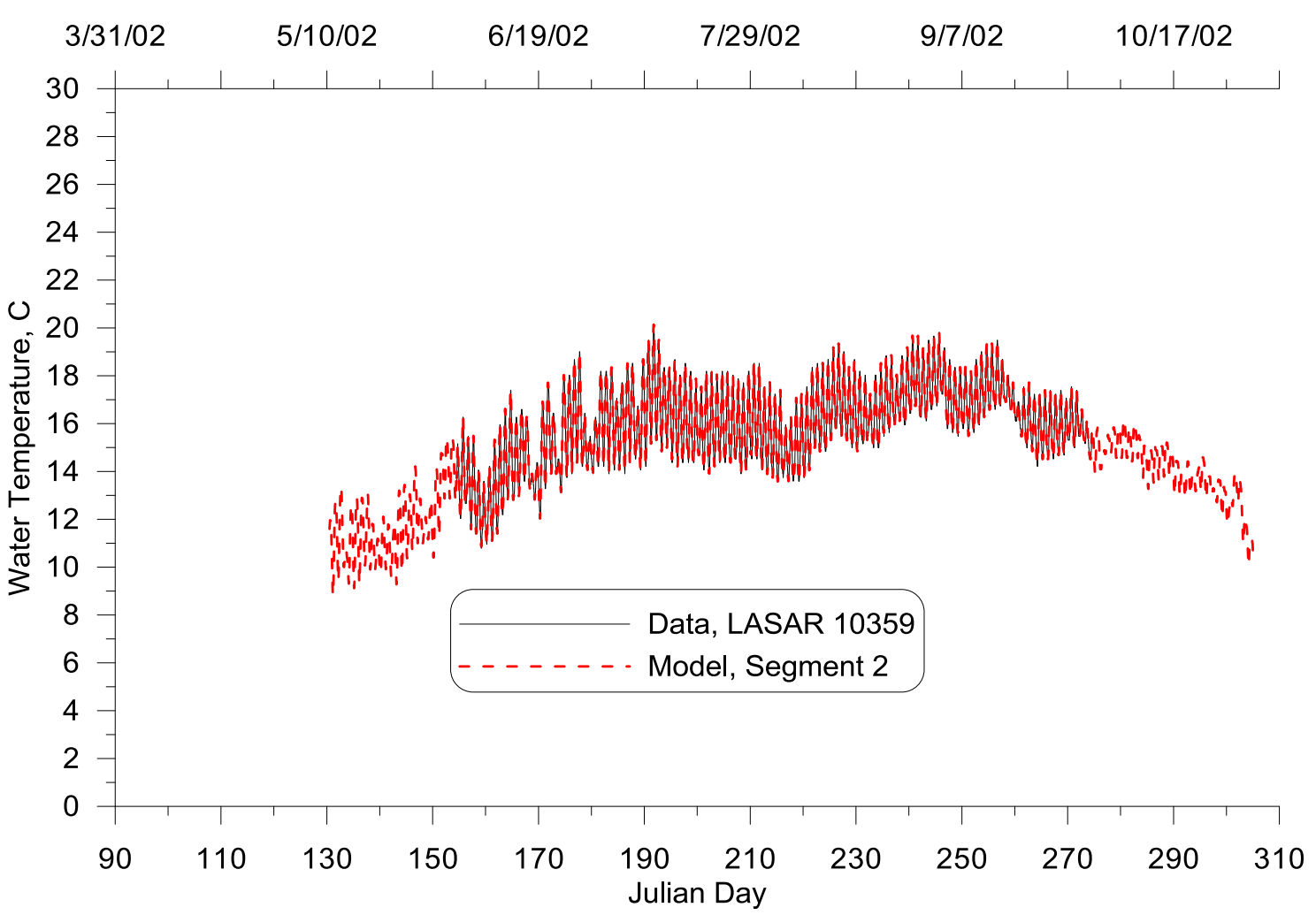

Figure 120: Upper Willamette River near Springfield model-data continuous temperature comparison, 2002

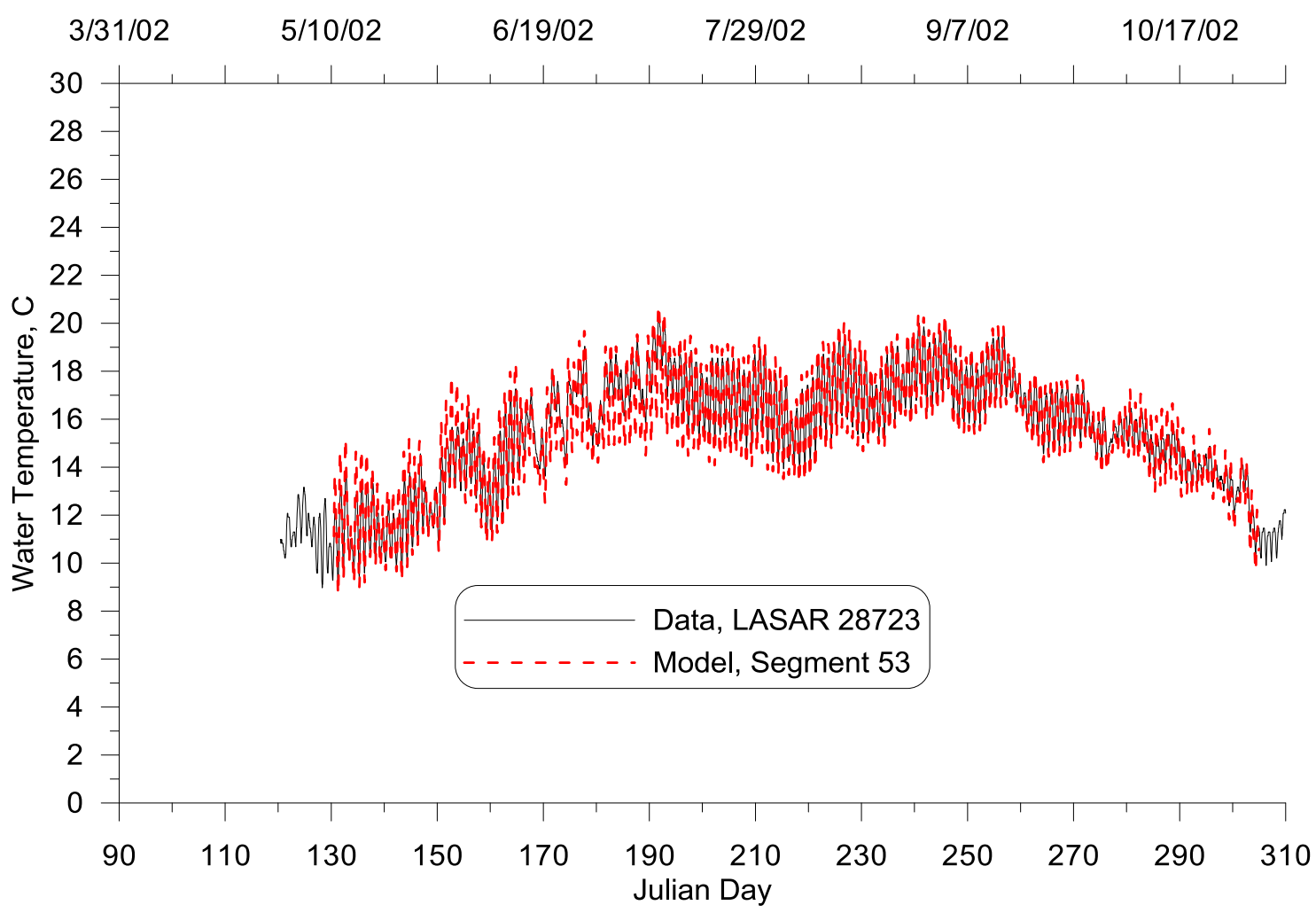

Figure 121: Upper Willamette River above McKenzie River model-data continuous temperature comparison, 2002 


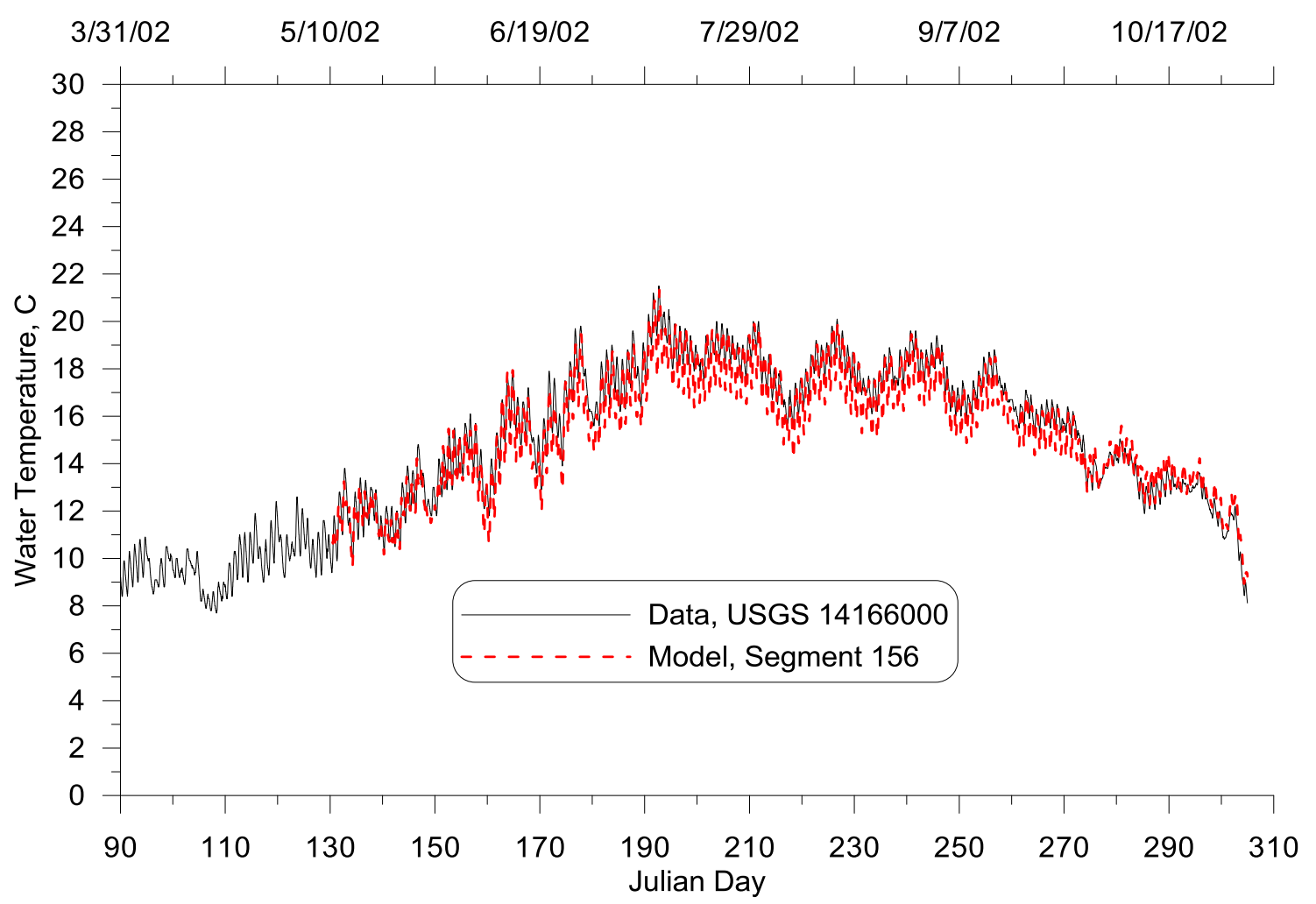

Figure 122: Upper Willamette River at Harrisburg model-data continuous temperature comparison, 2002

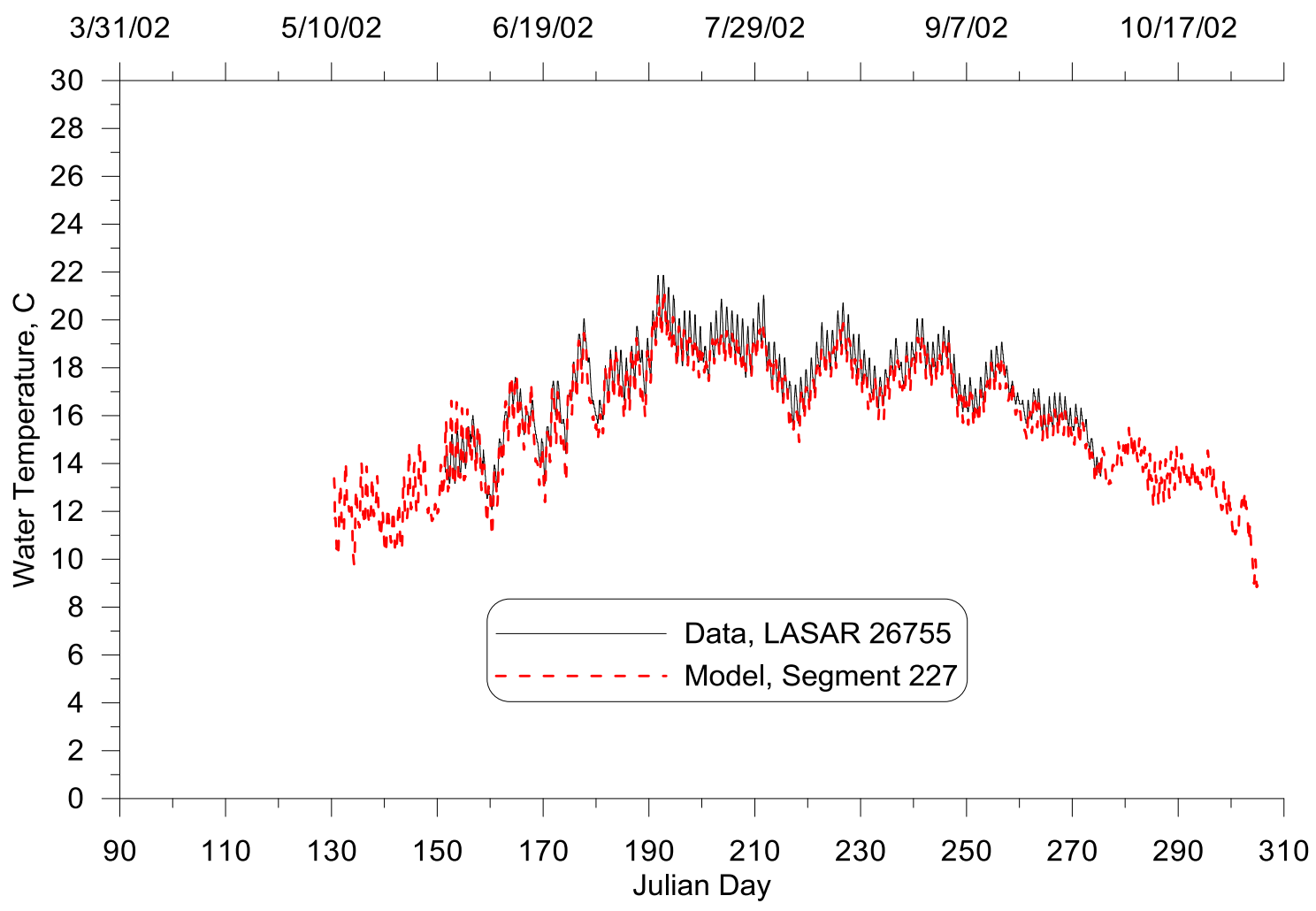

Figure 123: Upper Willamette River above Long Tom River model-data continuous temperature comparison, 2002 


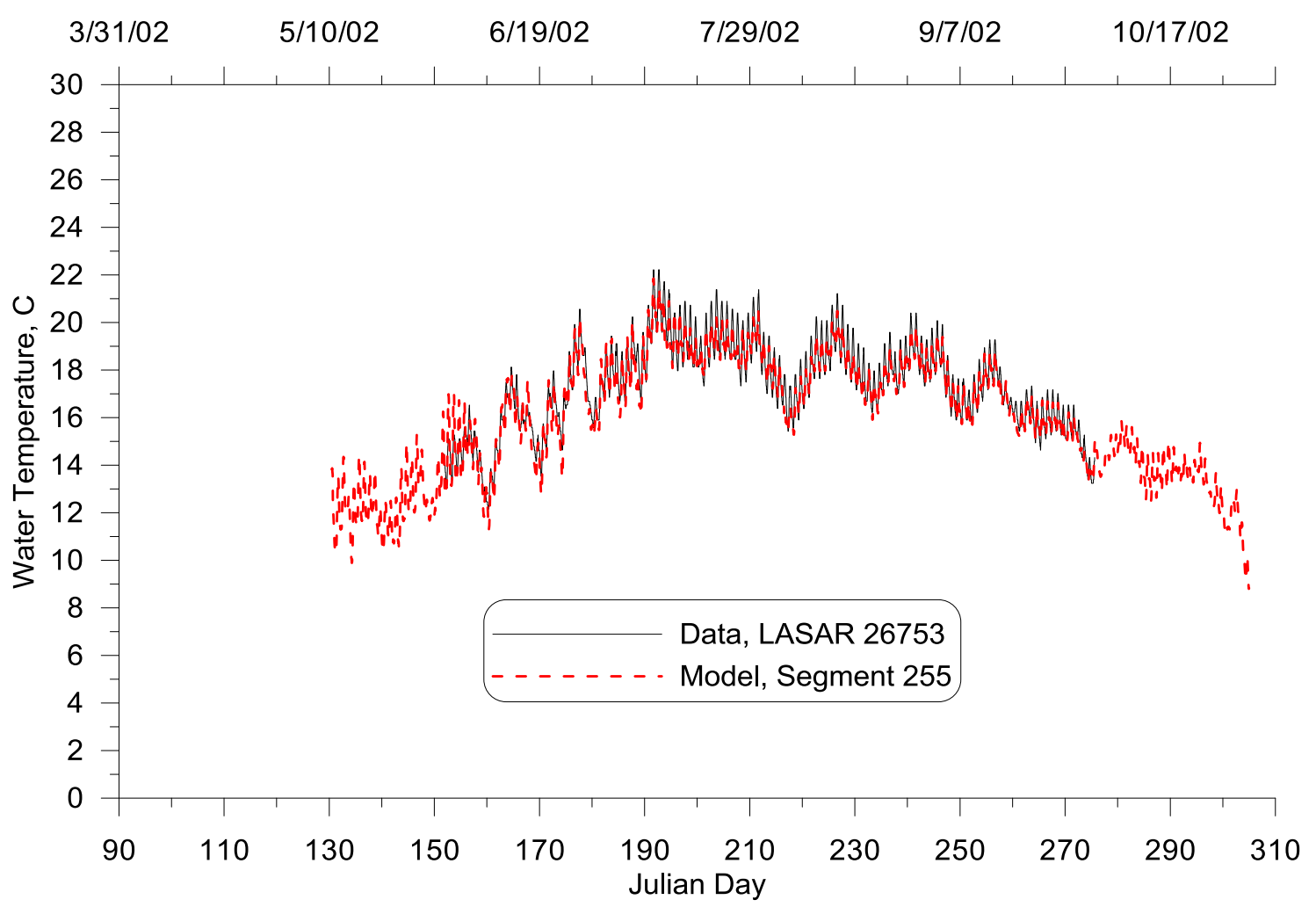

Figure 124: Upper Willamette River at RM 147.4 model-data continuous temperature comparison, 2002

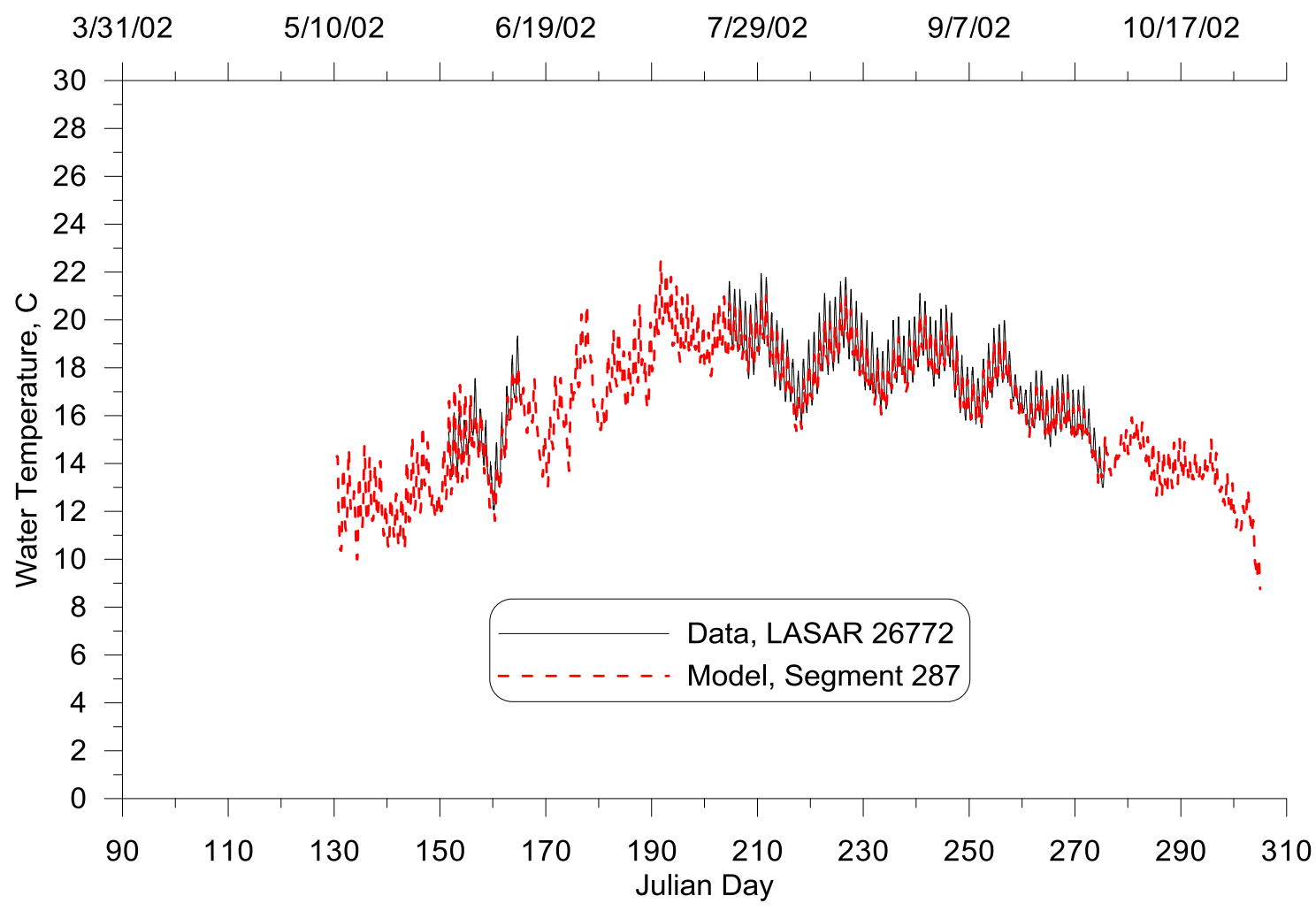

Figure 125: Upper Willamette River at RM 142.4 model-data continuous temperature comparison, 2002 


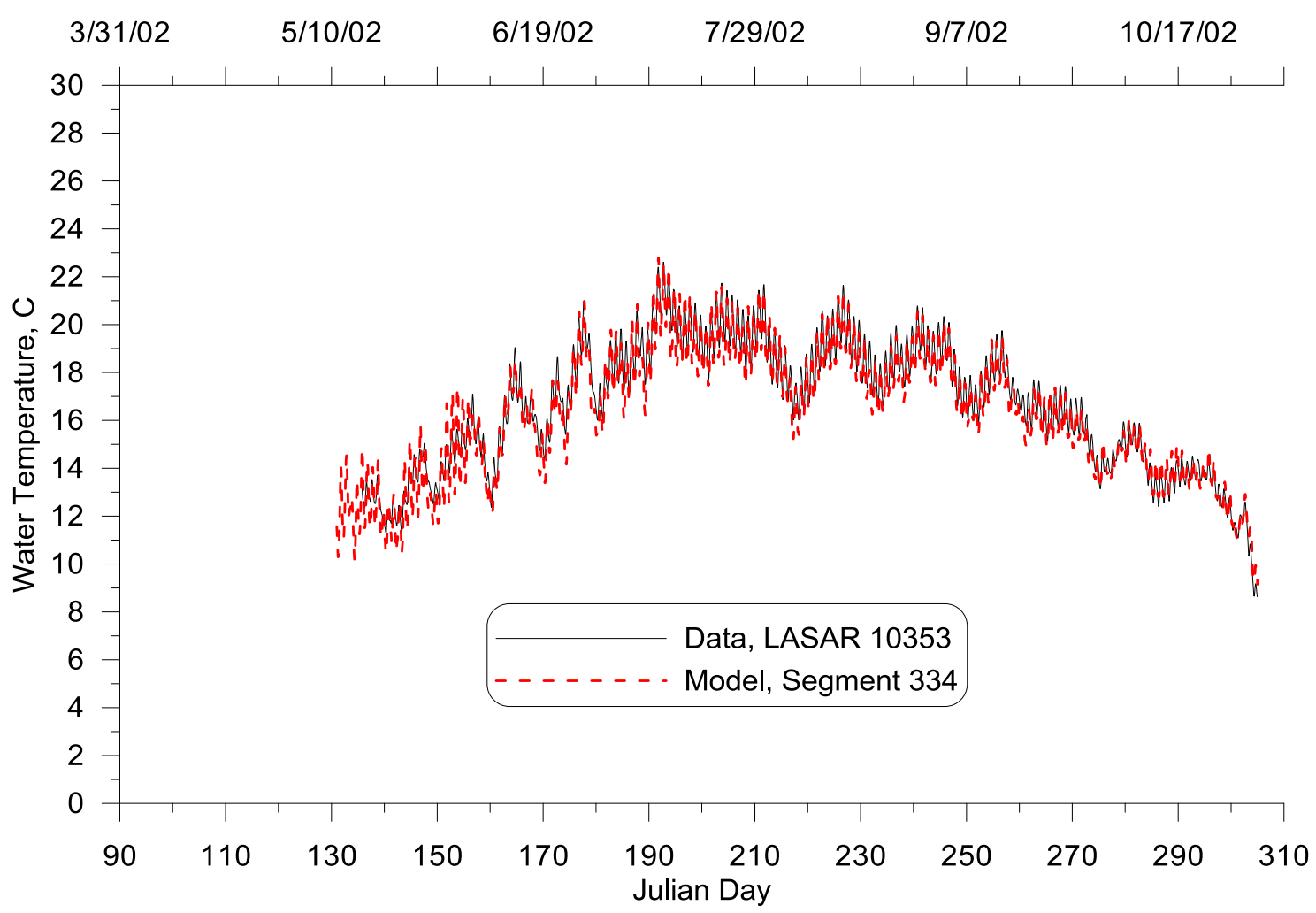

Figure 126: Upper Willamette River at Corvallis model-data continuous temperature comparison, 2002

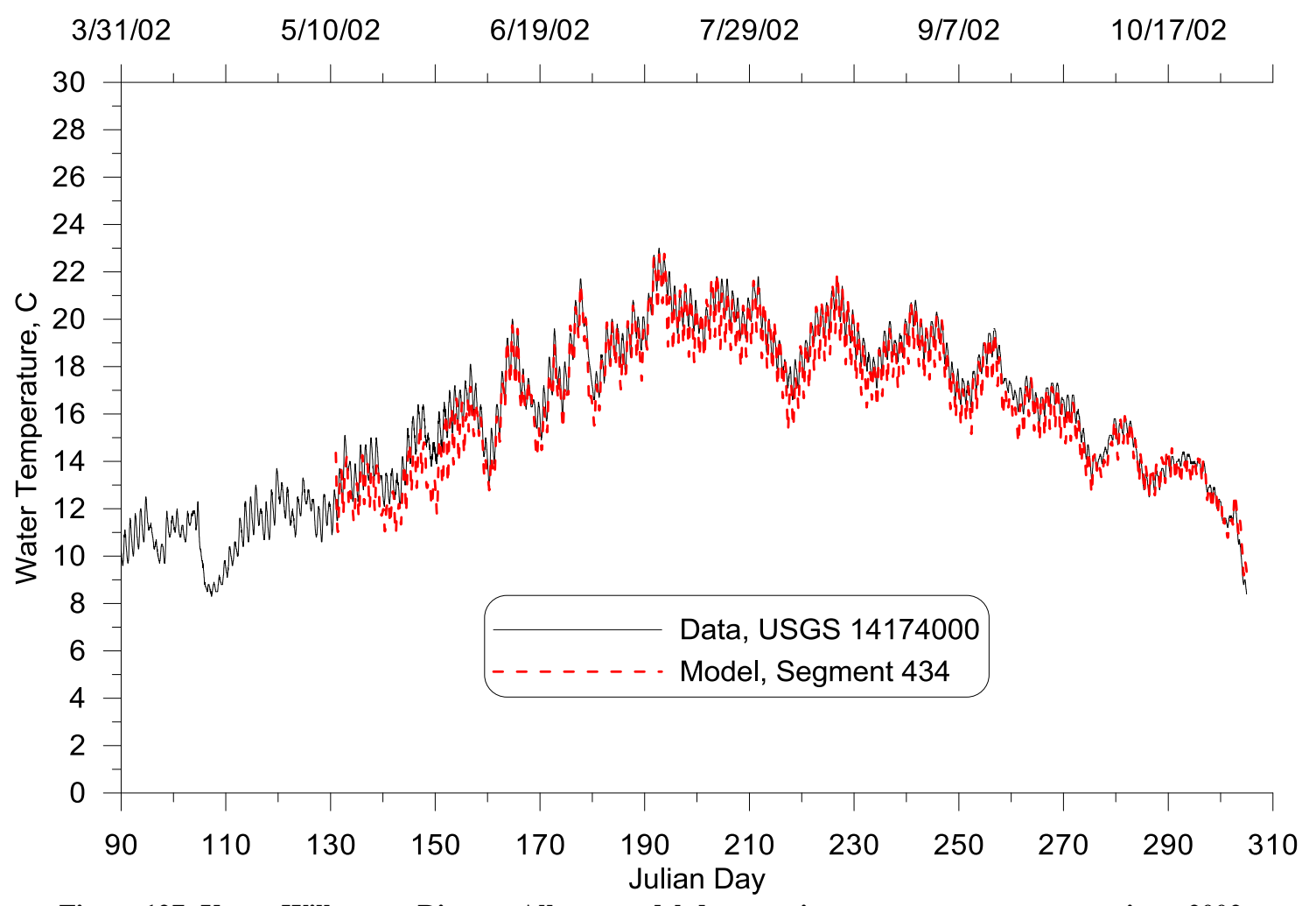

Figure 127: Upper Willamette River at Albany model-data continuous temperature comparison, 2002 


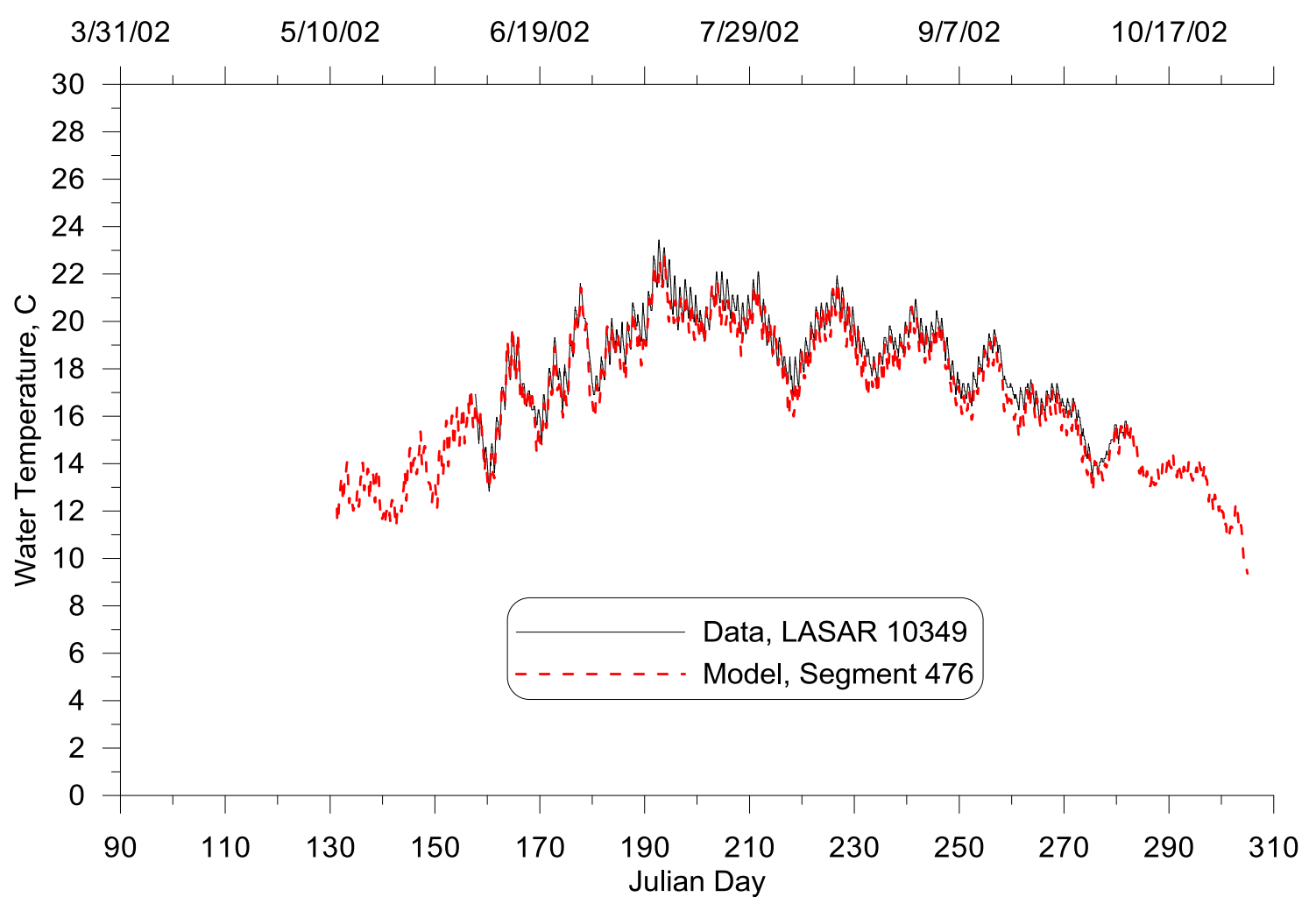

Figure 128: Upper Willamette River at Conser Rd model-data continuous temperature comparison, 2002

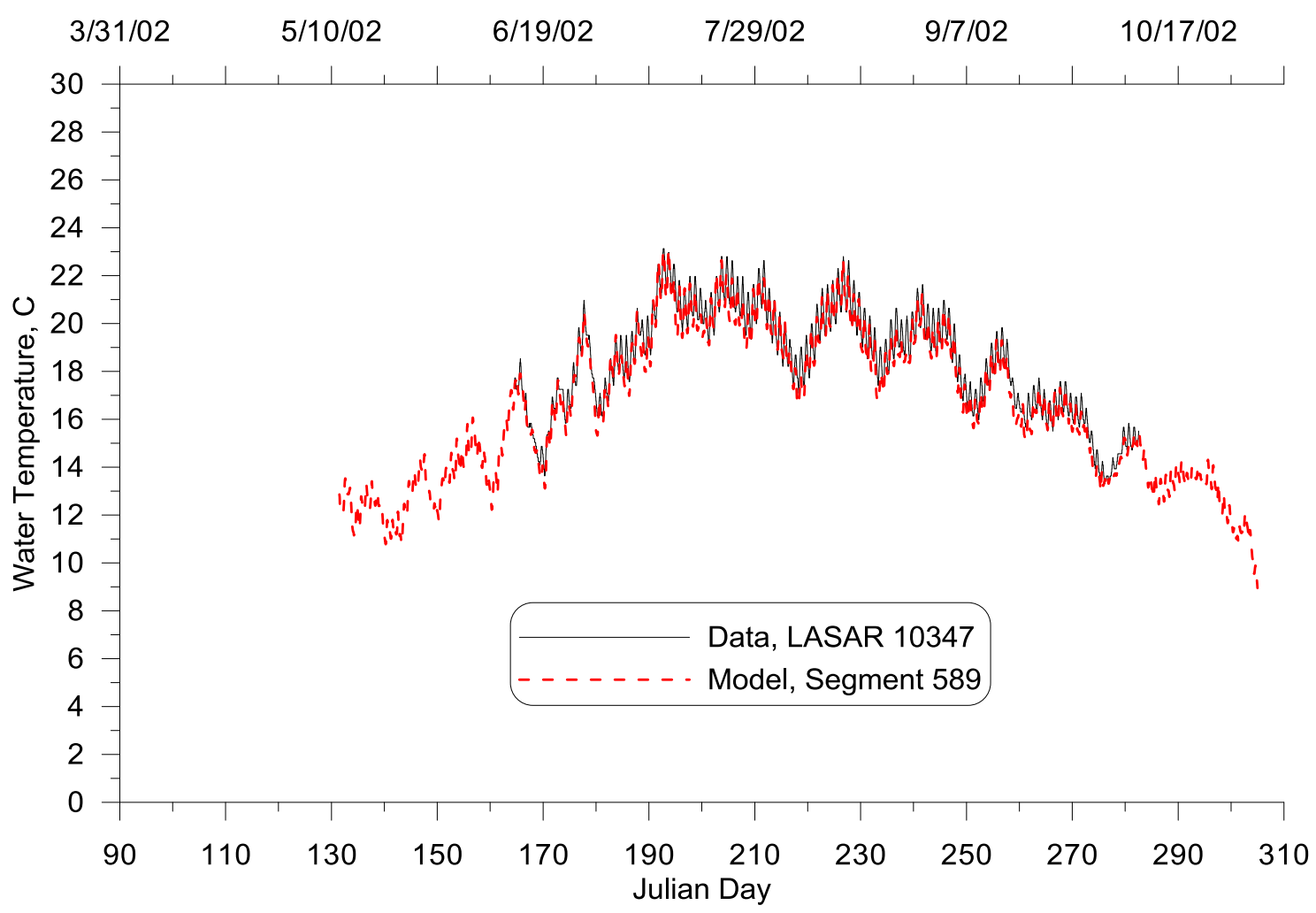

Figure 129: Upper Willamette River at South River Rd model-data continuous temperature comparison, 2002 


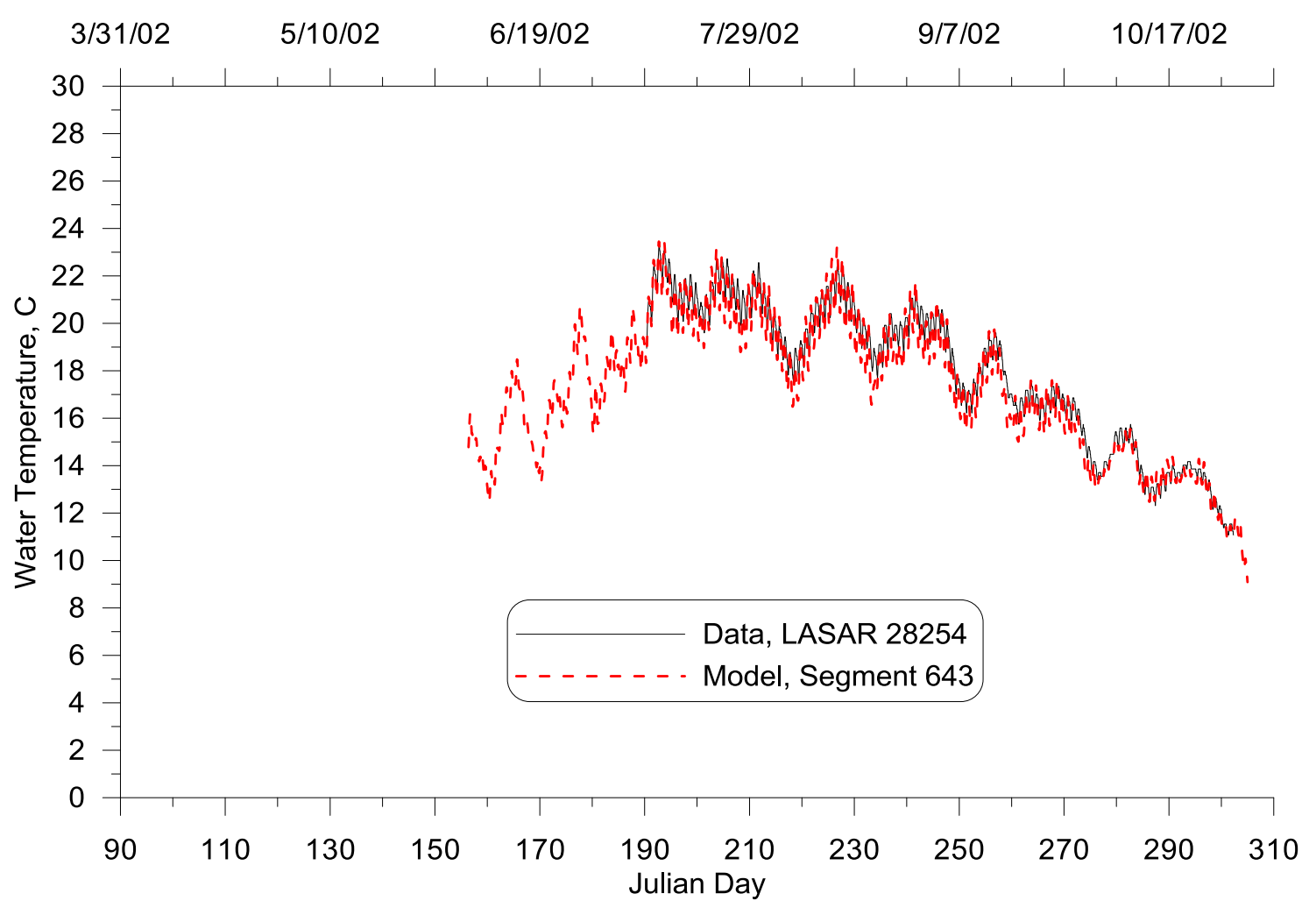

Figure 130: Upper Willamette River above Rickreall Creek model-data continuous temperature comparison, 2002 


\subsubsection{Clackamas River}

\section{Introduction}

Clackamas River is a right-bank tributary of Willamette River. Following the original set up in Clackamas River V3.1 model, Clackamas River V3.7 model was built from Rivermill Reservoir (RM 22.6) to the river's confluence with the Willamette River (RM 0). The model consists of 2 branches, 149 segments, and 40 layers. The model grid is shown in Figure 131.

Clackamas River V3.7 model calibration period is from April 1 to September 30 in 2001 and from April 1 to October in 2002.

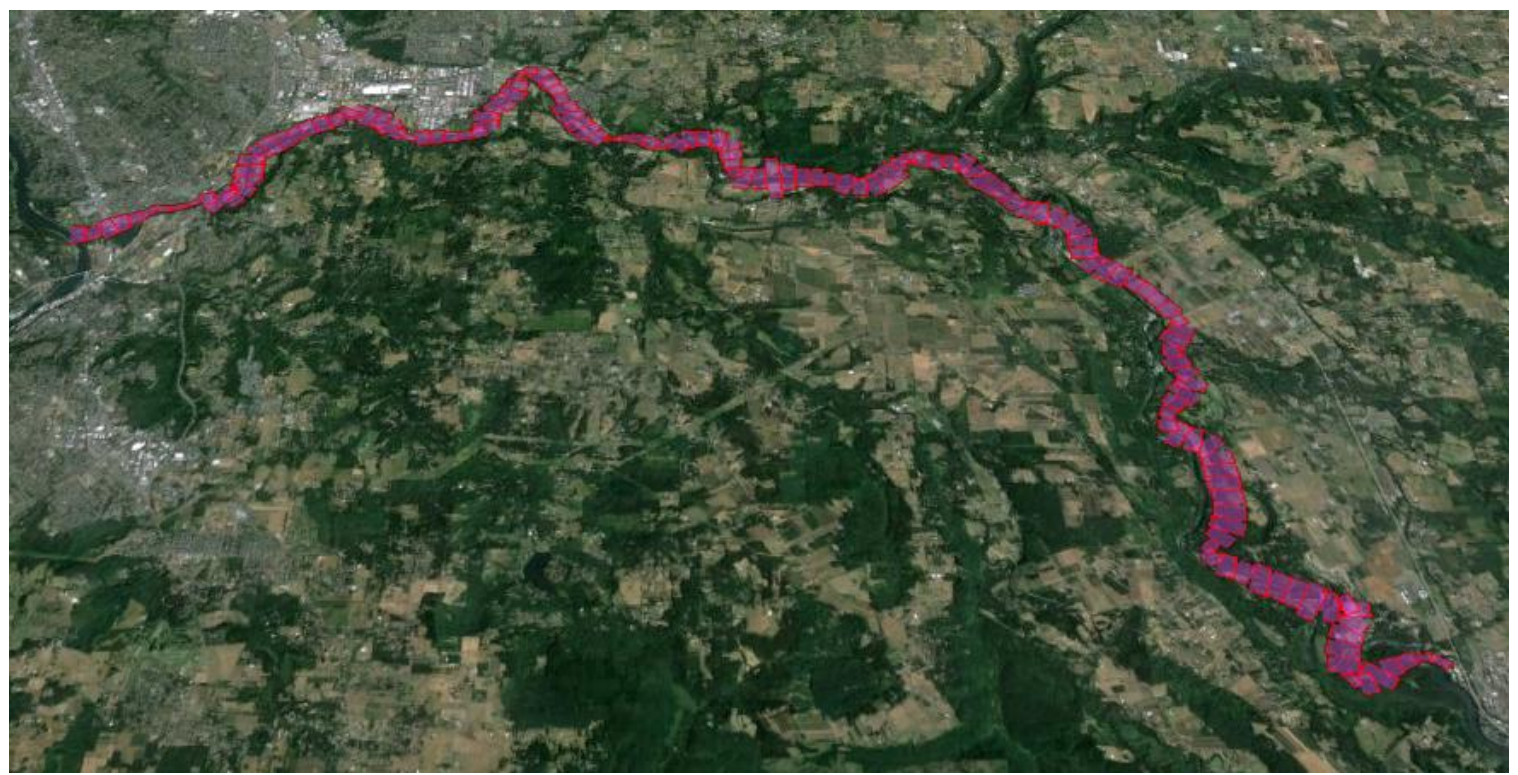

Figure 131: Clackamas River model grid

\section{Hydrodynamics}


Flow rate and water surface elevation was first tested using the original setting in V3.1 model. As the model showed good agreement with data, no further calibrations were conducted.

\section{Year 2001}

Figure 132 through 135 show the water level and flow comparison between model predictions and measured data. Error statistics are summarized in Table 14.

The flow predictions matched well with data for the both sites. For the water level at segment 2, however, the model over estimated at high flow conditions, and under estimated at low flow conditions. The 1-meter layer depth might result in coarse bathymetry and led this problem to occur. Similar problem existed in V3.1 model, but was not as severe as in V3.7 model.

Table 14: Clackamas River hydrodynamic calibration statistics, 2001

\begin{tabular}{|c|c|c|c|c|c|c|}
\hline \multicolumn{7}{|c|}{ Flow } \\
\hline Gage ID & RM & $\begin{array}{c}\text { Model } \\
\text { Segment }\end{array}$ & $\begin{array}{c}\text { Number of } \\
\text { Comparisons }\end{array}$ & $\mathrm{ME}, \mathrm{m}^{3} / \mathrm{s}$ & $\mathrm{AME}, \mathrm{m}^{3} / \mathrm{s}$ & RMSE, $\mathrm{m}^{3} / \mathrm{s}$ \\
\hline USGS 14210000 & 22.22 & 2 & 8664 & 0.021 & 0.564 & 1.169 \\
\hline USGS 14211010 & 2.41 & 133 & 5380 & -0.004 & 1.213 & 2.192 \\
\hline \multicolumn{7}{|c|}{ Water Level } \\
\hline Gage ID & $\mathrm{RM}$ & $\begin{array}{c}\text { Model } \\
\text { Segment }\end{array}$ & $\begin{array}{c}\text { Number of } \\
\text { Comparisons }\end{array}$ & ME, $\mathrm{m}$ & AME, $\mathrm{m}$ & RMSE, $\mathrm{m}$ \\
\hline USGS 14210000 & 22.22 & 2 & 8664 & -0.314 & 0.539 & 0.619 \\
\hline USGS 14211010 & 2.41 & 133 & 5380 & -0.078 & 0.098 & 0.11 \\
\hline
\end{tabular}




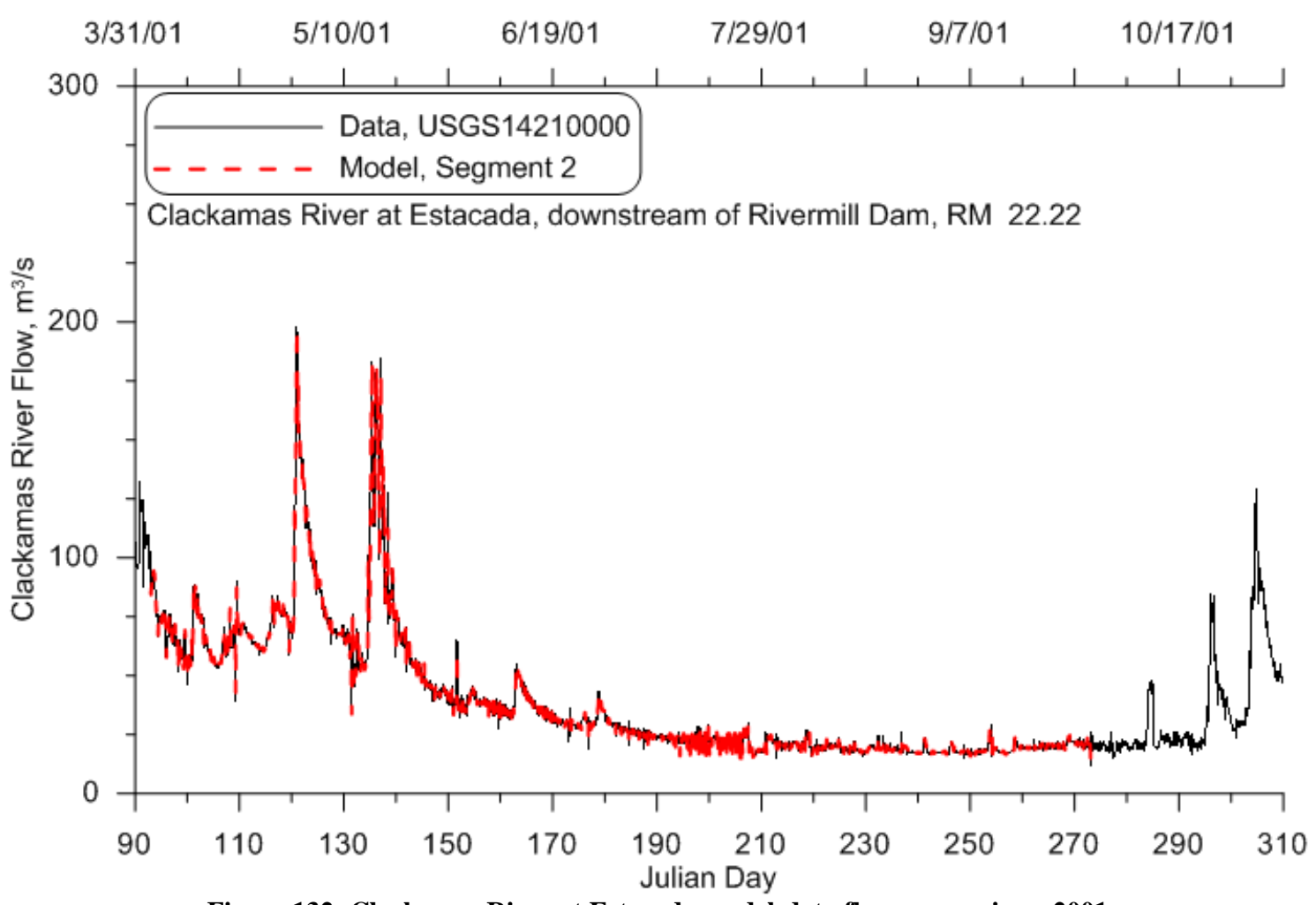

Figure 132: Clackamas River at Estacada model-data flow comparison, 2001

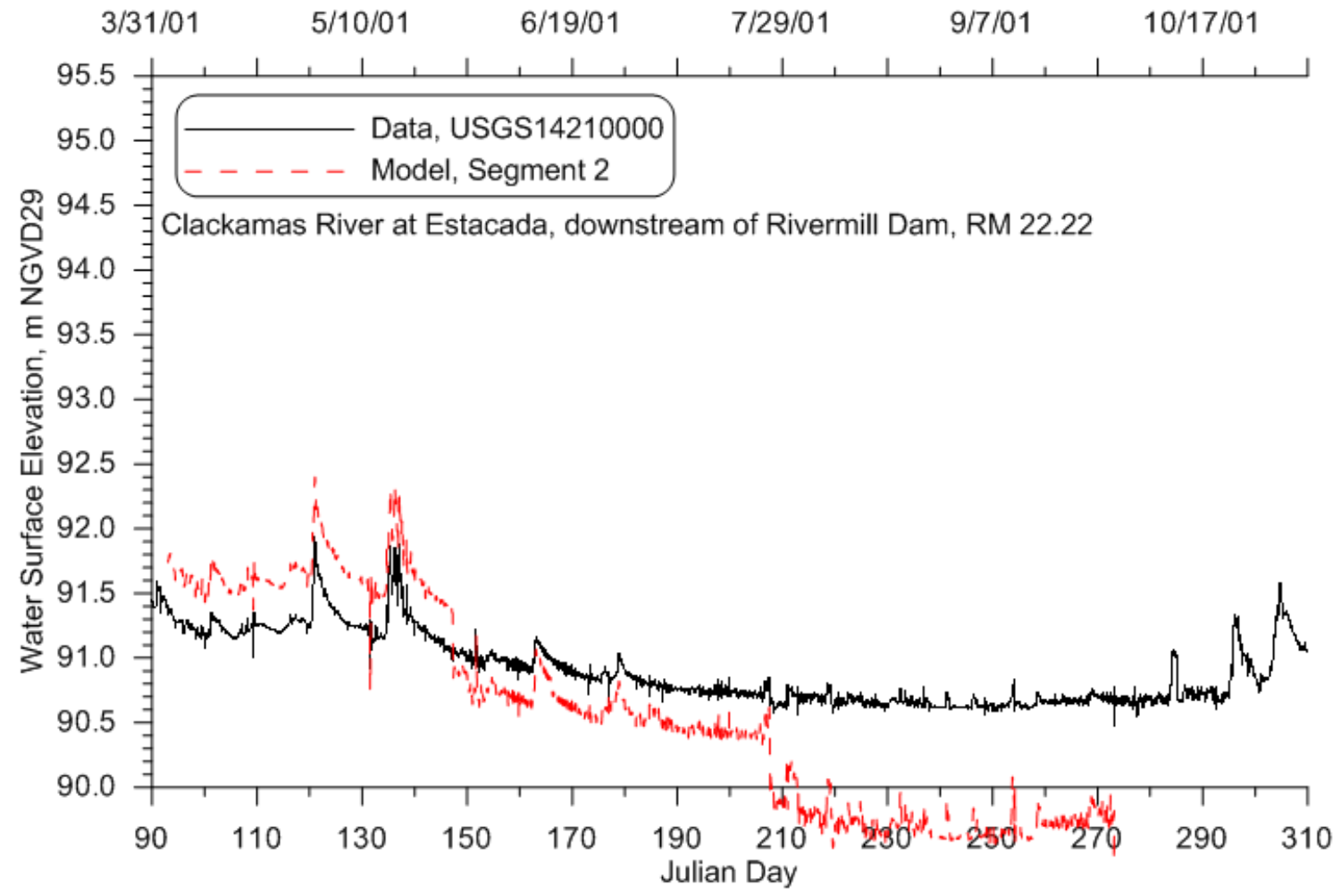

Figure 133: Clackamas River at Estacada model-data water level comparison, 2001 


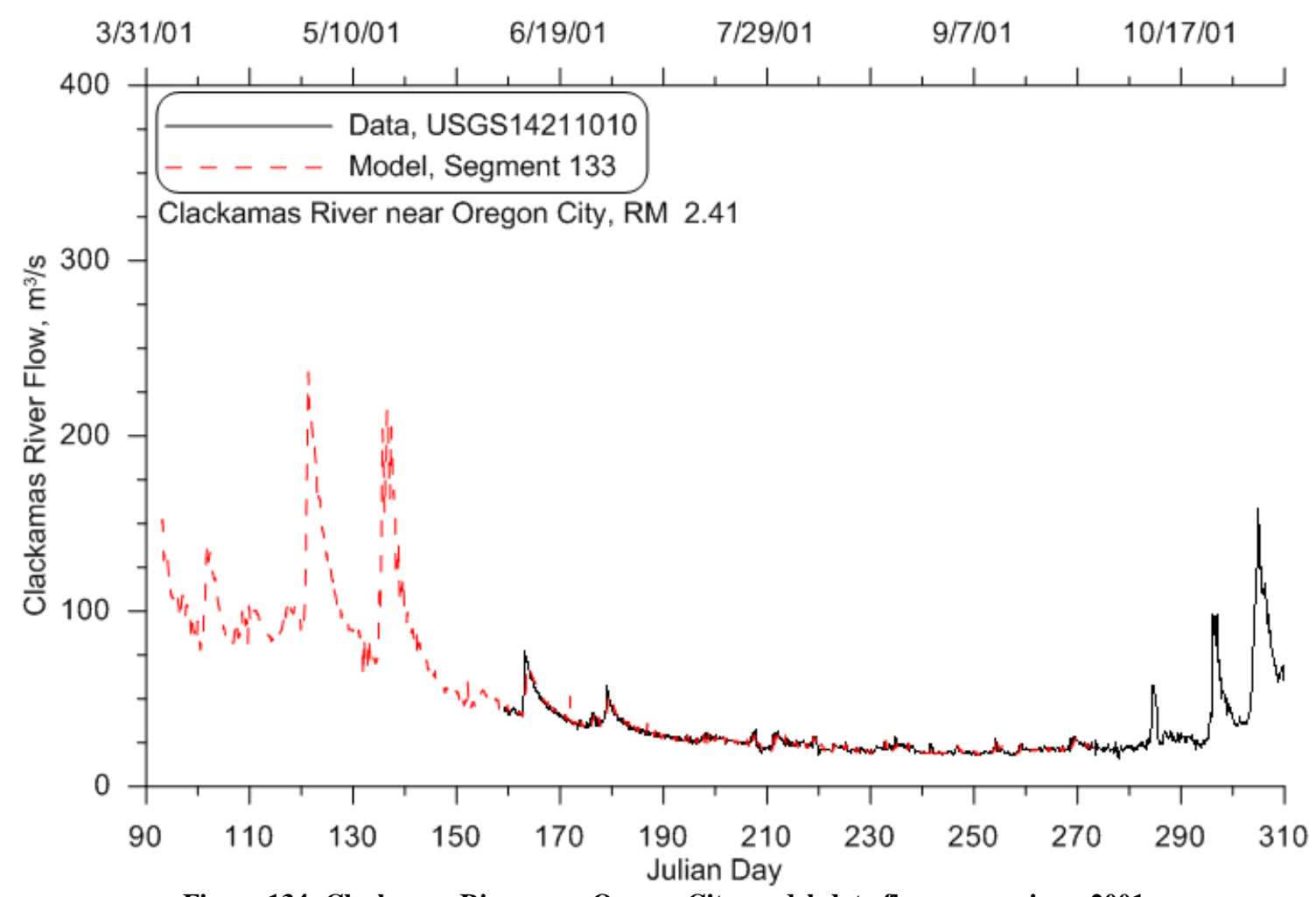

Figure 134: Clackamas River near Oregon City model-data flow comparison, 2001

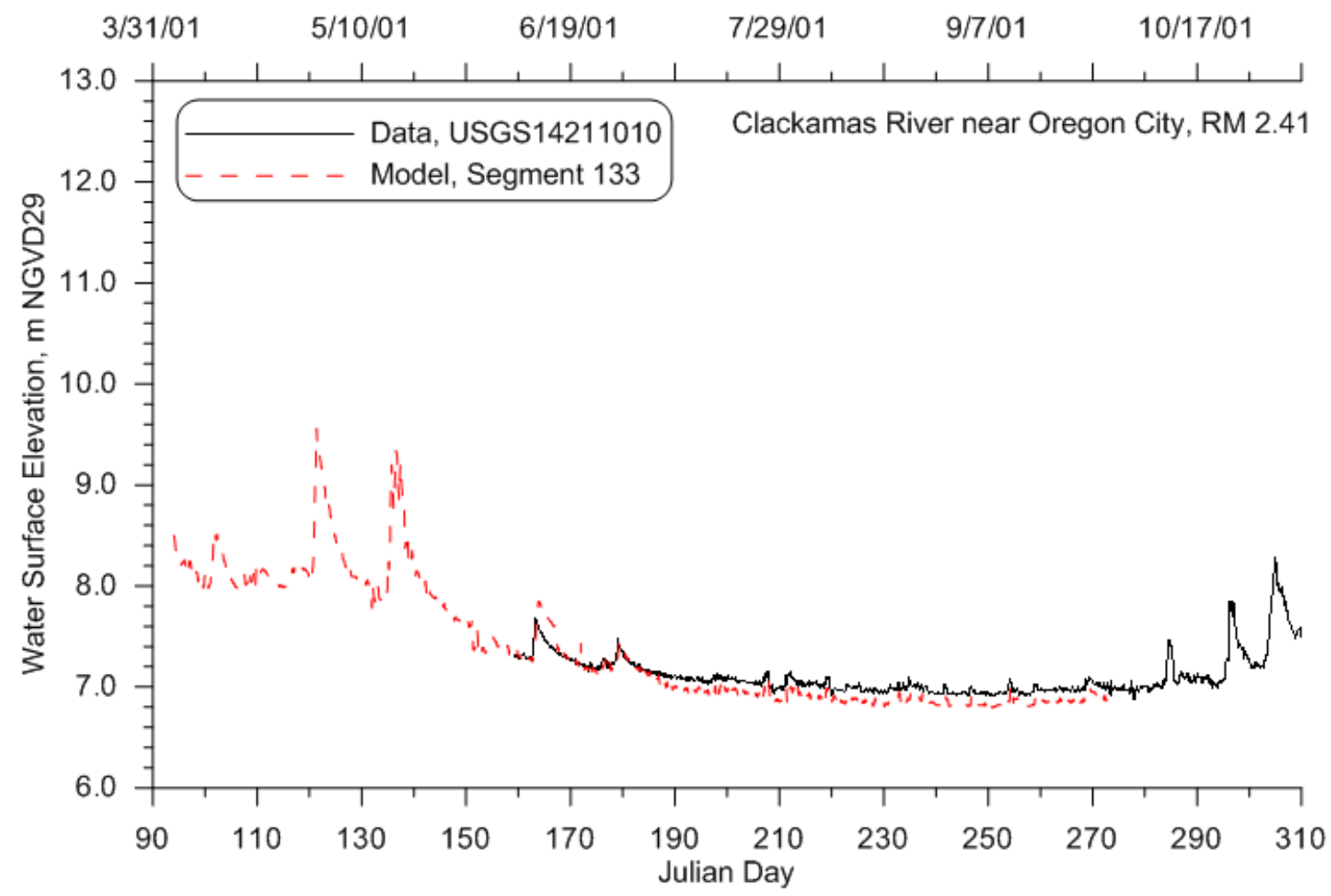

Figure 135: Clackamas River near Oregon City model-data water level comparison, 2001

\section{Year 2002}


The hydrodynamic calibration period in 2002 was from April to September. Figure 136 through 140 show the water level and flow comparison between model predictions and measured data. Error statistics are summarized in Table 15.

The model predicted rapidly changing flow rate in two periods in 2002 at Estacada (Segment 2), and resulted in oscillation of flow curve in Figure 136. This was caused by stability issues. The time step at these two unstable periods was 10s. Time step was then decreased to $5 \mathrm{~s}$, and the stability issues disappeared.

Table 15: Clackamas River hydrodynamic calibration statistics, 2002

\begin{tabular}{|c|c|c|c|c|c|c|}
\hline \multicolumn{7}{|c|}{ Flow } \\
\hline Gage ID & $\mathrm{RM}$ & $\begin{array}{c}\text { Model } \\
\text { Segment }\end{array}$ & $\begin{array}{c}\text { Number of } \\
\text { Comparisons }\end{array}$ & $\mathrm{ME}, \mathrm{m}^{3} / \mathrm{s}$ & AME, $\mathrm{m}^{3} / \mathrm{s}$ & RMSE, $\mathrm{m}^{3} / \mathrm{s}$ \\
\hline USGS 14210000 & 22.22 & 2 & 8679 & -0.148 & 0.573 & 2.65 \\
\hline USGS 14211010 & 2.41 & 133 & 8649 & 7.131 & 8.736 & 17.662 \\
\hline \multicolumn{7}{|c|}{ Water Level } \\
\hline Gage ID & RM & $\begin{array}{c}\text { Model } \\
\text { Segment }\end{array}$ & $\begin{array}{c}\text { Number of } \\
\text { Comparisons }\end{array}$ & ME, $m$ & AME, $m$ & RMSE, m \\
\hline USGS 14210000 & 22.22 & 2 & 8664 & 0.198 & 0.341 & 0.391 \\
\hline USGS 14211010 & 2.41 & 133 & 8687 & 0.244 & 0.245 & 0.338 \\
\hline
\end{tabular}




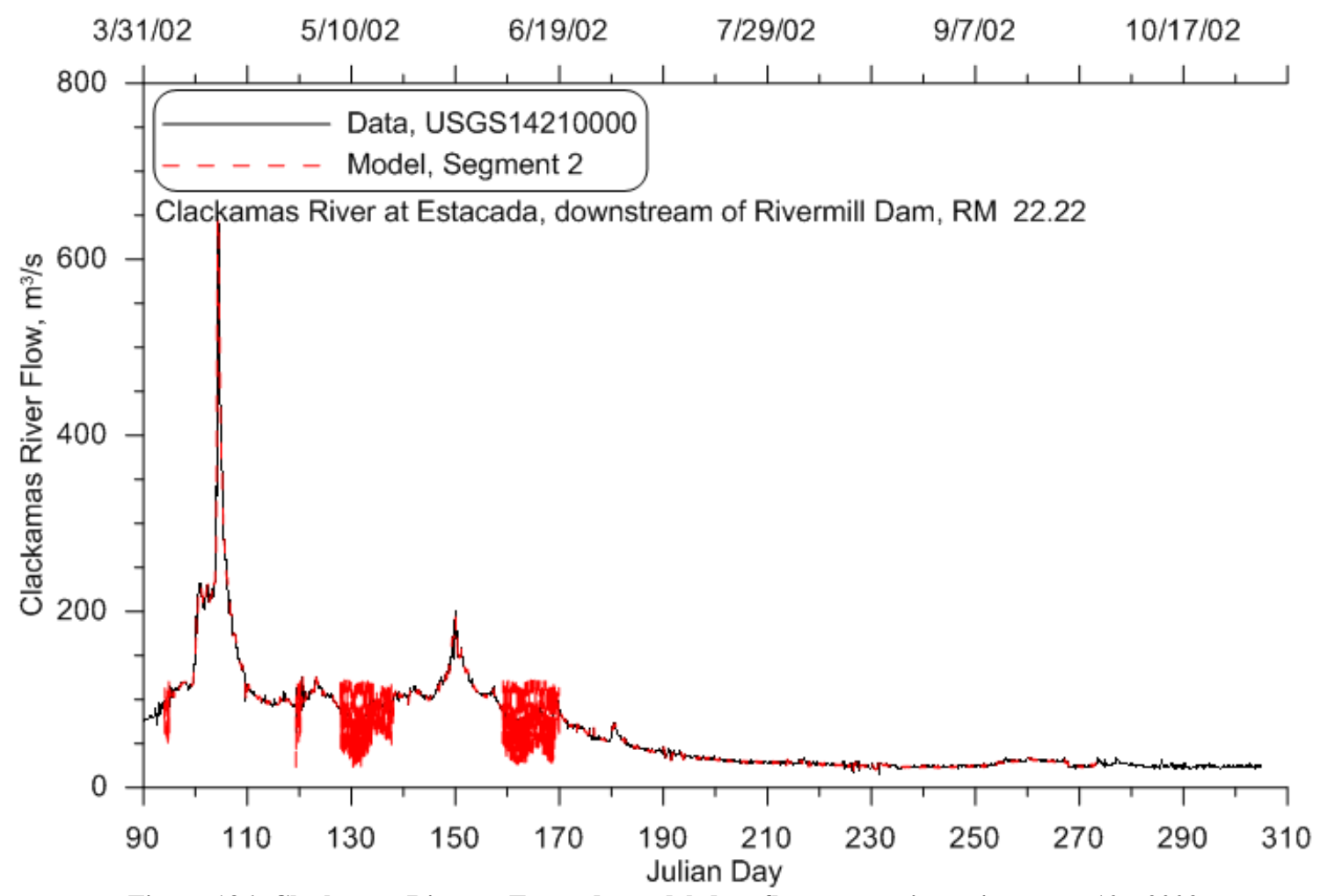

Figure 136: Clackamas River at Estacada model-data flow comparison, time step=10s, 2002

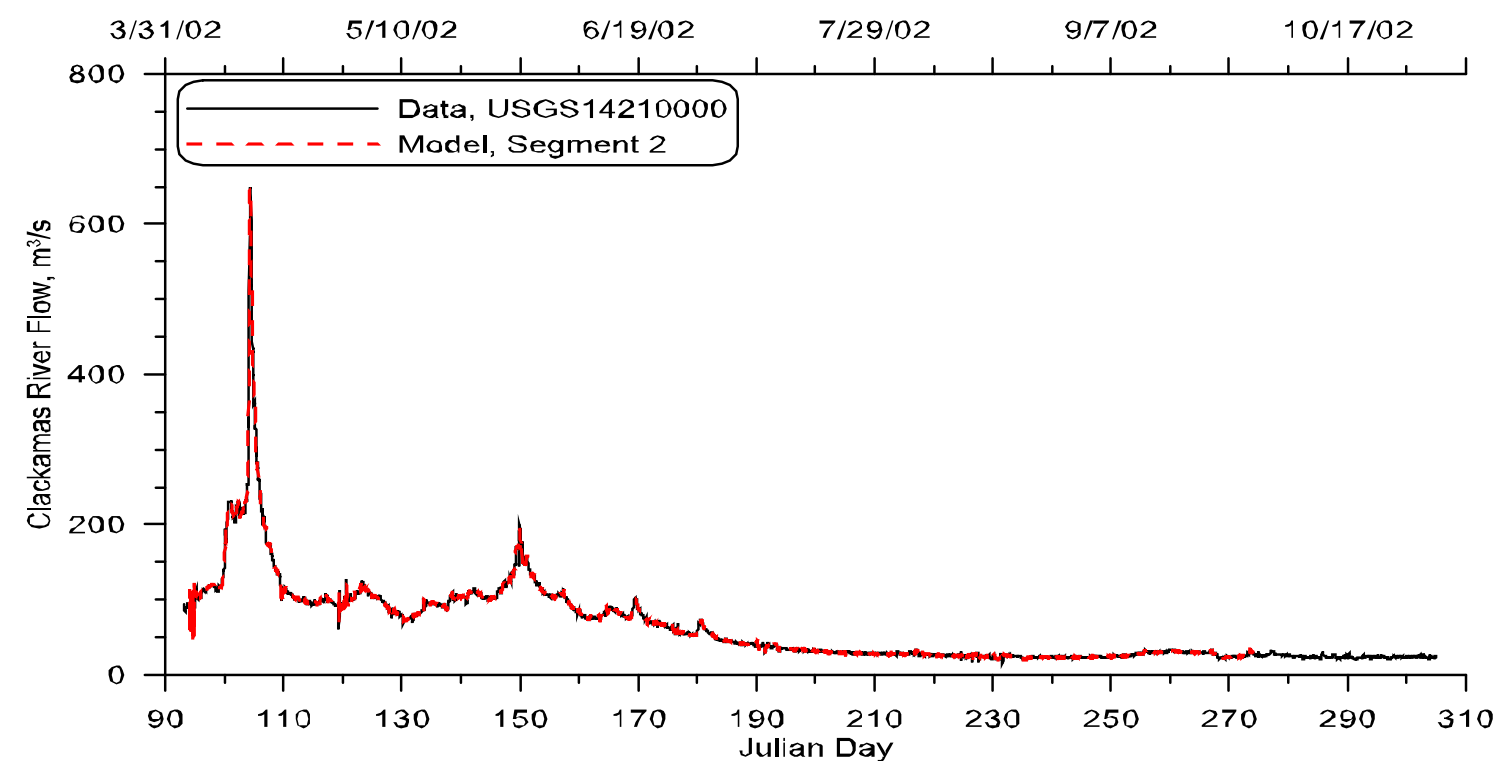

Figure 137: Clackamas River at Estacada model-data flow comparison, time step=5s, 2002 


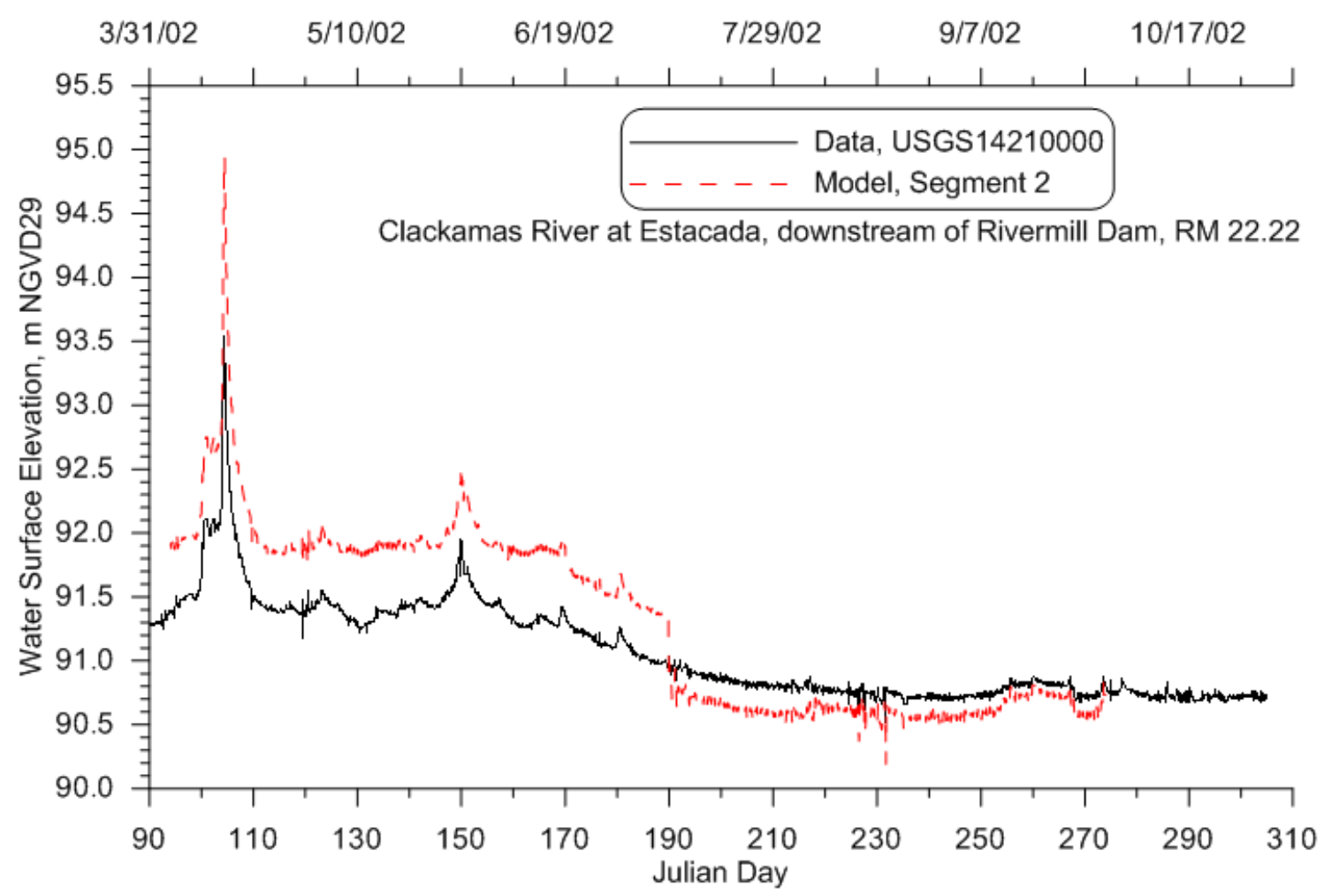

Figure 138: Clackamas River at Estacada model-data water level comparison, 2002

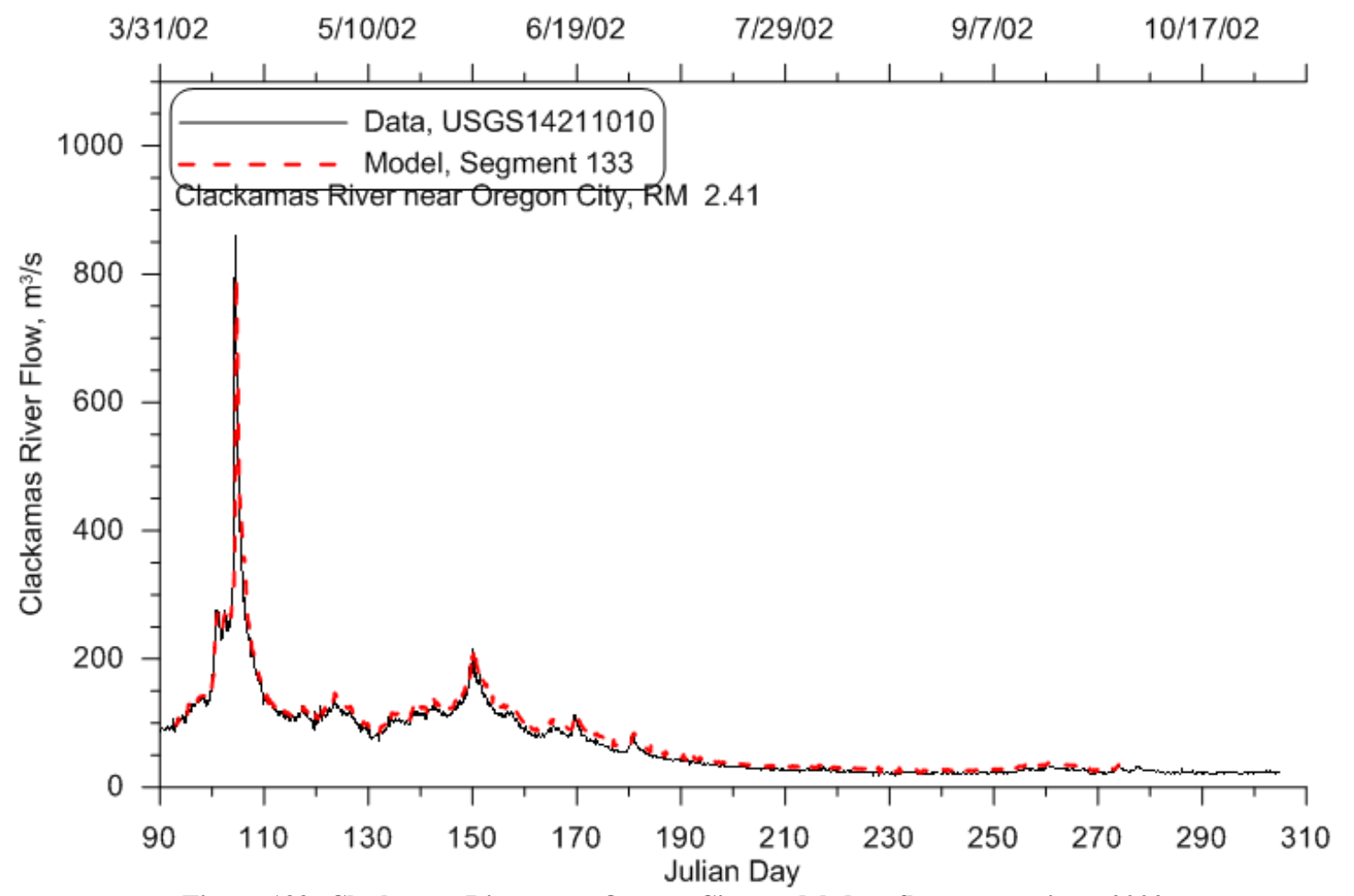

Figure 139: Clackamas River near Oregon City model-data flow comparison, 2002 


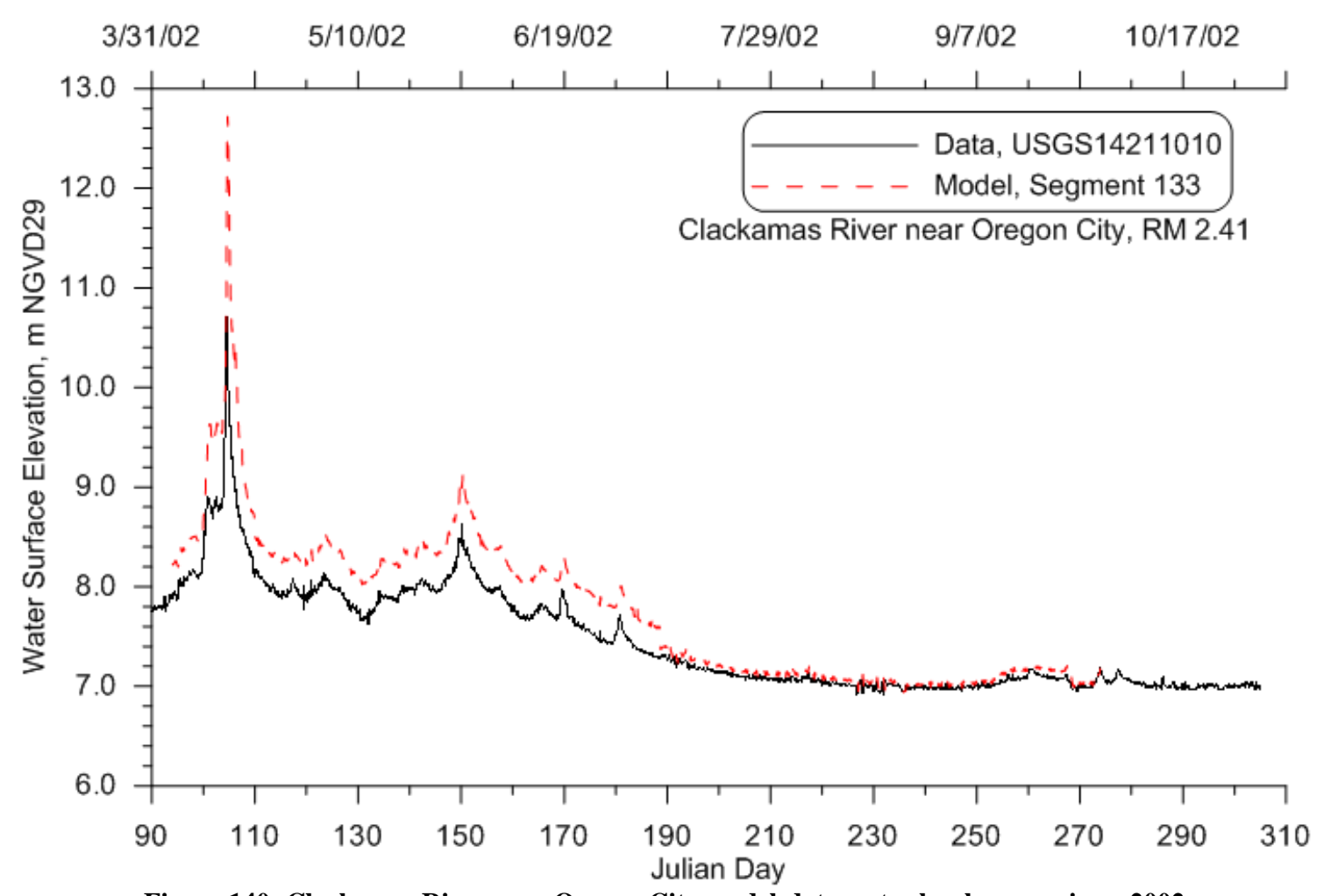

Figure 140: Clackamas River near Oregon City model-data water level comparison, 2002

\section{Temperature}

\section{Year 2001}

Figure 141 through 146 show the continuous temperature comparison between model predictions and measured data. Error statistics are summarized in Table 16. Predicted temperature matched data very well for all the 6 sites with the RMSEs below $1.04{ }^{\circ} \mathrm{C}$.

Table 16: Clackamas River continuous water temperature calibration model-data error statistics, 2001

\begin{tabular}{|c|c|c|c|c|c|c|}
\hline \multirow[t]{2}{*}{ Site ID } & \multirow[t]{2}{*}{ RM } & \multirow{2}{*}{$\begin{array}{l}\text { Model } \\
\text { Segment }\end{array}$} & \multicolumn{3}{|c|}{ Continuous Temperature } & \multirow[b]{2}{*}{ RMSE, ${ }^{\circ} \mathrm{C}$} \\
\hline & & & $\begin{array}{l}\text { Number of } \\
\text { Comparisons }\end{array}$ & $\mathrm{ME},{ }^{\circ} \mathrm{C}$ & AME, ${ }^{\circ} \mathrm{C}$ & \\
\hline USGS 14210000 & 22.22 & 2 & 3831 & 0.005 & 0.015 & 0.024 \\
\hline PGE CRMCIV & 20.64 & 12 & 3934 & 0.2 & 0.563 & 0.784 \\
\hline PGE CRUPEC & 16.30 & 41 & 4379 & 0.282 & 0.735 & 0.923 \\
\hline PGE CRBART & 13.25 & 60 & 3852 & -0.001 & 0.734 & 0.888 \\
\hline PGE CRATCB & 8.11 & 93 & 4306 & 0.07 & 0.778 & 0.955 \\
\hline PGE CRATOC & 2.41 & 133 & 4379 & -0.087 & 0.823 & 1.033 \\
\hline
\end{tabular}




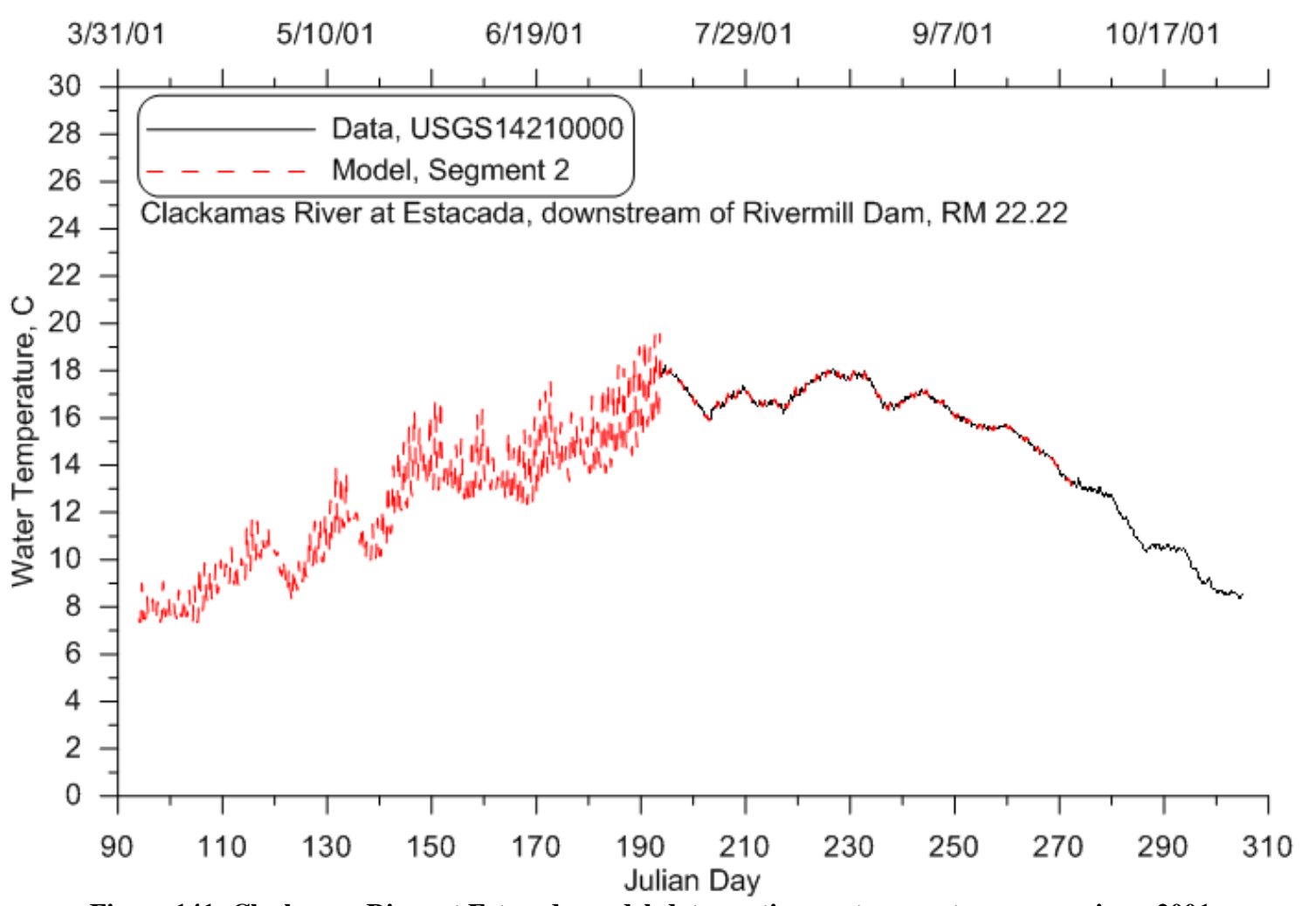

Figure 141: Clackamas River at Estacada model-data continuous temperature comparison, 2001 


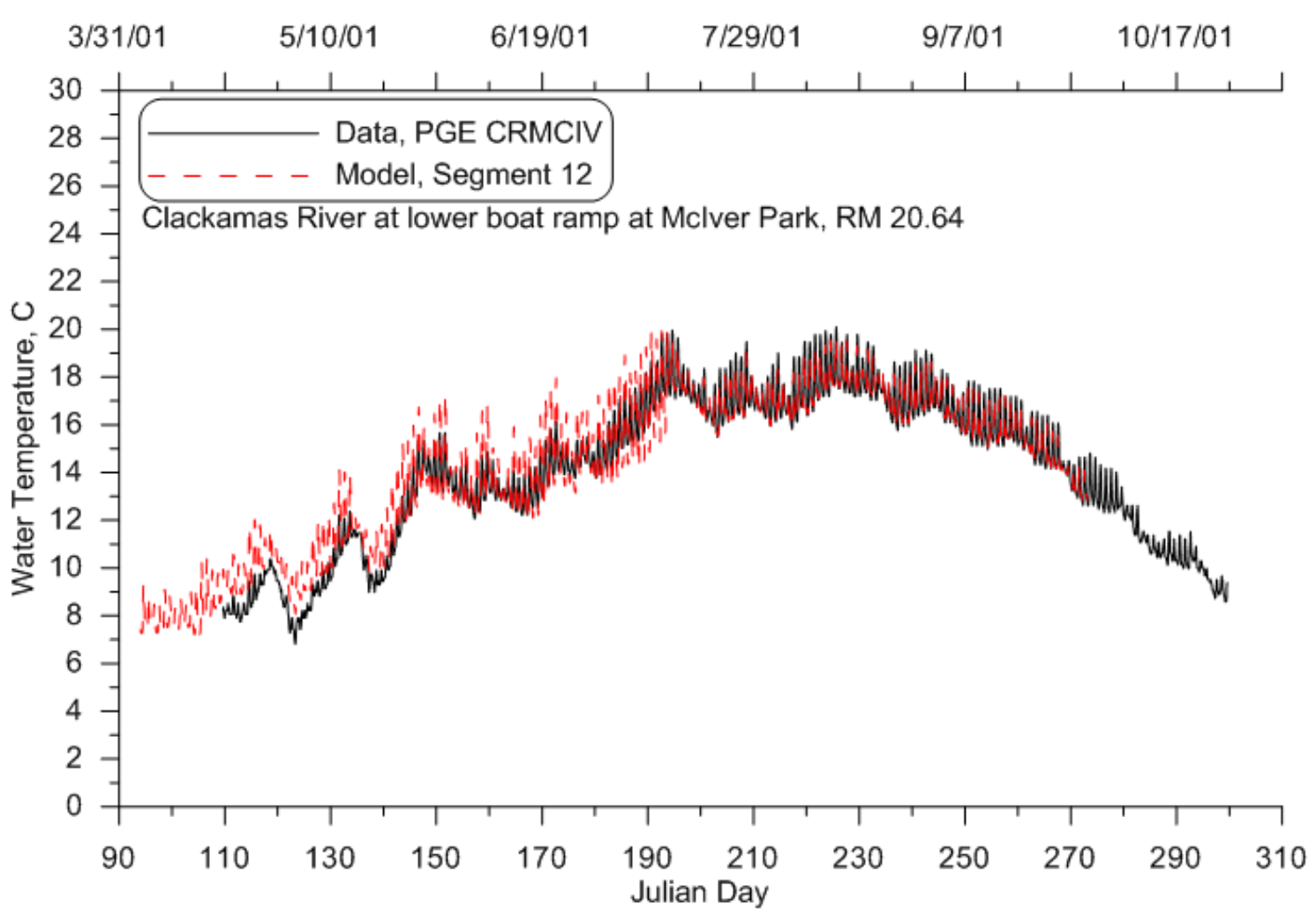

Figure 142 : Clackamas River at McIver Park model-data continuous temperature comparison, 2001

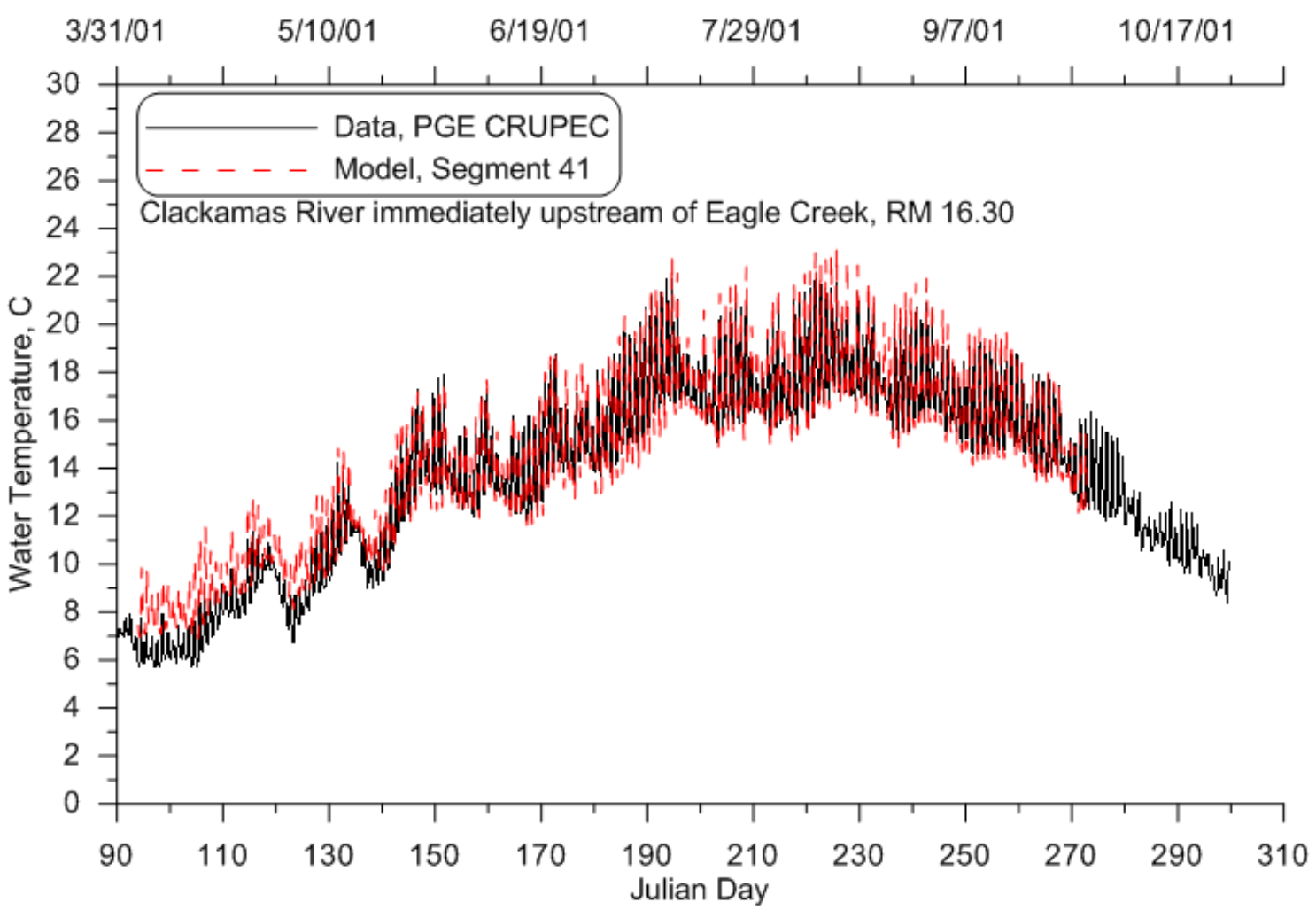

Figure 143: Clackamas River upstream of Eagle Creek model-data continuous temperature comparison, 2001 


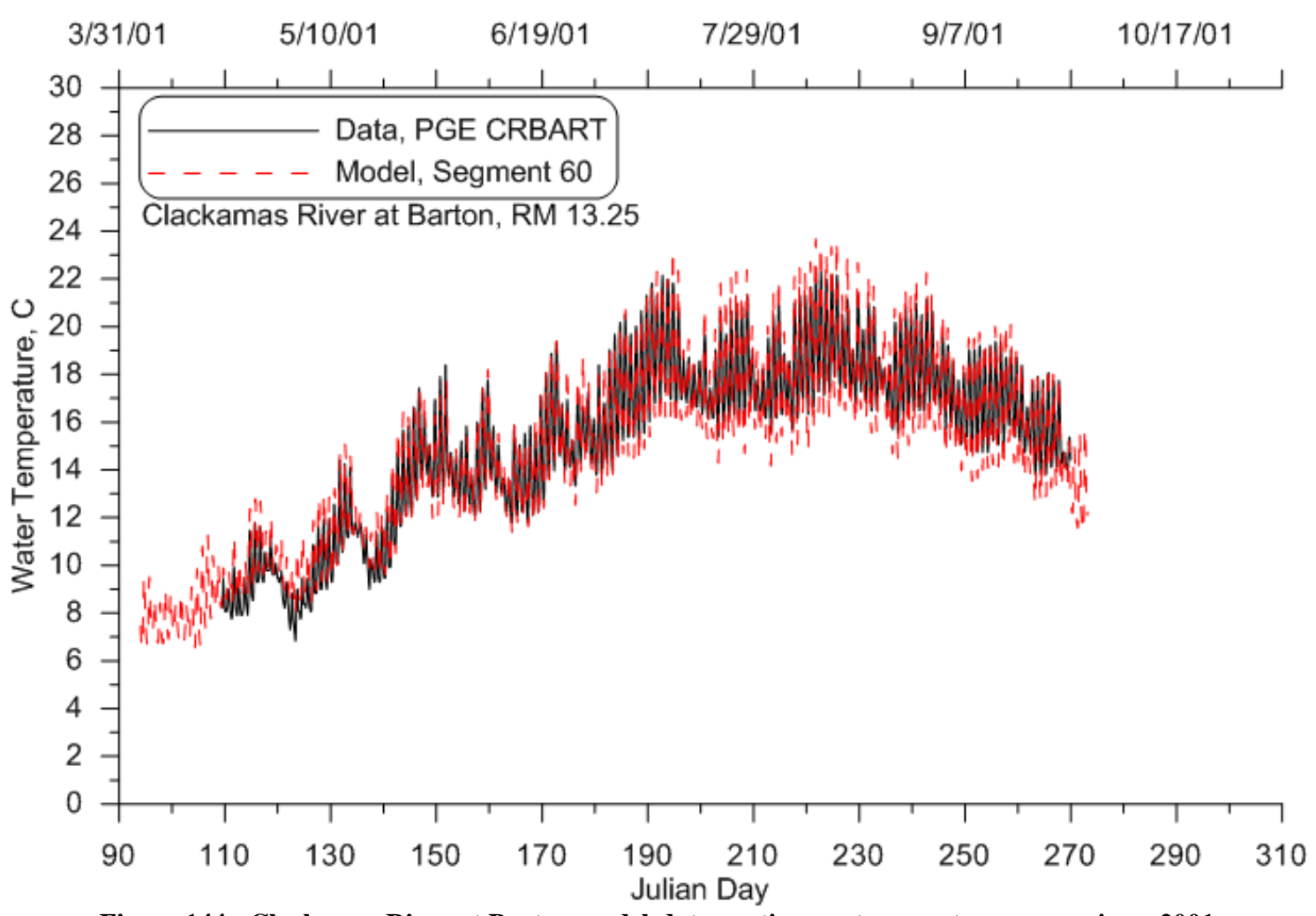

Figure 144 : Clackamas River at Barton model-data continuous temperature comparison, 2001

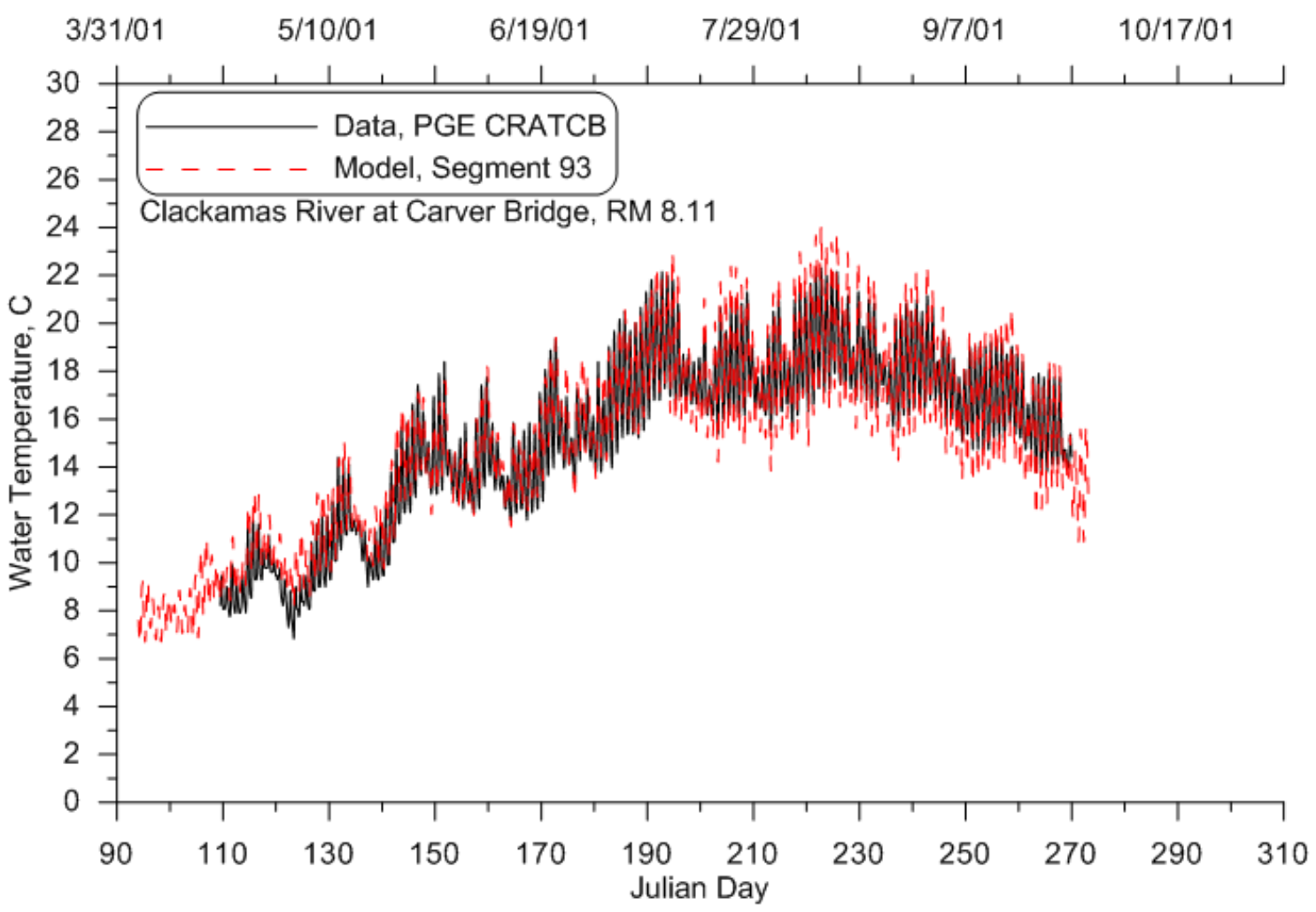

Figure 145: Clackamas River at Carver Bridge model-data continuous temperature comparison, 2001 


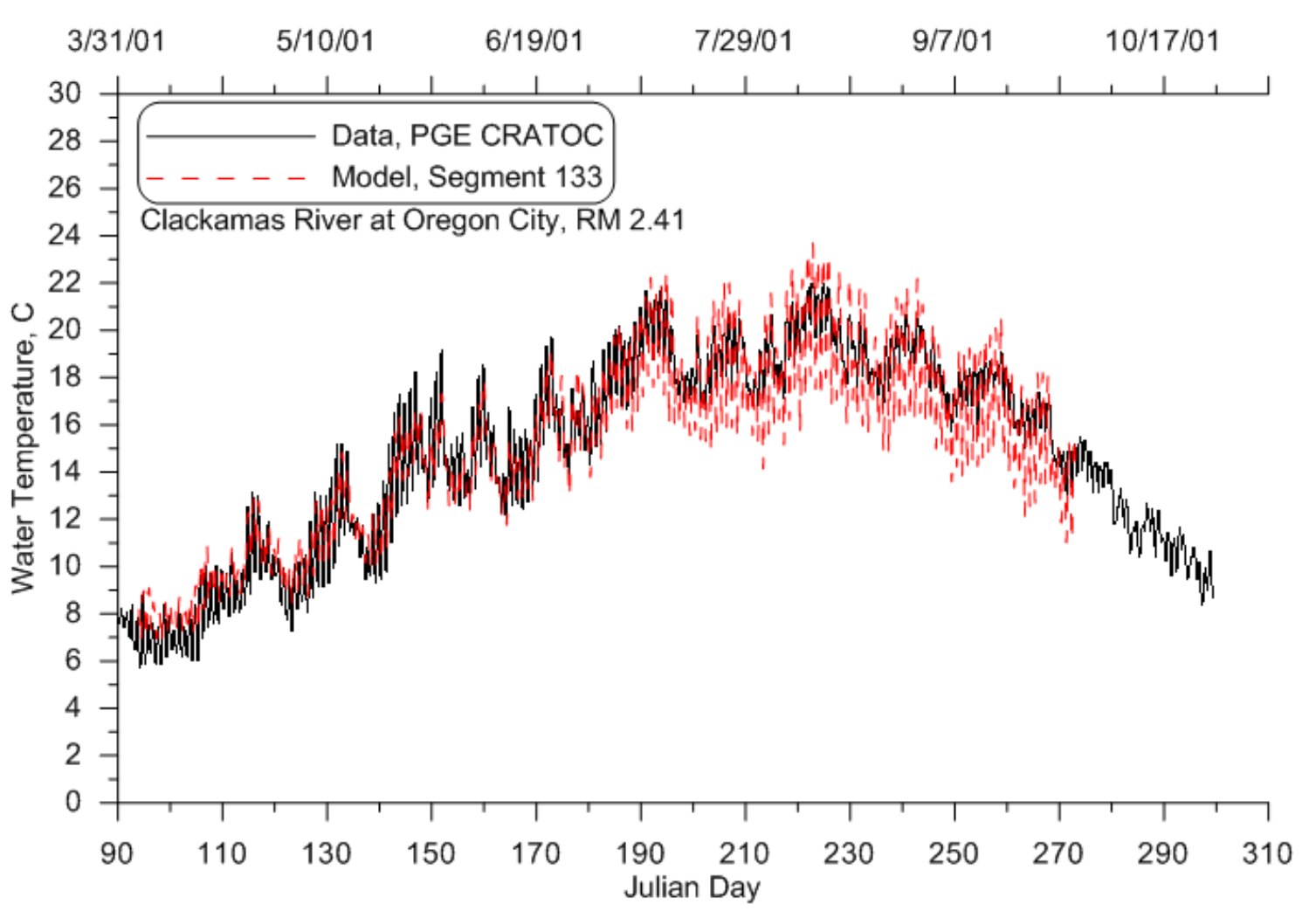

Figure 146: Clackamas River at Oregon City model-data continuous temperature comparison, 2001

\section{Year 2002}

Figure 147 through 152 show the continuous temperature comparison between model predictions and measured data. Error statistics are summarized in Table 17. Predicted temperature matched data very well for all the 3 sites with the RMSEs below $0.72{ }^{\circ} \mathrm{C}$.

Table 17: Clackamas River continuous water temperature calibration model-data error statistics, 2002

\begin{tabular}{|c|c|c|c|c|c|c|}
\hline \multirow[b]{2}{*}{ Site ID } & \multirow[b]{2}{*}{$\mathrm{RM}$} & \multirow{2}{*}{$\begin{array}{c}\text { Model } \\
\text { Segment }\end{array}$} & \multicolumn{3}{|c|}{ Continuous Temperature } & \multirow[b]{2}{*}{$\mathrm{RMSE},{ }^{\circ} \mathrm{C}$} \\
\hline & & & $\begin{array}{l}\text { Number of } \\
\text { Comparisons }\end{array}$ & $\mathrm{ME},{ }^{\circ} \mathrm{C}$ & $\mathrm{AME},{ }^{\circ} \mathrm{C}$ & \\
\hline USGS 14210000 & 22.22 & 2 & 8687 & 0.008 & 0.016 & 0.027 \\
\hline LASAR 30439 & 16.30 & 41 & 1309 & -0.287 & 0.348 & 0.429 \\
\hline USGS 14211010 & 2.41 & 133 & 4922 & -0.416 & 0.577 & 0.713 \\
\hline
\end{tabular}




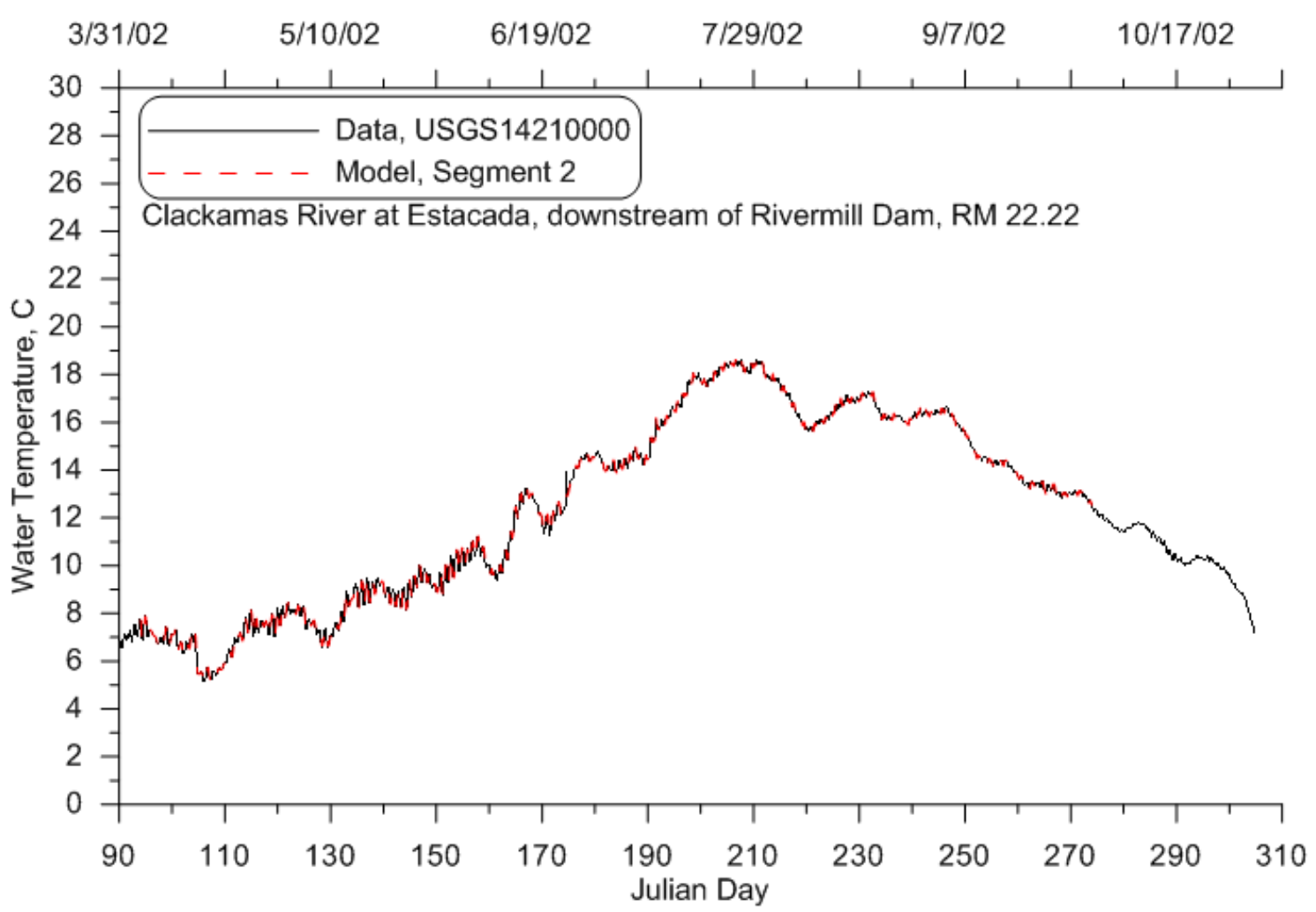

Figure 147: Clackamas River at Estacada model-data continuous temperature comparison, 2002

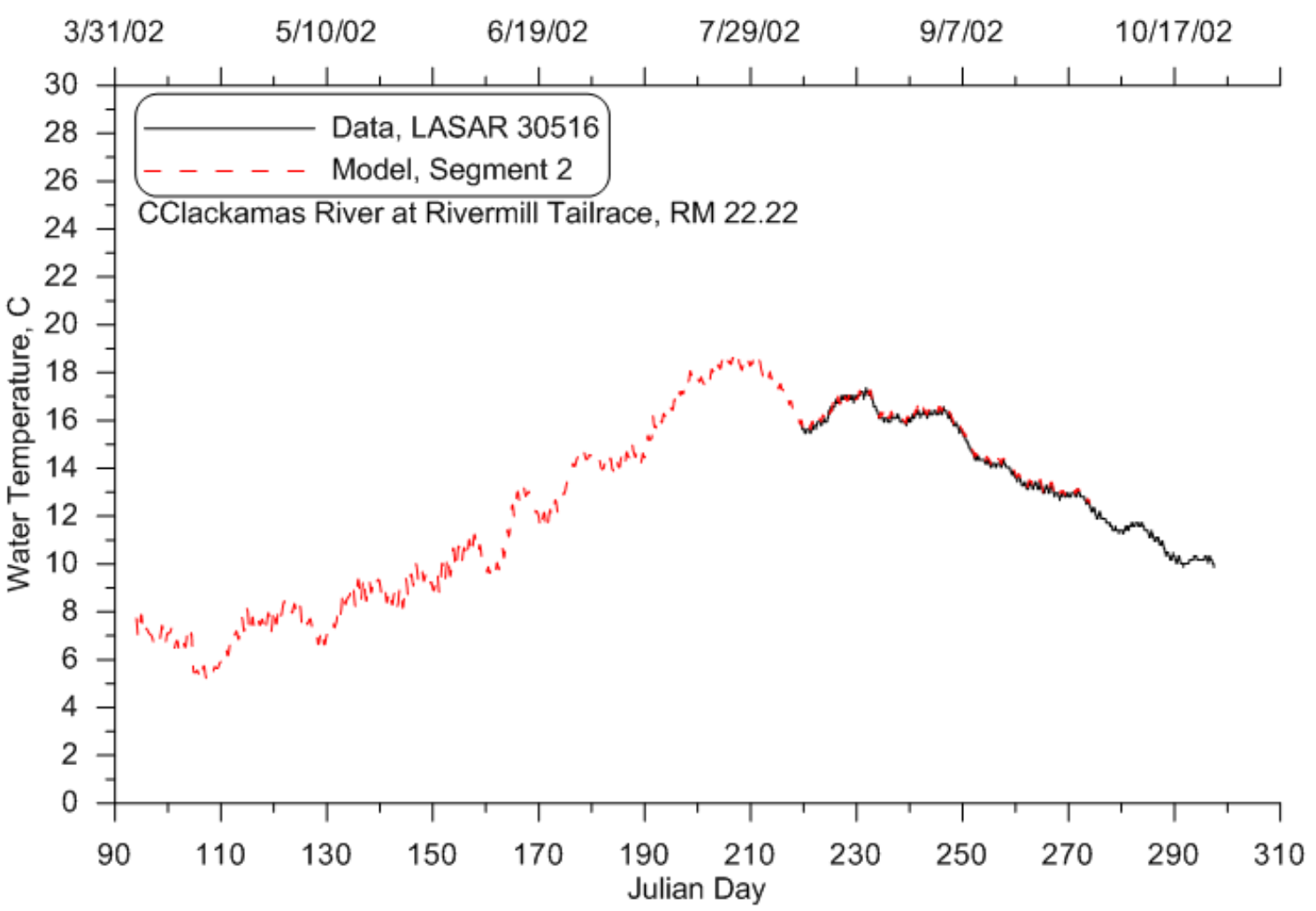

Figure 148 : Clackamas River at Rivermill Tailrace model-data continuous temperature comparison, 2002 


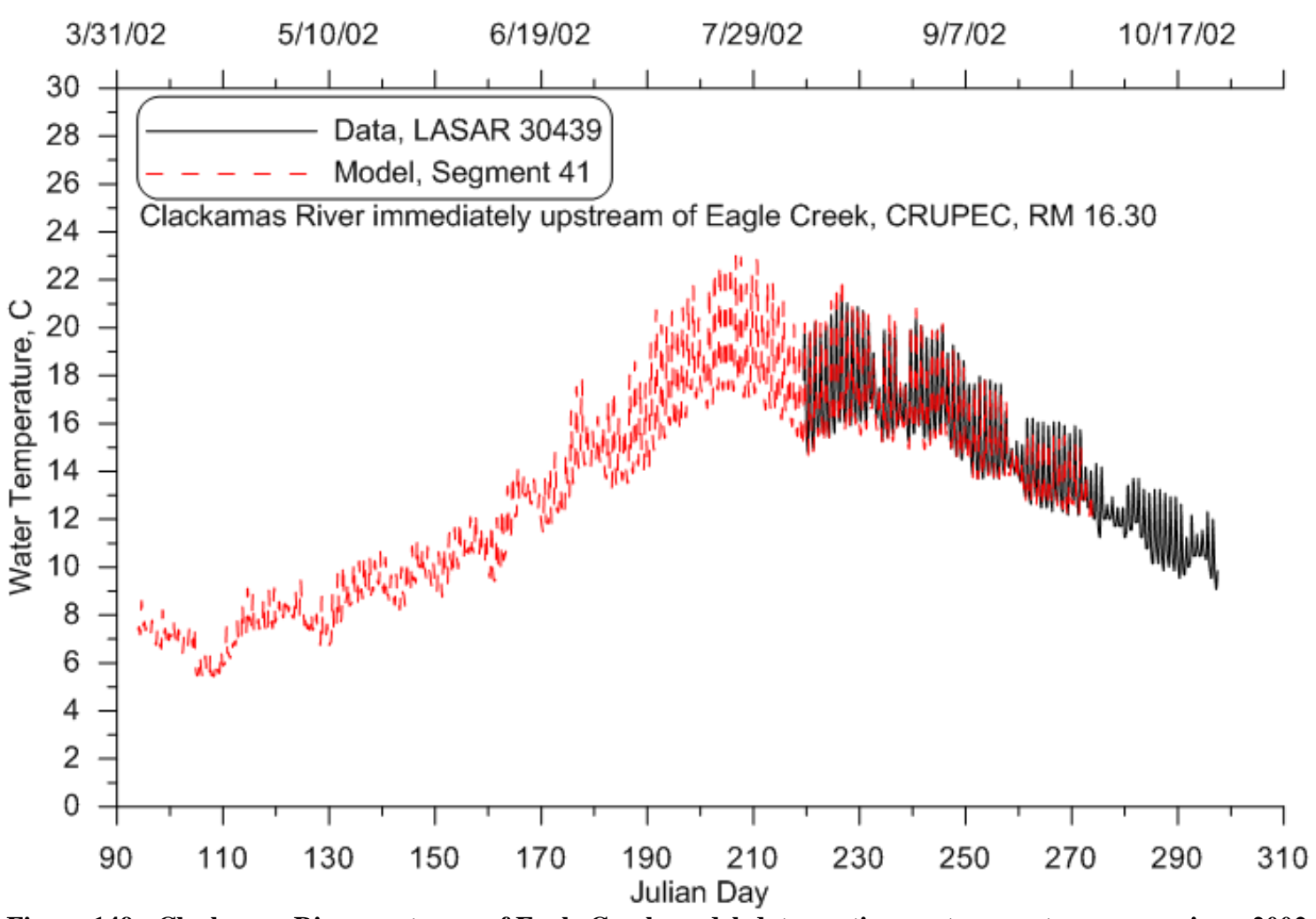

Figure 149 : Clackamas River upstream of Eagle Creek model-data continuous temperature comparison, 2002

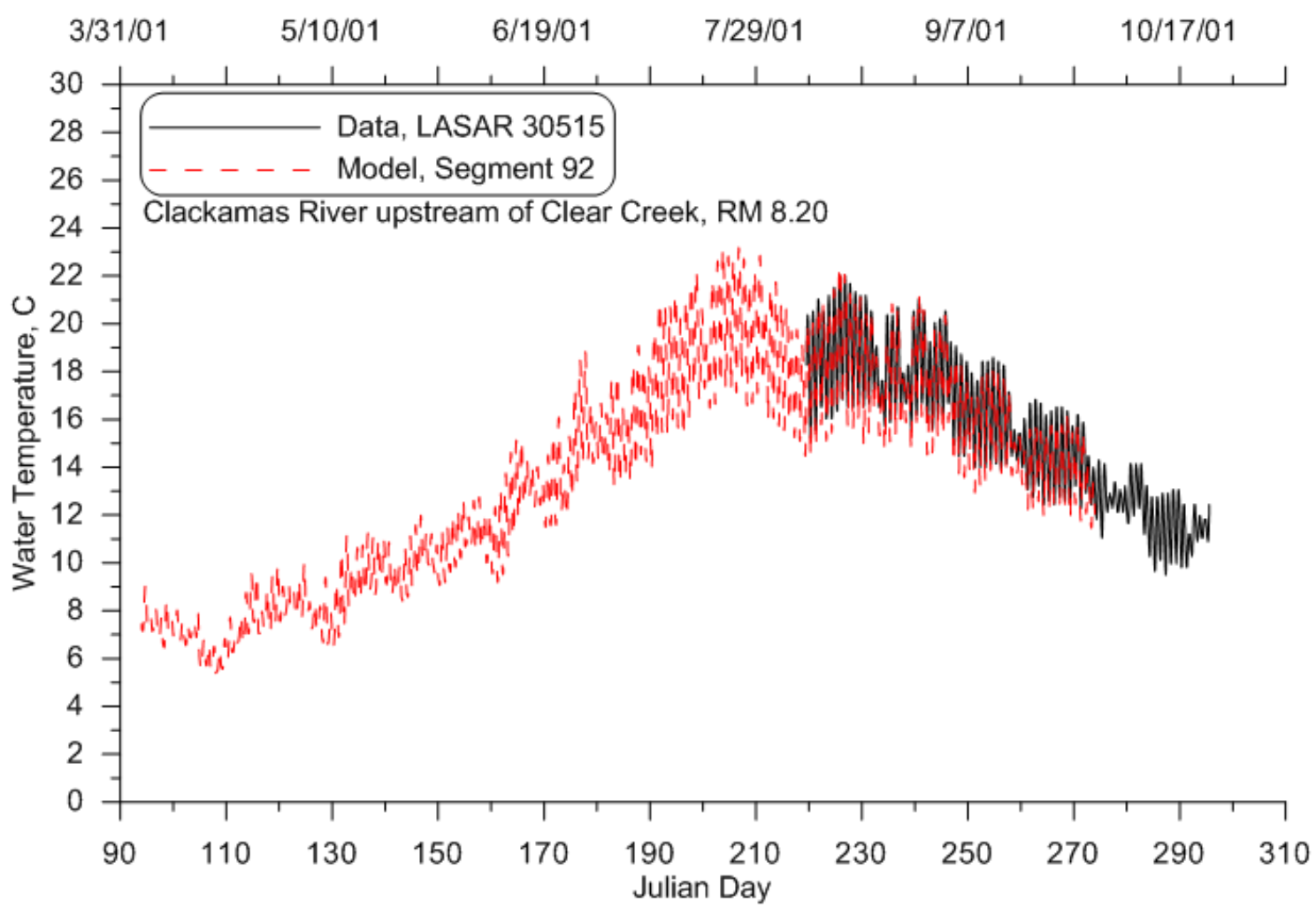

Figure 150 : Clackamas River upstream of Clear Creek model-data continuous temperature comparison, 2002 


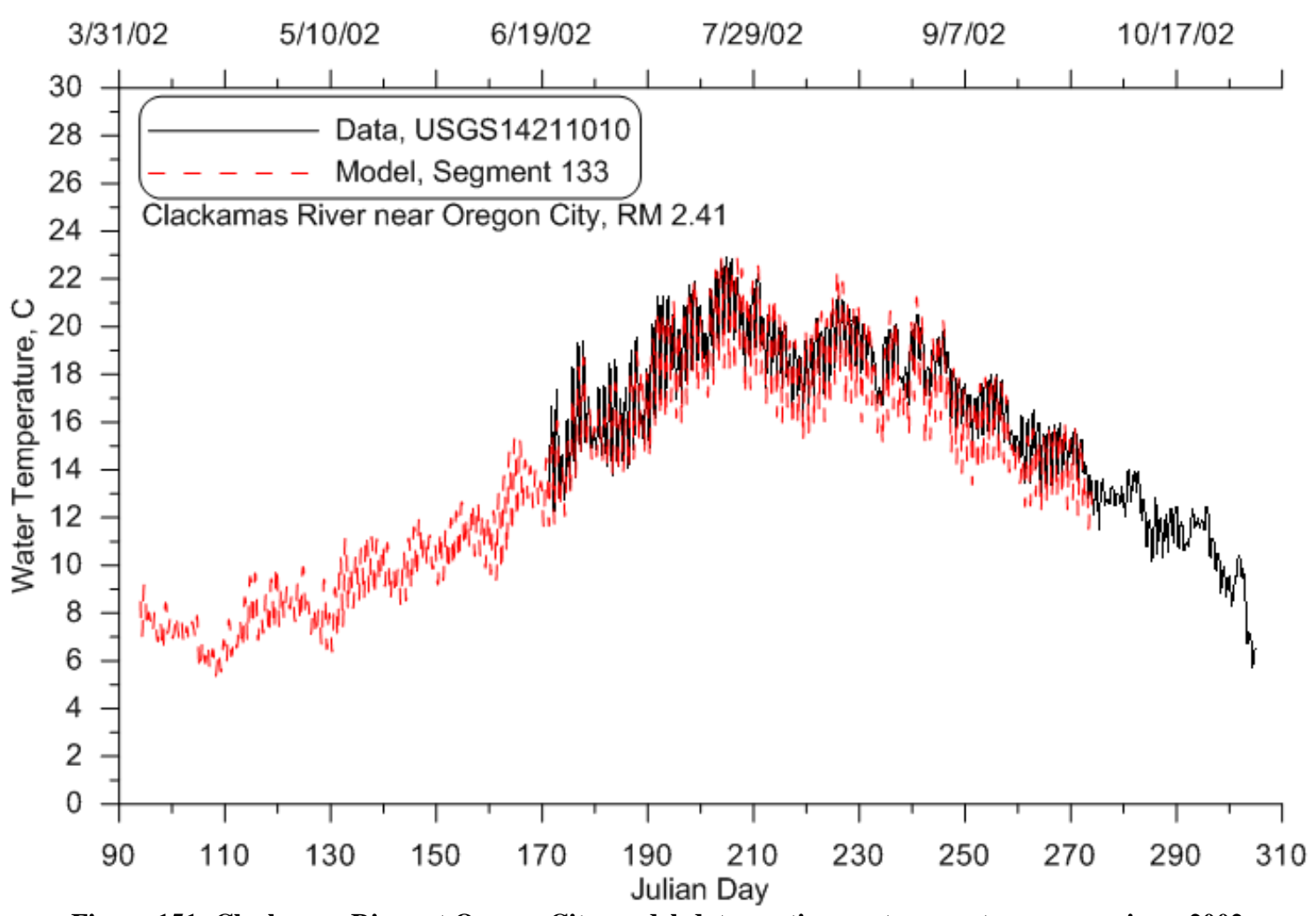

Figure 151: Clackamas River at Oregon City model-data continuous temperature comparison, 2002

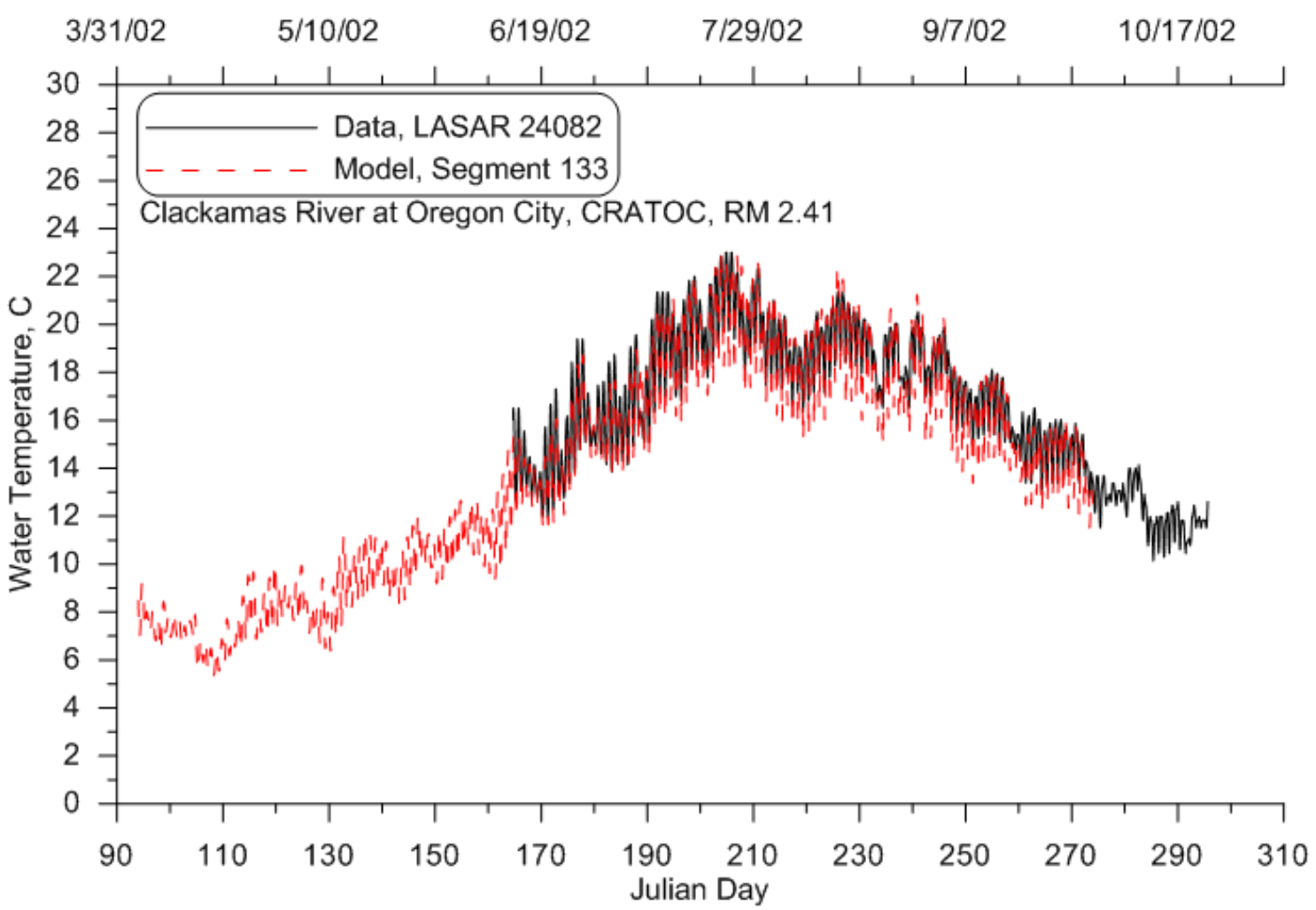

Figure 152: Clackamas River at Oregon City model-data continuous temperature comparison, 2002 


\subsubsection{McKenzie River}

\section{Introduction}

McKenzie River model domain includes South Fork McKenzie River from Cougar Reservoir and McKenzie River. Blue River was treated as a tributary into the system. Leaburg Canal and Walterville Canal were included in the system as loop branches. The model was set up as 7 water bodies including 7 branches, 474 segments and 23 layers. There are 13 tributaries flows into the systems. The model grid is shown in Figure 153.

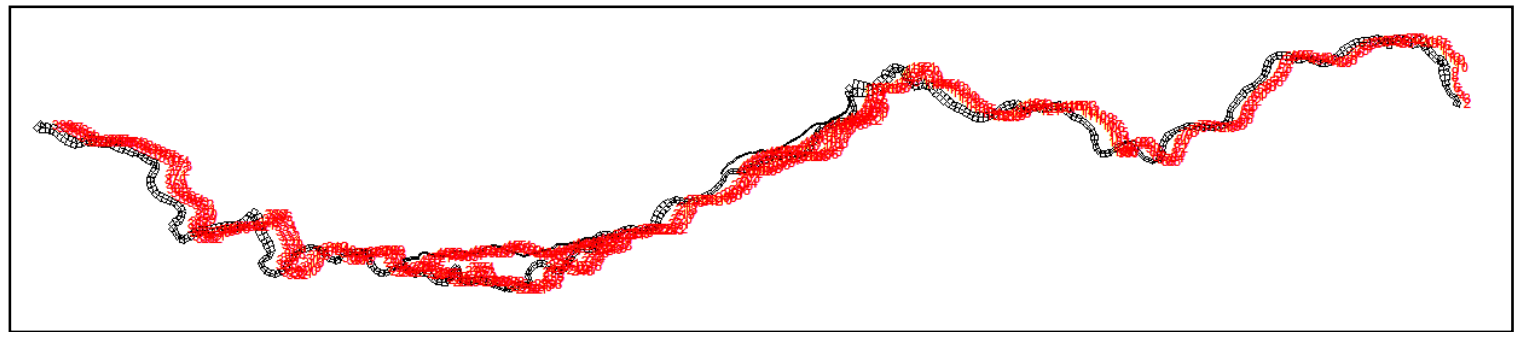

Figure 153: McKenzie River model grid

\section{Hydrodynamics}

Flow rate and water surface elevation was first tested using the original setting in V3.1 model. As the model showed good agreement with data, no further calibrations were conducted.

\section{Year 2001}

The McKenzie River calibration period in 2001 was from April to September. Figure 154 through 161 show the water level and flow comparison between model predictions and 
measured data. The figures showed that flow predictions matched well with data. Error statistics are summarized in Table 18.

Table 18: McKenzie River hydrodynamic calibration model-data error statistics, 2001

\begin{tabular}{|c|c|c|c|c|c|c|c|}
\hline \multicolumn{8}{|c|}{ Flow } \\
\hline \multicolumn{2}{|c|}{ Gage ID } & $\mathrm{RM}$ & $\begin{array}{c}\text { Model } \\
\text { Segment }\end{array}$ & $\begin{array}{c}\text { Number of } \\
\text { Comparisons }\end{array}$ & $\mathrm{ME}, \mathrm{m}^{3} / \mathrm{s}$ & $\mathrm{AME}, \mathrm{m}^{3} / \mathrm{s}$ & RMSE, $\mathrm{m}^{3} / \mathrm{s}$ \\
\hline \multicolumn{2}{|c|}{ USGS 14159500} & 60.39 & 4 & 7008 & 0 & 0.025 & 0.076 \\
\hline \multicolumn{2}{|c|}{ USGS 14162500} & 44.56 & 108 & 7008 & -0.019 & 0.264 & 0.424 \\
\hline \multicolumn{2}{|c|}{ USGS 14163150} & 34.11 & 177 & 7008 & -0.033 & 0.208 & 0.487 \\
\hline \multicolumn{2}{|c|}{ USGS 14163900} & 24.97 & 240 & 6996 & -0.051 & 0.313 & 0.619 \\
\hline \multicolumn{8}{|c|}{ Water Level } \\
\hline \multicolumn{2}{|c|}{ Gage ID } & $\mathrm{RM}$ & $\begin{array}{c}\text { Model } \\
\text { Segment }\end{array}$ & $\begin{array}{c}\text { Number of } \\
\text { Comparisons }\end{array}$ & ME, $\mathrm{m}$ & AME, $m$ & RMSE, $m$ \\
\hline \multicolumn{2}{|c|}{ USGS 14159500} & 60.39 & 4 & 7008 & -0.006 & 0.026 & 0.036 \\
\hline \multicolumn{2}{|c|}{ USGS 14162500} & 44.56 & 108 & 7008 & -0.088 & 0.088 & 0.092 \\
\hline \multicolumn{2}{|c|}{ USGS 14163150} & 34.11 & 177 & 7008 & -0.026 & 0.026 & 0.033 \\
\hline \multicolumn{2}{|c|}{ USGS 14163900} & 24.97 & 240 & 6996 & 0.159 & 0.159 & 0.162 \\
\hline \multicolumn{2}{|c|}{$3 / 31 / 01$} & $5 / 10 / 01$ & $6 / 19 / C$ & $7 / 29 / 01$ & & $/ 01$ & 0/17/01 \\
\hline 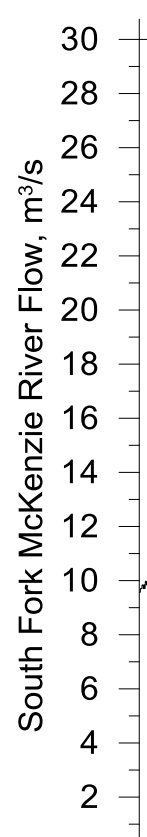 & , & 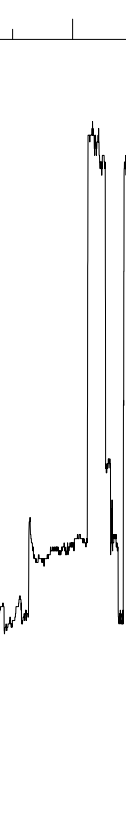 & ( & $\mid$ & Wh & $\perp$ & | \\
\hline 07 & 1 & 1 & 1 & 11 & $T$ & $T$ & 1 \\
\hline 90 & 110 & 130 & $150 \quad 170$ & $\begin{array}{lr}190 & 210 \\
\text { Julian Day }\end{array}$ & 230 & 270 & $290 \quad 310$ \\
\hline
\end{tabular}

Figure 154: South Fork McKenzie River below Cougar Dam model-data flow comparison, 2001 


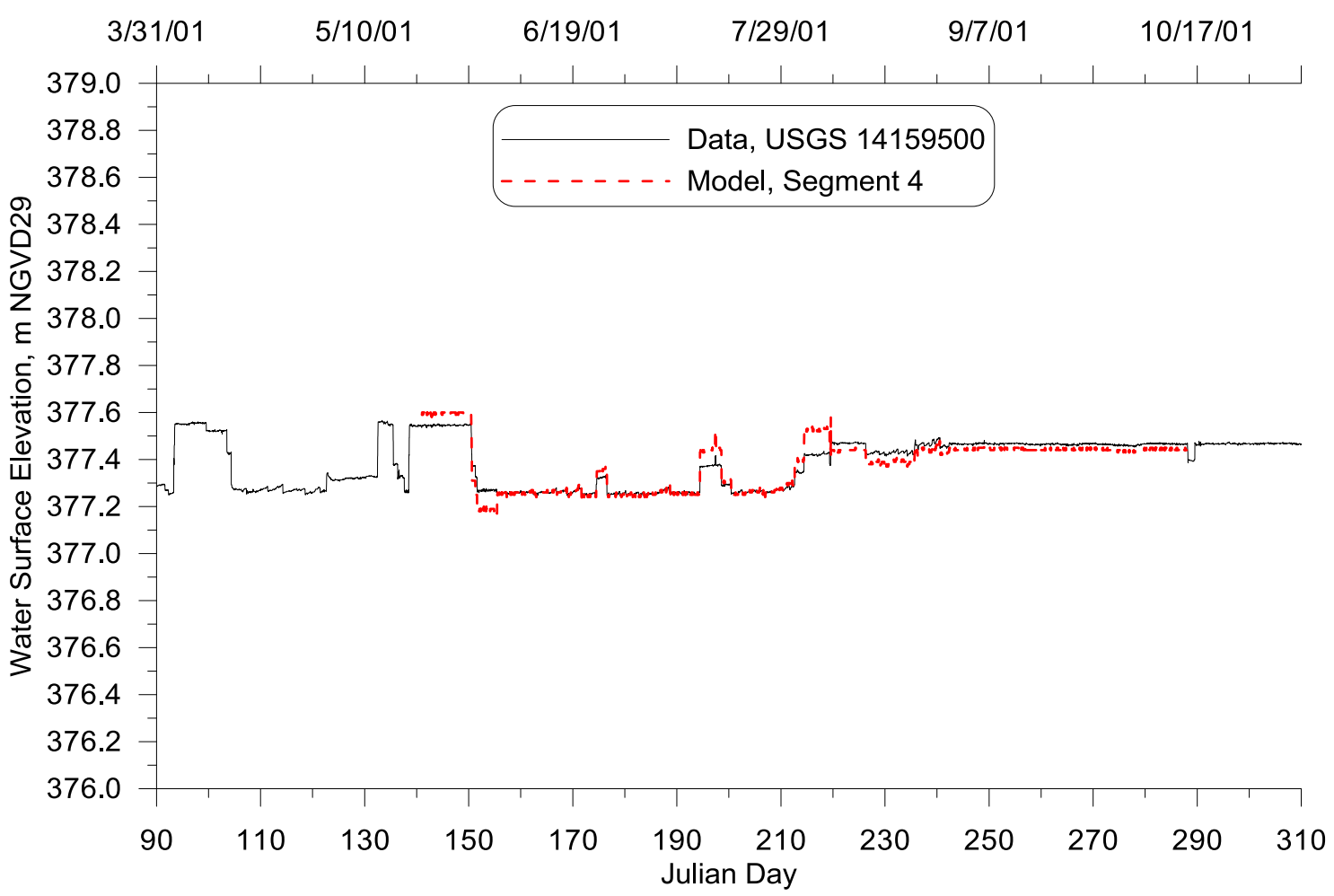

Figure 155: South Fork McKenzie River below Cougar Dam model-data water level comparison, 2001

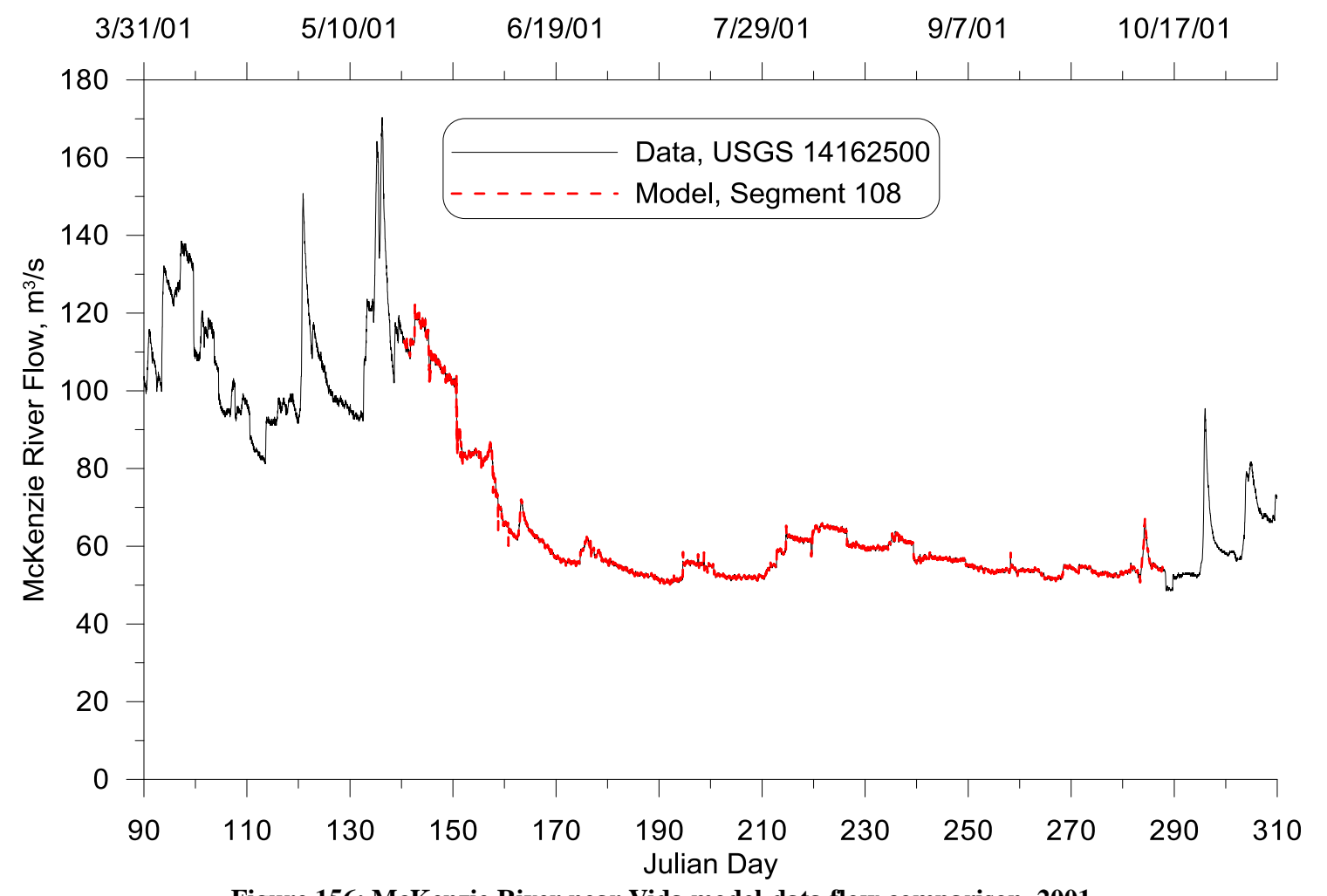

Figure 156: McKenzie River near Vida model-data flow comparison, 2001 


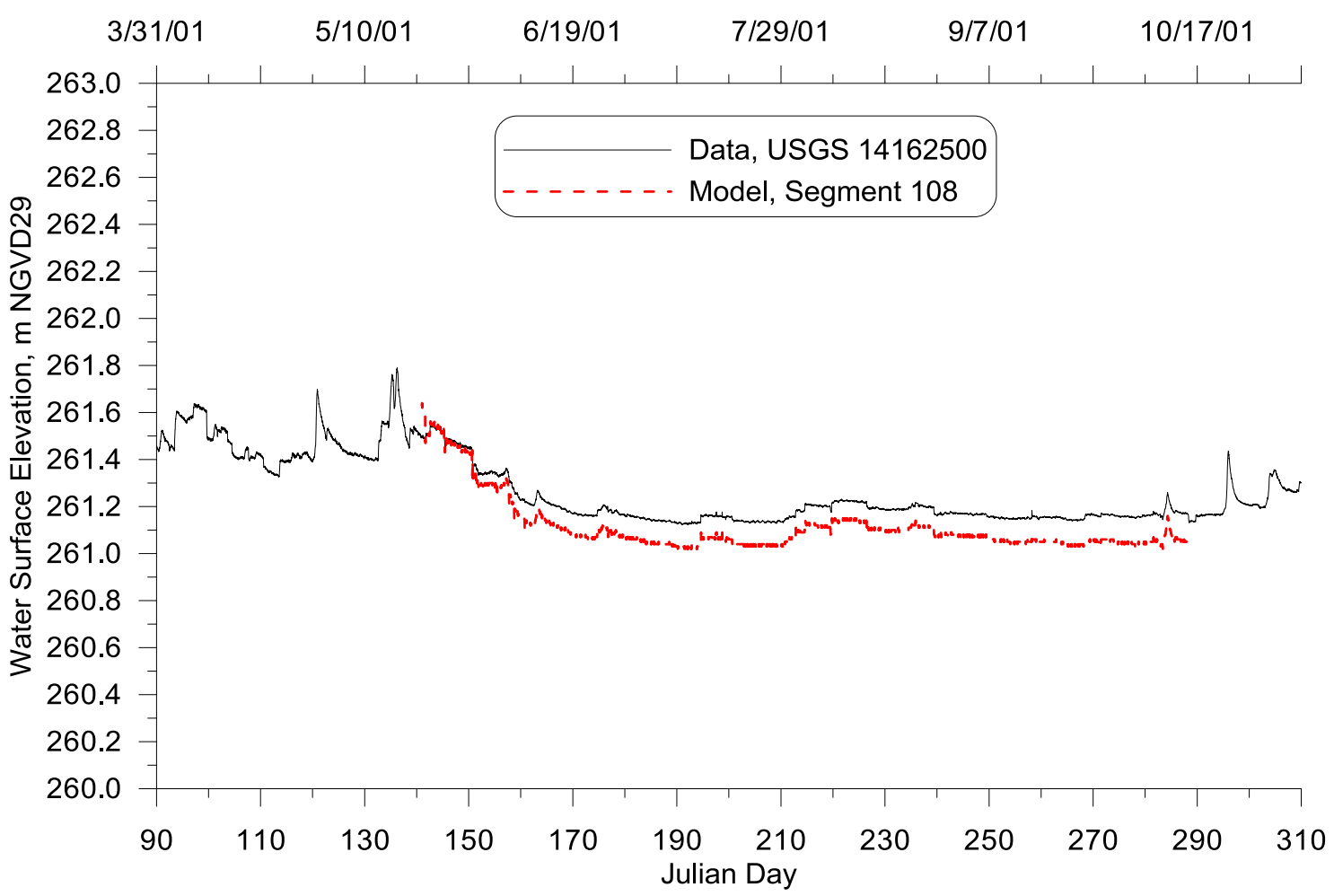

Figure 157: McKenzie River near Vida model-data water level comparison, 2001

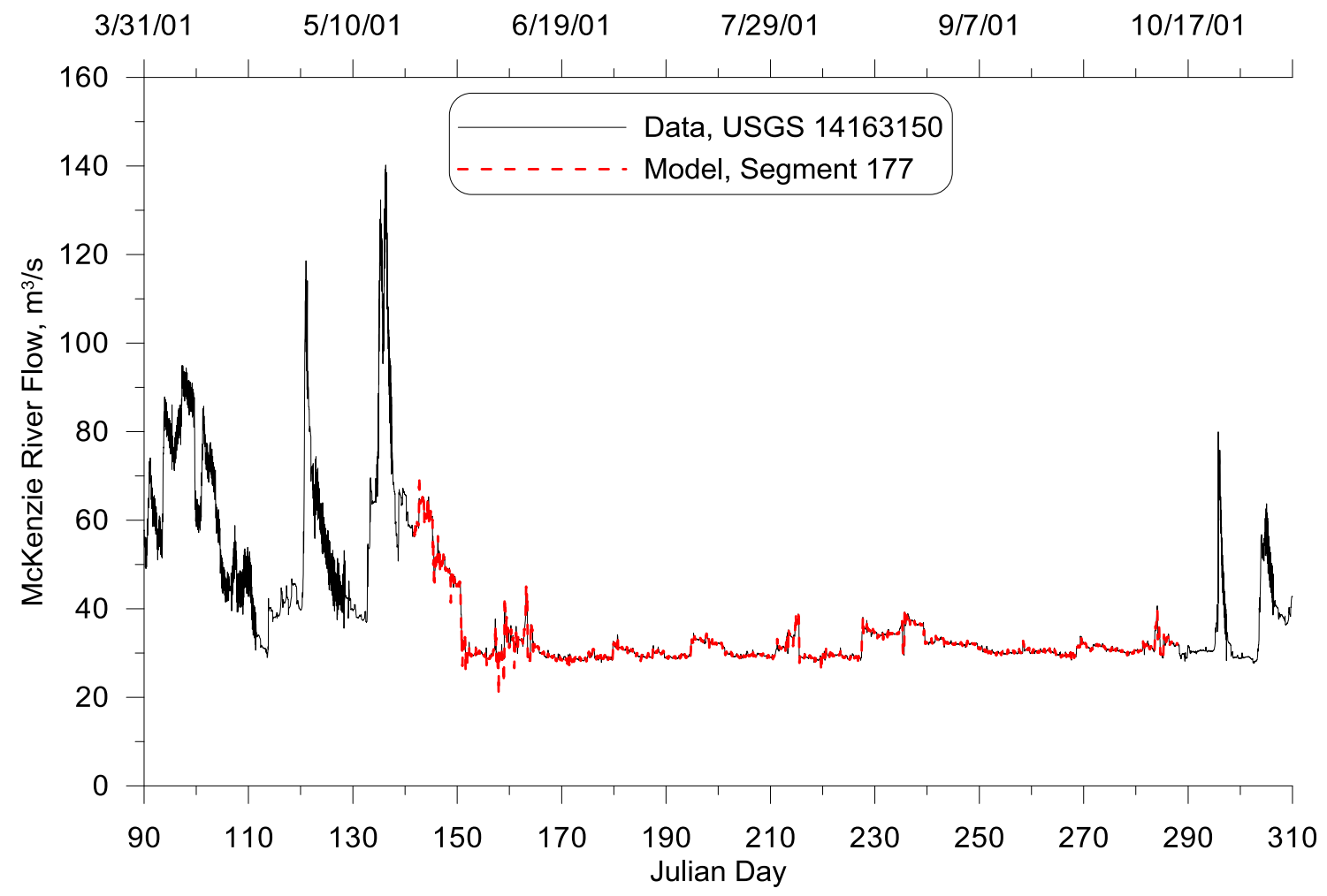

Figure 158: McKenzie River below Leaburg Dam model-data flow comparison, 2001 


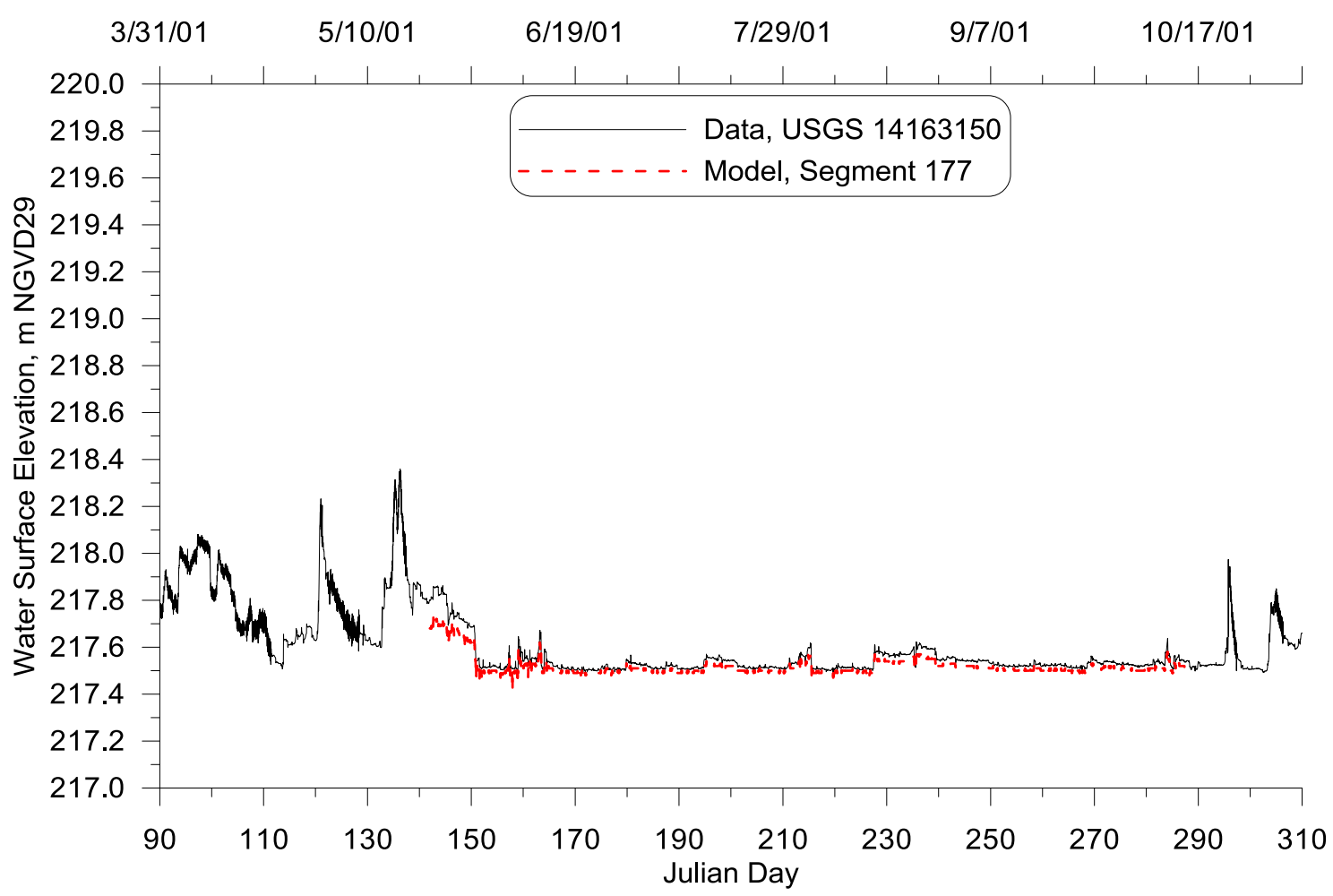

Figure 159: McKenzie River below Leaburg Dam model-data water level comparison, 2001

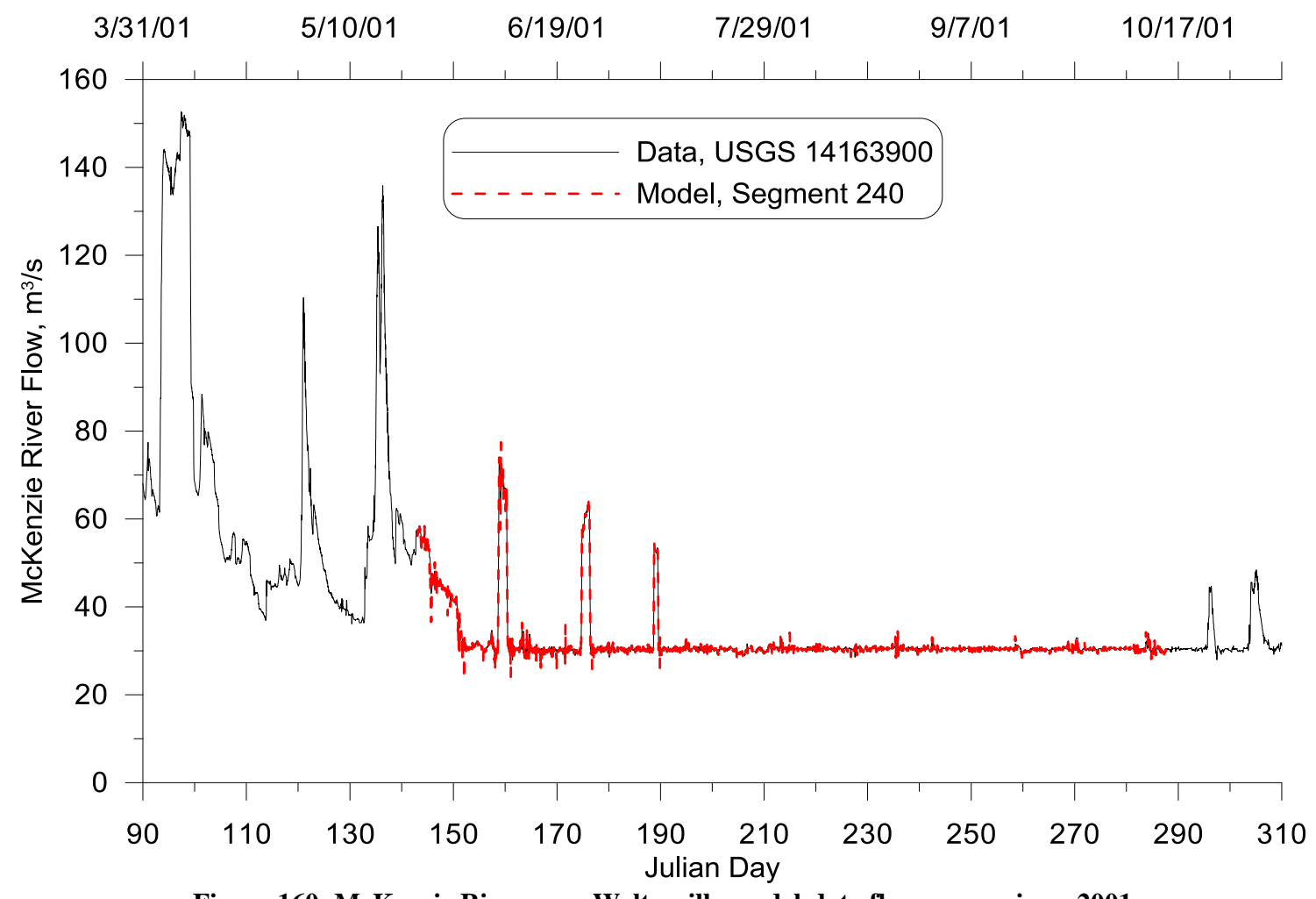

Figure 160: McKenzie River near Walterville model-data flow comparison, 2001 


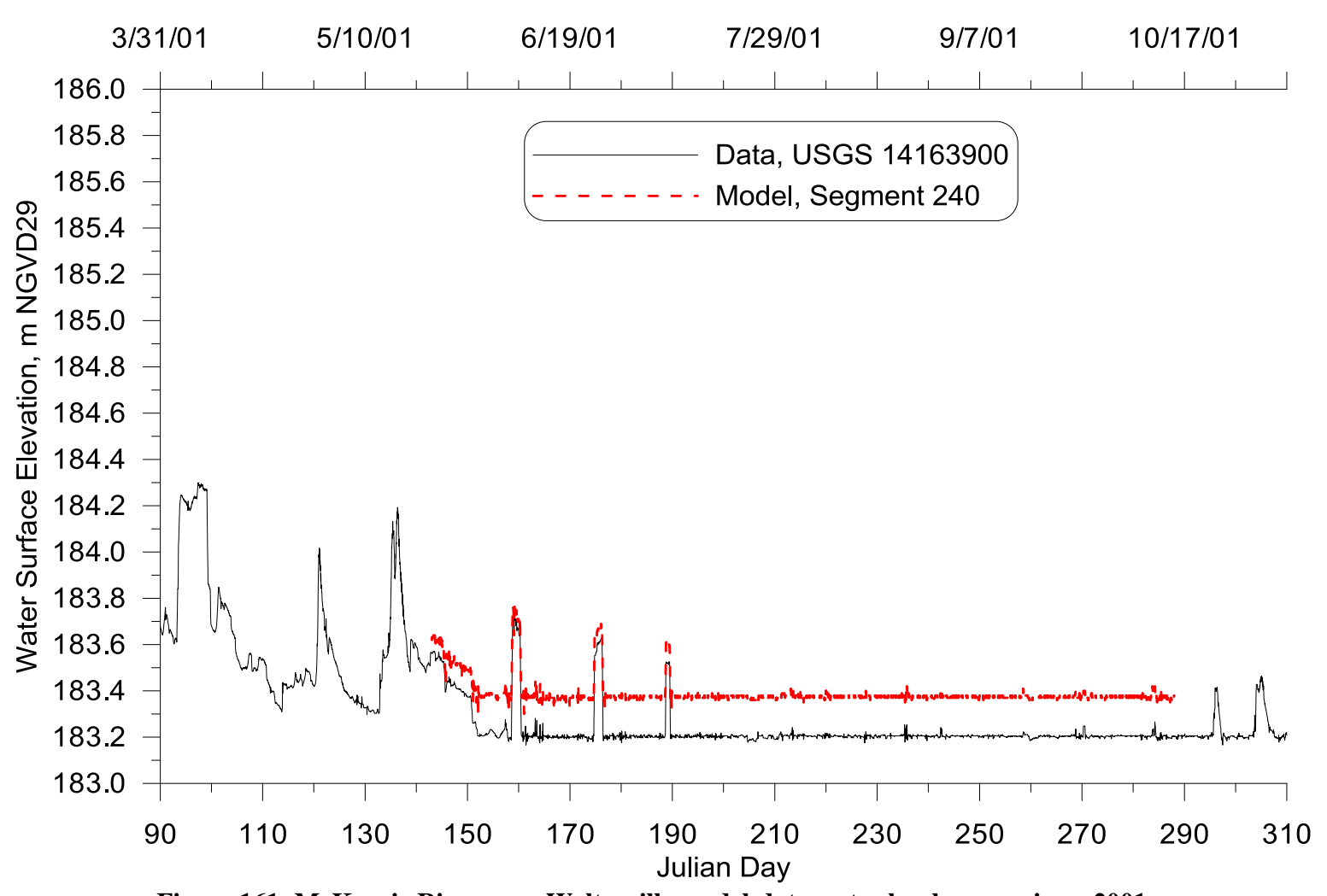

Figure 161: McKenzie River near Walterville model-data water level comparison, 2001

\section{Year 2002}

The McKenzie River calibration period in 2002 was from April to October. Figure 162 through 169 show the water level and flow comparison between model predictions and measured data. The figures showed that flow predictions matched well with data. Error statistics are summarized in Table 19.

Table 19: McKenzie River hydrodynamic calibration model-data error statistics, 2002

\begin{tabular}{|c|c|c|c|c|c|c|}
\hline \multicolumn{7}{|c|}{ Flow } \\
\hline Gage ID & RM & $\begin{array}{c}\text { Model } \\
\text { Segment }\end{array}$ & $\begin{array}{c}\text { Number of } \\
\text { Comparisons }\end{array}$ & ME, $\mathrm{m}^{3} / \mathrm{s}$ & AME, $\mathrm{m}^{3} / \mathrm{s}$ & RMSE, $\mathrm{m}^{3} / \mathrm{s}$ \\
\hline USGS 14159500 & 60.39 & 4 & 10175 & 0.003 & 0.046 & 0.295 \\
\hline USGS 14162500 & 44.56 & 108 & 10174 & -0.029 & 0.54 & 1.365 \\
\hline USGS 14163150 & 34.11 & 177 & 10174 & -0.053 & 0.957 & 2.273 \\
\hline USGS 14163900 & 24.97 & 240 & 10174 & -0.073 & 1.293 & 4.511 \\
\hline \multicolumn{7}{|c|}{ Water Level } \\
\hline
\end{tabular}




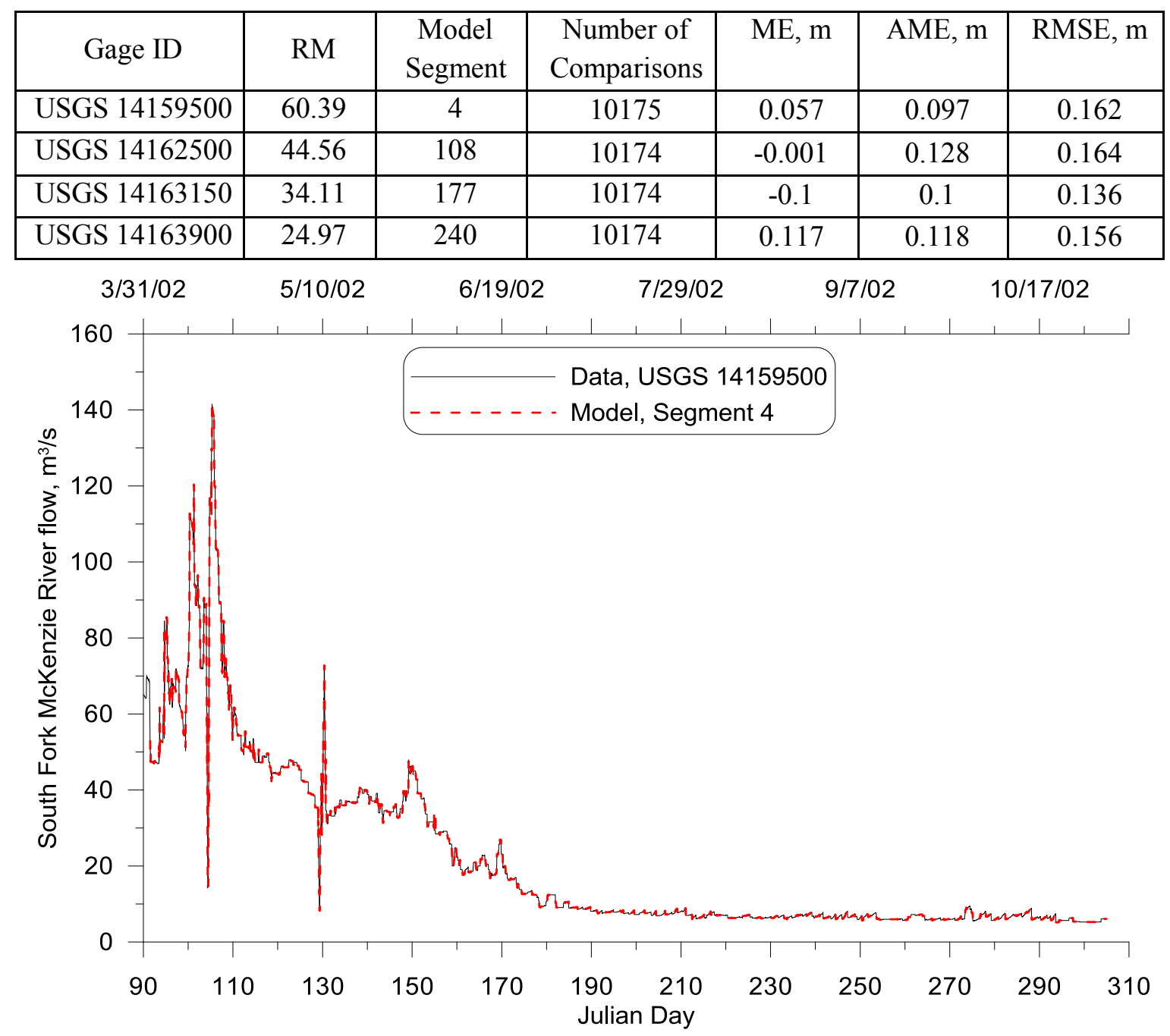

Figure 162: South Fork McKenzie River below Cougar Dam model-data flow comparison, 2002 


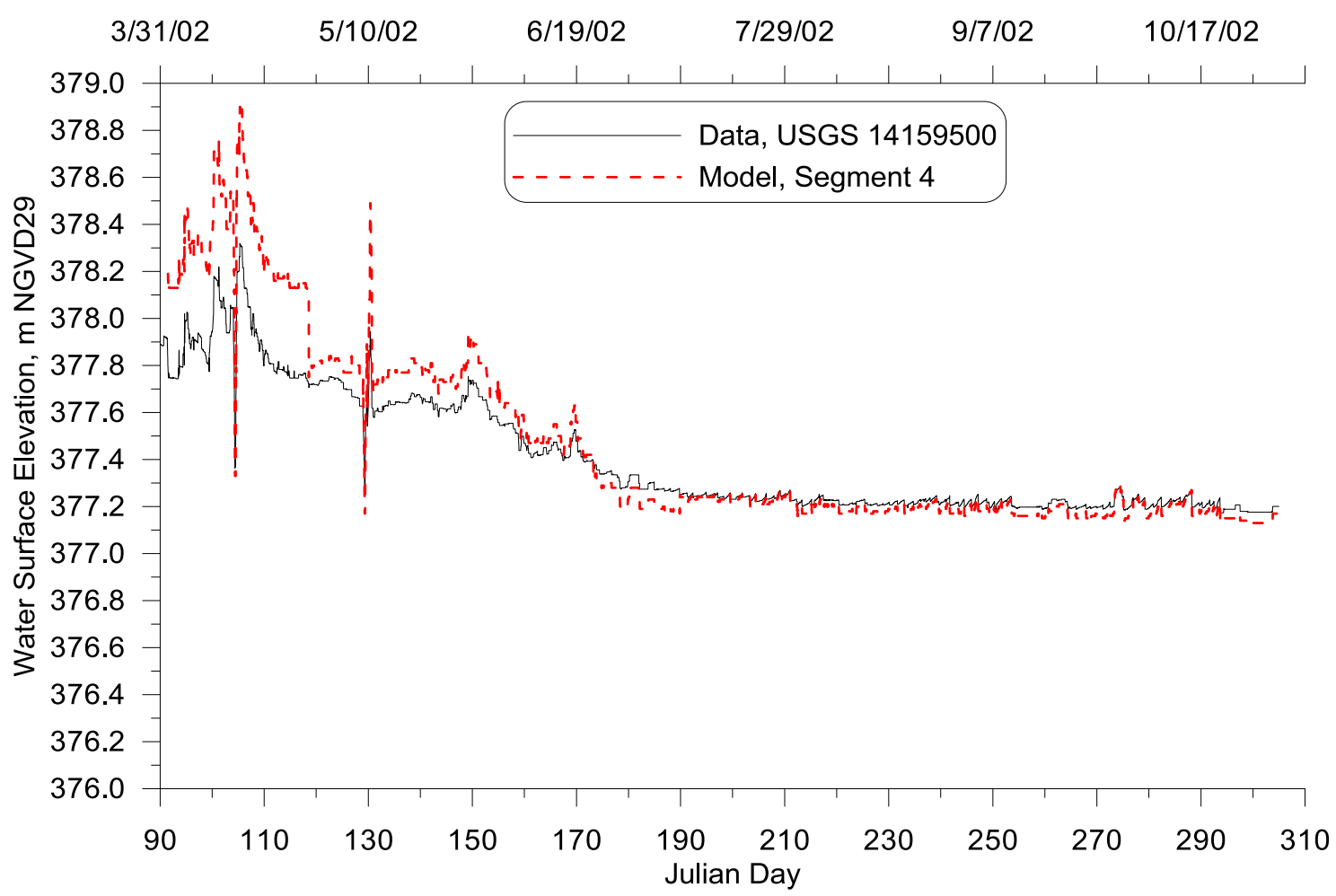

Figure 163: South Fork McKenzie River below Cougar Dam model-data water level comparison, 2002

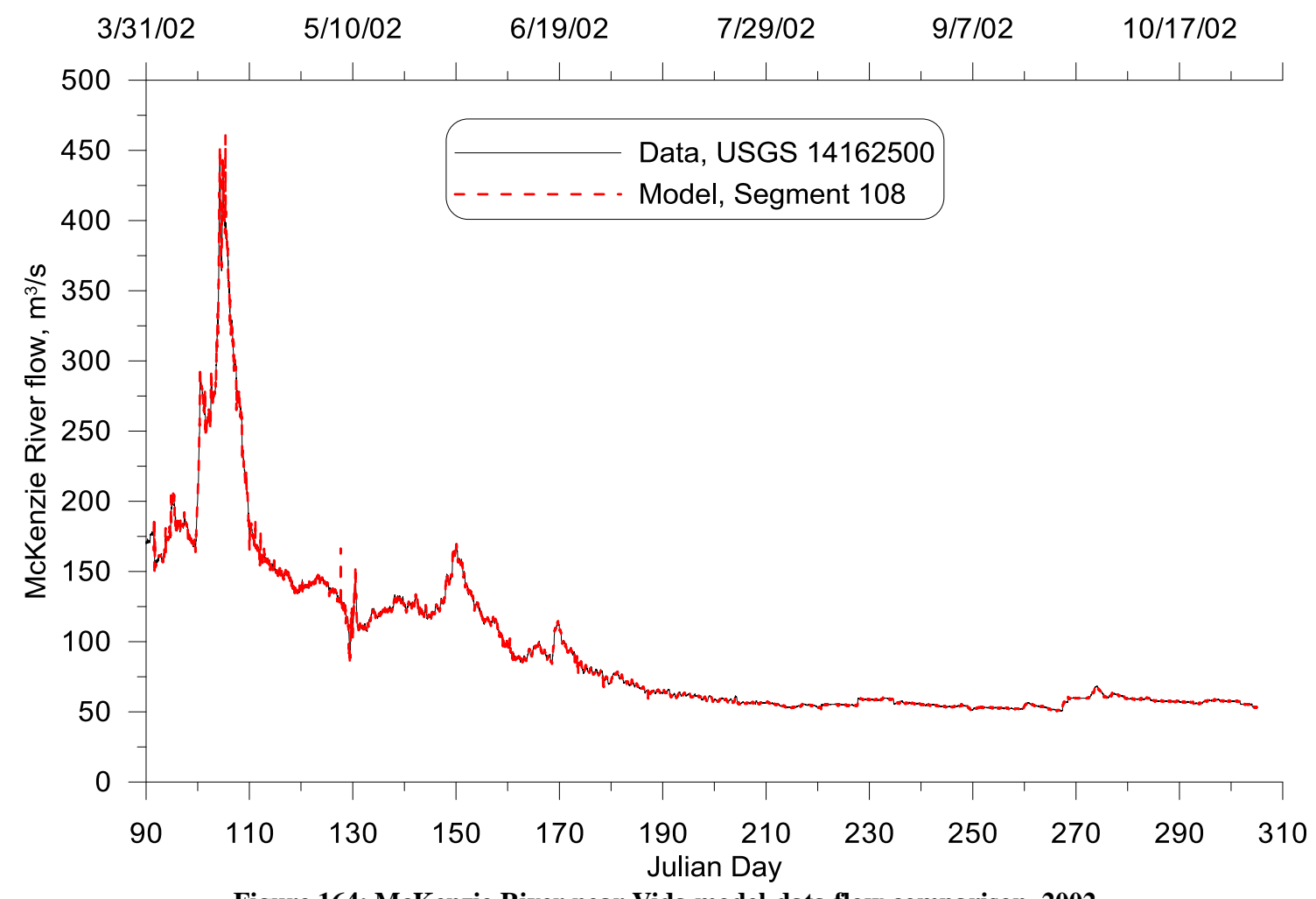

Figure 164: McKenzie River near Vida model-data flow comparison, 2002 


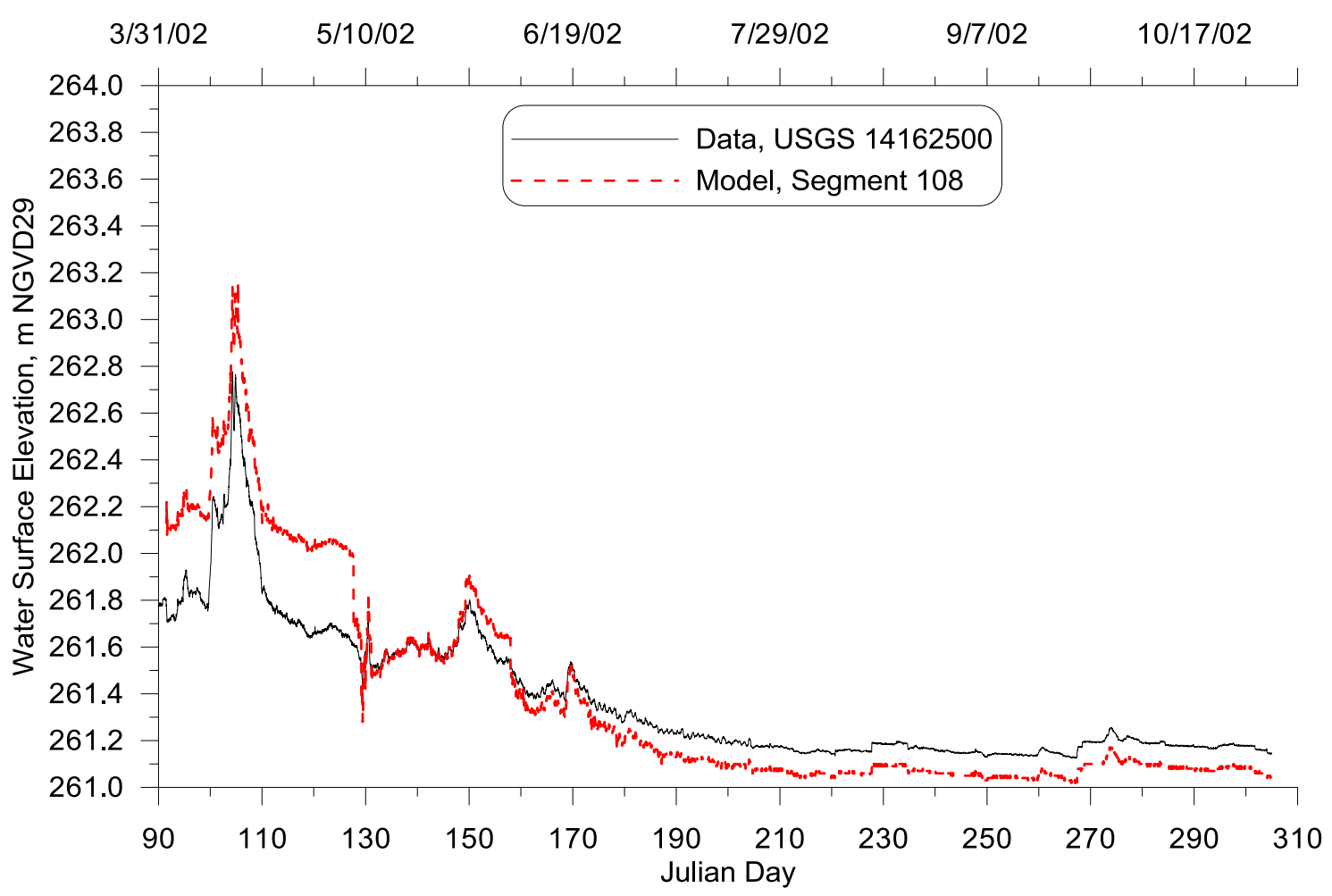

Figure 165: McKenzie River near Vida model-data water level comparison, 2002

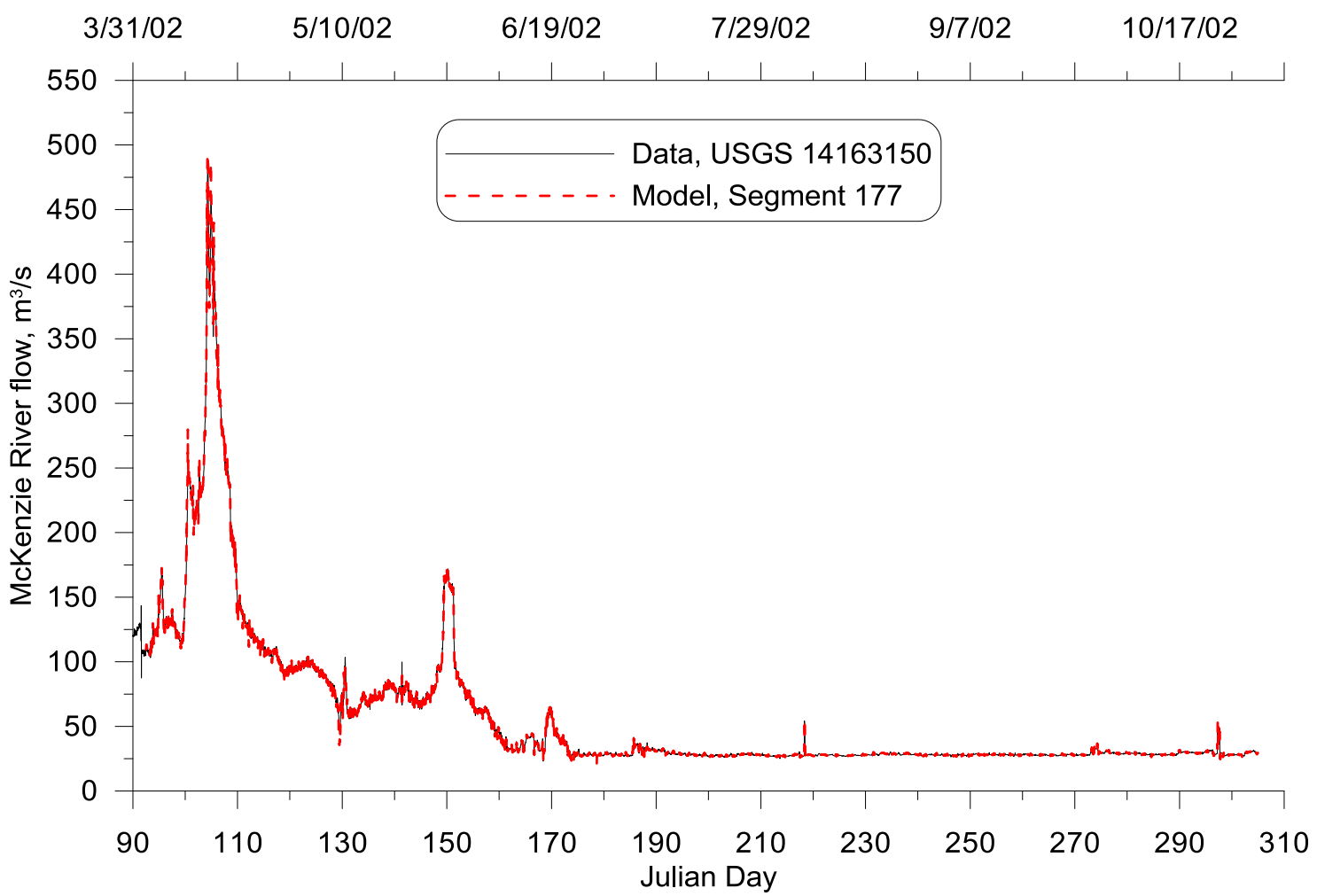

Figure 166: McKenzie River below Leaburg Dam model-data flow comparison, 2002 


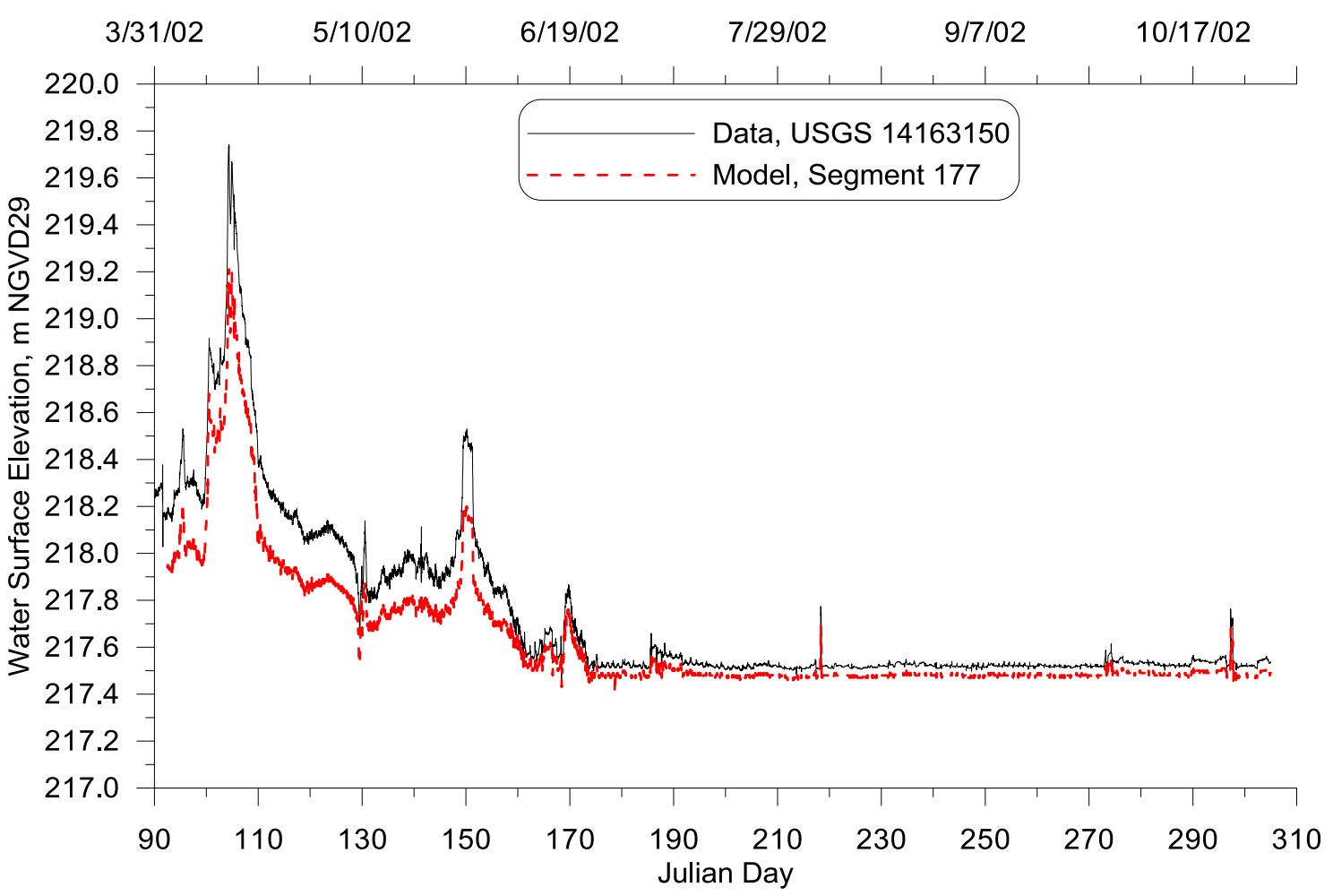

Figure 167: McKenzie River below Leaburg Dam model-data water level comparison, 2002

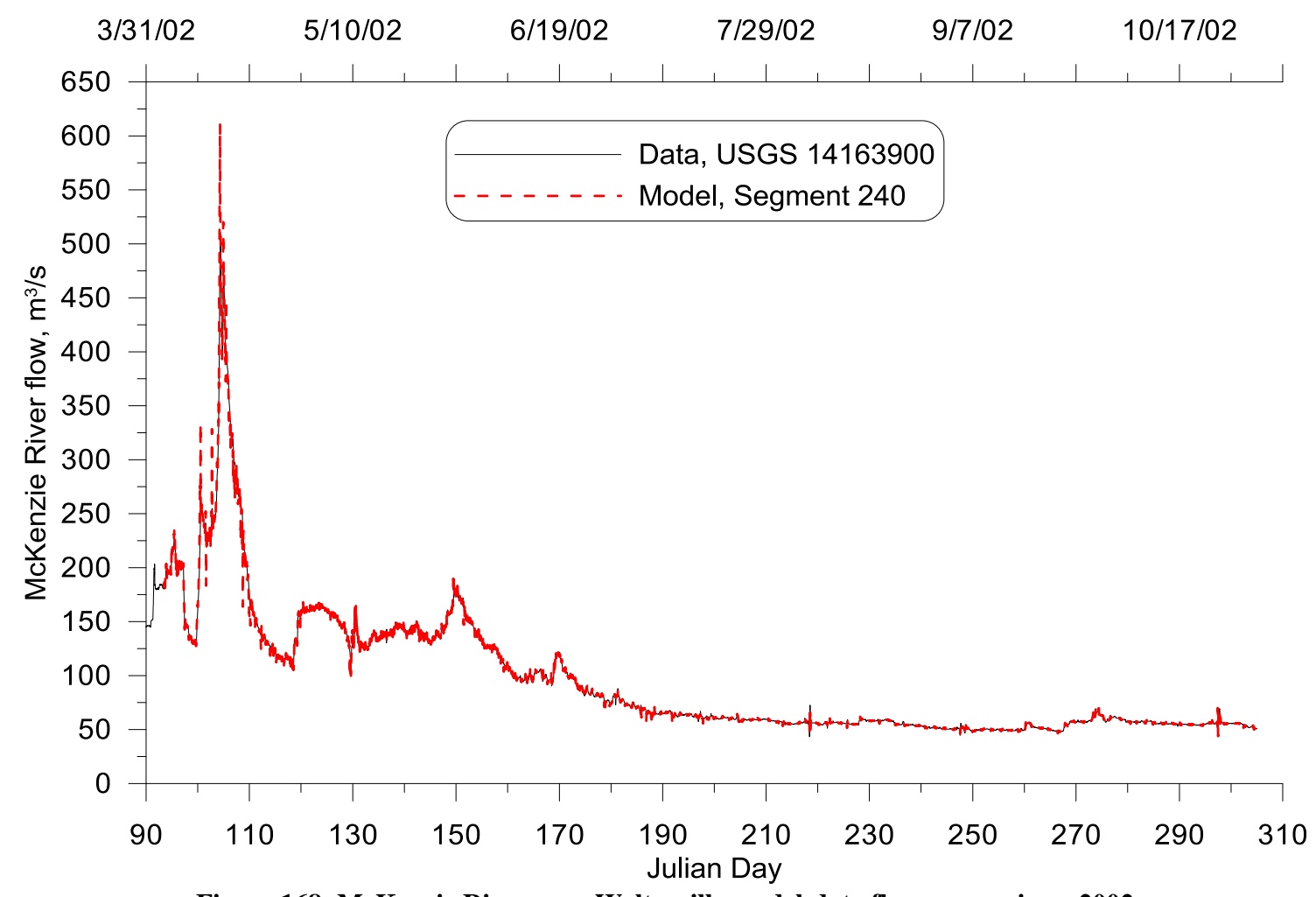

Figure 168: McKenzie River near Walterville model-data flow comparison, 2002 


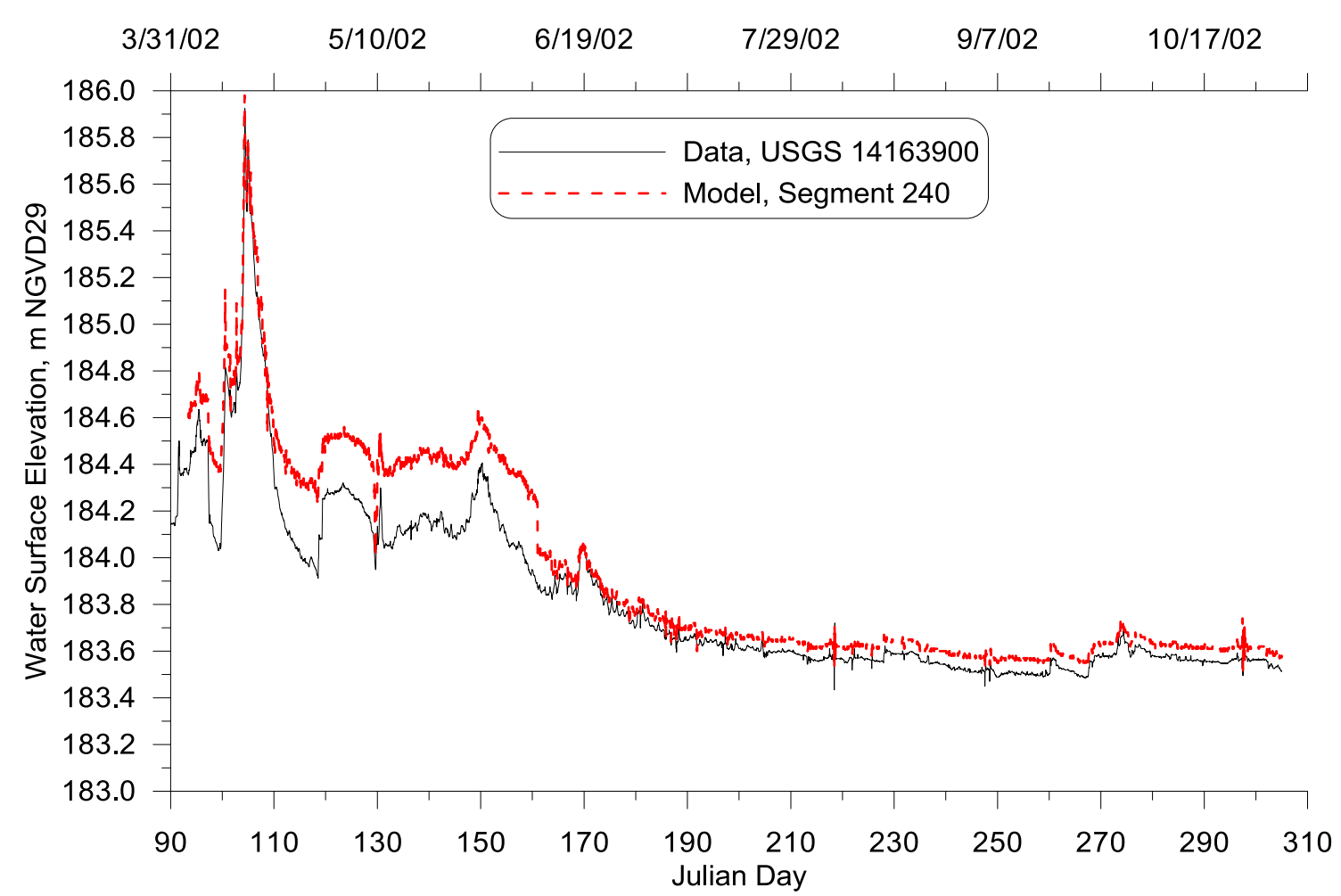

Figure 169: McKenzie River near Walterville model-data water level comparison, 2002

\section{Temperature}

\section{Year 2001}

Figure 170 through 180 show the McKenzie River continuous temperature comparison between model predictions and measured data in 2001. Error statistics are summarized in Table 20. Predicted temperature matched data very well for all the 11 sites with the RMSEs below $1.0^{\circ} \mathrm{C}$.

Table 20: McKenzie River continuous water temperature calibration model-data error statistics, 2001

\begin{tabular}{|c|c|c|c|c|c|c|}
\hline \multirow[b]{2}{*}{ Site ID } & \multirow[b]{2}{*}{ RM } & \multirow{2}{*}{$\begin{array}{l}\text { Model } \\
\text { Segment }\end{array}$} & \multicolumn{4}{|c|}{ Continuous Temperature } \\
\hline & & & $\begin{array}{l}\text { Number of } \\
\text { Comparisons }\end{array}$ & $\mathrm{ME},{ }^{\circ} \mathrm{C}$ & AME, ${ }^{\circ} \mathrm{C}$ & $\mathrm{RMSE},{ }^{\circ} \mathrm{C}$ \\
\hline USGS 14159500 & 60.39 & 4 & 6982 & 0.065 & 0.109 & 0.164 \\
\hline LASAR 26770 & 50.99 & 65 & 6638 & -0.399 & 0.594 & 0.673 \\
\hline USGS 14162500 & 44.56 & 108 & 7104 & -0.425 & 0.531 & 0.618 \\
\hline LASAR 25610 & 35.72 & 167 & 5711 & -0.445 & 0.739 & 0.89 \\
\hline
\end{tabular}




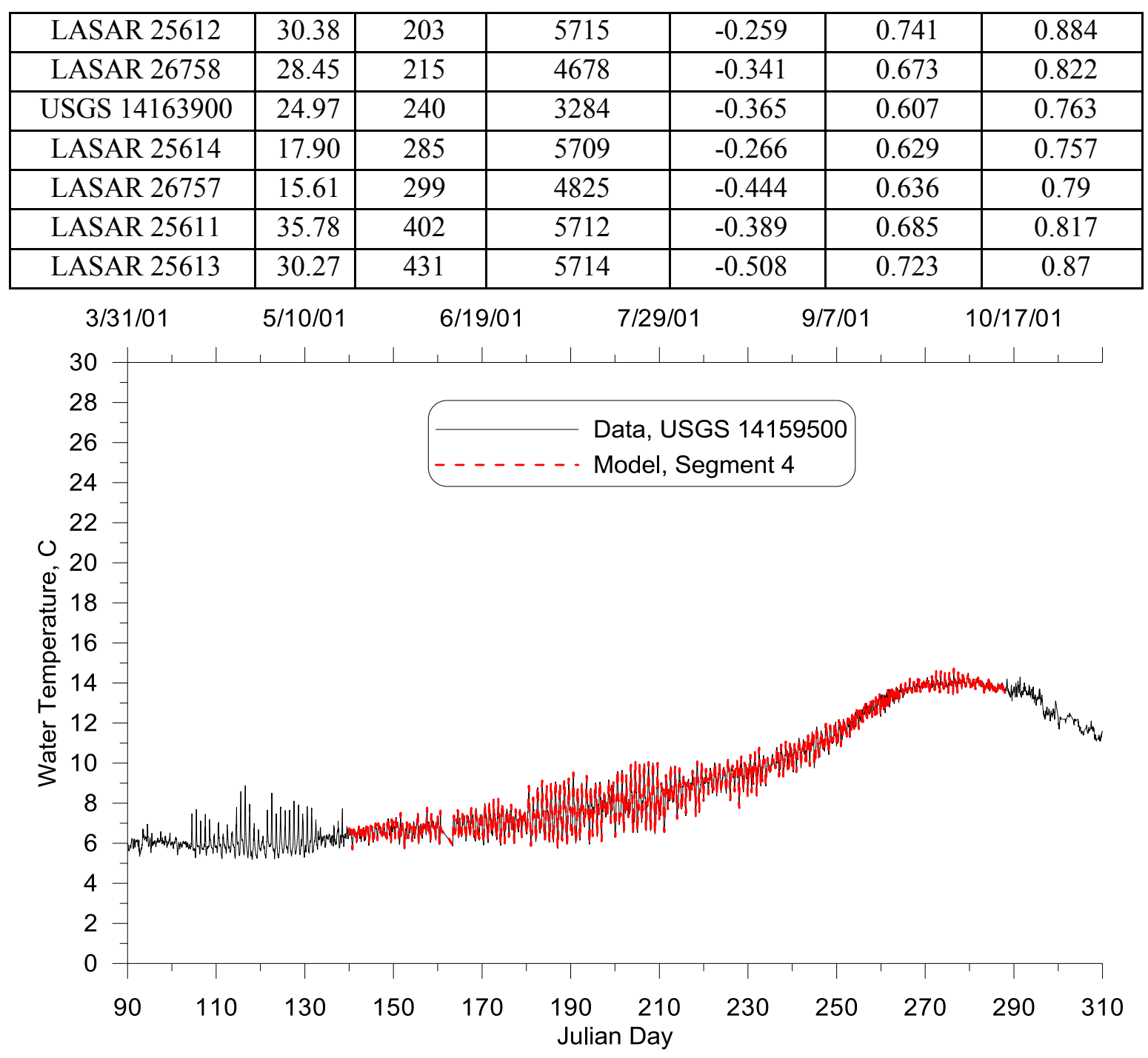

Figure 170: South Fork McKenzie River below Cougar Dam model-data continuous temperature comparison, 2001 


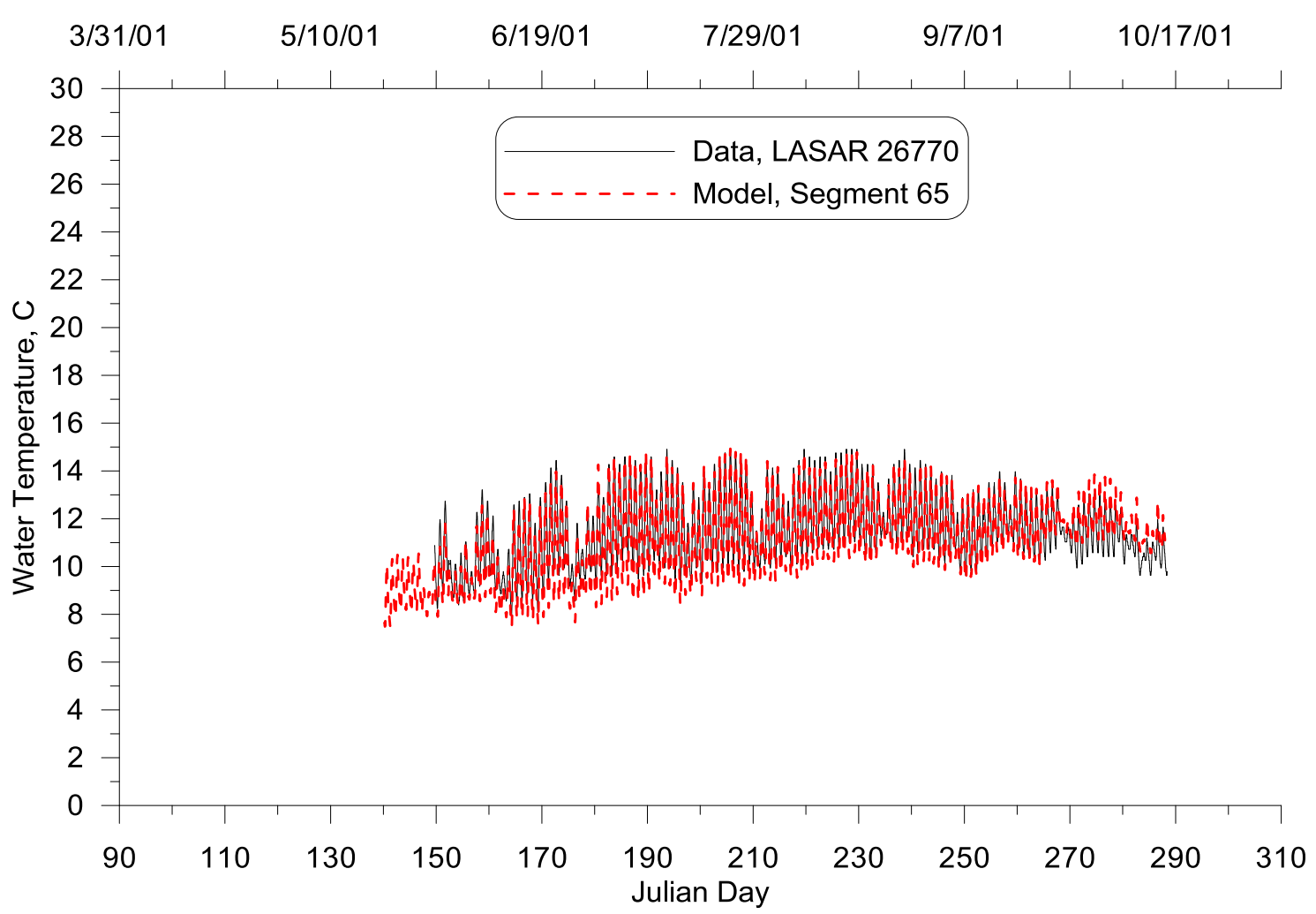

Figure 171: McKenzie River below Cougar River model-data continuous temperature comparison, 2001

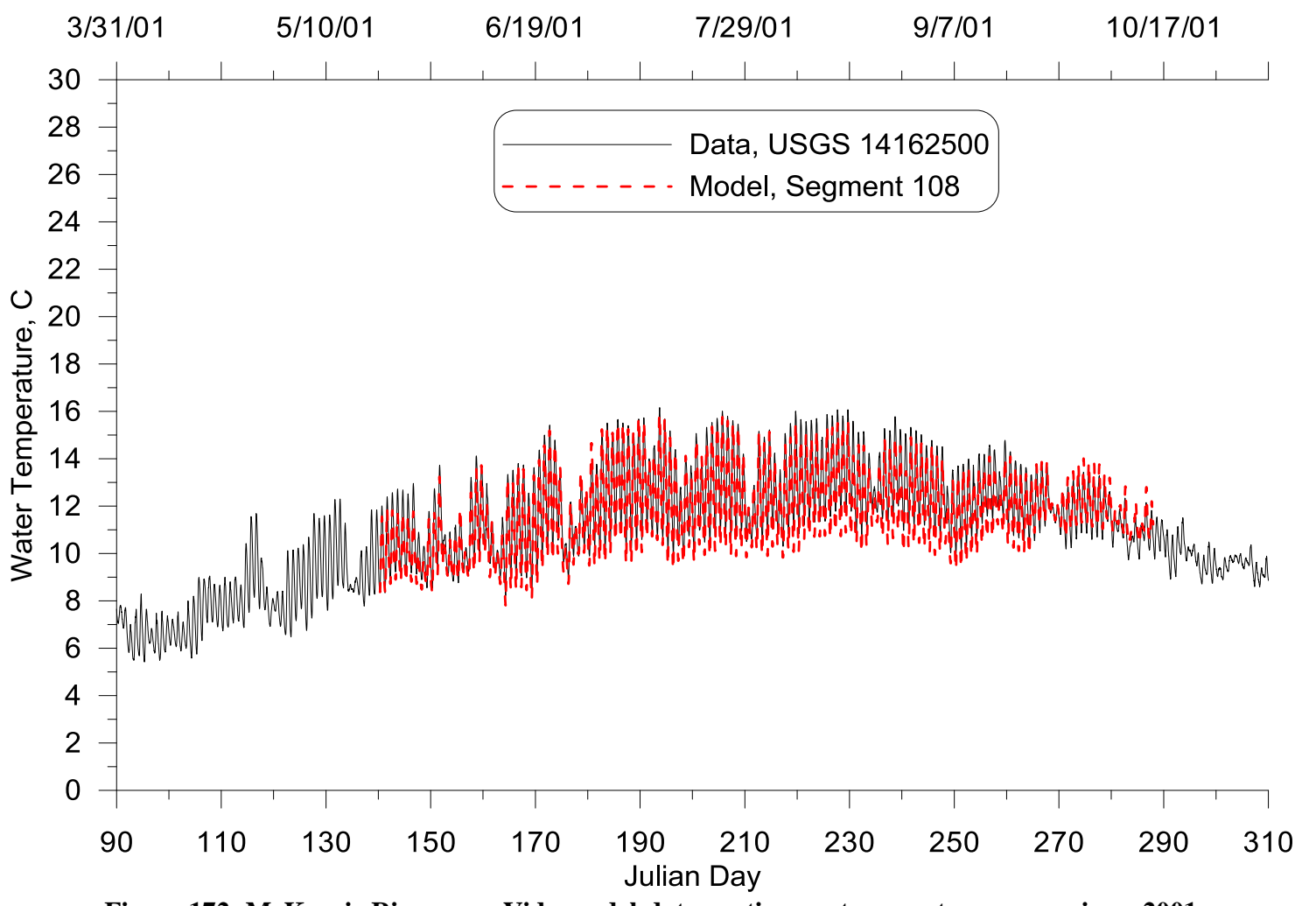

Figure 172: McKenzie River near Vida model-data continuous temperature comparison, 2001 


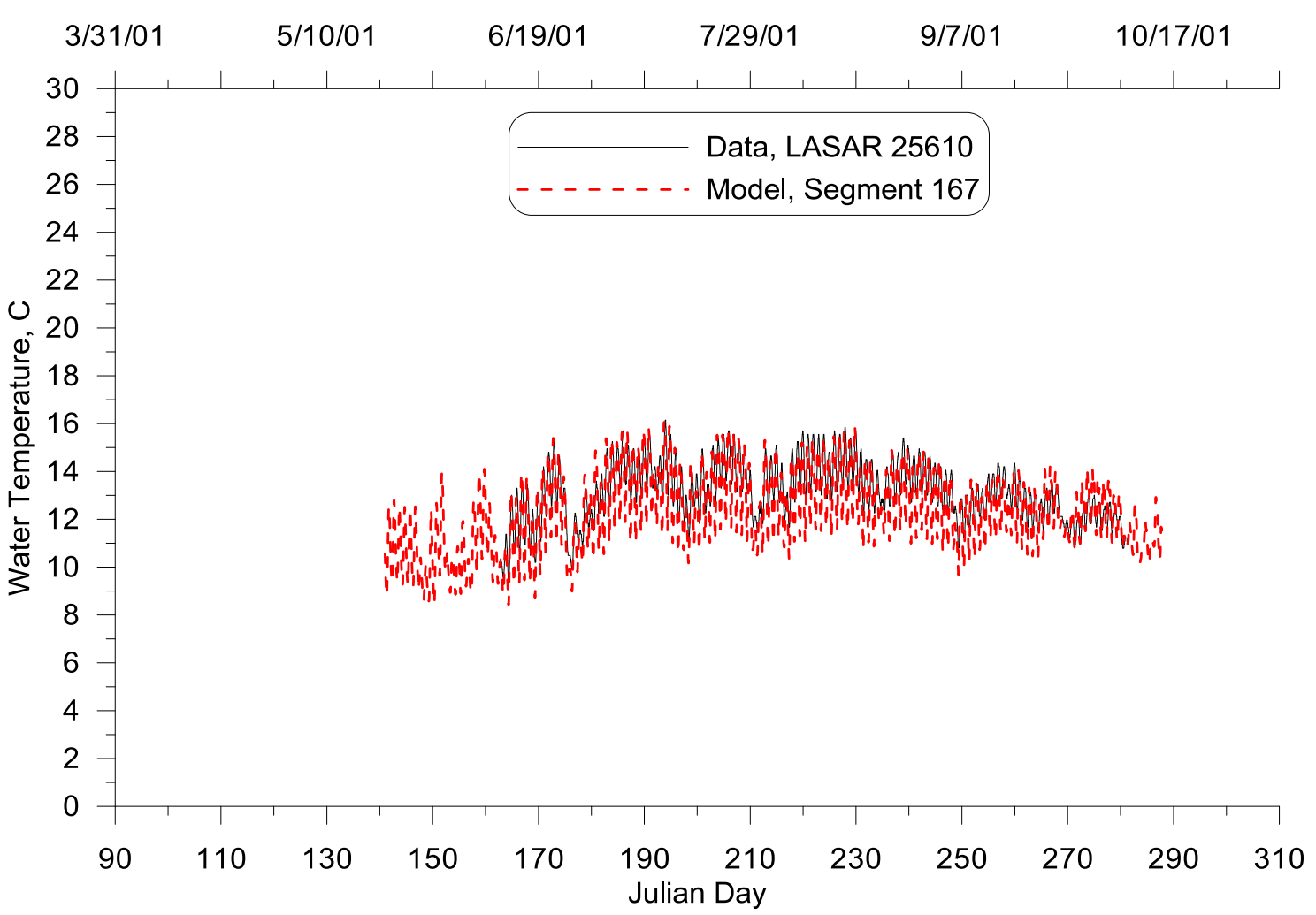

Figure 173: McKenzie River below Leaburg Dam model-data continuous temperature comparison, 2001

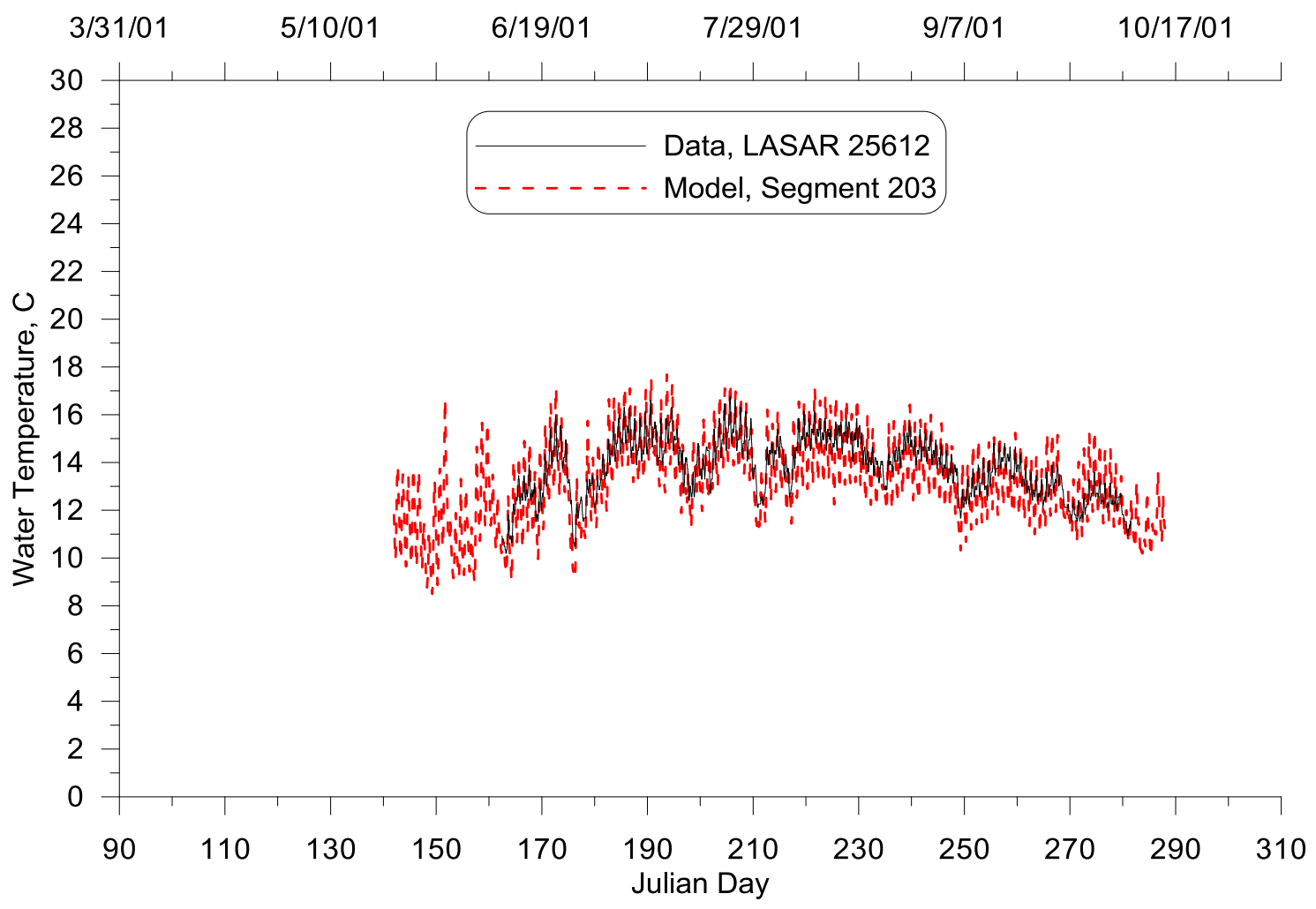

Figure 174: McKenzie River above the Leaburg tailrace model-data continuous temperature comparison, 2001 


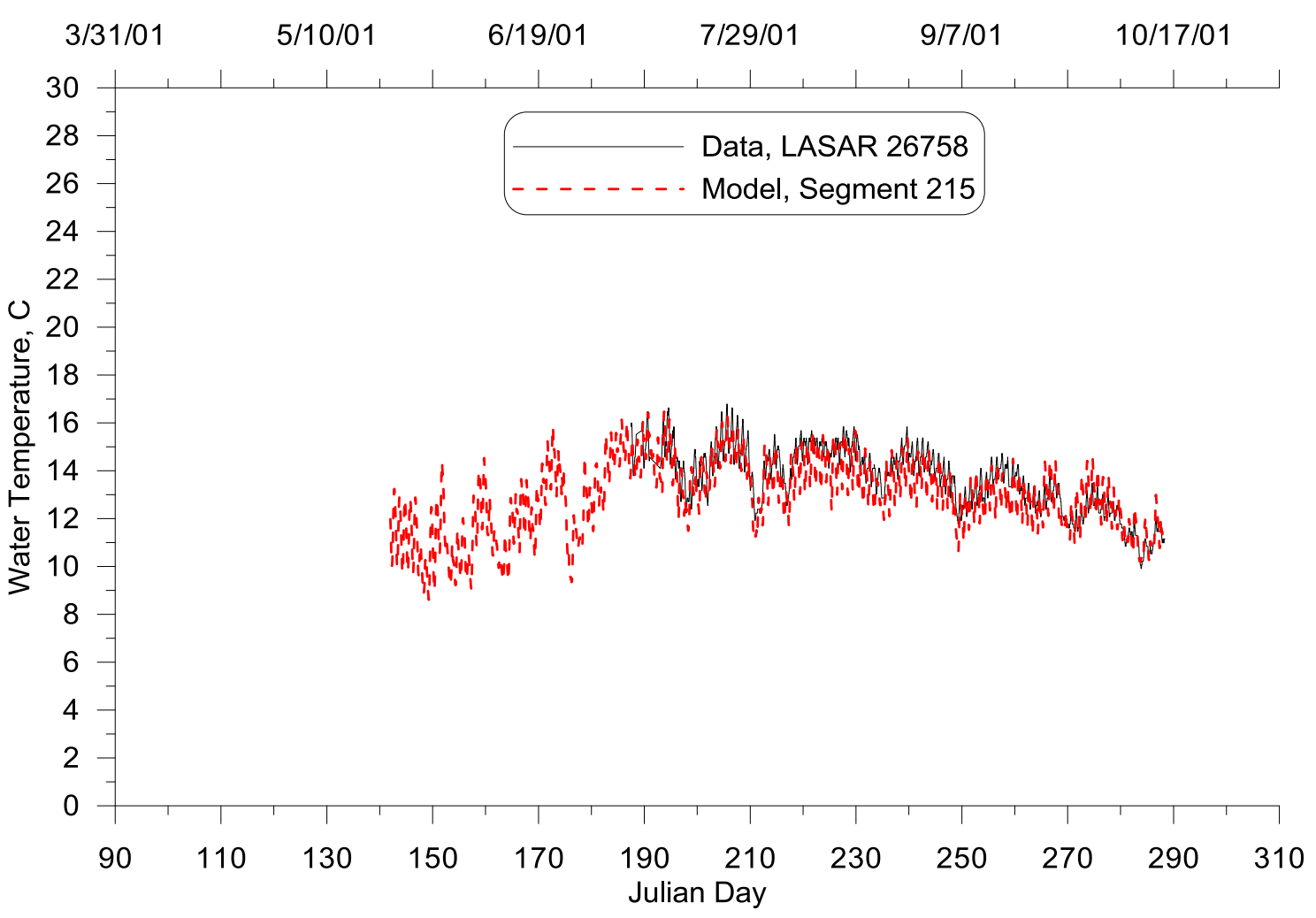

Figure 175: McKenzie River at Deerborn model-data continuous temperature comparison, 2001

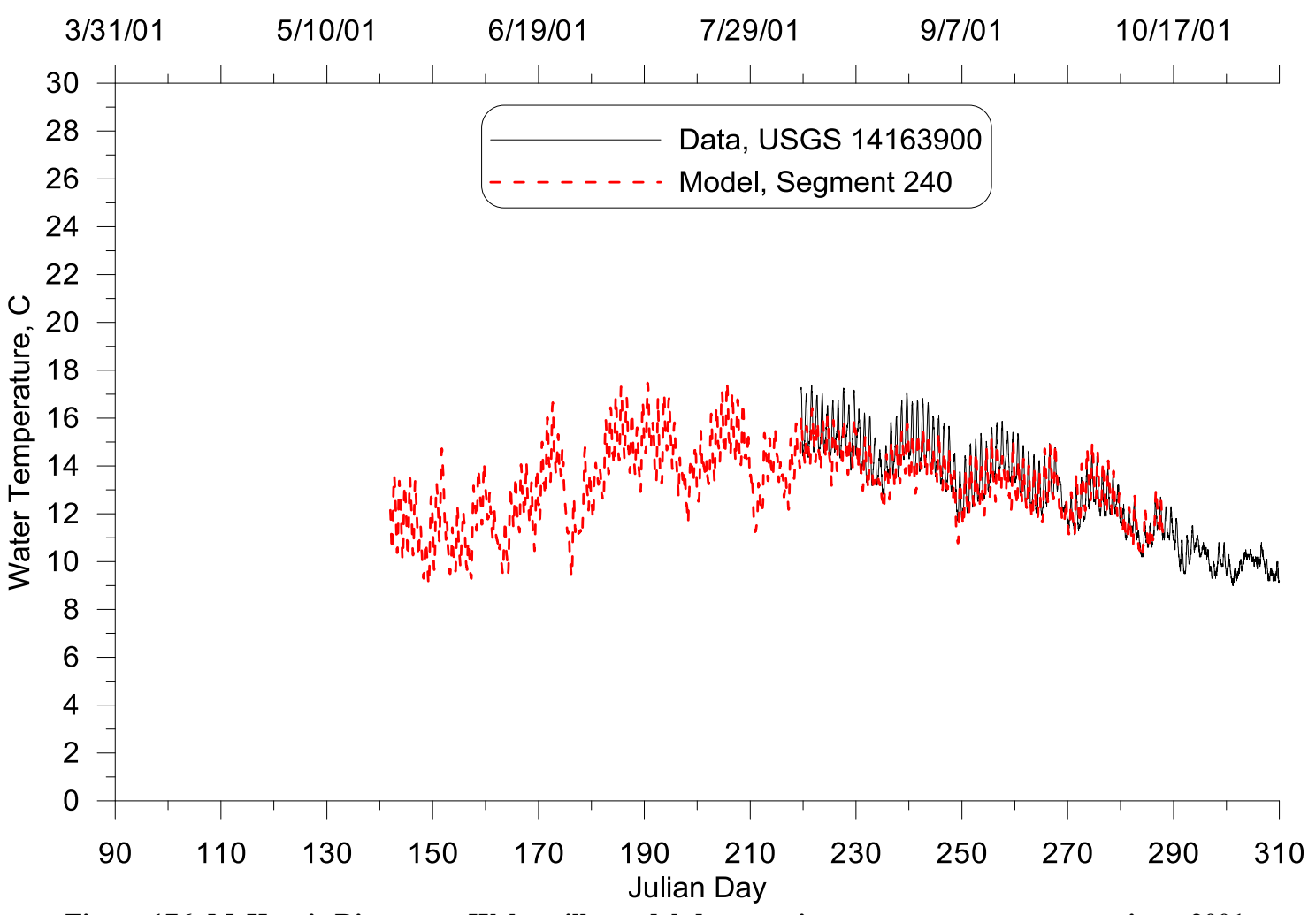

Figure 176: McKenzie River near Walterville model-data continuous temperature comparison, 2001 


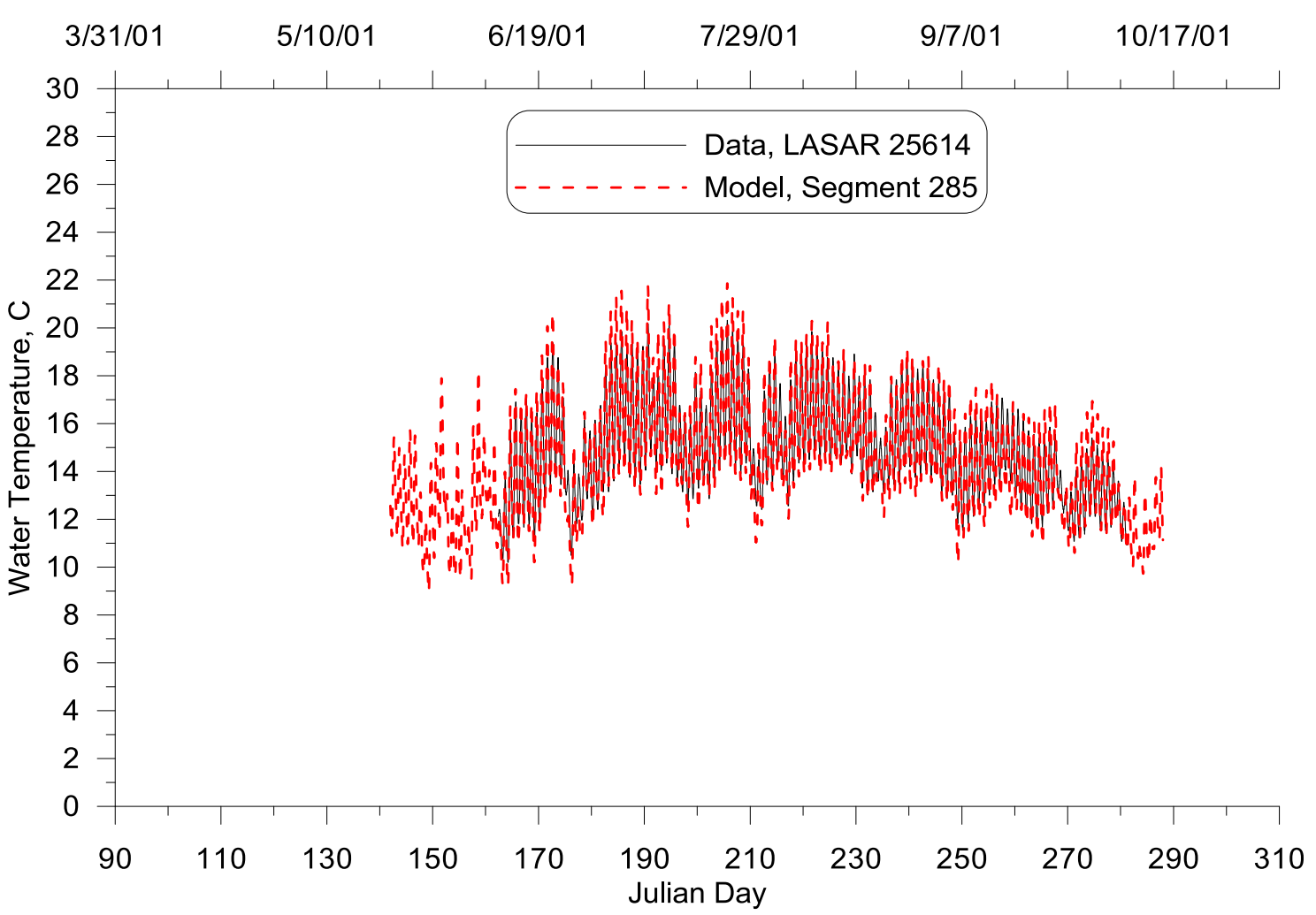

Figure 177: McKenzie River above Walterville Tailrace model-data continuous temperature comparison, 2001

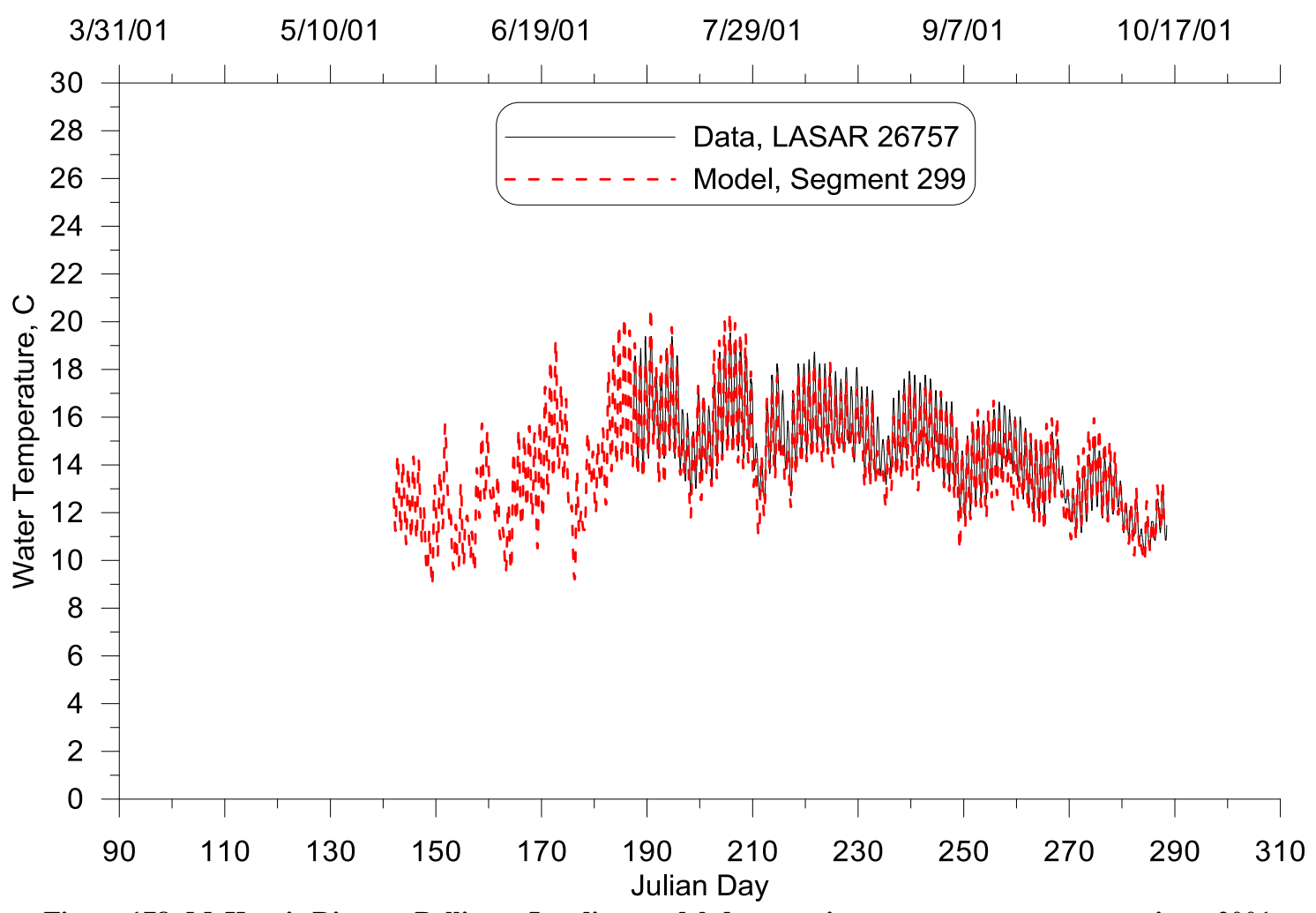

Figure 178: McKenzie River at Bellinger Landing model-data continuous temperature comparison, 2001 


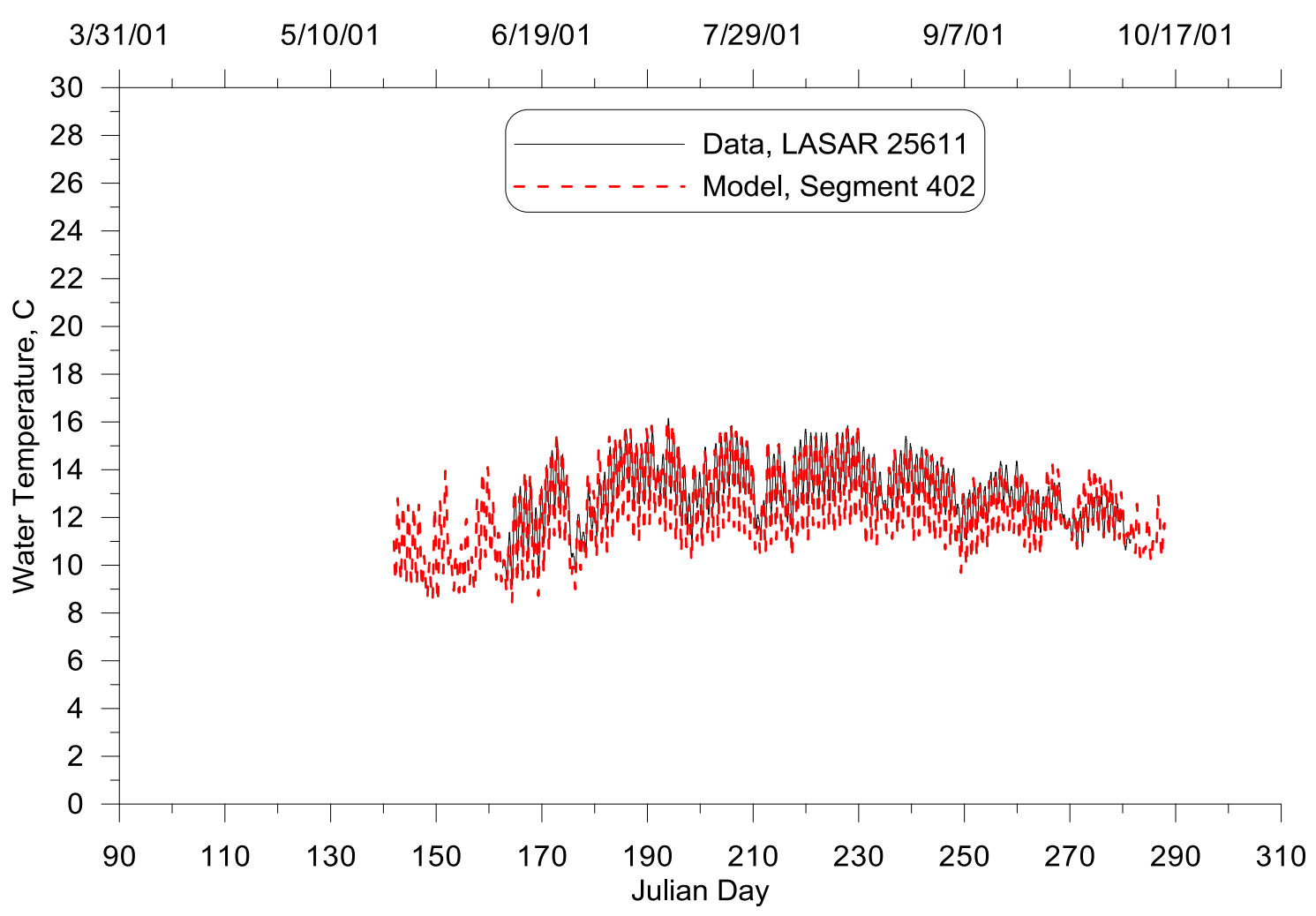

Figure 179: Leaburg Canal Intake, upstream end model-data continuous temperature comparison, 2001

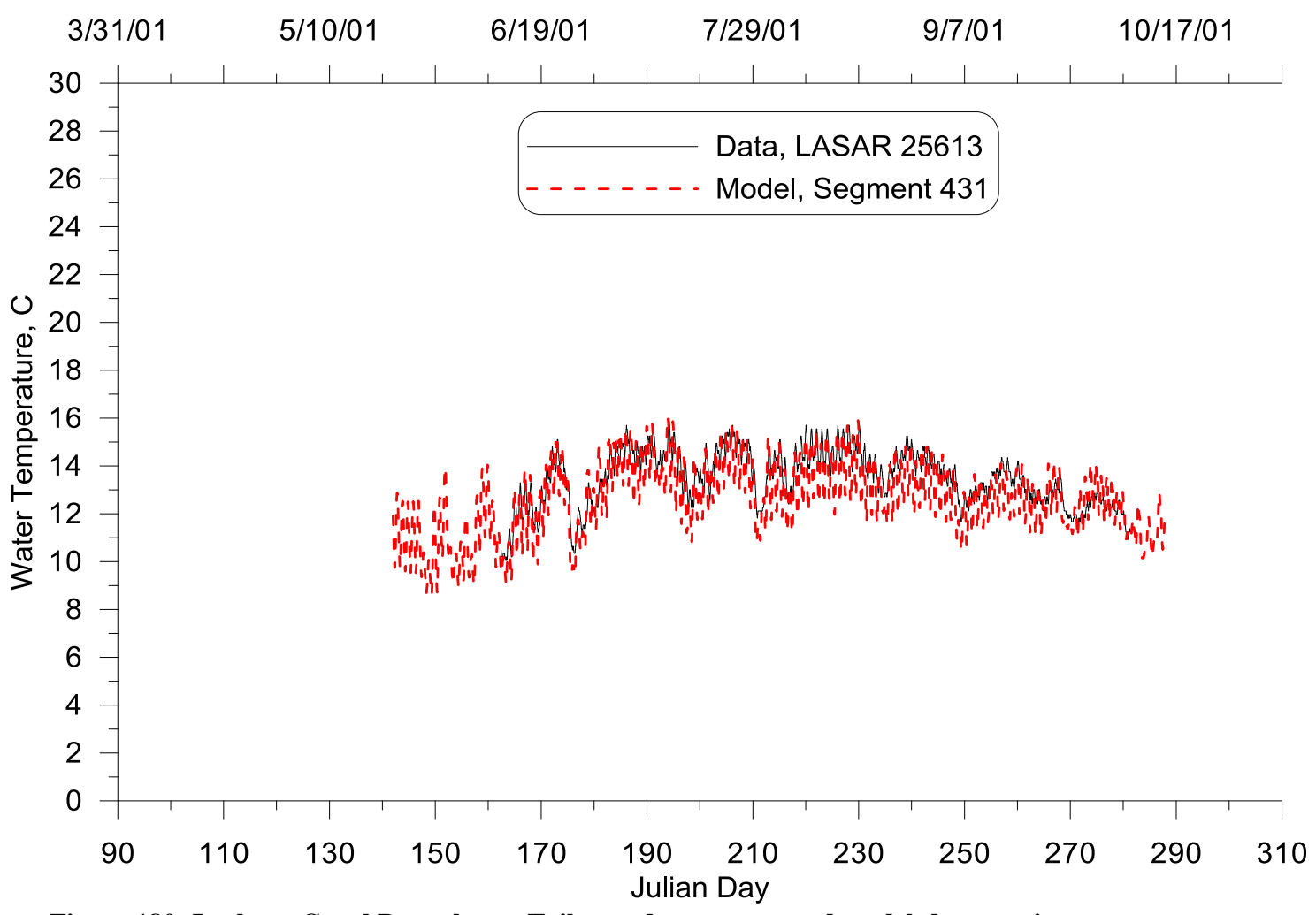

Figure 180: Leaburg Canal Powerhouse Tailrace, downstream end model-data continuous temperature comparison, 


\section{Year 2002}

Figure 181 through 192 show the McKenzie River continuous temperature comparison between model predictions and measured data in 2002. Error statistics are summarized in Table 21. Predicted temperature matched data very well for all the 12 sites with the RMSEs below $0.96^{\circ} \mathrm{C}$.

Table 21: McKenzie River continuous water temperature calibration model-data error statistics, 2002

\begin{tabular}{|c|c|c|c|c|c|c|}
\hline \multirow{2}{*}{ Site ID } & \multirow{2}{*}{$\mathrm{RM}$} & \multirow{2}{*}{$\begin{array}{c}\text { Model } \\
\text { Segment }\end{array}$} & & \multicolumn{4}{|c|}{ Continuous Temperature } \\
\cline { 5 - 7 } & & & $\begin{array}{c}\text { Number of } \\
\text { Comparisons }\end{array}$ & ME, ${ }^{\circ} \mathrm{C}$ & AME, ${ }^{\circ} \mathrm{C}$ & \multirow{2}{*}{ RMSE, ${ }^{\circ} \mathrm{C}$} \\
\hline USGS 14159500 & 60.39 & 4 & 10271 & 0.035 & 0.098 & 0.15 \\
\hline LASAR 26770 & 50.99 & 65 & 5856 & -0.134 & 0.324 & 0.397 \\
\hline USGS 14162500 & 44.56 & 108 & 10270 & 0.333 & 0.403 & 0.507 \\
\hline LASAR 28504 & 40.74 & 132 & 3385 & 0.345 & 0.406 & 0.509 \\
\hline LASAR 25610 & 35.72 & 167 & 5668 & 0.284 & 0.644 & 0.803 \\
\hline LASAR 26758 & 28.45 & 215 & 5666 & 0.164 & 0.666 & 0.81 \\
\hline USGS 14163900 & 24.97 & 240 & 10270 & 0.167 & 0.521 & 0.662 \\
\hline LASAR 26757 & 15.61 & 299 & 4870 & 0.011 & 0.437 & 0.551 \\
\hline LASAR 29645 & 10.40 & 333 & 5857 & -0.048 & 0.534 & 0.654 \\
\hline LASAR 10376 & 3.38 & 378 & 5715 & 0.079 & 0.508 & 0.628 \\
\hline LASAR 25611 & 35.78 & 402 & 5669 & 0.403 & 0.654 & 0.831 \\
\hline LASAR 25613 & 30.27 & 431 & 5667 & 0.314 & 0.764 & 0.954 \\
\hline
\end{tabular}




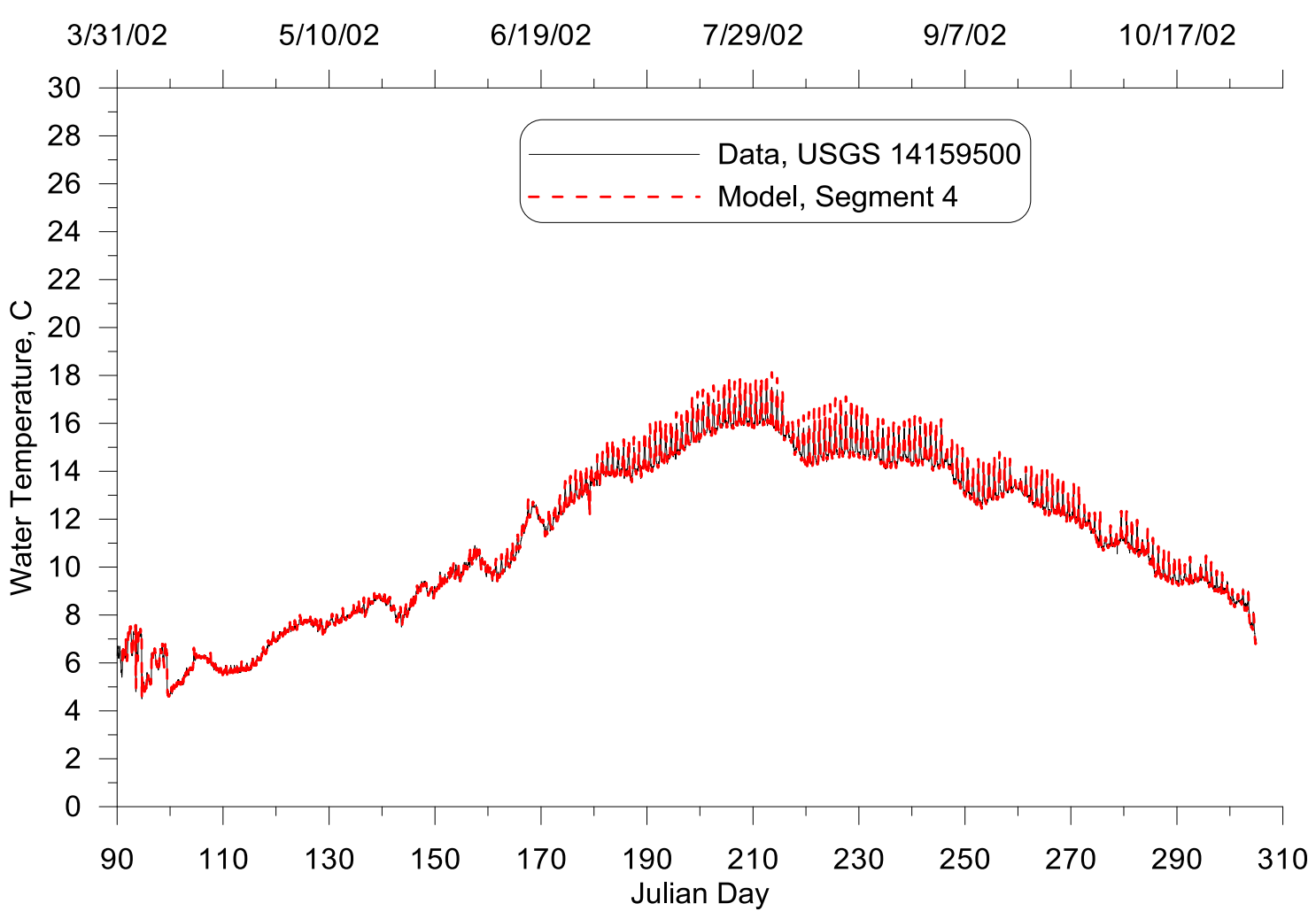

Figure 181: South Fork McKenzie below Cougar Dam model-data continuous temperature comparison, 2002

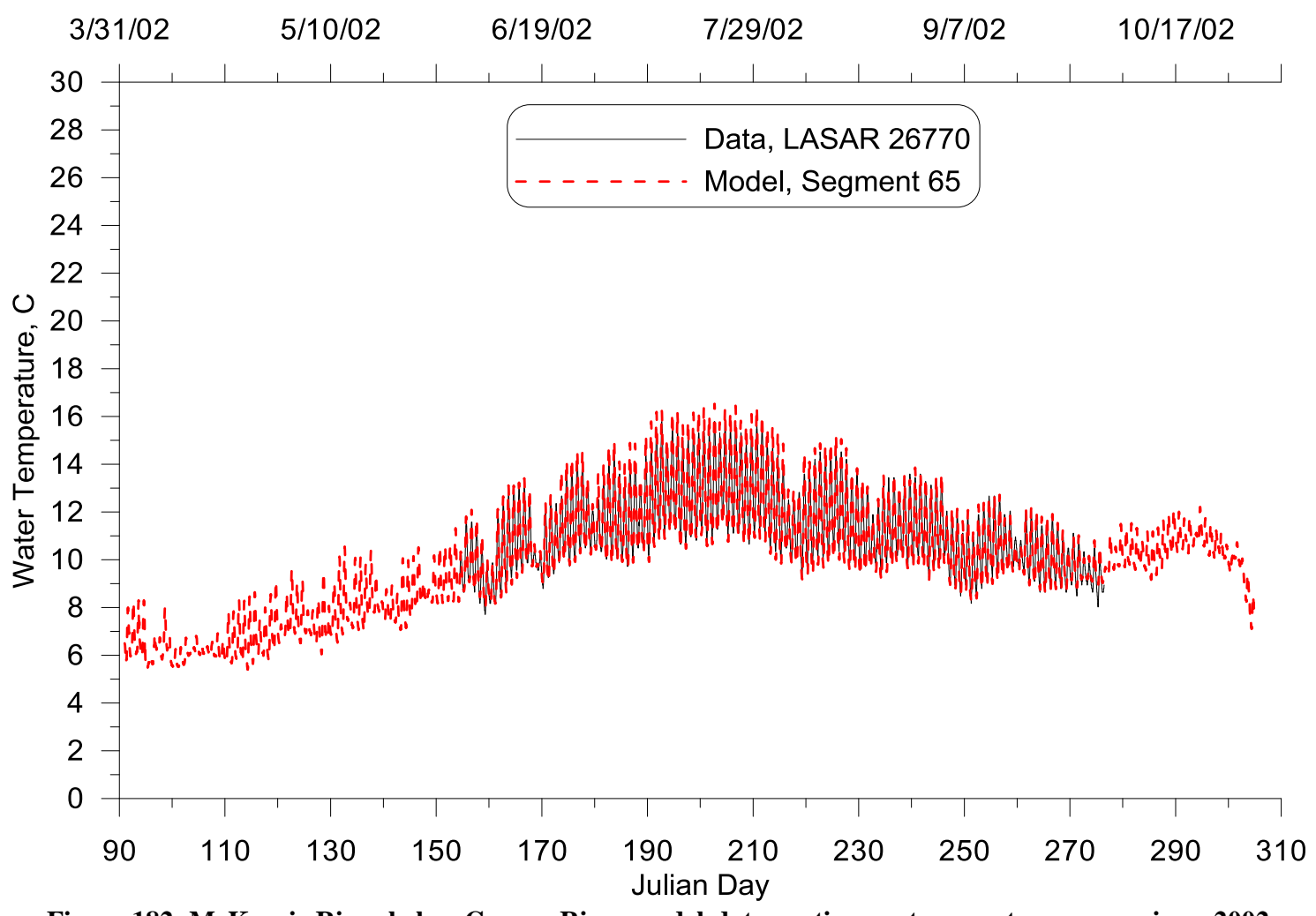

Figure 182: McKenzie River below Cougar River model-data continuous temperature comparison, 2002 


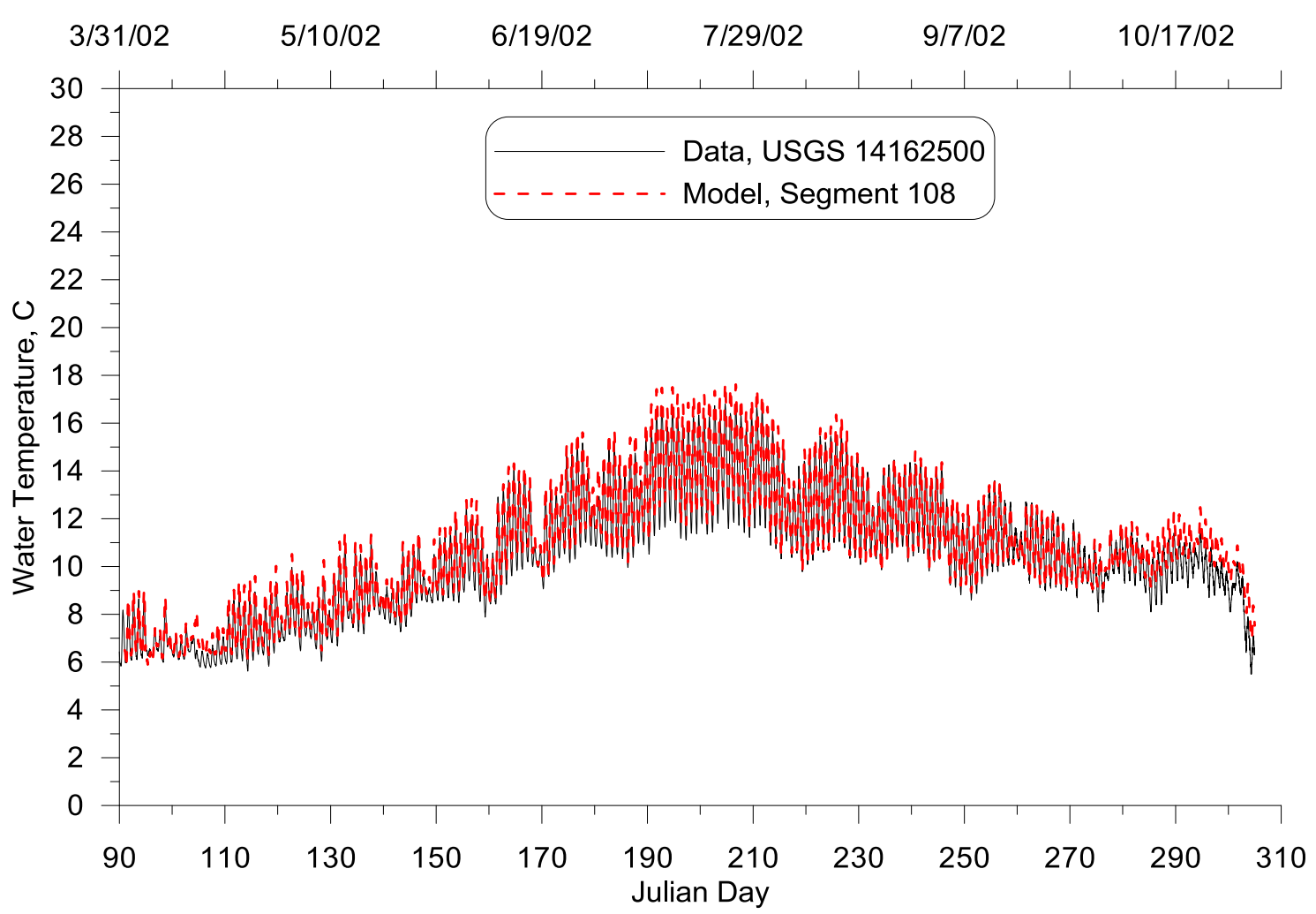

Figure 183: McKenzie River near Vida model-data continuous temperature comparison, 2002

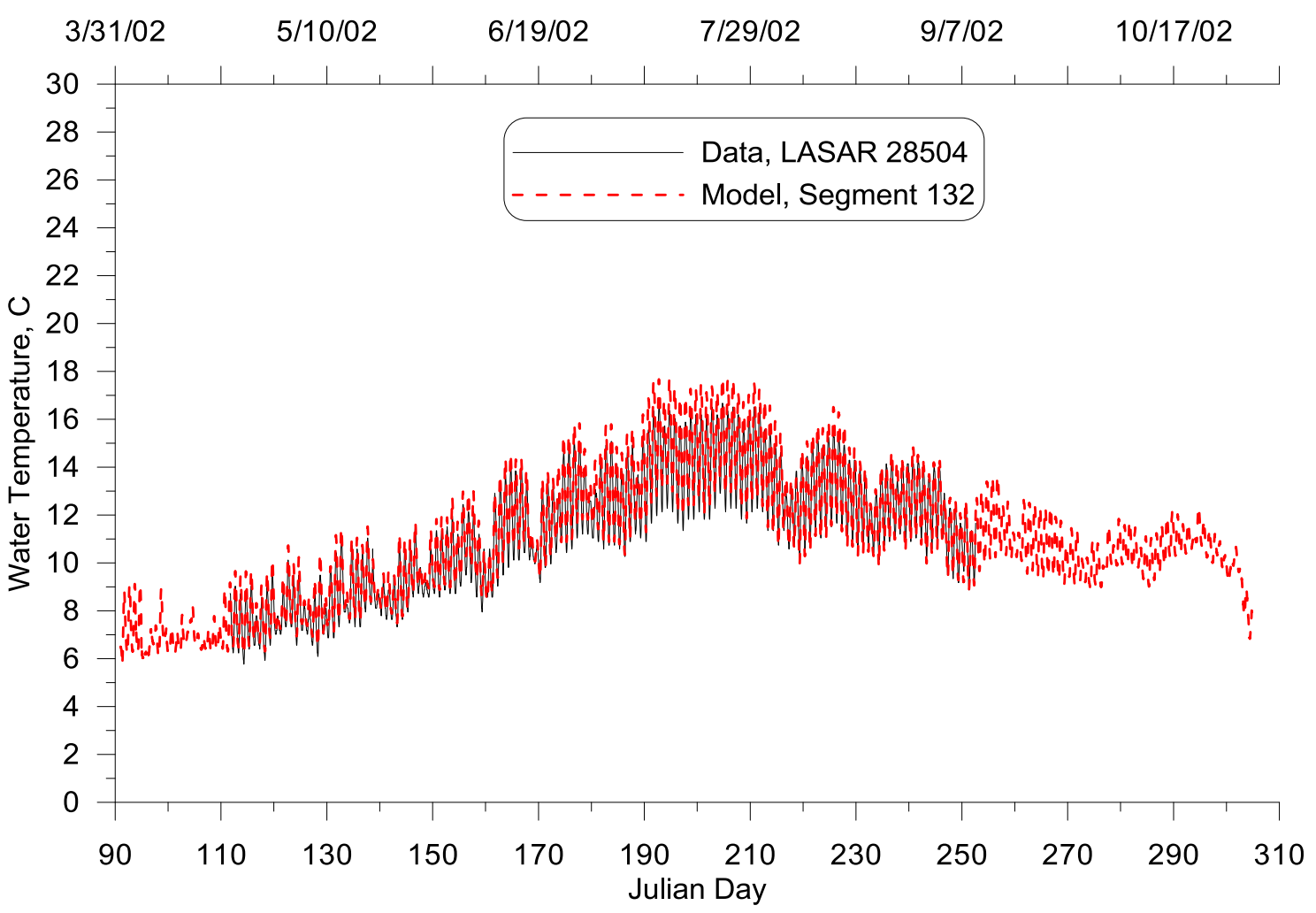

Figure 184: McKenzie River at Helfrich boat ramp model-data continuous temperature comparison, 2002 


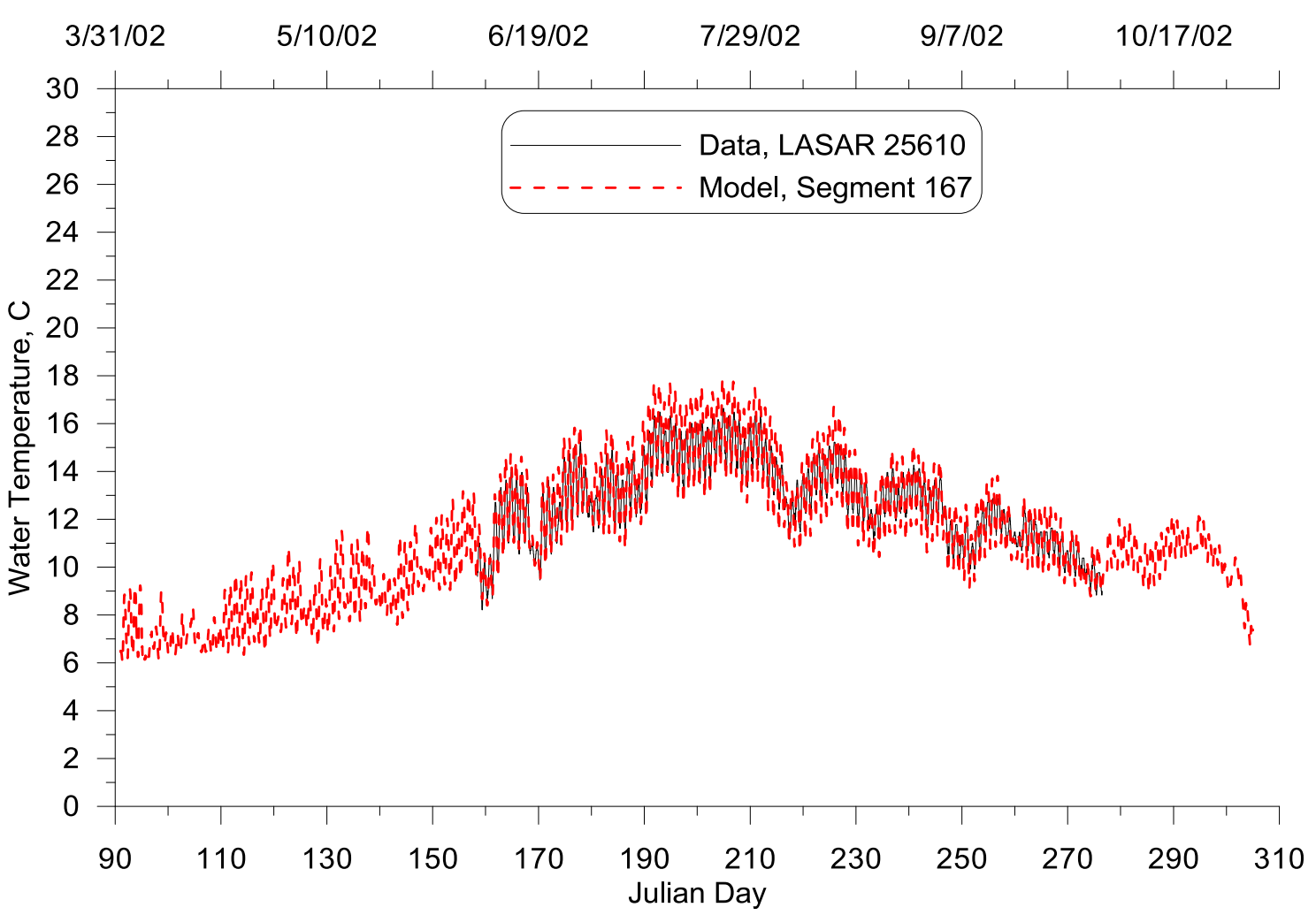

Figure 185: McKenzie River below Leaburg Dam model-data continuous temperature comparison, 2002

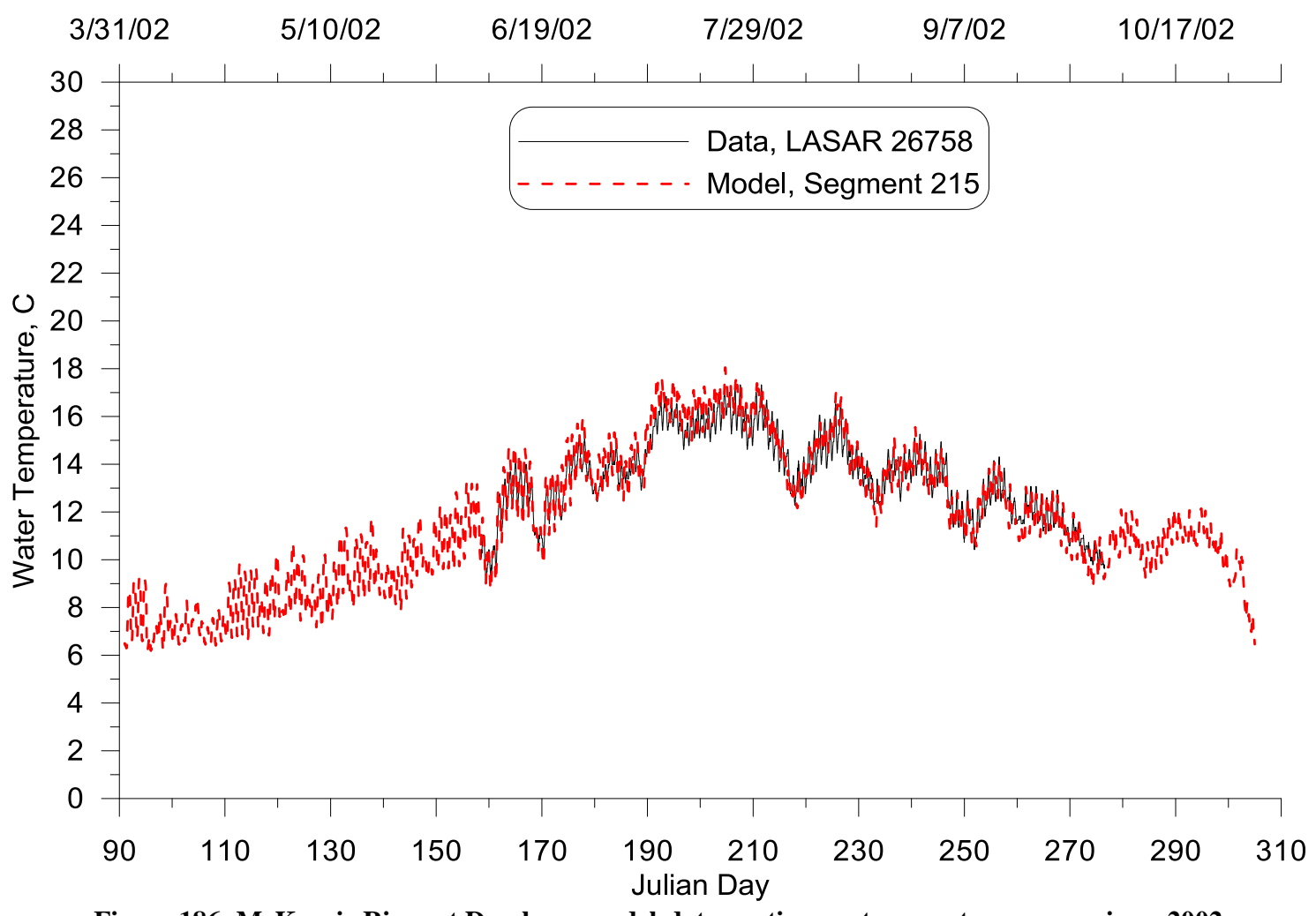

Figure 186: McKenzie River at Deerborn model-data continuous temperature comparison, 2002 


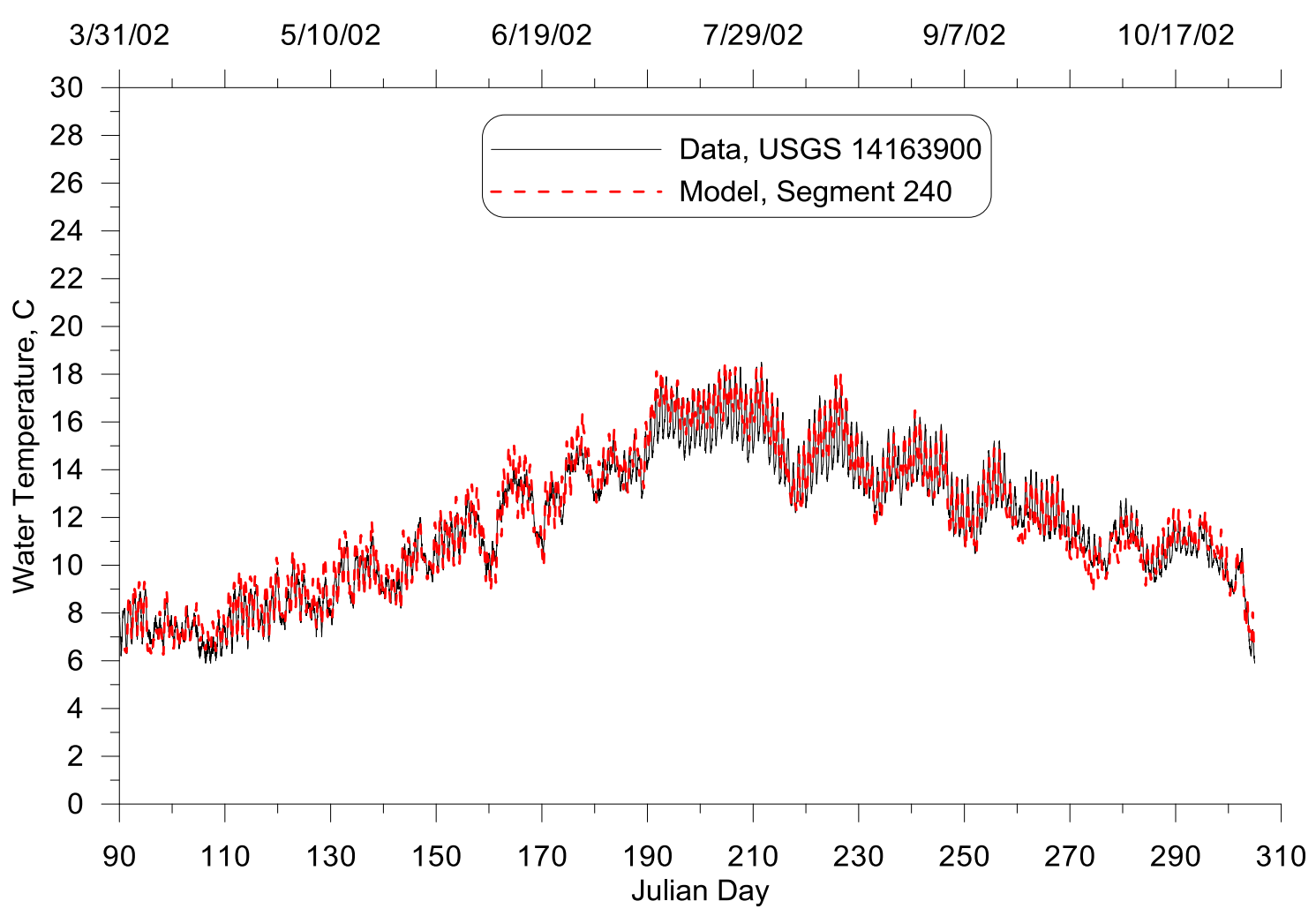

Figure 187: McKenzie River near Walterville model-data continuous temperature comparison, 2002

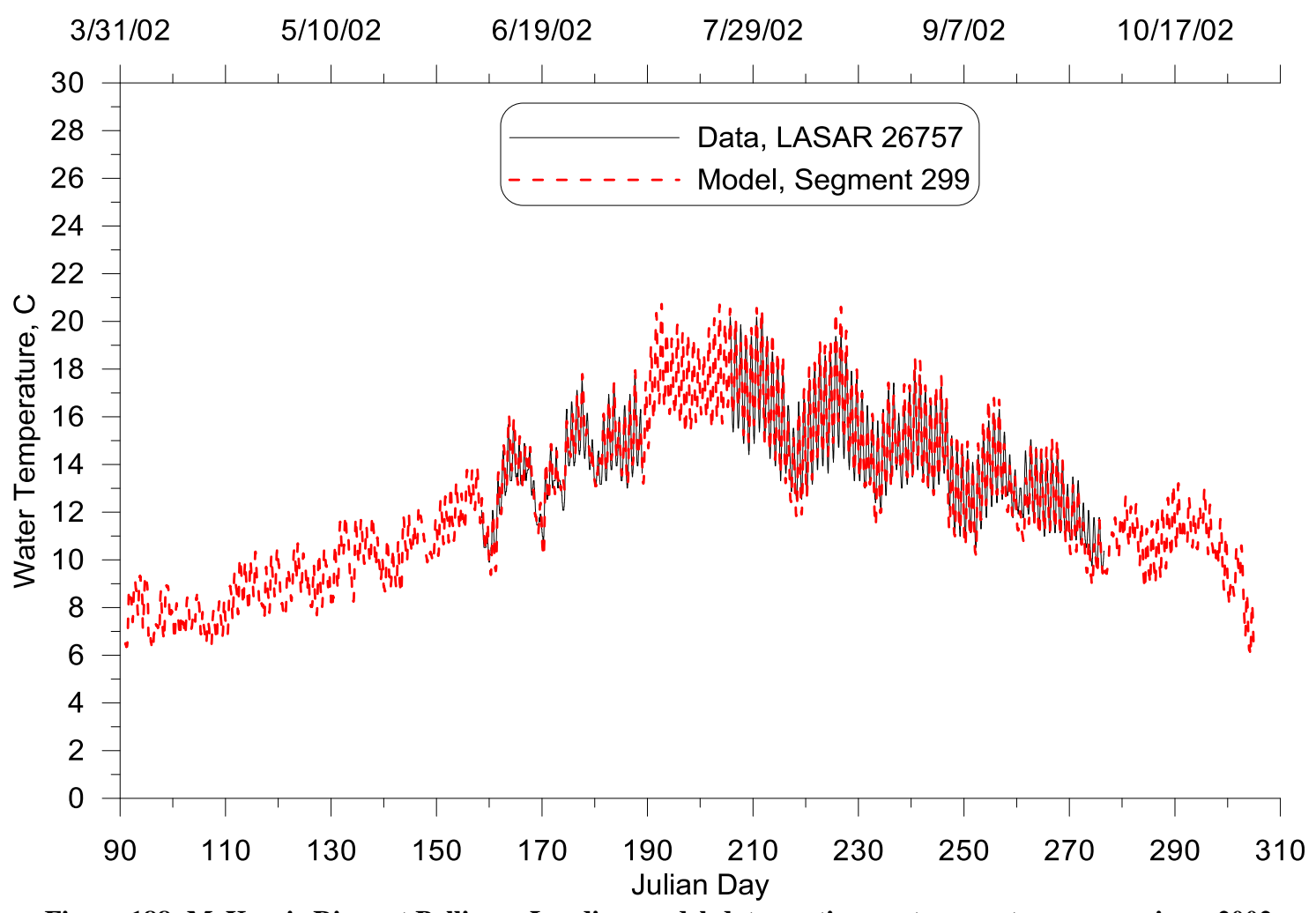

Figure 188: McKenzie River at Bellinger Landing model-data continuous temperature comparison, 2002 


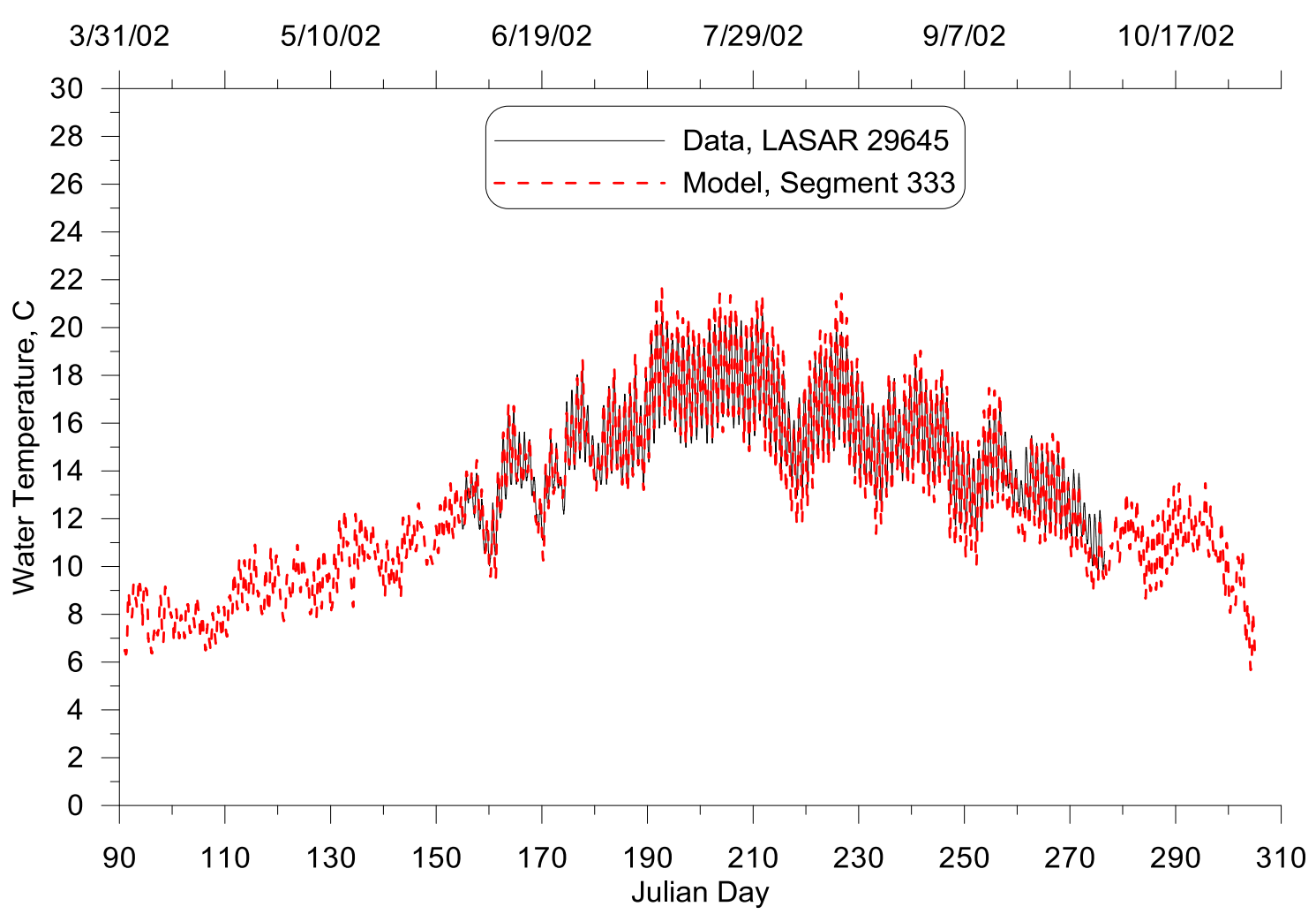

Figure 189: McKenzie River above Mohawk River model-data continuous temperature comparison, 2002

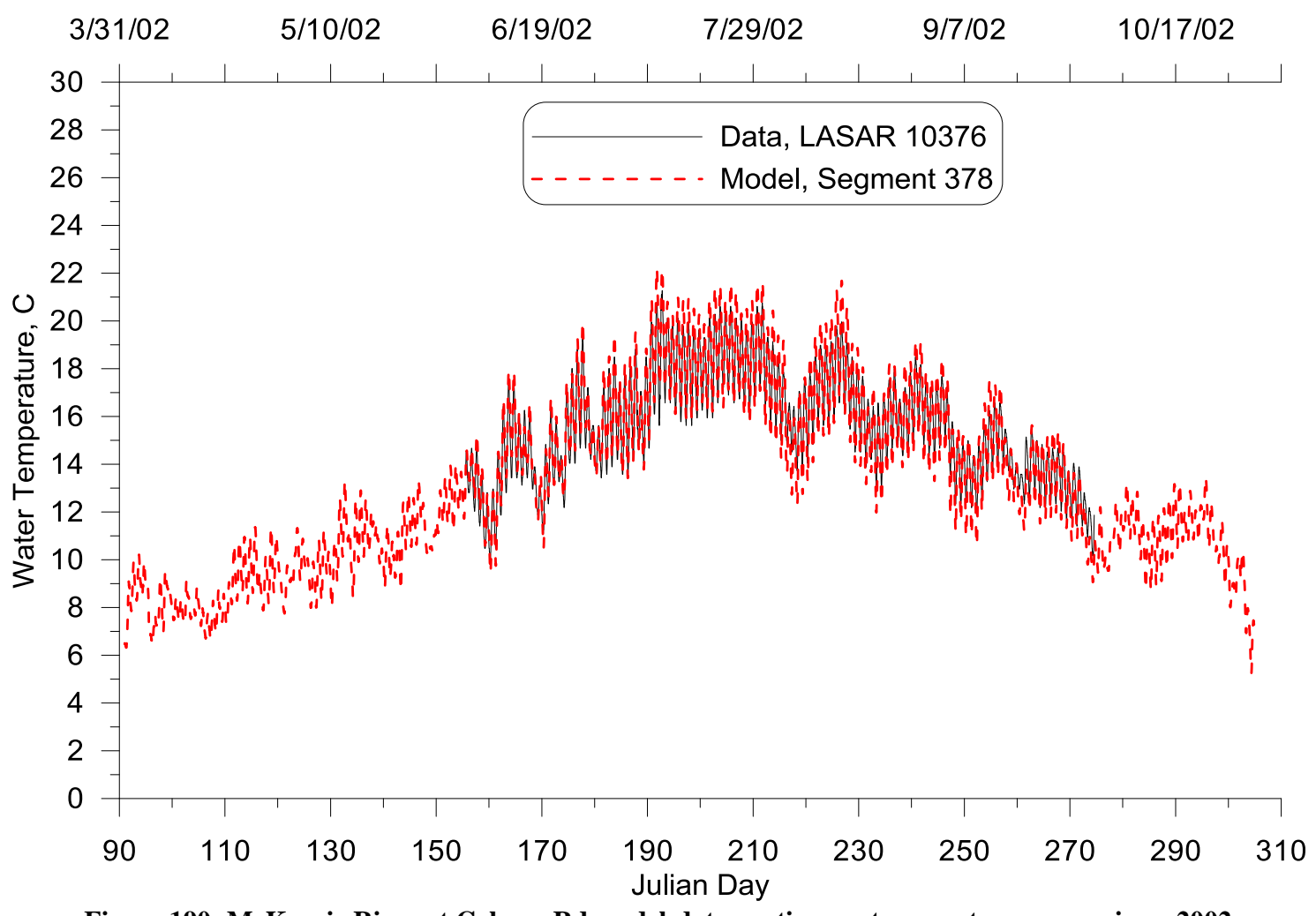

Figure 190: McKenzie River at Coburg Rd model-data continuous temperature comparison, 2002 


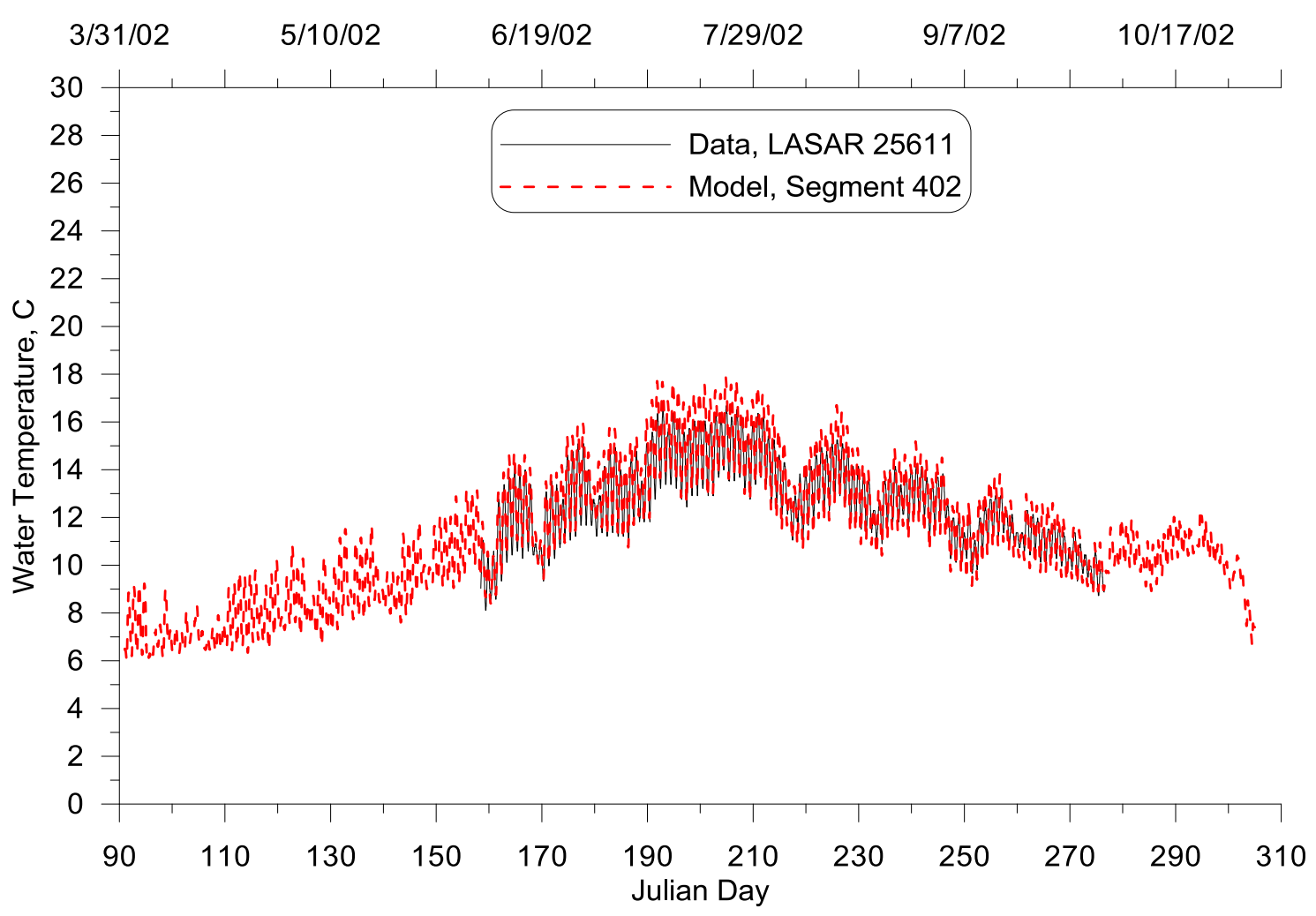

Figure 191: Leaburg Canal Intake, upstream end model-data continuous temperature comparison, 2002

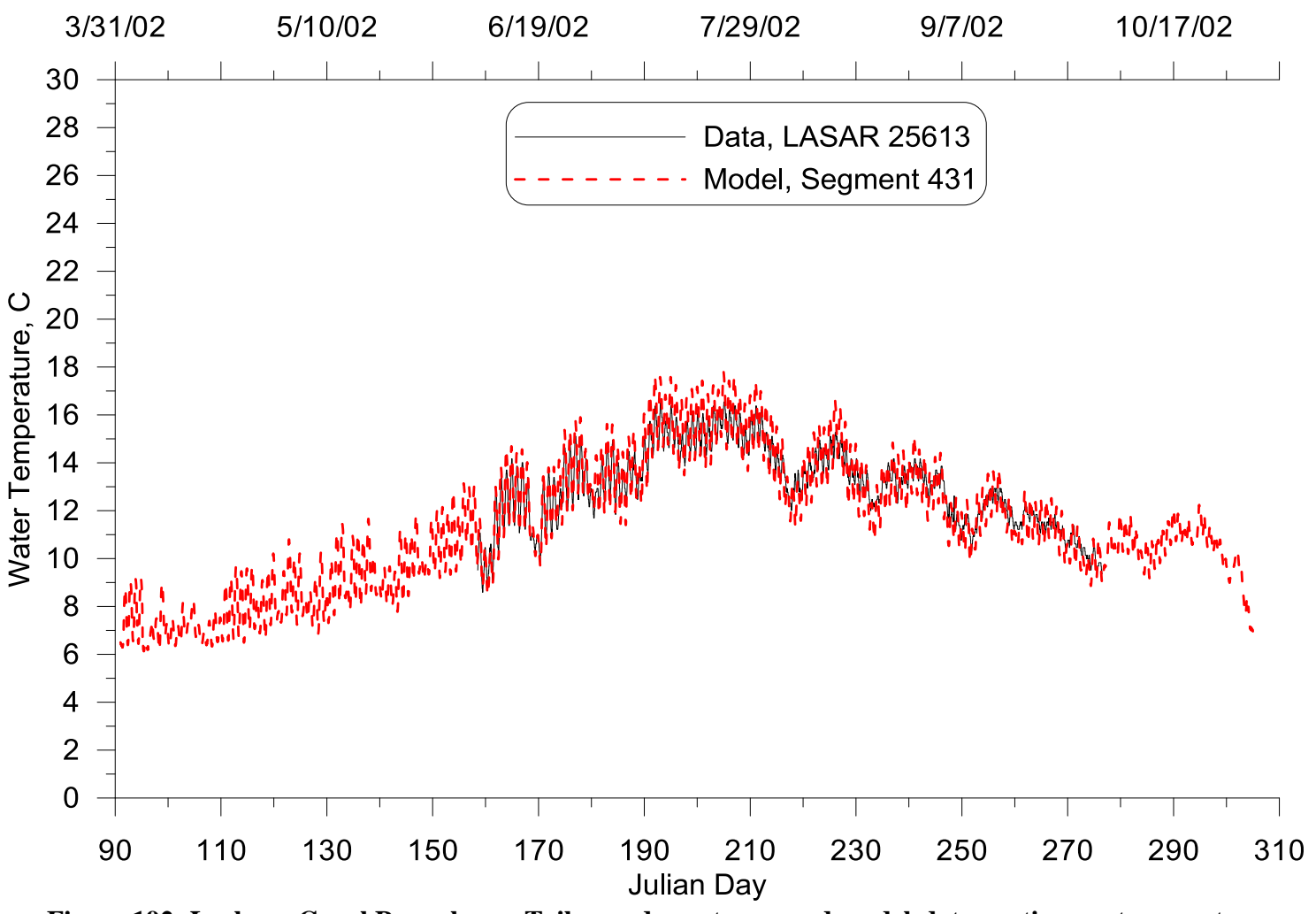

Figure 192: Leaburg Canal Powerhouse Tailrace, downstream end model-data continuous temperature comparison, 


\subsubsection{Long Tom River}

\section{Introduction}

The Long Tom River domain starts from Fern Ridge Dam at RM 23.7 and ends at its confluence with the Willamette River. The model was set up as 1 water body including 14 branches, with 187 segments and 22 layers. The model grid is shown in Figure 193. There were no tributaries flows into the system. Several spillways/weirs/dams were added in Version 3.1 model to represent the natural stone barriers along the upstream section of the river.

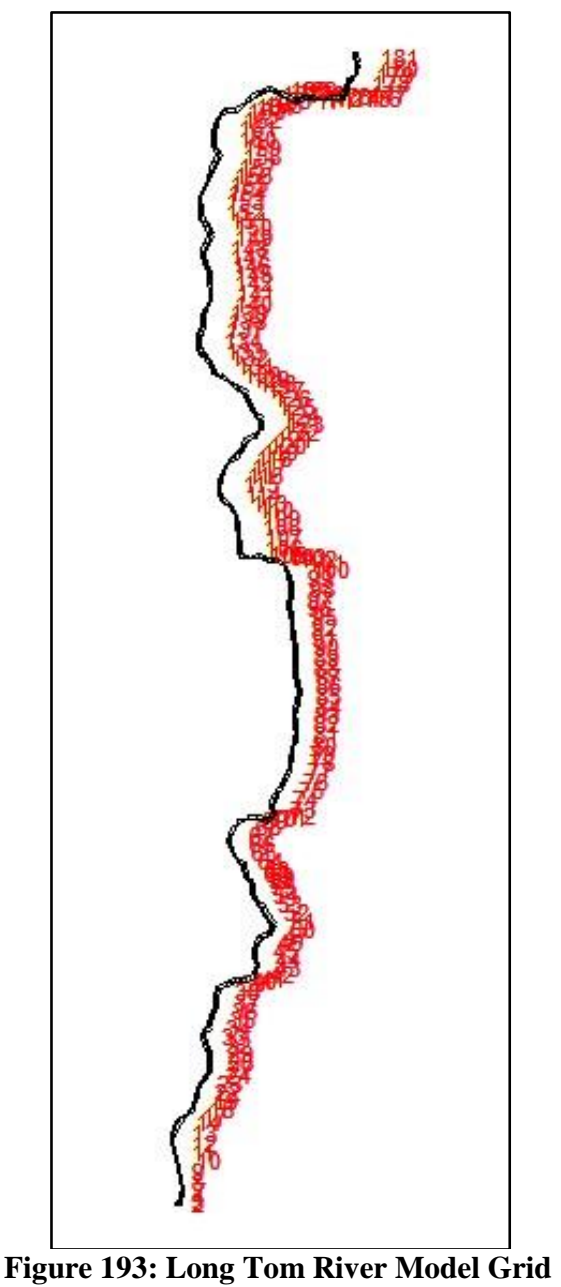




\section{Hydrodynamics}

The flow calibration was done in Version 3.1, in which distributed tributaries were added to compensate the lacking of tributary inflow data. While calibrating water level, Manning's friction coefficient and hydraulic equivalent slope were chosen to be the calibration parameters. It was found out that by delicately adjusting Manning's friction coefficient and hydraulic equivalent slope, calculation time can be greatly reduced.

\section{Year 2001}

The hydrodynamic calibration period in 2001 was from June to October. Figure 194 through 197 show the water level and flow comparison between model predictions and measured data. Error statistics are summarized in Table 22.

The flow predictions result matched well with data for the both sites. For water level, at segment 2, however, the model over estimated at high flow conditions, and under estimated at low flow conditions. The 1-meter layer depth might result in coarse bathymetry and led this problem to occur. Similar problem existed in V3.1 model, but was not as severe as in V3.7 model.

Table 22 Long Tom River hydrodynamic calibration model-data error statistics, 2001

\begin{tabular}{|c|c|c|c|c|c|c|}
\hline \multicolumn{7}{|c|}{ Flow } \\
\hline Gage ID & RM & $\begin{array}{c}\text { Model } \\
\text { Segment }\end{array}$ & $\begin{array}{c}\text { Sample } \\
\text { size, N }\end{array}$ & $\mathrm{ME}, \mathrm{m}^{3} / \mathrm{s}$ & $\mathrm{AME}, \mathrm{m}^{3} / \mathrm{s}$ & RMSE, $\mathrm{m}^{3} / \mathrm{s}$ \\
\hline USGS 14169000 & 23.47 & 2 & 5760 & 0 & 0.003 & 0.012 \\
\hline USGS 14170000 & 6.86 & 134 & 5559 & 0.026 & 0.109 & 0.138 \\
\hline \multicolumn{7}{|c|}{ Water Level } \\
\hline Gage ID & RM & $\begin{array}{c}\text { Model } \\
\text { Segment }\end{array}$ & $\begin{array}{c}\text { Sample } \\
\text { size, N }\end{array}$ & $\mathrm{ME}, \mathrm{m}$ & $\mathrm{AME}, \mathrm{m}$ & RMSE, $m$ \\
\hline USGS 14169000 & 23.47 & 2 & 5760 & -0.048 & 0.049 & 0.052 \\
\hline USGS 14170000 & 6.86 & 134 & 5559 & -0.099 & 0.099 & 0.099 \\
\hline
\end{tabular}




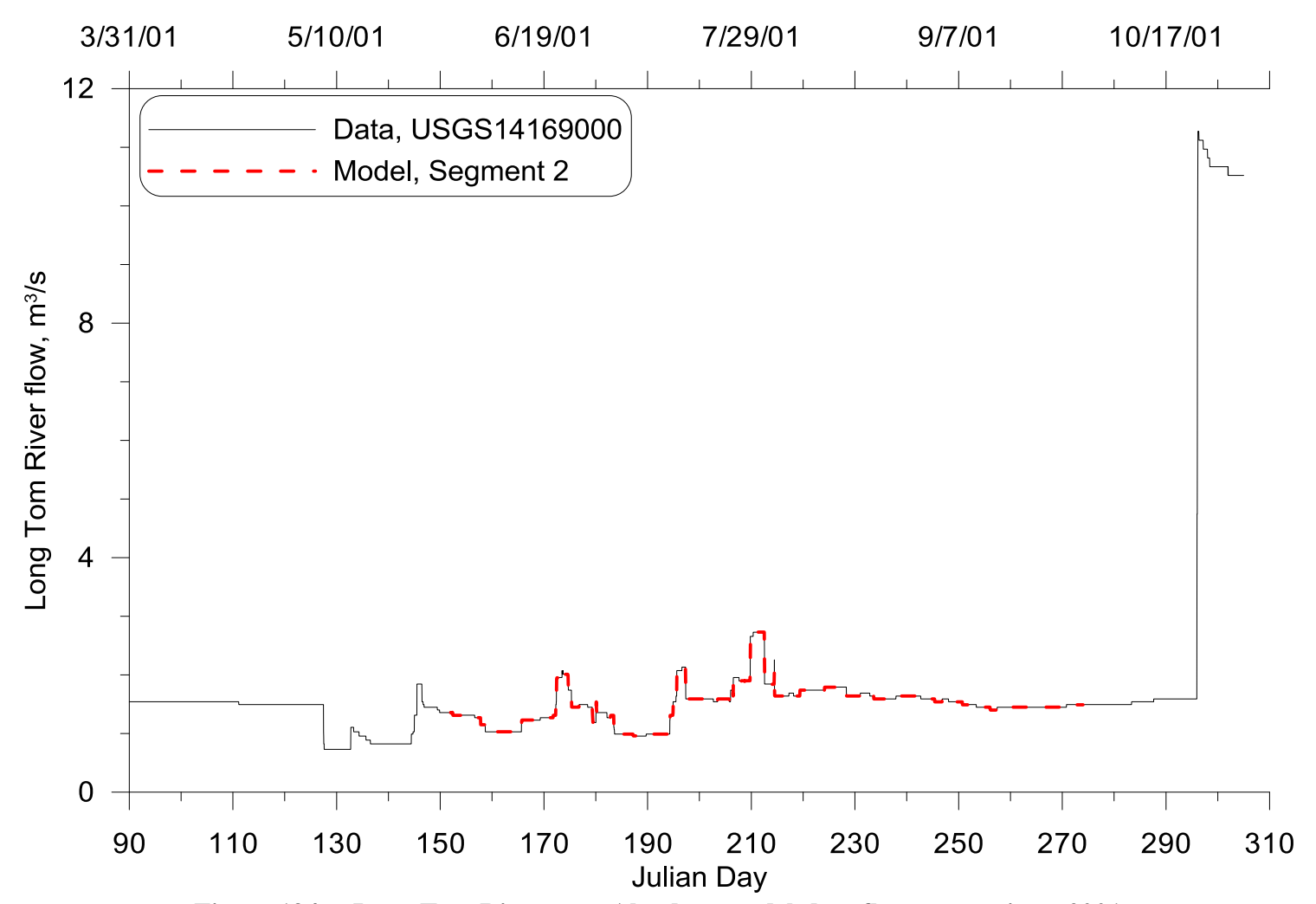

Figure 194: Long Tom River near Alvadore model-data flow comparison, 2001

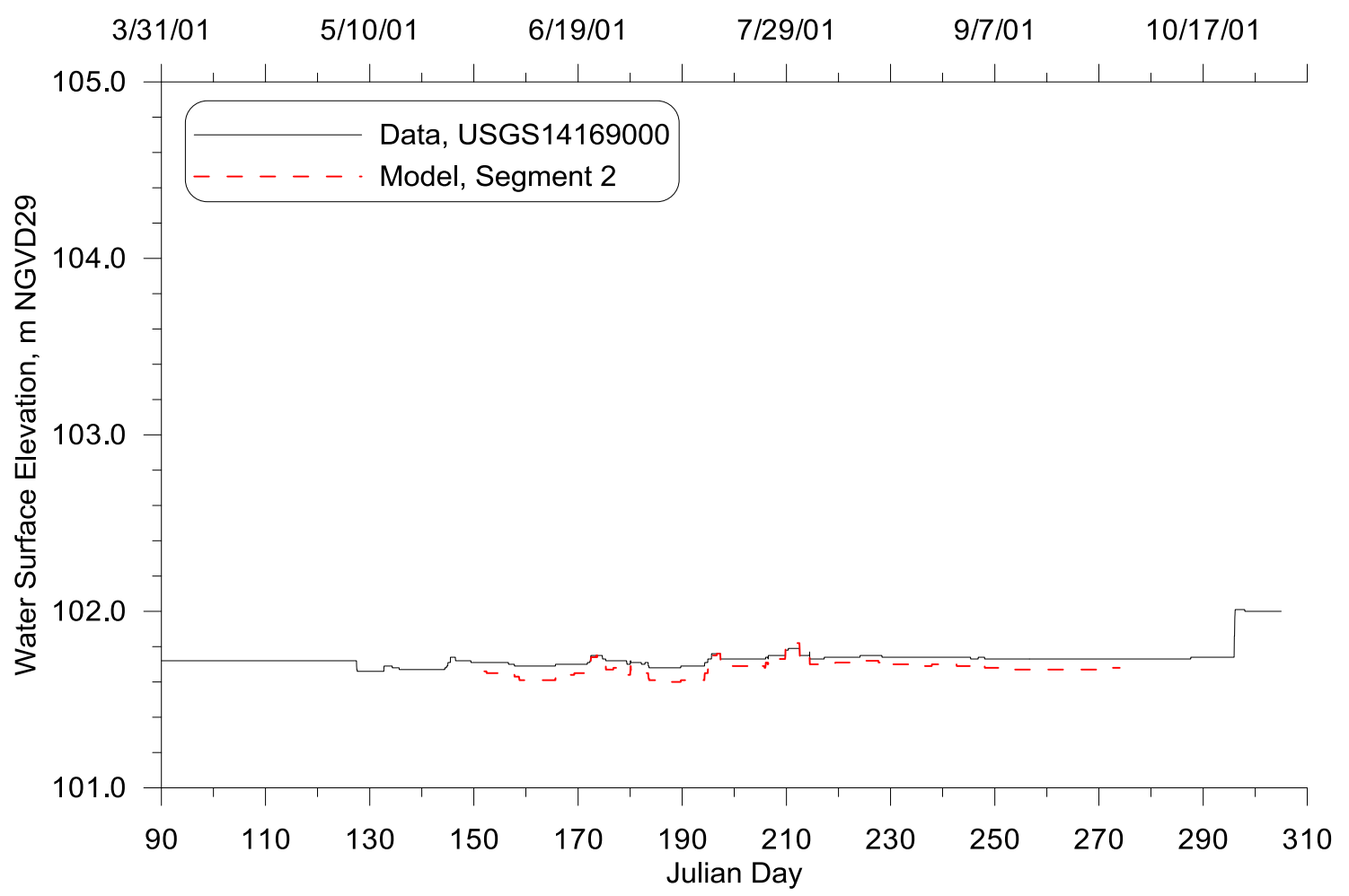

Figure 195: Long Tom River near Alvadore model-data water level comparison, 2001 


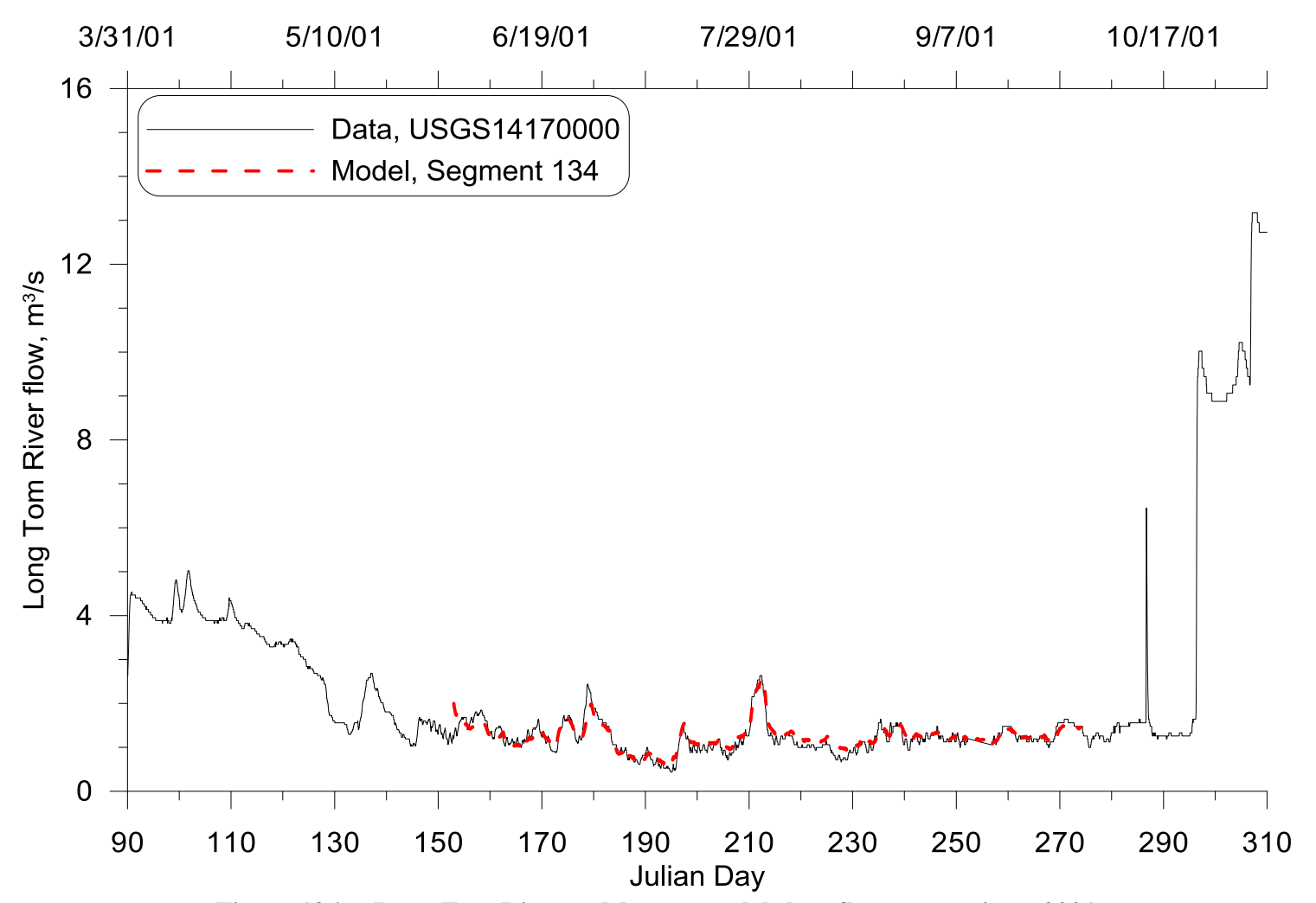

Figure 196: Long Tom River at Monroe model-data flow comparison, 2001

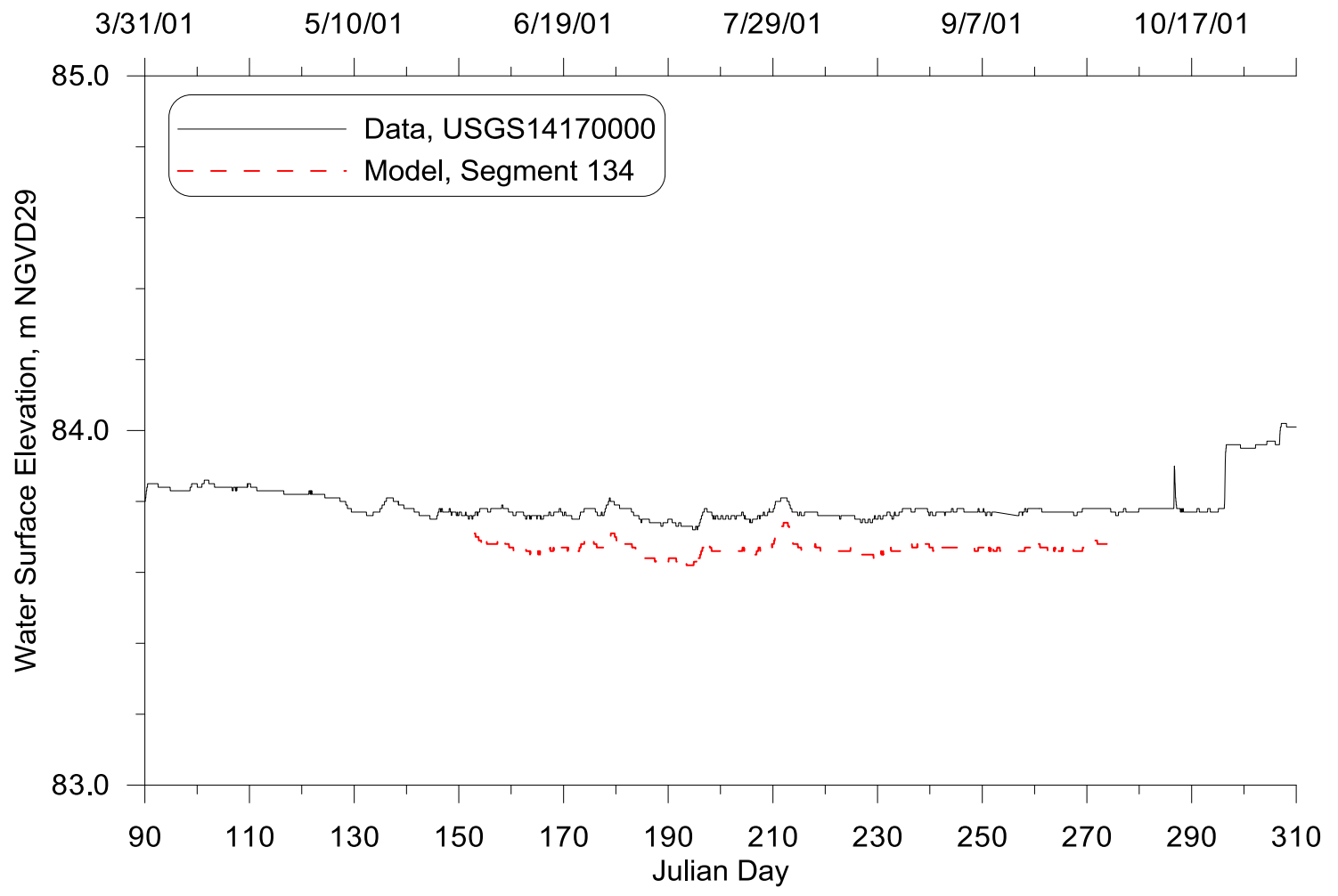

Figure 197: Long Tom River at Monroe model-data water level comparison, 2001 


\section{Year 2002}

The hydrodynamic calibration period in 2002 was from April to October. Figure 198 through 201 show the water level and flow comparison between model predictions and measured data. Error statistics are summarized in Table 23. Both the simulated flow and water level matched well with data.

Table 23 Long Tom River hydrodynamic calibration model-data error statistics, 2002

\begin{tabular}{|c|c|c|c|c|c|c|}
\hline \multicolumn{7}{|c|}{ Flow } \\
\hline Gage ID & RM & $\begin{array}{c}\text { Model } \\
\text { Segment }\end{array}$ & $\begin{array}{c}\text { Sample } \\
\text { size, N }\end{array}$ & ME, m ${ }^{3} / \mathrm{s}$ & AME, m $3 / \mathrm{s}$ & RMSE, ${ }^{3} / \mathrm{s}$ \\
\hline USGS 14169000 & 23.47 & 2 & 8688 & 0.002 & 0.007 & 0.077 \\
\hline USGS 14170000 & 6.86 & 134 & 8688 & -0.246 & 0.325 & 0.595 \\
\hline \multicolumn{7}{|c|}{ Water Level } \\
\hline Gage ID & RM & $\begin{array}{c}\text { Model } \\
\text { Segment }\end{array}$ & $\begin{array}{c}\text { Sample } \\
\text { size, N }\end{array}$ & ME, m & AME, m & RMSE, m \\
\hline USGS 14169000 & 23.47 & 2 & 8688 & -0.029 & 0.046 & 0.058 \\
\hline USGS 14170000 & 6.86 & 134 & 8688 & -0.074 & 0.075 & 0.078 \\
\hline
\end{tabular}




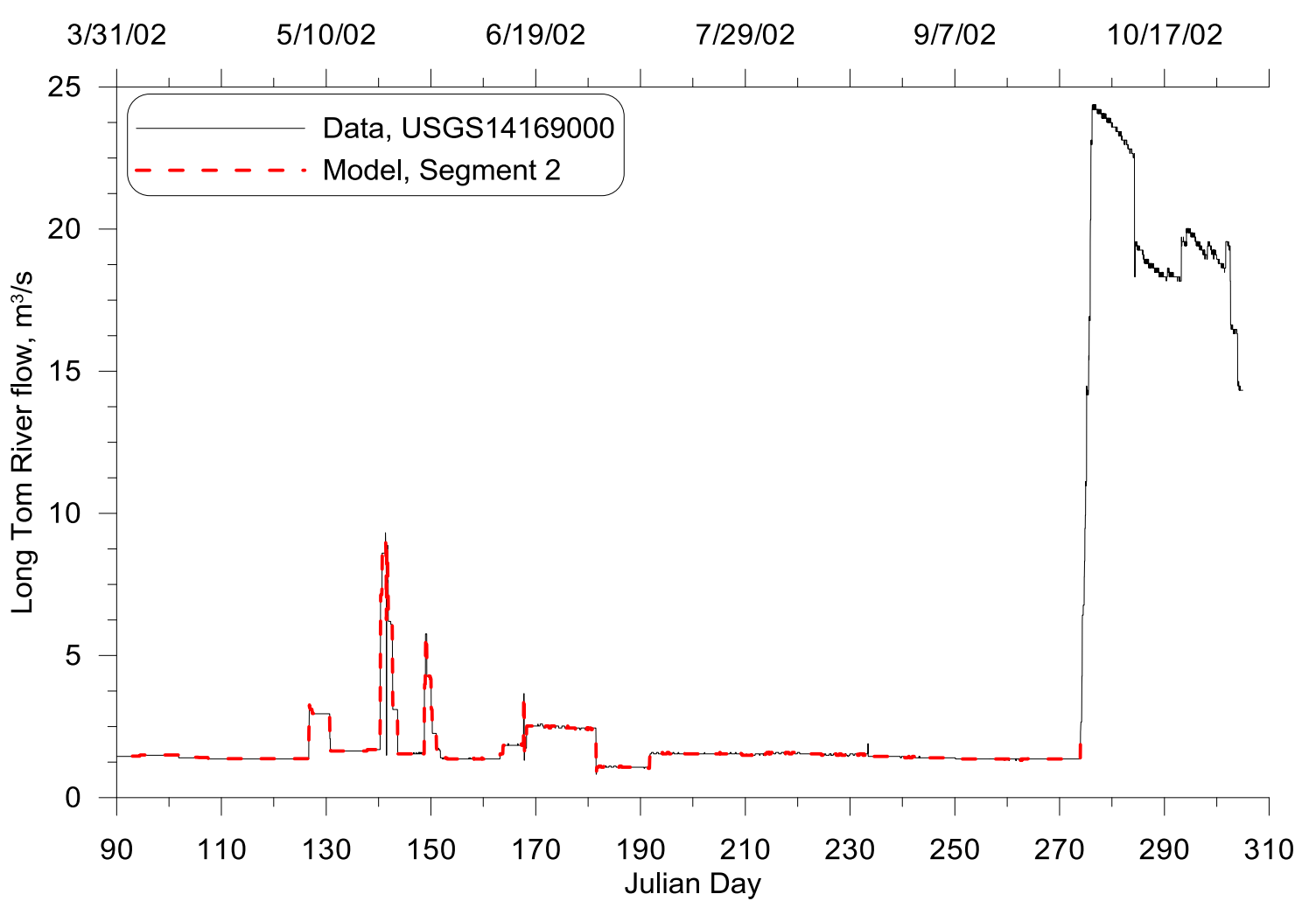

Figure 198 Long Tom River near Alvadore model-data flow comparison, 2002

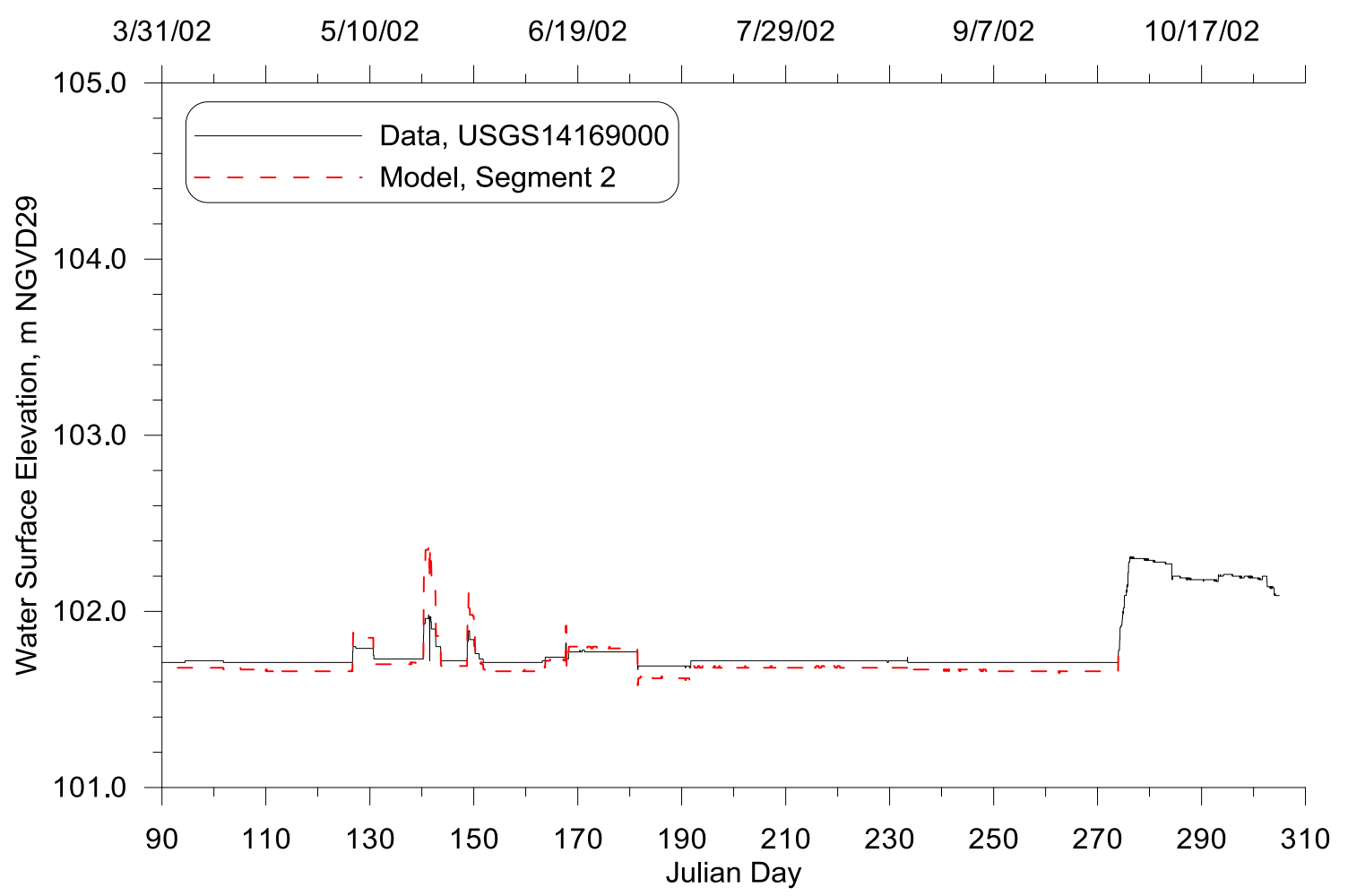

Figure 199 Long Tom River near Alvadore model-data water level comparison, 2002 


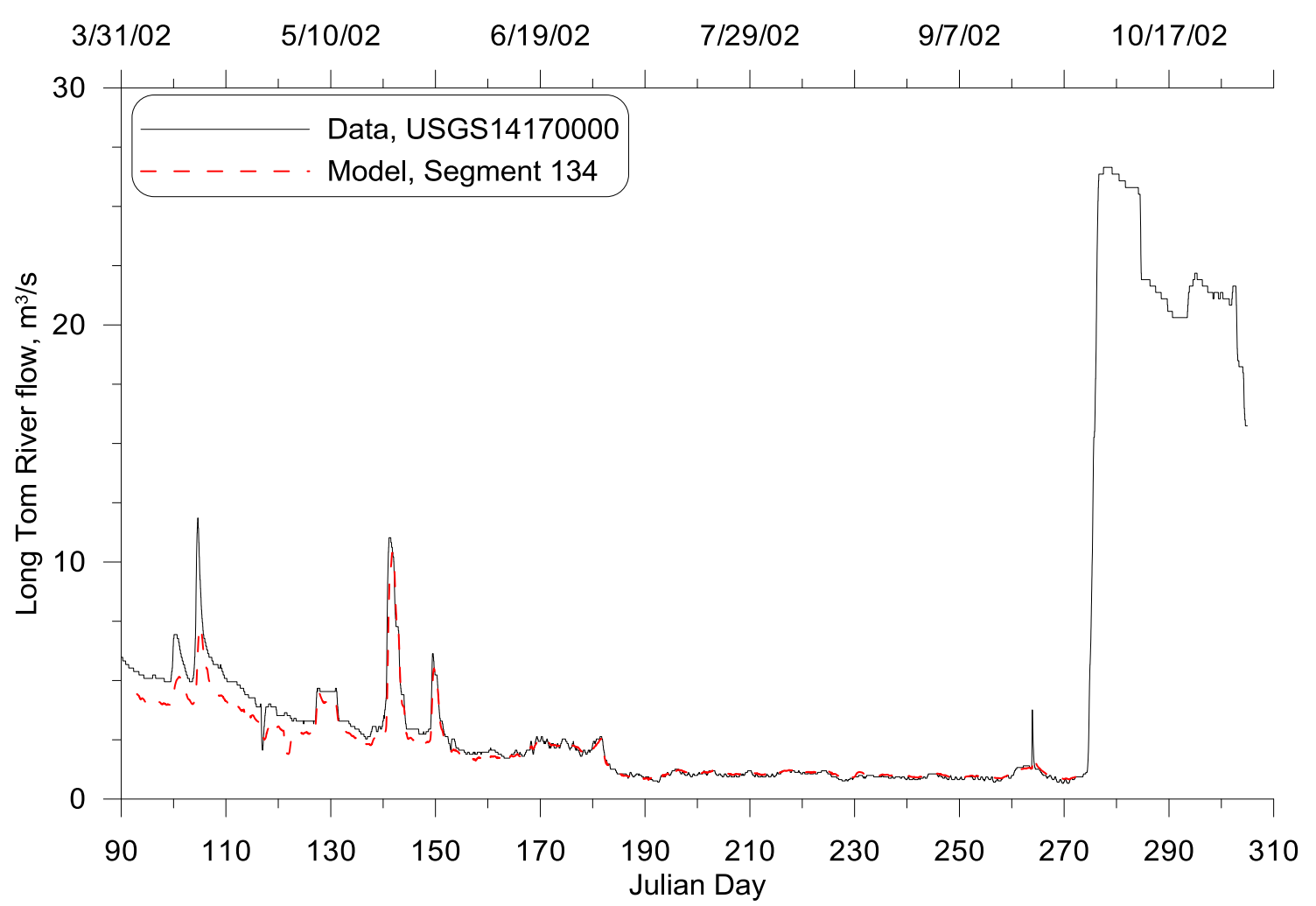

Figure 200 Long Tom River at Monroe model-data flow comparison, 2002

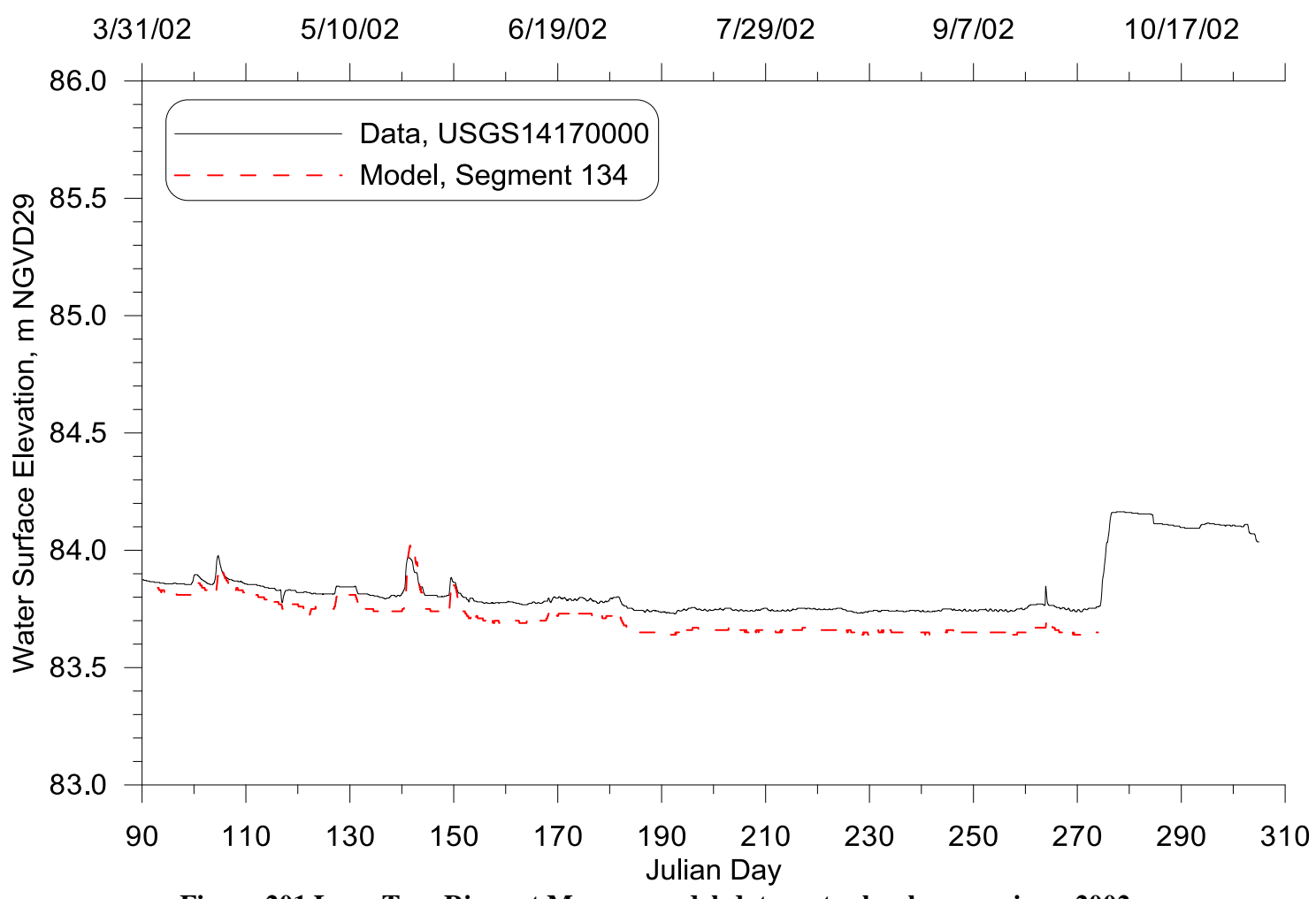

Figure 201 Long Tom River at Monroe model-data water level comparison, 2002 


\section{Temperature}

\section{Year 2001}

Figure 202 through 205 show the continuous temperature comparison between model predictions and measured data. Error statistics are summarized in Table 24. The current calibration result had the RMSEs below $1.3{ }^{\circ} \mathrm{C}$. Overall the model captured the temperature dynamics well.

Table 24 Long Tom River continuous water temperature calibration model-data error statistics, 2001

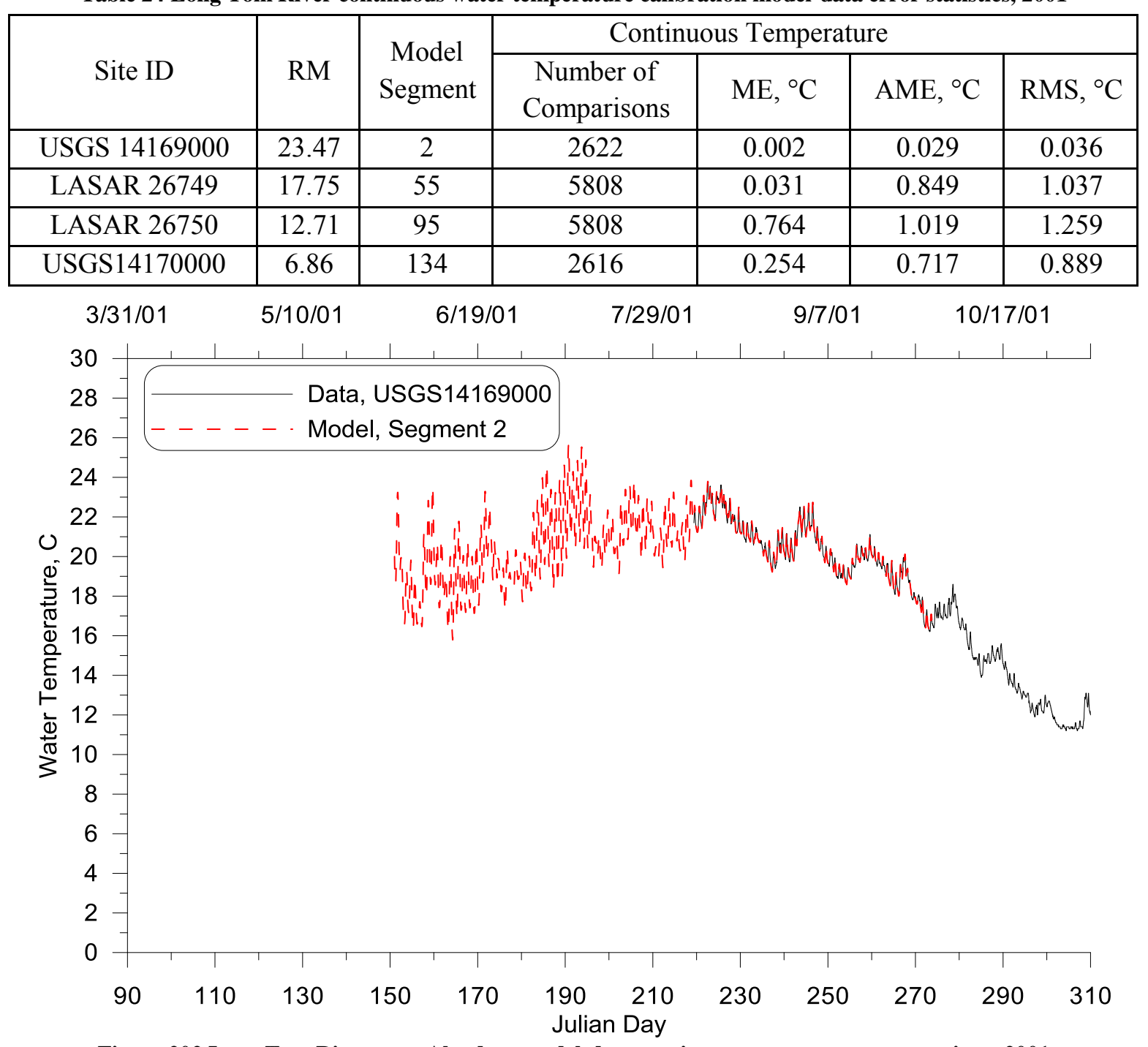

Figure 202 Long Tom River near Alvadore model-data continuous temperature comparison, 2001 


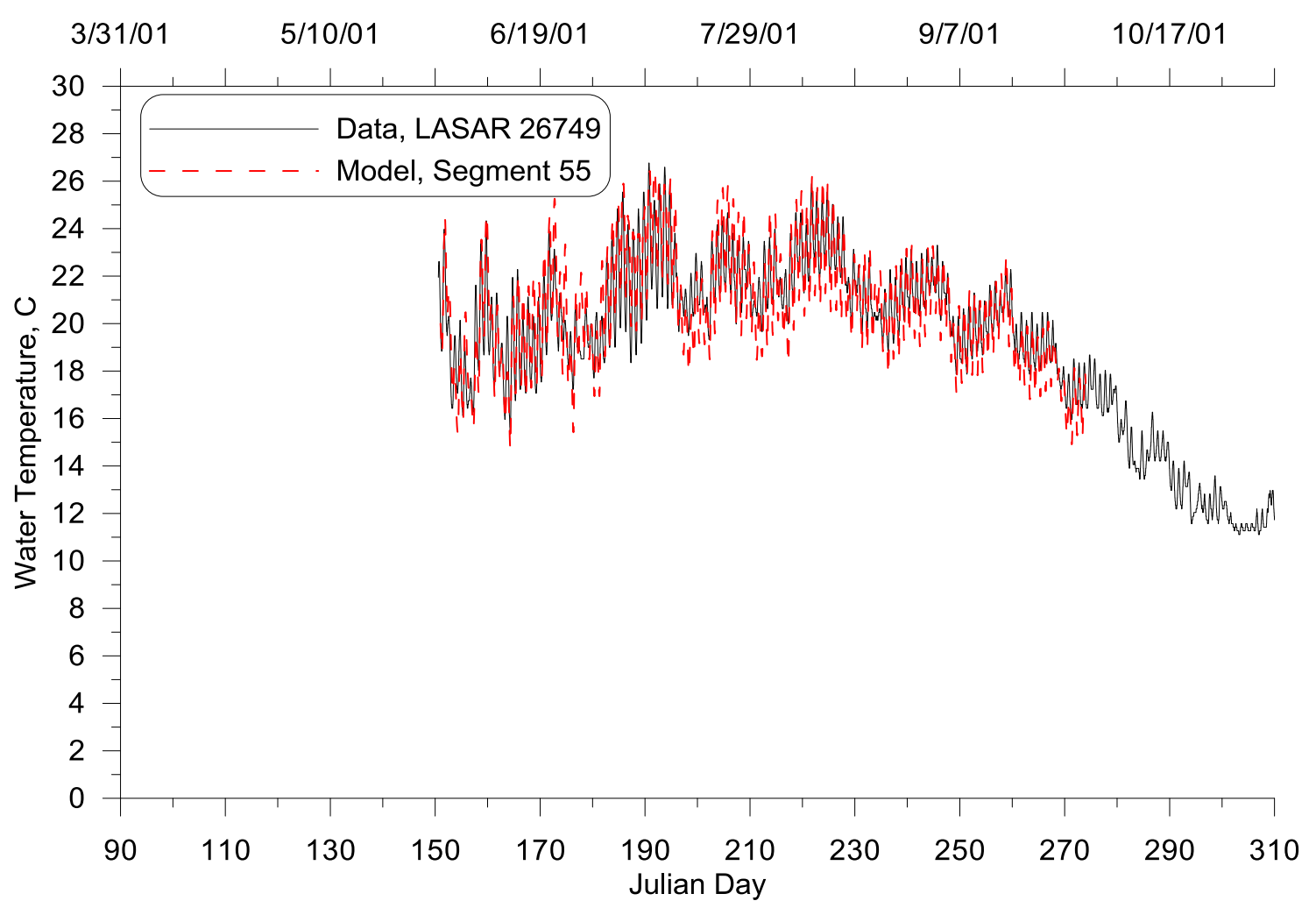

Figure 203 Long Tom River at RM 19.8 model-data continuous temperature comparison, 2001

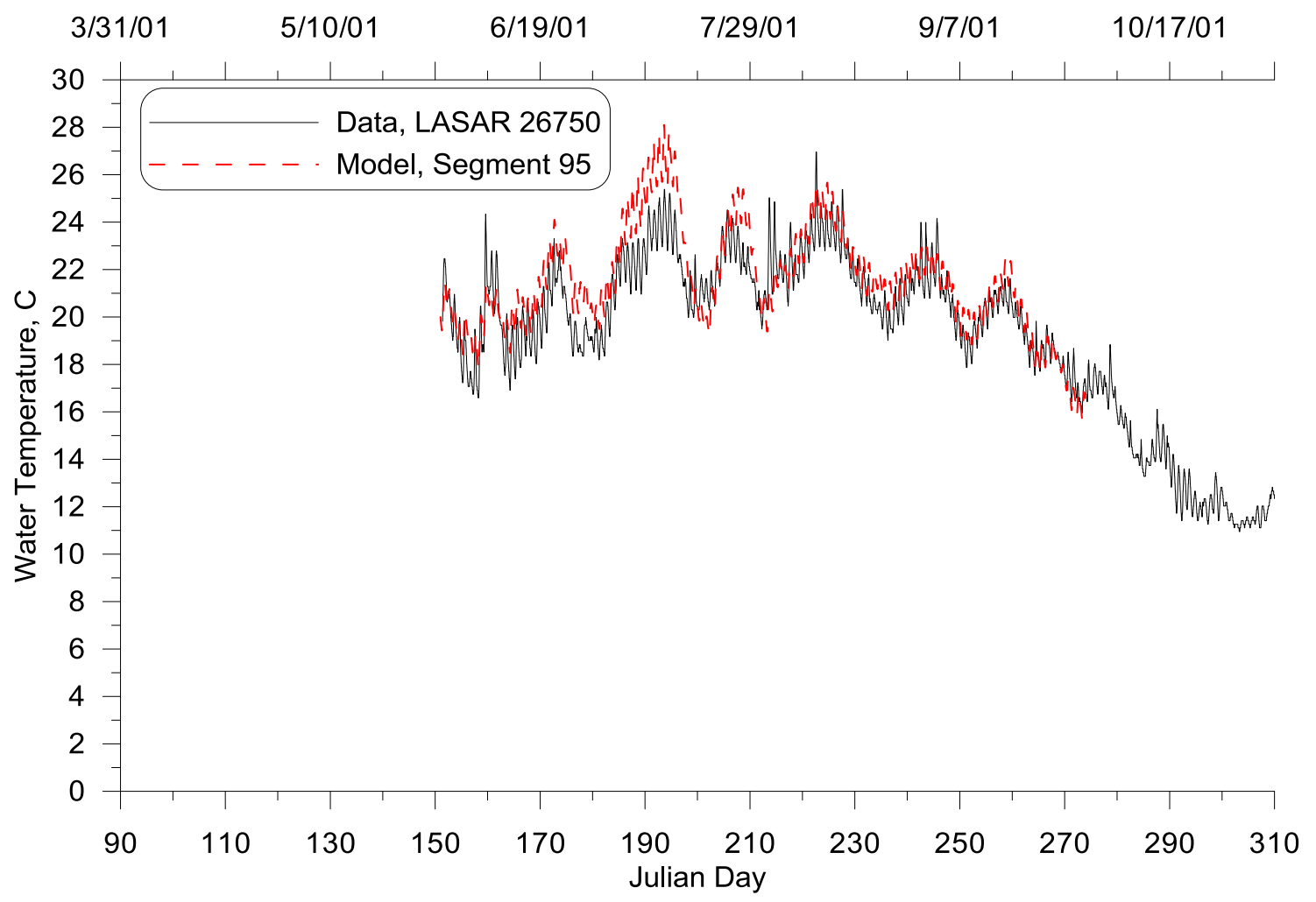

Figure 204 Long Tom River at RM 12.3 model-data continuous temperature comparison, 2001 


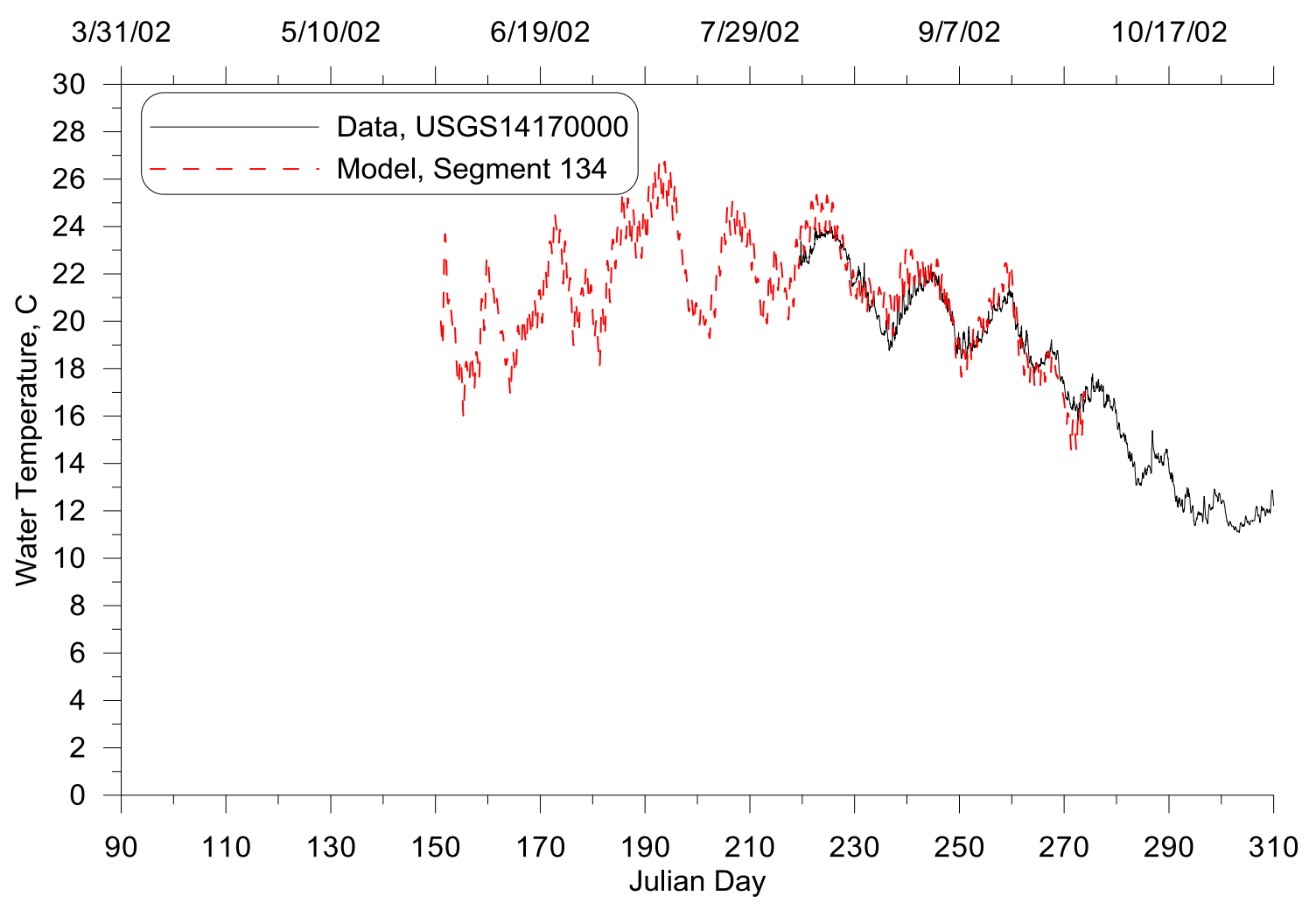

Figure 205 Long Tom River at Monroe model-data continuous temperature comparison, 2001

Year 2002

Figure 206 through 210 show the continuous temperature comparison between model predictions and measured data. Error statistics are summarized in Table 25. The current calibration result had the RMSEs below $1.3^{\circ} \mathrm{C}$.

Table 25 Long Tom River continuous water temperature calibration model-data error statistics, 2002

\begin{tabular}{|c|c|c|c|c|c|c|}
\hline \multirow{2}{*}{ Site ID } & \multirow{2}{*}{ RM } & \multirow{2}{*}{$\begin{array}{c}\text { Model } \\
\text { Segment }\end{array}$} & \multicolumn{4}{|c|}{ Continuous Temperature } \\
\cline { 4 - 7 } & & & $\begin{array}{c}\text { Number of } \\
\text { Comparisons }\end{array}$ & ME, ${ }^{\circ} \mathrm{C}$ & AME, ${ }^{\circ} \mathrm{C}$ & RMS, ${ }^{\circ} \mathrm{C}$ \\
\hline USGS 14169000 & 23.47 & 2 & 8688 & 0.001 & 0.041 & 0.052 \\
\hline LASAR 26749 & 17.75 & 55 & 5922 & -0.496 & 0.757 & 0.899 \\
\hline LASAR 26750 & 12.71 & 95 & 5884 & 0.155 & 0.558 & 0.721 \\
\hline USGS14170000 & 6.86 & 134 & 8688 & -0.107 & 0.779 & 0.997 \\
\hline LASAR 29644 & 0.91 & 176 & 5882 & 0.003 & 0.981 & 1.234 \\
\hline
\end{tabular}




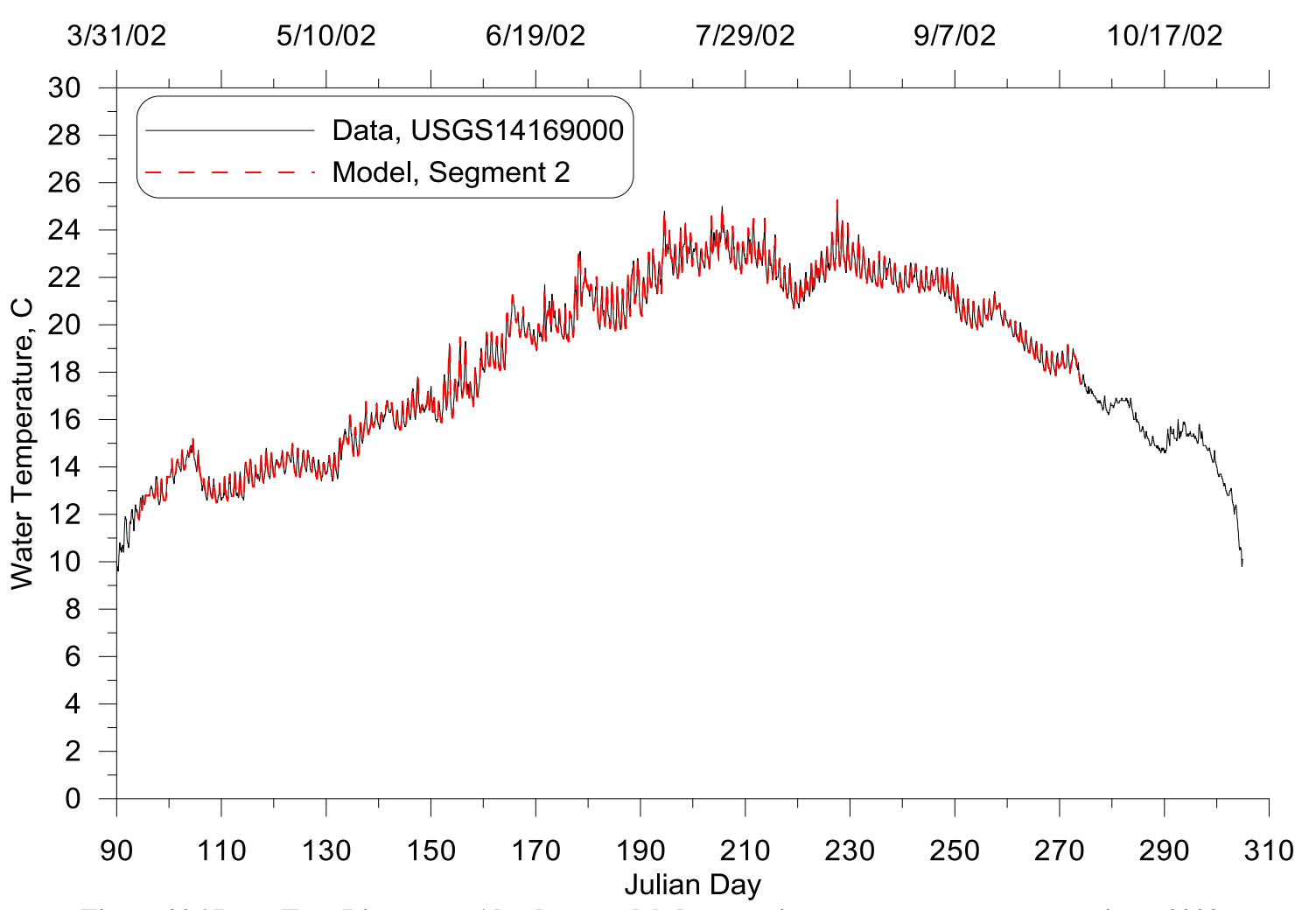

Figure 206 Long Tom River near Alvadore model-data continuous temperature comparison, 2002

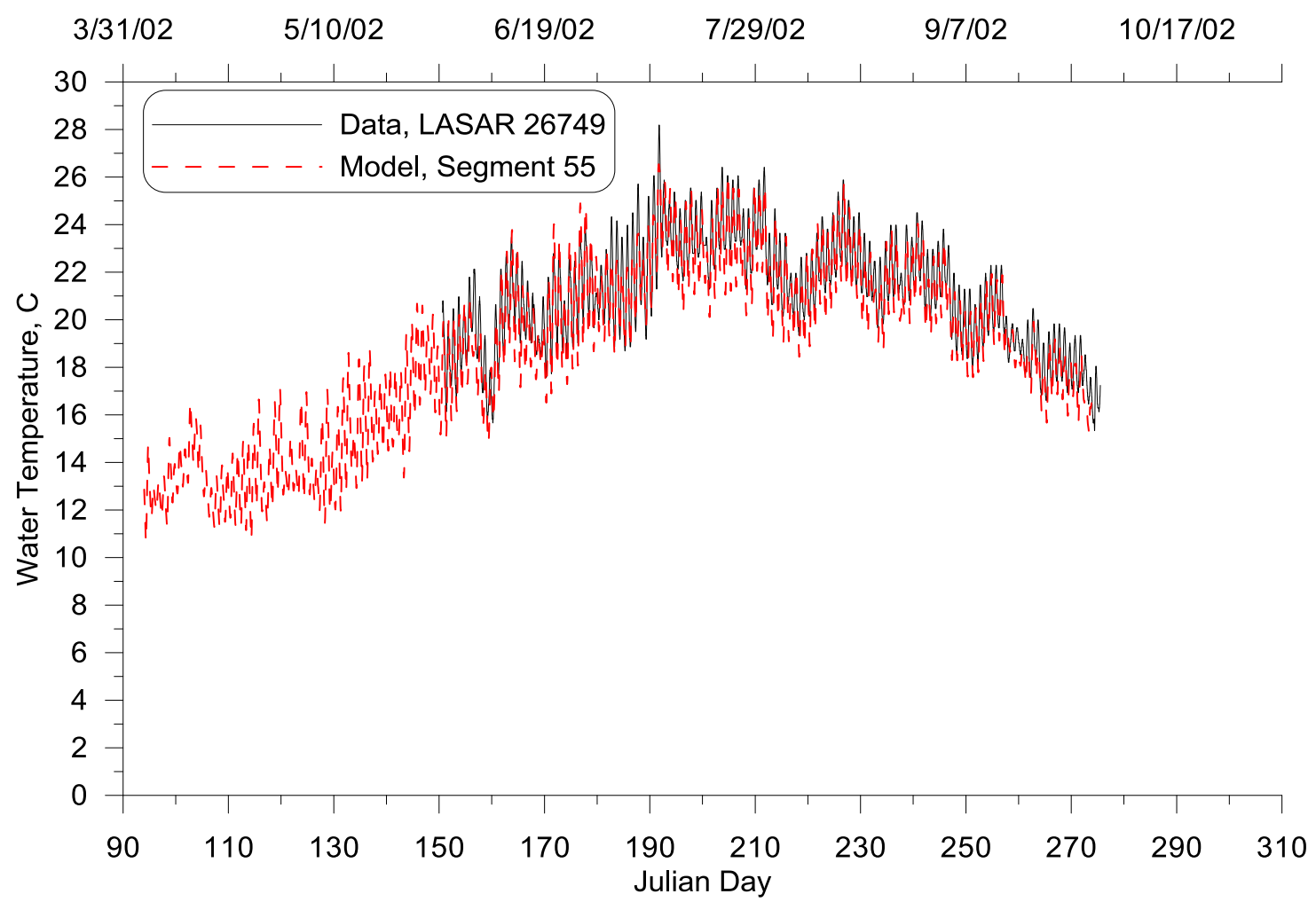

Figure 207 Long Tom River at RM 19.8 model-data continuous temperature comparison, 2002 


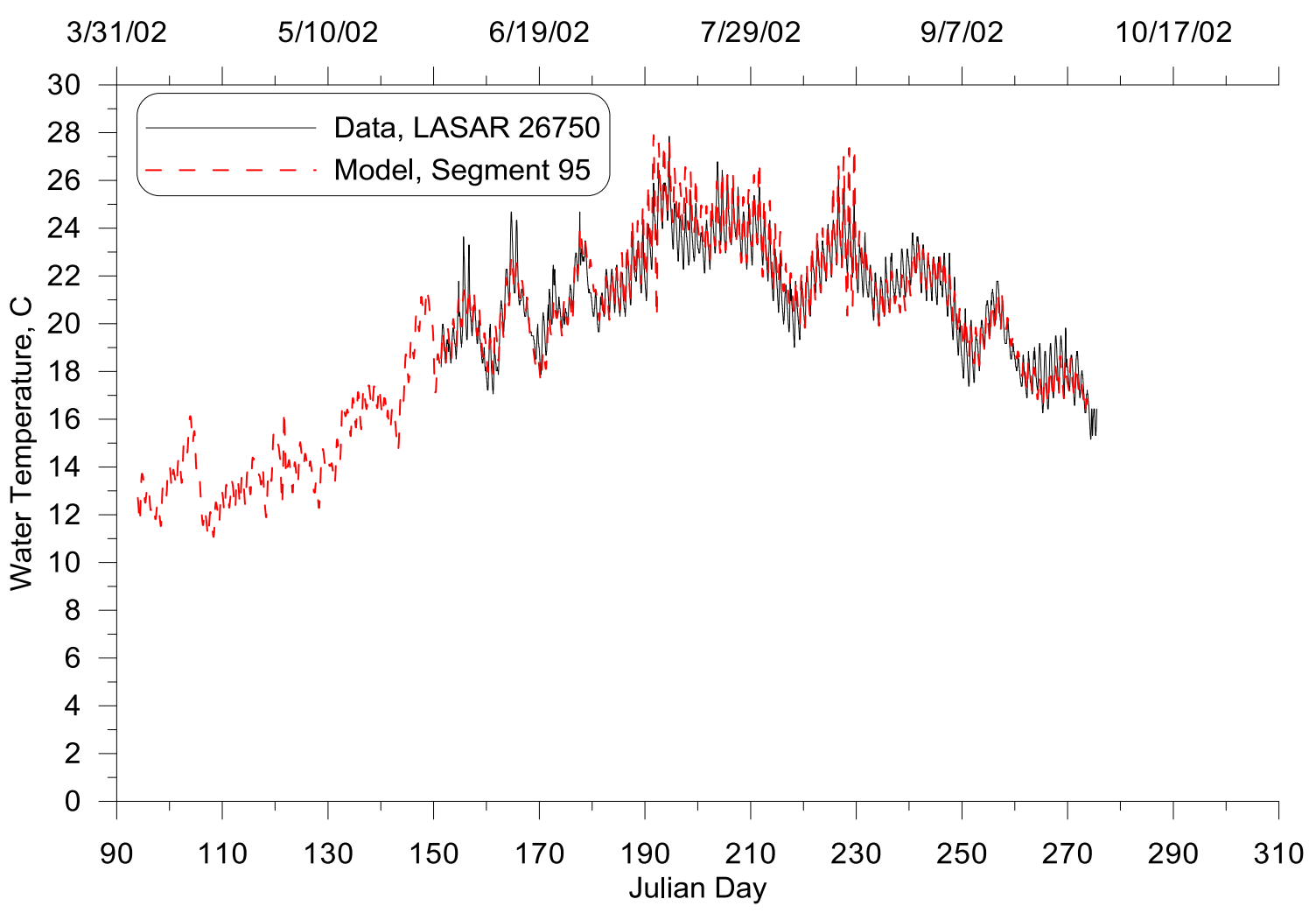

Figure 208 Long Tom River at RM 12.3 model-data continuous temperature comparison, 2002

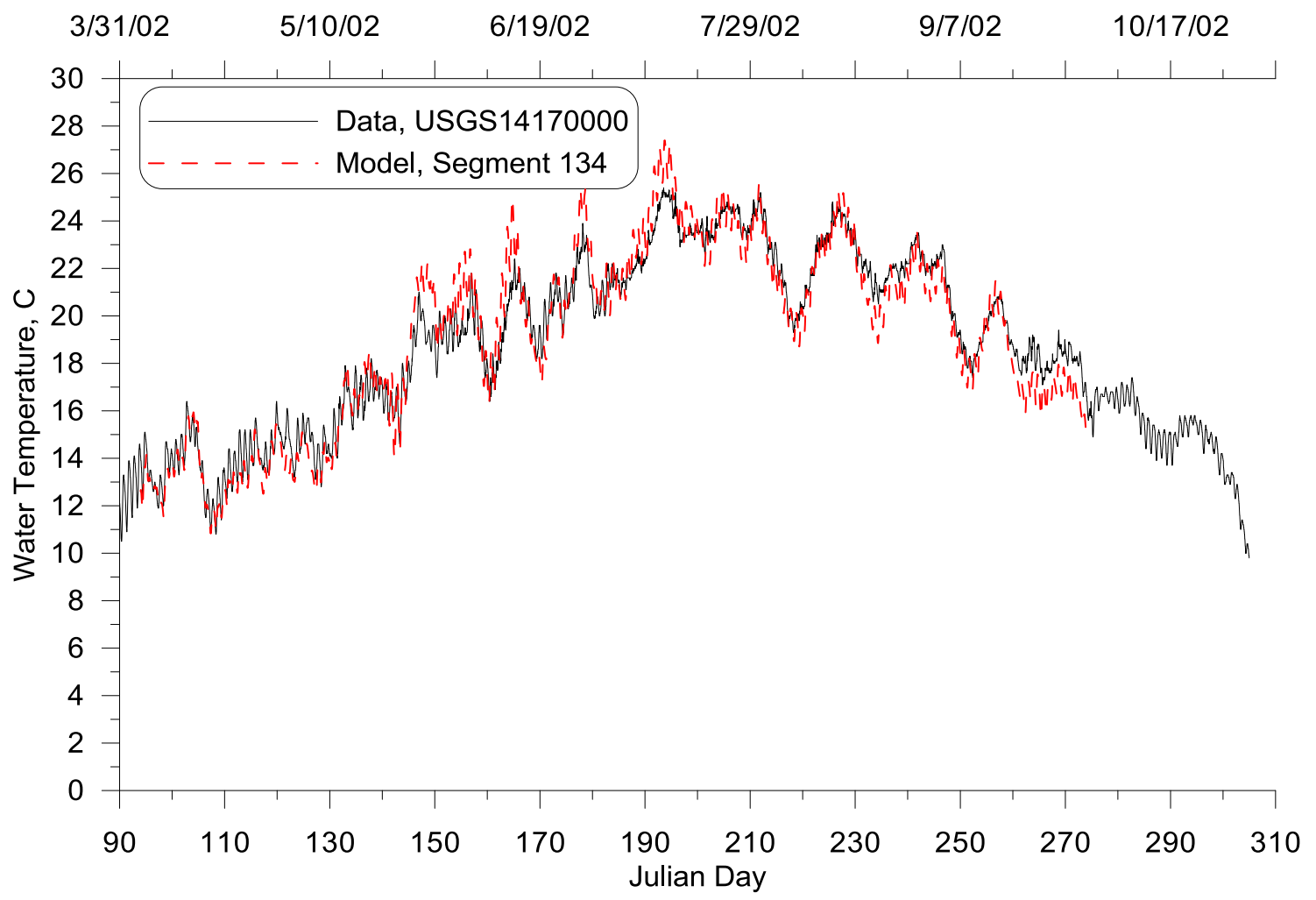

Figure 209 Long Tom River at Monroe model-data continuous temperature comparison, 2002 


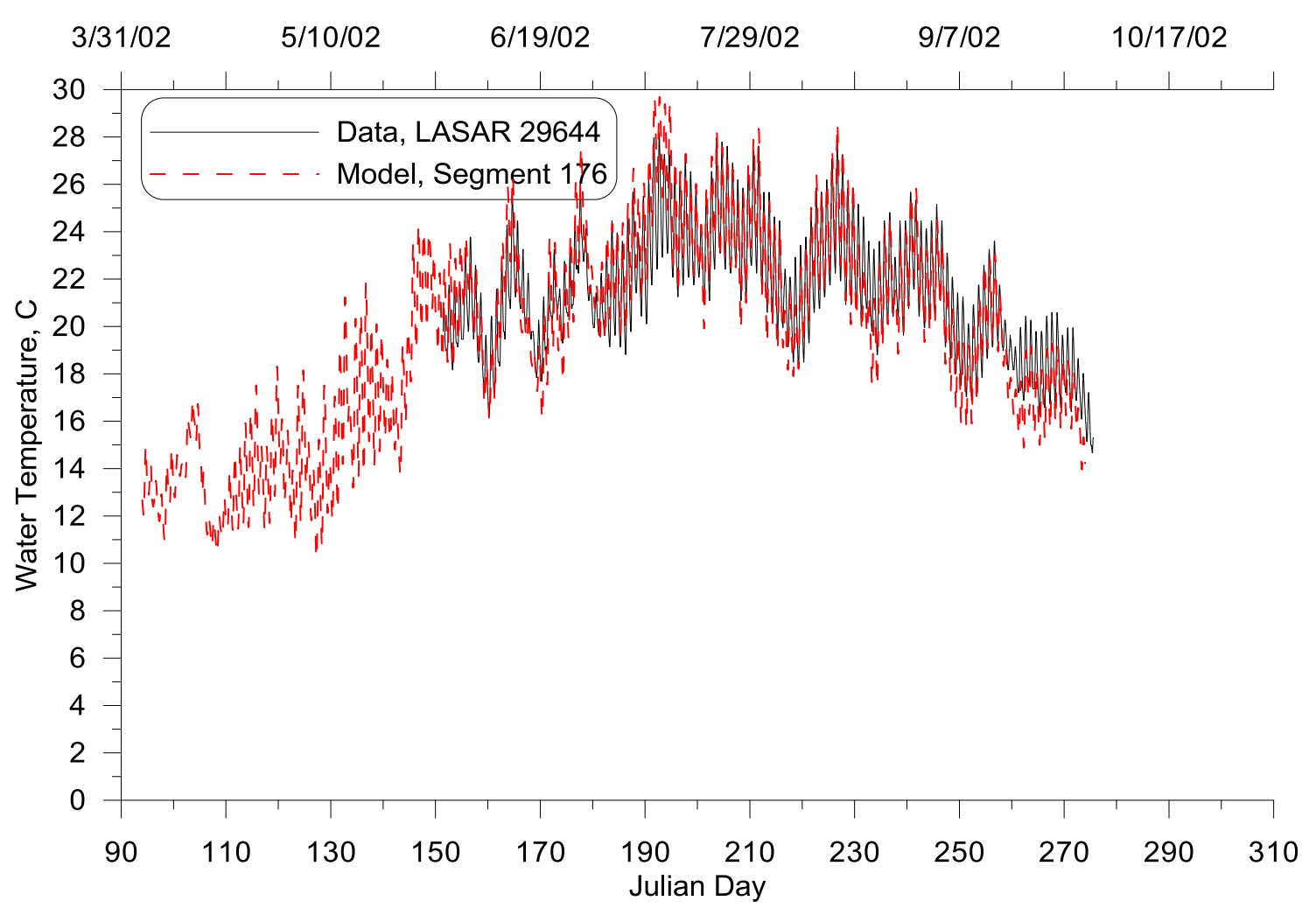

Figure 210 Long Tom River near mouth model-data continuous temperature comparison, 2002

\subsubsection{Summary and Conclusions}

\section{Accuracy}

The continuous model-data error statistics of the Version 3.1 models and Version 3.7 models are summarized in Table 26. The testing results showed improved accuracy when Lower Willamette River was converted to Version 3.7 and similar or slightly degraded accuracy on other river applications when they were converted. Because of the limited time that was spent on calibration, most of the six river models still had a potential for further calibration and improvement in accuracy. CE-QUAL-W2 Version 3.7 has the equivalent ability as Version 3.1 to achieve high-accuracy temperature predictions. 
When setting the river models with the old calibration parameters in Version 3.1, most models produce the same or similar result, in which cases no further calibration was conducted. However, there were a few locations where Version 3.7 water level results did not show agreement with field measured data. Oftentimes, Version 3.1 water level results showed similar results at those locations. The water level prediction inaccuracy was resulted from insufficiency of river cross-section data.

Table 26: Comparison of CE-QUAL-W2 Version 3.1 and Version 3.7 temperature predictions accuracy on six river systems

\begin{tabular}{|c|c|c|c|c|}
\hline \multirow{2}{*}{$\begin{array}{c}\text { River System } \\
\text { Name }\end{array}$} & \multirow{2}{*}{\multicolumn{2}{|c|}{ Simulation Period }} & \multicolumn{2}{|c|}{ Continuous Temperature RMSE Range ${ }^{\circ} \mathrm{C}$} \\
\hline & & & \multirow{2}{*}{$\begin{array}{c}\text { CE-QUAL-W2 Version } \\
3.1 \\
0.16-0.76\end{array}$} & \multirow{2}{*}{$\begin{array}{c}\text { CE-QUAL-W2 } \\
\text { Version } 3.7 \\
0.08-0.64\end{array}$} \\
\hline \multirow{2}{*}{ Lower Willamette } & 2001 & 63 days & & \\
\hline & 2002 & 182 days & $0.09-0.81$ & $0.07-0.78$ \\
\hline \multirow{2}{*}{$\begin{array}{c}\text { Middle } \\
\text { Willamette }\end{array}$} & 2001 & 66 days & $0.07-0.81$ & $0.07-0.83$ \\
\hline & 2002 & 66 days & $0.48-0.85$ & $0.50-0.93$ \\
\hline \multirow[t]{2}{*}{ Upper Willamette } & 2001 & 105 days & $0.05-0.81$ & $0.05-0.88$ \\
\hline & 2002 & 175 days & $0.16-0.74$ & $0.17-0.73$ \\
\hline \multirow{2}{*}{ Clackamas River } & 2001 & 183 days & $0.03-0.86$ & $0.02-1.03$ \\
\hline & 2002 & 183 days & $0.03-0.68$ & $0.03-0.71$ \\
\hline \multirow[t]{2}{*}{ McKenzie River } & 2001 & 148 days & $0.16-0.99$ & $0.16-0.89$ \\
\hline & 2002 & 214 days & $0.16-0.76$ & $0.15-0.95$ \\
\hline \multirow{2}{*}{ Long Tom River } & 2001 & 123 days & $0.04-1.07$ & $0.04-1.26$ \\
\hline & 2002 & 183 days & $0.05-1.16$ & $0.05-1.23$ \\
\hline
\end{tabular}

\section{Stability}

Stability issues occurred at all the six river models except Lower Willamette River. The models suffered stability issues were characterized with one or more of the following features: very low flow rate (as low as $1.0 \mathrm{~m}^{3} / \mathrm{s}$ in some cases), dramatically changing flow rate at flood events or reservoir operations, complex branch connections and hydraulic structures, steep slope where segments easily dry up, complex and uneven 
underwater topography. To solve this problem, four techniques were applied to make the model run:

- Reducing the maximum time step and time step fraction.

- Smoothing the branch bathymetry by even the river bed and adjusting widths.

- Delicately adjusting Slopec (the hydraulic equivalent slope) for different branches to reach a best working Slopec combination.

- Adjusting Manning's friction coefficients.

Although the presented six rivers were able to run through the simulation periods in 2001 and 2002, these models were not stable and might not run through another year. The reduced time step also resulted in the reduction of calculation speed, which was presented below.

\section{Speed}

The CPU runtime of CE-QUAL-W2 Version 3.7 model at six river systems applications are summarized in Table 27. The runtime the two simulation years were different because the flow conditions were different in different years so the time steps were different.

Table 27: CPU runtime of CE-QUAL-W2 Version 3.7 model at six river systems applications in 2001 and 2002

\begin{tabular}{|c|c|c|c|}
\hline \multirow{2}{*}{ River System Name } & \multicolumn{2}{|c|}{ Simulation Period } & CPU Runtime (minutes) \\
\cline { 3 - 4 } & & CE-QUAL-W2 version 3.7 \\
\hline \multirow{2}{*}{ Lower Willamette } & 2001 & 63 days & 5.57 \\
\cline { 2 - 4 } & 2002 & 182 days & 17.31 \\
\hline \multirow{2}{*}{ Middle Willamette } & 2001 & 66 days & 59.8 \\
\cline { 2 - 4 } & 2002 & 66 days & 28.4 \\
\hline \multirow{2}{*}{ Upper Willamette } & 2001 & 105 days & 133.3 \\
\cline { 2 - 4 } & 2002 & 175 days & 137.0 \\
\hline Clackamas River & 2001 & 183 days & 17.6 \\
\hline
\end{tabular}




\begin{tabular}{|c|c|c|c|}
\hline & 2002 & 183 days & 26.0 \\
\hline \multirow{2}{*}{ McKenzie River } & 2001 & 148 days & 99.8 \\
\cline { 2 - 4 } & 2002 & 214 days & 159.7 \\
\hline \multirow{2}{*}{ Long Tom River } & 2001 & 123 days & 4.84 \\
\cline { 2 - 4 } & 2002 & 183 days & 7.21 \\
\hline
\end{tabular}

Based on the CPU runtime for the two simulation periods in year 2001 and 2002, runtime for one year simulation was estimated and summarized in Figure 211. Middle Willamette River, Upper Willamette River and McKenzie River were the three rivers that took the longest time to run for one year, with runtime over 200 minutes.

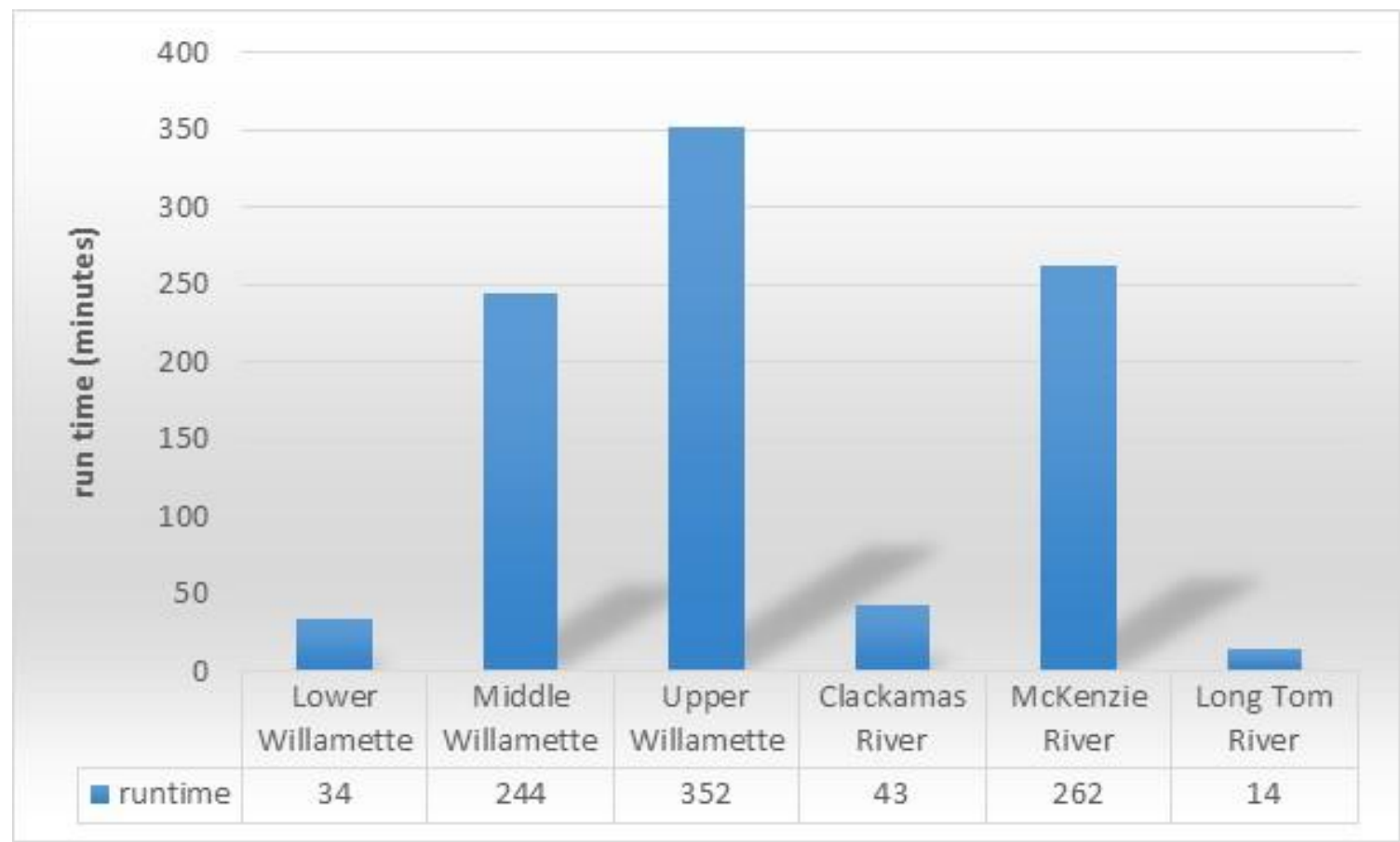

Figure 211: Estimated runtime for one year simulation using CE-QUAL-W2 Version 3.7

In summary, the CE-QUAL-W2 Version 3.7 has the ability to predict continuous river temperature accurately; however, it suffers some stability issues and runs slowly, especially for rivers with steep slope. 


\section{Chapter 3 Development of Steady-State Model for}

\section{Hydrodynamics}

\subsection{New Expectation from River Hydrodynamic and Temperature}

\section{Model}

With the recent advances of research on climate change, it becomes possible to look into the future of watersheds and water bodies. Willamette Water 2100 is a five year project in which faculty from Oregon State University, the University of Oregon and Portland State University are cooperating with each other, and trying to evaluate how climate change, population growth and economic growth will change water in the Willamette River Basin. An integrated model framework incorporated Geographic Information System, hydrologic models, ecological models, socio-economic models, and a decision-making model.

One of the research tasks is to model the hydrodynamics and temperature in the Willamette River in the future, using input information from climate change models, hydrologic models and other models. The modeling results will assist protecting endangered species and also provide data for management decision making.

Since hydrodynamic and water temperature models for the whole Willamette River System are already developed, it is logical to use these existing models for the Willamette Water 2100 project. However, to simulate the river systems on a decadal or centennial timescale, it would take too long, for either CE-QUAL-W2 Version 3.7 or Version 3.1 to 
run the models. Besides, the stability issues with CE-QUAL-W2 may cause difficulties during low-flow periods. As a result, the existing river models with CE-QUAL-W2 cannot be directly used for the Willamette Water 2100 Project.

To summarize, a hydrodynamic and water temperature model is needed to simulate the Willamette River Systems. The expectations from this model includes:

- Running fast,

- High accuracy of hydrodynamic and water temperature predictions,

- Ability to model temperature basing on dynamic shading,

- Including various hydraulic structures,

- Preferably having a smooth connection with many of the reservoir models within the basin that utilizes CE-QUAL-W2 Version 3.7,

- Ability to model stratified water quality.

\subsection{Model Development Theory}

To meet the current project requirement, and also to meet future challenge of expanding the capacity and scope of water quality models, a new river hydrodynamic and temperature model was built based on existing water quality models. The new model was built based on CE-QUAL-W2 Version 3.7. This new model uses steady-state methods to calculate water level and velocity, and uses existing CE-QUAL-W2 code to calculate dynamic temperature. By calculating the hydrodynamics at steady-state, the time step for stability is relaxed and simulations can proceed at much longer time steps. The rest of the model framework is still used for water quality state variables, such as temperature. 


\subsubsection{CE-QUAL-W2 Version 3.7 as the base model}

The model theory and general description of CE-QUAL-W2 can be found in Section 1.1.4. The changes over different versions of CE-QUAL-W2 are described in Section 2.1.

\subsubsection{Coordinate System and Model Grid}

For most parts, the steady-state model uses the same coordinate system and model grid set up as CE-QUAL-W2 Version 3.7. The steady-state model is also a 2-D lateral averaged model. Figure 212 through Figure 214 show the comparison of a river top view, cross-section view, and side view in the real world (on the left) and in the model (on the right).
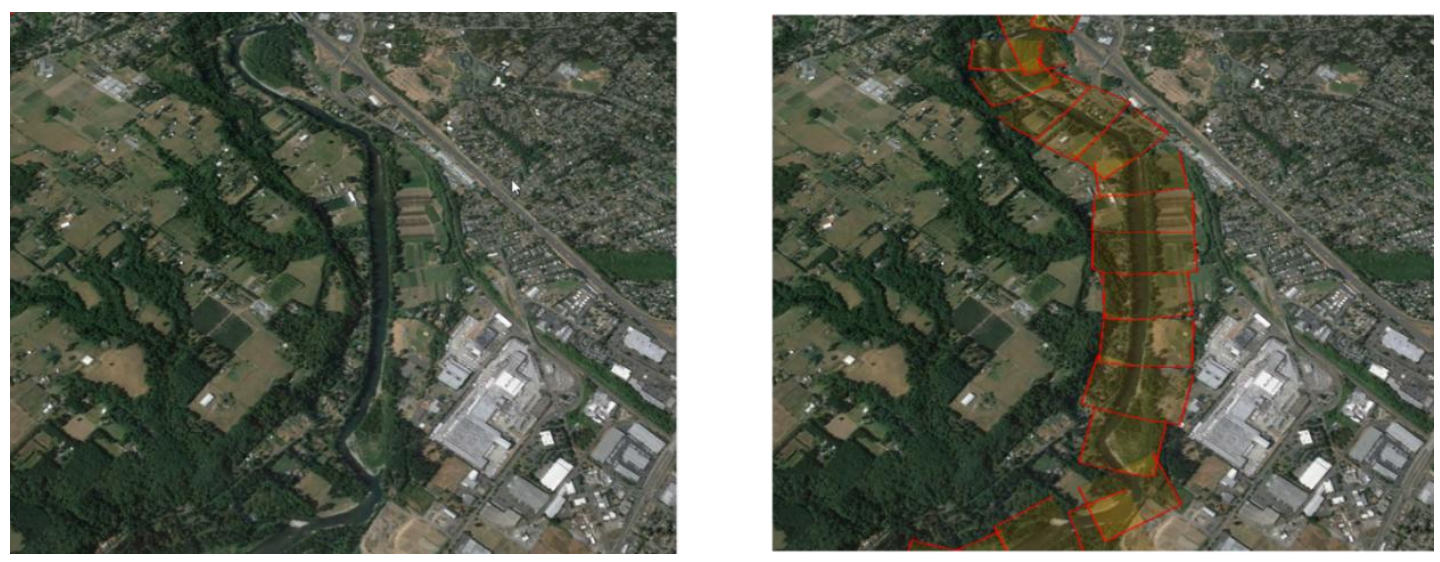

Figure 212: Comparison of river top view in the real world (left) and in the steady-steady model (right) 

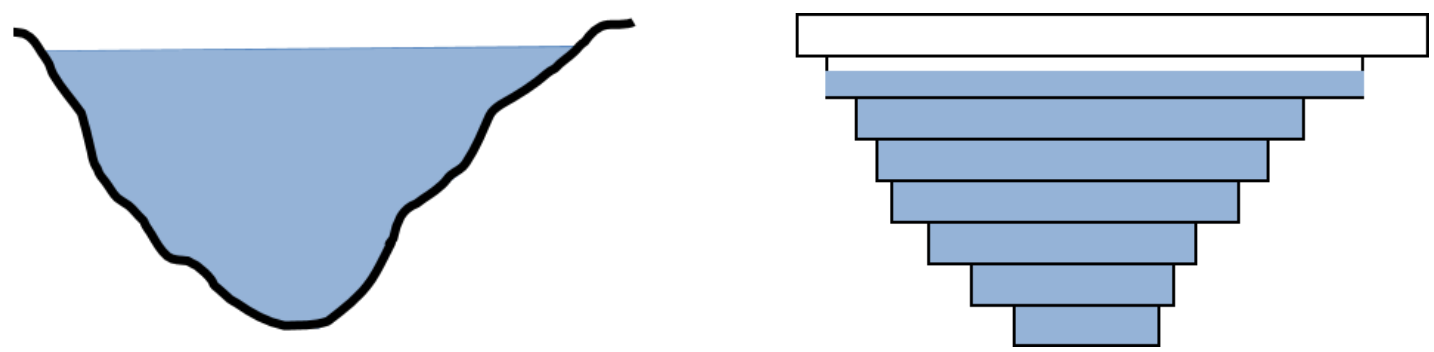

Figure 213: Comparison of river cross-section view in the real world (left) and in the steady-steady model (right)
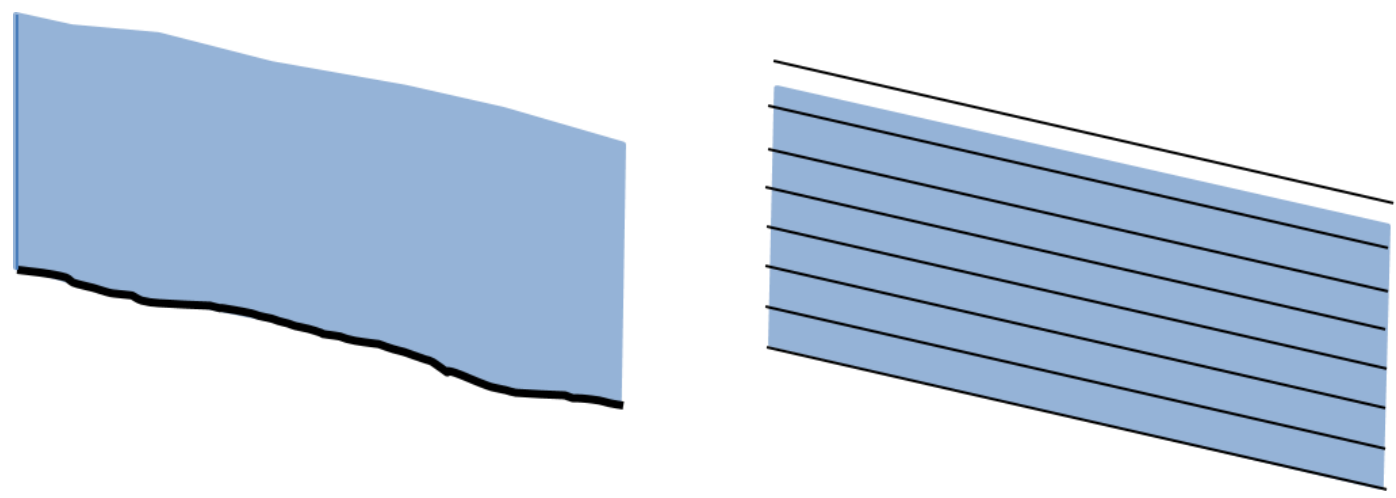

Figure 214: Comparison of river side view in the real world (left) and in the steady-steady model (right)

The modeled system is described with:

- Cell: the smallest unit in the model. It is a rectangular cubic, within which temperature is assumed to be a single value. A common dimension of a cell in the steady-state model would be 250-meters long, 5-meter wide, and 1-meter tall. On the right side of Figure 213, each rectangular represent a cell.

- Segment: includes several cells laying over each other. In the steady-state model, longitudinal velocity is the same within one segment. The right side of Figure 213 represents a segment.

- Branch: includes several segments. Branch is usually a representation of a river or part of a river. All the segments under one branch share the same slope and 
hydraulic equivalent slope. However, Manning's friction coefficient is differentiated among segments.

- Water body: may include one or more branch(s). All the segments within one water body share the same top layer during calculation, as a result branches with very different bottom elevation should be separated into different water bodies.

\section{Hydraulic Structures}

The model is able to model a variety of hydraulic structures, including spillways, weirs, gates, pipes, pumps, withdraws, dam outflow.

\section{Tributary and Distributed Tributary}

CE-QUAL-W2 provides the flexibility to specify inflow from tributaries and distributed tributaries are distributed evenly from top layer to bottom layer. The steady state model does not support users to specify which layer tributaries enters, or distribute tributary flow according to density. Under Tributary Inflow Placement (TRIB PLACE), DISTR should be used for all tributaries.

\section{Loop branch}

Loop branches were used to represent flow around an island. In the code, loop branch was defined as a branch that is connected to a main branch by internal head boundary conditions at both ends. Figure 215 shows an example of a loop branch in the real world. Based on the way loop branches were defined in the code, loop branch and main branch should be in the same water body, and loop branch should be defined after its main 
branch in the control file. Besides, additional tributaries should not be defined at the same segment of UHS(JB) or DHS(JB)+1.
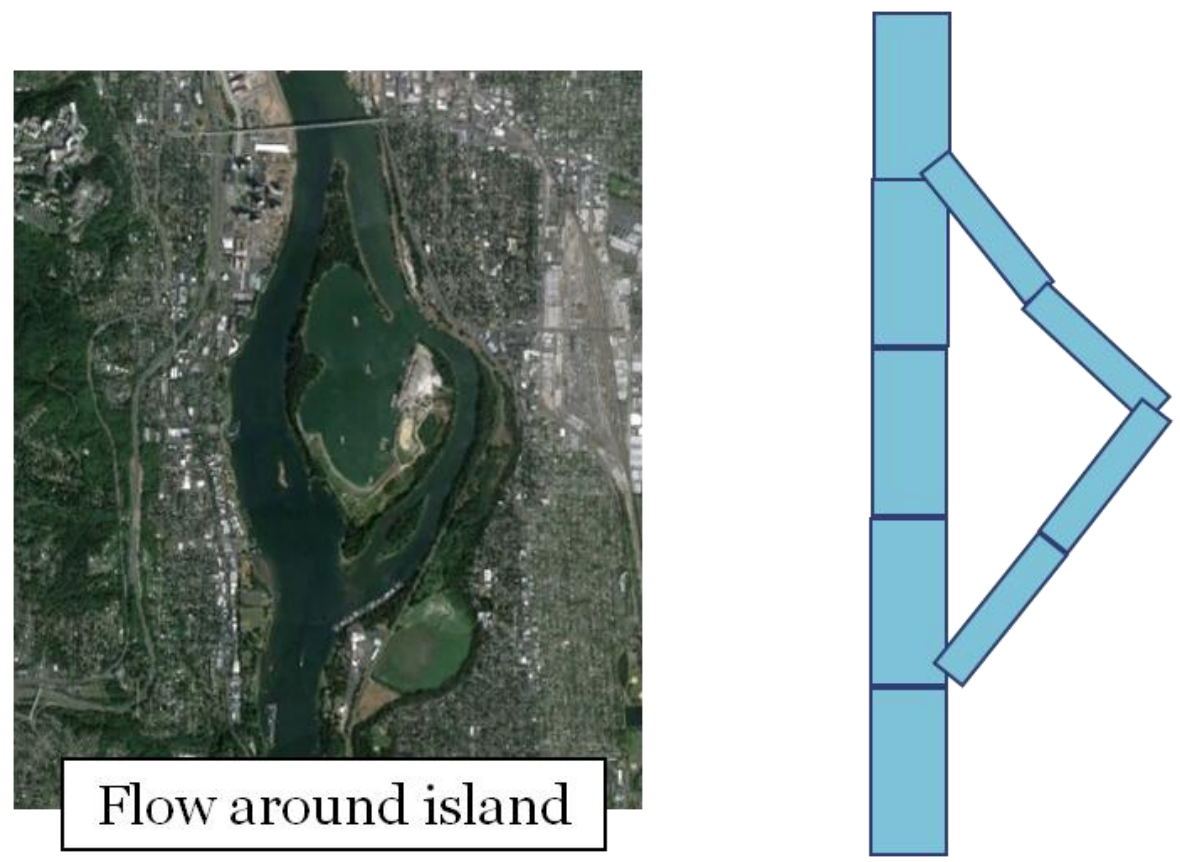

Figure 215: Example of a loop branch in the real world and in model

Flow in loop branch and main branch is determined by applying Manning's equation in both branches, as is shown in Figure 216. Bisection (Press el al., 1992) is employed to find a water level at which the flow rate at two branches sum up to the flow rate in the upstream adjacent segment.

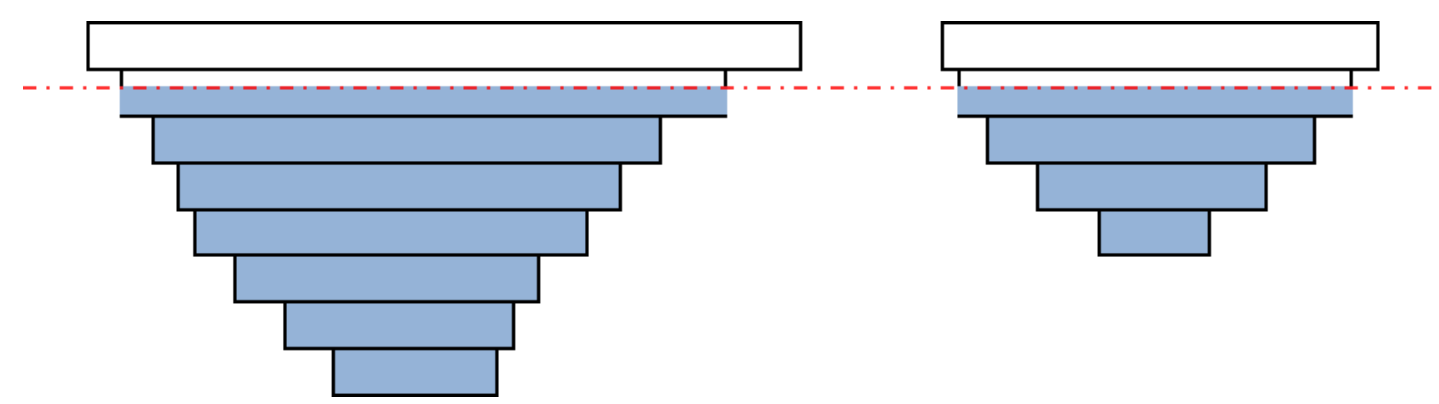

Figure 216: Flow distribution at the beginning of loop branch 
During calibration, the friction coefficient of the first segment in loop branch can be calibrated together with the connected main branch segment to ensure that the right amount of water flows into loop branch. At the end of loop branch, the friction coefficient can be deliberately raised to a high value to represent the resistance when loop branch flows back into main branch.

\section{Branch and water body connections}

At the connection between different branches, flow and heat should be conserved transporting from upstream to downstream. As the downstream bottom layer and upstream bottom layer are not necessarily at the same elevation, there are several different scenarios to transport flow and heat to downstream. Figure 217 shows an example of dividing flow in a cell to cells in the downstream branch.

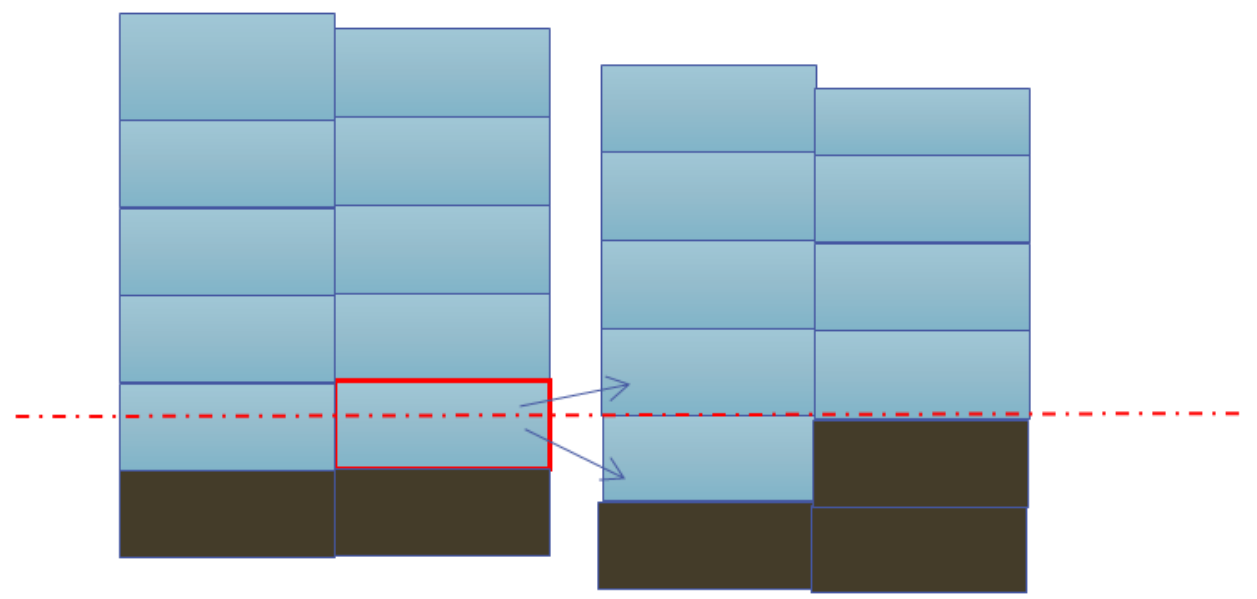

Figure 217: An example of transporting flow between branches

\subsubsection{Steady-State Hydrodynamic Calculation}


The steady-state hydrodynamic calculation method already exists in CE-QUAL-W2 Version 3.7. CE-QUAL-W2 Version 3.7 uses this method to estimate the initial water level and velocity at the first time step, so that simulation can start with estimated initial water level and velocity, instead of inputted initial condition. The steady-state model uses the same method to calculate hydrodynamics, but for every time step of simulation.

In every time step of steady-state hydrodynamic calculation, flow in each model segment is first estimated. Inflow, outflow, flow from upstream, tributary, distributaries, withdraws are all considered. Precipitation and evaporation as sources/sinks for flow balance are considered in CE-QUAL-W2 V3.7, but not in CE-QUAL-W2 steady-state model. This will not influence hydrodynamic calculation, as distributed tributaries are often used to make up flow data deficiency.

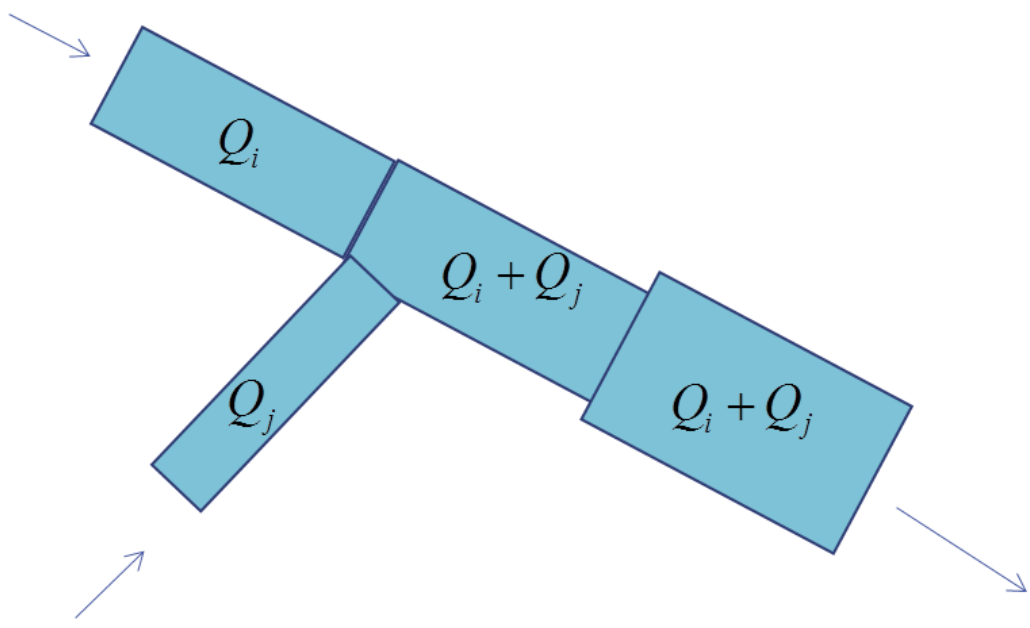

Figure 218: Flow rate calculation in the Steady-state model

Second, with estimated flow data, water level in each segment is solved from Manning's normal depth equation: 


$$
Q_{i}=\frac{1}{n_{i}} A_{i} R_{h i}^{2 / 3} S_{i}^{1 / 2}
$$

Where

$Q_{i}$ is the flow rate at segment $\mathrm{i}$,

$n_{i}$ is the Manning's friction coefficient for segment $\mathrm{i}$,

$A_{i}$ is the wetted cross-section area of segment $\mathrm{i}$,

$R_{h i}$ is the hydraulic radius of segment $\mathrm{i}$,

$S_{i}$ is the slope of the branch (in calculation, SLOPEC is used).

Hydraulic radius $R_{h i}$ is calculated from:

$$
R_{h i}=\frac{A_{i}}{P_{i}}
$$

Where

$P_{i}$ is the wetted perimeter of segment $\mathrm{i}$.

Because $A_{i}$ and $P_{i}$ are functions of water level, Manning's normal depth equation cannot be directly solved. In CE-QUAL-W2 Version 3.7, the method of bisection (Press et al., 1992) is used to find normal depth. 
Third, water level is first smoothed out within branches, then within the whole river system. Smoothing is basically replacing upstream water level with downstream water level when the former is smaller than the later one. Smoothing ensures downstream obstacles able to hold water in the upstream, and reduces inaccuracy resulted from uneven water surface.
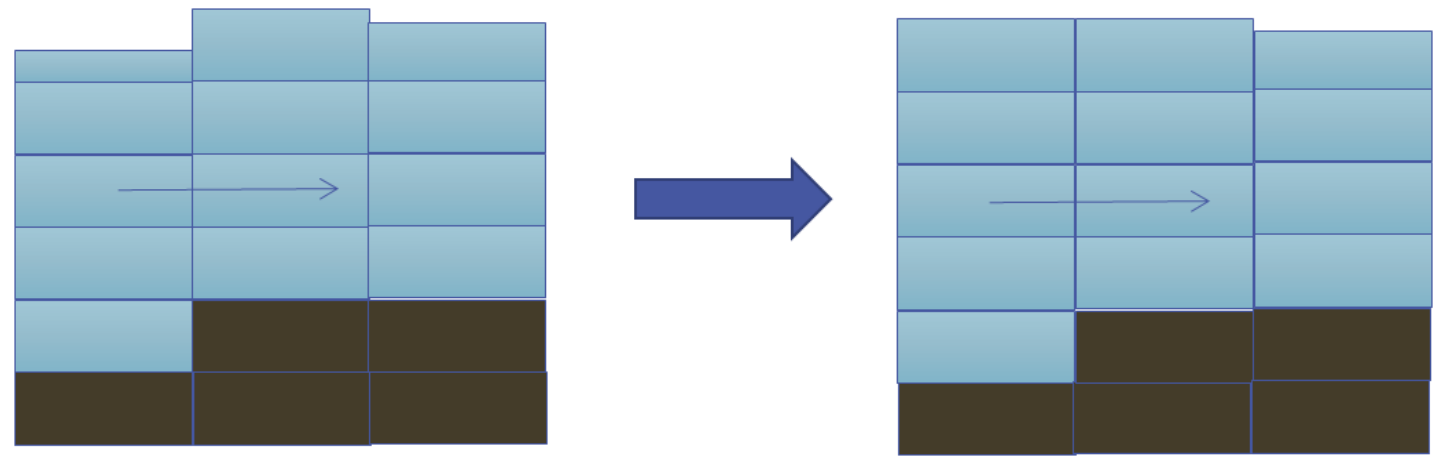

Figure 219: Water surface elevation smoothing

Fourth, average velocity is calculated in every segment, using

$$
U_{\text {avgi }}=\frac{Q_{i}}{A_{i}}
$$

$U_{\text {avgi }}$ is the average velocity of segment $\mathrm{i}$. This velocity is later assigned to every active layer of the segment. 


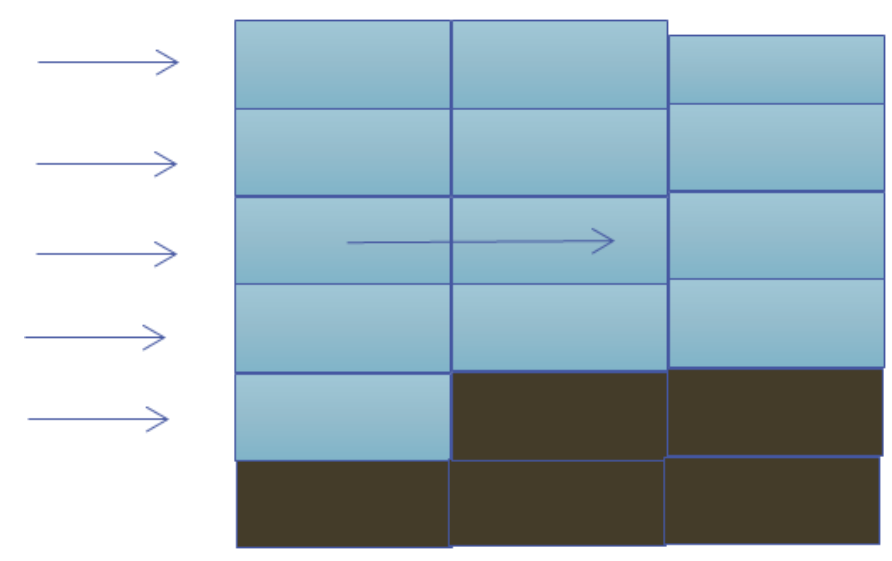

Figure 220: Longitudinal velocity calculation

Last, vertical velocity is calculated for each layer to make sure the amount of water that enters a cell equals the amount of water that leaves a cell.

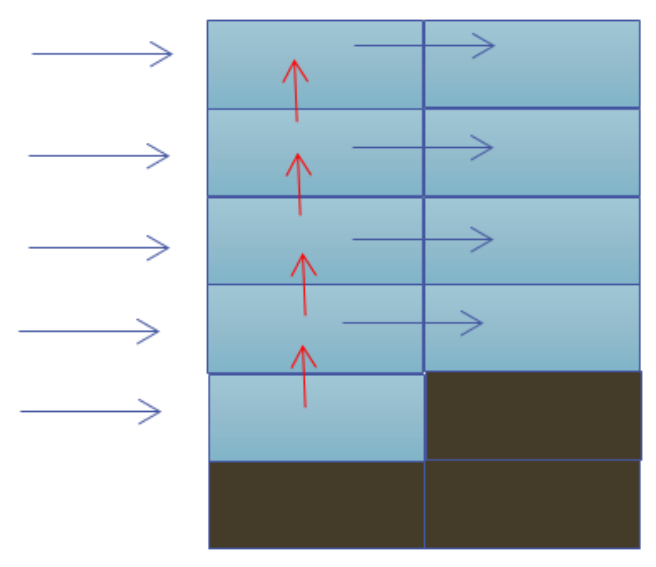

Figure 221: Vertical velocity calculation

\subsubsection{Dynamic Temperature Calculation}

Unlike hydrodynamics, temperature is estimated at unsteady-state; in other words, temperature at each time step is assumed to be related to temperature at earlier time steps. The governing equation for temperature predictions is conservation of heat: 


$$
\frac{\partial B \Phi}{\partial t}+\frac{\partial U B \Phi}{\partial x}+\frac{\partial W B \Phi}{\partial z}-\frac{\partial\left(B D_{x} \frac{\partial \Phi}{\partial x}\right)}{\partial x}-\frac{\partial\left(B D_{z} \frac{\partial \Phi}{\partial z}\right)}{\partial z}=r_{\Phi} B
$$

Where

B is channel width,

$\mathrm{t}$ is time,

$\mathrm{x}$ and $\mathrm{z}$ are the two dimensions,

$\mathrm{U}$ and $\mathrm{W}$ are velocity in $\mathrm{x}$ and $\mathrm{z}$,

$\Phi$ is temperature,

$D_{x}$ and $D_{z}$ are the dispersion coefficients in $\mathrm{x}$ and $\mathrm{z}$,

$r_{\Phi}$ is sources and sinks of heat.

Dispersion coefficients $D_{x}$ and $D_{z}$ are input into the model. Figure 222 shows the theory of the temperature calculation governing equation in the steady-state model. To put things simple, the above equation is basically saying that the temperature change in a cell equals to the heat budget change due to flow, heat sources and sink. Heat sources and sinks include: short/ long wave radiation with dynamic topographic shading and vegetation shading, air-water heat exchange, sediment-water heat exchange. Ice formation and ice cover exists in CE-QUAL-W2 Version 3.7, but it was not tested in the steady-state model yet, so for ice covered rivers the model should be used with caution. 


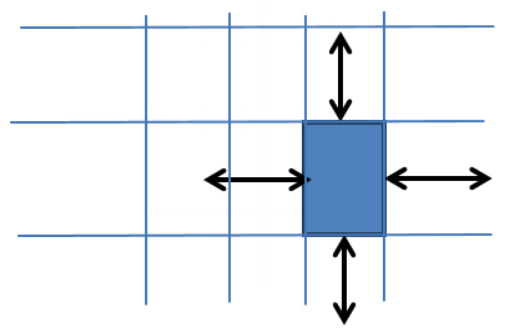

Figure 222: Sketch of heat conservation of a cell

The temperature calculation governing equation is solved using numerical method. There are 3 transport solution schemes available in CE-QUAL-W2: Upwind, Quickest, and Ultimate quickest. THETA is a parameter that allows user to specify how much percentage of implicit scheme is employed, with 0 indicating the numerical scheme is totally explicit, and 1 indicating totally implicit. Ultimate quickest numerical scheme together with THETA set to 0.55 is found to be most accurate in CE-QUAL-W2 model. The same setting is employed in the steady-state model for temperature predictions.

\subsection{Model Development Process}

The model development process can be separated into two stages: (1) building the steadystate model prototype, and (2) constantly refining the prototype.

The first stage focused on putting steady-state hydrodynamics and dynamic temperature calculation together. The hydrodynamic calculation module was replaced with Manning's equation, which calculates water level and velocity at steady state. After that, effort was focused on making the manning's equation properly connect with other parts within the code, and to make code run without errors. 
The second stage focused on the correctness of the code. As was shown in Figure 223, the model development process involved a lot of testing and refining of the prototype. Clackamas River was relatively simple compared to other river systems, so it was chosen to be the first river system to be tested with the new code. For debugging purposes, an ideal state was created, where the temperature of all the inflow from upstream and tributaries were set to $20^{\circ} \mathrm{C}$, and all the heat exchange activities were neglected. As a result, temperature in every cell and every segment should be $20{ }^{\circ} \mathrm{C}$ if the code is correct. All the real world models were first tested at this ideal state before real world cases were tested and calibrated.

\section{Model Testing and Refining Process}

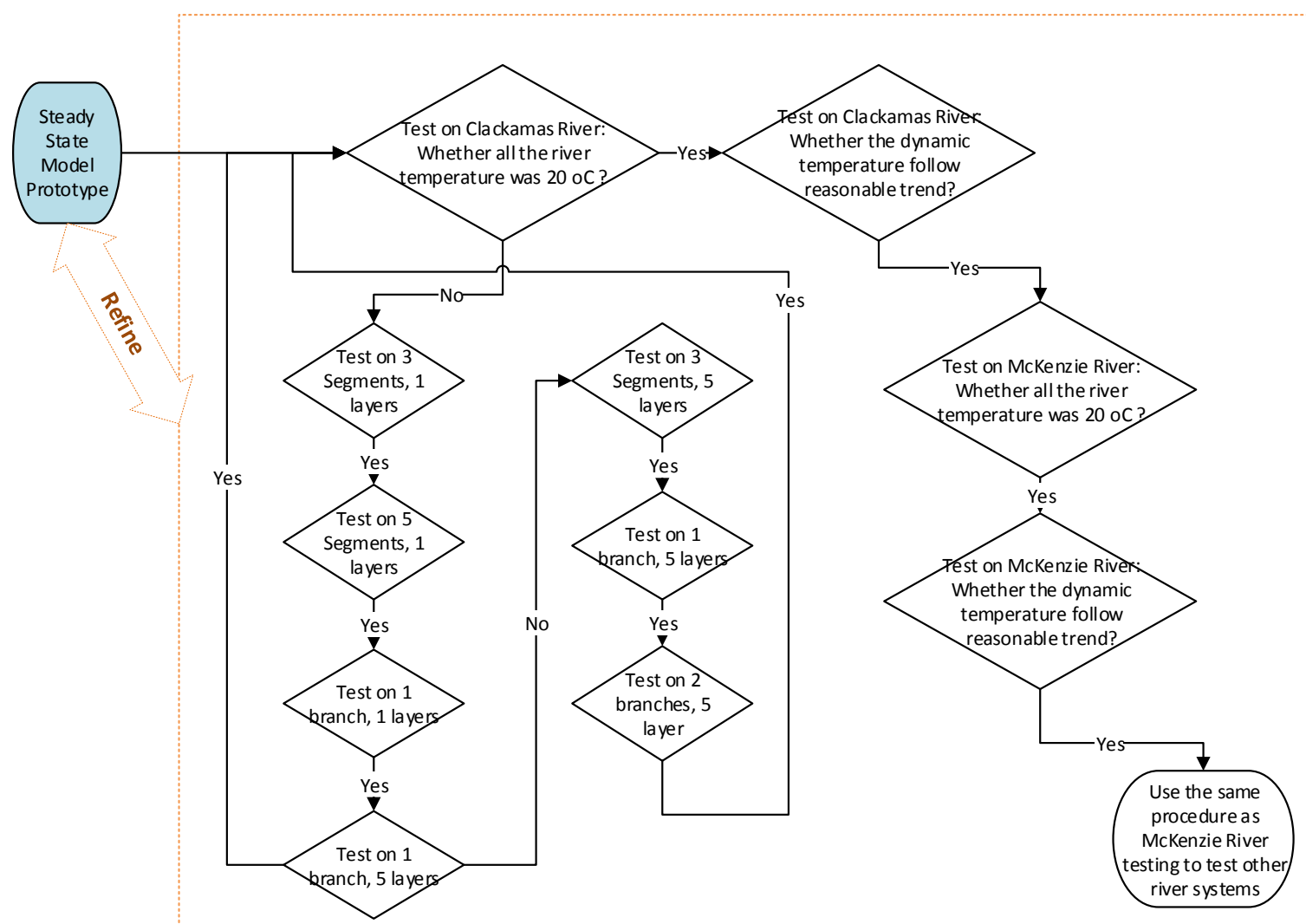

Figure 223: Steady-State Model testing and refining process flow chart 


\subsection{Converting V3.7 models to Steady-state models}

Most parts of the model setting up for CE-QUAL-W2 steady-state model is identical to the setting up for CE-QUAL-W2 V3.7. The procedures to convert an existing Version 3.7 model to steady-state include:

- In the control file ("W2_con.npt"), initial water surface elevation calculation (INITUWL) must be turned to "ON" to make sure that the executable (w2_ivf3211.11.exe) is able to run.

- In the control file ("W2_con.npt"), precipitation should be turned off, as the steady-state model is not developed incorporating precipitation data.

- In the control file ("W2_con.npt"), a new coefficient named "DMZ" should be added under the card "Hydraulic coefficients". DMZ specifies the vertical diffusion coefficient for each water body.

After make these changes, paste the steady-state executable into the work dictionary folder. The executable should be able to run when it is double clicked. Now the maximum time step can be set to a bigger value, for example 120 seconds.

The remaining work would be re-calibrated to ensure accurate prediction. Manning's friction coefficient, the equivalent slope are generally chosen as calibration parameters.

In Chapter 4, an example case shows what if an existing Version 3.7 model is converted to steady-state without re-calibration.

\subsection{Testing of New Steady State Model Codes}


Three river models within the Willamette River System were tested with the New Steady State Model Codes, they were: Clackamas River, McKenzie River, Long Tom River. Attempts have been made to convert and calibrate Middle Willamette River model and Upper Willamette River model to steady-state model, but the calibration work is still going on. For Lower Willamette/ Columbia River model, because flow characteristics in Lower Willamette River and Columbia River are strongly influenced by tides, and the steady-state model does not have the ability to simulate the tidal effects, the Lower Willamette River / Columbia River model is not converted to steady-state.

The calibration results of the three tested river models were presented with details in the following sections.

\subsubsection{Clackamas River}

\section{Hydrodynamics}

Manning's friction coefficient and hydraulic equivalent slope were the only two parameters used to calibrate the model.

\section{Year 2001}

Clackamas River hydrodynamic model-data error statistics in 2001 are summarized in Table 28. Figure 224 through 227 show the flow rate and water level comparison at different sites. The model was overestimating water level at high flow period and underestimating water level at low flow period. Similar result appeared in Version 3.1 and Version 3.7 model. Finer bathymetry data would be needed to solve this problem. 
Table 28: Clackamas River hydrodynamic calibration statistics, 2001

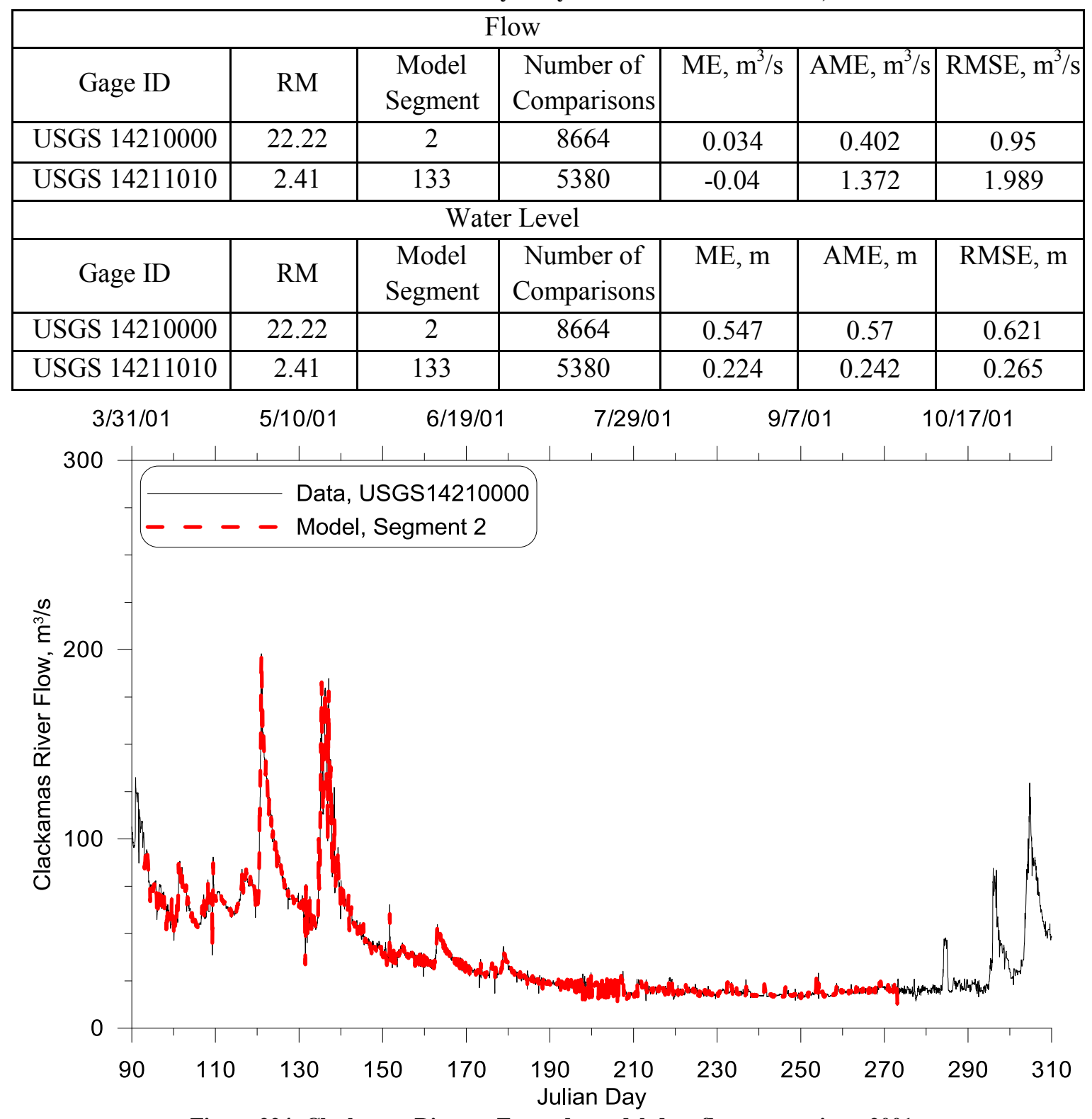

Figure 224: Clackamas River at Estacada model-data flow comparison, 2001 


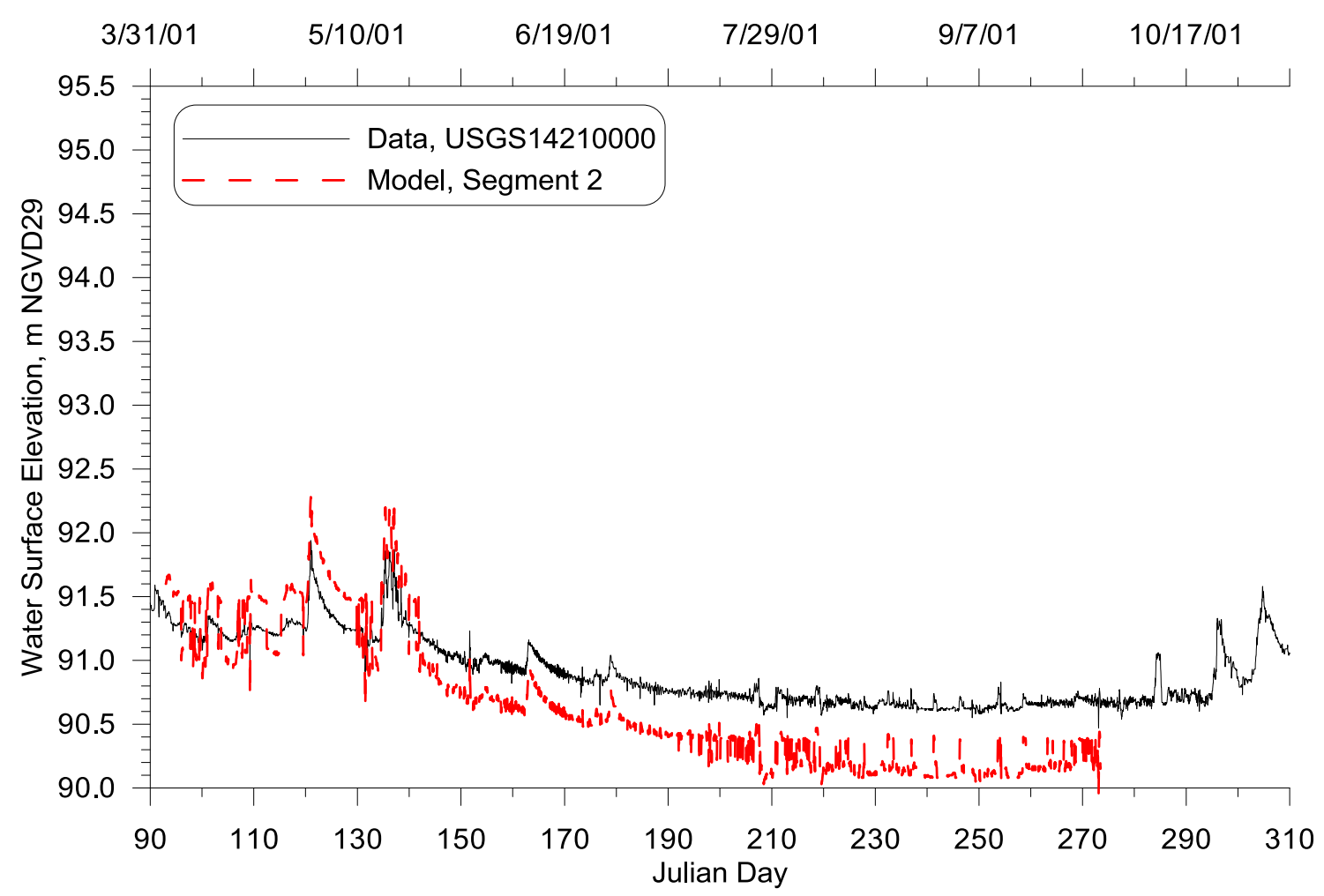

Figure 225: Clackamas River at Estacada model-data water level comparison, 2001

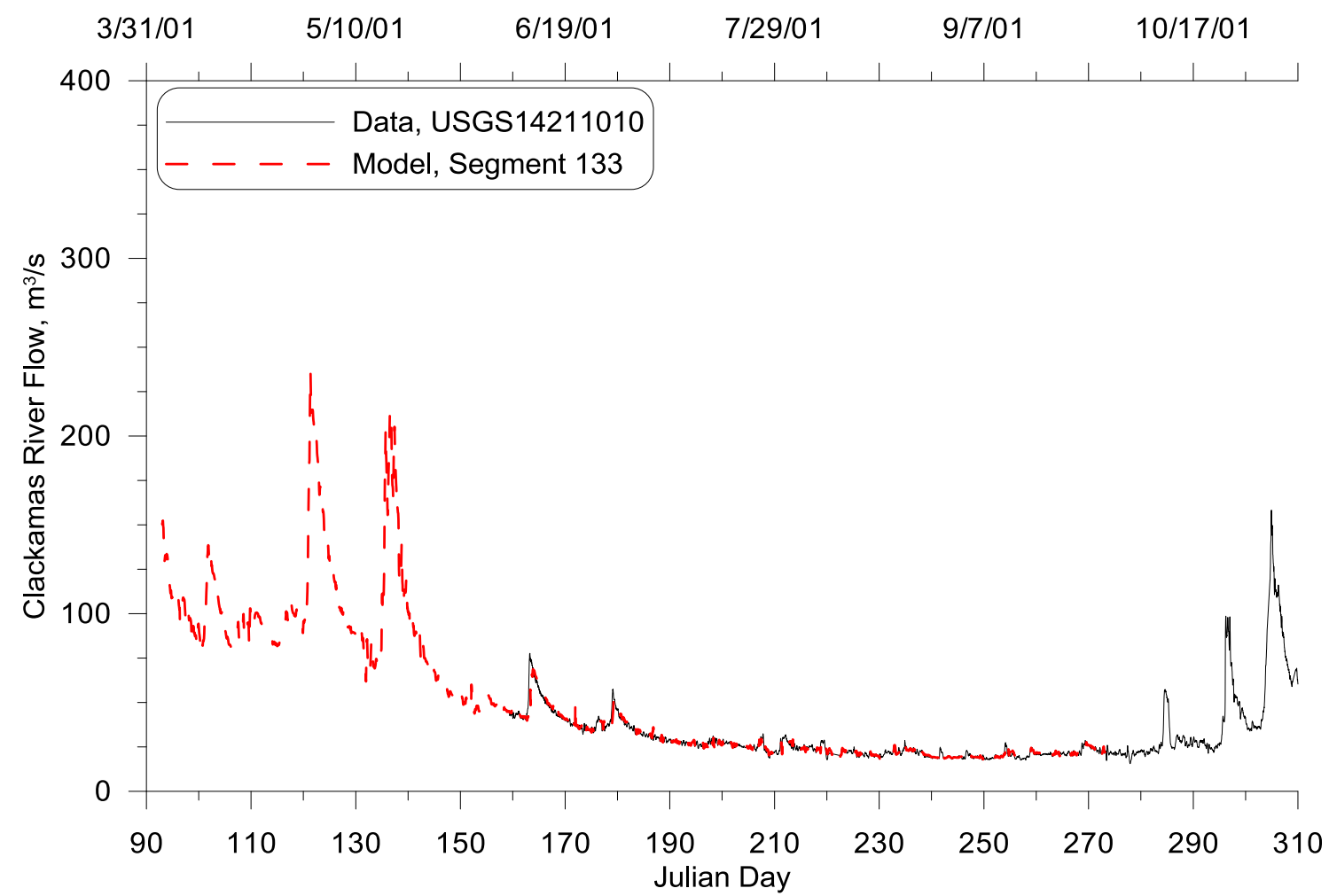

Figure 226: Clackamas River near Oregon City model-data flow comparison, 2001 


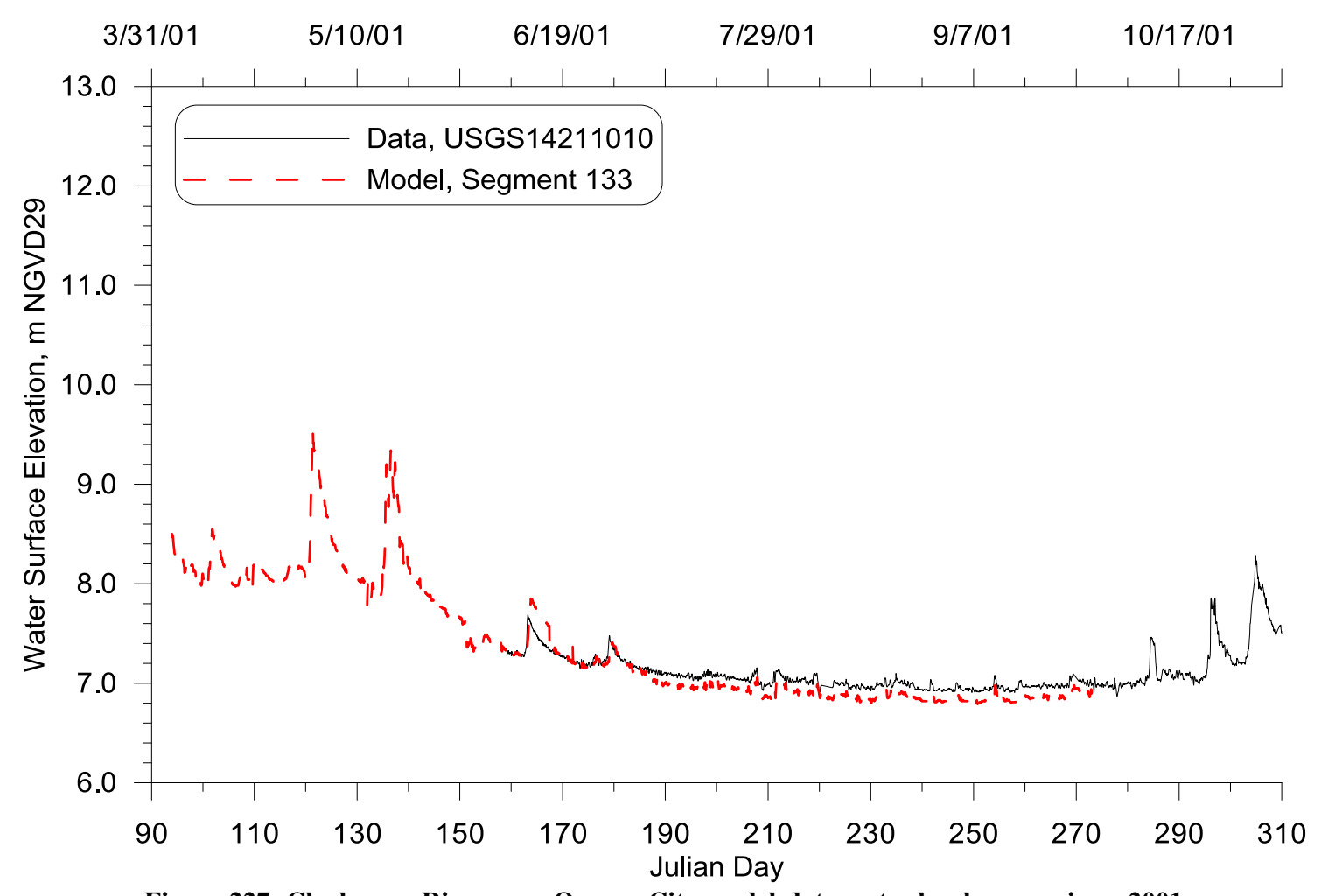

Figure 227: Clackamas River near Oregon City model-data water level comparison, 2001

\section{Year 2002}

Clackamas River hydrodynamic model-data error statistics in 2002 are summarized in Table 29. Figure 228 through 231 show the flow rate and water level comparison at different sites. The model experienced the same problem for water level at segment 2 in 2002 as in 2001. Another problem was that the model was overestimating the water level at peak flow, which occurred at Julia Day 97. This would be the first problem to look at if there were more time for calibration. 
Table 29: Clackamas River hydrodynamic calibration statistics, 2002

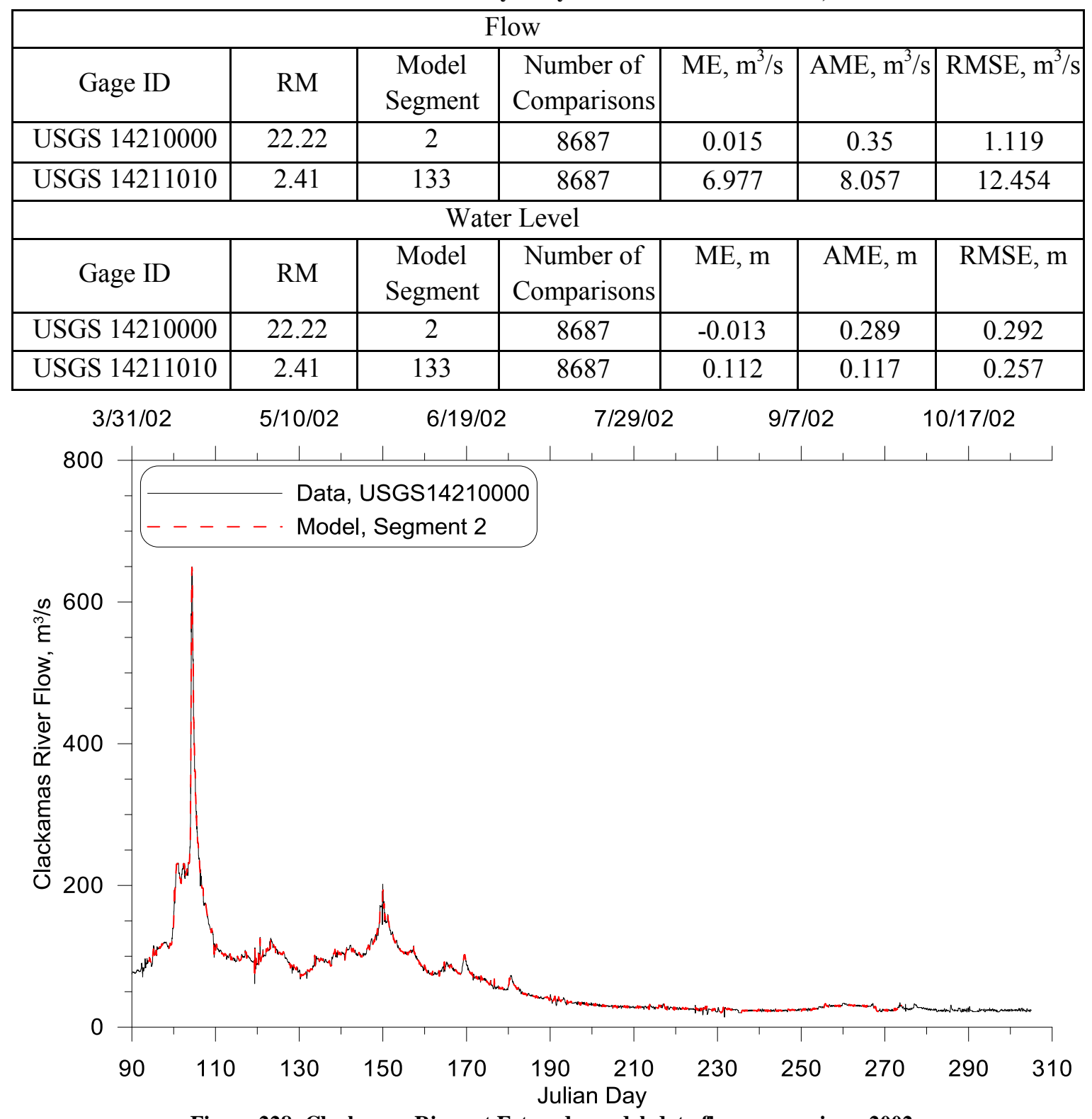

Figure 228: Clackamas River at Estacada model-data flow comparison, 2002 


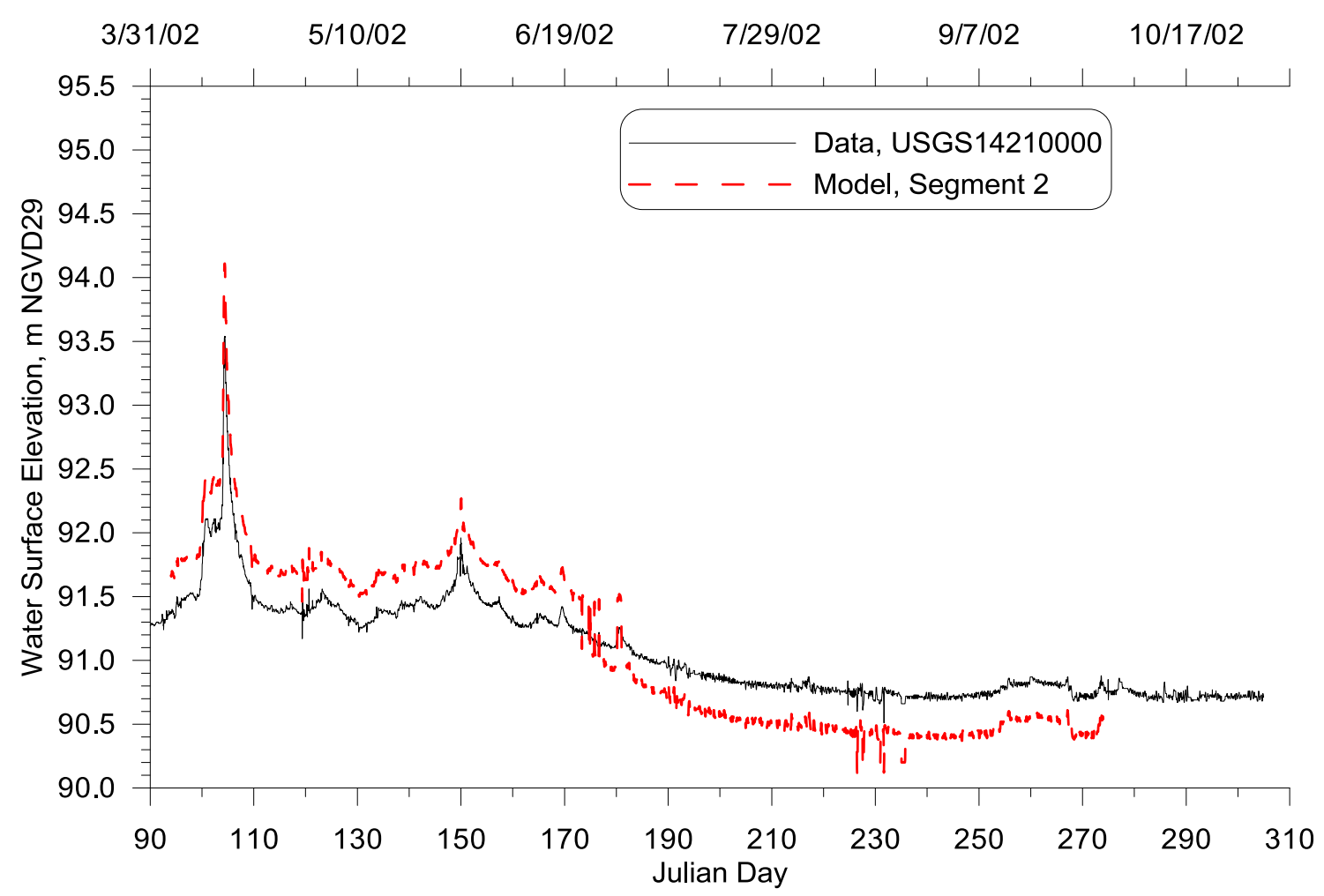

Figure 229: Clackamas River at Estacada model-data water level comparison, 2002

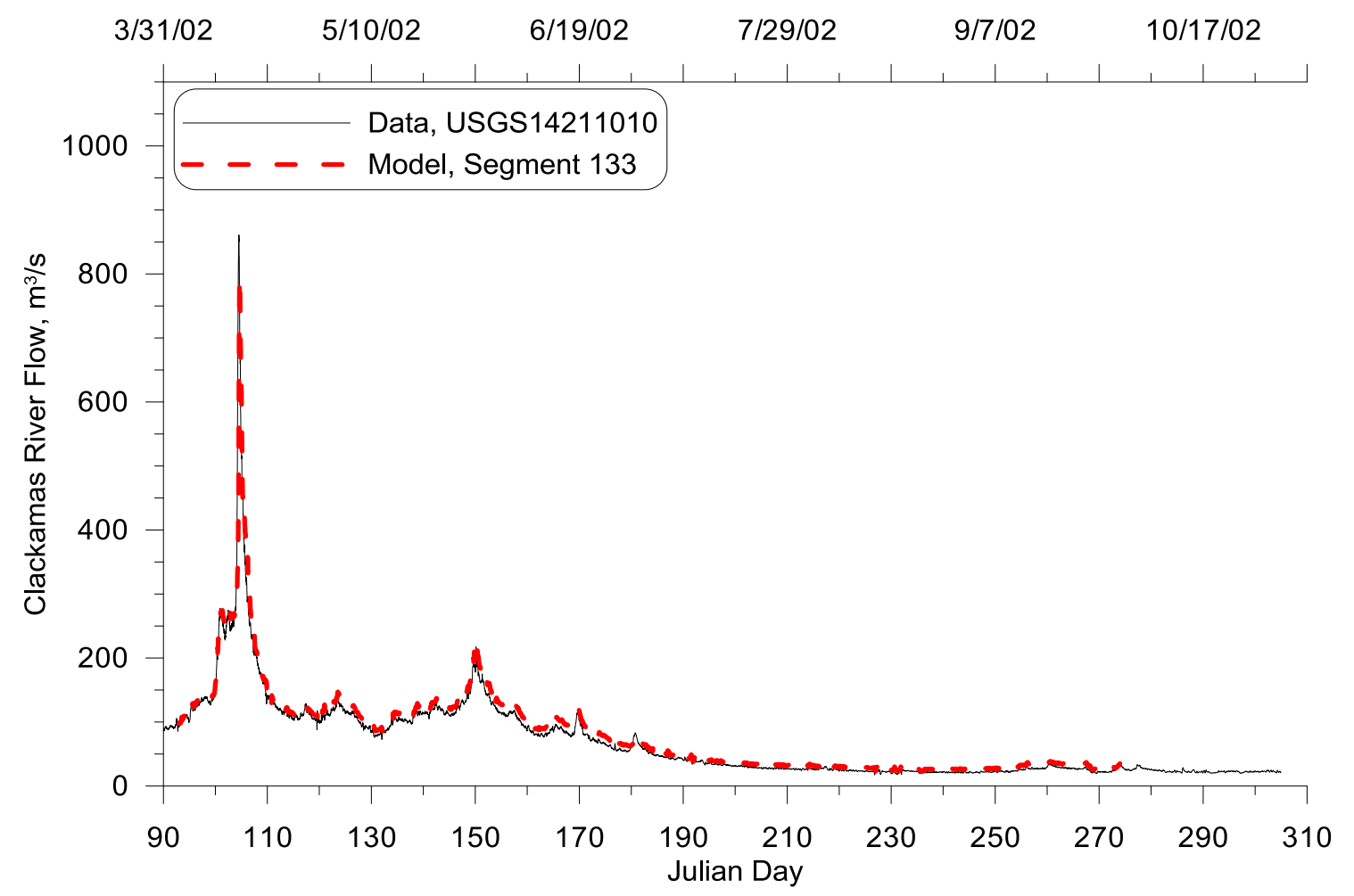

Figure 230: Clackamas River near Oregon City model-data flow comparison, 2002 


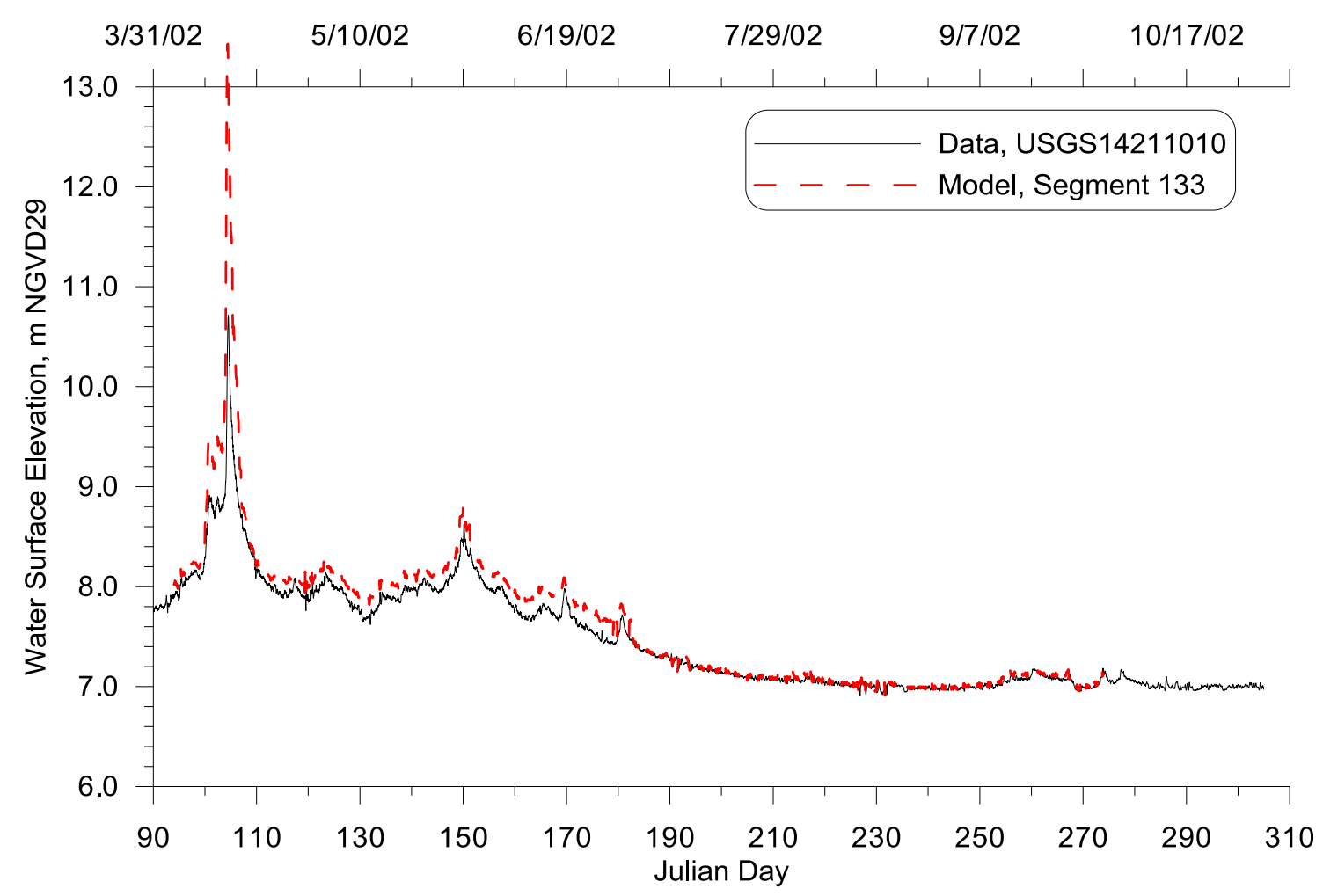

Figure 231: Clackamas River near Oregon City model-data water level comparison, 2002

\section{Temperature}

\section{Year 2001}

Clackamas River continuous water temperature calibration model-data error statistics in 2001 are summarized in Table 30. Figure 232 through 237 show the continuous temperature comparison at different sites. The current calibration result had the RMSEs below $1.1{ }^{\circ} \mathrm{C}$. 
Table 30: Clackamas River continuous water temperature calibration model-data error statistics, 2001

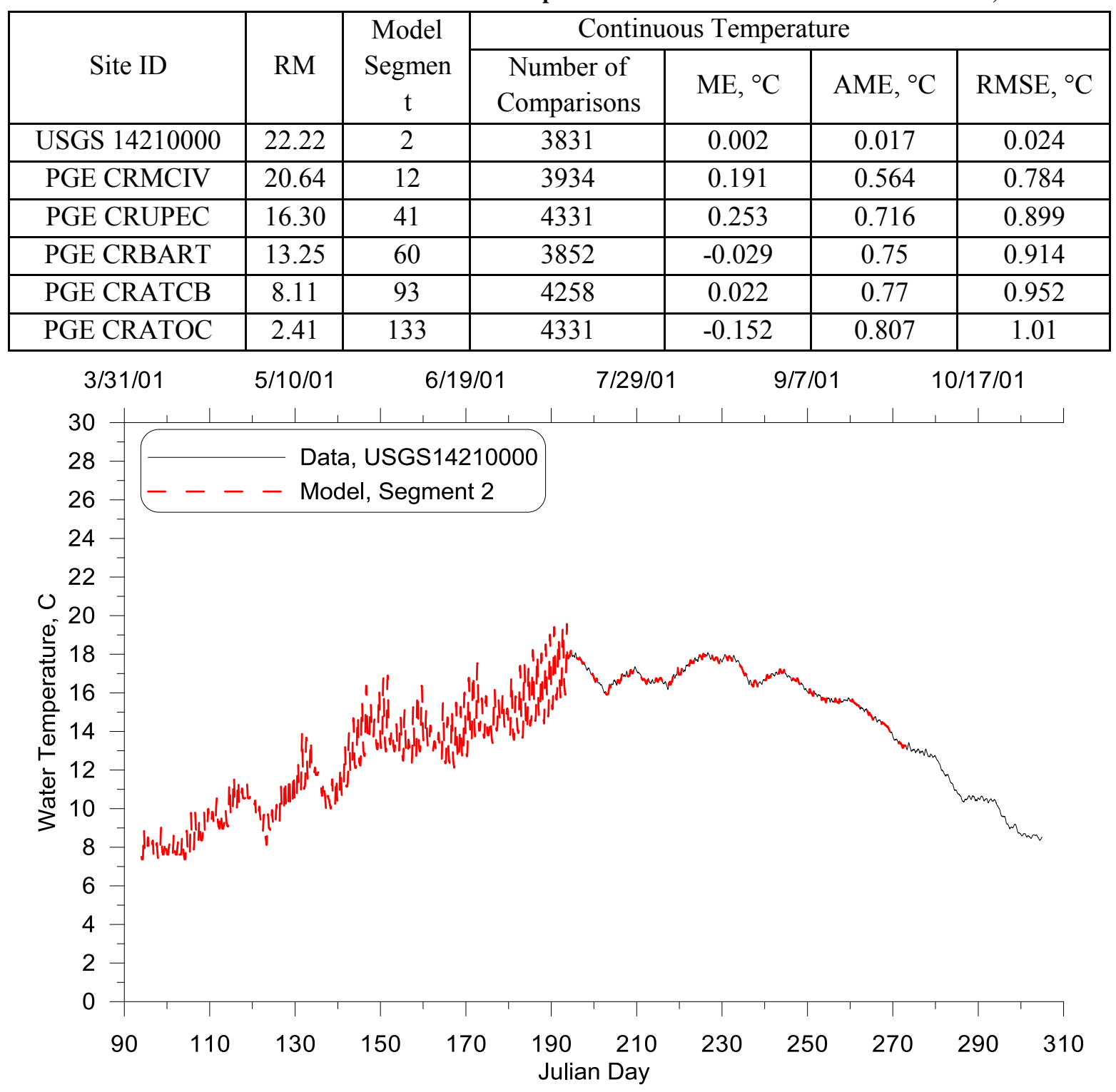

Figure 232: Clackamas River at Estacada model-data continuous temperature comparison, 2001 


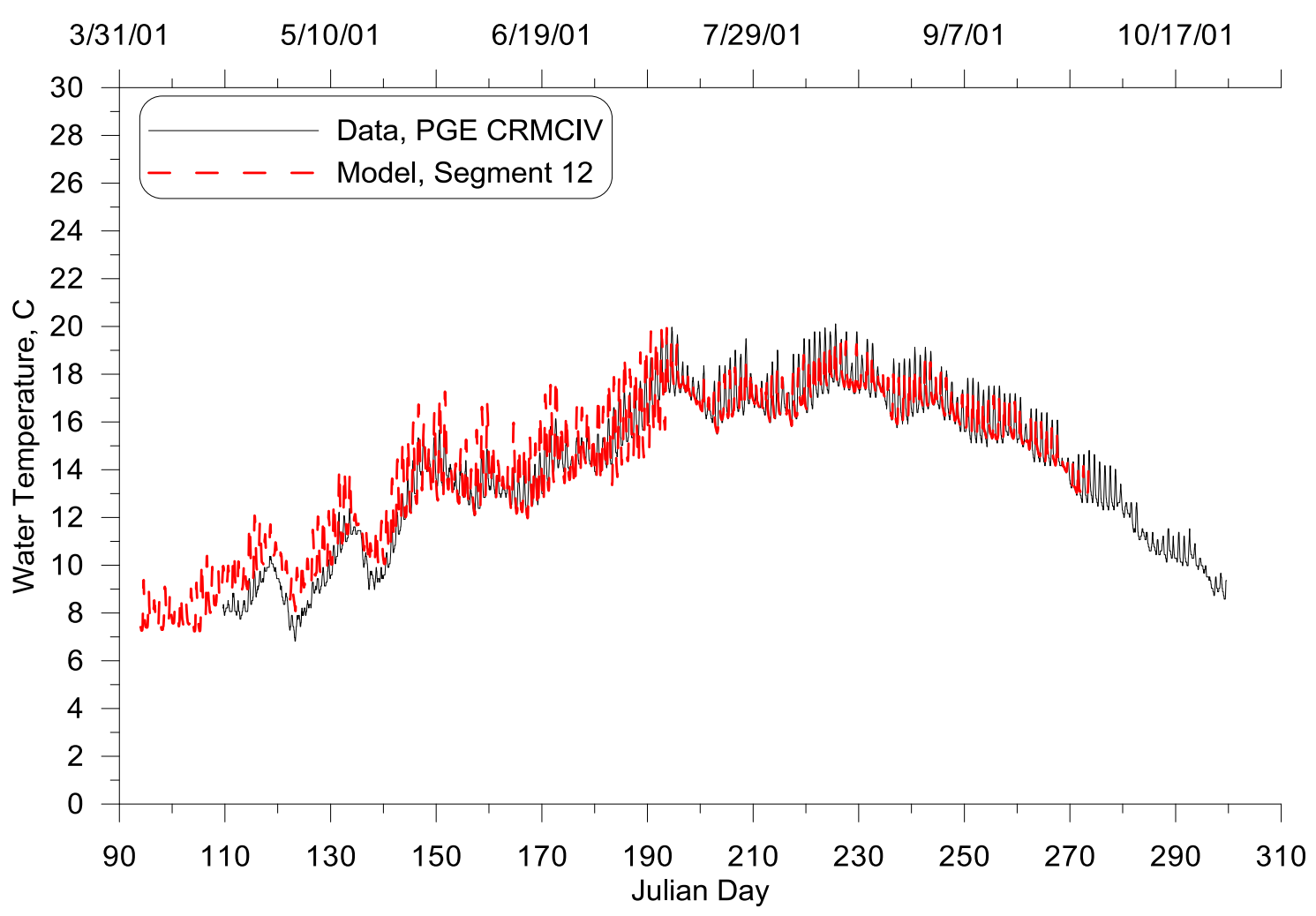

Figure 233: Clackamas River at McIver Park model-data continuous temperature comparison, 2001

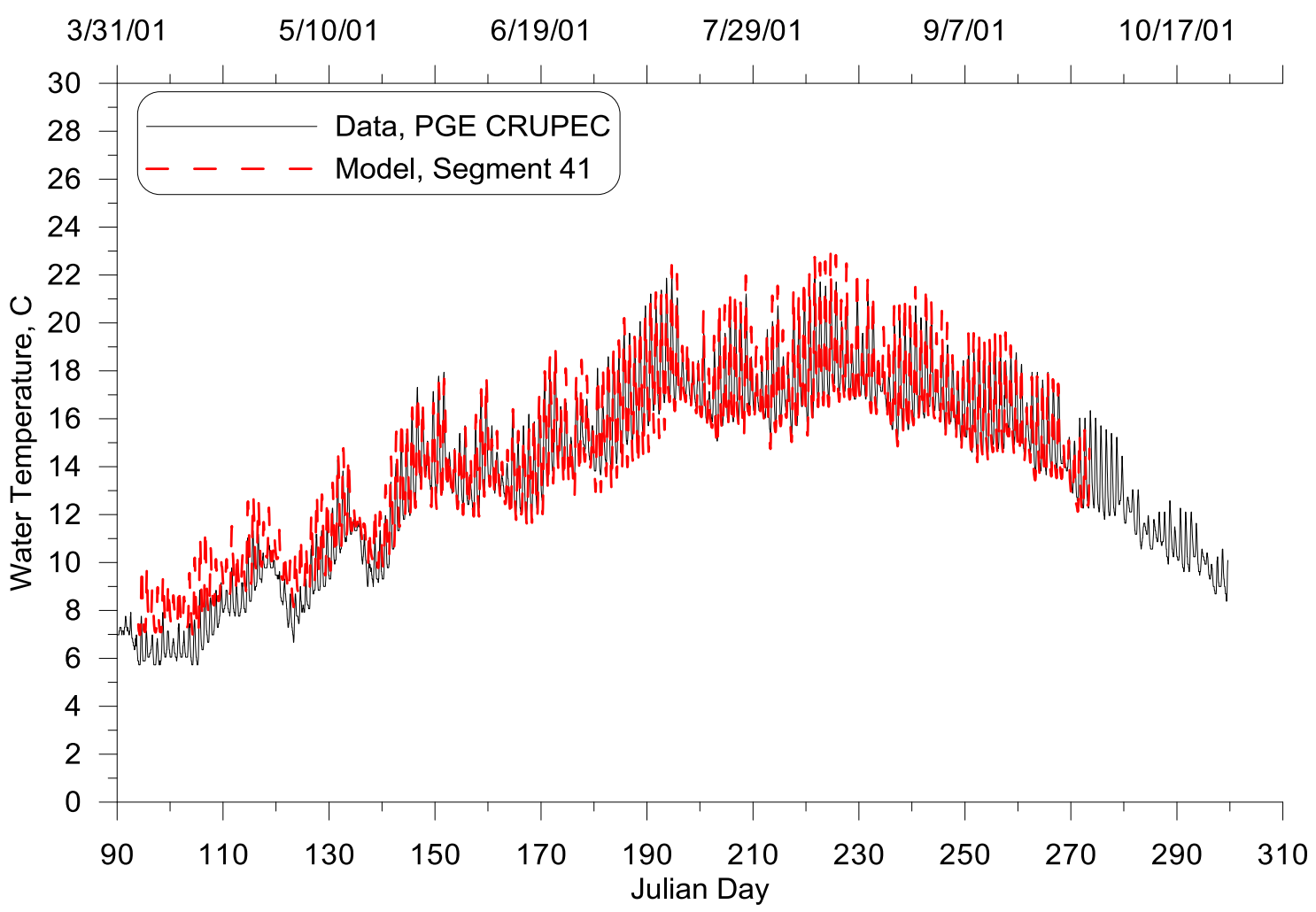

Figure 234: Clackamas River upstream of Eagle Creek model-data continuous temperature comparison, 2001 


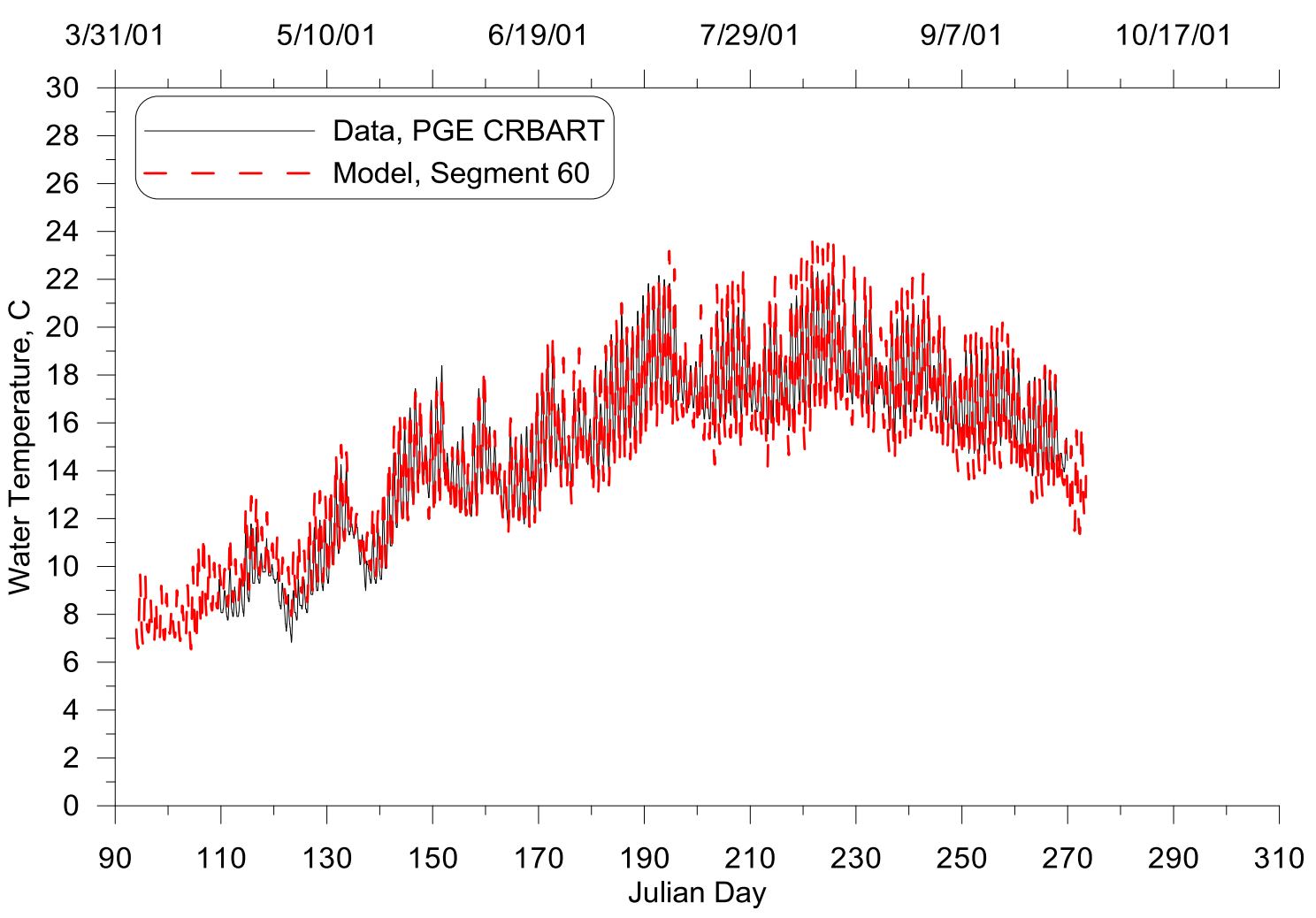

Figure 235: Clackamas River at Barton model-data continuous temperature comparison, 2002

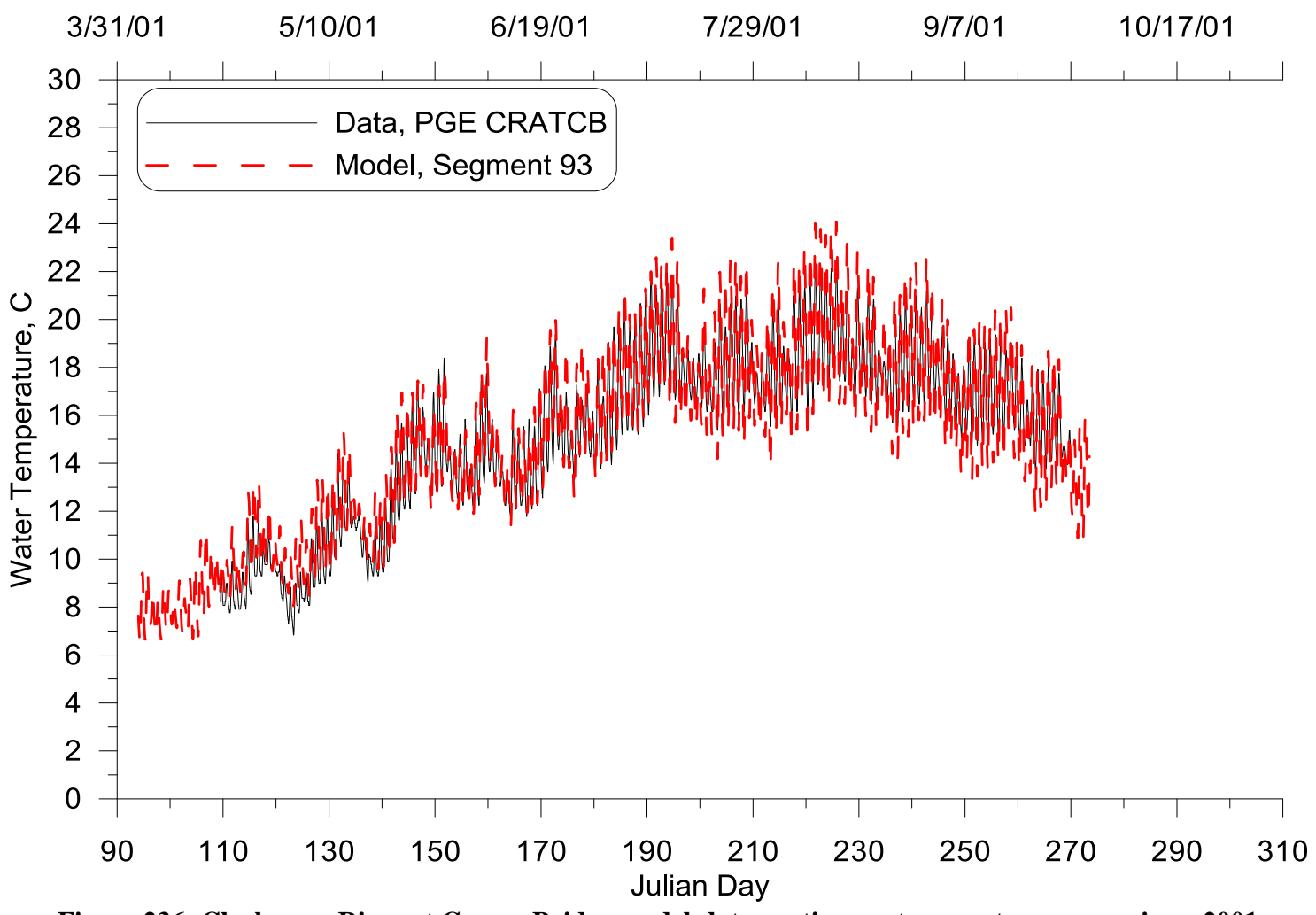

Figure 236: Clackamas River at Carver Bridge model-data continuous temperature comparison, 2001 


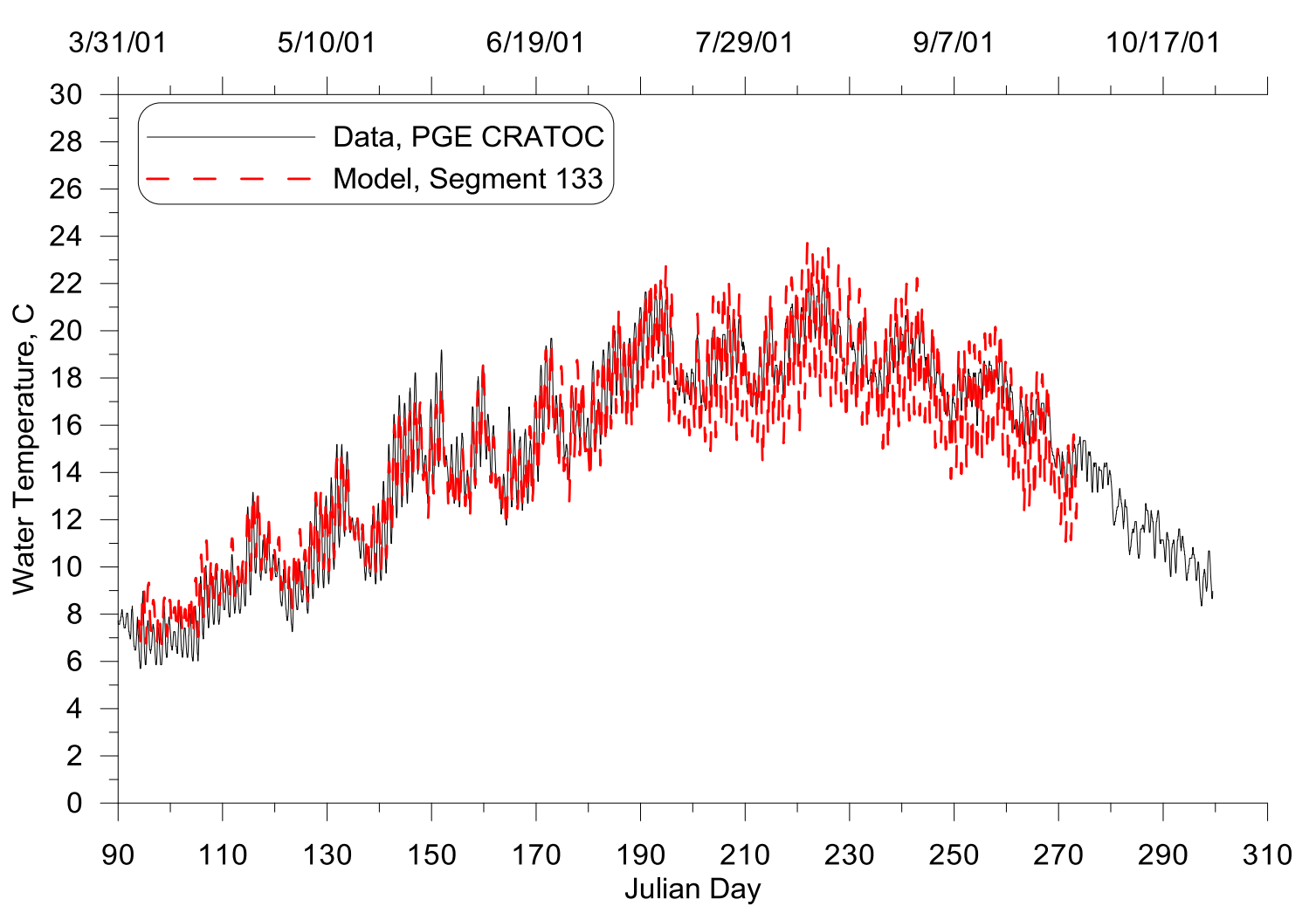

Figure 237: Clackamas River at Oregon City model-data continuous temperature comparison, 2001

Year 2002

Clackamas River continuous water temperature calibration model-data error statistics in 2002 are summarized in Table 31. Figure 238 through 241 show the continuous temperature comparison at different sites. The current calibration result had the RMSEs below $1.1^{\circ} \mathrm{C}$.

Table 31: Clackamas River continuous water temperature calibration model-data error statistics, 2002

\begin{tabular}{|c|c|c|c|c|c|c|}
\hline \multirow[b]{2}{*}{ Site ID } & \multirow[b]{2}{*}{$\mathrm{RM}$} & \multirow{2}{*}{$\begin{array}{c}\text { Model } \\
\text { Segment }\end{array}$} & \multicolumn{4}{|c|}{ Continuous Temperature } \\
\hline & & & $\begin{array}{l}\text { Number of } \\
\text { Comparisons }\end{array}$ & $\mathrm{ME},{ }^{\circ} \mathrm{C}$ & $\mathrm{AME},{ }^{\circ} \mathrm{C}$ & $\mathrm{RMSE},{ }^{\circ} \mathrm{C}$ \\
\hline USGS 14210000 & 22.22 & 2 & 8687 & 0.007 & 0.014 & 0.024 \\
\hline LASAR 30439 & 16.30 & 41 & 1309 & -0.314 & 0.368 & 0.466 \\
\hline LASAR 30515 & 8.20 & 92 & 1307 & -0.382 & 0.644 & 0.775 \\
\hline USGS 14211010 & 2.41 & 133 & 4922 & -0.493 & 0.862 & 1.065 \\
\hline
\end{tabular}




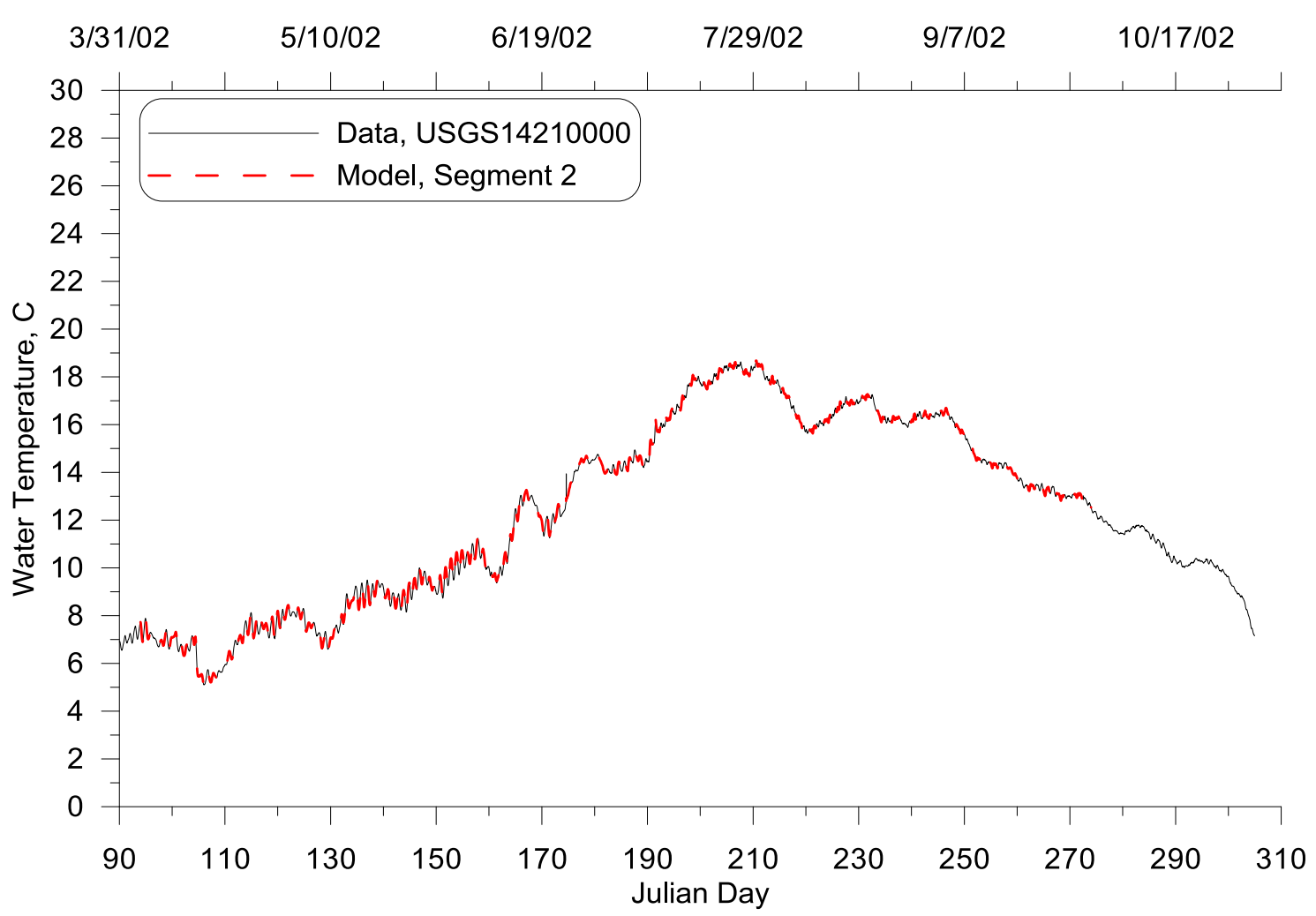

Figure 238: Clackamas River at Estacada model-data continuous temperature comparison, 2002

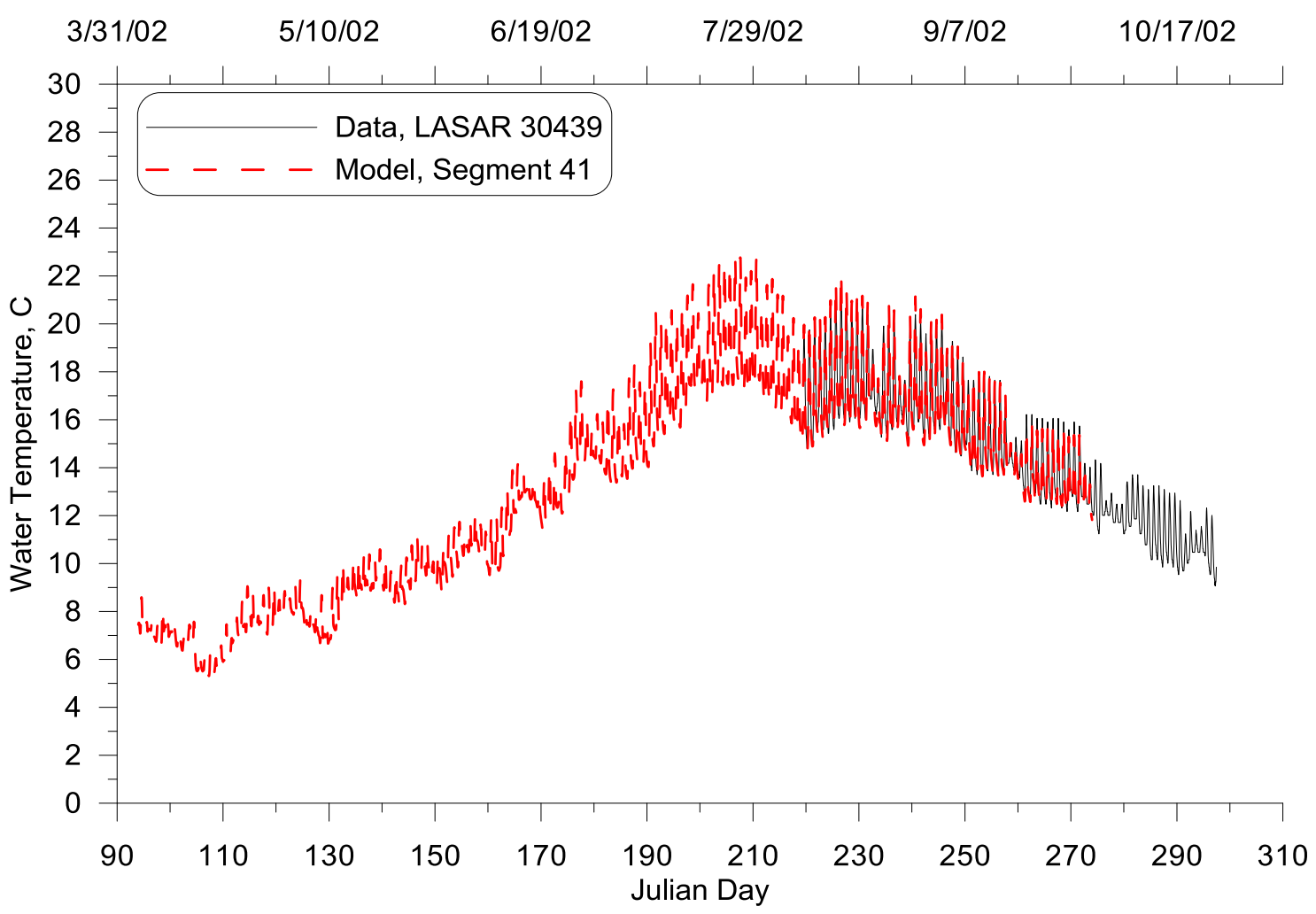

Figure 239: Clackamas River upstream of Eagle Creek model-data continuous temperature comparison, 2002 


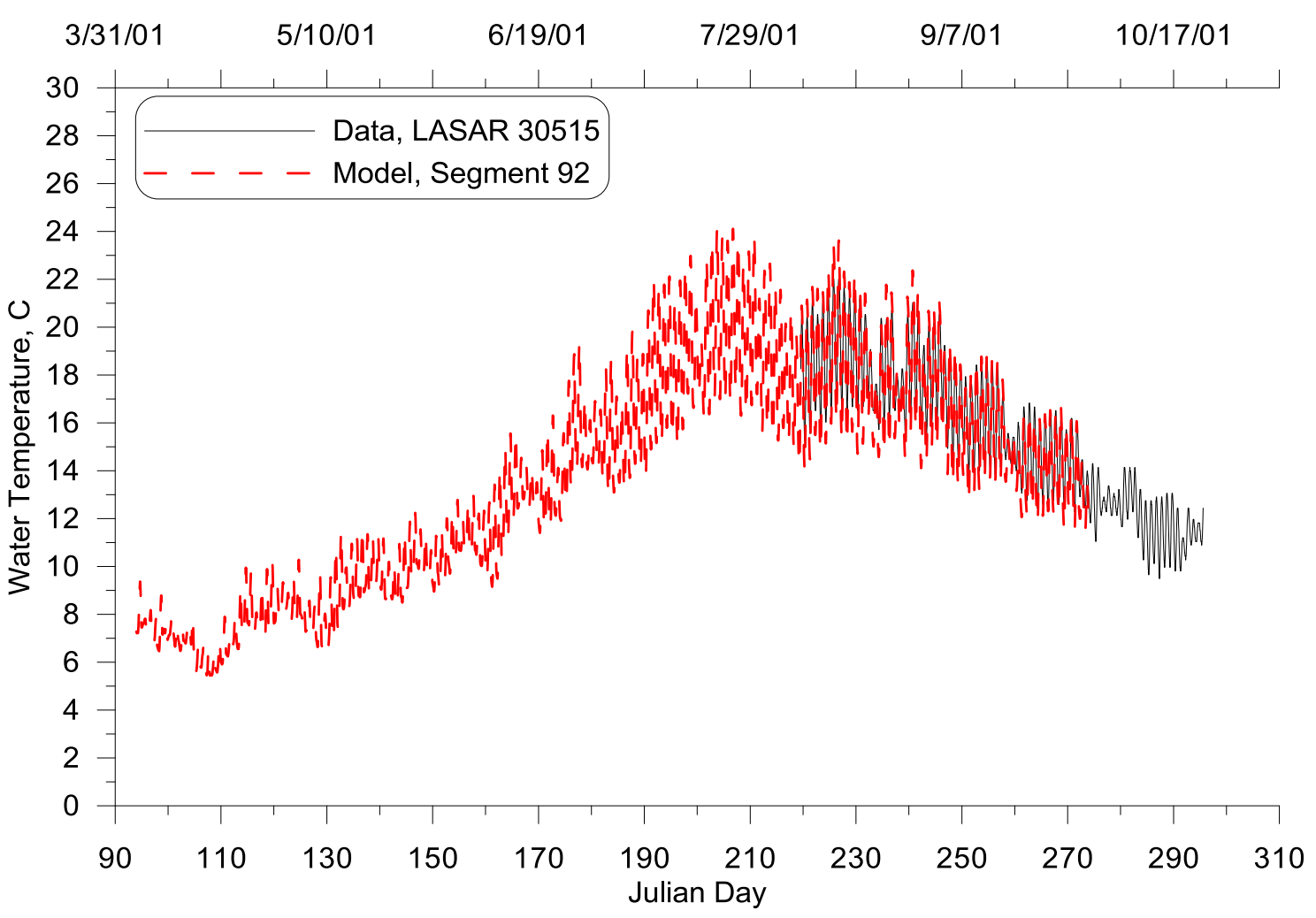

Figure 240: Clackamas River upstream of Clear Creek model-data continuous temperature comparison, 2002

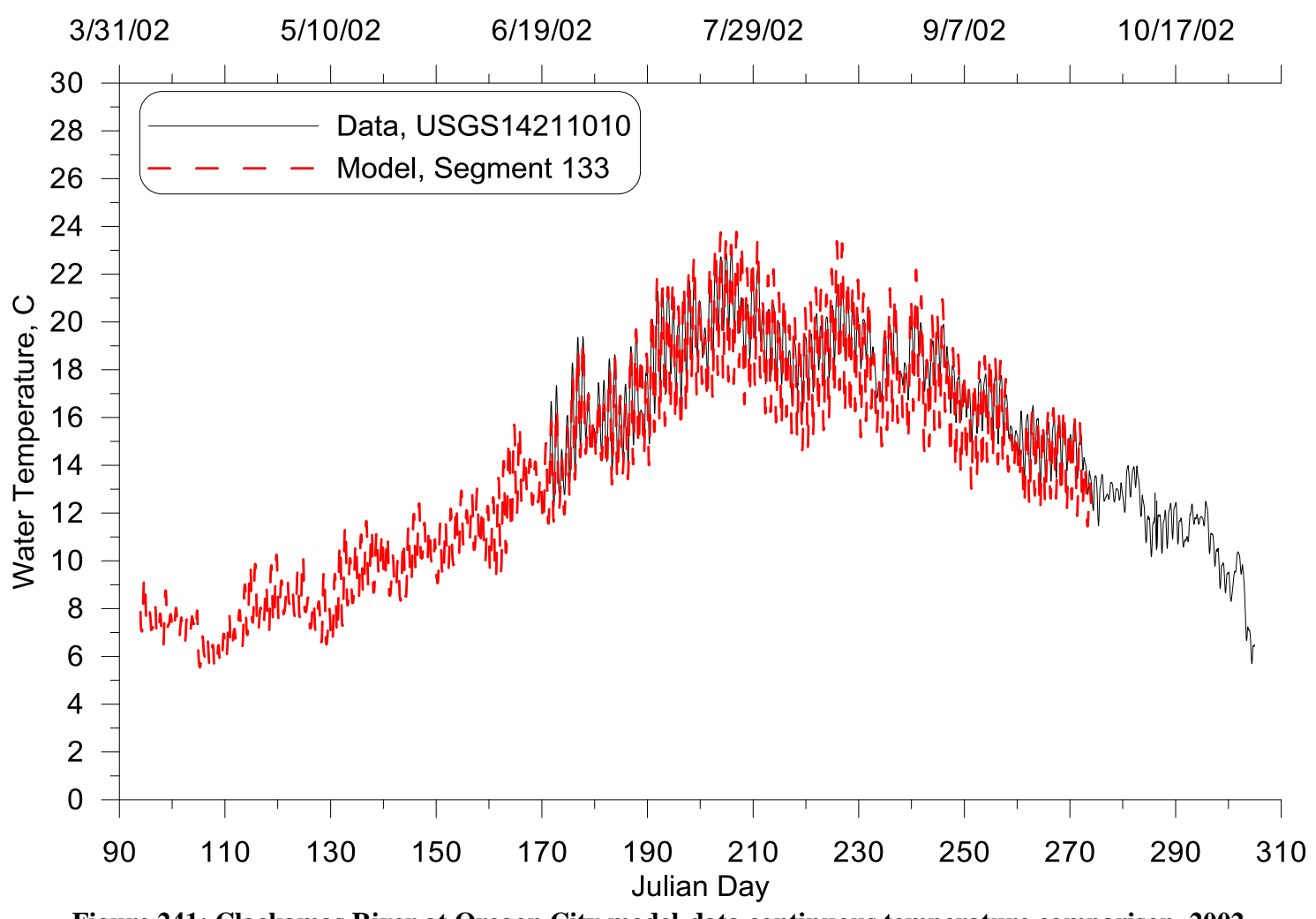

Figure 241: Clackamas River at Oregon City model-data continuous temperature comparison, 2002 


\subsubsection{McKenzie River}

\section{Hydrodynamics}

Manning's friction coefficient and hydraulic equivalent slope were the only two parameters used to calibrate the model.

\section{Year 2001}

McKenzie River hydrodynamic model-data error statistics in 2001 are summarized in Table 32. Figure 242 through 249 show the flow rate and water level comparison at different sites. Overall, the Steady-State model was able to predict both flow rate and water level very well. For segment 240, the model was overestimating the water level. This was because water level during the simulation period fell into one single layer, and only by adjusting friction coefficient the water level could not be gotten for the whole simulation period. More accurate bathymetry data would needed to get the right water level. As the water temperature results were acceptable, further calibration was not conducted. 
Table 32: McKenzie River hydrodynamic calibration model-data error statistics, 2001

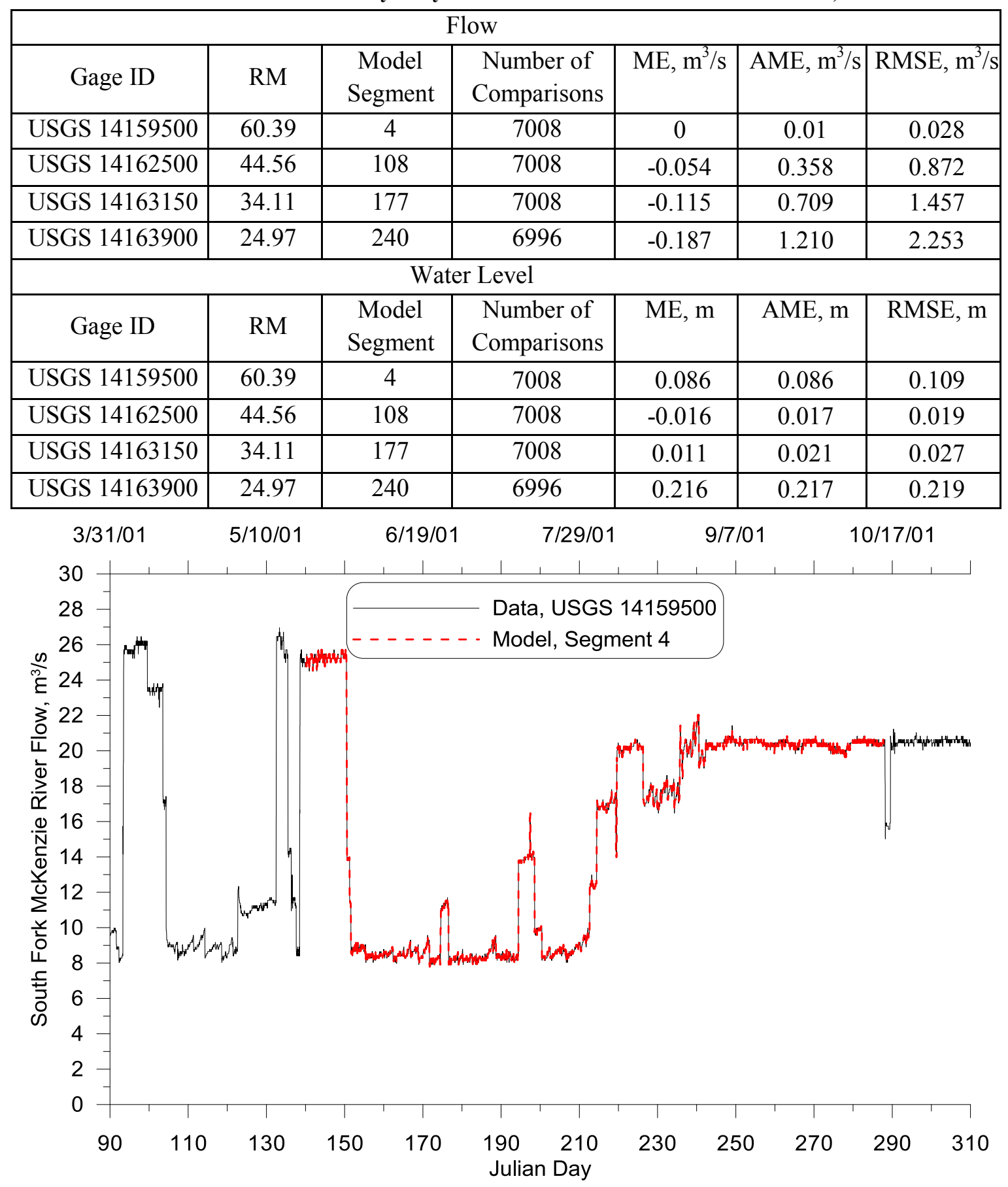

Figure 242: South Fork McKenzie River below Cougar Dam model-data flow comparison, 2001 


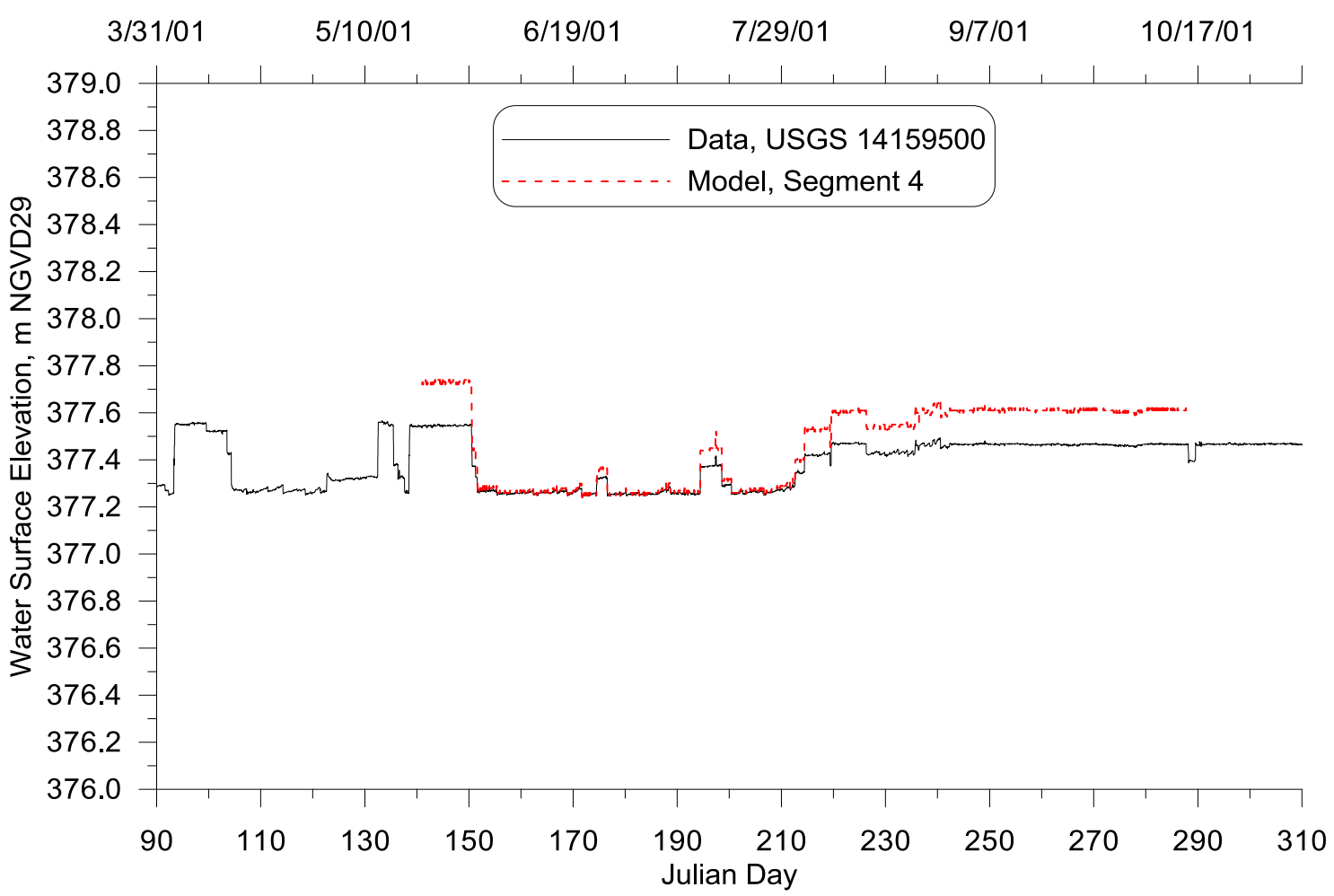

Figure 243: South Fork McKenzie River below Cougar Dam model-data water level comparison, 2001

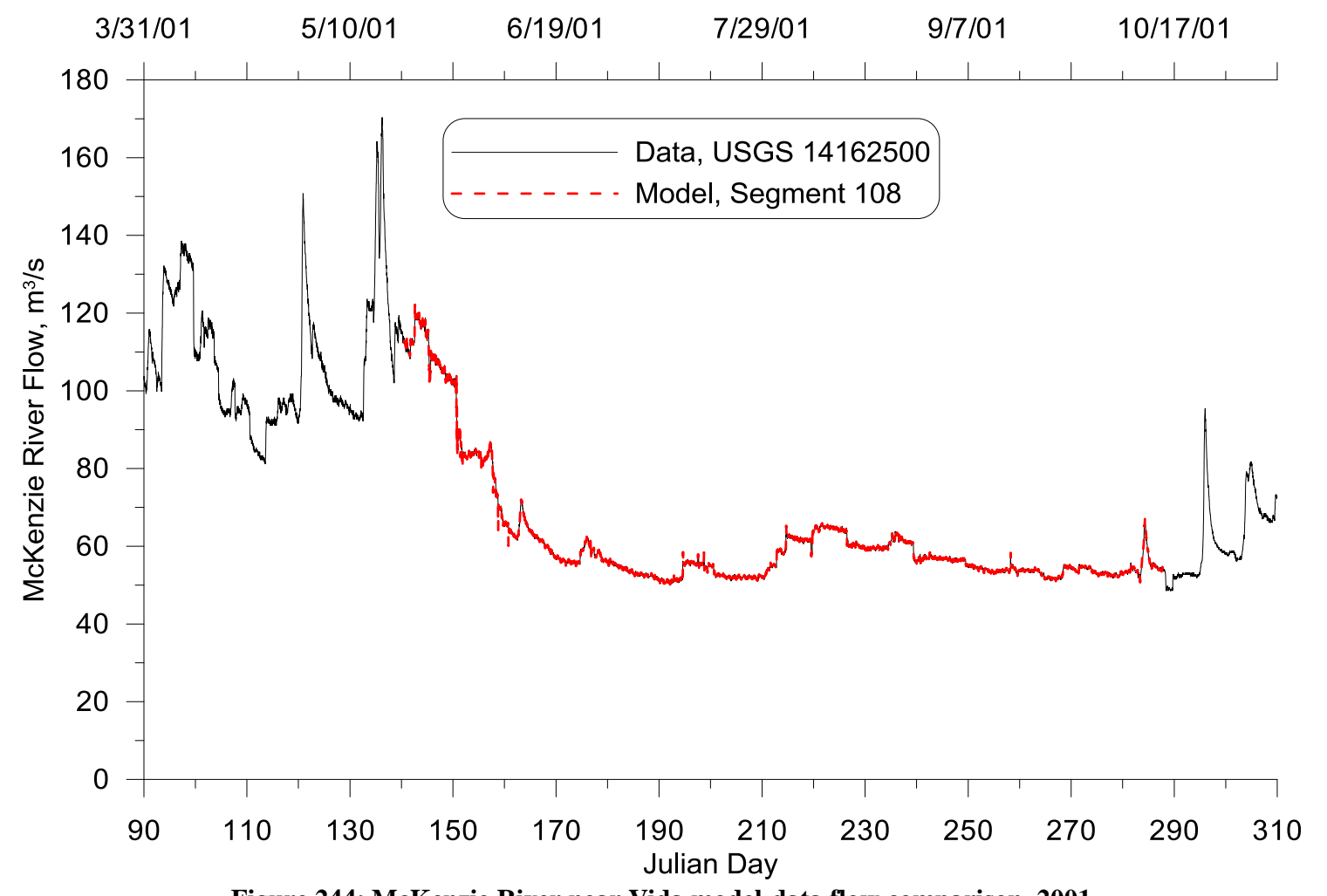

Figure 244: McKenzie River near Vida model-data flow comparison, 2001 


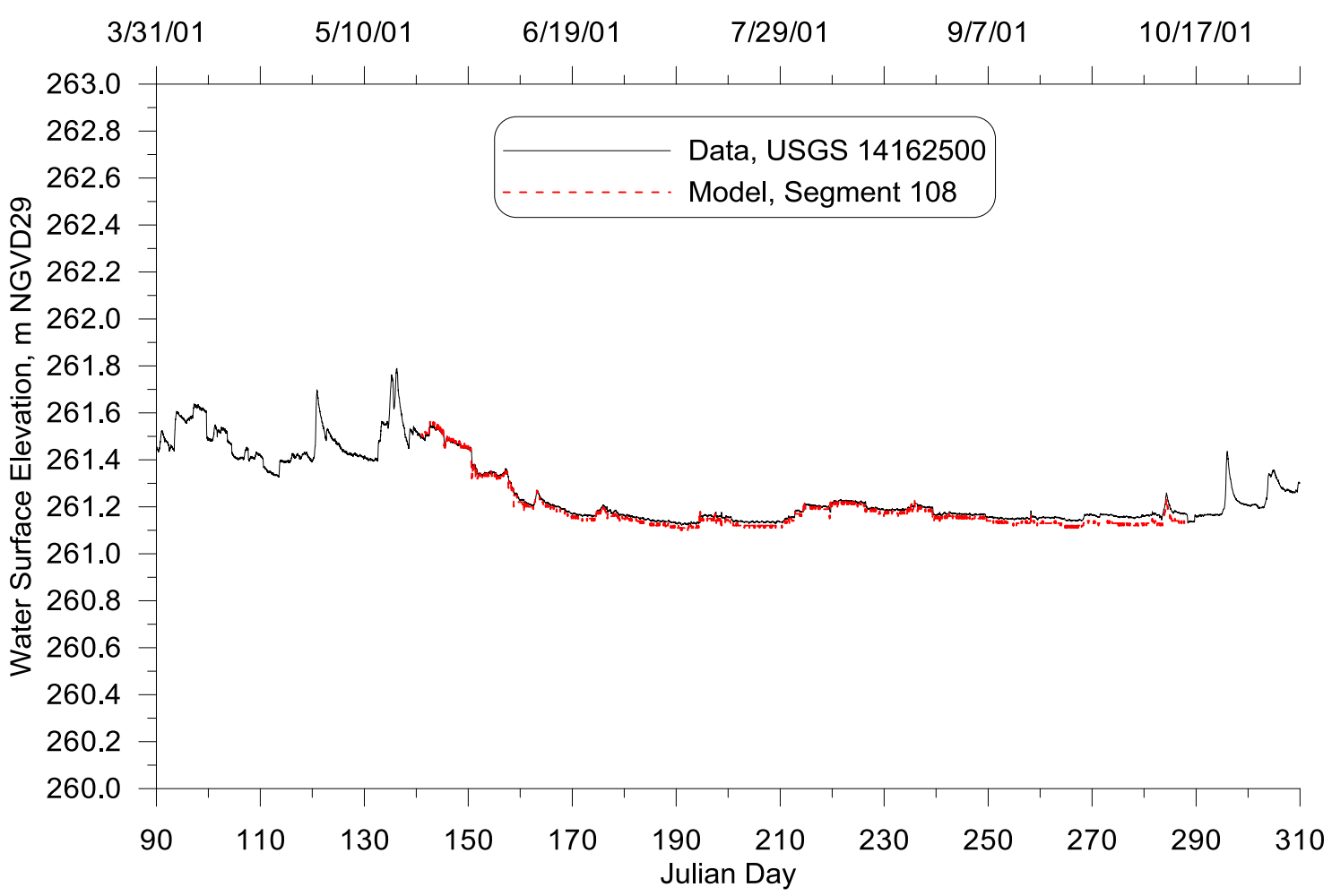

Figure 245: McKenzie River near Vida model-data water level comparison, 2001

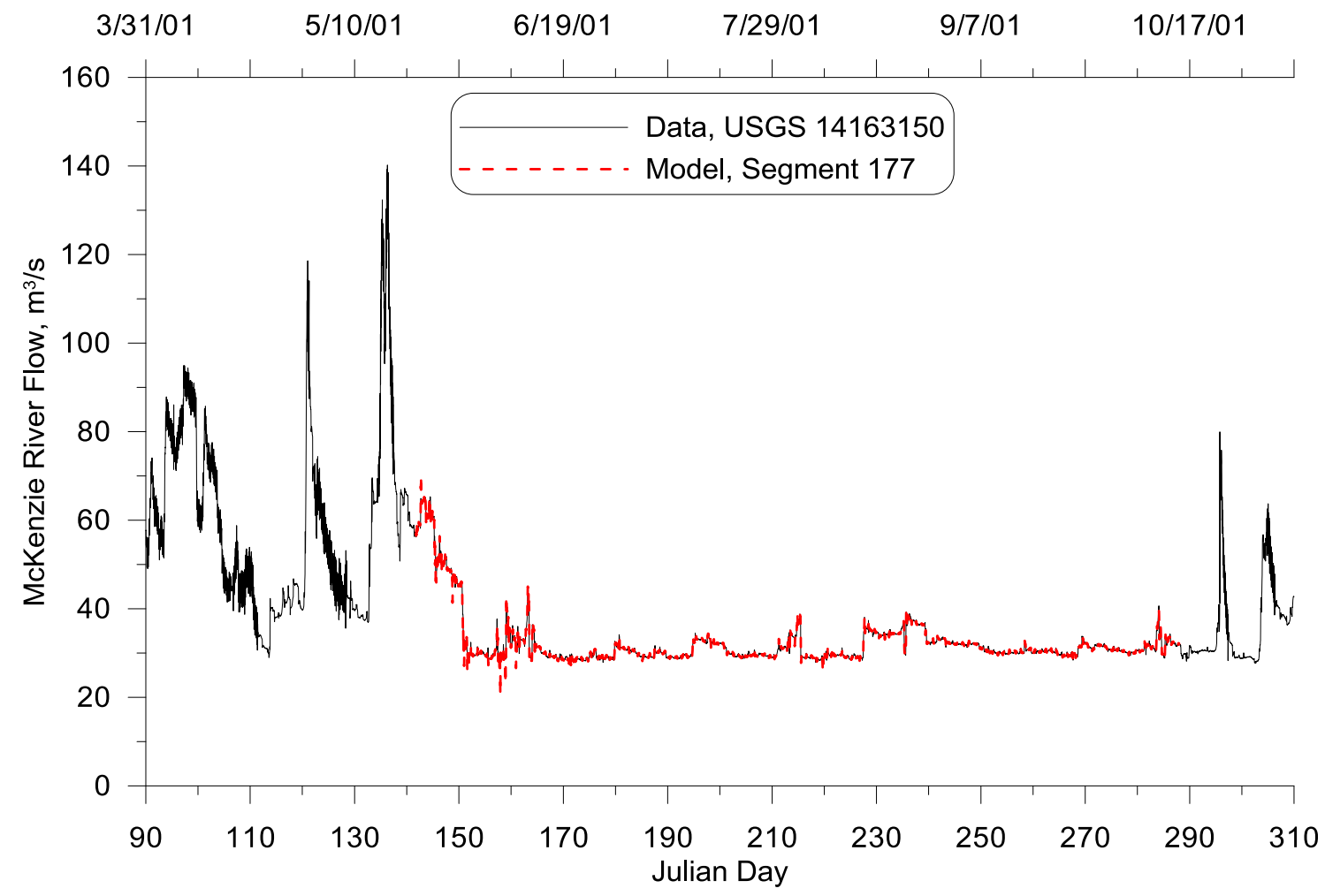

Figure 246: McKenzie River below Leaburg Dam model-data flow comparison, 2001 


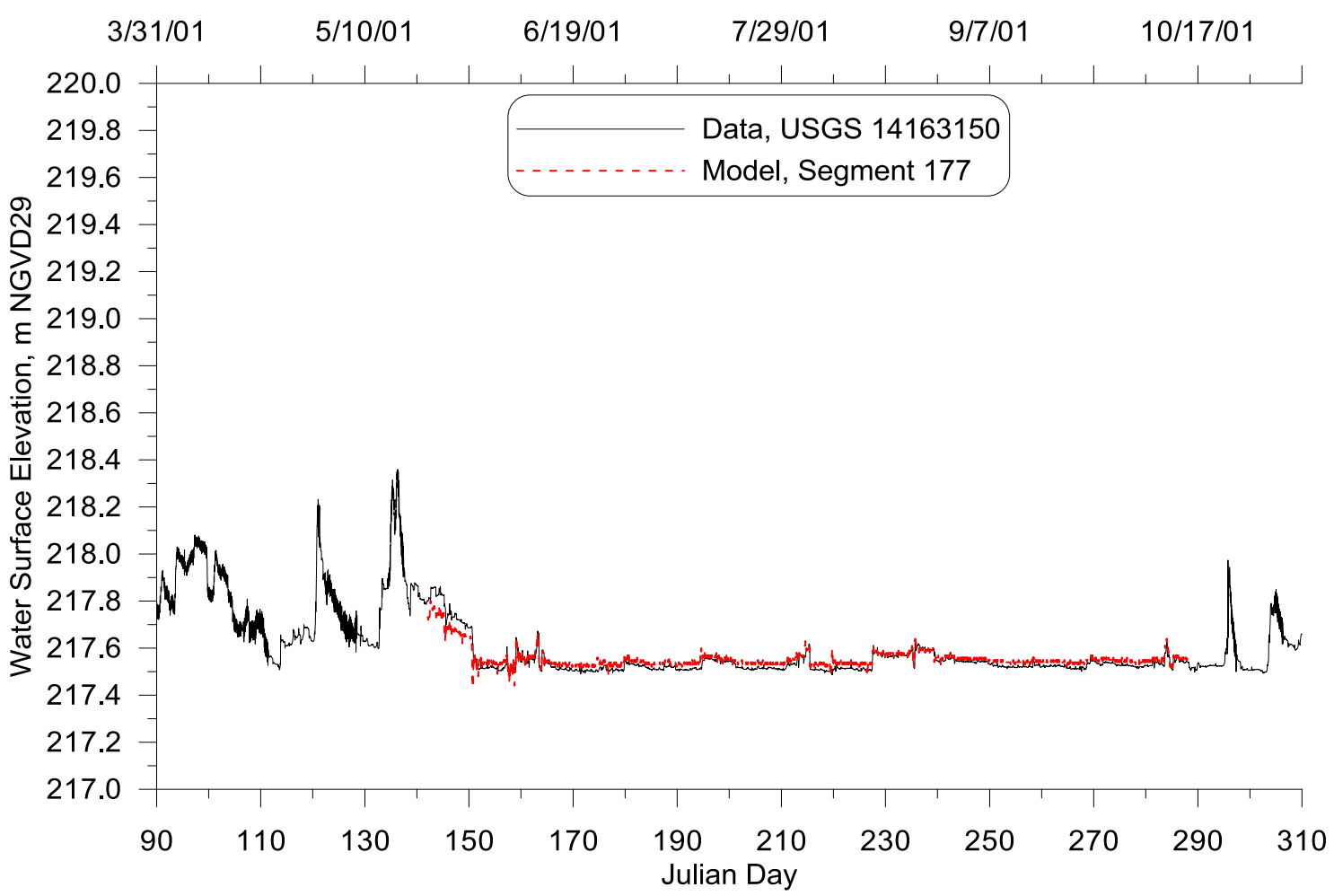

Figure 247: McKenzie River below Leaburg Dam model-data water level comparison, 2001

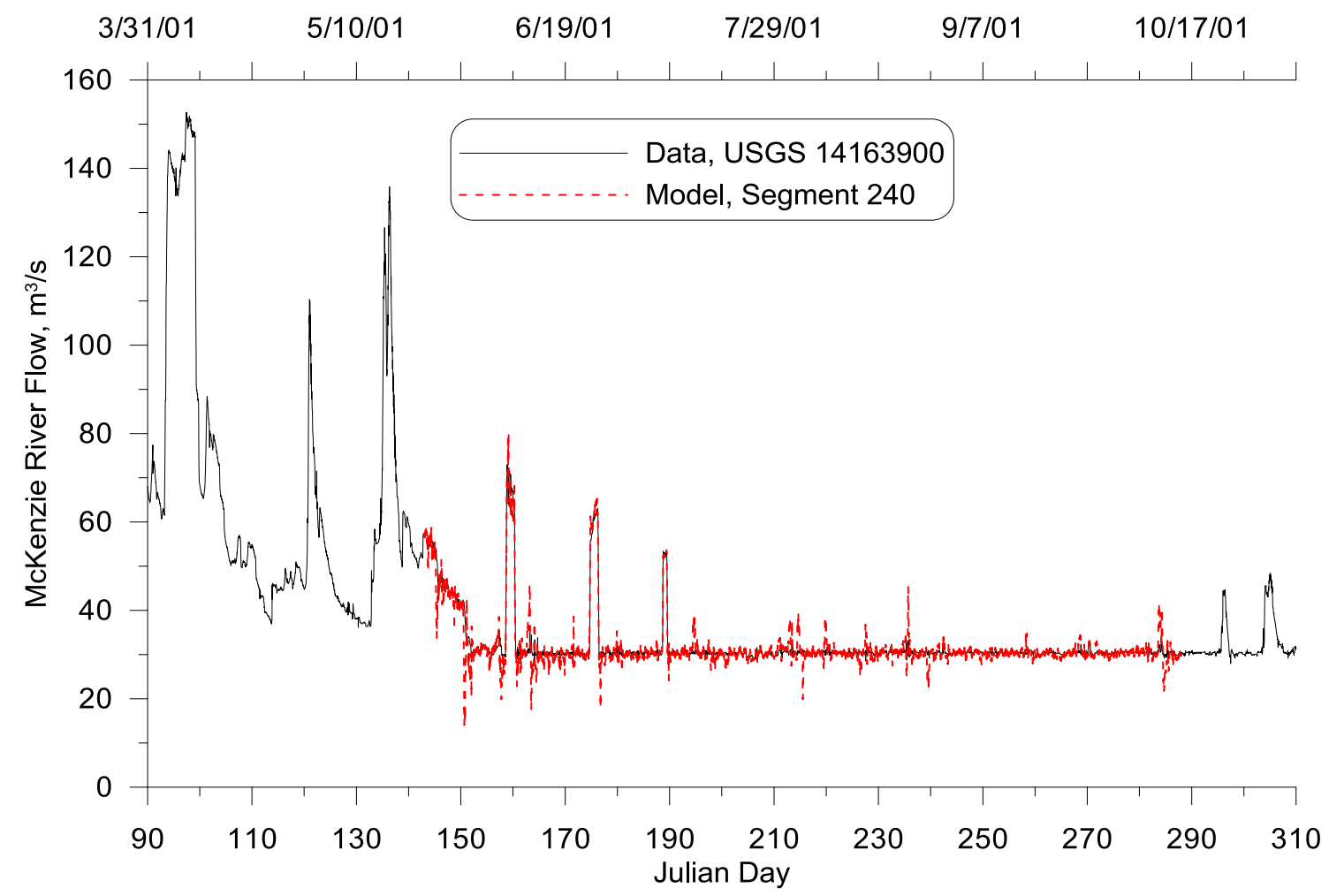

Figure 248: McKenzie River near Walterville model-data flow comparison, 2001 


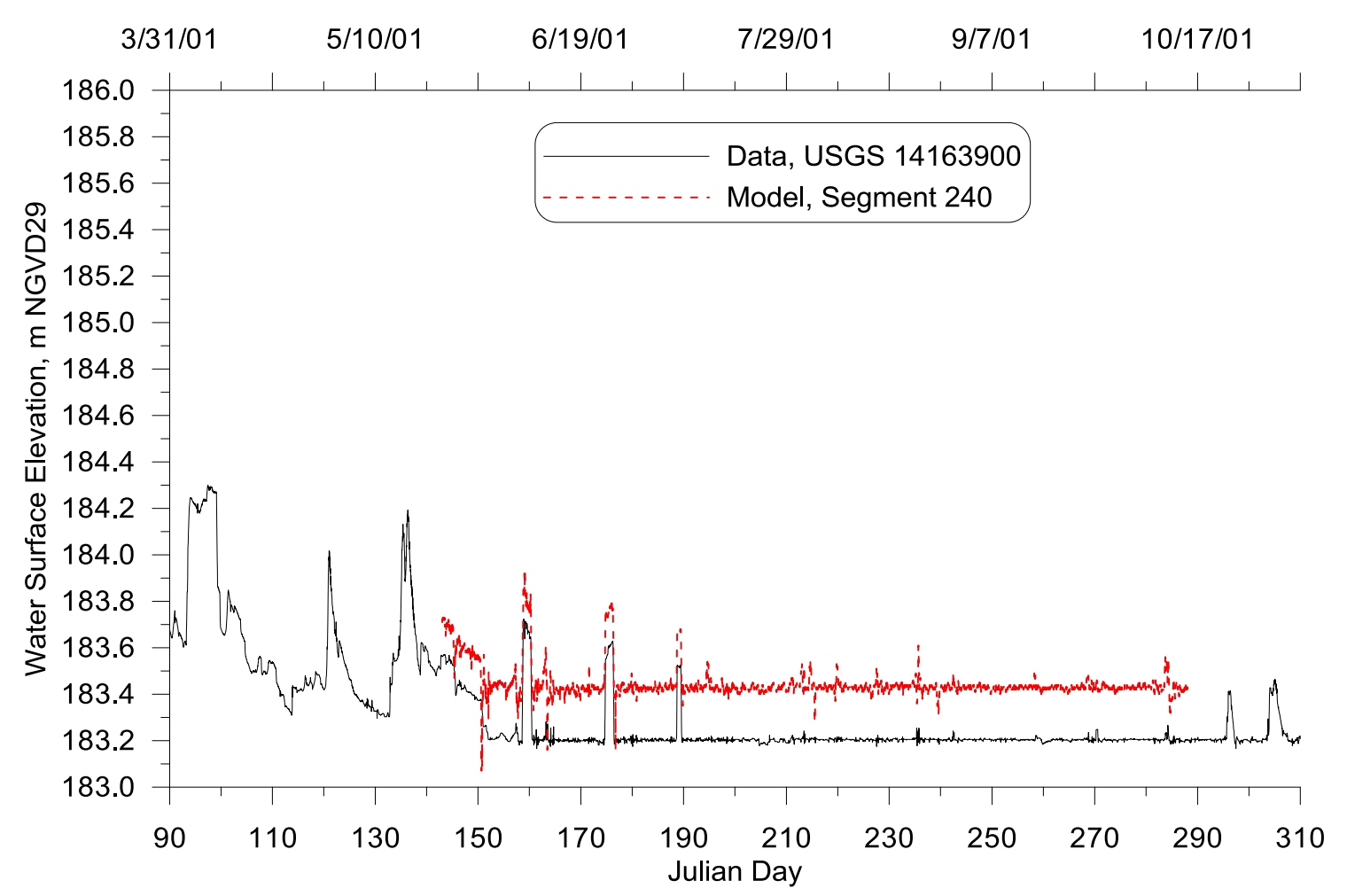

Figure 249: McKenzie River near Walterville model-data water level comparison, 2001

\section{Year 2002}

McKenzie River hydrodynamic model-data error statistics in 2002 are summarized in Table 33. Figure 250 through 257 show the flow rate and water level comparison at different sites. Overall, the Steady-State model was able to predict both flow rate and water level well. As hydrodynamic calibration was conducted first for year 2001 and then tested on year 2002, simulation results in year 2002 was not as good as year 2001.Continuous water level at Segment 4, Segment 177, and Segment 240 were either overestimating or underestimating estimating. However, as the calibration as a whole was acceptable, calibration was not further conducted. 
Table 33: McKenzie River hydrodynamic calibration model-data error statistics, 2002

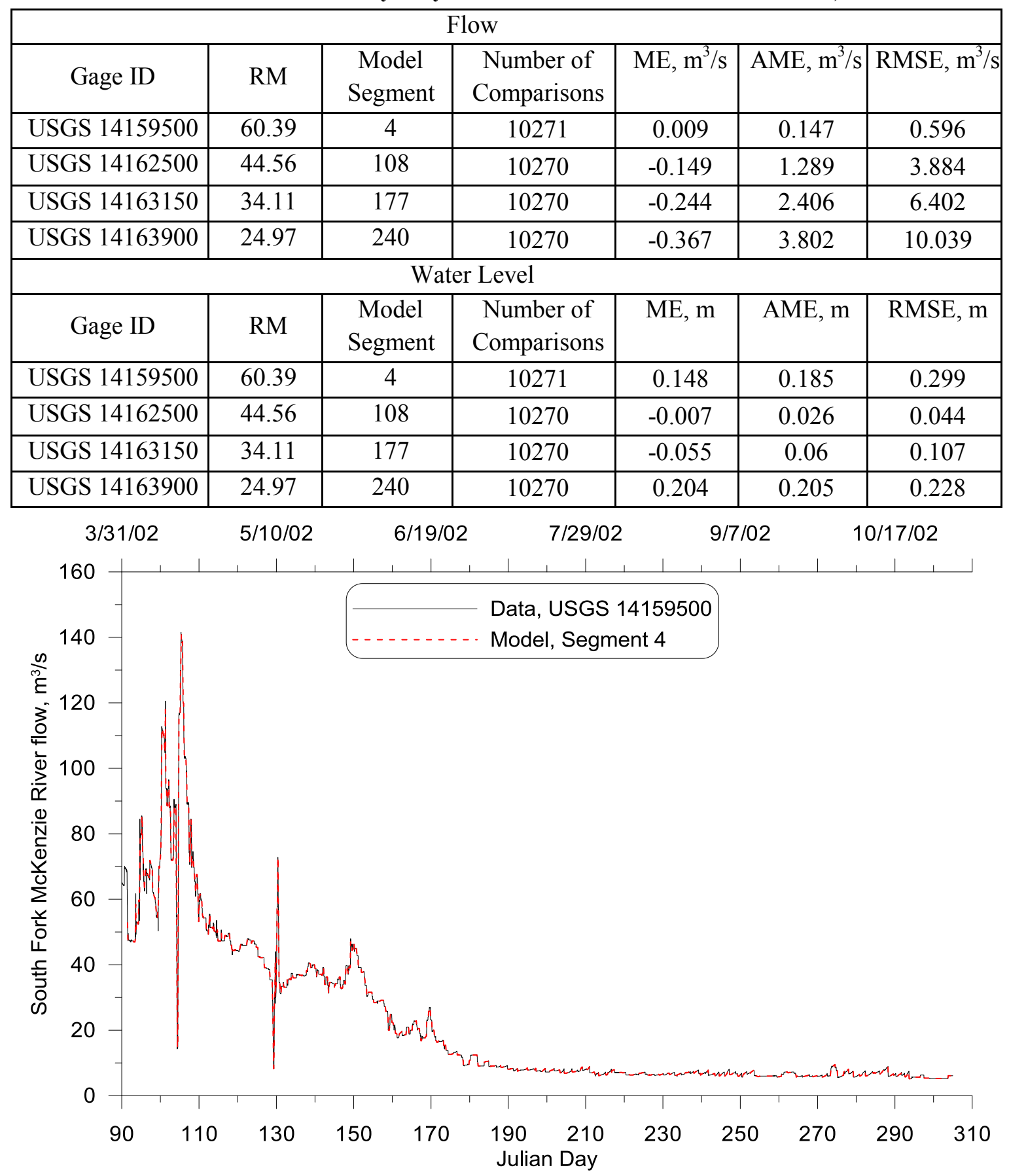

Figure 250: South Fork McKenzie River below Cougar Dam model-data flow comparison, 2002 


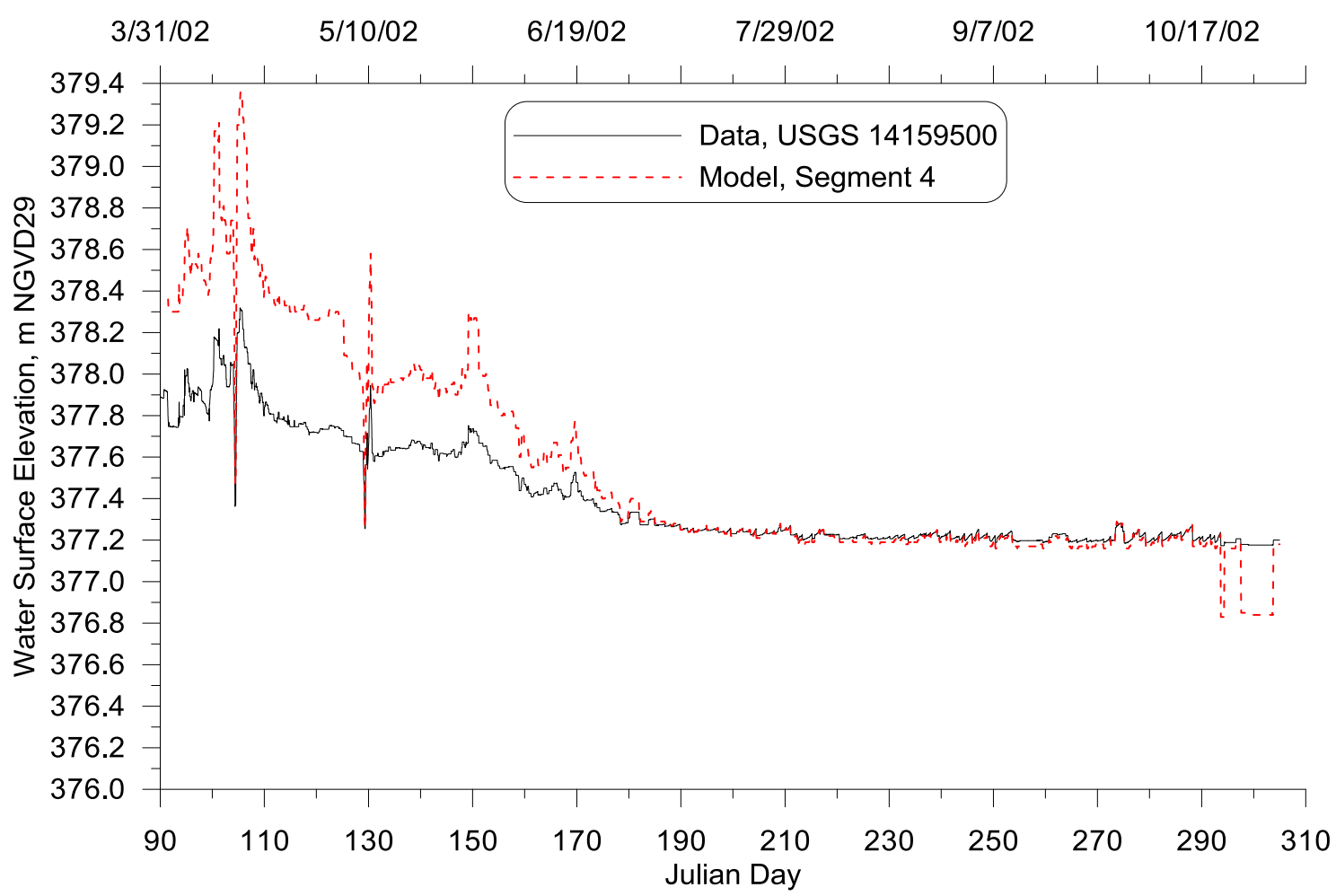

Figure 251: South Fork McKenzie River below Cougar Dam model-data water level comparison, 2002

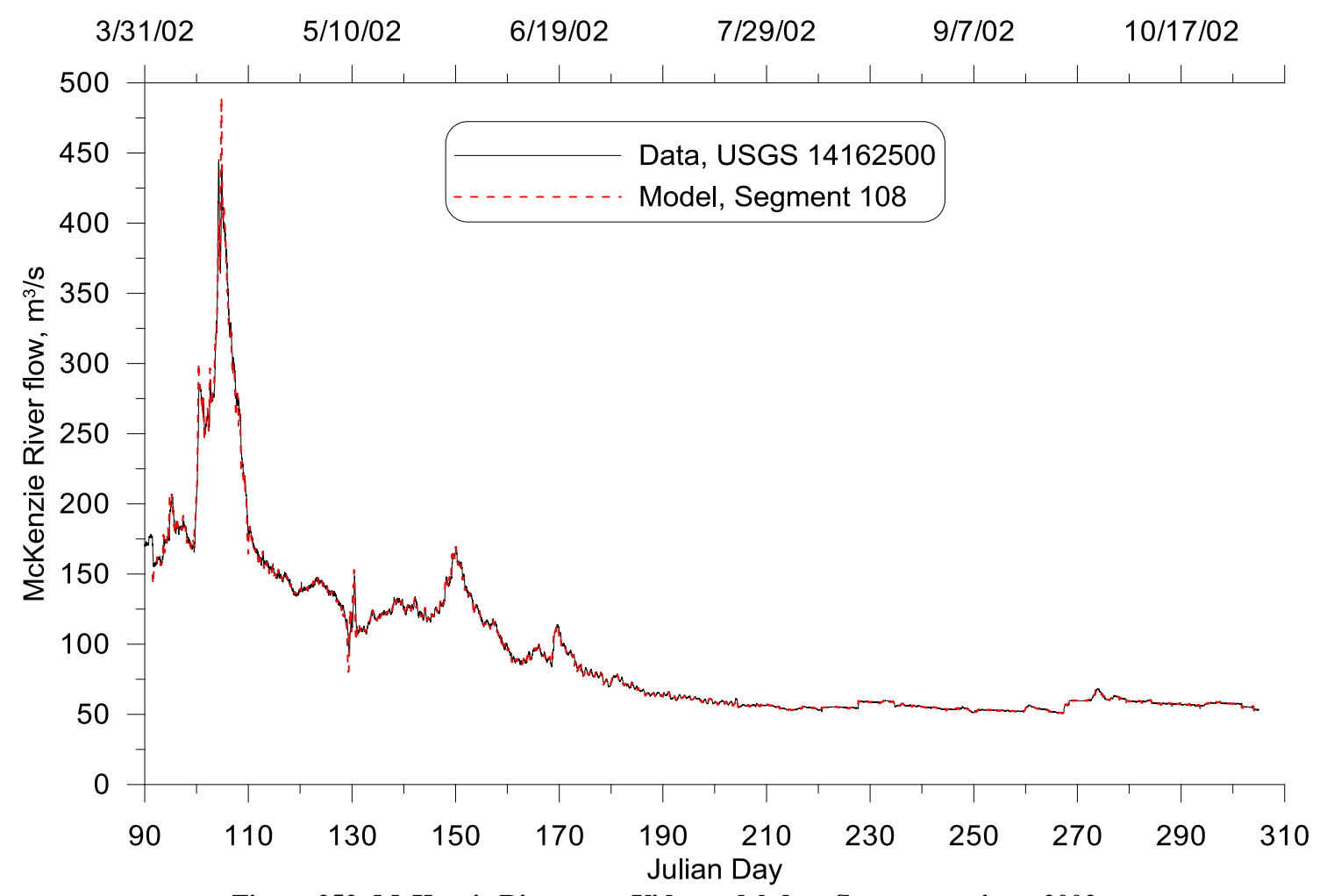

Figure 252: McKenzie River near Vida model-data flow comparison, 2002 


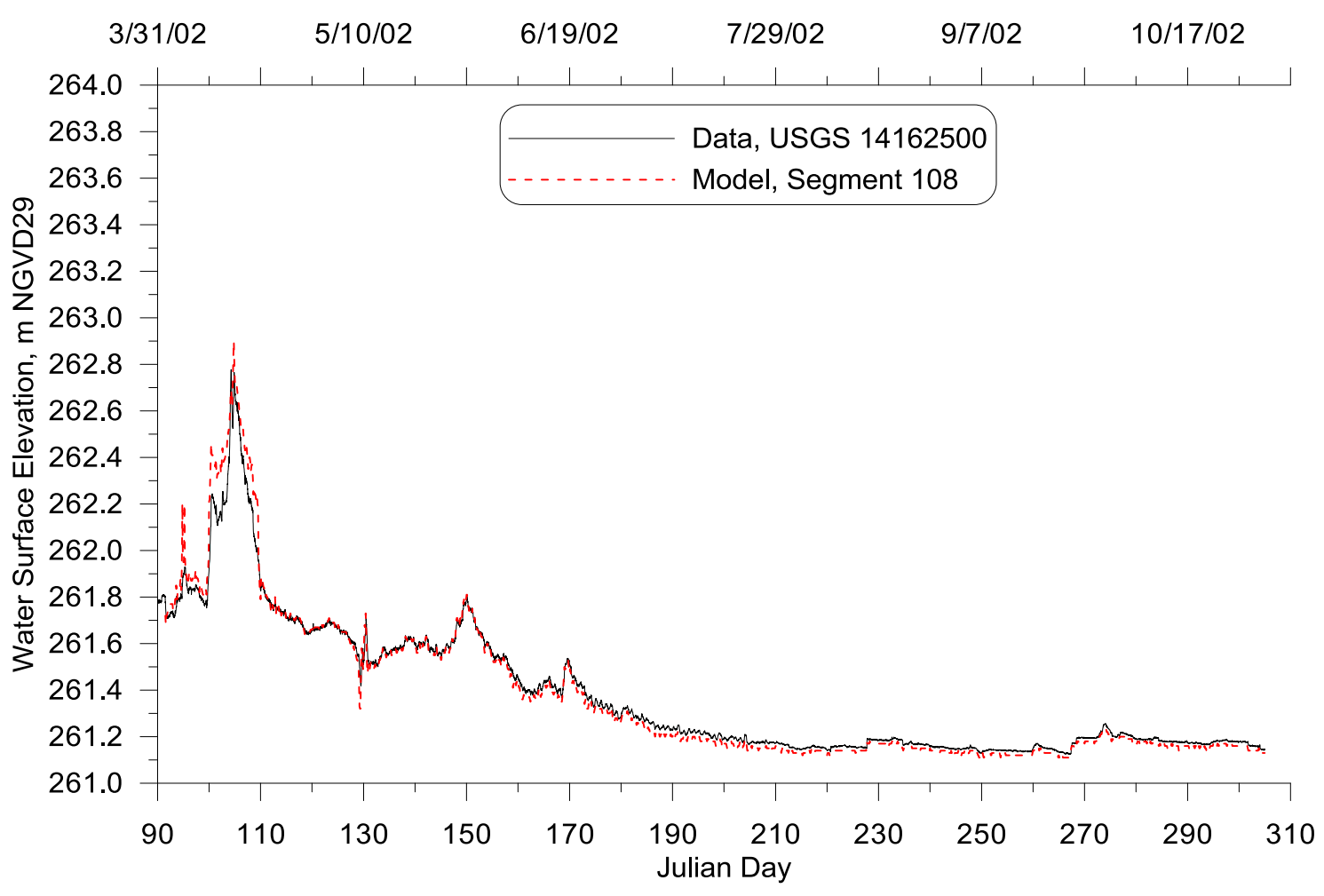

Figure 253: McKenzie River near Vida model-data water level comparison, 2002

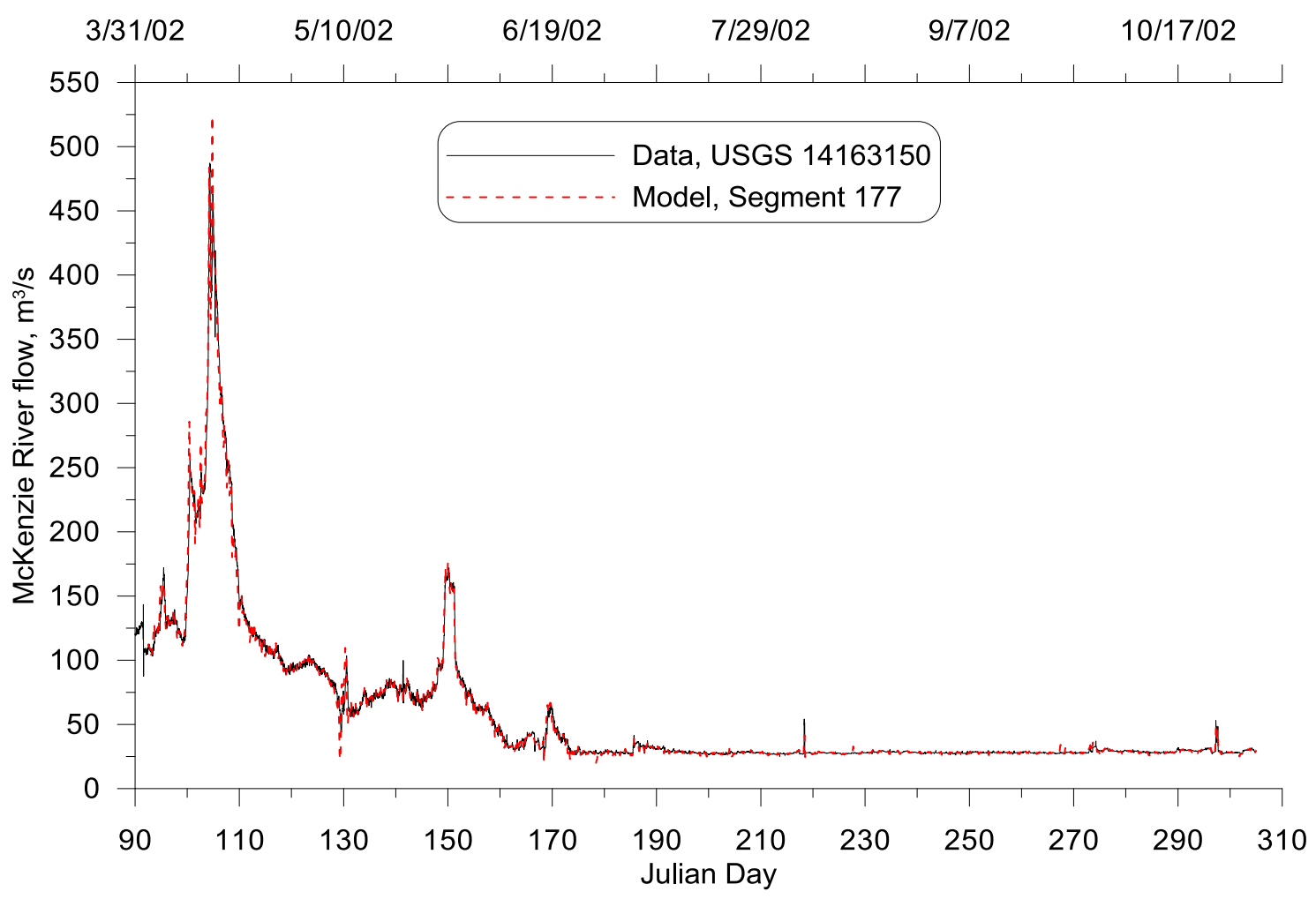


Figure 254: McKenzie River below Leaburg Dam model-data flow comparison, 2002

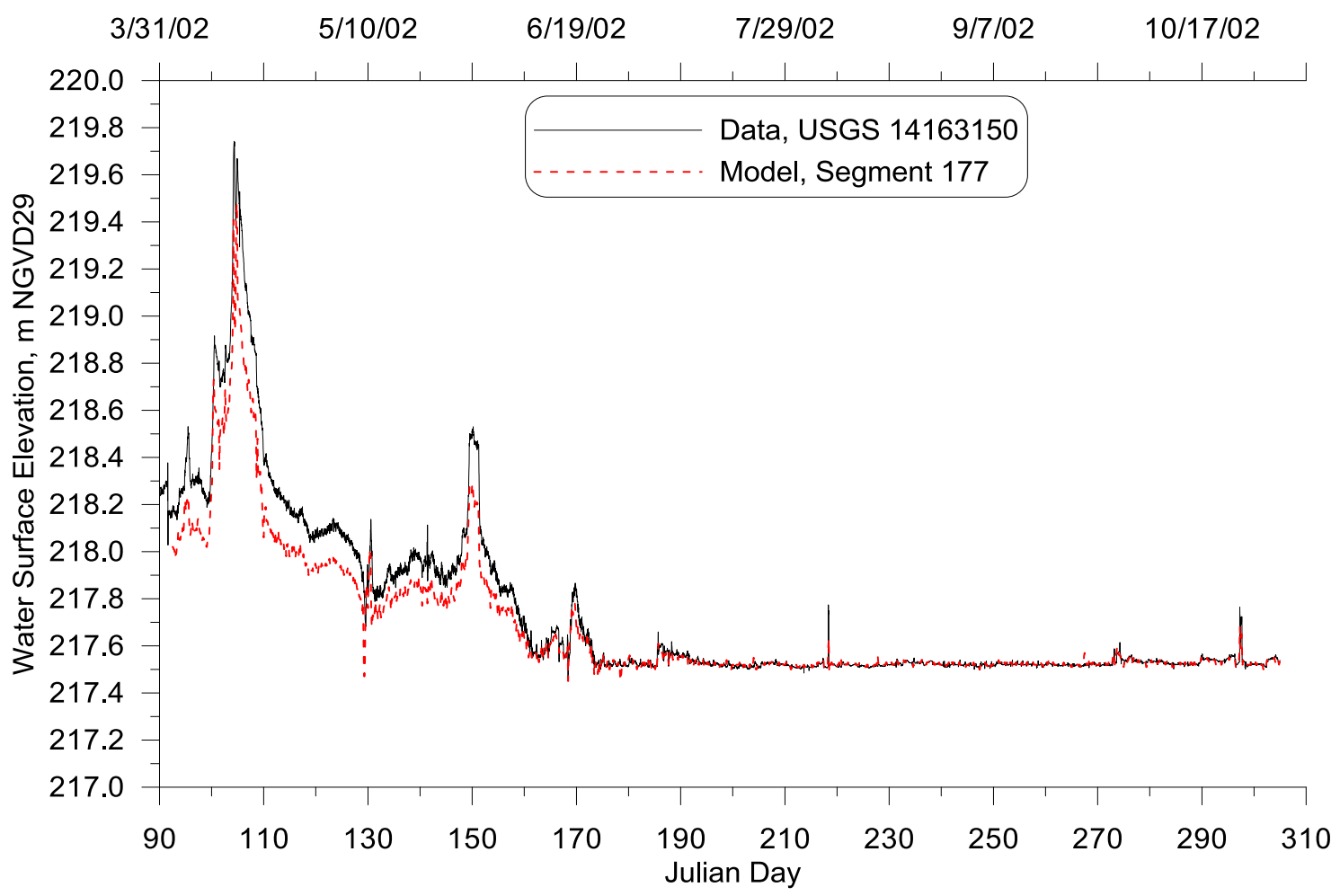

Figure 255: McKenzie River below Leaburg Dam model-data water level comparison, 2002

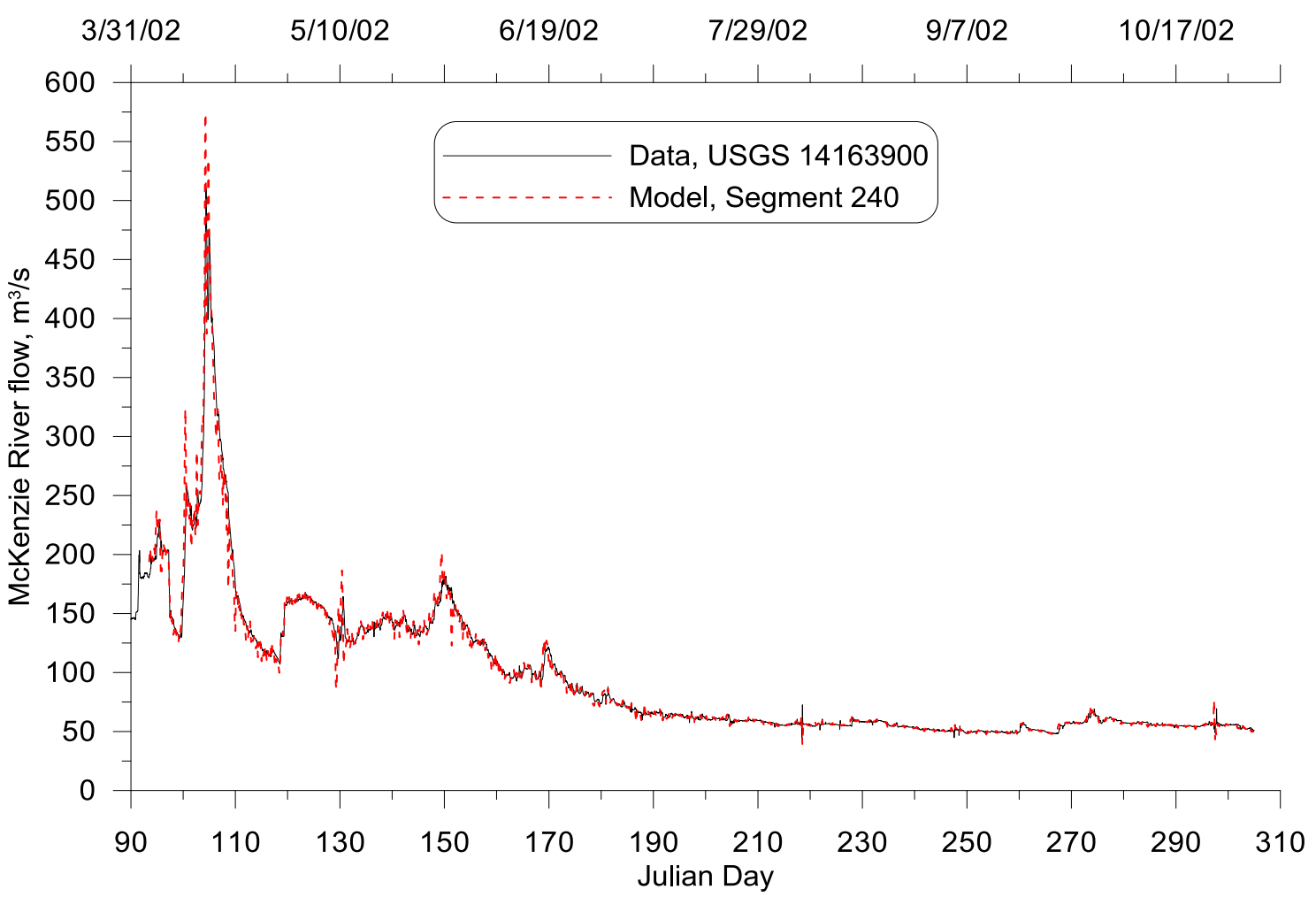

Figure 256: McKenzie River near Walterville model-data flow comparison, 2002 


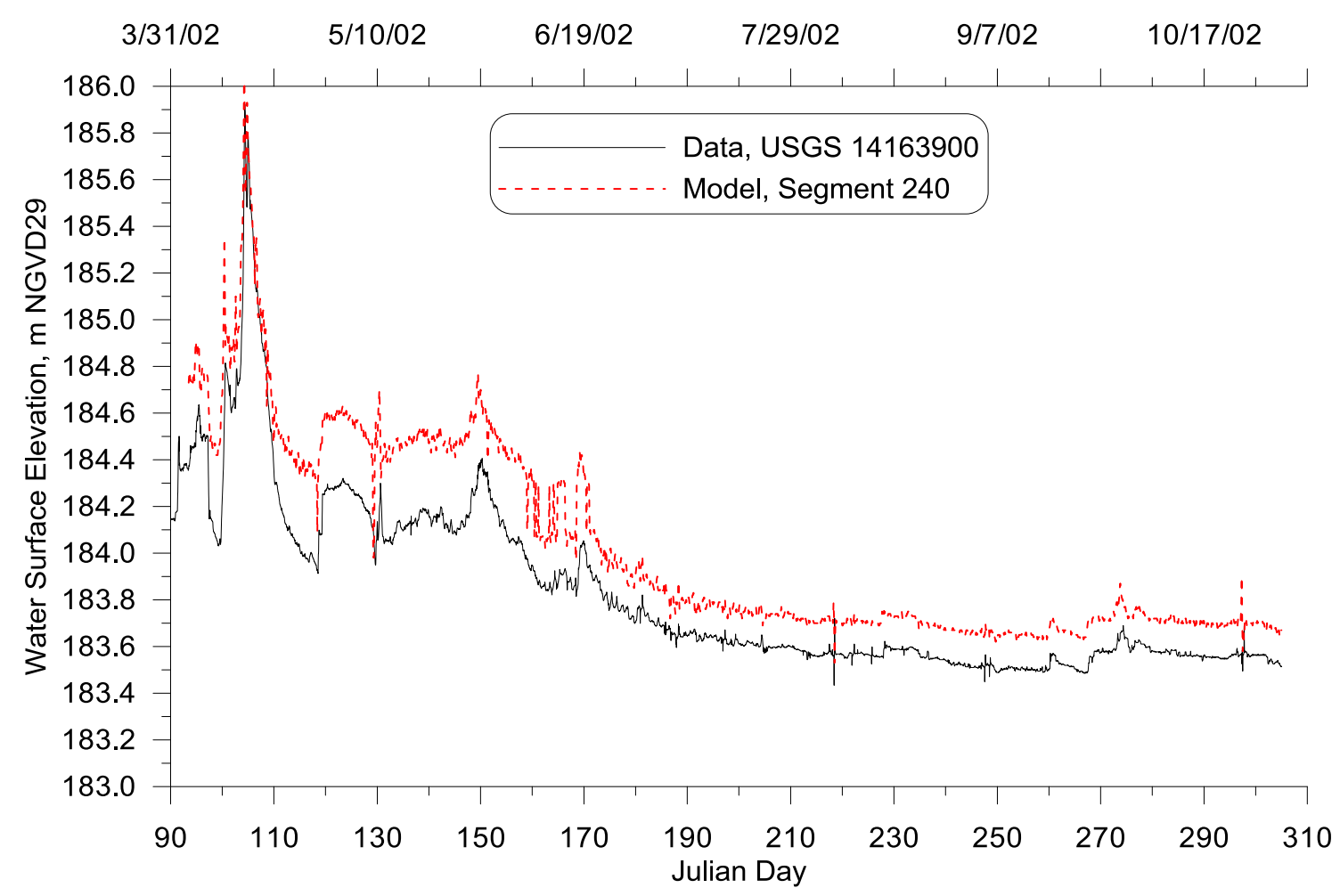

Figure 257: McKenzie River near Walterville model-data water level comparison, 2002

\section{Temperature}

\section{Year 2001}

McKenzie River continuous water temperature calibration model-data error statistics in 2001 are summarized in Table 34. Figure 258 through 267 show the continuous temperature comparison at different sites. The current calibration result had the RMSEs below $0.89^{\circ} \mathrm{C}$. 
Table 34: McKenzie River continuous water temperature calibration model-data error statistics, 2001

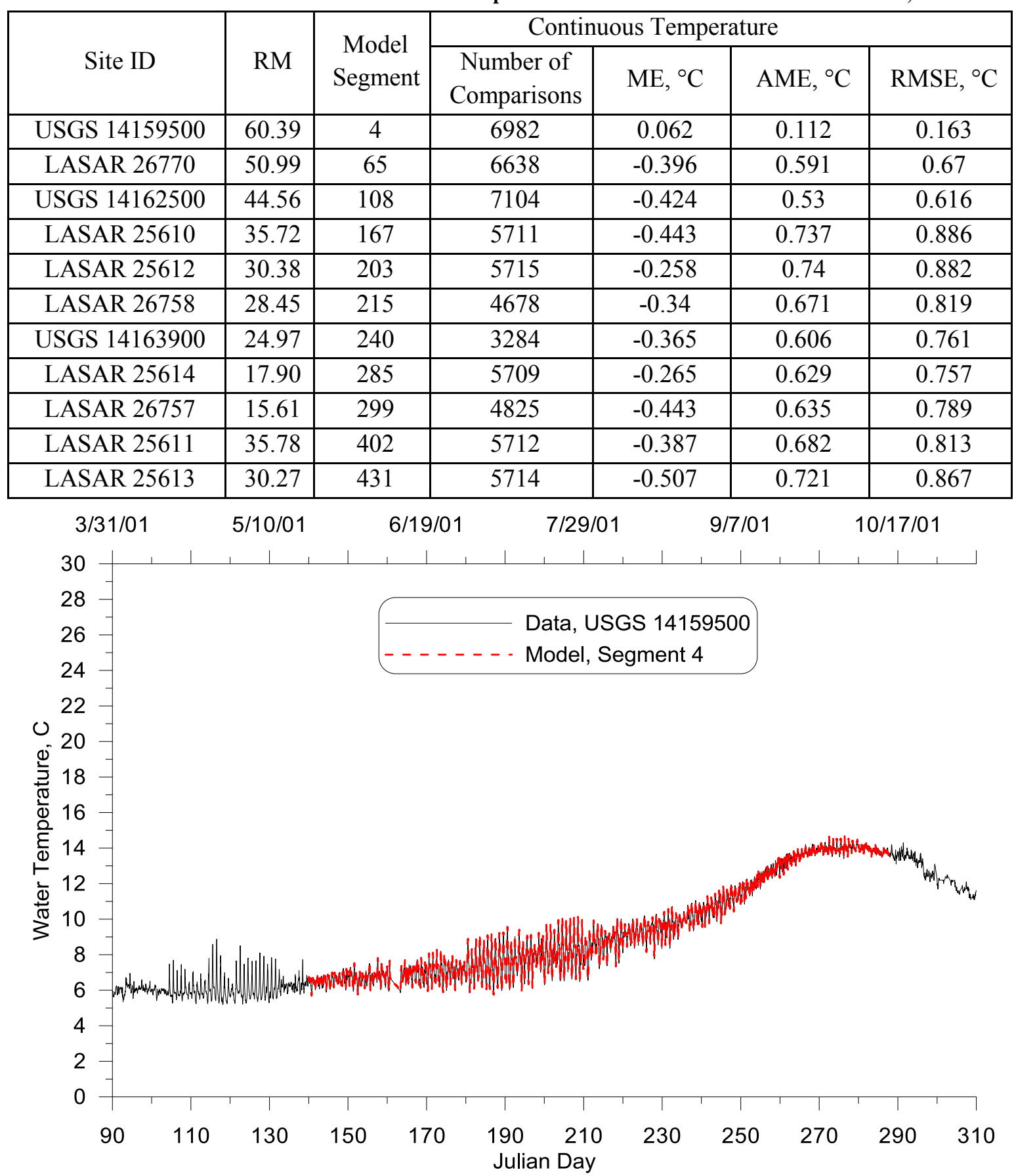

Figure 258: South Fork McKenzie River below Cougar Dam model-data continuous temperature comparison, 2001 


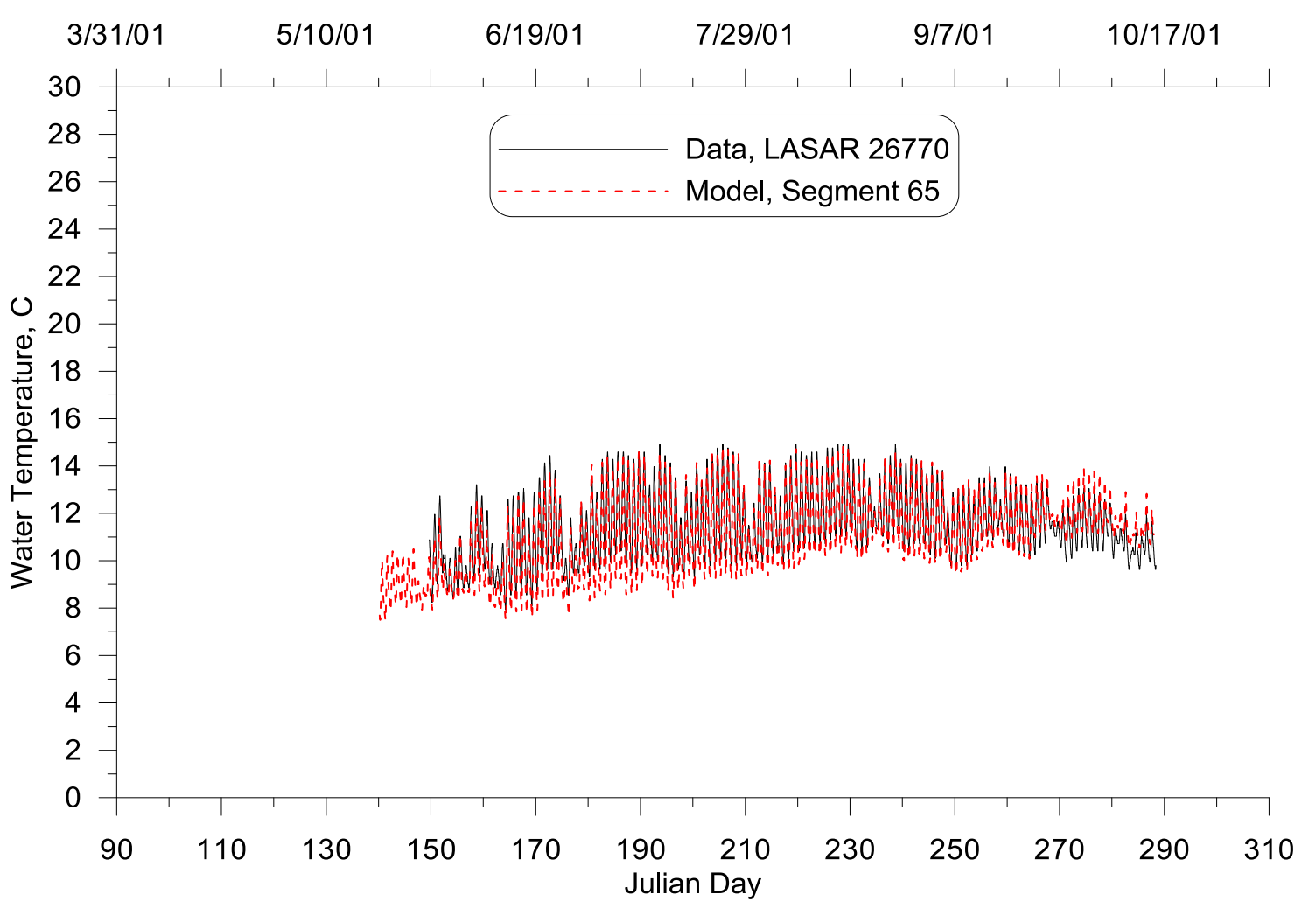

Figure 259: McKenzie River below Cougar River model-data continuous temperature comparison, 2001

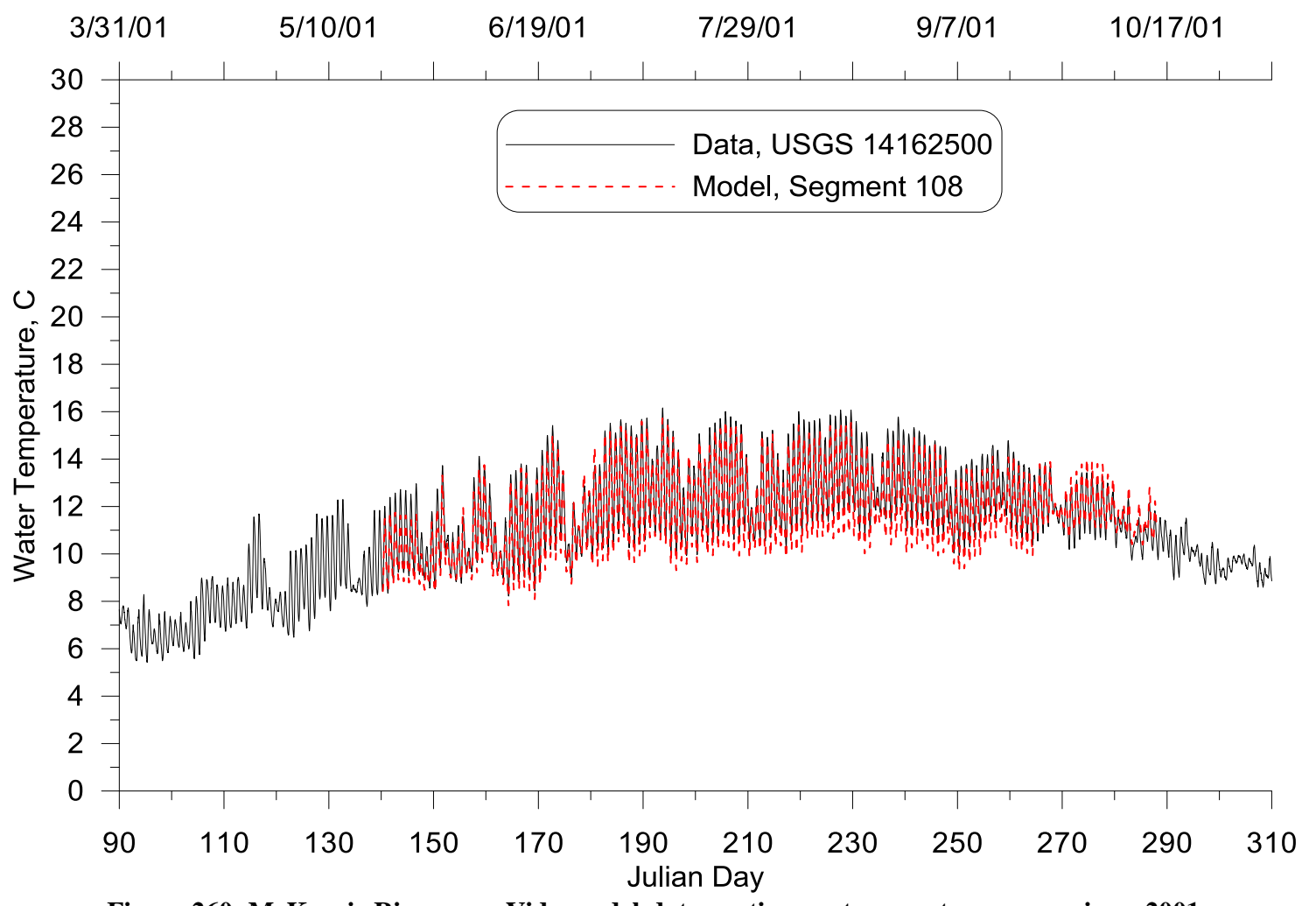

Figure 260: McKenzie River near Vida model-data continuous temperature comparison, 2001 


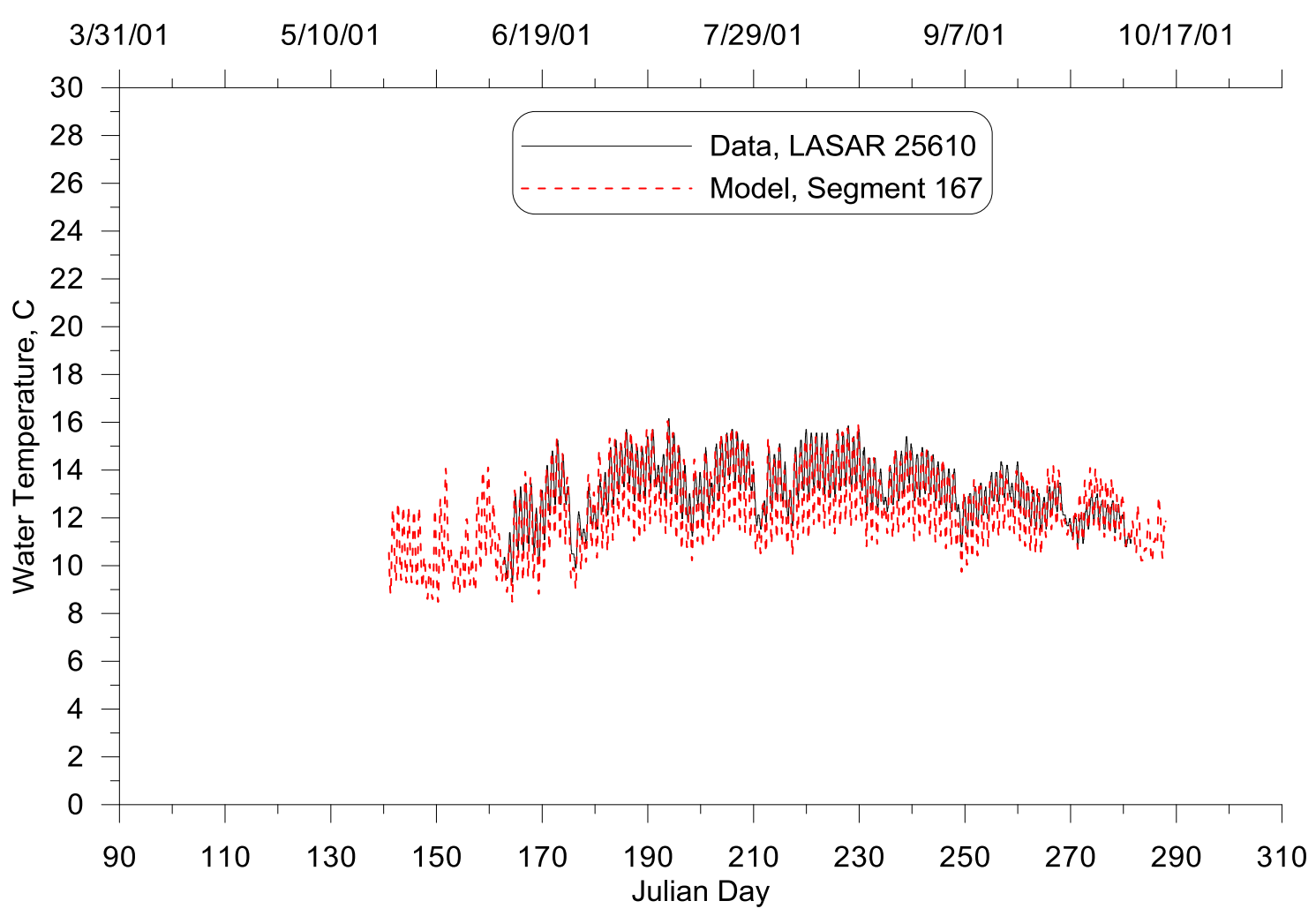

Figure 261: McKenzie River below Leaburg Dam model-data continuous temperature comparison, 2001

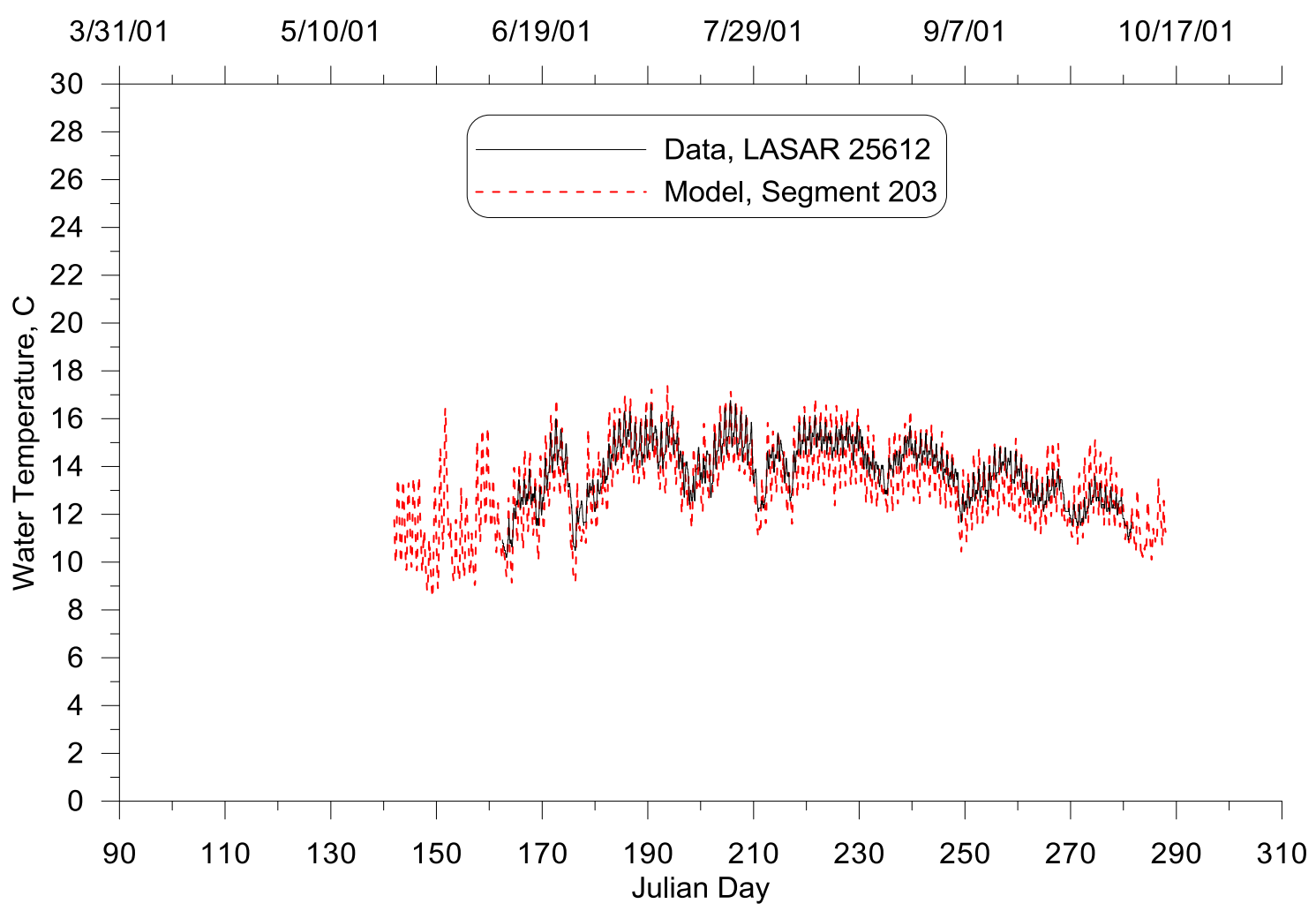

Figure 262: McKenzie River above the Leaburg tailrace model-data continuous temperature comparison, 2001 


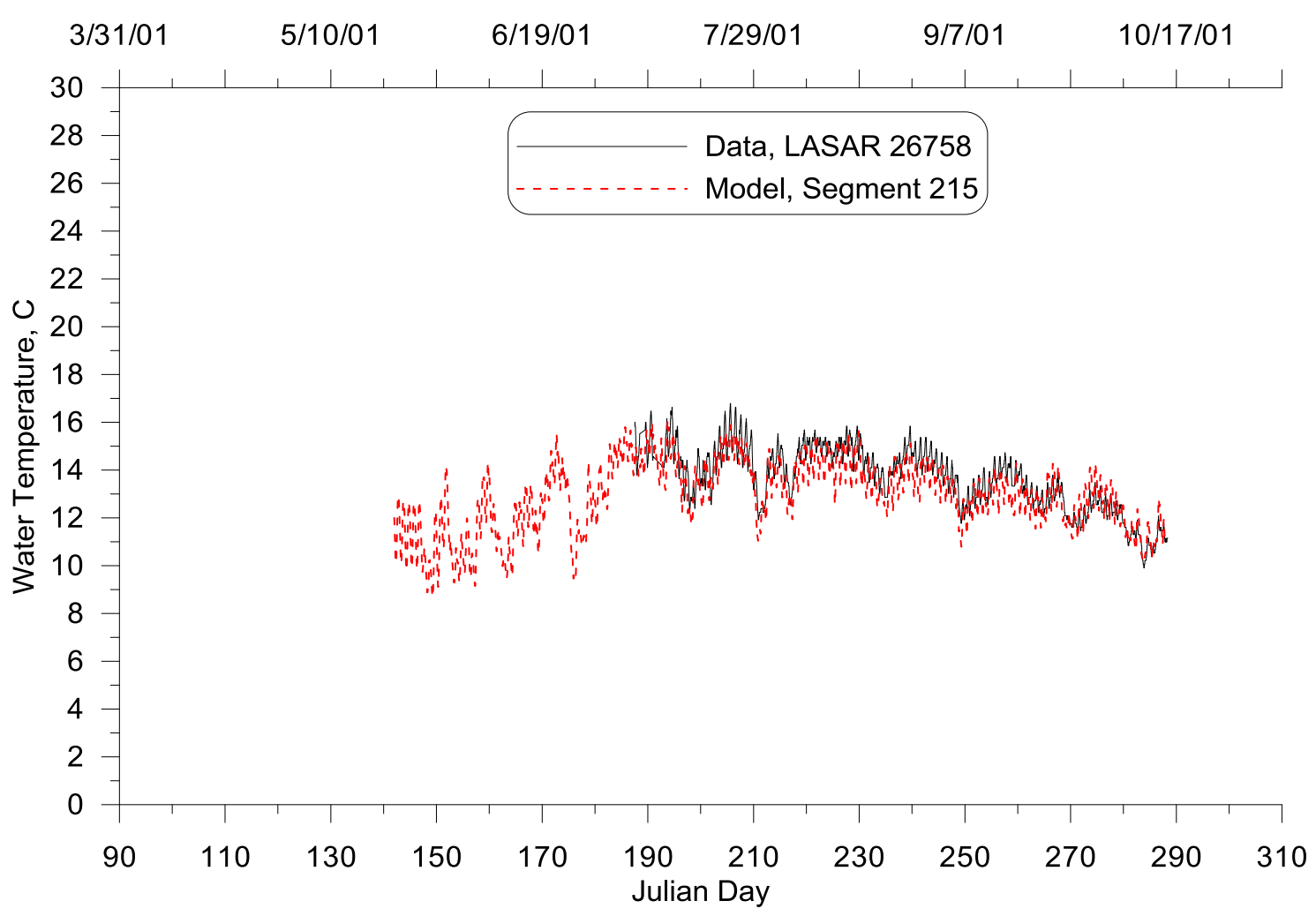

Figure 263: McKenzie River at Deerborn model-data continuous temperature comparison, 2001

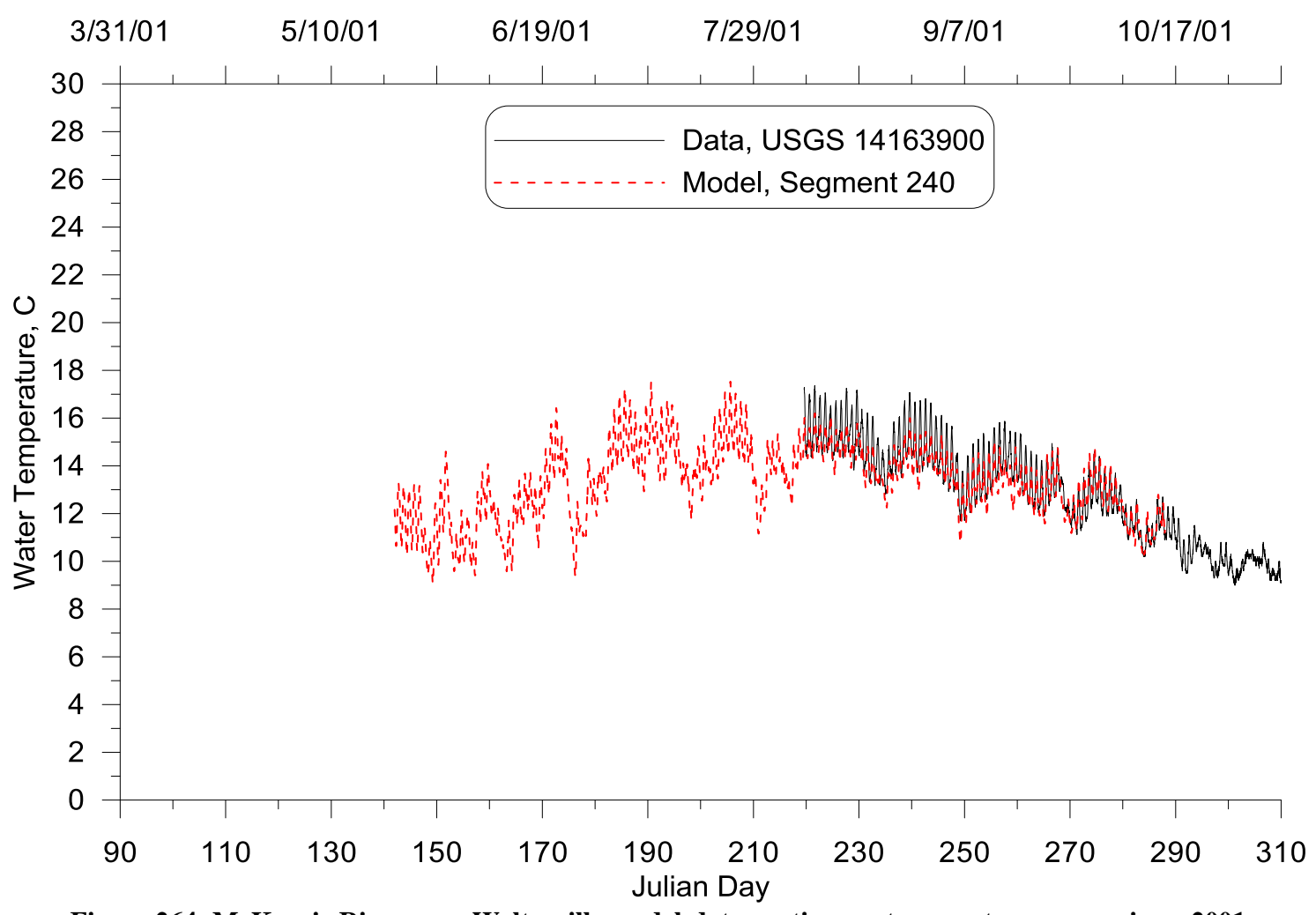

Figure 264: McKenzie River near Walterville model-data continuous temperature comparison, 2001 


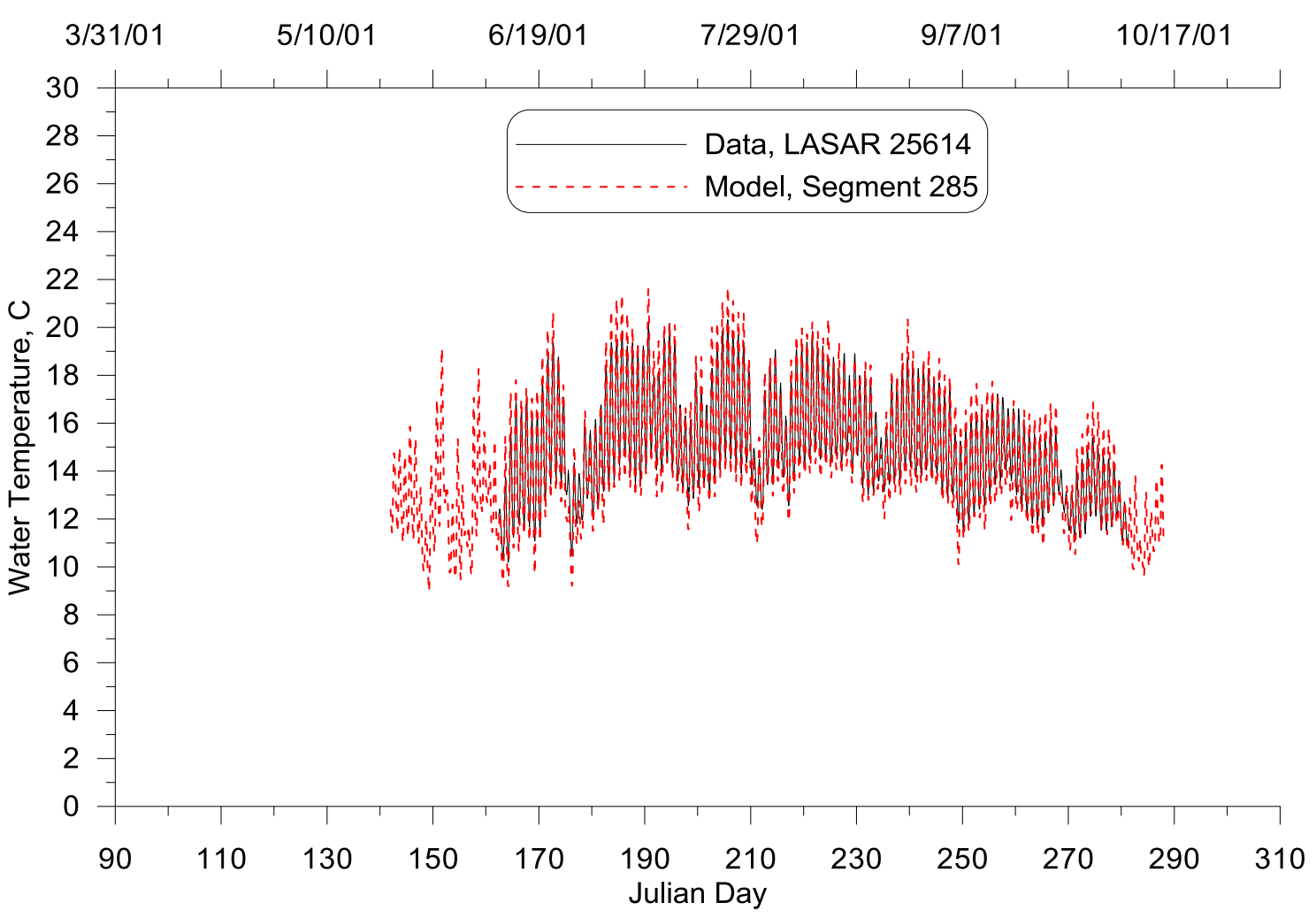

Figure 265: McKenzie River above Walterville Tailrace model-data continuous temperature comparison, 2001

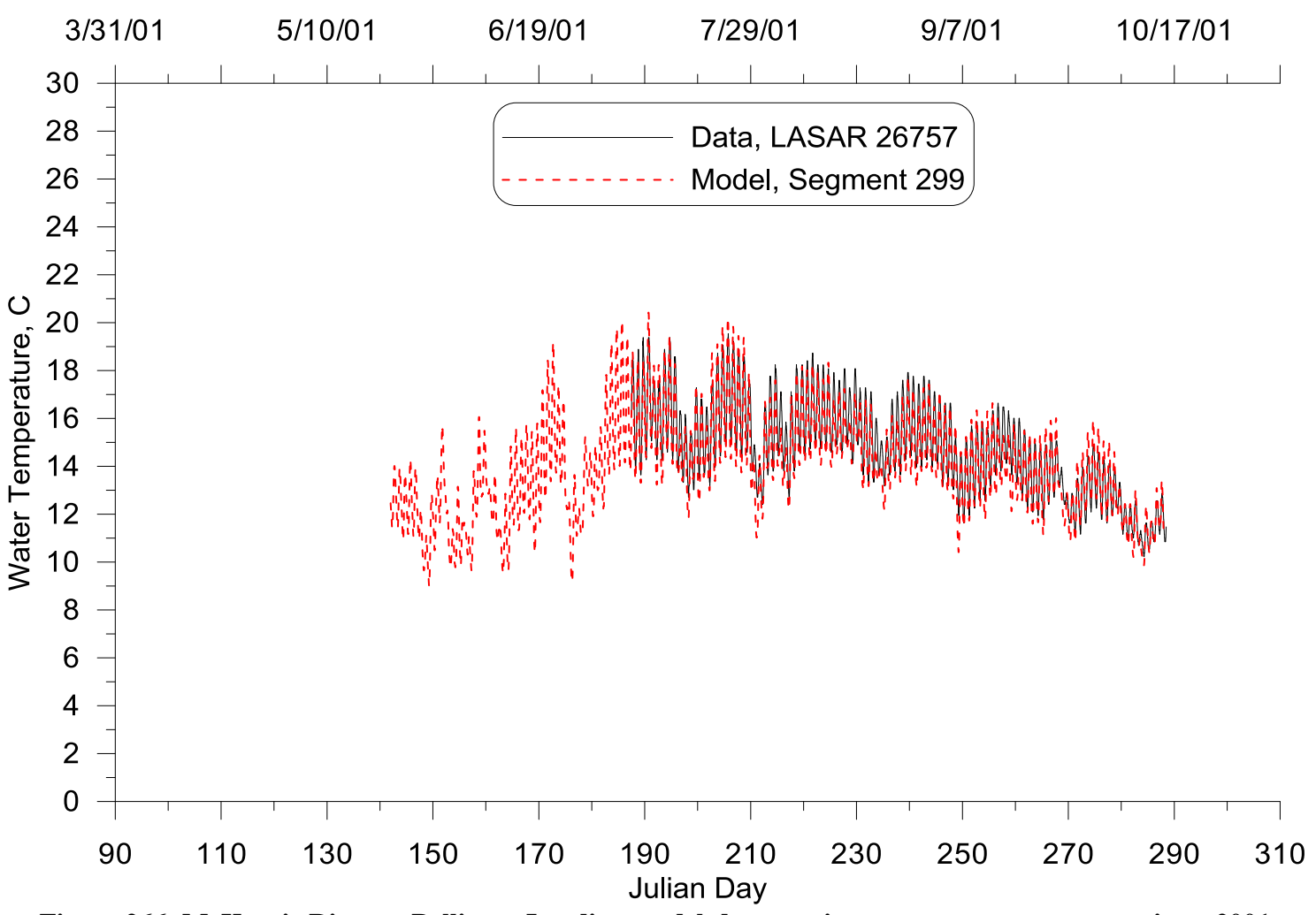

Figure 266: McKenzie River at Bellinger Landing model-data continuous temperature comparison, 2001 


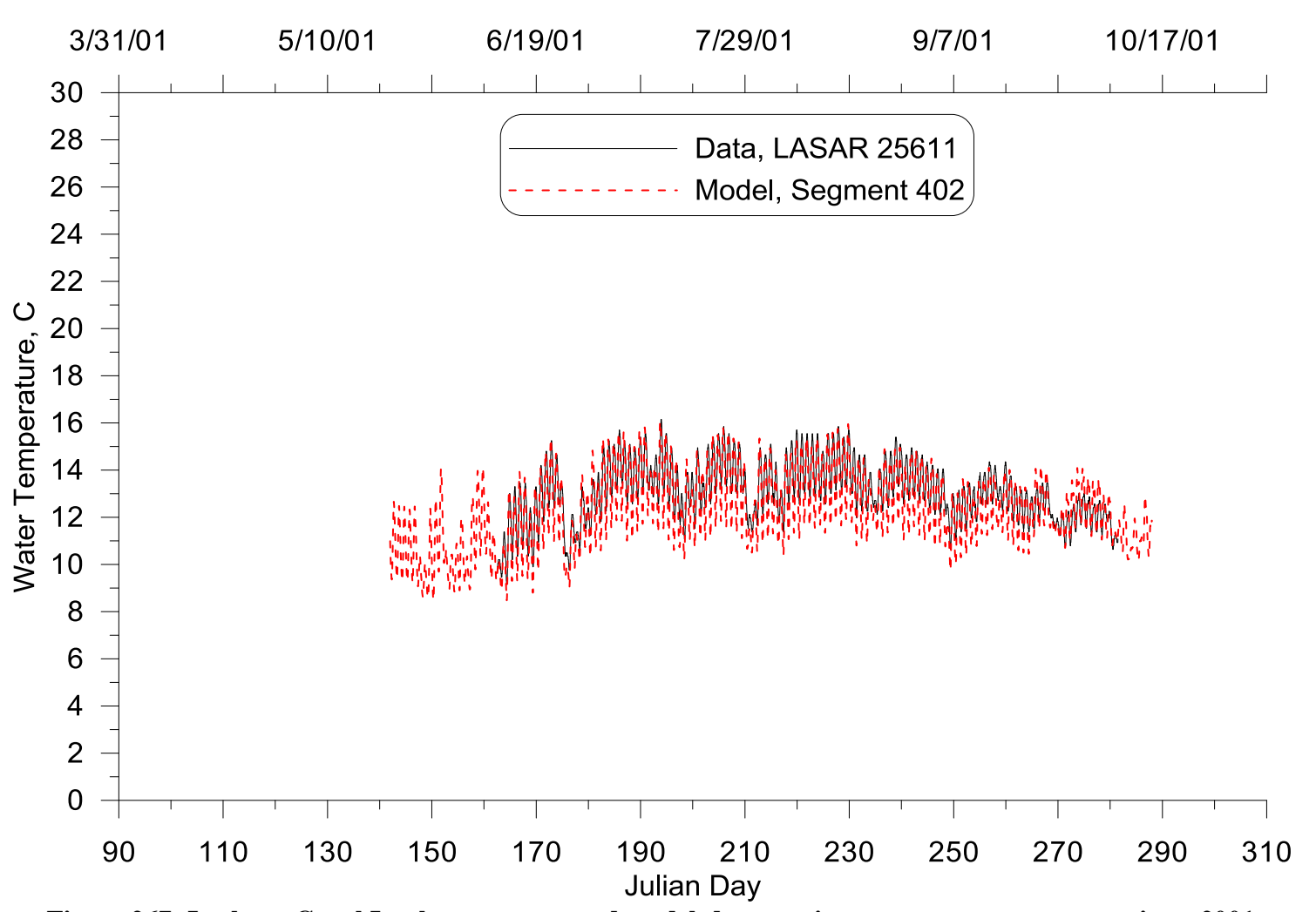

Figure 267: Leaburg Canal Intake, upstream end model-data continuous temperature comparison, 2001

Year 2002

McKenzie River continuous water temperature calibration model-data error statistics in 2001 are summarized in Table 35. Figure 268 through 279 show the continuous temperature comparison at different sites. The current calibration result had the RMSEs below $0.79^{\circ} \mathrm{C}$. 
Table 35: McKenzie River continuous water temperature calibration model-data error statistics, 2002

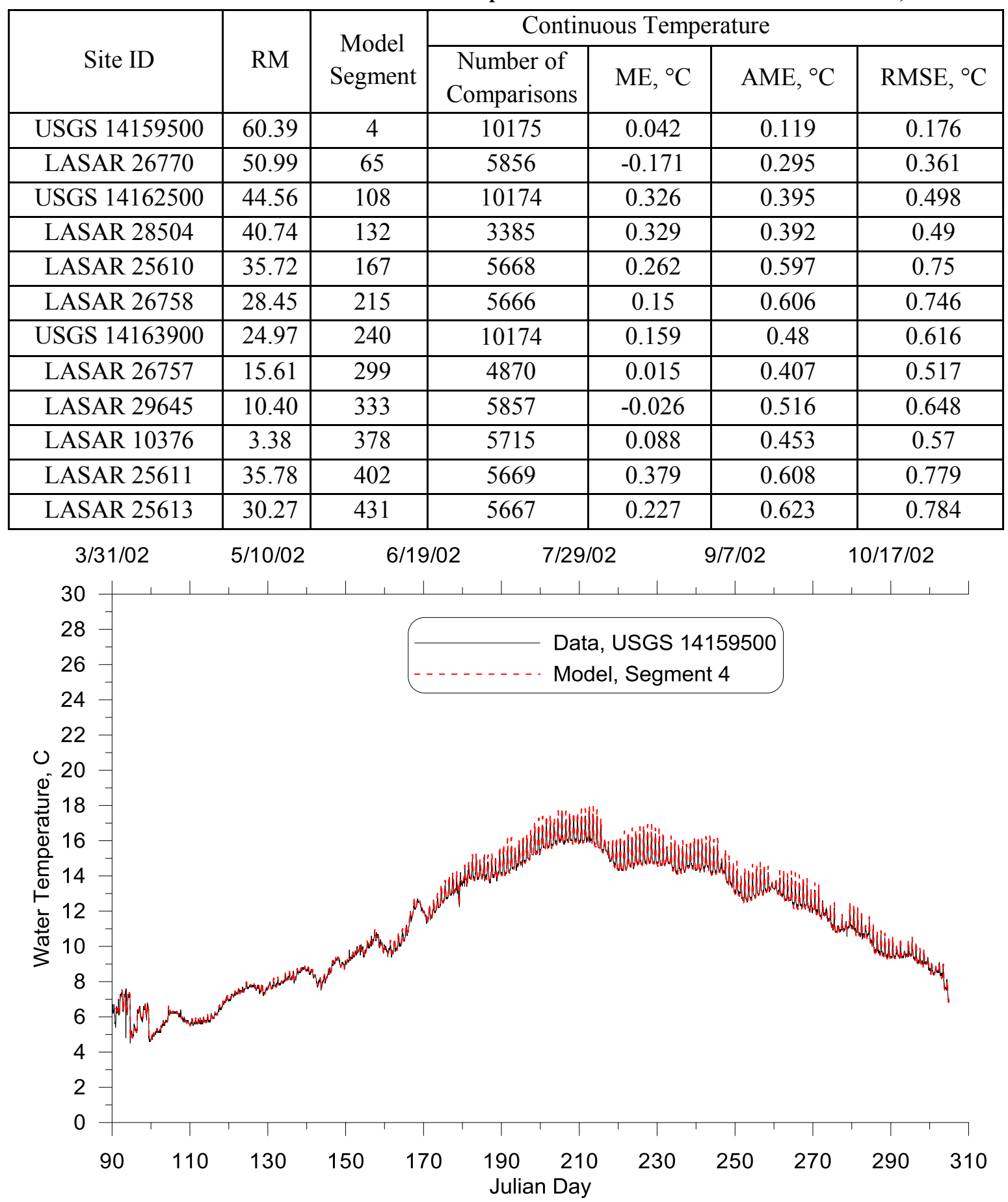

Figure 268: South Fork McKenzie below Cougar Dam model-data continuous temperature comparison, 2002 


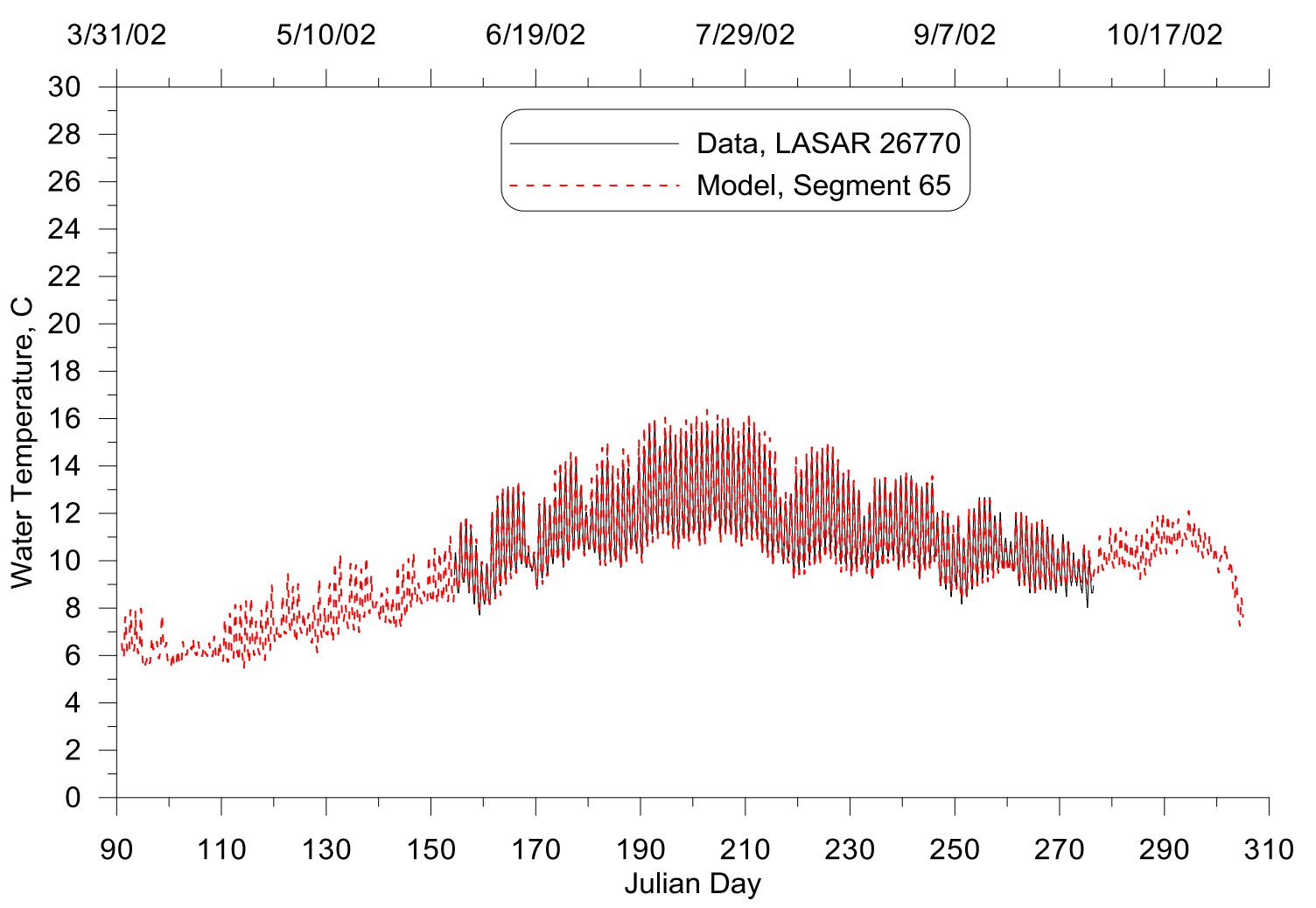

Figure 269: McKenzie River below Cougar River model-data continuous temperature comparison, 2002

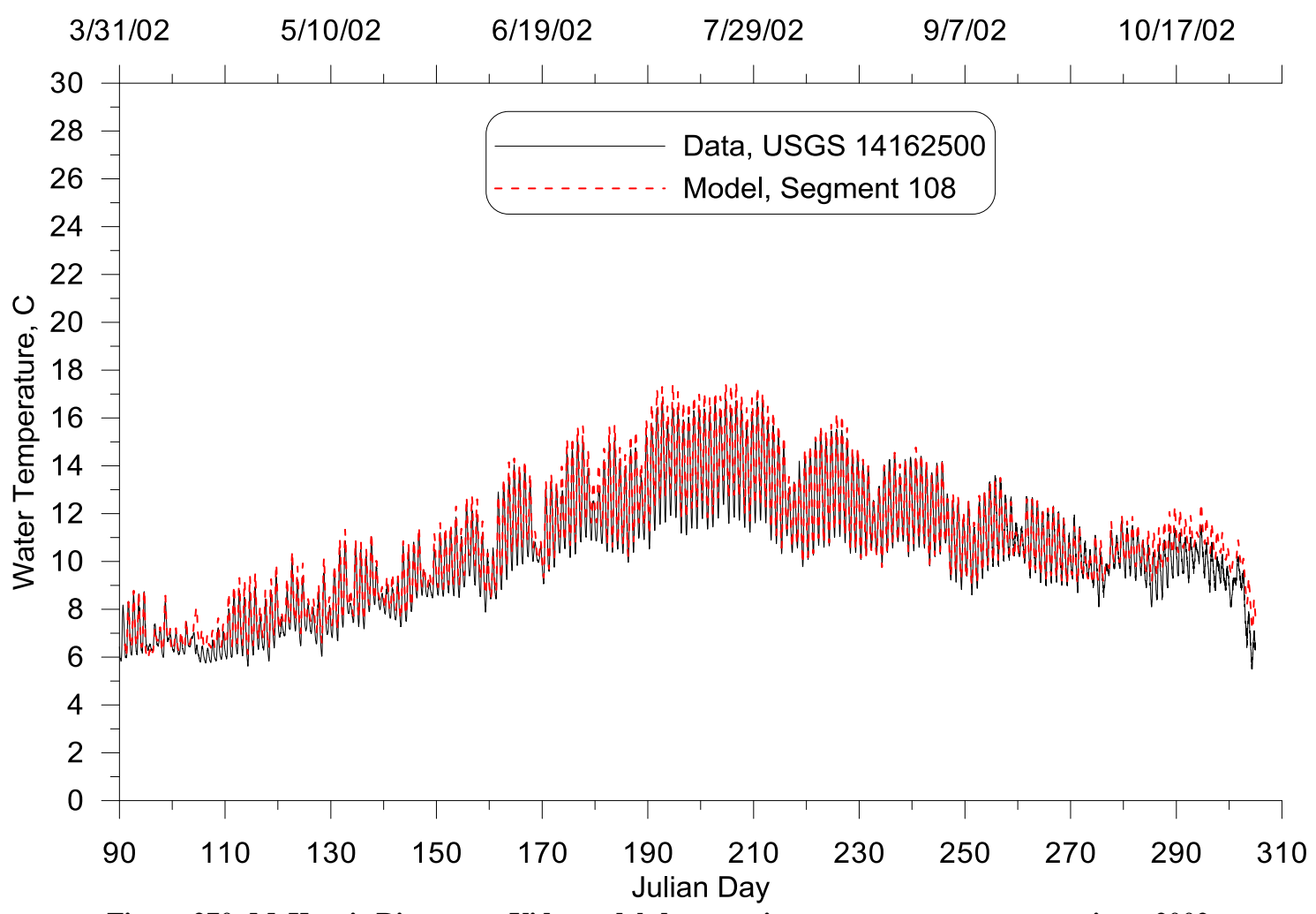

Figure 270: McKenzie River near Vida model-data continuous temperature comparison, 2002 


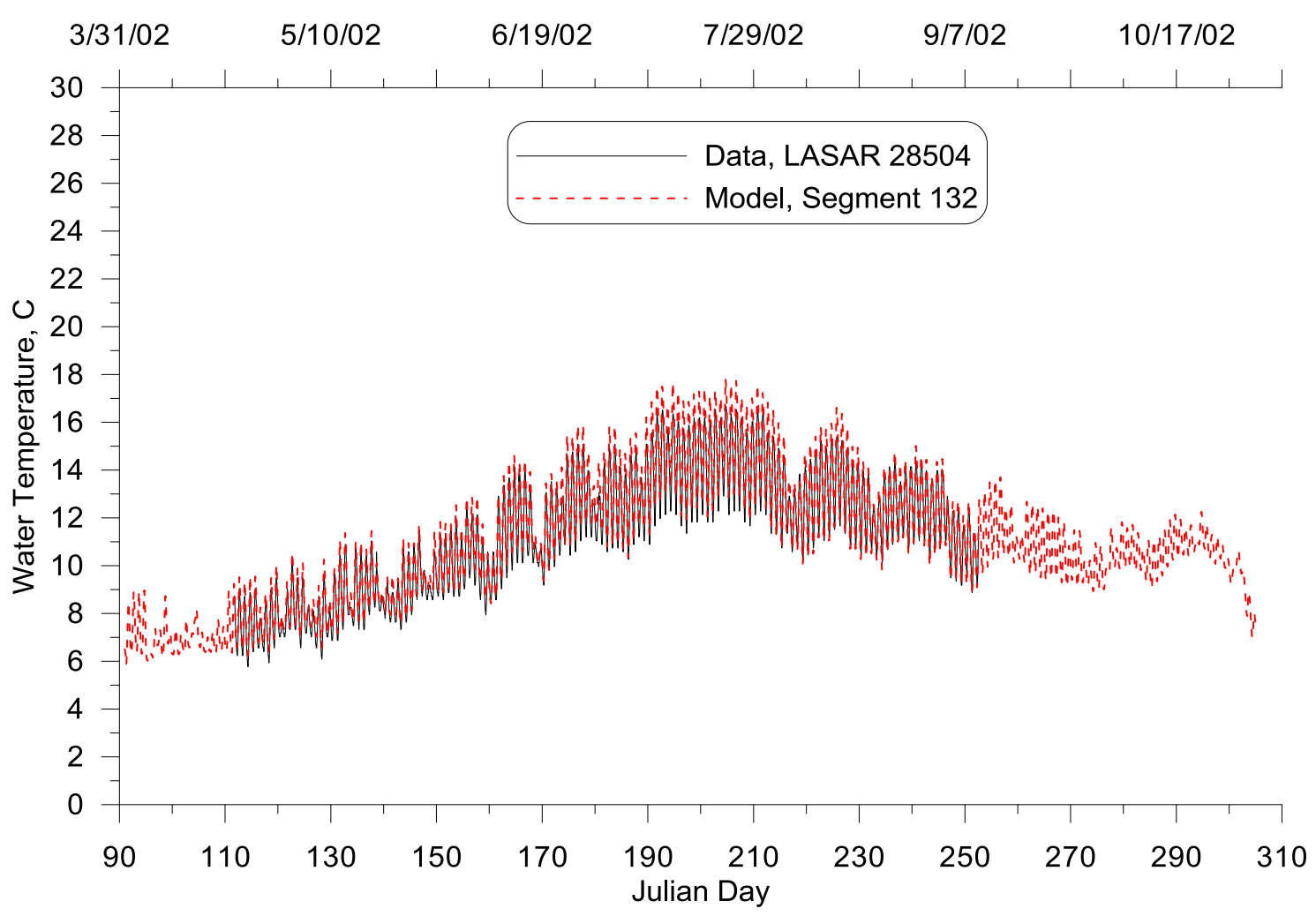

Figure 271: McKenzie River at Helfrich boat ramp model-data continuous temperature comparison, 2002

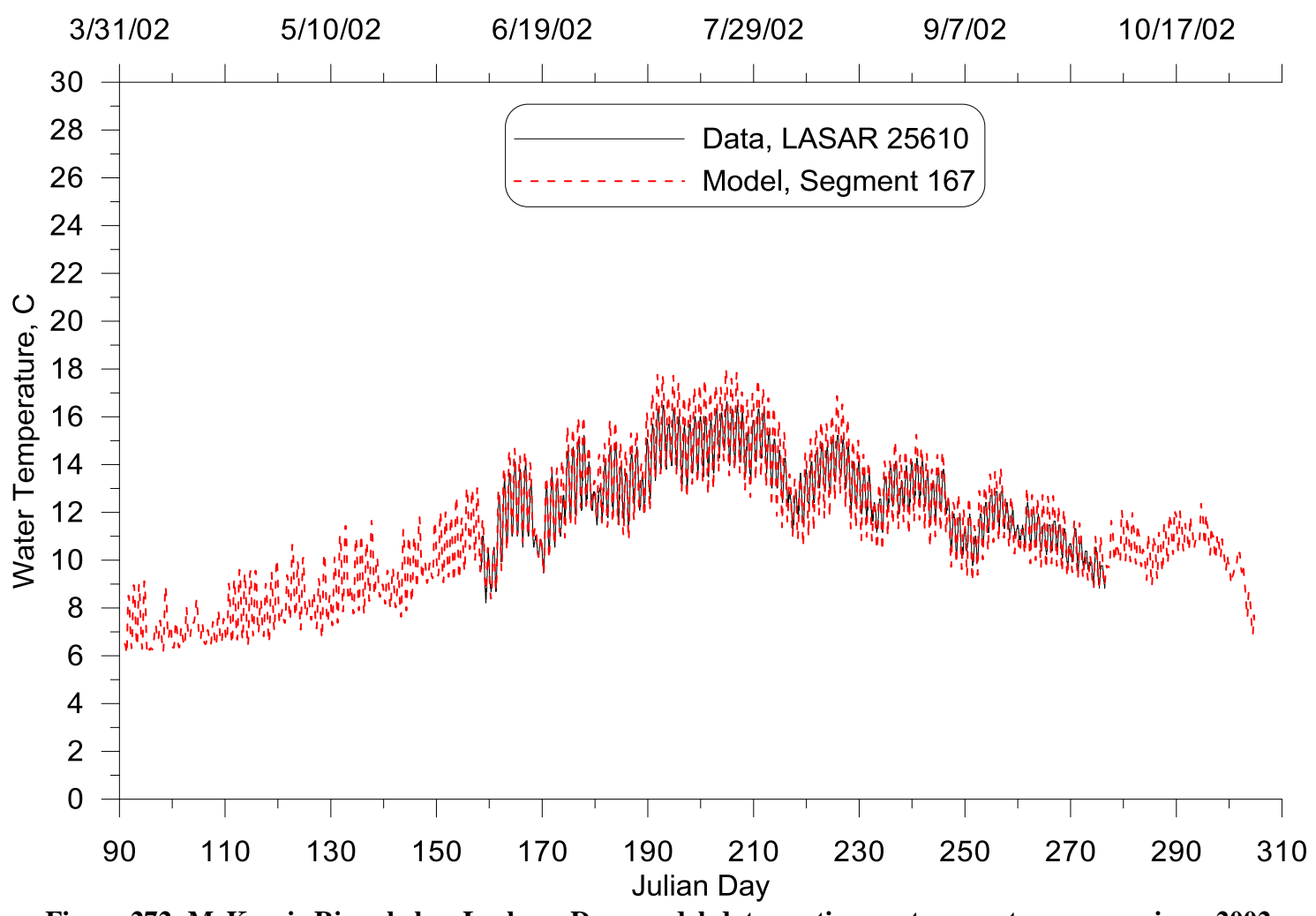

Figure 272: McKenzie River below Leaburg Dam model-data continuous temperature comparison, 2002 


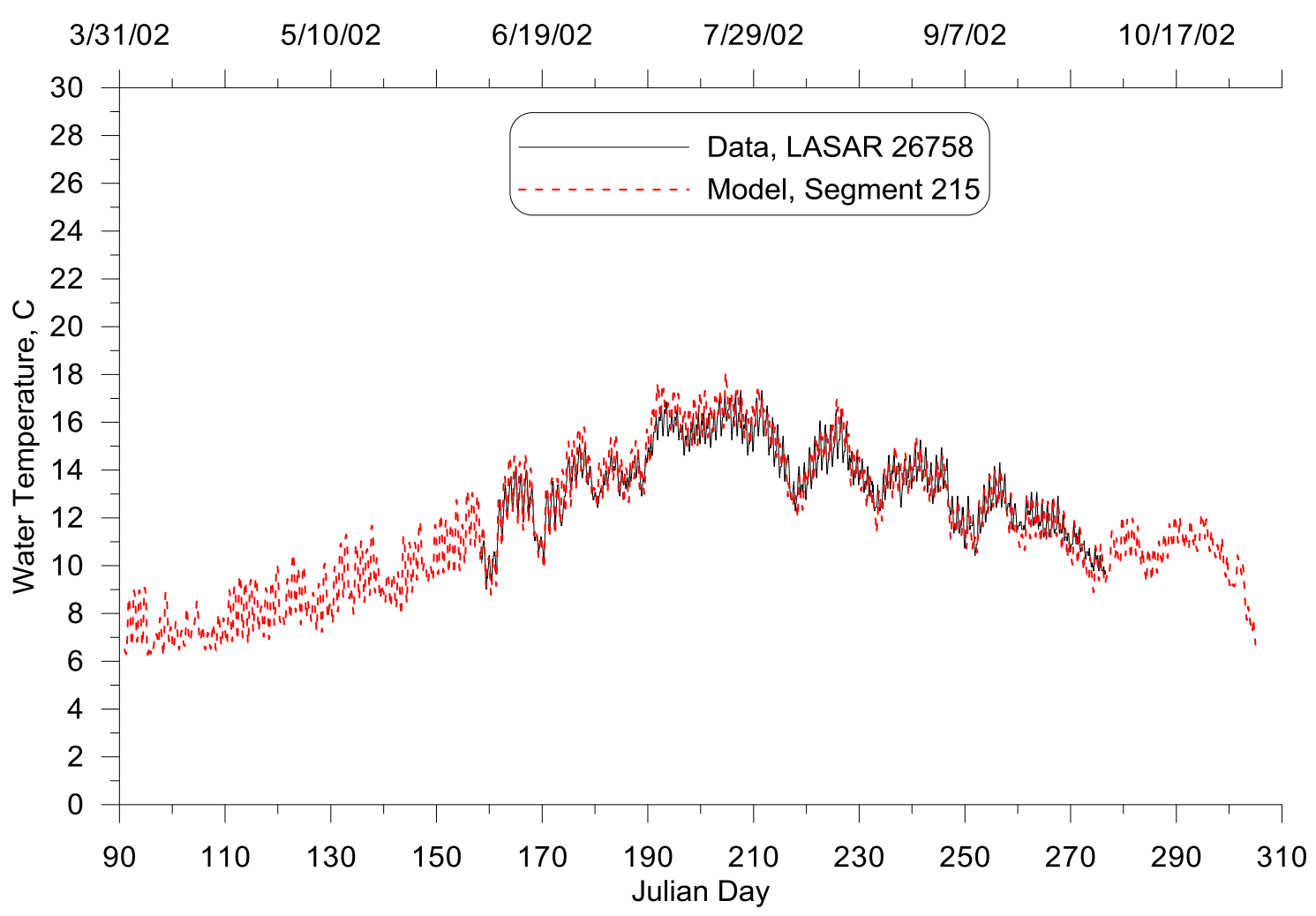

Figure 273: McKenzie River at Deerborn model-data continuous temperature comparison, 2002

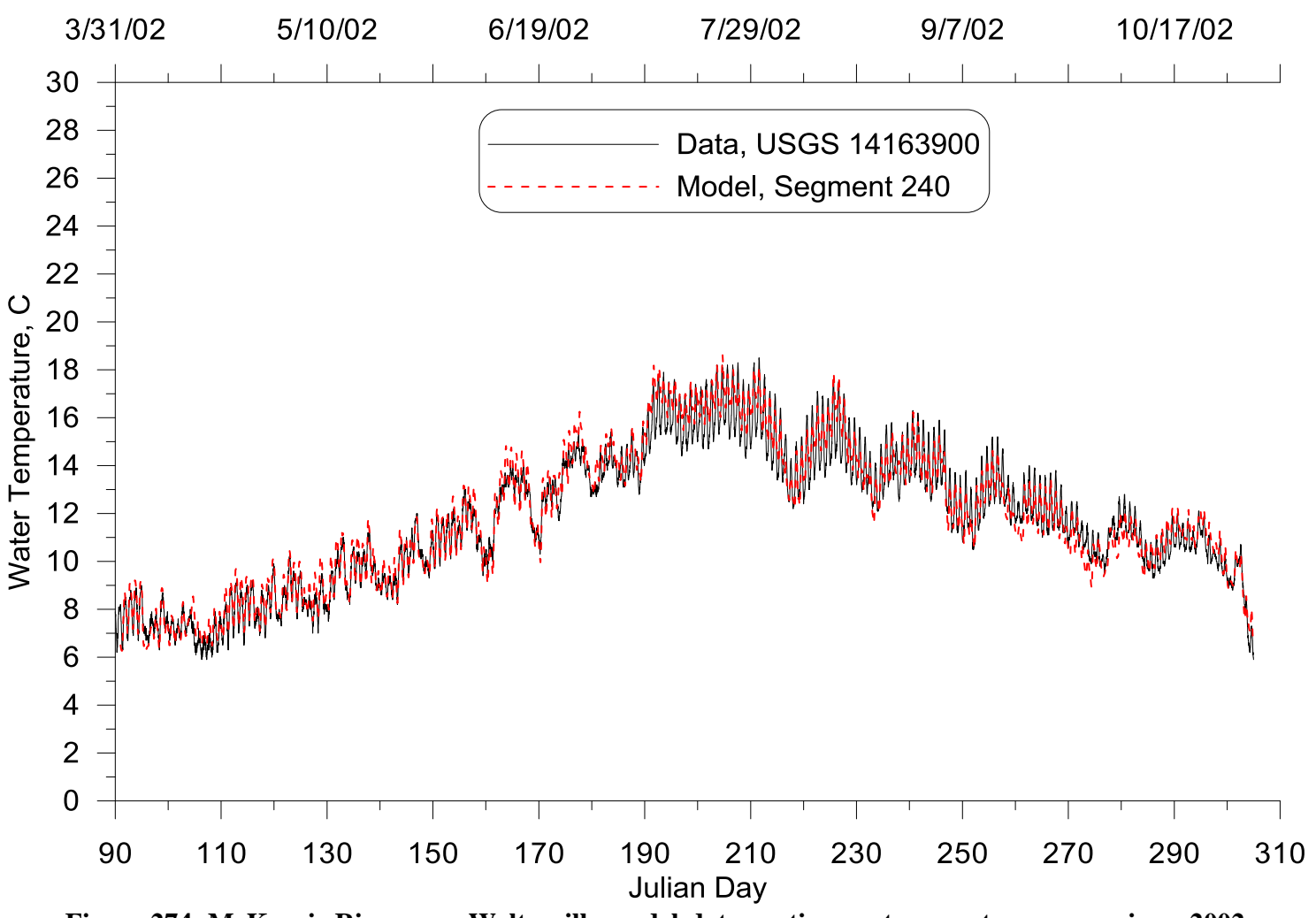

Figure 274: McKenzie River near Walterville model-data continuous temperature comparison, 2002 


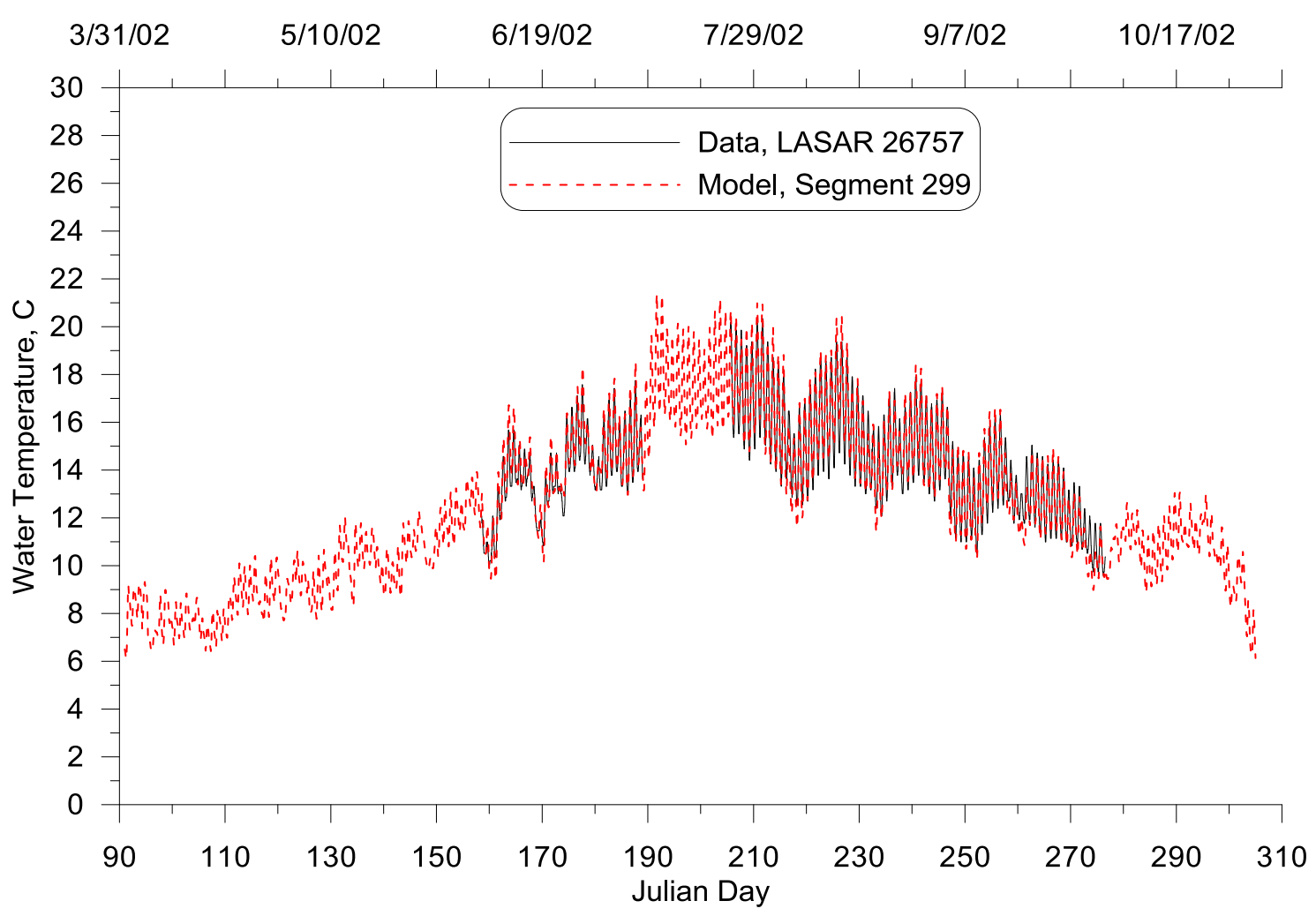

Figure 275: McKenzie River at Bellinger Landing model-data continuous temperature comparison, 2002

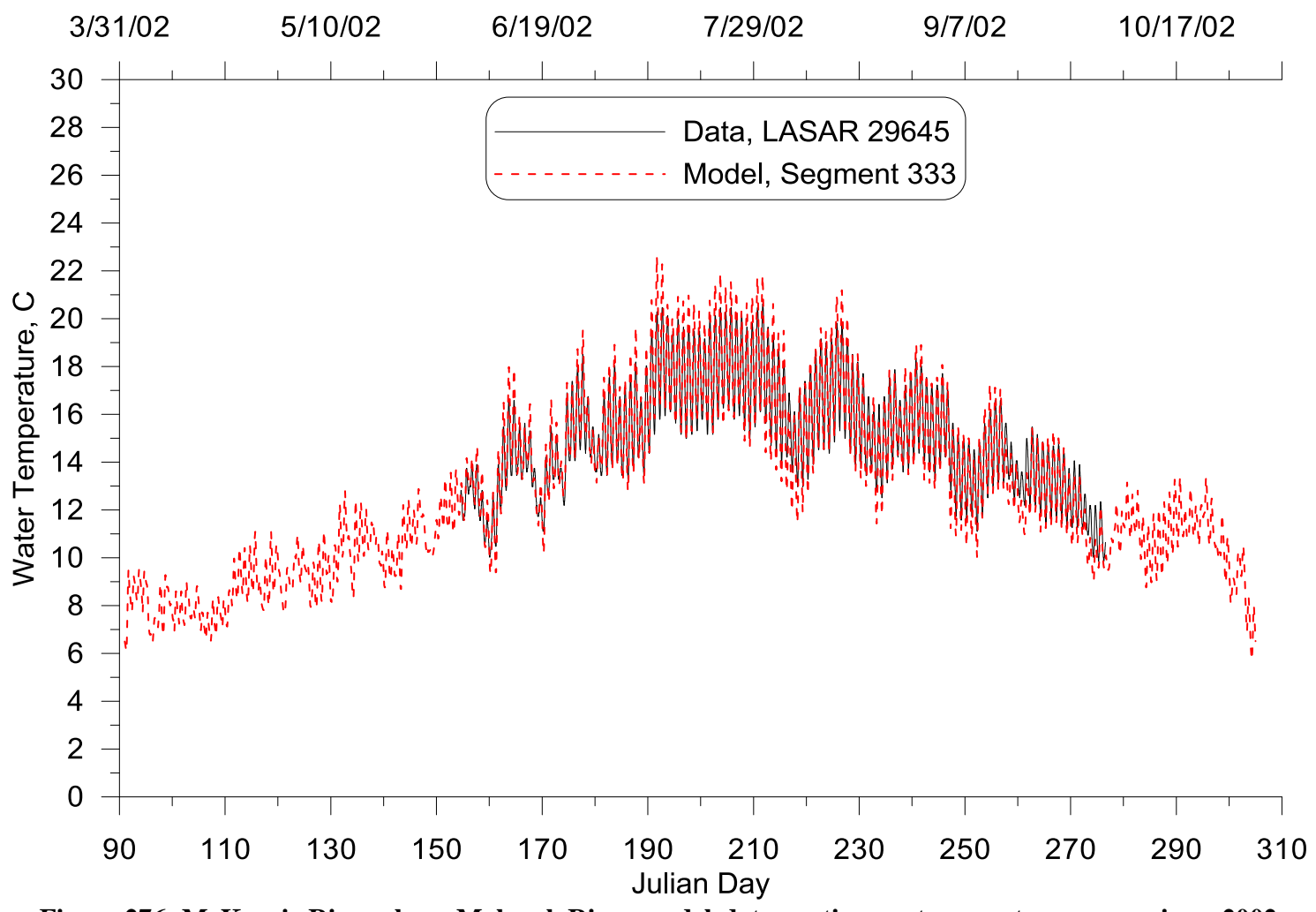

Figure 276: McKenzie River above Mohawk River model-data continuous temperature comparison, 2002 


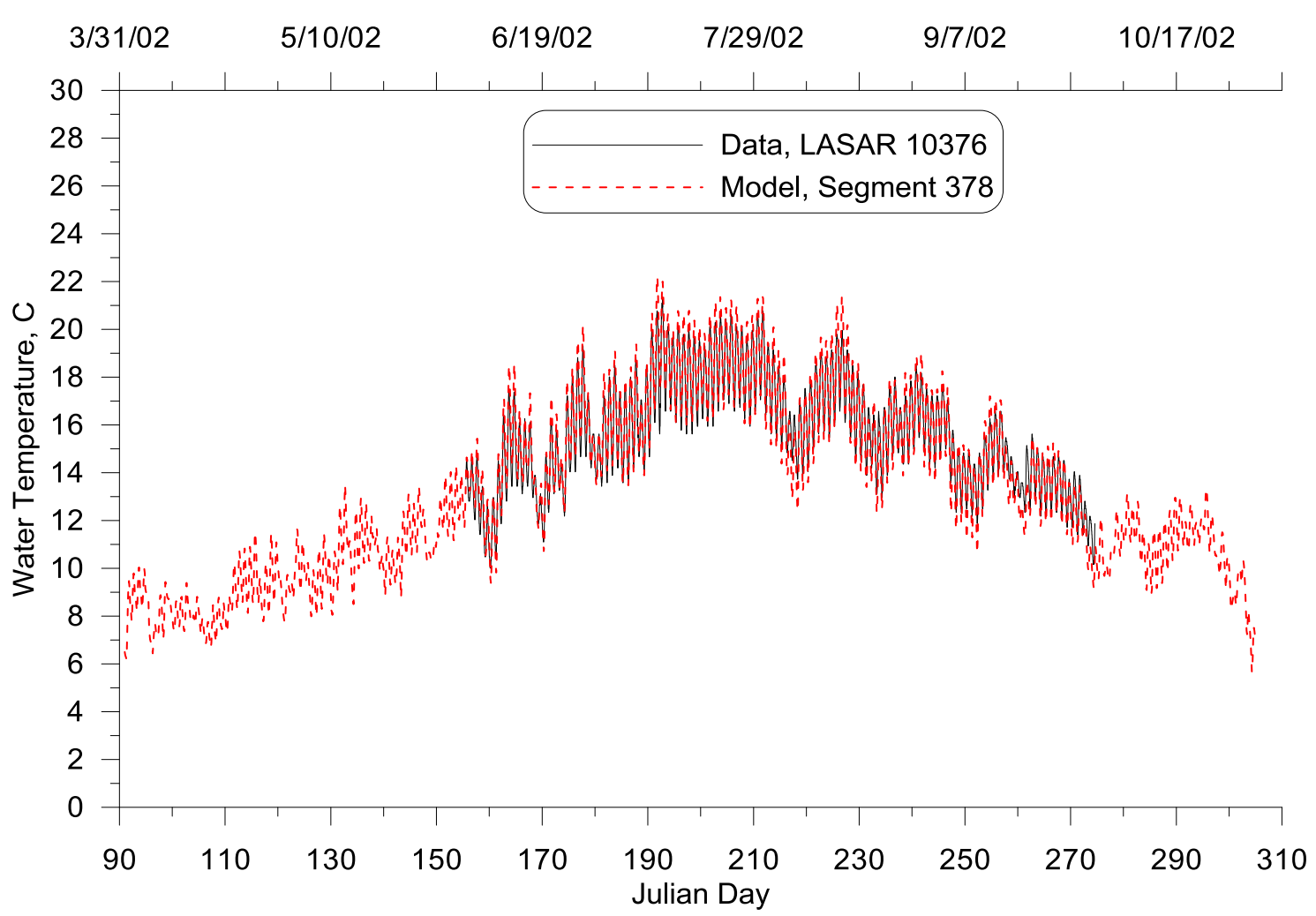

Figure 277: McKenzie River at Coburg Rd model-data continuous temperature comparison, 2002

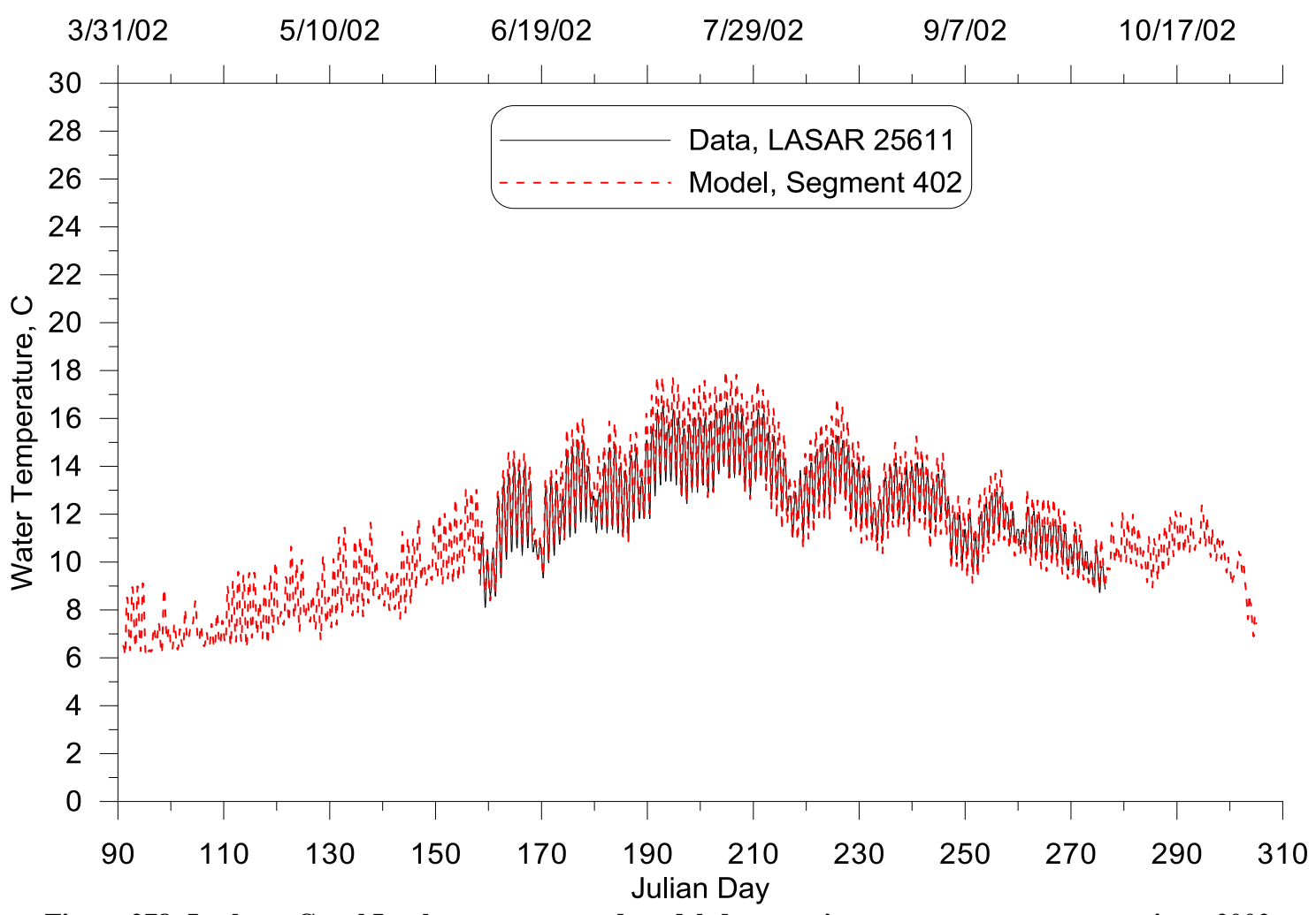

Figure 278: Leaburg Canal Intake, upstream end model-data continuous temperature comparison, 2002 


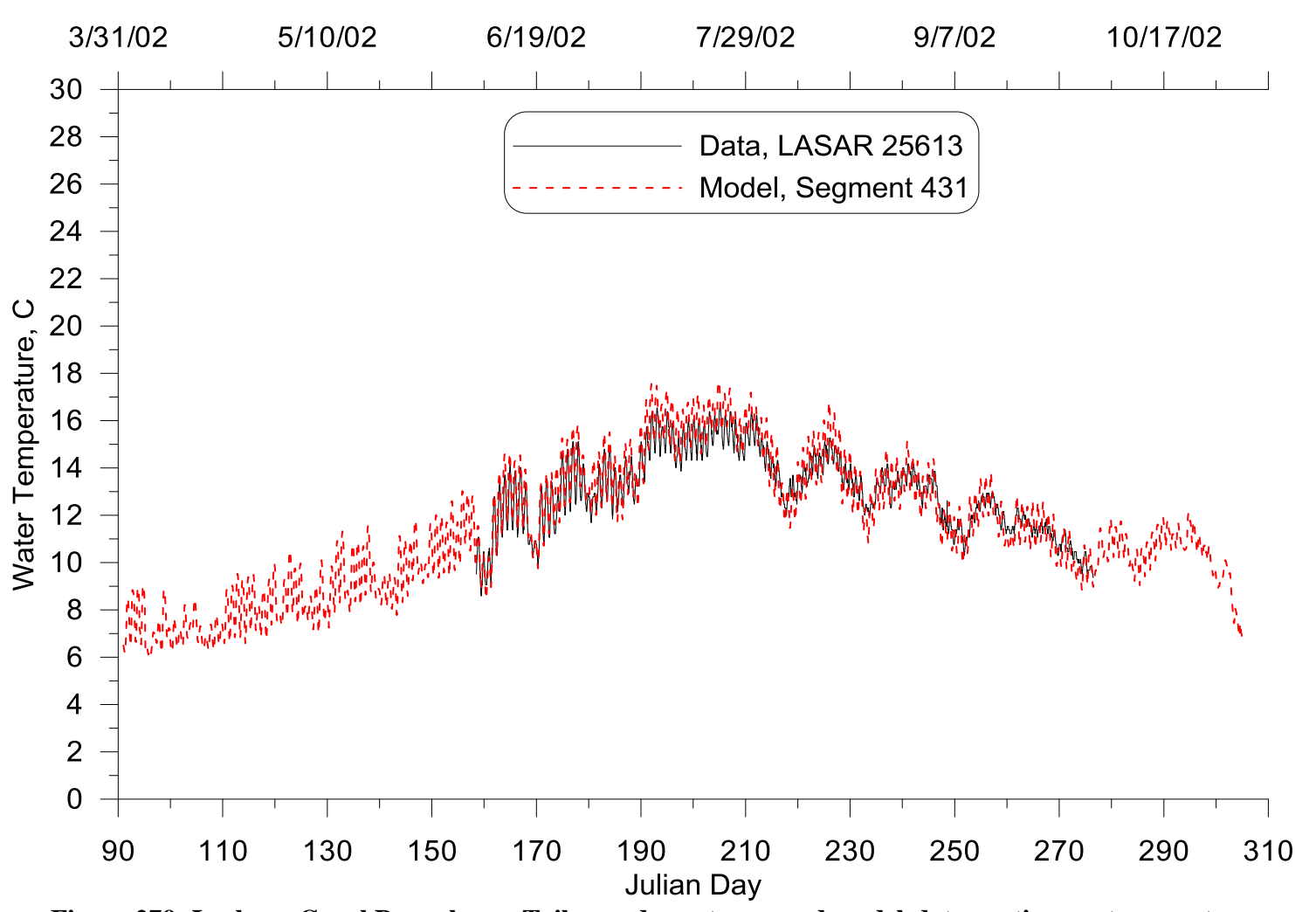

Figure 279: Leaburg Canal Powerhouse Tailrace, downstream end model-data continuous temperature comparison, 2002

\subsubsection{Long Tom River}

In Long Tom River CE-QUAL-W2 version 3.1 model, there is a side branch that represent an irrigation channel. This side branch was connected to the system with a lateral gate in the upstream, and an internal head boundary in the downstream.

In the current calibrated steady-state model, this side branch was deleted. The code which enable a side branch is connected to a main branch with a dynamic pump is underdevelopment. In the future study, this side branch should be added back to the model grid.

\section{Hydrodynamics}


Adjustment of spillway bottom elevation was performed to all the spillways to calibrate water level. Manning's friction coefficient and hydraulic equivalent slope were also adjusted.

\section{Year 2001}

Long Tom River hydrodynamic model-data error statistics in 2001 are summarized in Table 36. Figure 280 through 283 show the flow rate and water level comparison at different sites. The Steady-State model was able to predict both flow rate and water level very well.

Table 36 Long Tom River hydrodynamic calibration model-data error statistics, 2001

\begin{tabular}{|c|c|c|c|c|c|c|}
\hline \multicolumn{7}{|c|}{ Flow } \\
\hline Gage ID & RM & $\begin{array}{c}\text { Model } \\
\text { Segment }\end{array}$ & $\begin{array}{c}\text { Sample } \\
\text { size, } \mathrm{N}\end{array}$ & ME, $\mathrm{m}^{3} / \mathrm{s}$ & AME, $\mathrm{m}^{3 / \mathrm{s}}$ & RMSE, $\mathrm{m}^{3 / \mathrm{s}}$ \\
\hline USGS 14169000 & 23.47 & 2 & 5760 & 0 & 0.003 & 0.012 \\
\hline USGS 14170000 & 6.86 & 134 & 5559 & 0.053 & 0.126 & 0.178 \\
\hline \multicolumn{7}{|c|}{ Water Level } \\
\hline Gage ID & RM & $\begin{array}{c}\text { Model } \\
\text { Segment }\end{array}$ & $\begin{array}{c}\text { Sample } \\
\text { size, } \mathrm{N}\end{array}$ & ME, $\mathrm{m}$ & AME, $\mathrm{m}$ & RMSE, $\mathrm{m}$ \\
\hline USGS 14169000 & 23.47 & 2 & 5760 & -0.014 & 0.019 & 0.024 \\
\hline USGS 14170000 & 6.86 & 134 & 5559 & -0.024 & 0.025 & 0.026 \\
\hline
\end{tabular}




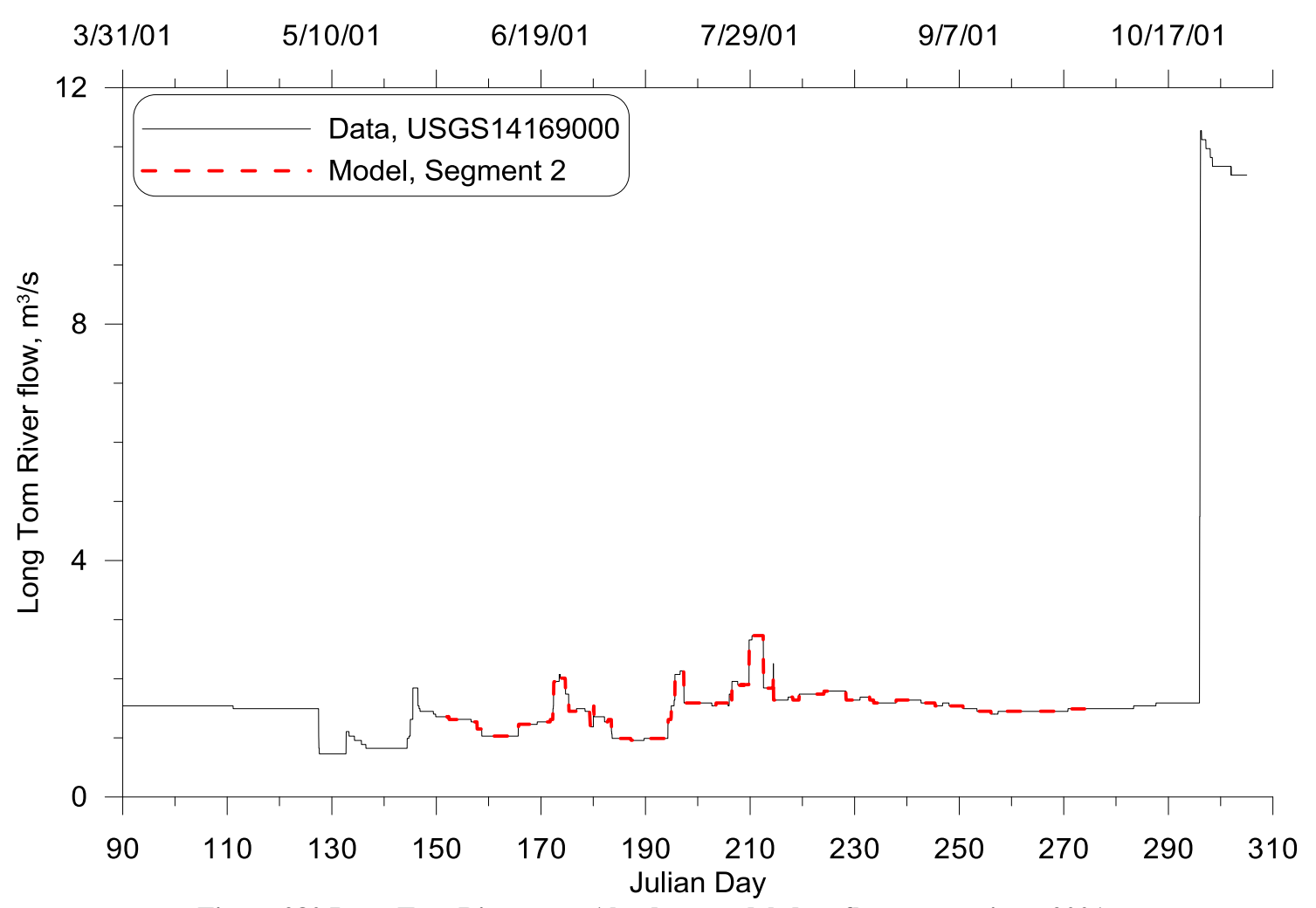

Figure 280 Long Tom River near Alvadore model-data flow comparison, 2001

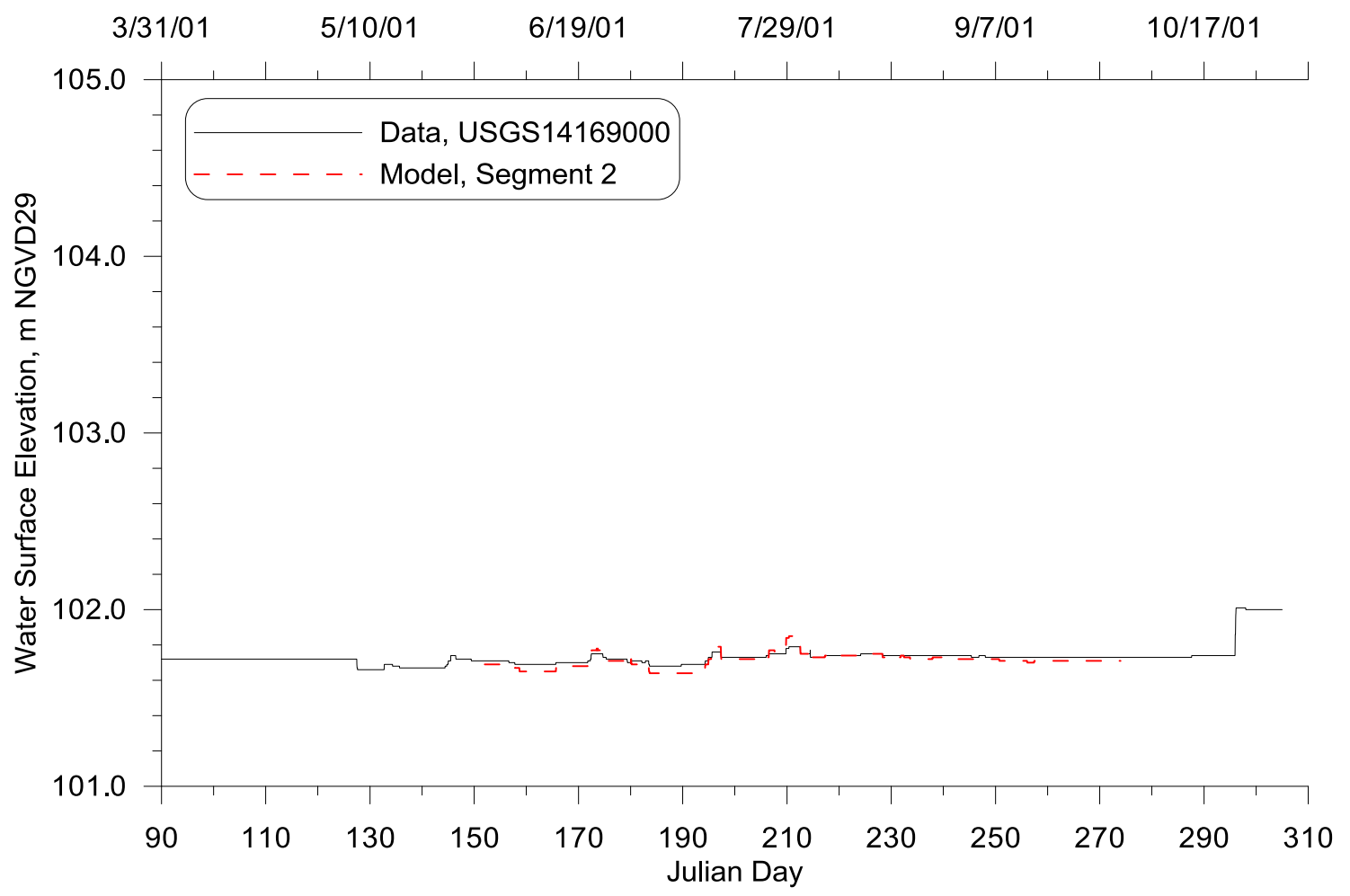

Figure 281: Long Tom River near Alvadore model-data water level comparison, 2001 


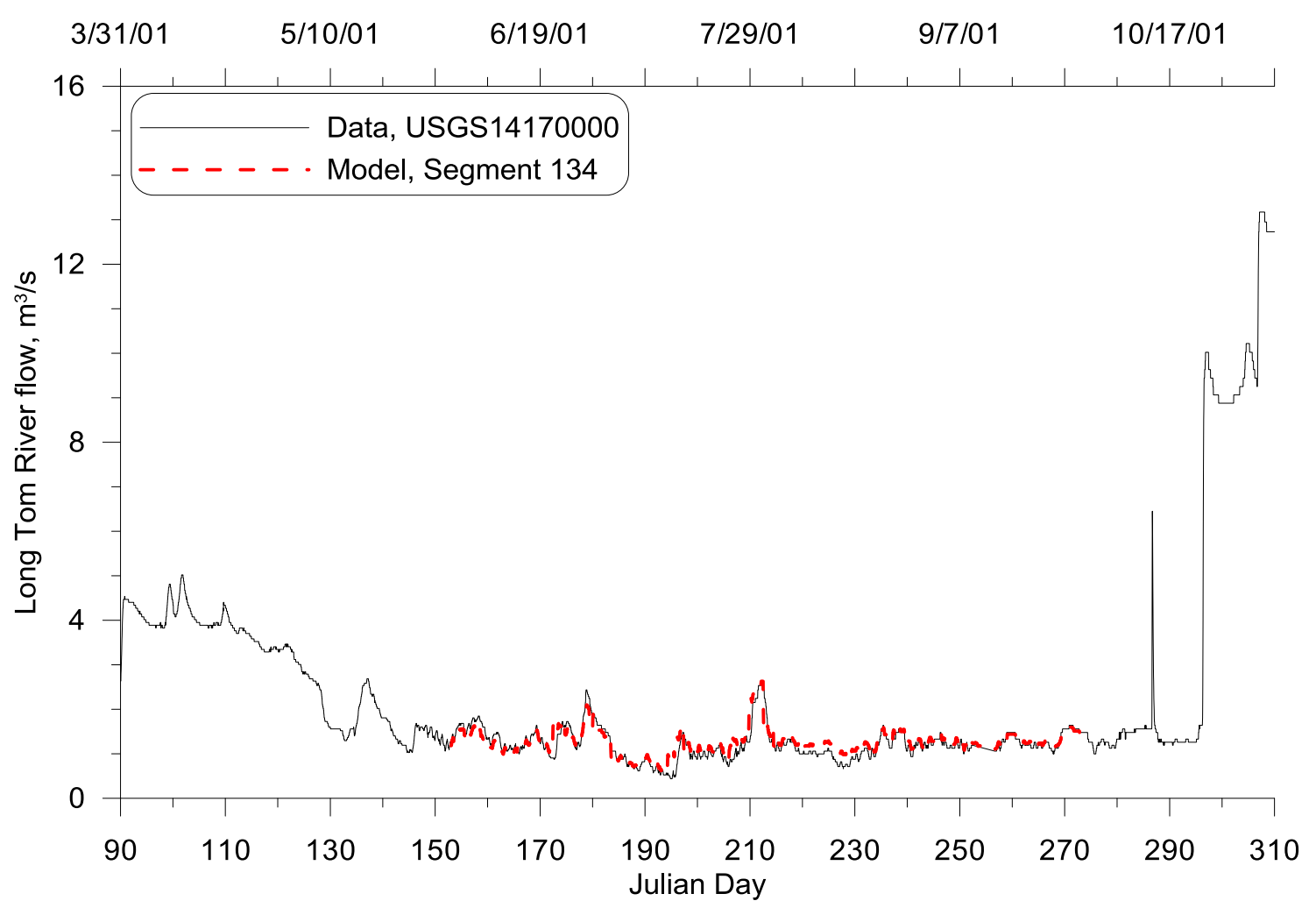

Figure 282: Long Tom River at Monroe model-data flow comparison, 2001

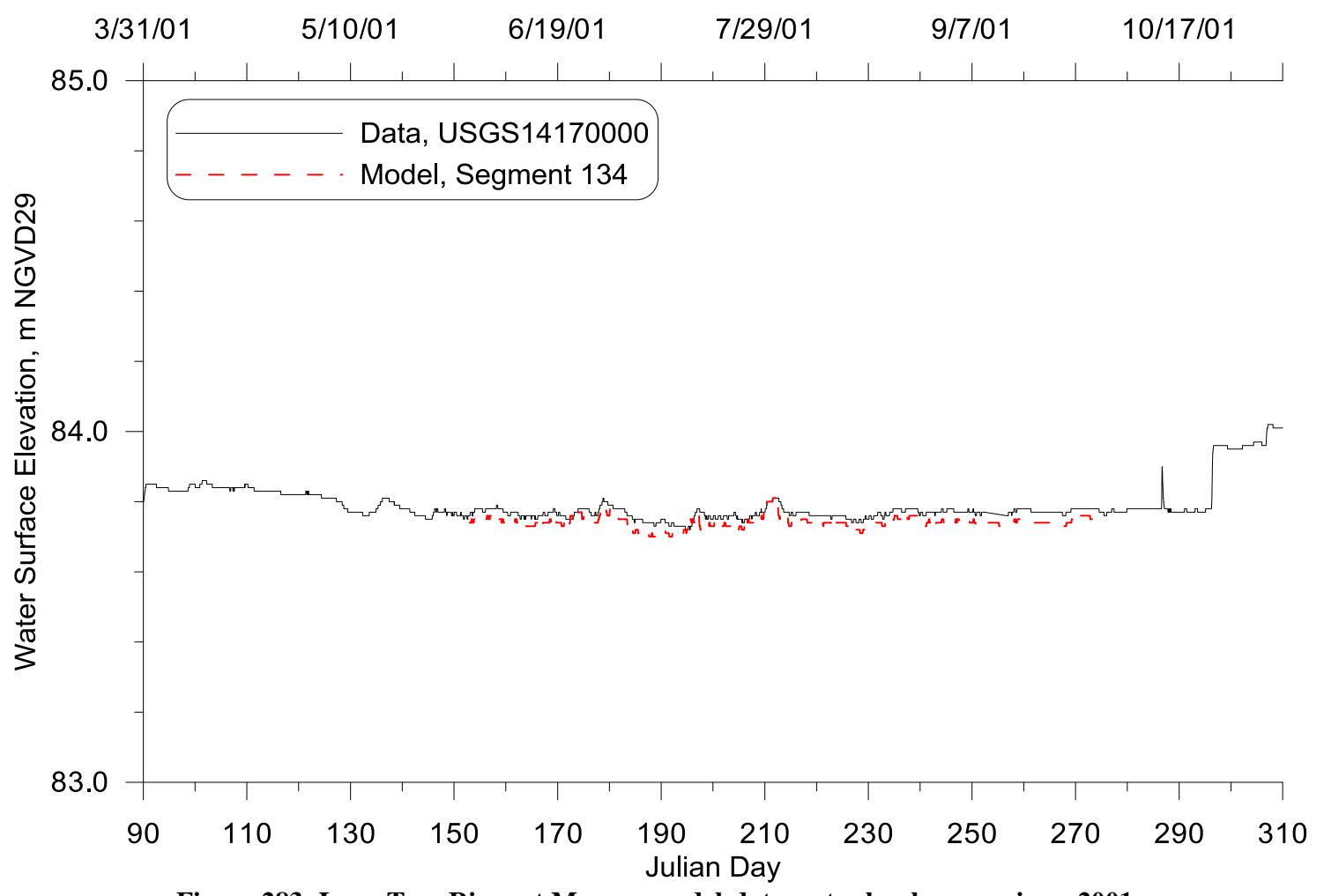

Figure 283: Long Tom River at Monroe model-data water level comparison, 2001 


\section{Year 2002}

Long Tom River hydrodynamic model-data error statistics in 2002 are summarized in Table 37. Figure 284 through 287 show the flow rate and water level comparison at different sites. The Steady-State model was able to predict both flow rate and water level very well.

Table 37 Long Tom River hydrodynamic calibration model-data error statistics, 2002

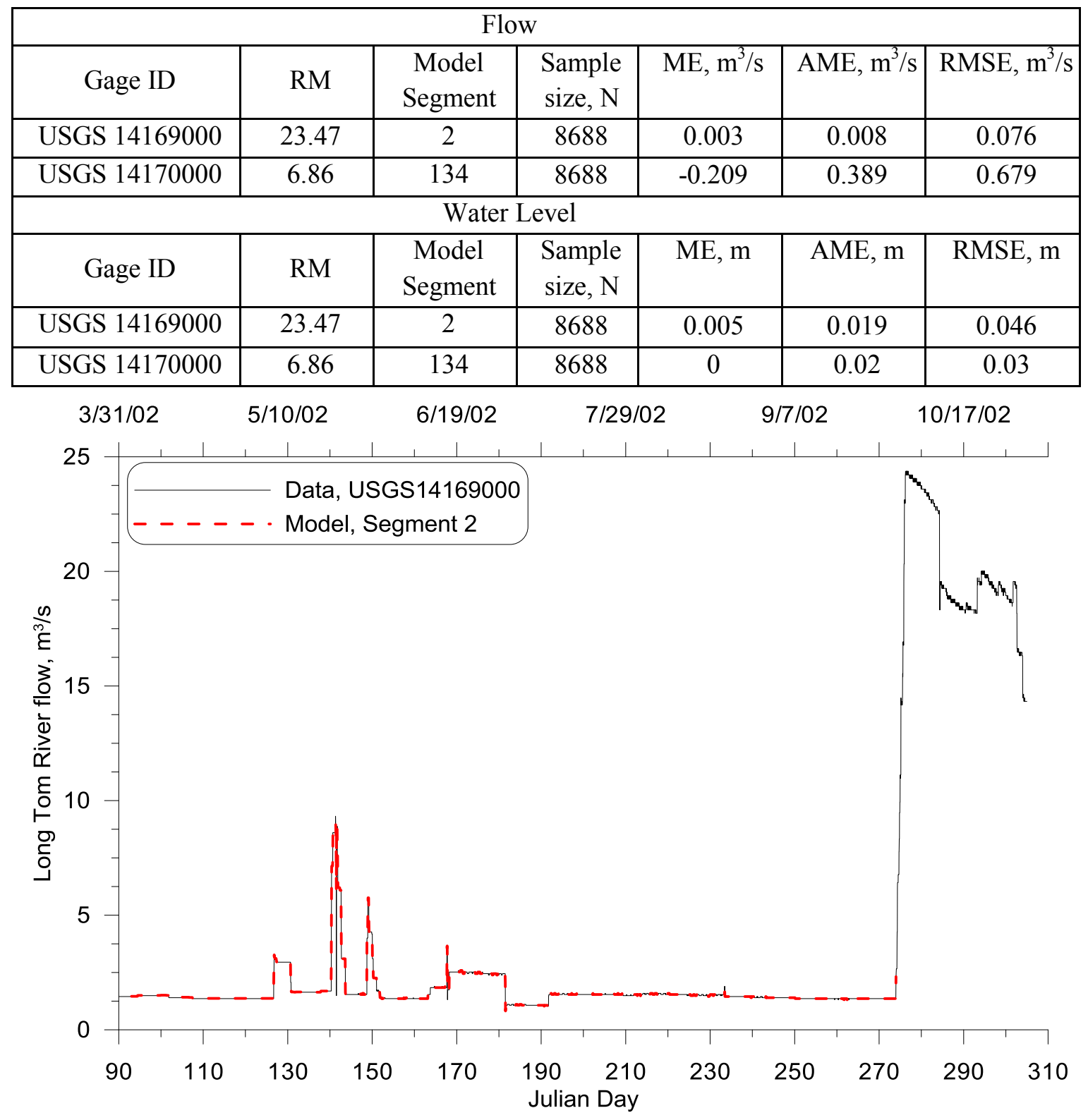


Figure 284: Long Tom River near Alvadore model-data flow comparison, 2002

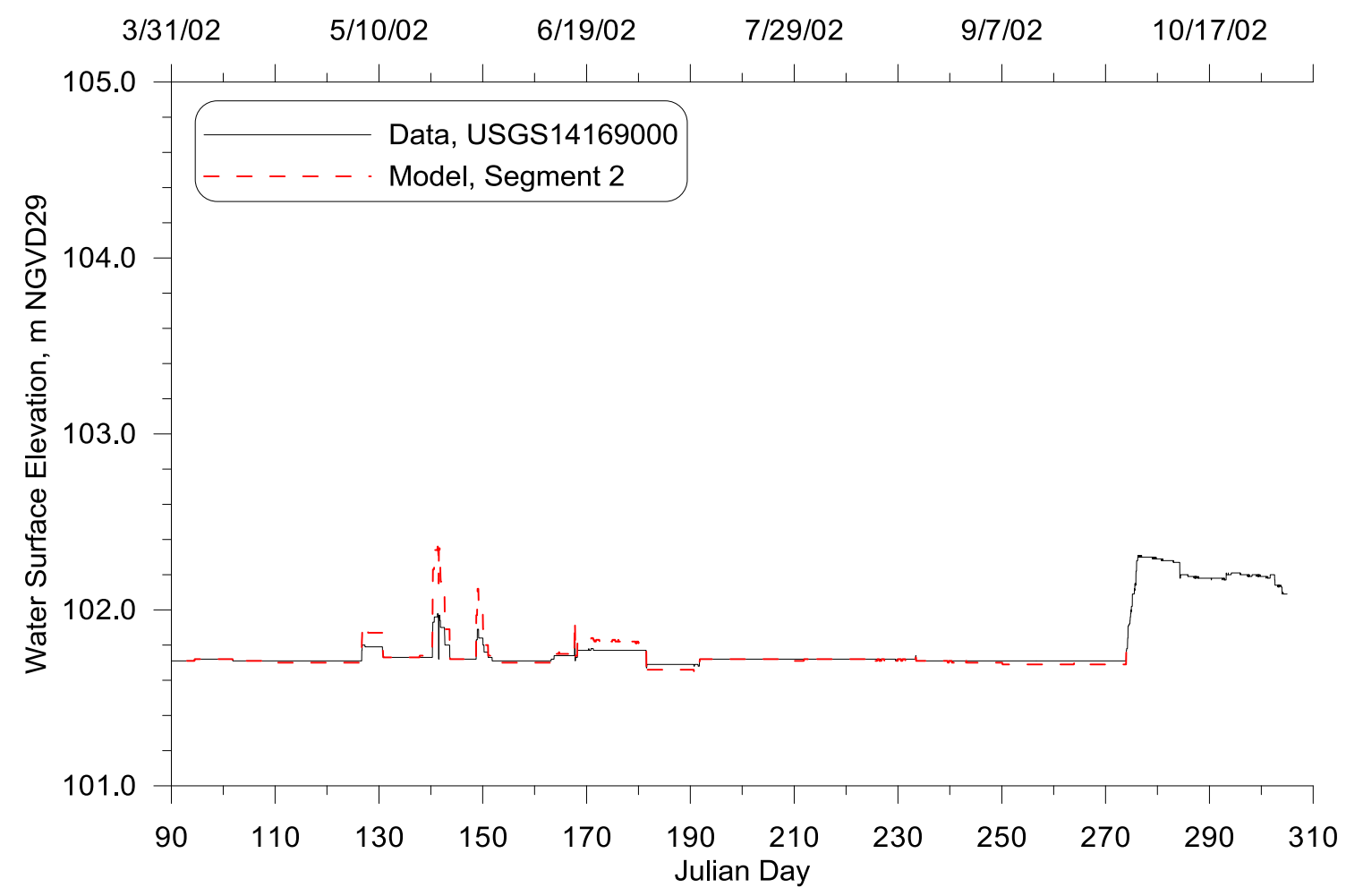

Figure 285: Long Tom River near Alvadore model-data water level comparison, 2002

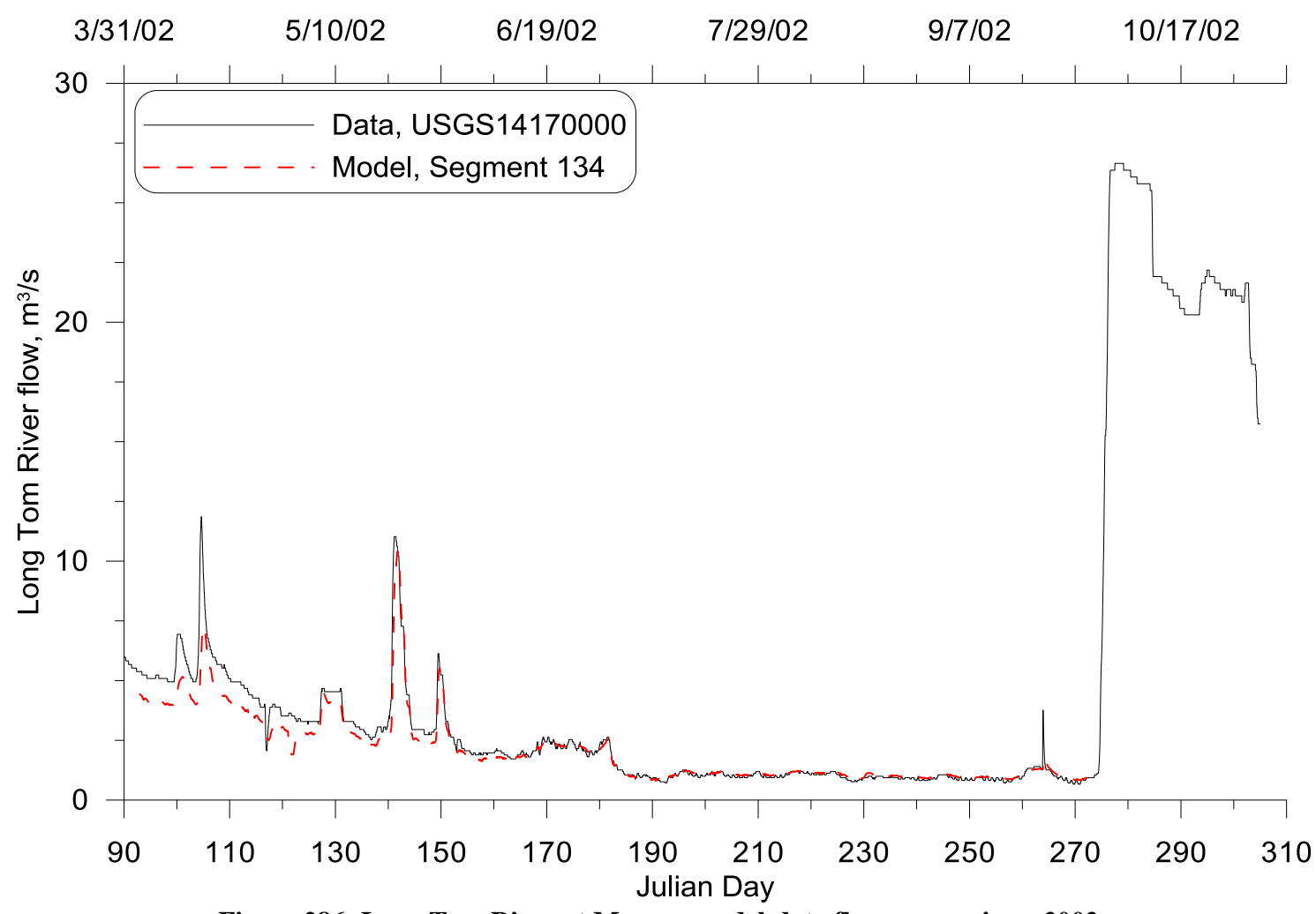

Figure 286: Long Tom River at Monroe model-data flow comparison, 2002 


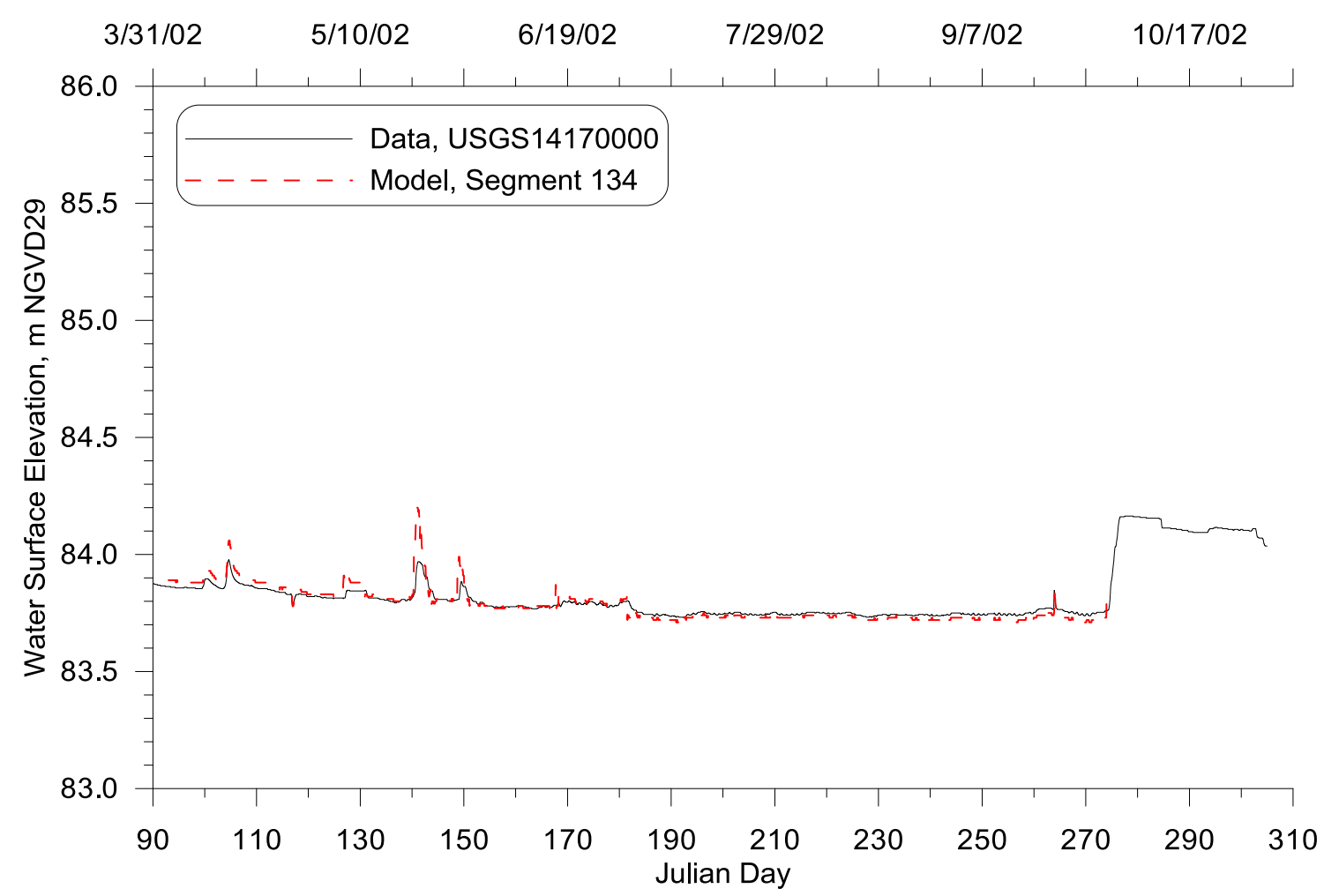

Figure 287: Long Tom River at Monroe model-data water level comparison, 2002

\section{Temperature}

\section{Year 2001}

Long Tom River continuous water temperature calibration model-data error statistics in 2001 are summarized in Table 38. Figure 288 through 291 show the continuous temperature comparison at different sites. The current calibration result had the RMSEs below $0.95{ }^{\circ} \mathrm{C}$, which was better than both the current Version 3.1 calibration results and the Version 3.7 calibration results. 
Table 38 Long Tom River continuous water temperature calibration model-data error statistics, 2001

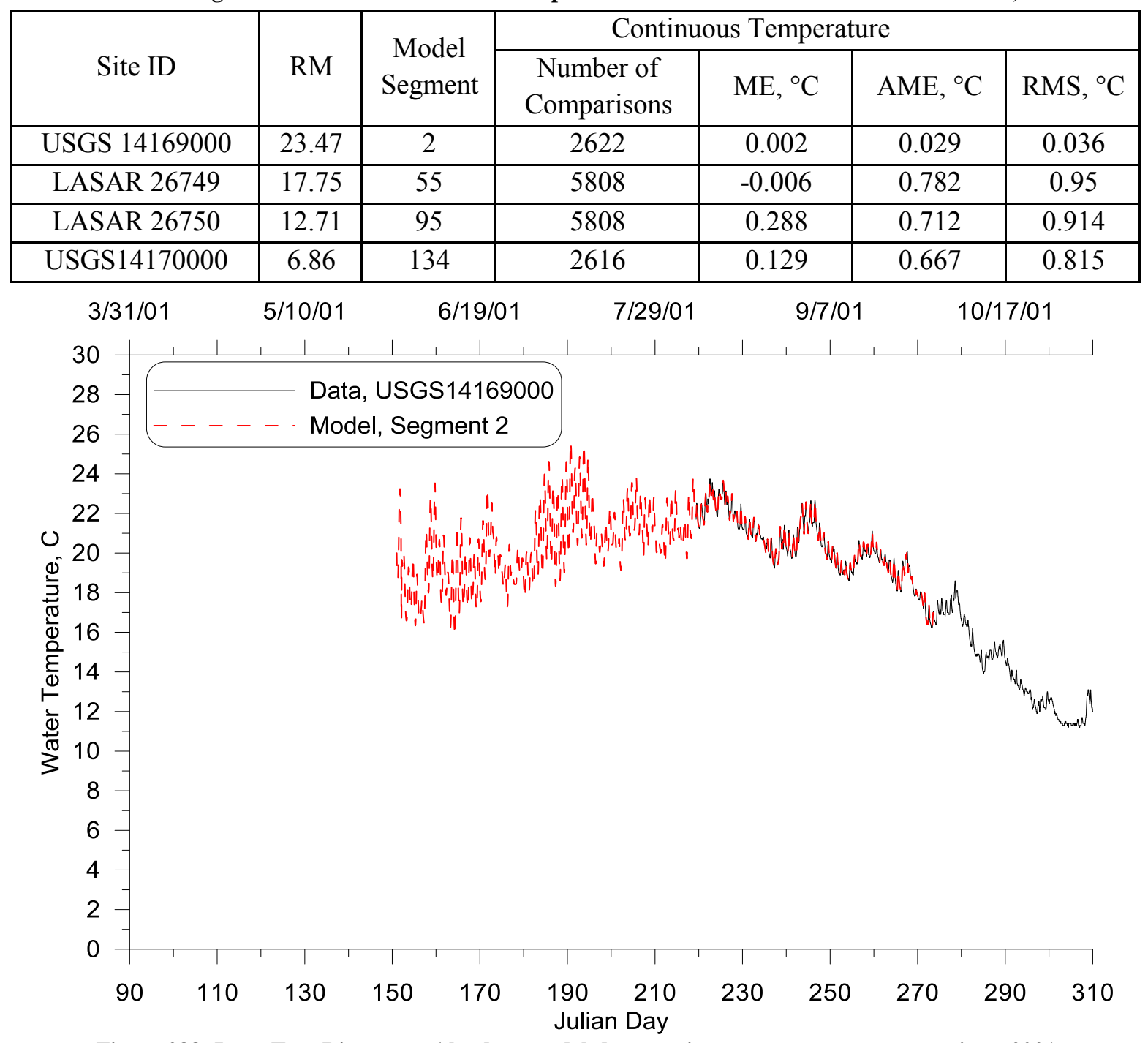

Figure 288: Long Tom River near Alvadore model-data continuous temperature comparison, 2001 


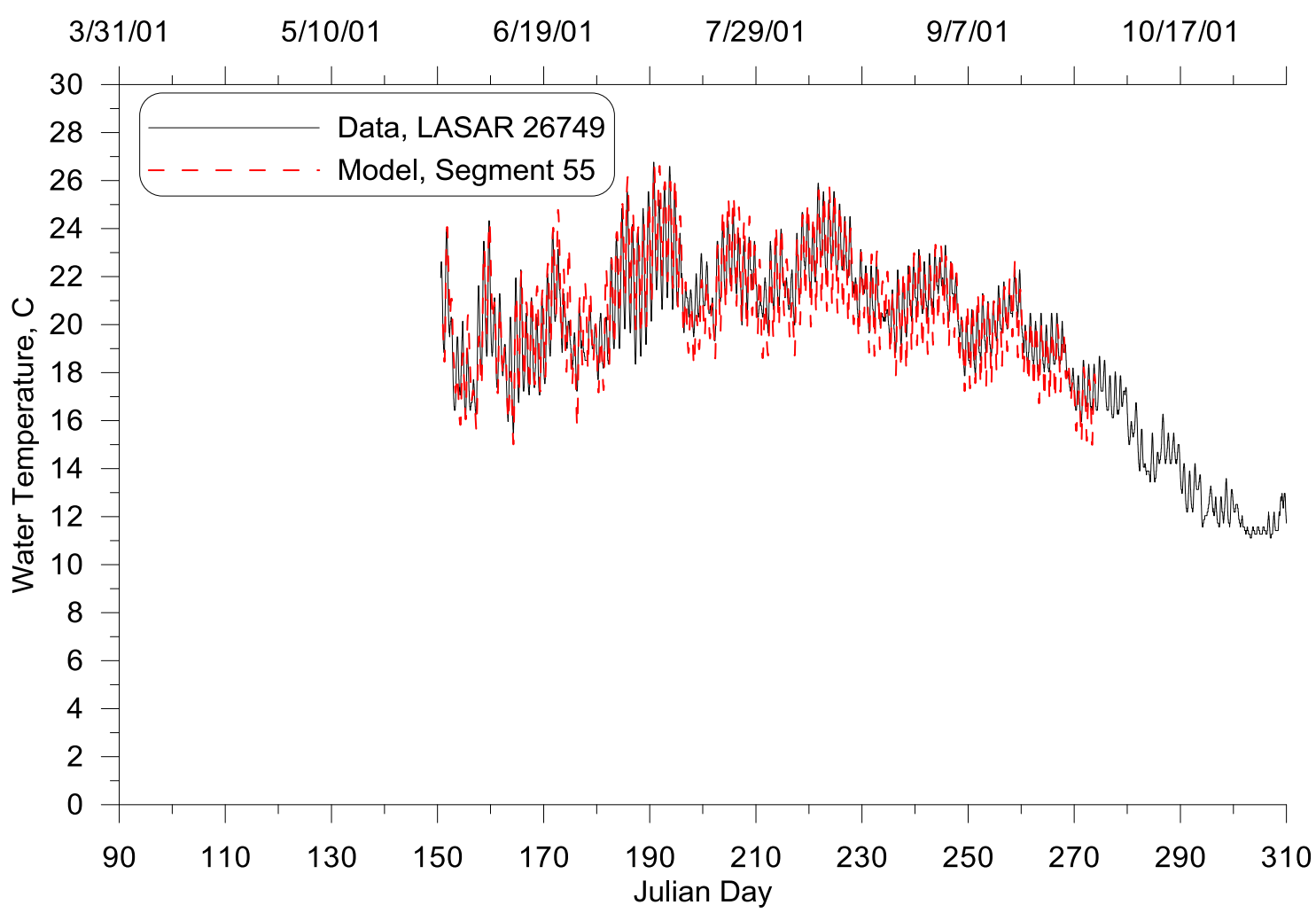

Figure 289: Long Tom River at RM 19.8 model-data continuous temperature comparison, 2001

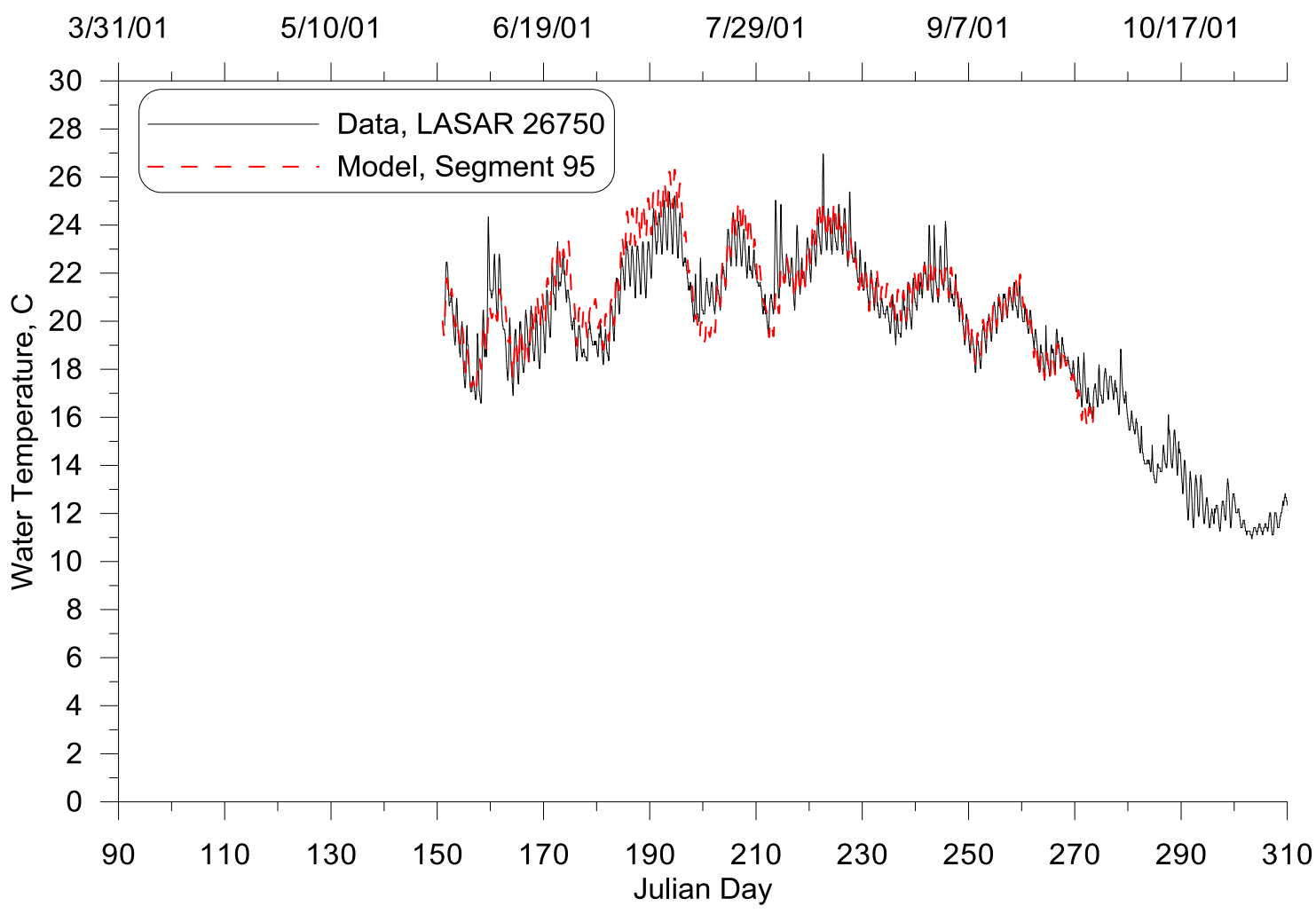

Figure 290: Long Tom River at RM 12.3 model-data continuous temperature comparison, 2001 


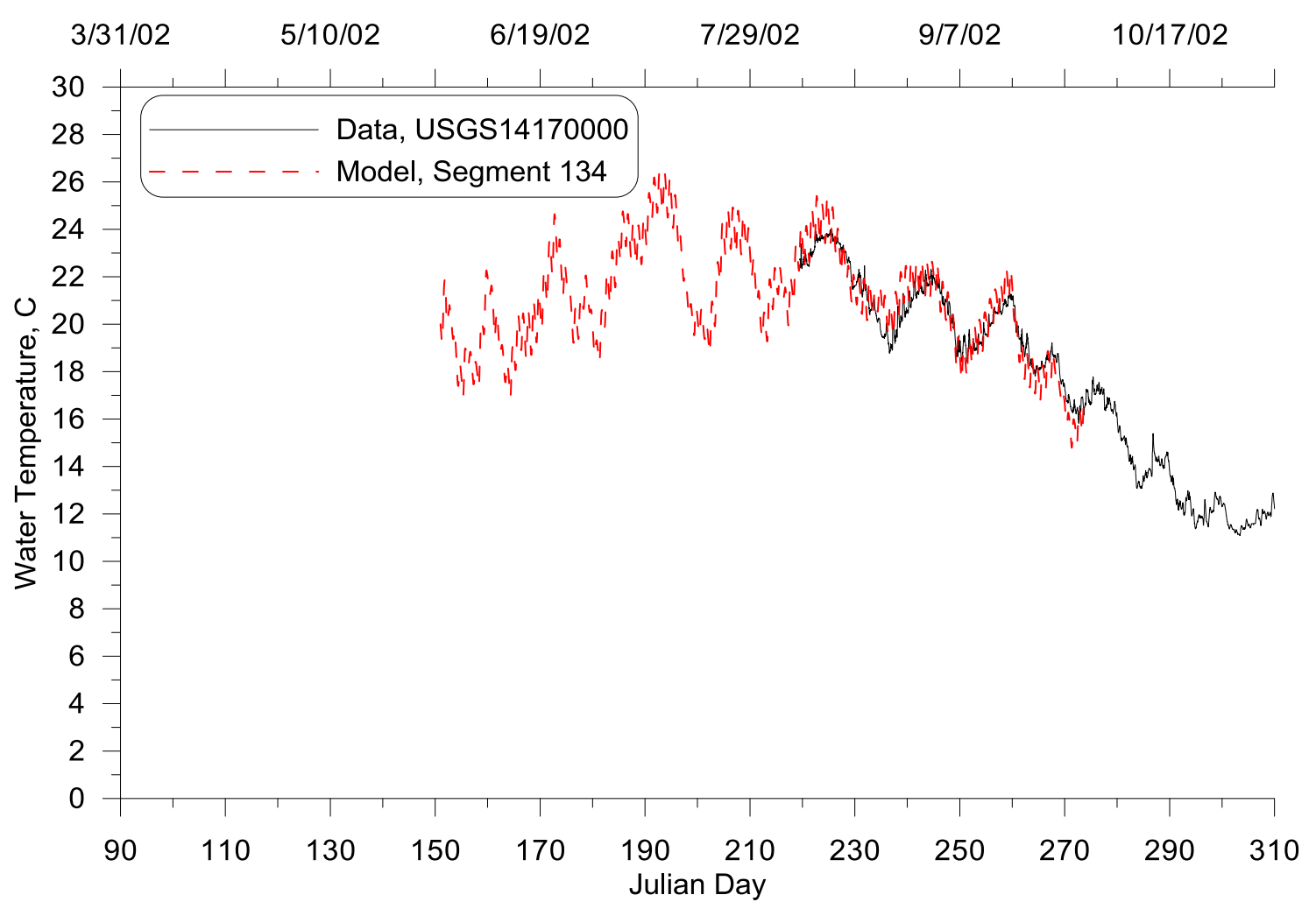

Figure 291: Long Tom River at Monroe model-data continuous temperature comparison, 2001

Year 2002

Long Tom River continuous water temperature calibration model-data error statistics in 2001 are summarized in Table 39. Figure 292 through 296 show the continuous temperature comparison at different sites. The current calibration result had the maximum RMSE $1.295{ }^{\circ} \mathrm{C}$, which was similar to maximum RMSE in the current Version 3.1 calibration results $\left(1.16^{\circ} \mathrm{C}\right)$ and the maximum RMSE in the Version 3.7 calibration result $\left(1.23{ }^{\circ} \mathrm{C}\right)$. 
Table 39 Long Tom River continuous water temperature calibration model-data error statistics, 2002

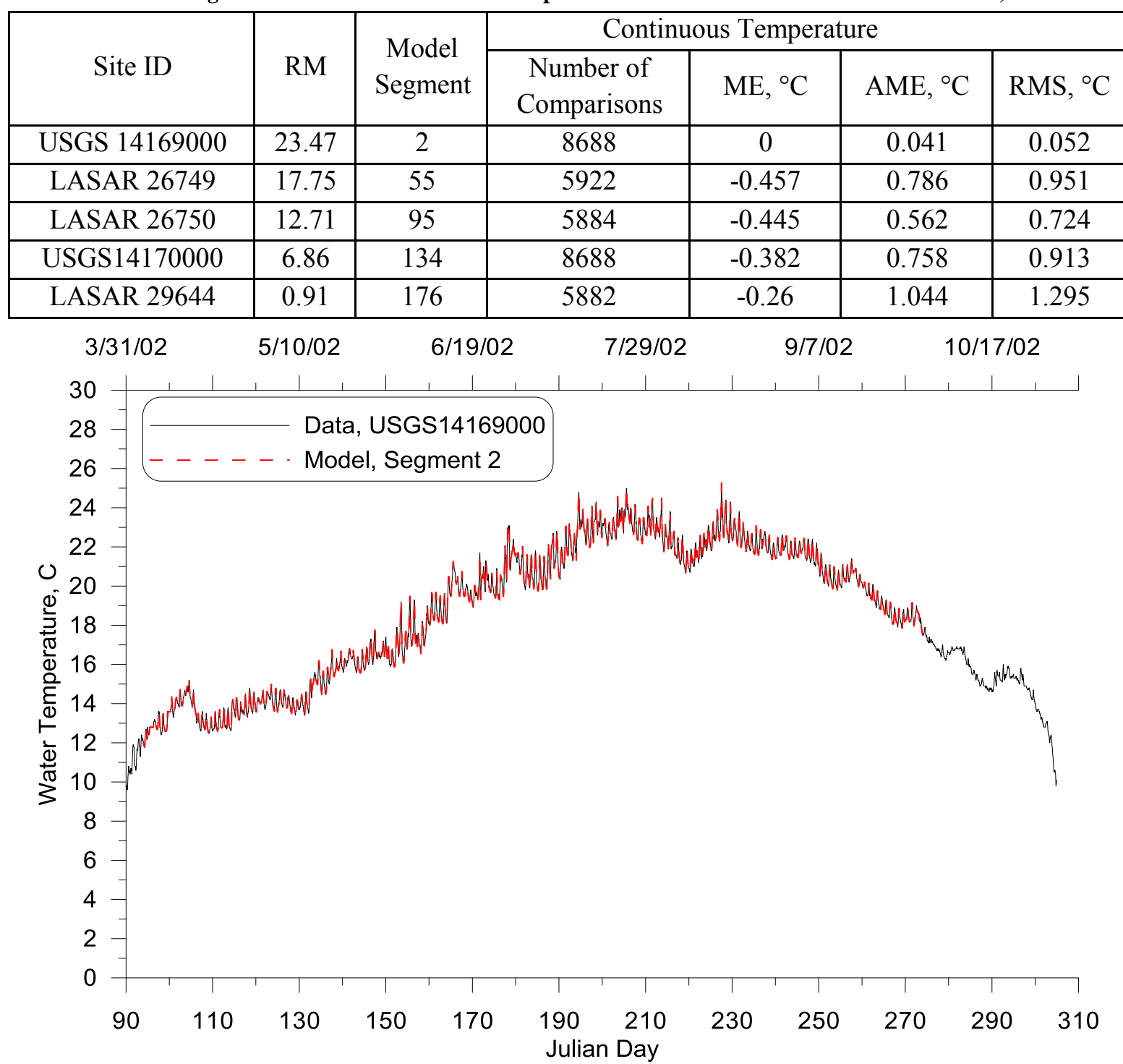

Figure 292: Long Tom River near Alvadore model-data continuous temperature comparison, 2002 


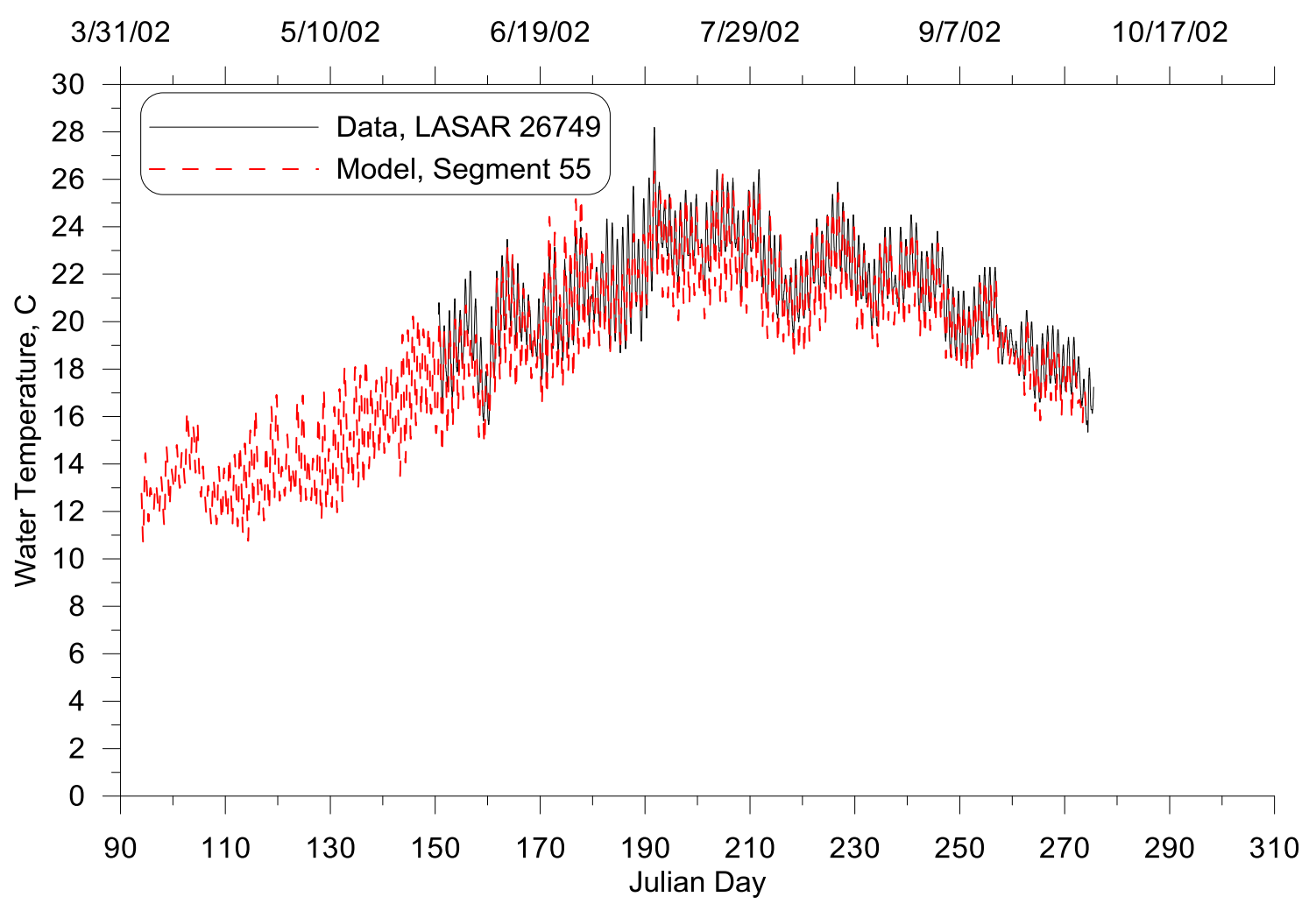

Figure 293: Long Tom River at RM 19.8 model-data continuous temperature comparison, 2002

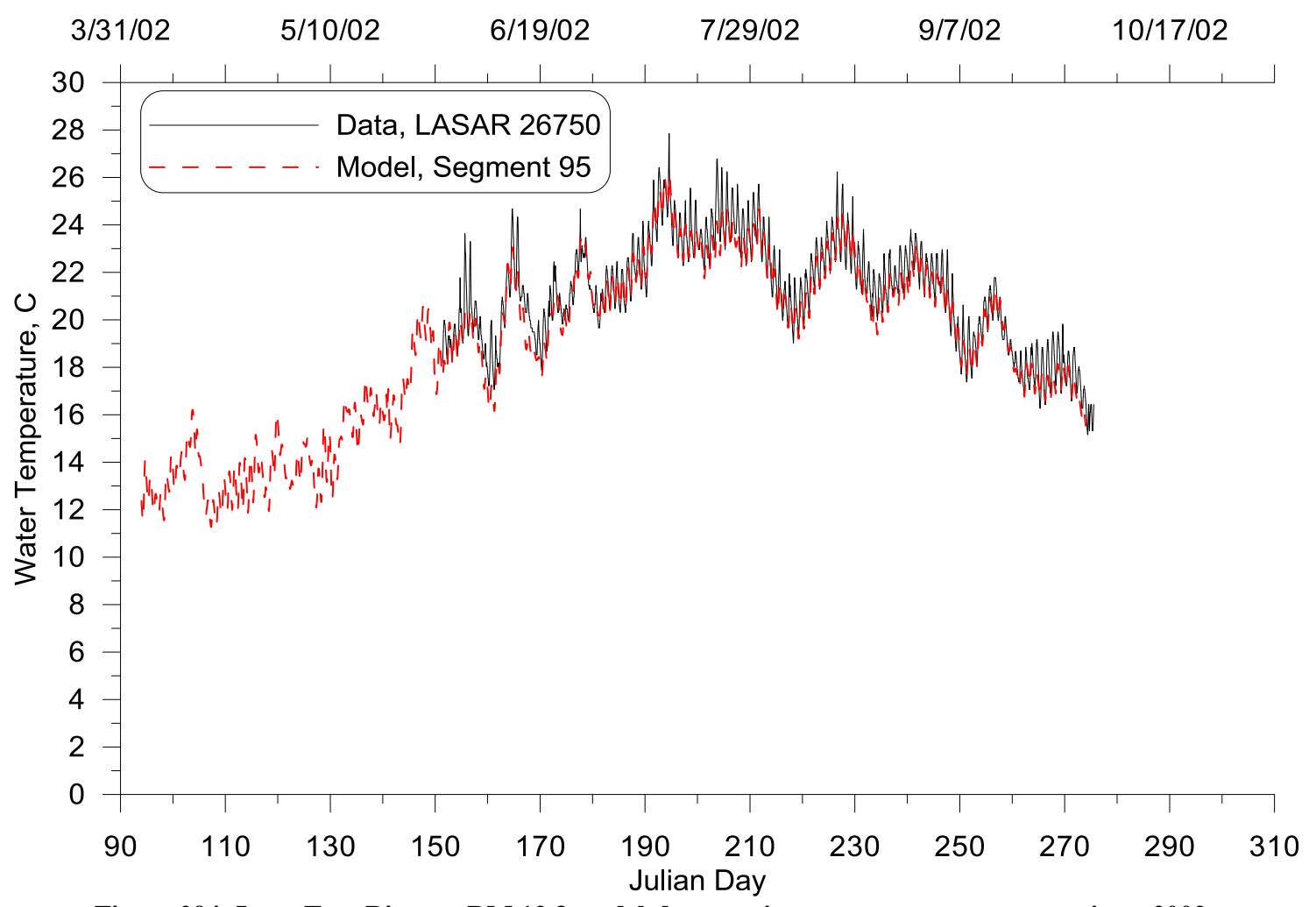

Figure 294: Long Tom River at RM 12.3 model-data continuous temperature comparison, 2002 


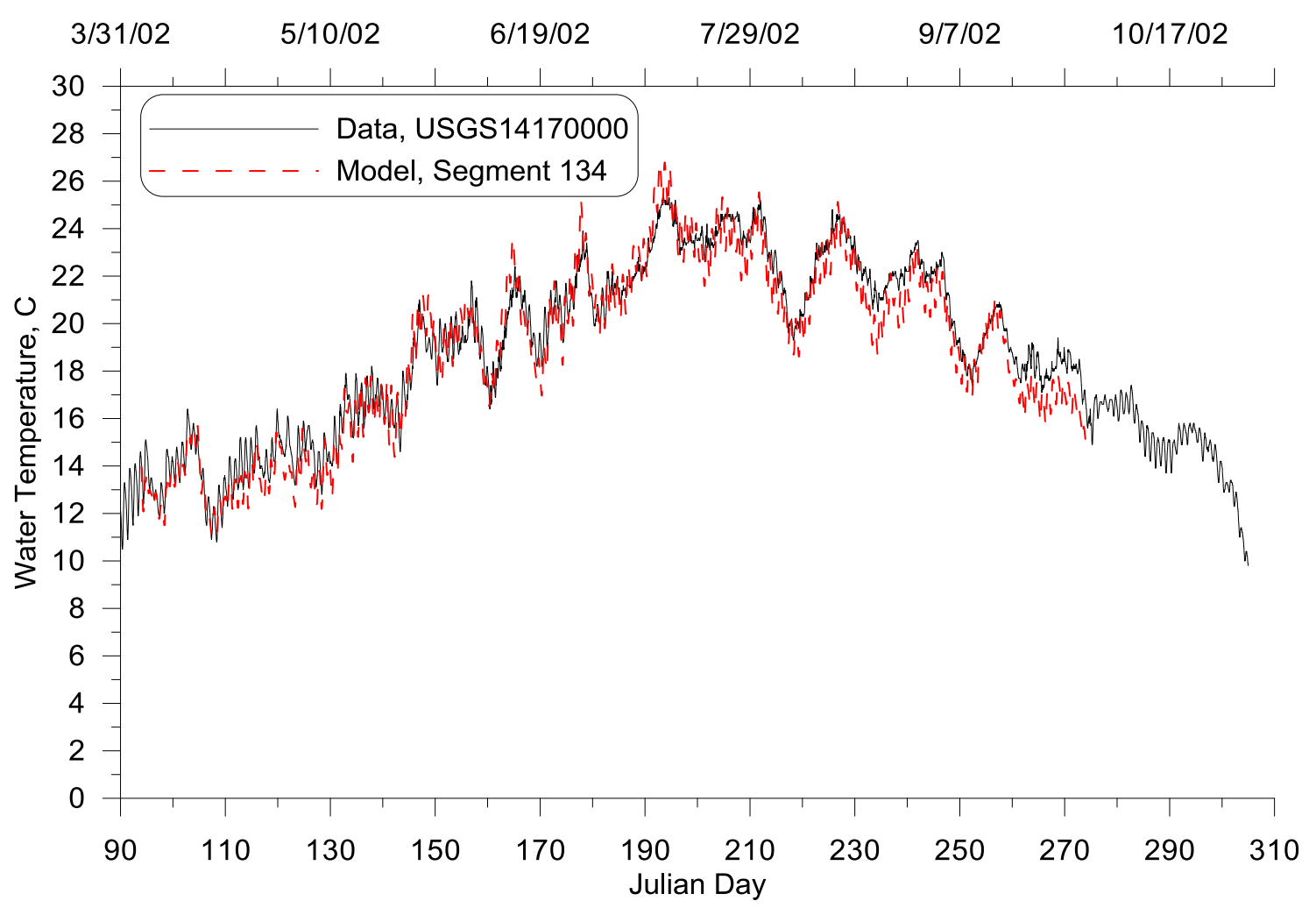

Figure 295: Long Tom River at Monroe model-data continuous temperature comparison, 2002

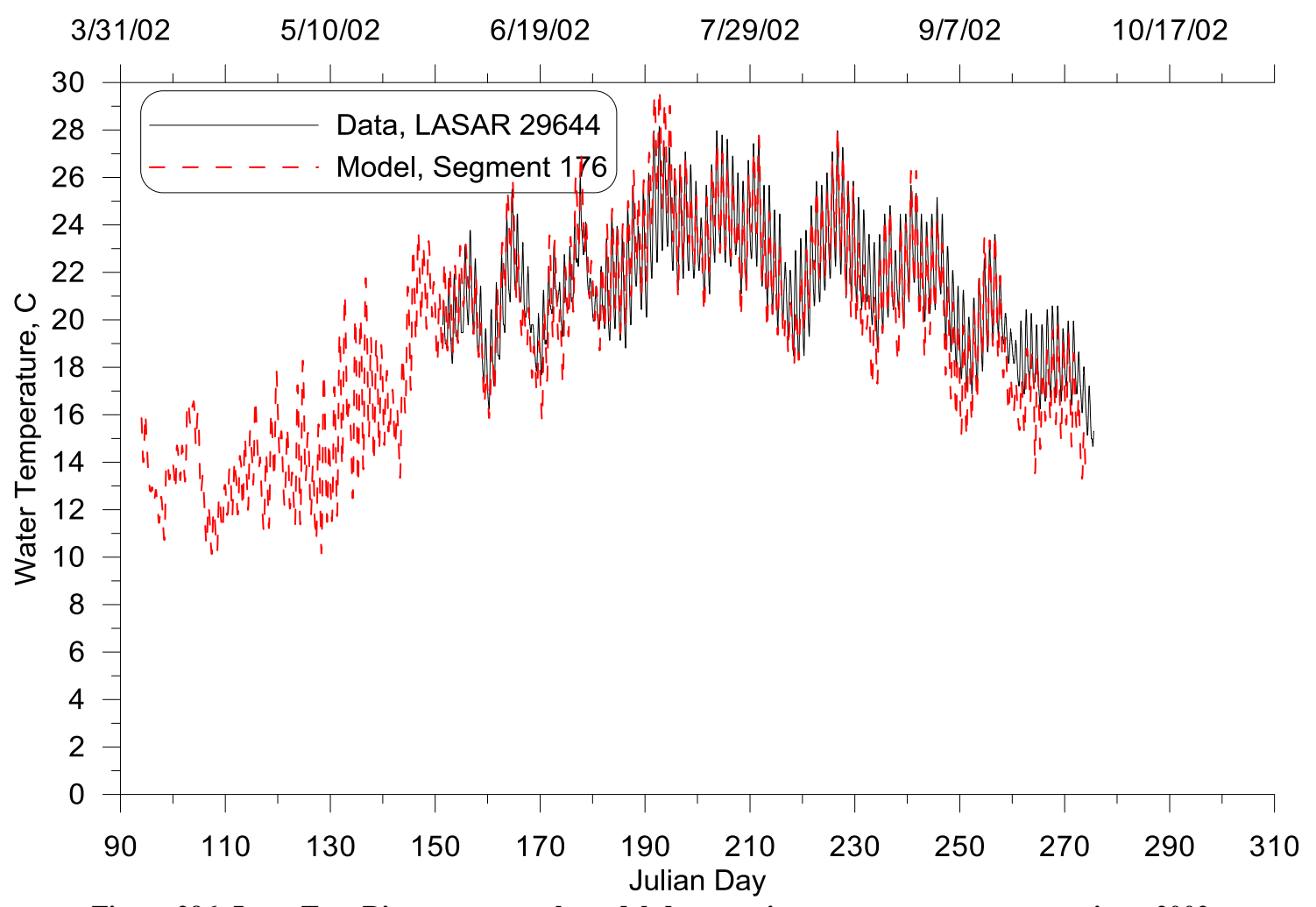

Figure 296: Long Tom River near mouth model-data continuous temperature comparison, 2002 


\section{Chapter 4 Summary and Conclusions}

This research presents (1) the conversion of Willamette River systems from CE-QUALW2 Version 3.1 to Version 3.7, (2) the development of a new hydrodynamic and temperature model which is based on CE-QUAL-W2 Version 3.7, and (3) testing of the new model.

In the first part of the research, six river models within the Willamette River Basin were converted from CE-QUAL-W2 Version 3.1 to Version 3.7. CE-QUAL-W2 Version 3.7 was proven to have the equivalent ability as Version 3.1 to achieve high-accuracy results of flow rate, water surface elevation and temperature on river applications, with the RMSE for continuous temperature model-data comparison below $1{ }^{\circ} \mathrm{C}$ for five out of the six river models. This research also found out that both CE-QUAL-W2 Version 3.1 and Version 3.7 ran relatively slow (up to several hours) for these six river models.

In the second part of the research, a new hydrodynamic and temperature model was developed based on CE-QUAL-W2 Version 3.7. The hydrodynamic calculation module was replaced with steady-state calculation methods. Water level was estimated using Manning's normal depth equation. Temperature was calculated using the same methods applied in CE-QUAL-W2 Version 3.7.

In the third part of the research, the newly developed model was tested on five river models in the Willamette River Basin. The calibration work is still ongoing for Middle Willamette River model and Upper Willamette River model, so only results from three river models are presented. This new model is assessed from the following three aspects: 


\section{Accuracy}

The continuous model-data error statistics of the Version 3.1 models, Version 3.7 models and steady-state models are summarized in Table 40. The steady-state models produced results similar to Version 3.1 models and Version 3.7 models. The increase in continuous model-data temperature RMSE did not exceed $0.2^{\circ} \mathrm{C}$. Sometimes the RMSE was smaller in the steady-state models than in Version 3.1 models and Version 3.7 models. The steady-state model has similar ability as the Version 3.1 and Version 3.7 models to achieve high-accuracy temperature predictions.

Table 40: Comparison of CE-QUAL-W2 Steady-State Model, CE-QUAL-W2 Version 3.1 and Version 3.7 temperature predictions accuracy on six river systems

\begin{tabular}{|c|c|c|c|c|c|}
\hline \multirow{2}{*}{$\begin{array}{c}\text { River System } \\
\text { Name }\end{array}$} & \multicolumn{2}{|c|}{ Simulation Period } & \multicolumn{3}{c|}{ Continuous Temperature RMSE Range ${ }^{\circ} \mathrm{C}$} \\
\cline { 4 - 6 } & 2001 & 183 days & $0.03-0.86$ & $0.02-1.03$ & $0.02-1.01$ \\
\hline \multirow{2}{*}{$\begin{array}{c}\text { Clackamas } \\
\text { River }\end{array}$} & 2002 & 183 days & $0.03-0.68$ & $0.03-0.71$ & $0.02-1.07$ \\
\cline { 2 - 6 } & 2001 & 148 days & $0.16-0.99$ & $0.16-0.89$ & $0.16-0.89$ \\
\hline $\begin{array}{c}\text { McKenzie } \\
\text { River }\end{array}$ & 2002 & 214 days & $0.16-0.76$ & $0.15-0.95$ & $0.18-0.78$ \\
\hline $\begin{array}{c}\text { Cersion 3.1 } \\
\text { Version 3.7 }\end{array}$ & $\begin{array}{c}\text { W2 Steady- } \\
\text { State }\end{array}$ \\
\hline $\begin{array}{c}\text { Long Tom } \\
\text { River }\end{array}$ & 2001 & 123 days & $0.04-1.07$ & $0.04-1.26$ & $0.04-0.95$ \\
\cline { 2 - 6 } & 2002 & 183 days & $0.05-1.16$ & $0.05-1.23$ & $0.05-1.30$ \\
\hline
\end{tabular}

\section{Stability}

Compared to the Version 3.7 models that are described in Chapter 2, the steady-state models are much more stable. The length of time step is no longer limited by stability issues with the hydrodynamics calculation, but only limited by stability issues with the temperature calculation. The maximum time steps in the three tested steady-state models 
ranged from 120 seconds to 180 seconds. The minimum time steps were generally set to 20 seconds which were used during flood events.

\section{Speed}

The CPU runtime of the steady-state model and Version 3.7 model for three river applications are summarized in Table 41. The estimated runtime for one year simulation using the steady-state model and Version 3.7 model is compared in Figure 297. The steady-state model is able to reduce computing time by up to $96 \%$.

Table 41: Comparison of CPU runtime of Steady-State Model and CE-QUAL-W2 Version 3.7 model for three river systems applications in 2001 and 2002

\begin{tabular}{|c|c|c|c|c|c|}
\hline \multirow{2}{*}{$\begin{array}{c}\text { River System } \\
\text { Name }\end{array}$} & \multirow{2}{*}{\multicolumn{2}{|c|}{ Simulation Period }} & \multicolumn{2}{|c|}{ CPU Runtime (minutes) } & \multirow{3}{*}{$\begin{array}{c}\begin{array}{c}\text { Time Reduce } \\
\text { by Fraction }\end{array} \\
90 \%\end{array}$} \\
\hline & & & \multirow{2}{*}{$\begin{array}{c}\text { CE-QUAL-W2 } \\
\text { version } 3.7 \\
17.6\end{array}$} & \multirow{2}{*}{$\begin{array}{c}\begin{array}{c}\text { Steady-state } \\
\text { model }\end{array} \\
1.7\end{array}$} & \\
\hline \multirow{2}{*}{ Clackamas River } & 2001 & 183 days & & & \\
\hline & 2002 & 183 days & 26.0 & 4.26 & $84 \%$ \\
\hline \multirow[t]{2}{*}{ McKenzie River } & 2001 & 148 days & 99.8 & 4.44 & $96 \%$ \\
\hline & 2002 & 214 days & 159.7 & 7.0 & $96 \%$ \\
\hline \multirow{2}{*}{ Long Tom River } & 2001 & 123 days & 4.84 & 1.91 & $61 \%$ \\
\hline & 2002 & 183 days & 7.21 & 4.33 & $40 \%$ \\
\hline
\end{tabular}




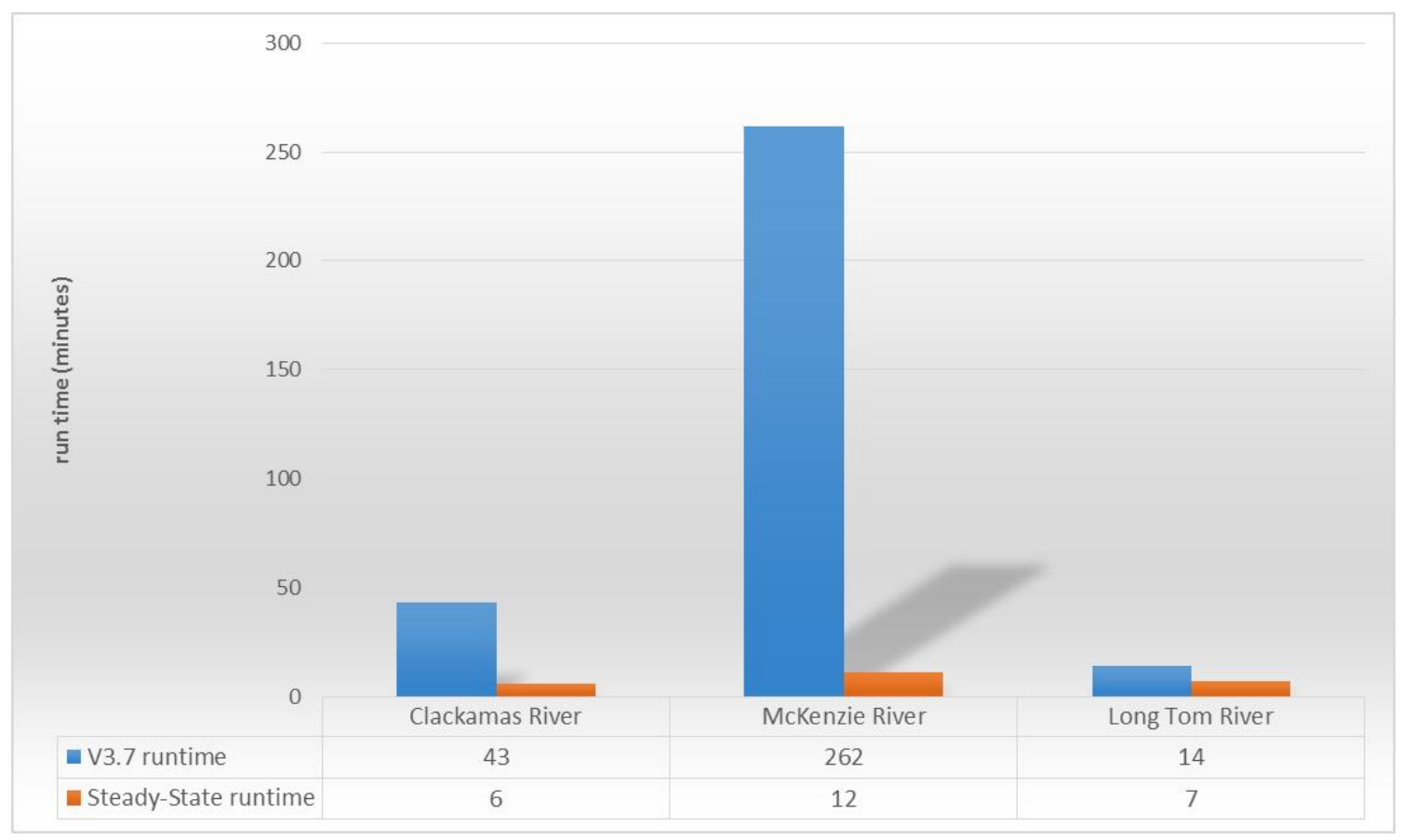

Figure 297: Comparison of estimated runtime for one year simulation using Steady-State Model and CE-QUALW2 Version 3.7

In summary, this new steady-state model is accurate, stable and fast. It not only meets the Willamette Water 2100 project requirements, but also has a great potential to be applied on other rivers around the world and to address river temperature concerns and fish habitat issues. 


\section{List of recommendations for future study}

\section{(1) Convert an existing CE-QUAL-W2 Version 3.7 model to steady-state model}

The detailed procedures to convert an existing CE-QUAL-W2 Version 3.7 model to steady-state model are described in Section 3.4.

It is easy to make changes in the control file to enable the steady-state executable to run, however re-calibration can be challenging for a new user. What if an existing Version 3.7 model is converted to steady-state without re-calibration? Figure 298 and Table 42 compared the results from Version 3.7, the steady-state model without re-calibration and the steady-state model after calibration. From Figure 298, the differences between results are not evident, because the temperature fluctuation during a day is bigger than difference between models. However, from Table 42, it is clear that without re-calibration the steady-state model results are not as accurate as the Version 3.7 model results, or the calibrated steady-state model results. The RMSE for continuous temperature model-data

comparisons can reach $1.3{ }^{\circ} \mathrm{C}$ in the un-calibrated steady-state model, while the RMSE is below $0.9^{\circ} \mathrm{C}$ in both calibrated Version 3.7 model and calibrated steady-state model. 


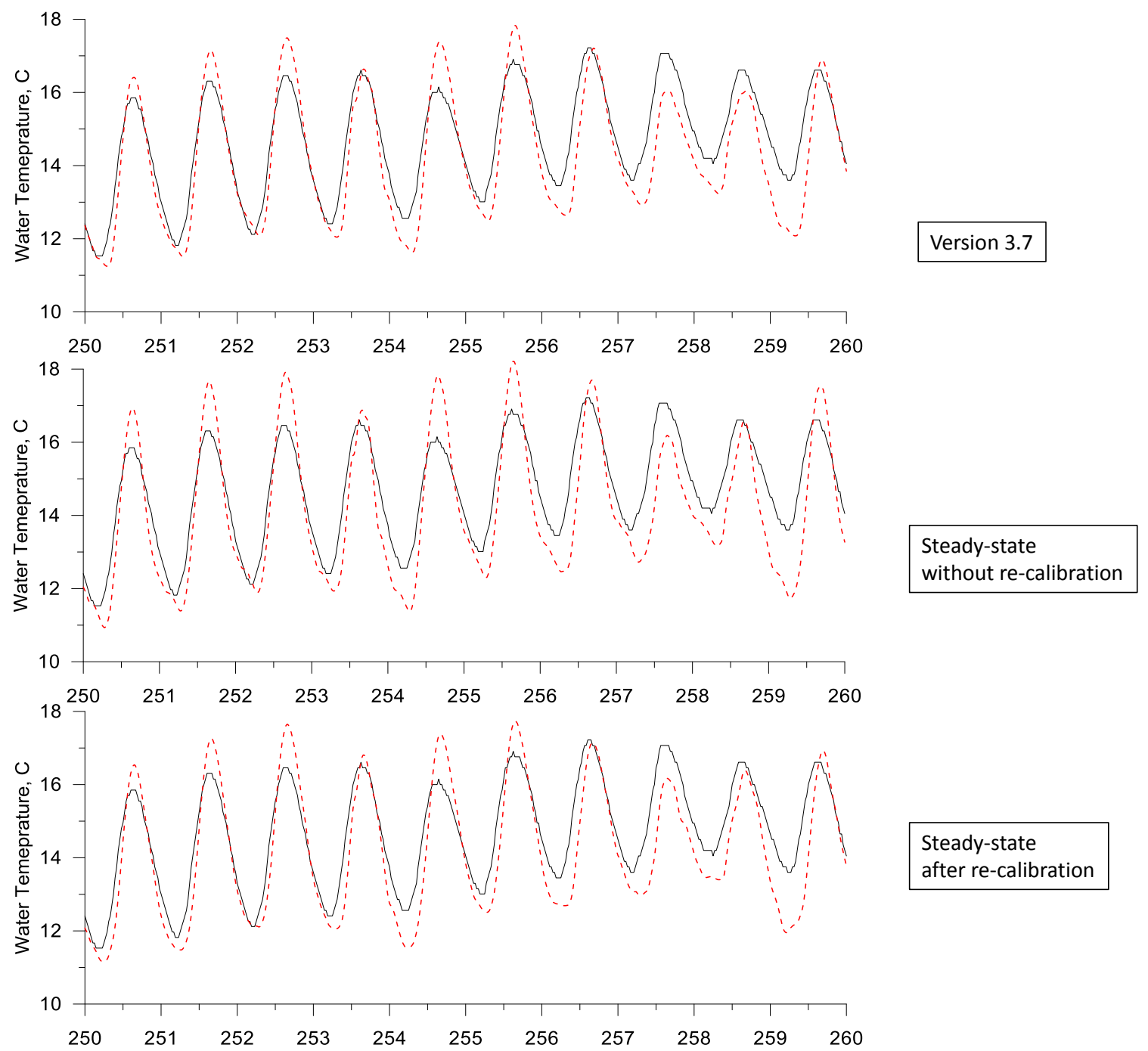

Figure 298: Continuous temperature comparison between models (red) VS data (black) at Segment 285 in McKenzie River model, 2001. From top down, the compared models are Version 3.7, steady-state model without re-calibration and steady-state model after calibration 
Table 42: McKenzie River continuous water temperature calibration model-data error statistics, 2001. From left to right, the compared models are Version 3.7, steady-state model without re-calibration and steady-state model after calibration

\begin{tabular}{|c|c|c|c|c|c|}
\hline \multirow[b]{2}{*}{ Site ID } & \multirow[b]{2}{*}{$\mathrm{RM}$} & \multirow[b]{2}{*}{$\begin{array}{c}\text { Model } \\
\text { Segment }\end{array}$} & \multicolumn{3}{|c|}{ Continuous Temperature RMSE, ${ }^{\circ} \mathrm{C}$} \\
\hline & & & Version 3.7 & $\begin{array}{l}\text { steady-state } \\
\text { model } \\
\text { without re- } \\
\text { calibration }\end{array}$ & $\begin{array}{l}\text { steady-state } \\
\text { model after } \\
\text { calibration }\end{array}$ \\
\hline USGS 14159500 & 60.39 & 4 & 0.164 & 0.117 & 0.163 \\
\hline LASAR 26770 & 50.99 & 65 & 0.673 & 0.741 & 0.67 \\
\hline USGS 14162500 & 44.56 & 108 & 0.618 & 0.75 & 0.616 \\
\hline LASAR 25610 & 35.72 & 167 & 0.89 & 1.273 & 0.886 \\
\hline LASAR 25612 & 30.38 & 203 & 0.884 & 1.301 & 0.882 \\
\hline LASAR 26758 & 28.45 & 215 & 0.822 & 1.157 & 0.819 \\
\hline USGS 14163900 & 24.97 & 240 & 0.763 & 0.969 & 0.761 \\
\hline LASAR 25614 & 17.90 & 285 & 0.757 & 0.902 & 0.757 \\
\hline LASAR 26757 & 15.61 & 299 & 0.79 & 0.909 & 0.789 \\
\hline LASAR 25611 & 35.78 & 402 & 0.817 & 1.201 & 0.813 \\
\hline LASAR 25613 & 30.27 & 431 & 0.87 & 1.232 & 0.867 \\
\hline
\end{tabular}

(2) Vertical diffusion coefficient

The current steady-state model has a problem with vertical diffusion. Giving this coefficient a value instead of zero resulted in inaccurate temperature prediction. However, setting this coefficient to zero means that there is no vertical diffusion between layers which is not true. The problem should be examined in future study.

\section{(3) The effects of irregularity in the grid}

In the steady-state model, as Manning's equation assumes steady flow, the water level is higher at segments with narrower width or higher river bed than the surrounding segments. However in the real world, critical flow condition may occur at segments with smaller cross-sections, where longitudinal velocity is bigger than velocity at regular cross-section and water level is accordingly lower. 
The following three scenarios show how the steady-state model deals with irregularity in the model grid. The slope of the three-segment branch is 0.00001 . Segment length is 250 meters, and layer thickness is 1 meter.

In the first scenario, the three segments have the same cross-section shape. The side view of this branch is shown in Figure 299. Given a specific flow rate, the water surface elevations in the three segments are very close to each other.

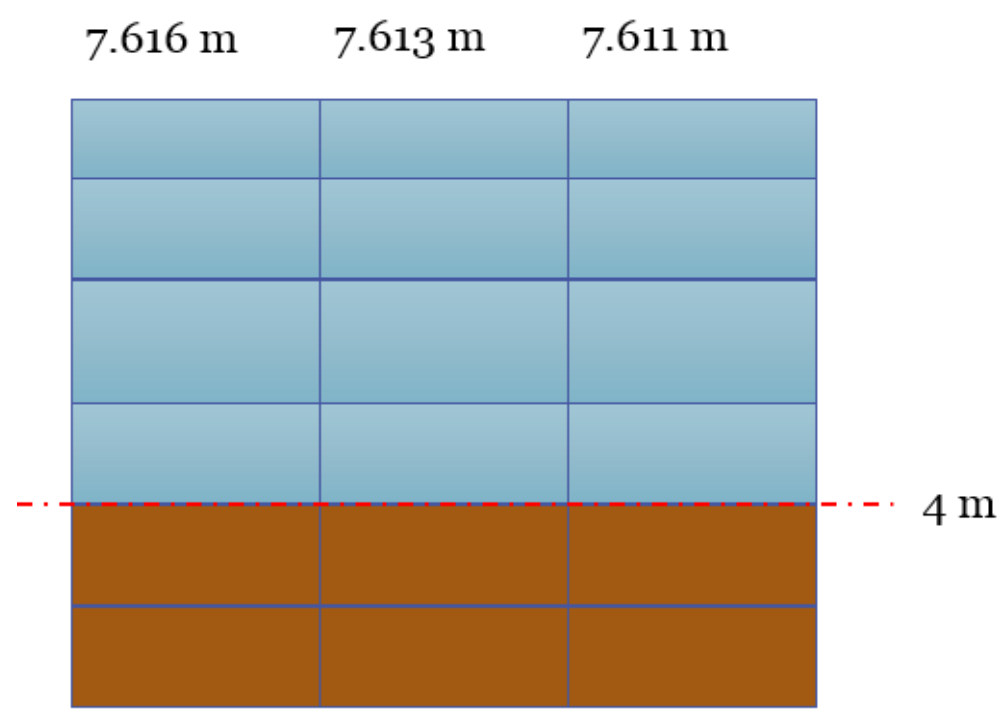

Segment 1 Segment 2 Segment 3

Figure 299: Side view of the example branch with even grid

In the second scenario, all other conditions are the same as the first scenario except that second segment have a higher river bed, as is shown in Figure 300. This results in a higher water surface elevation in the second segment. Because of the smoothing algorithm, the water surface elevation in the first segment is equal to the second segment. 


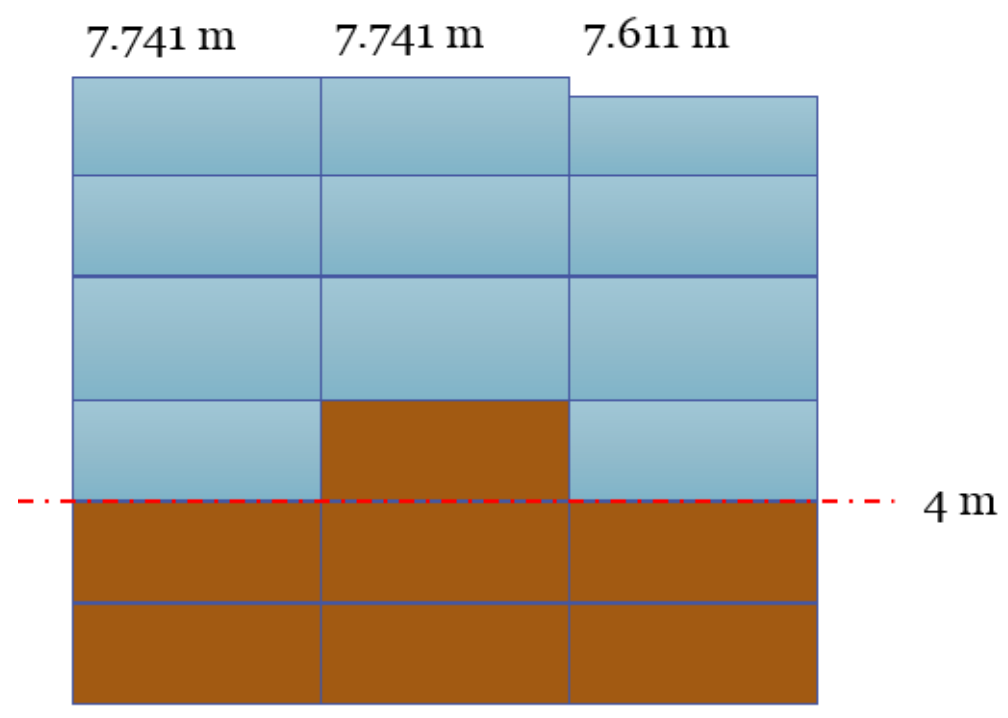

Segment 1 Segment 2 Segment 3

Figure 300: Side view of the example branch with higher river bed in the middle

In the third scenario, all other conditions are the same as the first scenario except that second segment has a lower river bed, as is shown in Figure 301. The water surface elevation in the second segment is equal to the third segment.

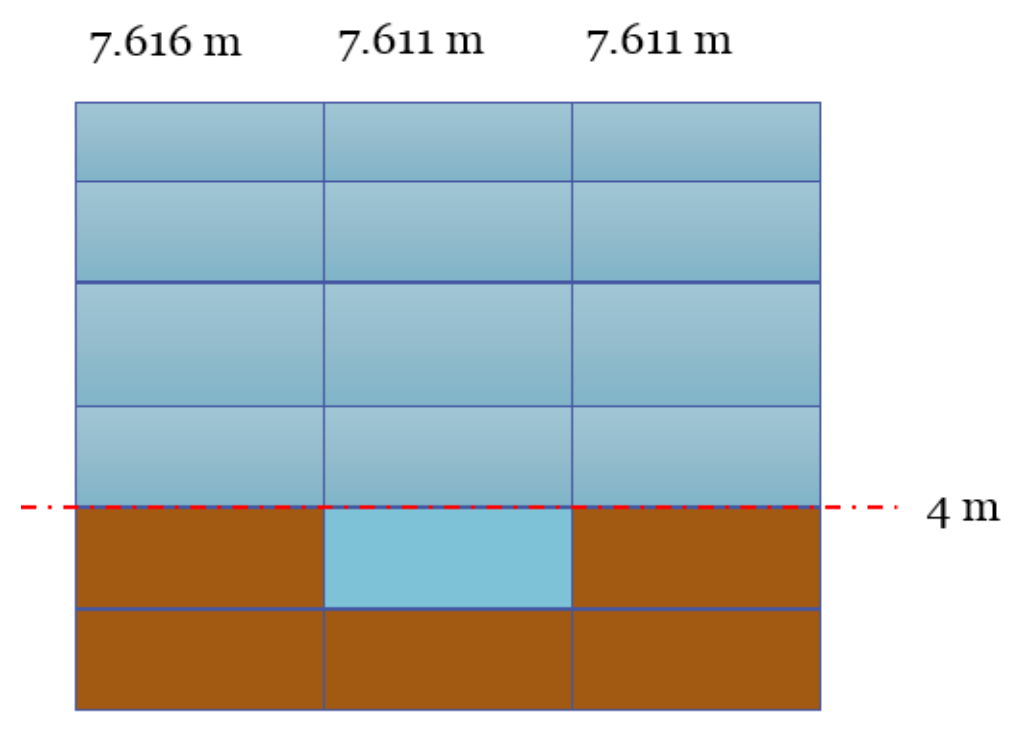

Segment 1 Segment 2 Segment 3

Figure 301: Side view of the example branch with lower river bed in the middle 


\section{(4) Explore new smoothing algorithm for branches with small slope or slope equals}

zero

First, the steady-state model has issues when the small slope (e.g., slope $=0.00001)$ and uneven underwater topography coexist. As is shown in the example above, a segment with narrow width or high river bed may raise up the water level upstream.

Second, the steady-state model would not work with branches where slope equals zero because Manning's equation calculates water level basing on slope.

To solve the two problems above, a new smoothing algorithm is needed. The smoothing algorithm used in the current steady-state model is described in Section 3.2.3. The new smoothing algorithm may fit a polynomial for a long section of segments.

\section{(5) Codes to ensure stability}

It was noticed in the steady-state model that even when the model encountered stability issues and the predicted temperature output was not a number ("NaN"), the model was still running. Some codes should be written to ensure a warning when the model encountered stability issues.

\section{(6) Season and time step}

All the three river systems have only been tested for part of the year. Most of the system simulation periods include summer and some include spring and fall, but none of them include winter. 
In winter and spring, flow rate is generally higher than the rest of the year in the Pacific Northwest, and time steps should be considerably smaller so that the calculation can be stable. Special attention should be paid to search for potential stability problems in the future simulation.

\section{(7) Water quality modules}

As long as the steady-state model is able to model flow rate, water level and temperature, the next step would be adding the water quality modeling capacity to this model. CEQUAL-W2 Version 3.7 is able to model 34 water quality constituents. Information about water quality should be gathered, so that the water quality constituents that need to be included in the model can be determined.

\section{(8) Use team based approach to new model development}

New model development is a challenging endeavor. It takes much time and effort to construct a new model with several complicated and interrelated parts, and it takes even more time and effort to make the model sound and robust. Team based approach is used by industries for new product development. This approach integrates different individuals' intelligence and perspective toward problem solving. There is a potential to utilize team based approach to develop new models in universities. 


\section{Reference}

Berger, C. J., McKillip, M. L., Annear, R. L., Khan, S. J., \& Wells, S. A. (2004). Willamette River Basin temperature TMDL model-Model calibration. Portland State University, Department of Civil and Environmental Engineering. Portland, Oregon.

Boyd, M., and Kasper, B. (2003). Analytical methods for dynamic open channel heat and mass transfer: Methodology for heat source model Version 7.0. Oregon Department of Environmental Quality, Portland, Oregon.

Chapra, S. C. (1997). Surface water-quality modeling (Vol. 1). New York: McGraw-Hill.

Chapra, S.C., G.J. Pelletier, and H. Tao. (2006). QUAL2K: A Modeling Framework for Simulating River and Stream Water Quality, Version 2.04: Documentation and User's Manual. Civil and Environmental Engineering Department, Tufts University, Medford, MA.

Cole, T., and Wells S. (2000) CE-QUAL-W2: A Two-Dimensional, Laterally Averaged, Hydrodynamic and Water Quality Model, Version 3.0. Instruction Report EL-001. Waterways Experiments Station, U.S. Army Corps of Eng., Vicksburg, MS.

Cole, T. and Wells, S. (2011) CE-QUAL-W2: A Two-Dimensional, Laterally Averaged, Hydrodynamic and Water Quality model, Version 3.7. Department of Civil and Environmental Engineering, Portland State University, Portland, OR. 
Danish Hydraulics Institute (1993) MIKE11: User Guide and Reference Manual. Danish Hydraulics Institute, Horsholm, Denmark.

Danish Hydraulic Institute (1996) MIKE21: User Guide and Reference Manual. Danish Hydraulic Institute, Horsholm, Denmark.

Drake, J., Bradford, A., \& Joy, D. (2010). Application of HEC-RAS 4.0 temperature model to estimate groundwater contributions to Swan Creek, Ontario, Canada. Journal of Hydrology, 389(3), 390-398.

Environmental Laboratory, 1995. CE-QUAL-RIV1: A Dynamic, One Dimensional (Longitudinal) Water Quality Model for Streams User's Manual. US Army Corps of Engineers, Waterway Experiment Station, MS, USA.

Elliott, J. M. (1981). Some aspects of thermal stress on freshwater teleosts. Stress and fish, 209, 245.

Hamrick, John M., William B. (2000) Mills, Analysis of water temperatures in Conowingo Pond as influenced by the Peach Bottom atomic power plant thermal discharge, Environmental Science \& Policy, Volume 3, 197-209

Brunner, G. W. (2010). HEC-RAS River Analysis System: User's Manual. US Army Corps of Engineers, Institute for Water Resources, Hydrologic Engineering Center. 
Metcalfe, N. B., Fraser, N. H., \& Burns, M. D. (1999). Food availability and the nocturnal vs. diurnal foraging trade - off in juvenile salmon. Journal of Animal Ecology, 68(2), 371-381.

Norton, G. E., \& Bradford, A. (2009). Comparison of two stream temperature models and evaluation of potential management alternatives for the Speed River, Southern Ontario. Journal of environmental management, 90(2), 866-878.

Parkinson, S. K. (2002). Project hydrology and hydraulic models applied to the Hells Canyon Reach of the Snake River. Technical Report E. 1-4 in License application for the Hells Canyon Complex. Idaho Power Company, Boise, ID.

Poole, G. C., \& Berman, C. H. (2001). An Ecological Perspective on In-Stream Temperature: Natural Heat Dynamics and Mechanisms of Human-Caused Thermal Degradation. Environmental management, 27(6), 787-802.

Press, W. H. (1992). Numerical recipes in Fortran 77: the art of scientific computing (Vol. 1). Cambridge university press.

Rivers-Moore, N. A., \& Lorentz, S. S. (2004). A simple, physically-based statistical model to simulate hourly water temperatures in a river. South African Journal of Science, 100(7/8), 331-333.

Santelmann M, McDonnell JJ, Bolte J, Chan S, Morzillo AT, Hulse D, Wright M. (2012). Willamette Water 2100: river basins as complex socio-ecological systems. Paper presented at the First International Conference on Water and Society, 155:575586. 
Sahoo, G. B., Schladow, S. G., \& Reuter, J. E. (2009). Forecasting stream water temperature using regression analysis, artificial neural network, and chaotic nonlinear dynamic models. Journal of Hydrology, 378(3/4), 325-342.

Sullivan, A. B., \& Rounds, S. (2004). Modeling Stream Flow and Water Temperature in the North Santiam and Santiam Rivers, Oregon, 2001-02. US Department of the Interior, US Geological Survey.

Theurer, F. D., Voos, K. A., \& Miller, W. J. (1985). Instream water temperature model (No. 16). Western Energy and Land Use Team, Division of Biological Services, Research and Development, Fish and Wildlife Service, US Department of the Interior.

Von Stackelberg, N. O., \& Neilson, B. T. (2012). A Collaborative Approach to Calibration of a Riverine Water Quality Model. Journal of Water Resources Planning and Management, doi: 10.1061/(ASCE)WR.1943-5452.0000332

Younus, M., Hondzo, M., \& Engel, B. A. (2000). Stream temperature dynamics in upland agricultural watersheds. Journal of Environmental Engineering, 126(6), 518-526. 


\title{
Appendix A: The steady-state model FORTRAN source code
}

\author{
w2_37_win.f90 \\ ! CE-QUAL-W2 computations \\ INTEGER(4) FUNCTION CE_QUAL_W2 (DLG) \\ ! IVF/CVF specific code \\ USE DFLOGM; USE MSCLIB; USE DFWIN, RENAMED => DLT; \\ !DEC\$ATTRIBUTES STDCALL :: ce_qual_w2 \\ !DEC $\$ A T T R I B U T E S$ REFERENCE :: $\bar{D}$ lg \\ USE IFPORT ! to get current working directory \\ USE MAIN \\ USE GLOBAL; USE NAMESC; USE GEOMC; USE LOGICC; USE PREC; USE SURFHE; USE KINETIC; \\ USE SHADEC; USE EDDY \\ USE STRUCTURES; USE TRANS; USE TVDC; USE SELWC; USE GDAYC; USE SCREENC; USE TDGAS; \\ USE RSTART \\ USE MACROPHYTEC; USE POROSITYC; USE ZOOPLANKTONC \\ USE INITIALVELOCITY; USE ENVIRPMOD \\ USE BIOENERGETICS \\ ! include "omp_lib.h" ! OPENMP directive to adjust the \# of processors TOGGLE FOR DEBUG \\ IMPLICIT NONE \\ EXTERNAL RESTART OUTPUT \\ TYPE (DIALOG) $::$ DLG \\ INTEGER :: RESULT, KTMAX \\ REAL :: DEPTH, XAREA, WSURF !XAREA WX5/23/13

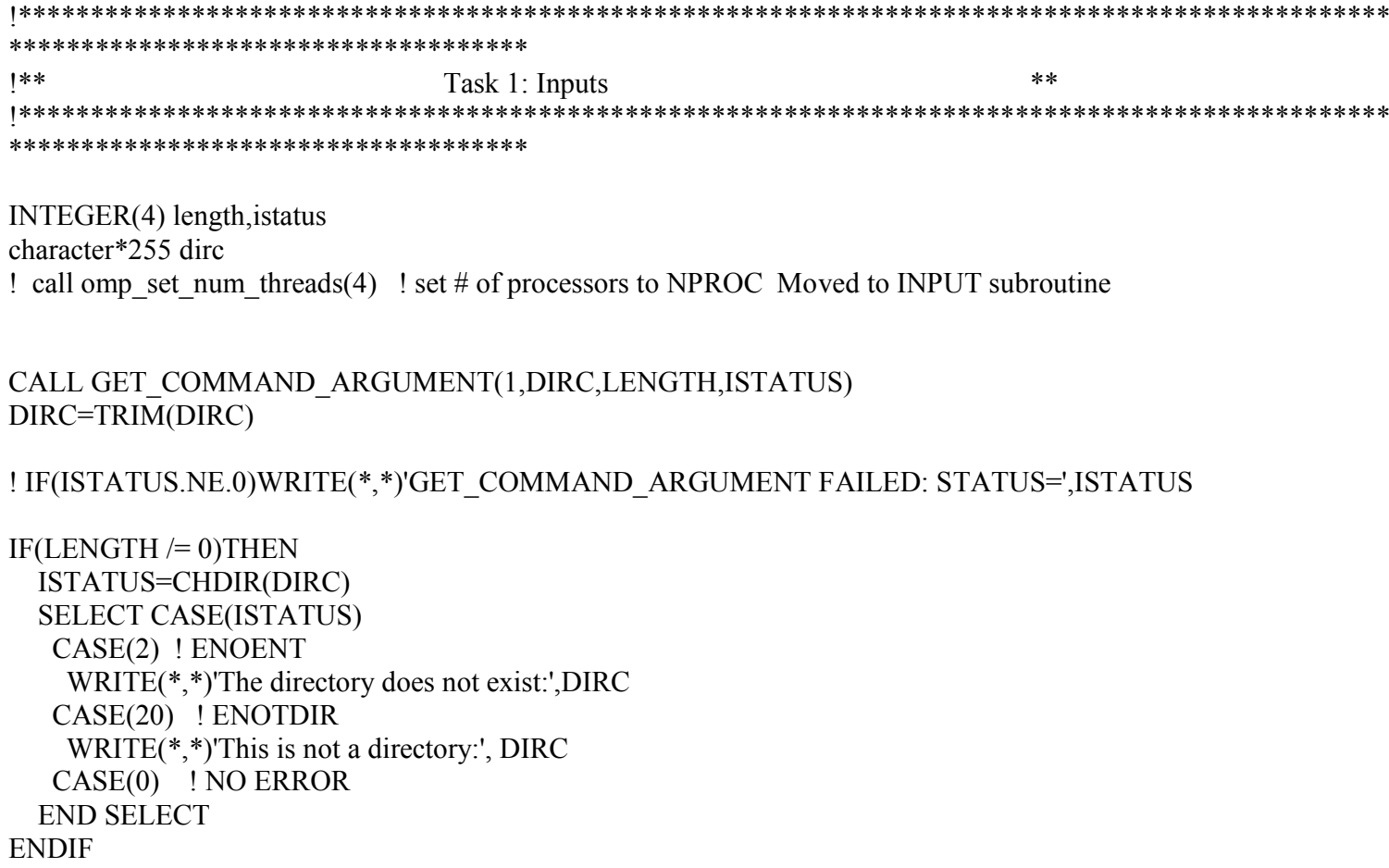




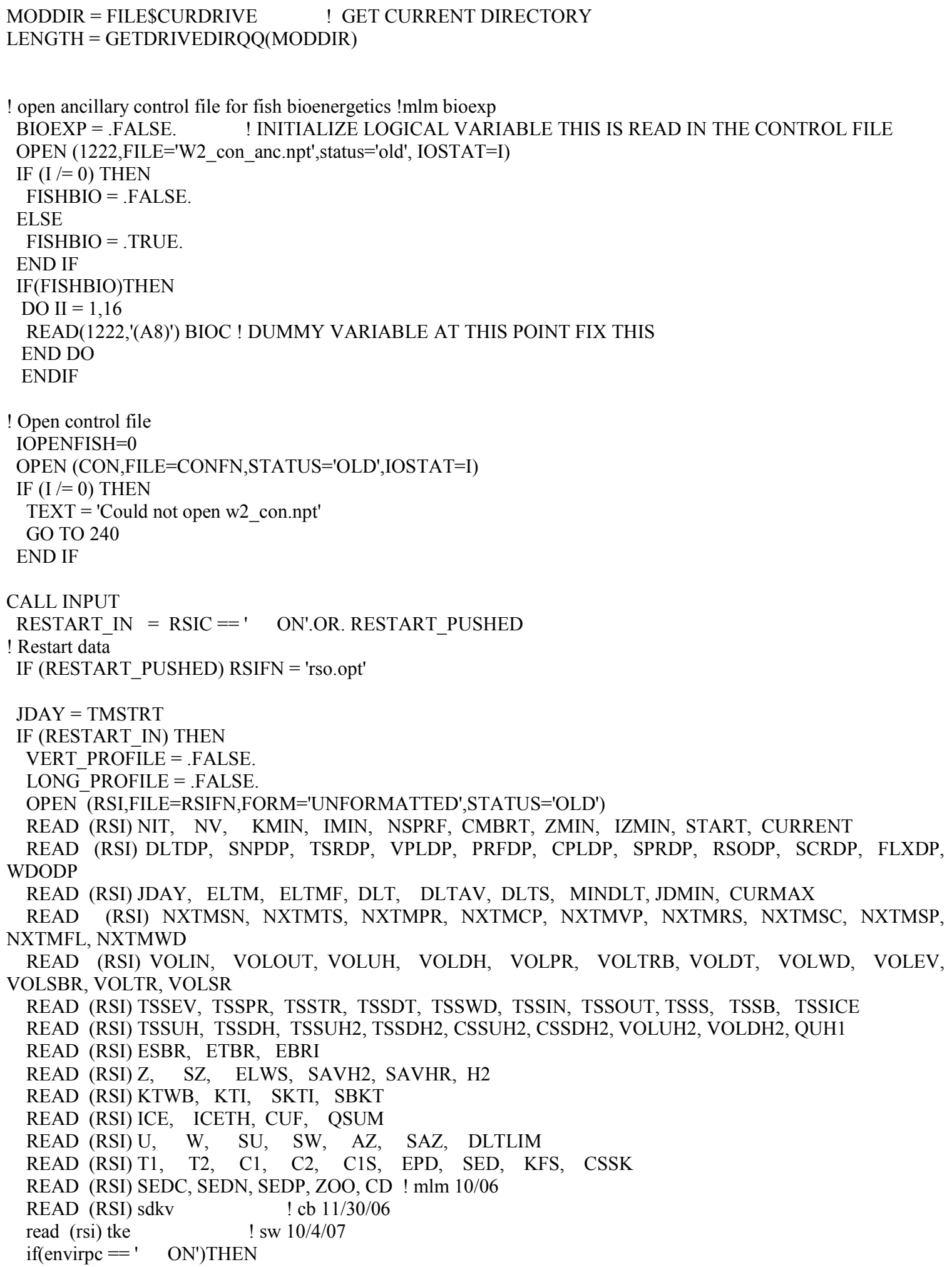


allocate(cc_e(NCT),c_int(NCT),c_top(NCT),cd_e(NDC),cd_int(NDC),cd_top(NDC),c_avg(NCT),cd_avg(NDC),cn_e( $\left.\mathrm{NCT}), \mathrm{cdn} \_\mathrm{e}(\mathrm{NDC})\right)$

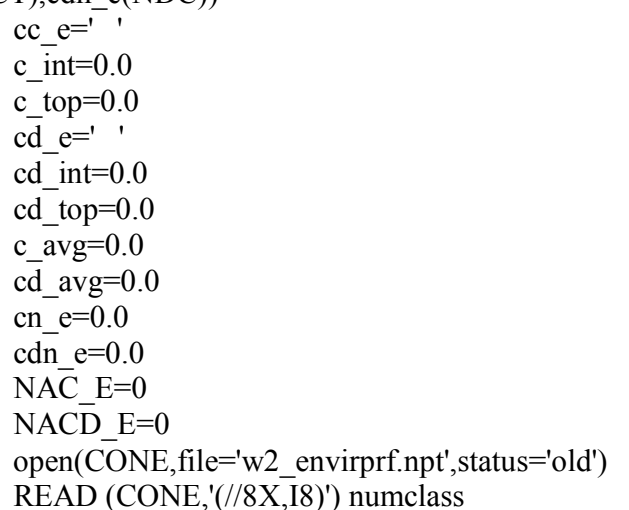

READ (CONE,'(//8X,I8)') numclass

Read (CONE,'(//8x,2(5x,a3,f8.3,f8.3))') VEL_VPR, VEL INT, VEL TOP,TEMP VPR,TEMP INT,TEMP TOP

READ (CONE,'(//(8X,(5X,A3,F8.0,F8.0)) )') (CC E(JC), C INT(JC), C TOP(JC), JC=1,NCT)

READ (CONE,'(//(8X,(5X,A3,F8.0,F8.0)))') (CD_E(JD),CD_INT(JD), CD_TOP(JD), JD=1,NDC)

close $(\mathrm{CONE})$

DO JC $=1, \mathrm{NCT}$

IF (CC_E(JC).EQ.' ON') THEN

NAC $\bar{E}=$ NAC E +1

CN_E(NAC_E $)=\overline{J C}$

END IF

End DO

$\mathrm{DO} \mathrm{JD}=1, \mathrm{NDC}$

IF (CD E(JD).EQ.' ON') THEN

NACD_E $=$ NACD_E+1

CDN_E(NACD_E $)=J D$

END IF

End DO

allocate

(c_cnt(NCT),cd_cnt(NDC),c_class(NCT,numclass),cd_class(NDC,numclass), c_tot(NCT),cd_tot(NDC),t_class(numcla

ss),v_class(numclass),c_sum(NCT),cd_sum(NDC))

allocate (conc_c(NCT,numclass),conc_cd(NDC,numclass))

READ(RSI)T_CLASS,V_CLASS,C_CLASS,CD_CLASS,T_TOT,T_CNT,SUMVOLT,V_CNT,V_TOT,C_TOT,C_C NT,CD_TOT,CD_CNT

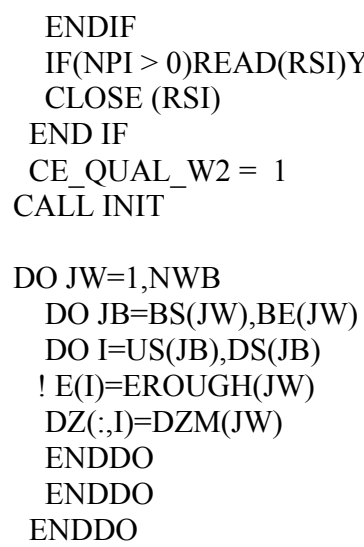

!WX 11/27/2012 


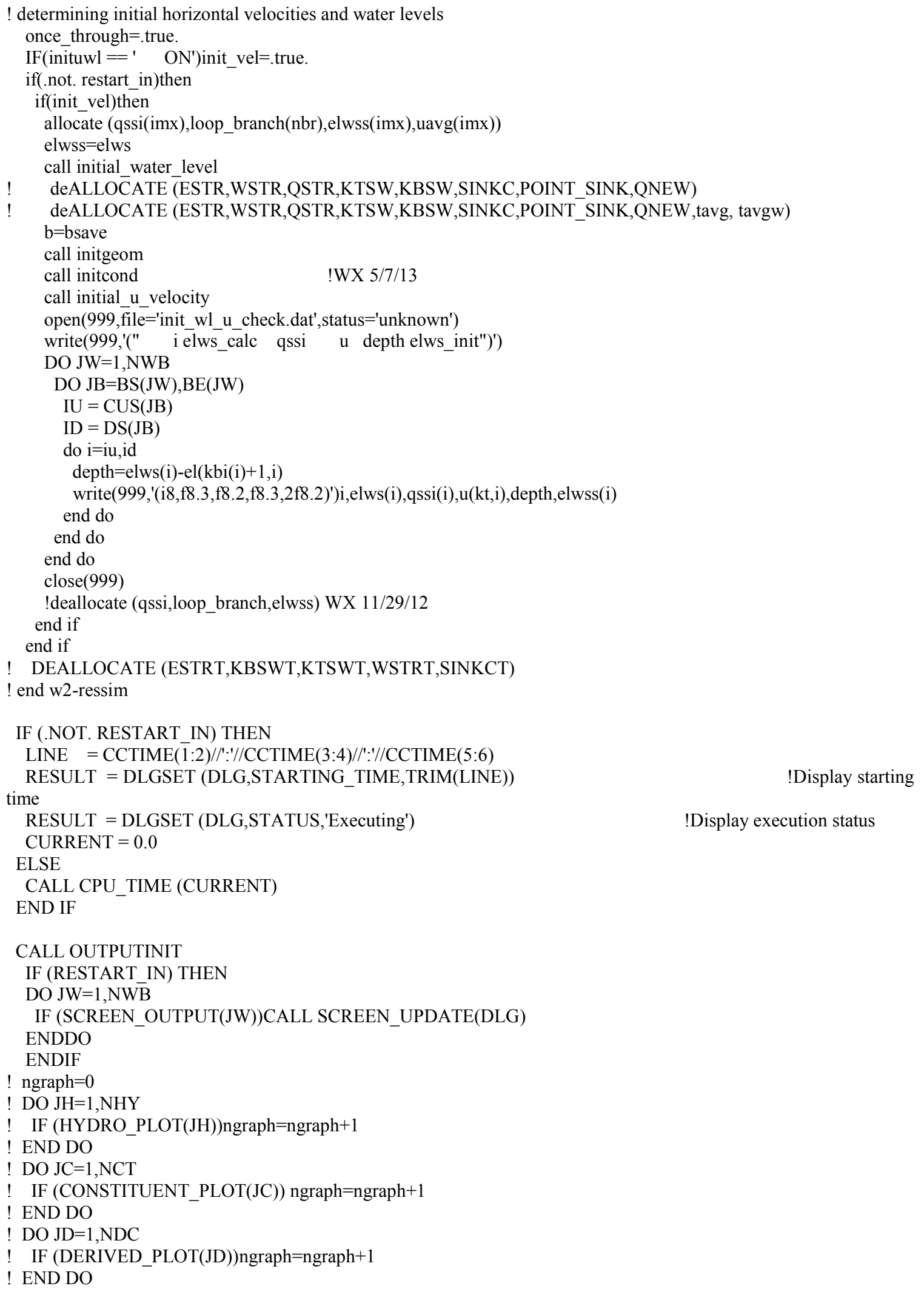




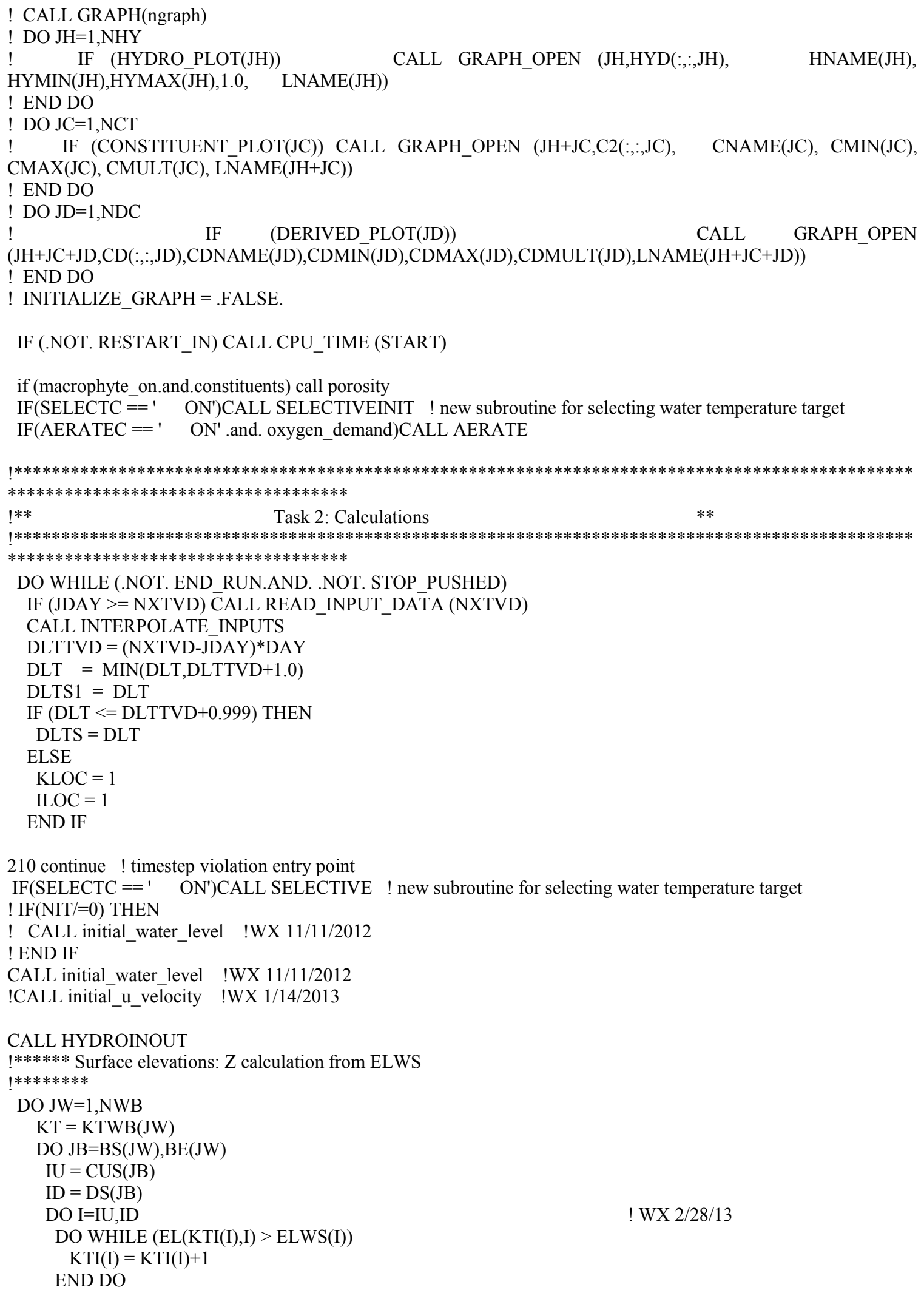




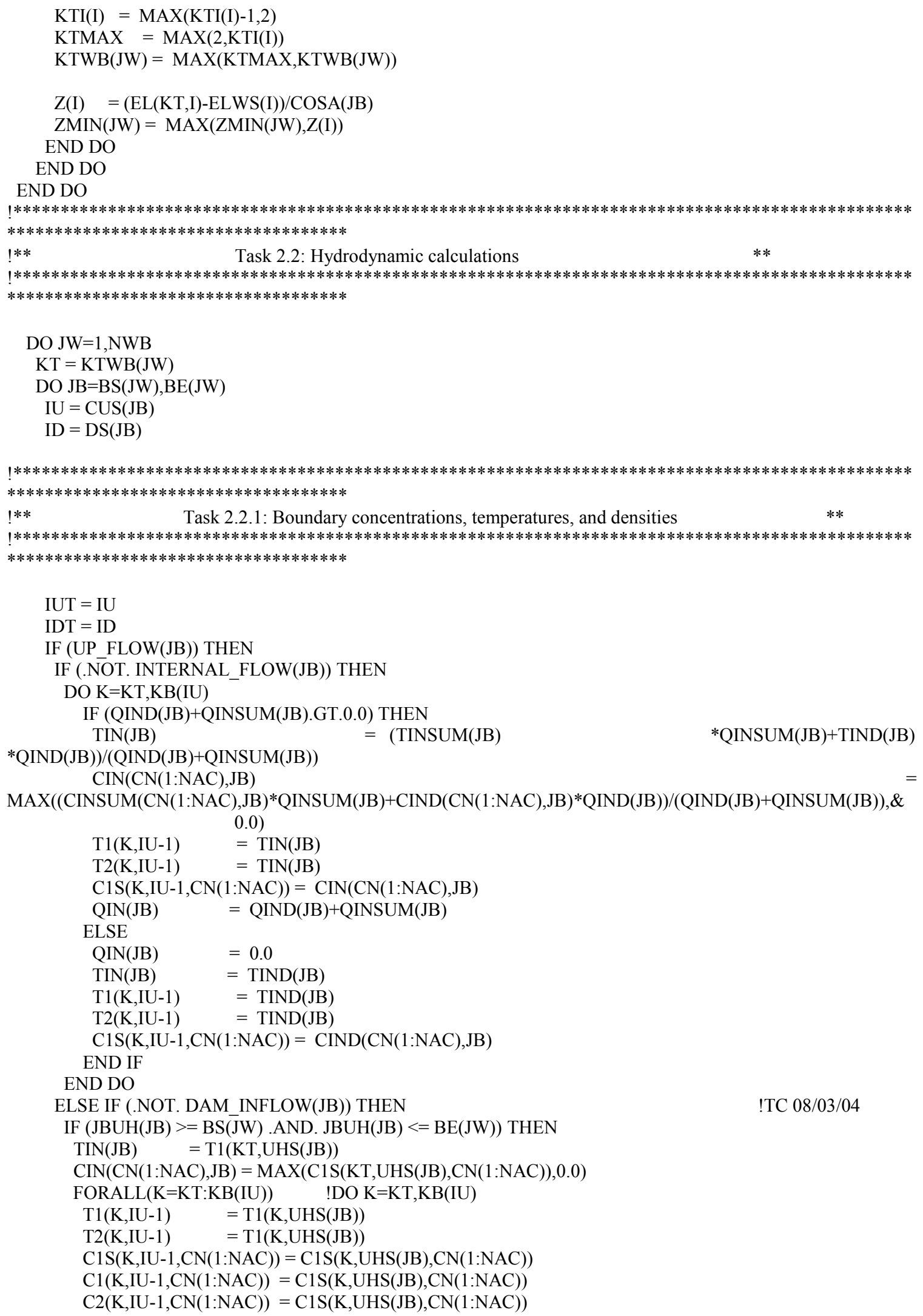




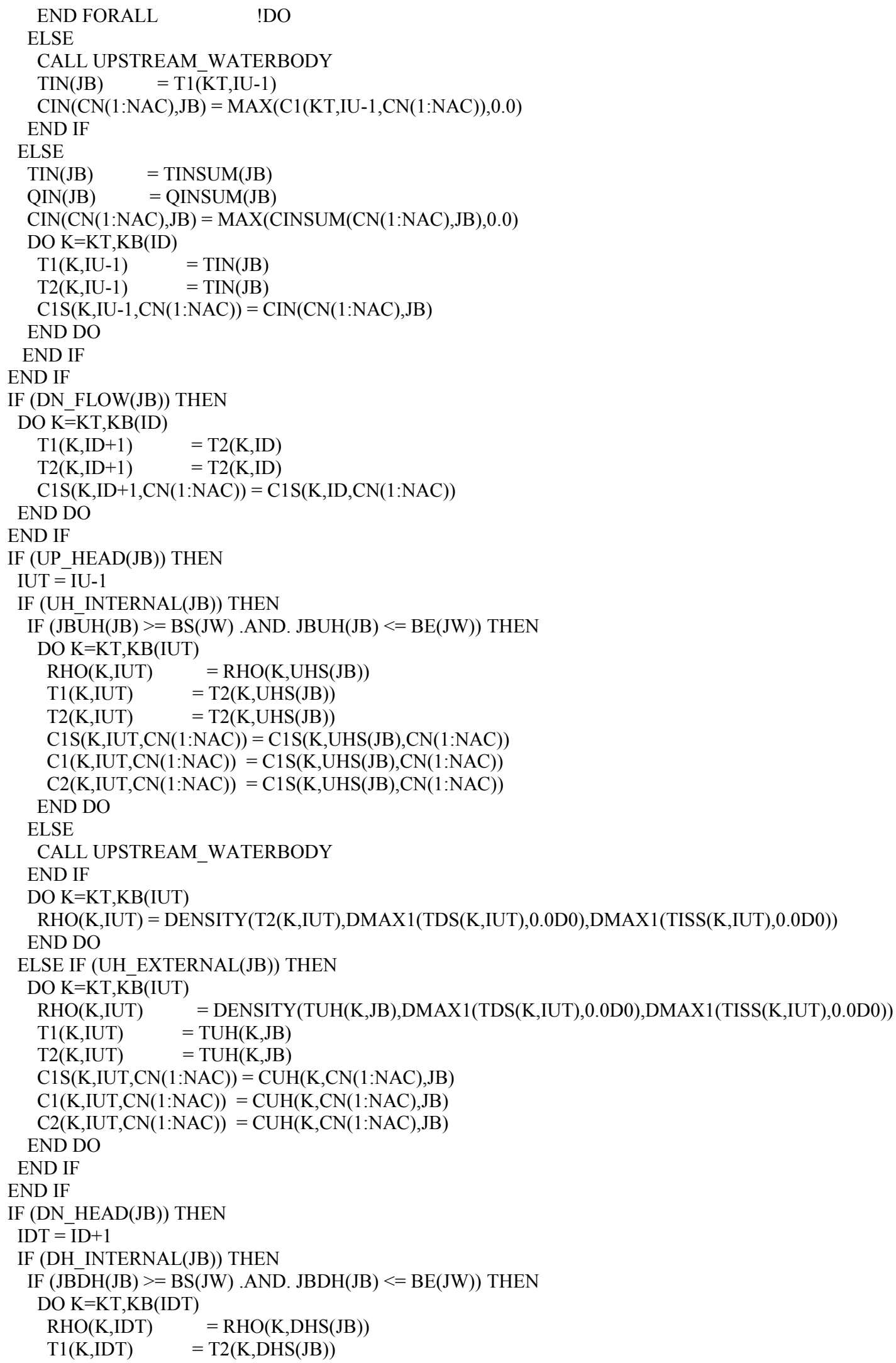




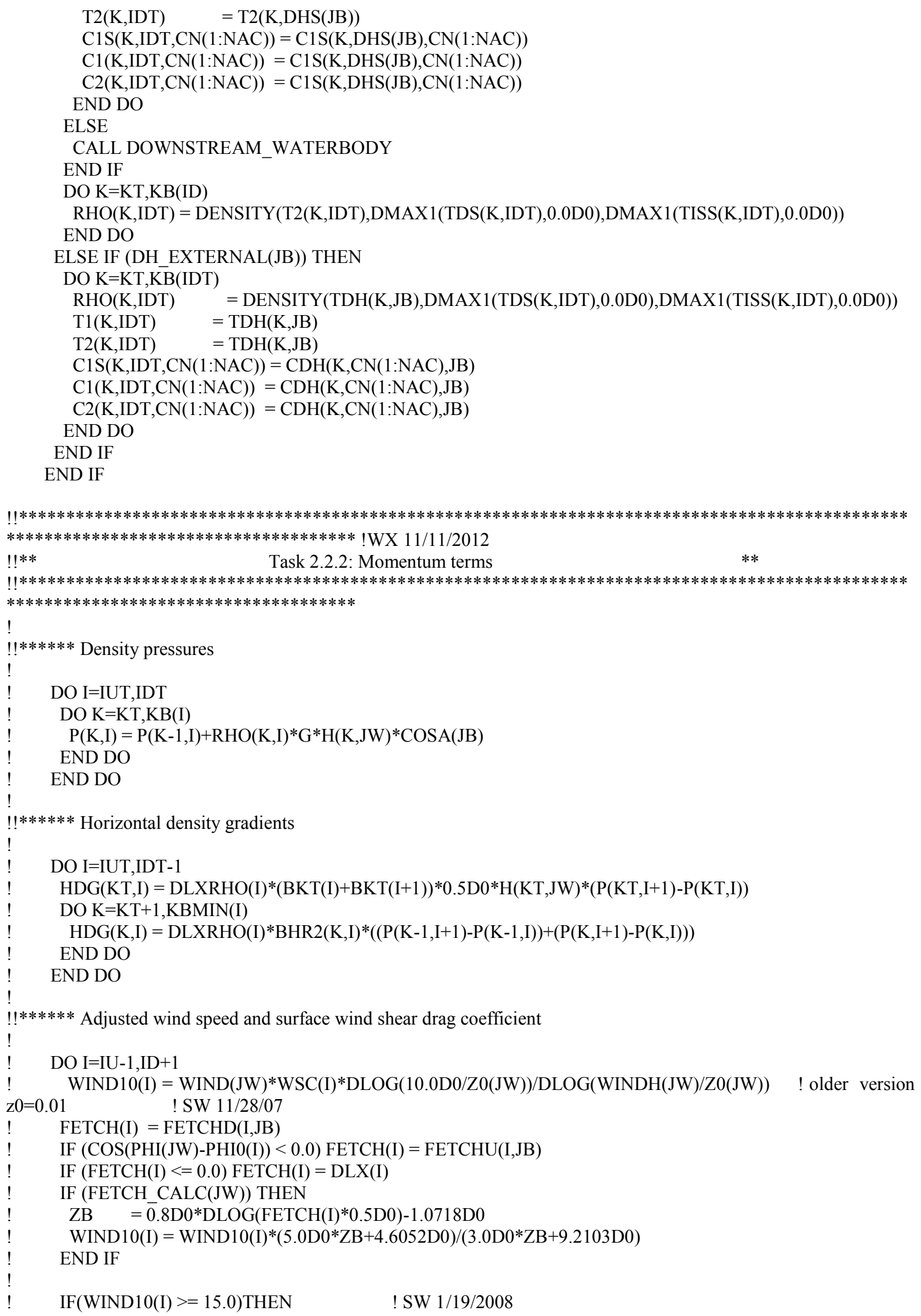




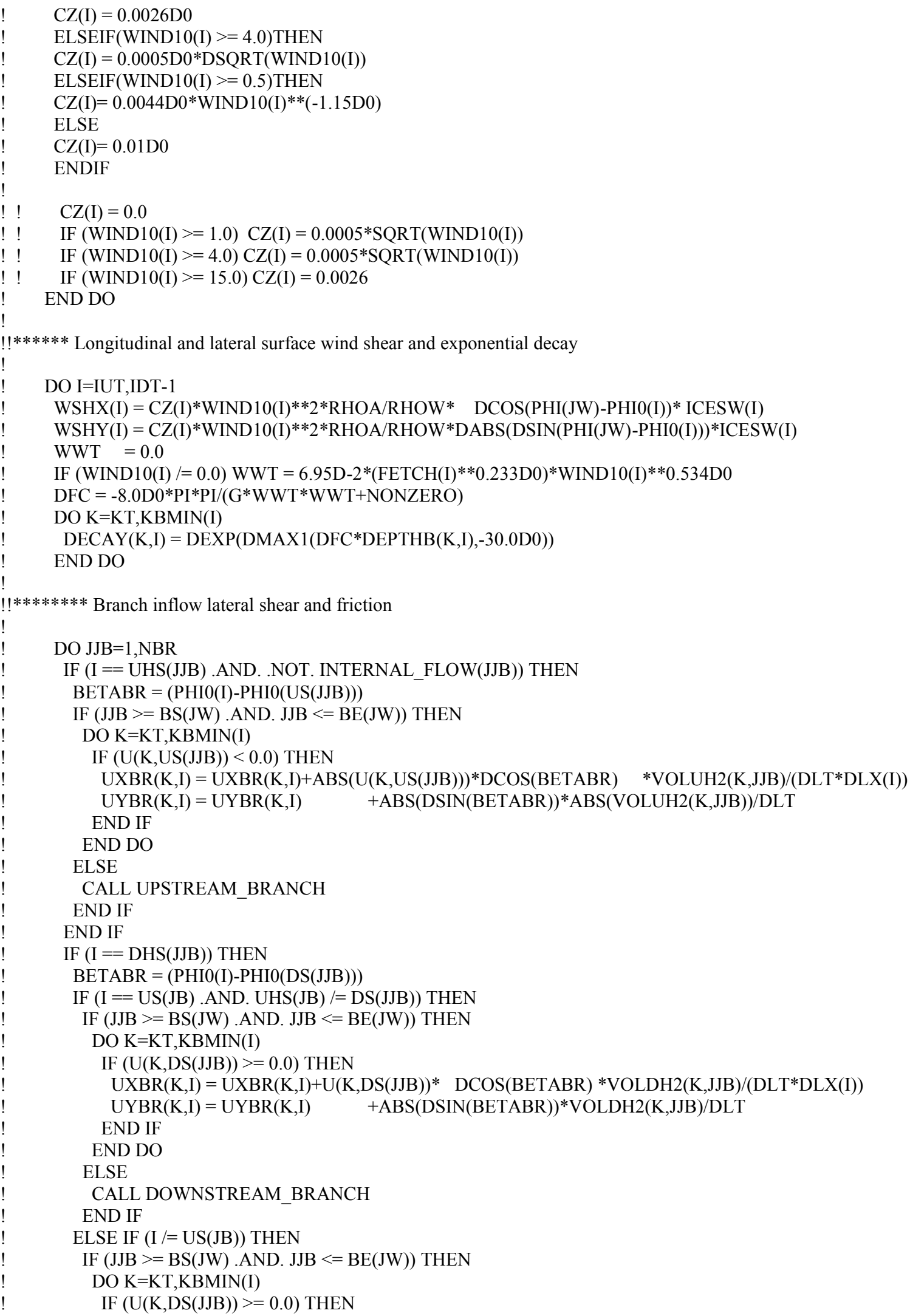




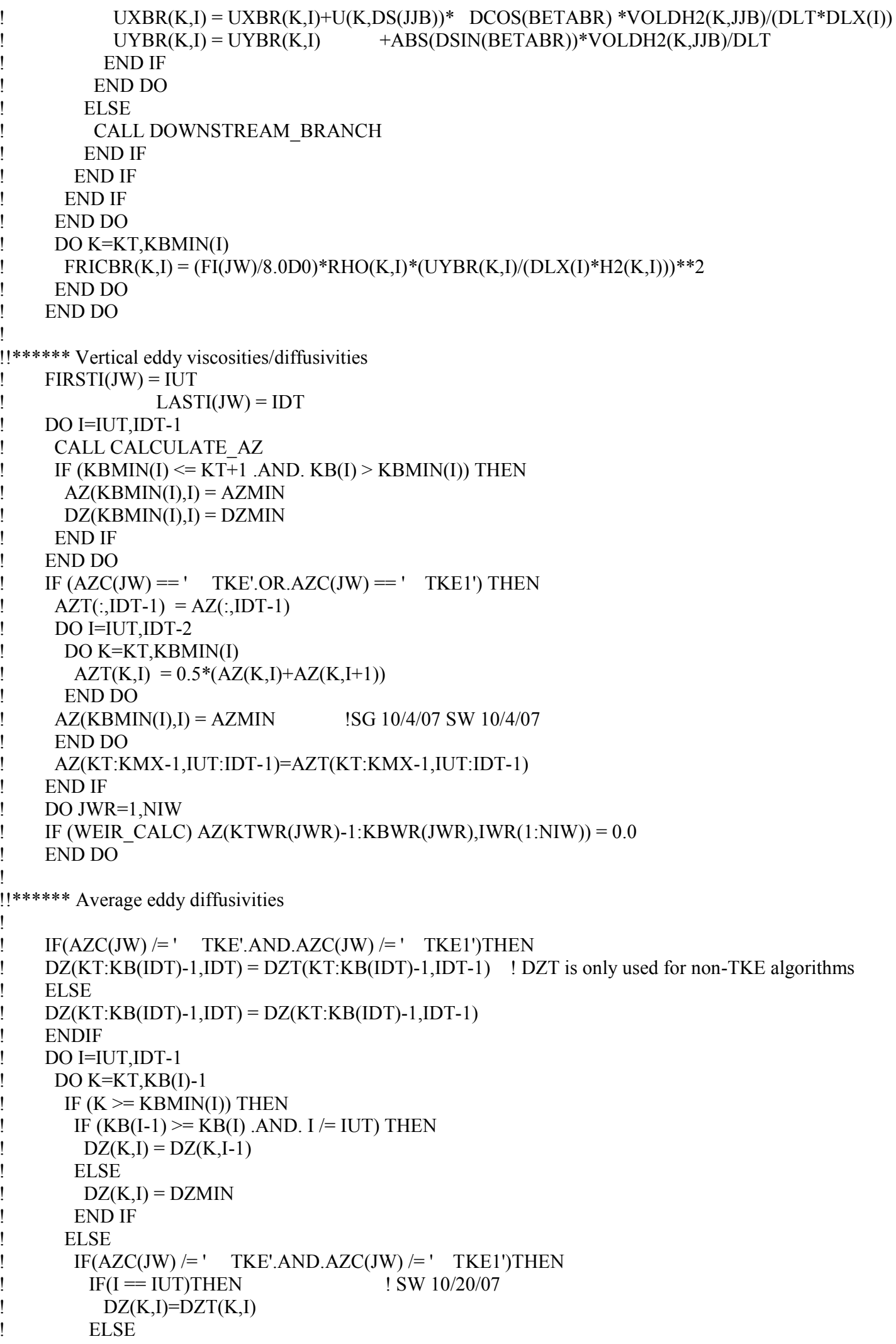


! $\quad \mathrm{DZ}(\mathrm{K}, \mathrm{I})=(\mathrm{DZT}(\mathrm{K}, \mathrm{I})+\mathrm{DZT}(\mathrm{K}, \mathrm{I}-1)) * 0.5 \mathrm{D} 0 \quad$ ! SW 10/20/07 $(\mathrm{DZT}(\mathrm{K}, \mathrm{I})+\mathrm{DZT}(\mathrm{K}+1, \mathrm{I})) * 0.5 ! \mathrm{FOR}$ NON-TKE ALGORITHMS, AVERAGE DZ FROM EDGES TO CELL CENTERS

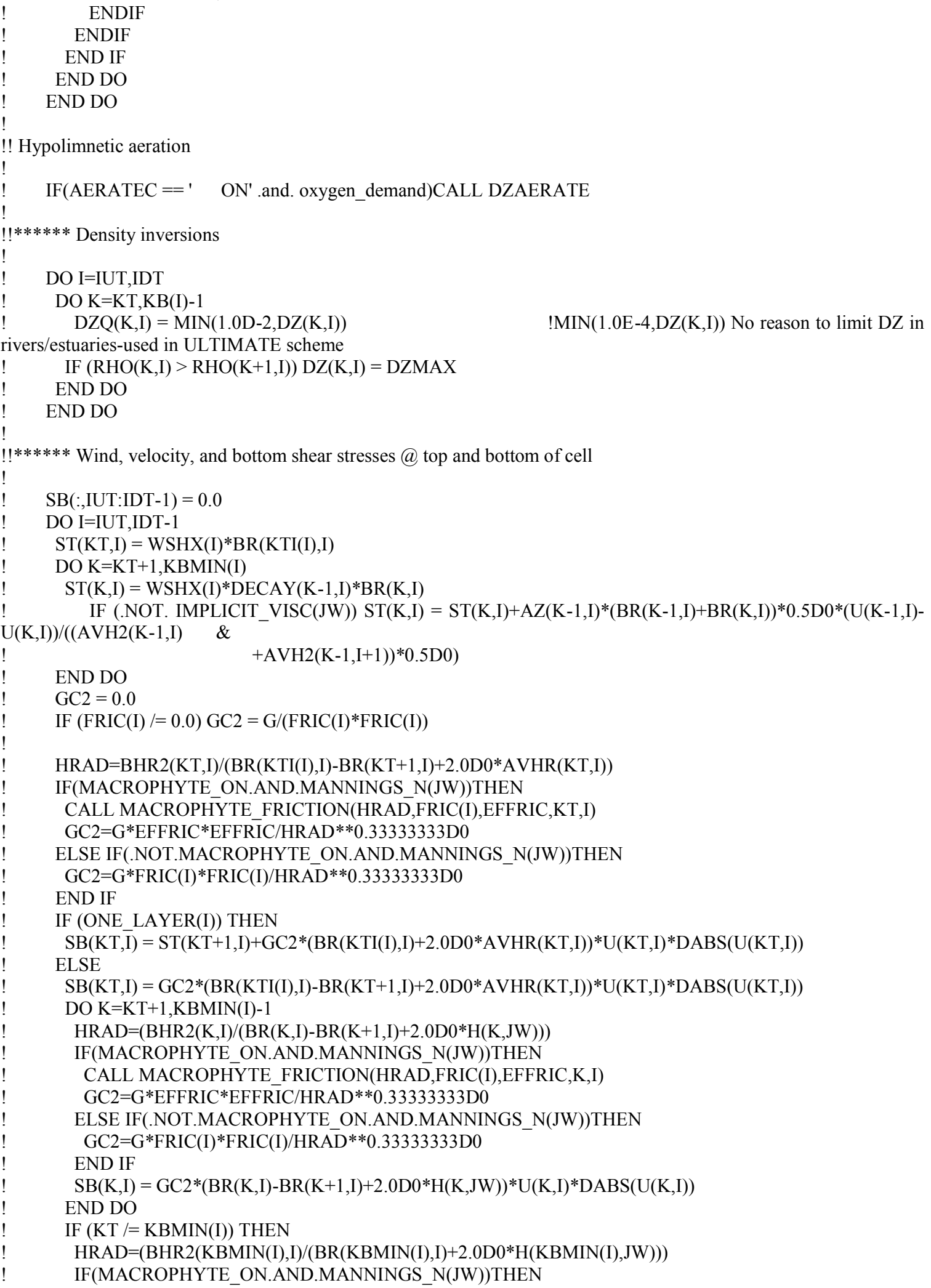




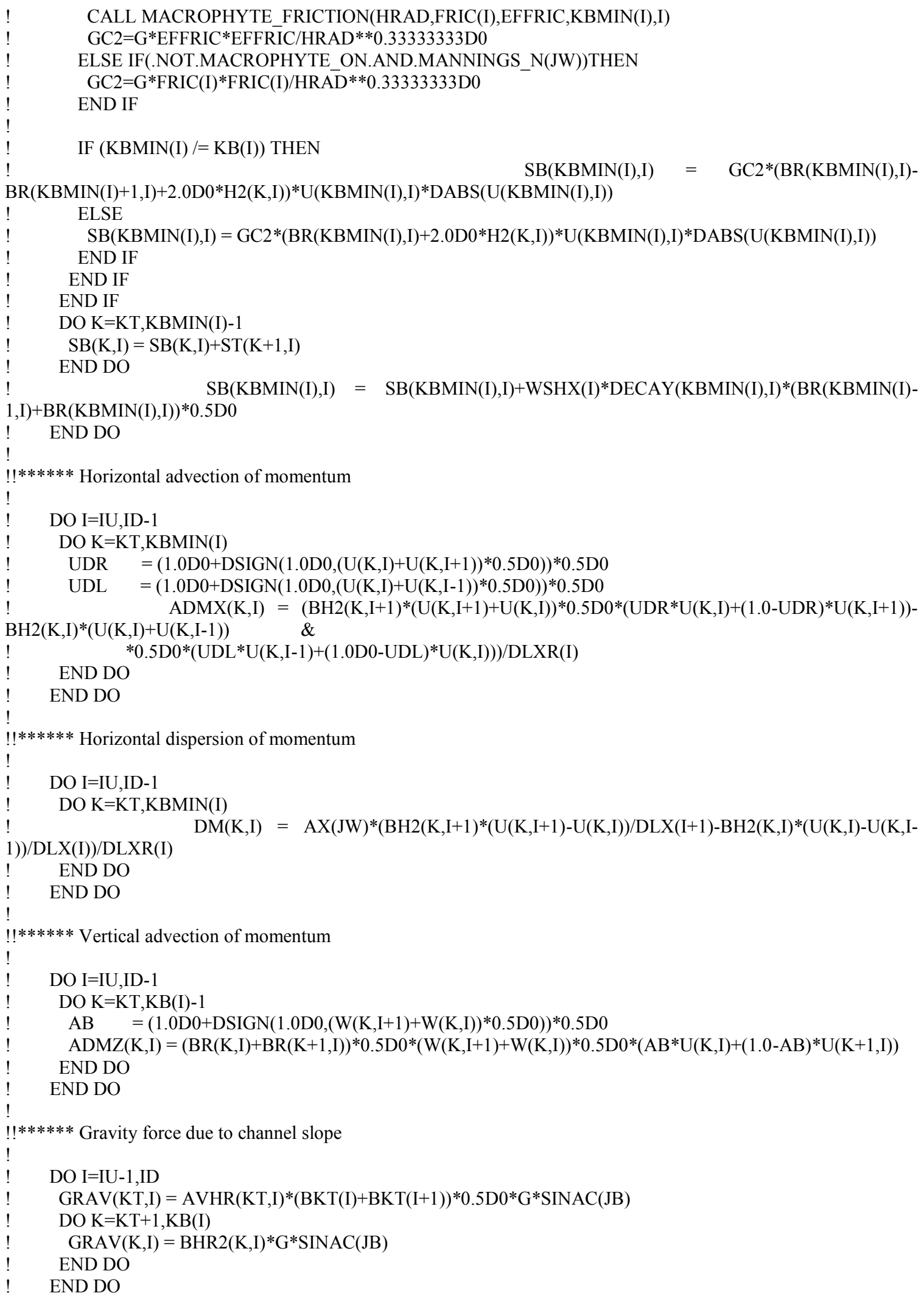




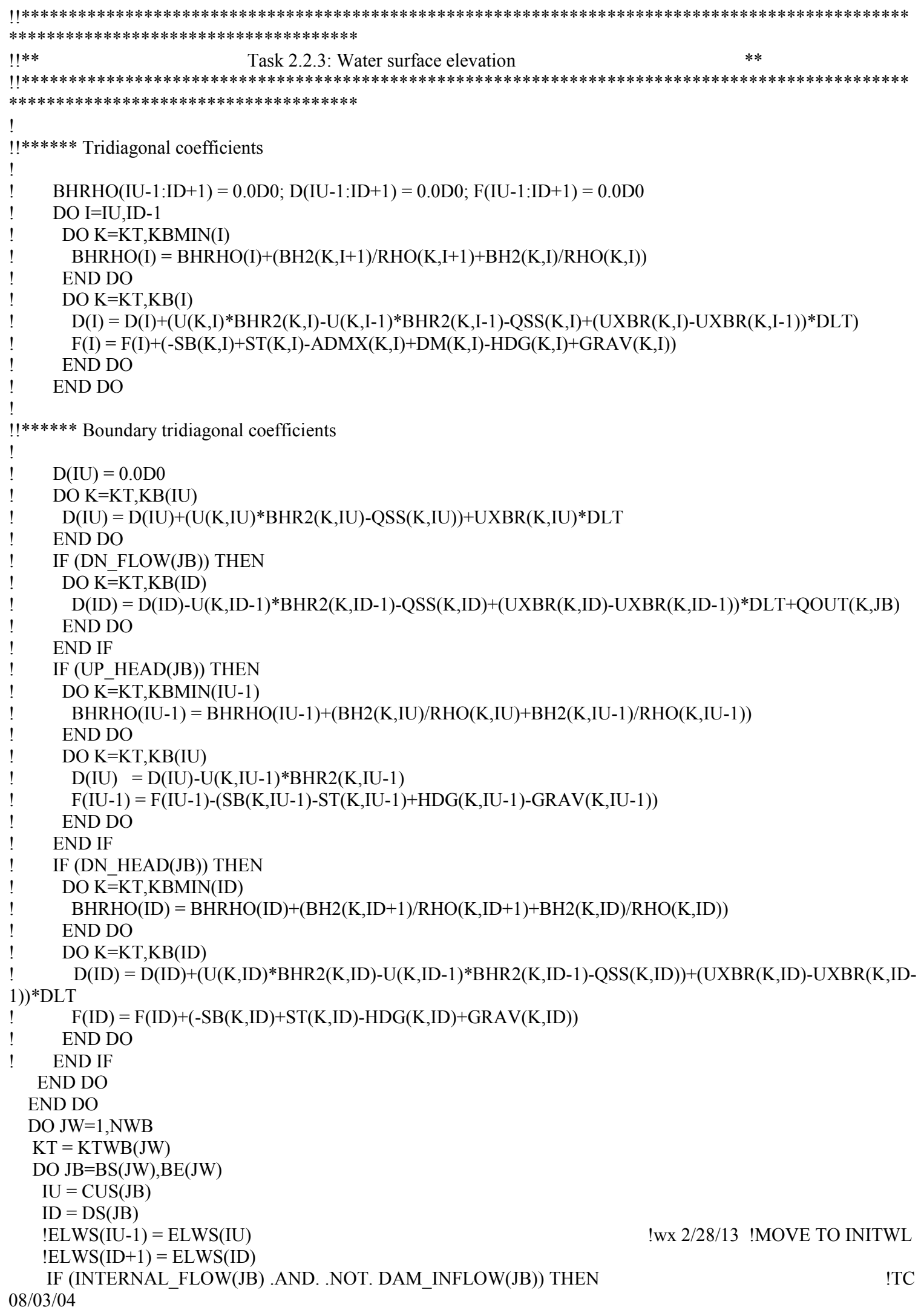




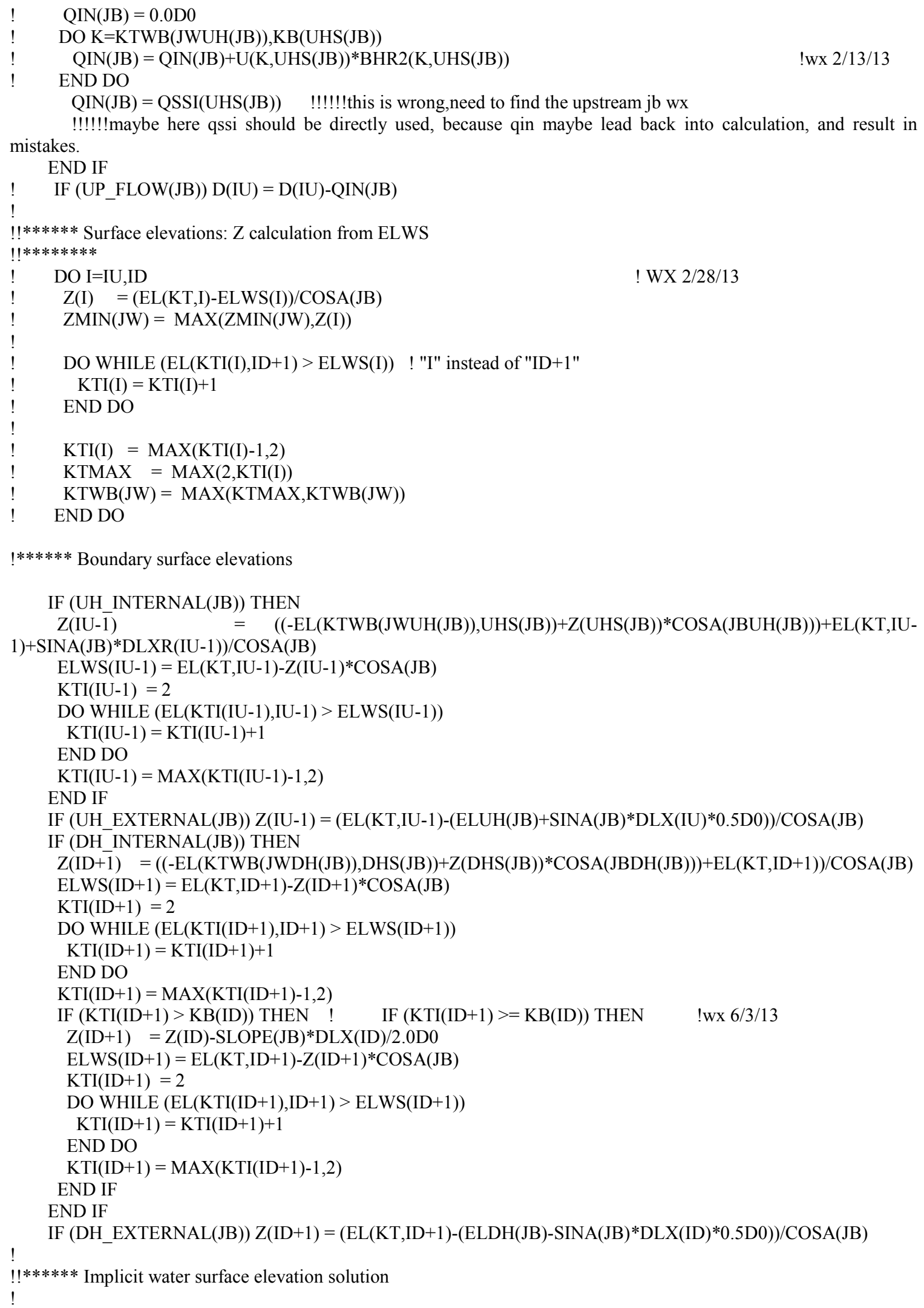




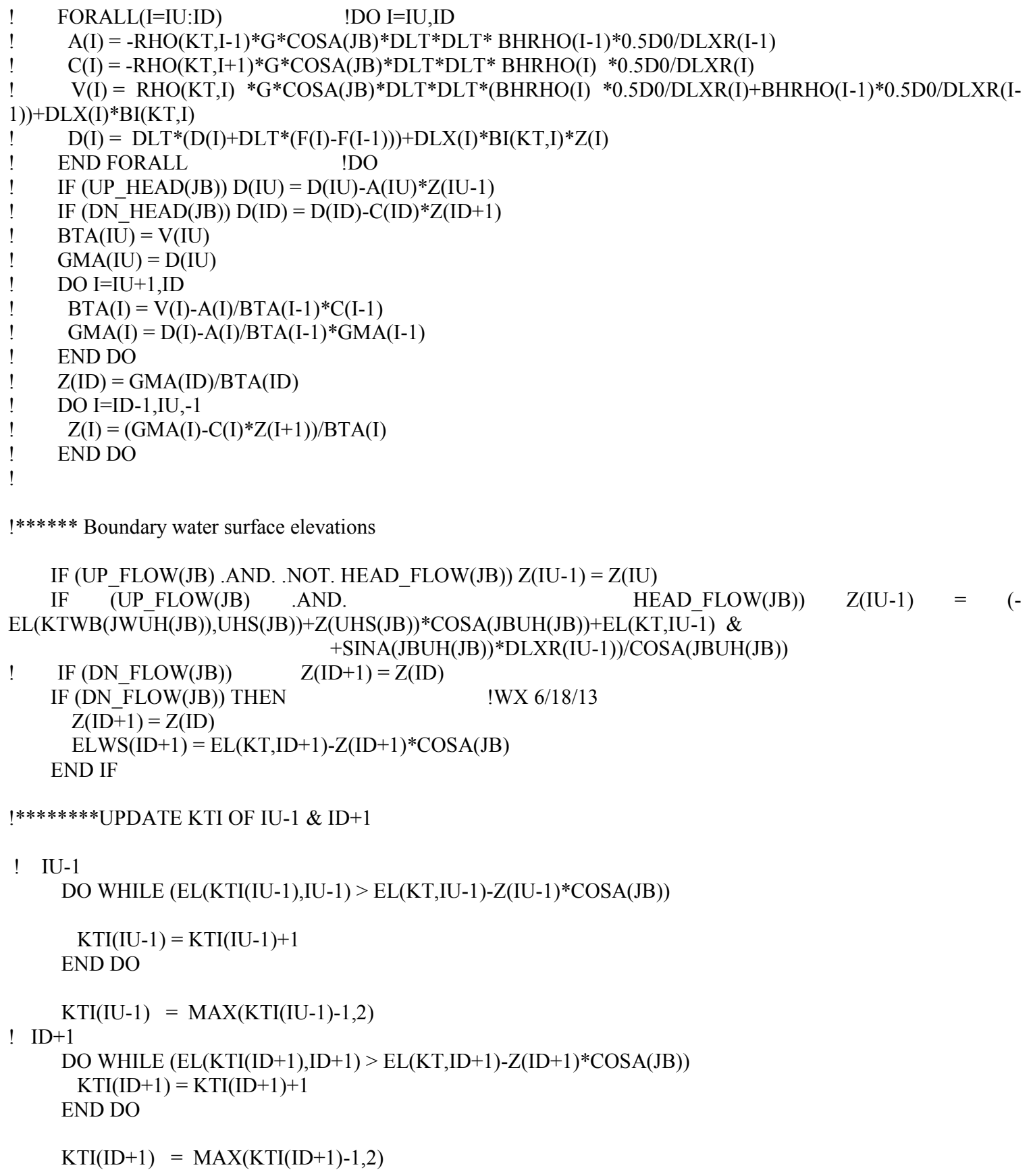




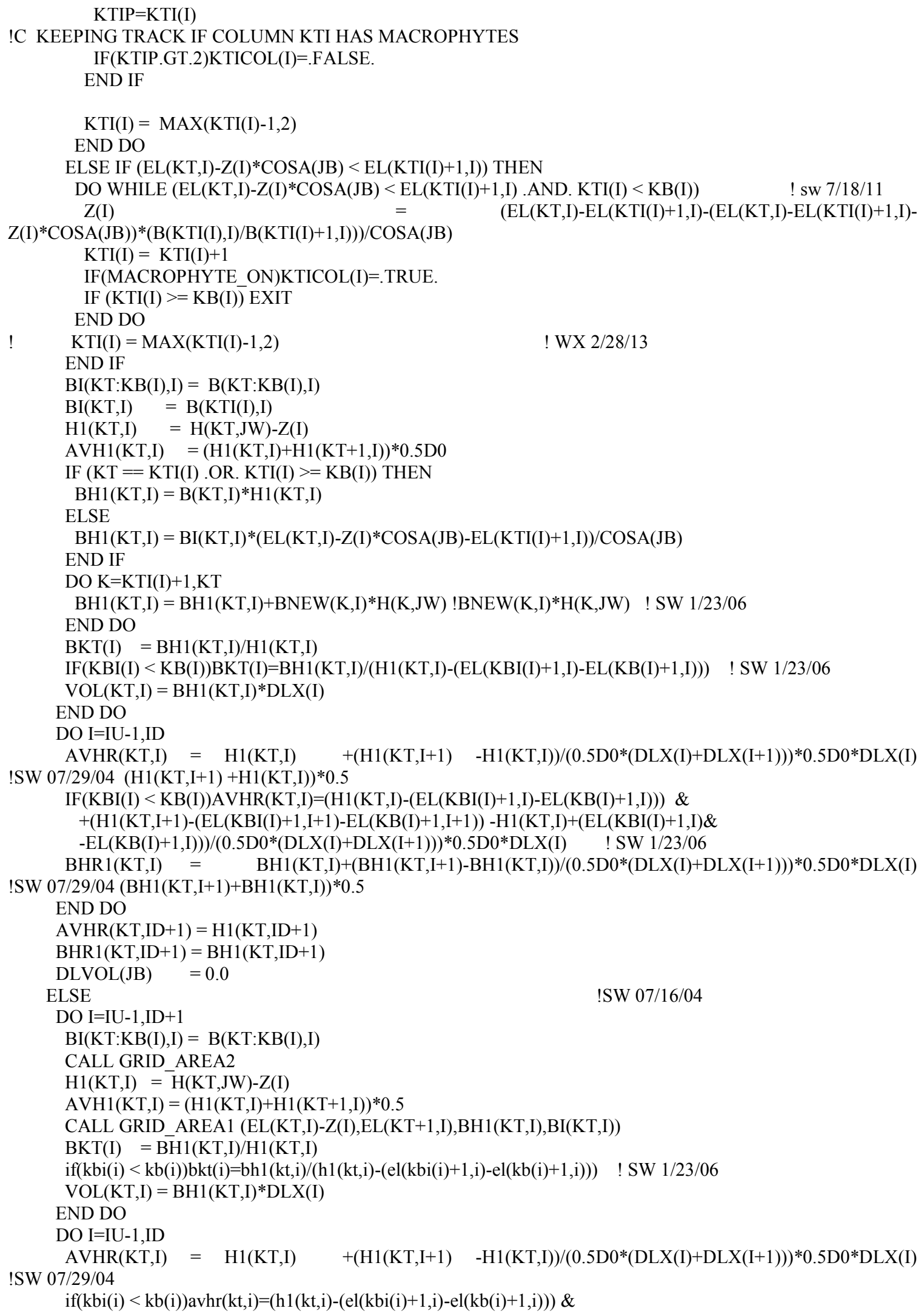




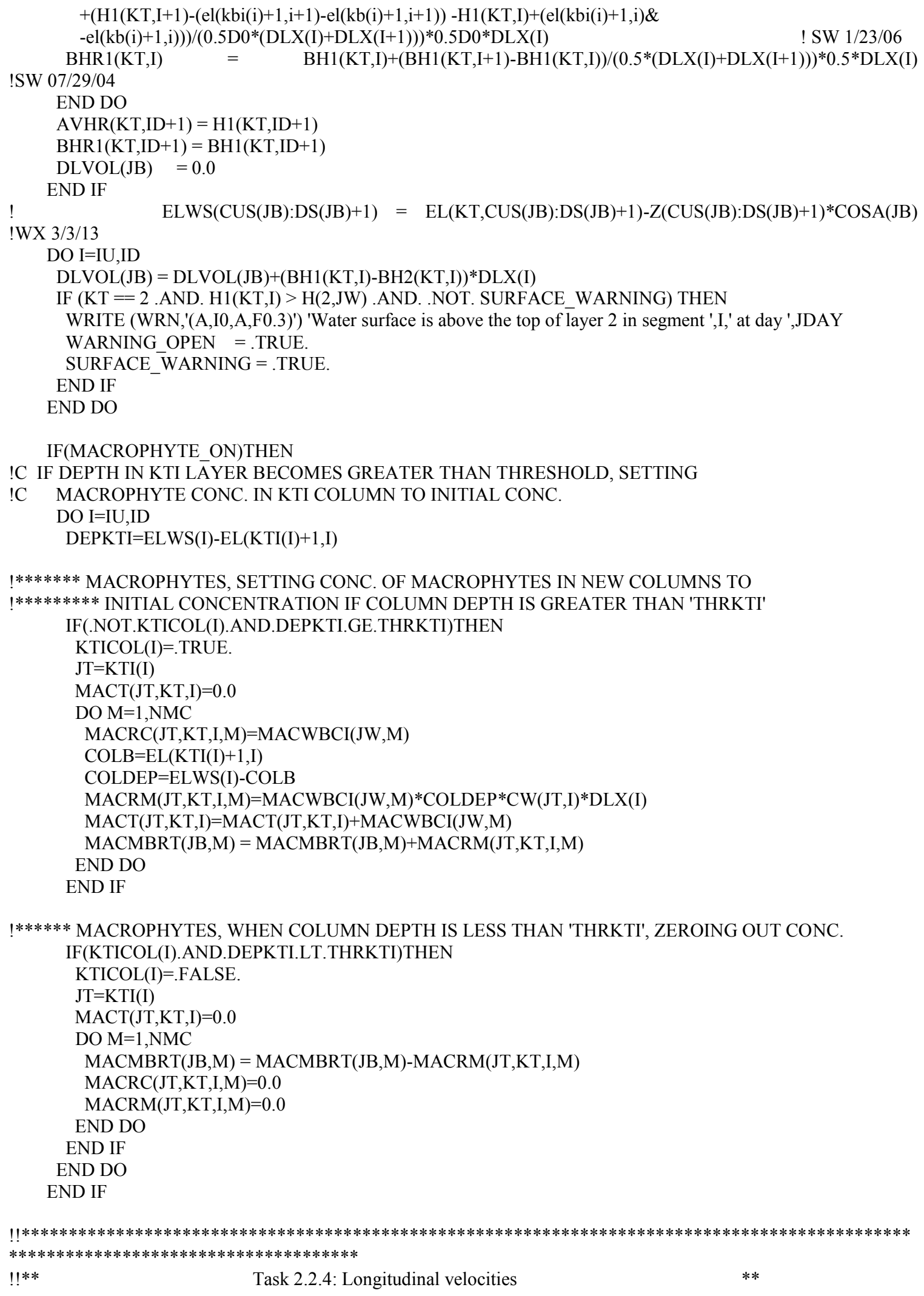




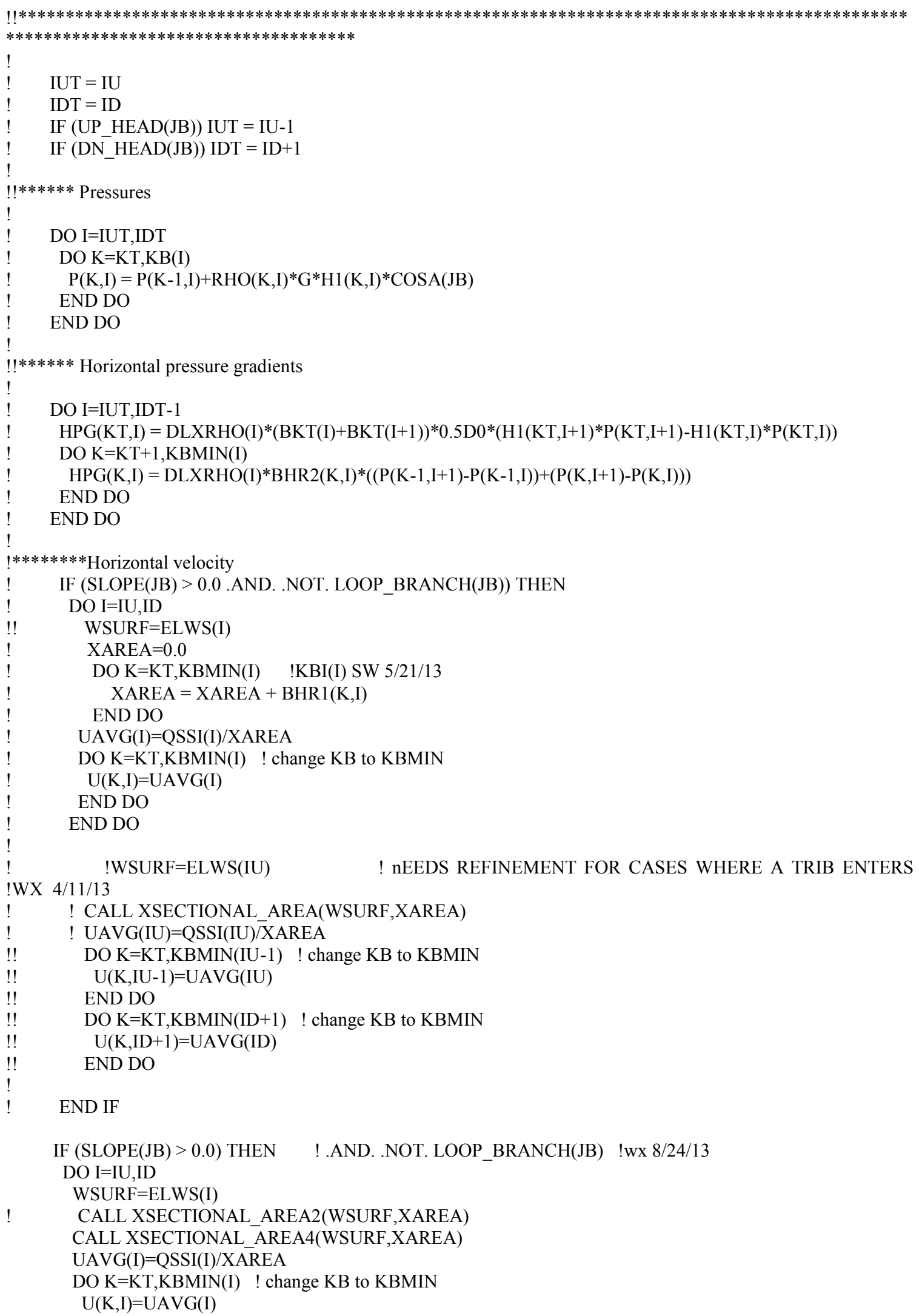




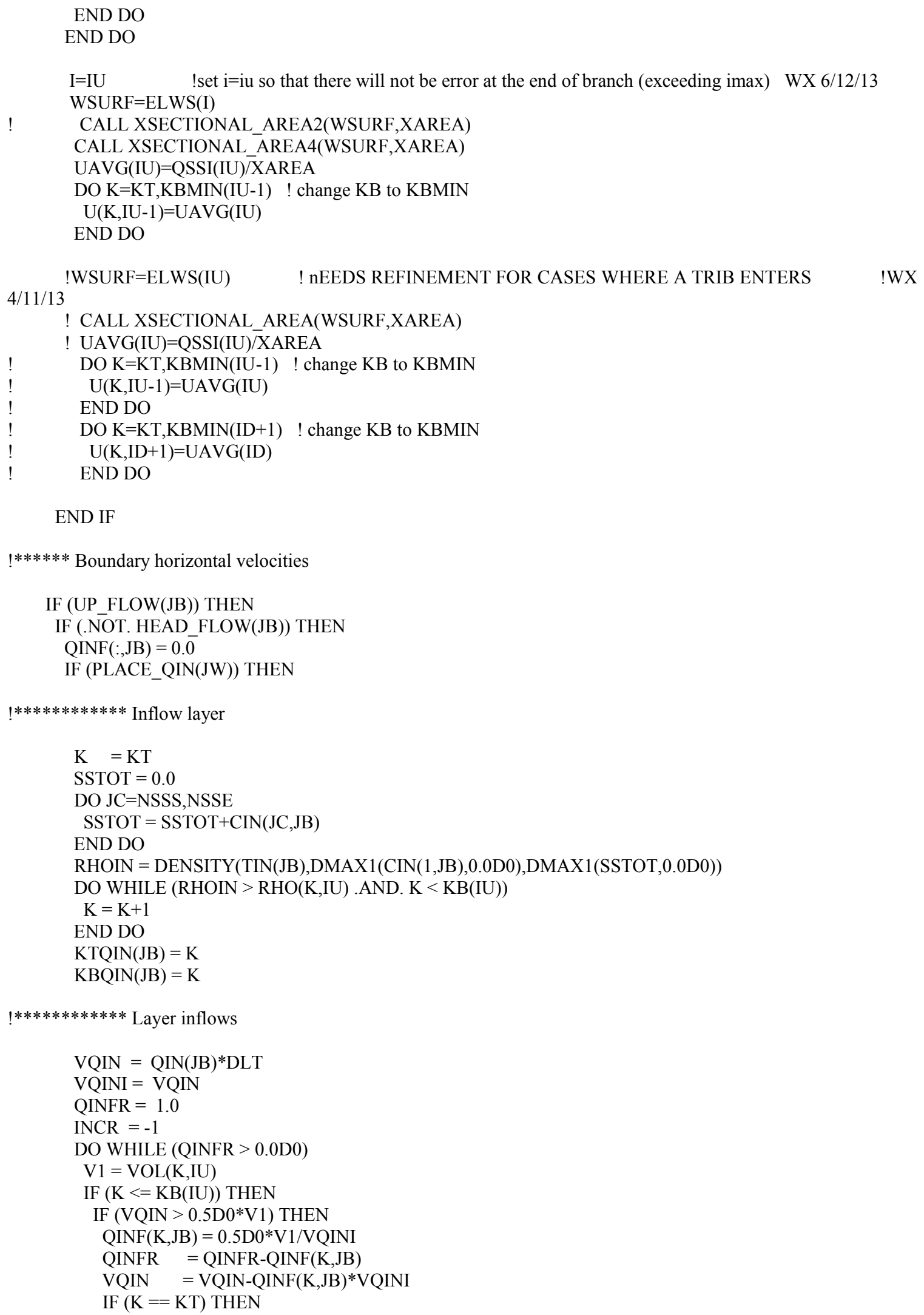




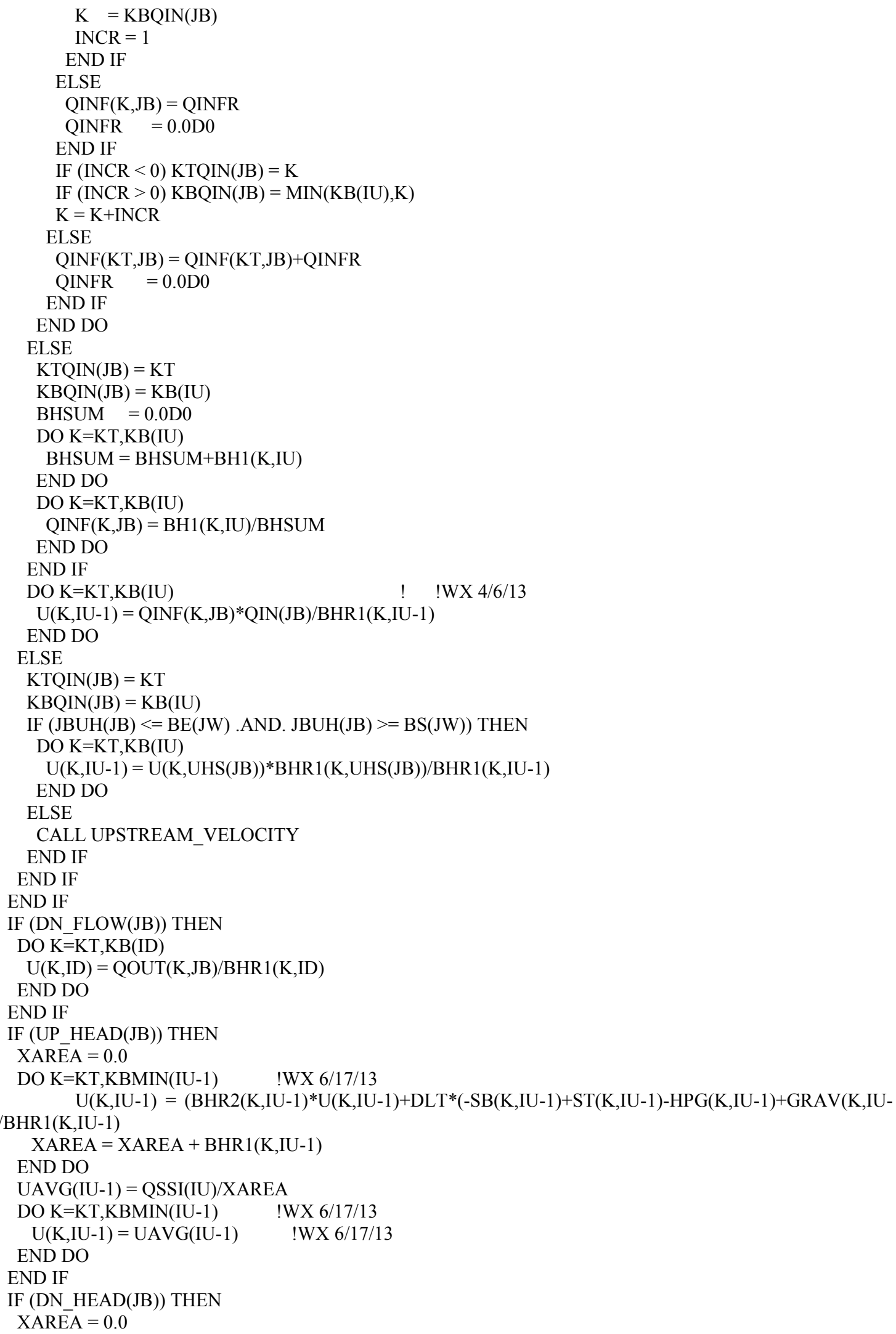




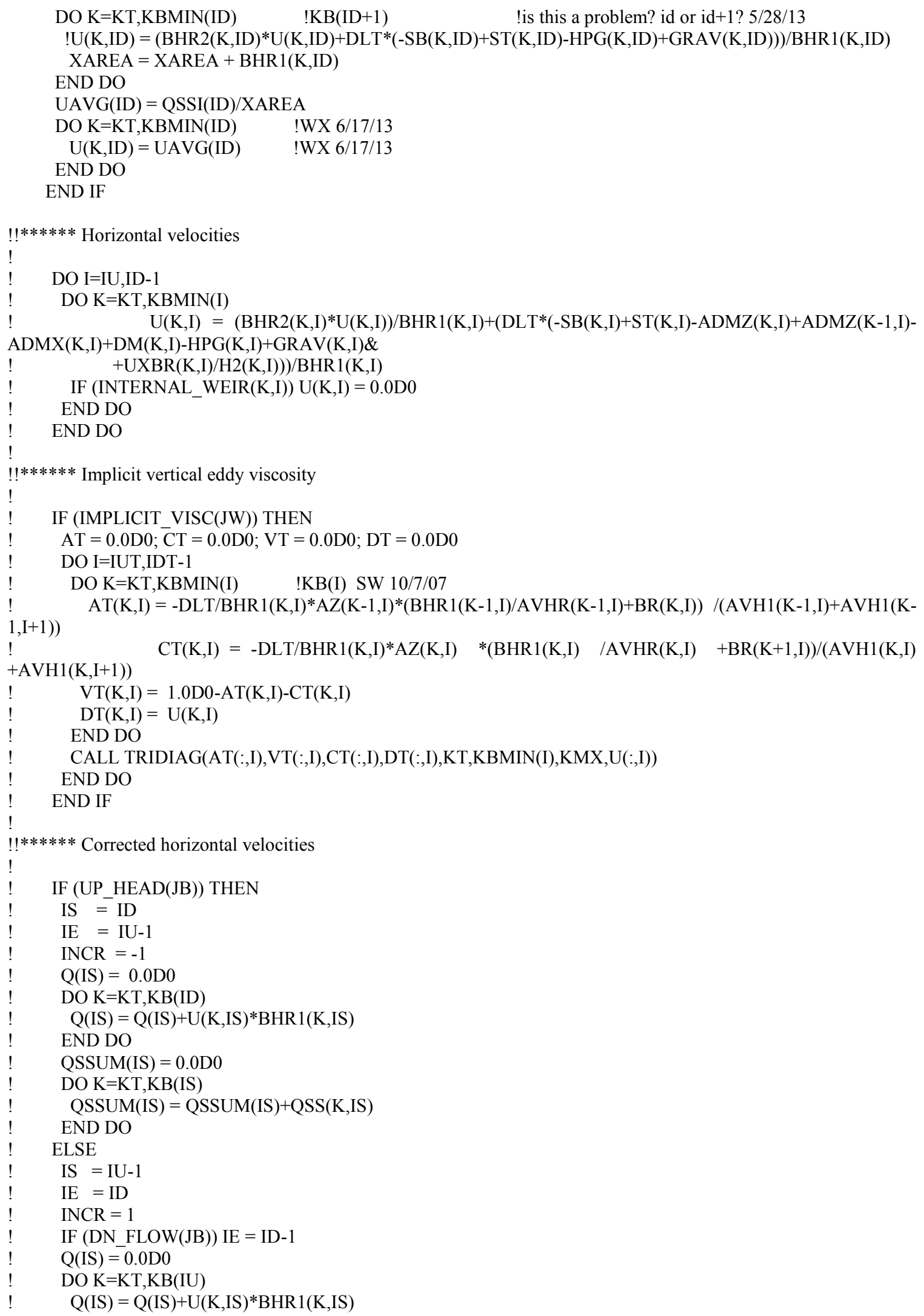




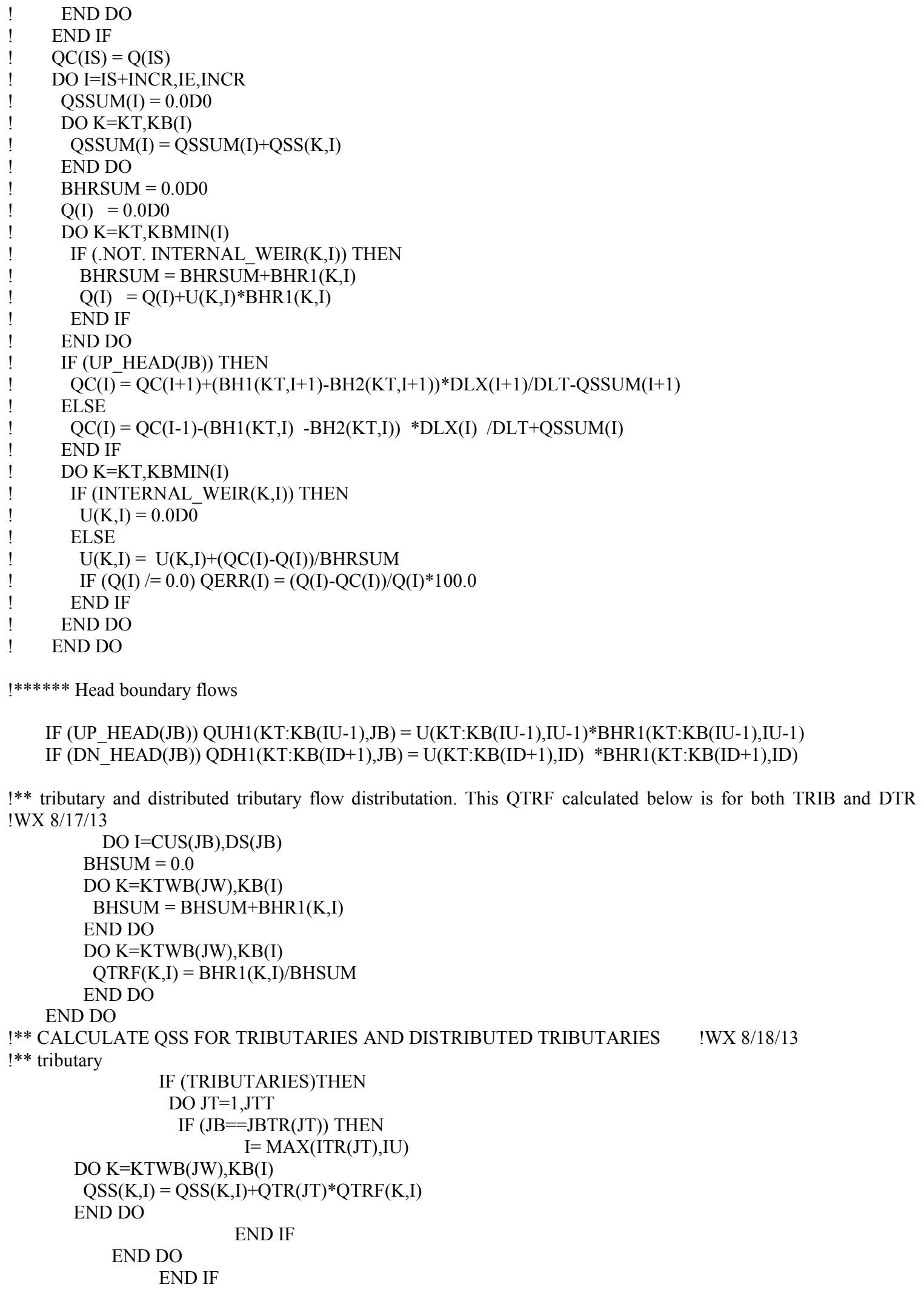




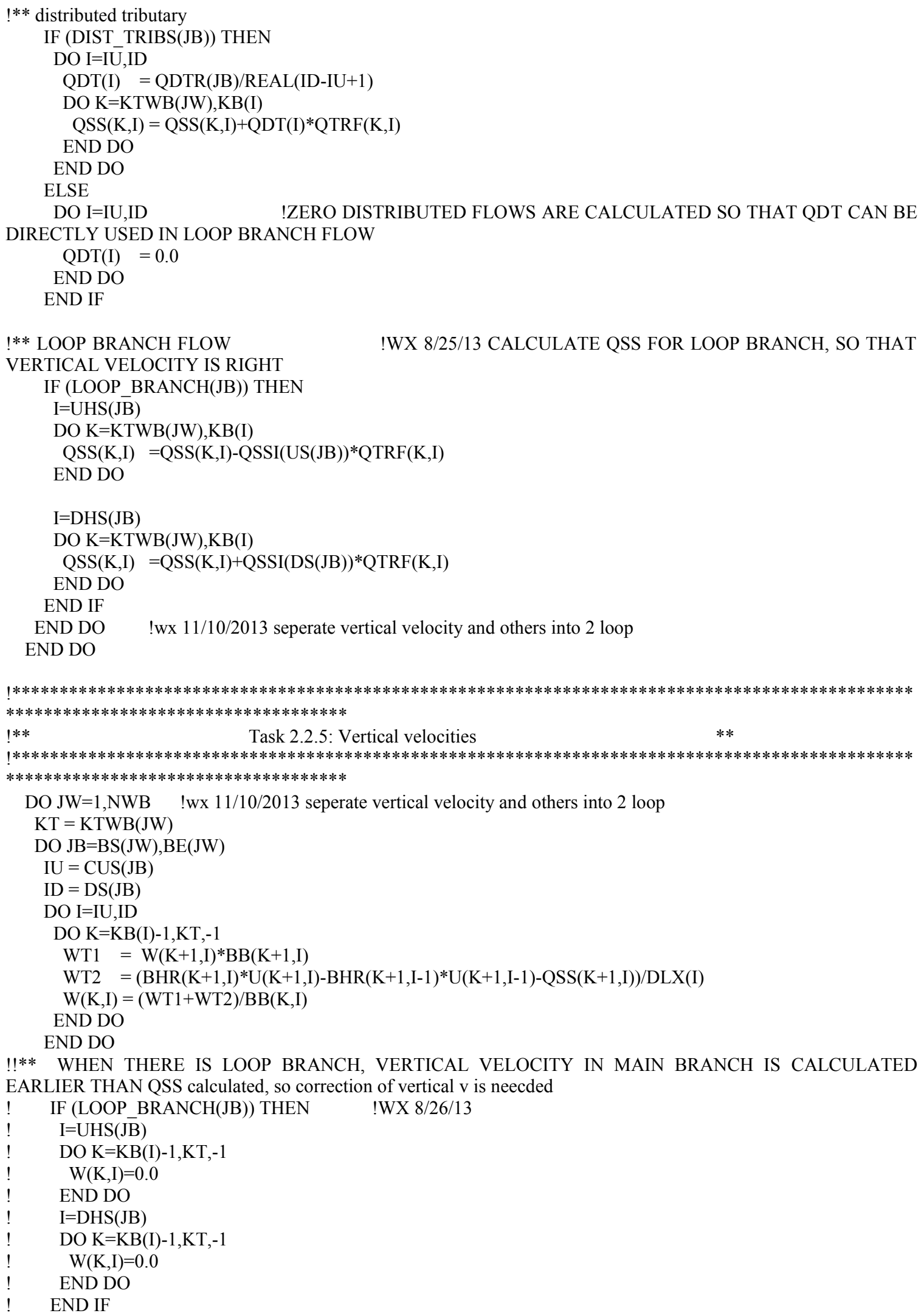




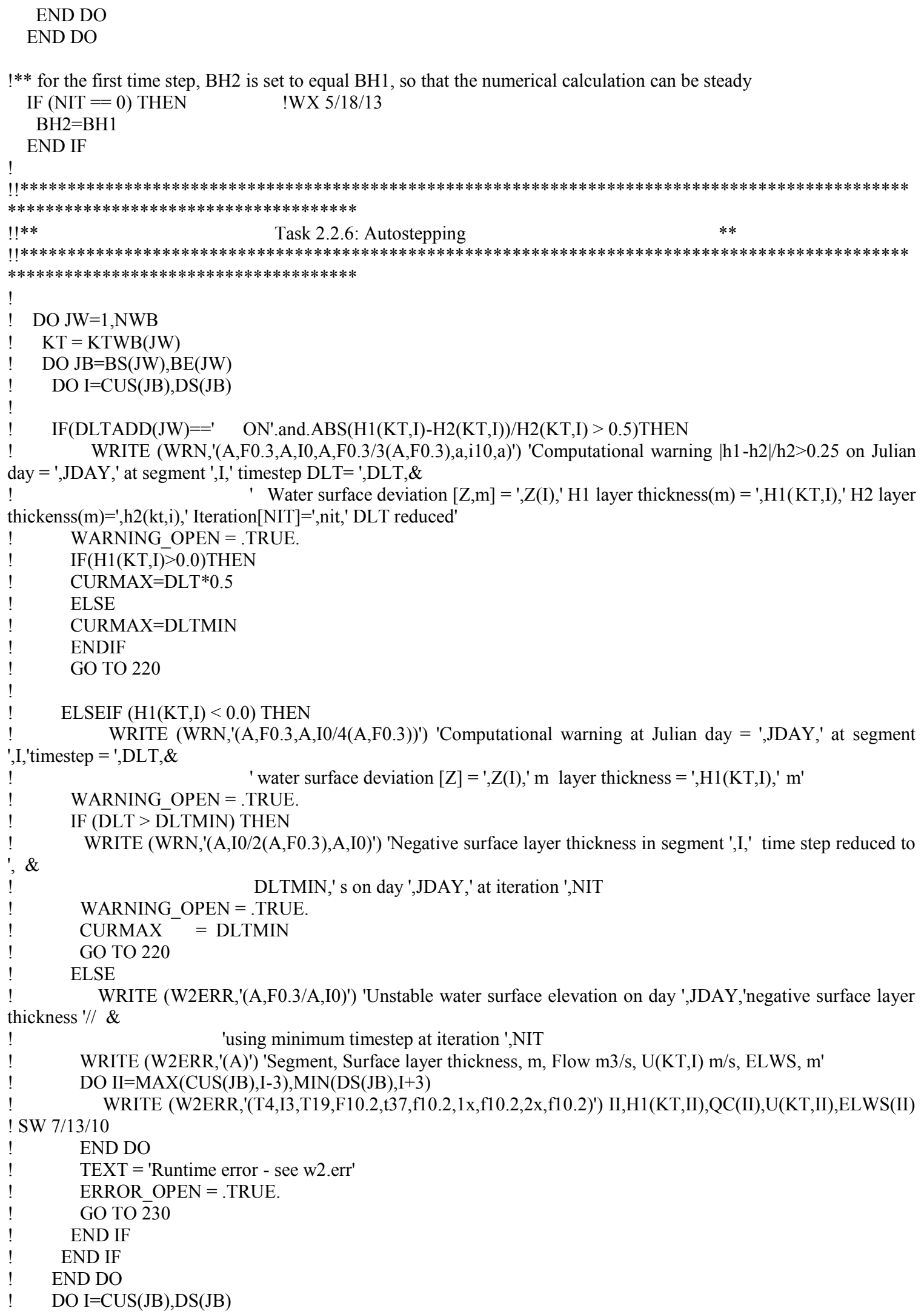




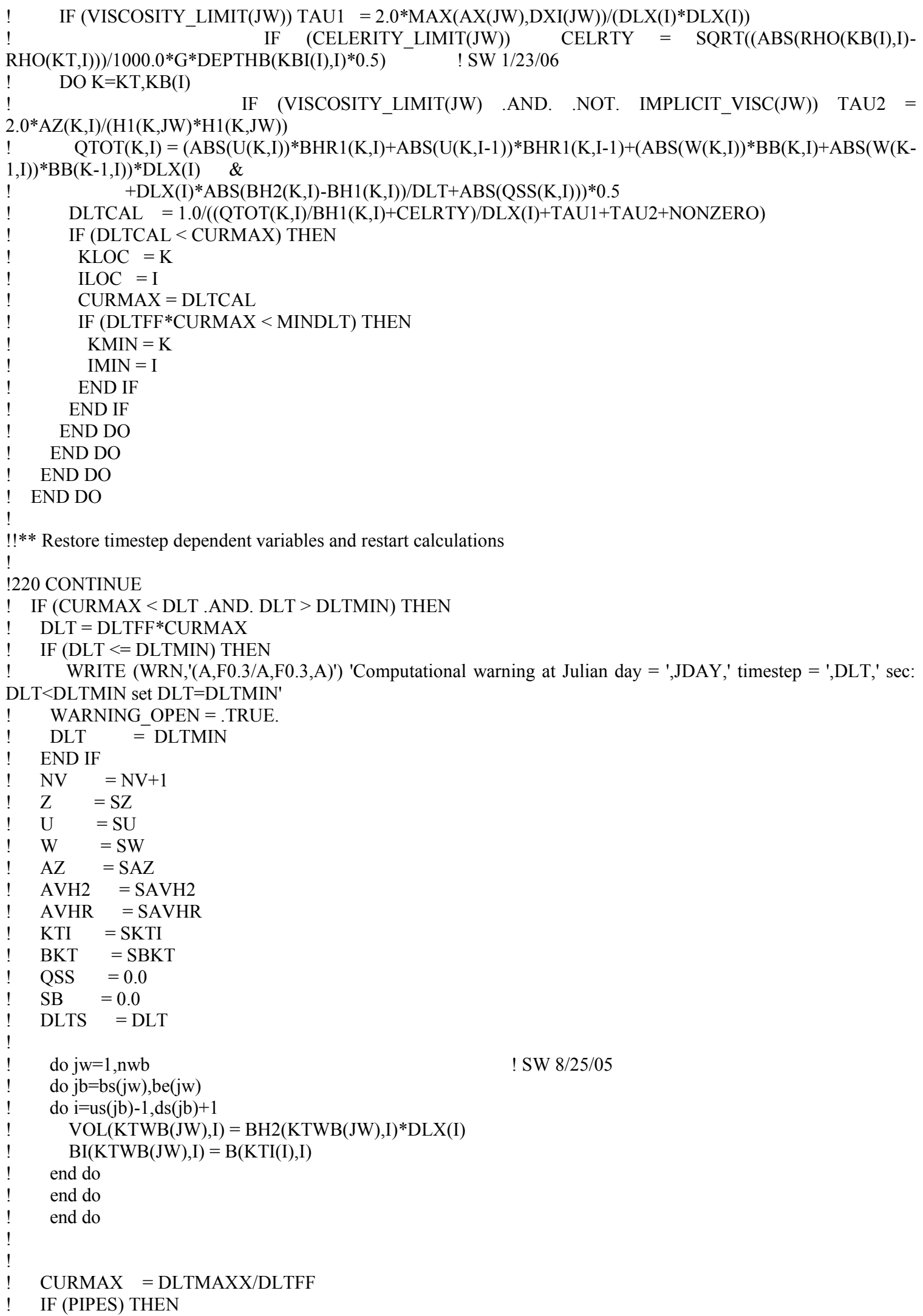

! SW 8/25/05 


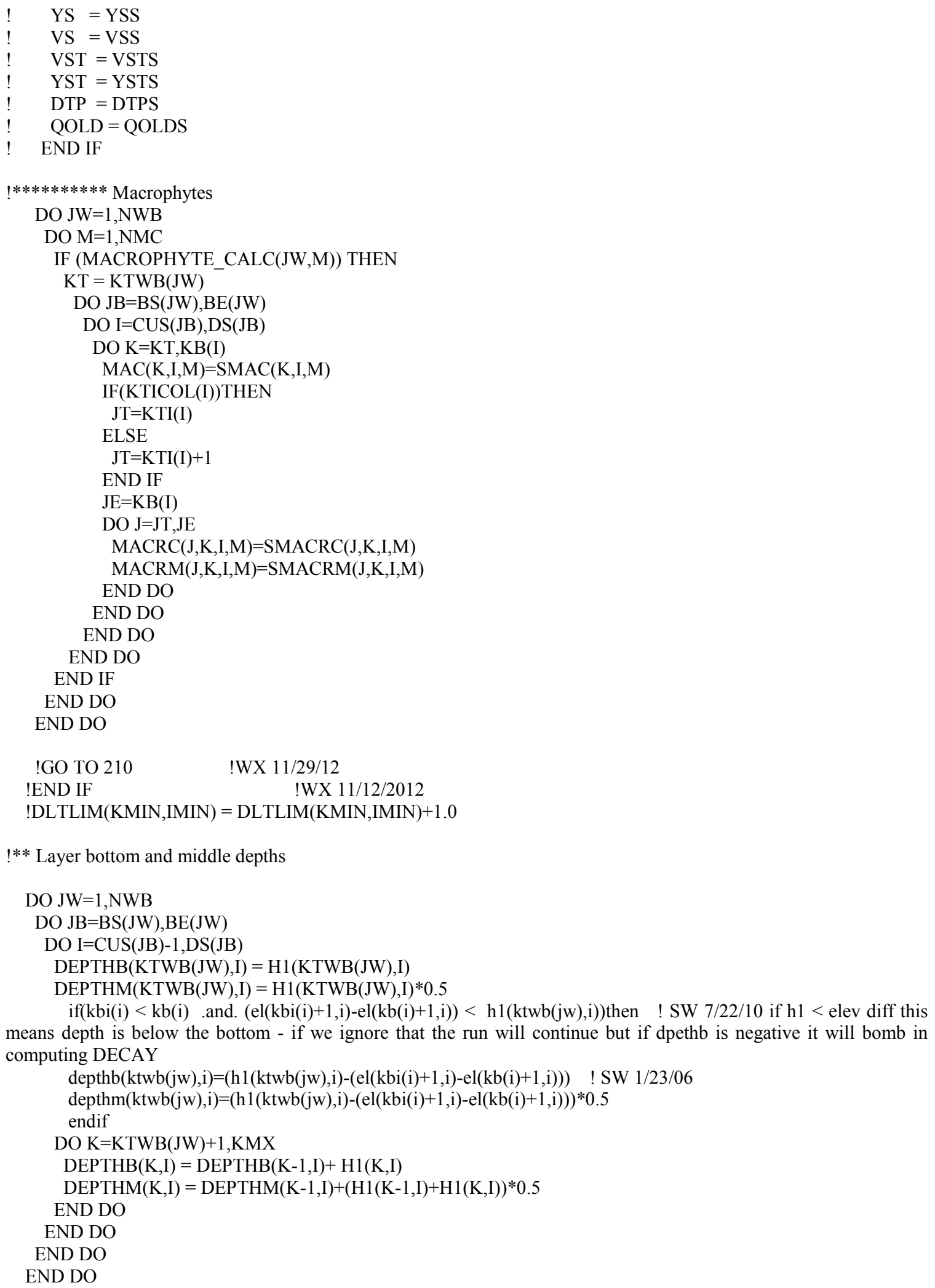

CALL temperature 
IF (CONSTITUENTS) CALL wqconstituents

CALL LAYERADDSUB

if(error_open)go to 230

\section{CALL BALANCES}

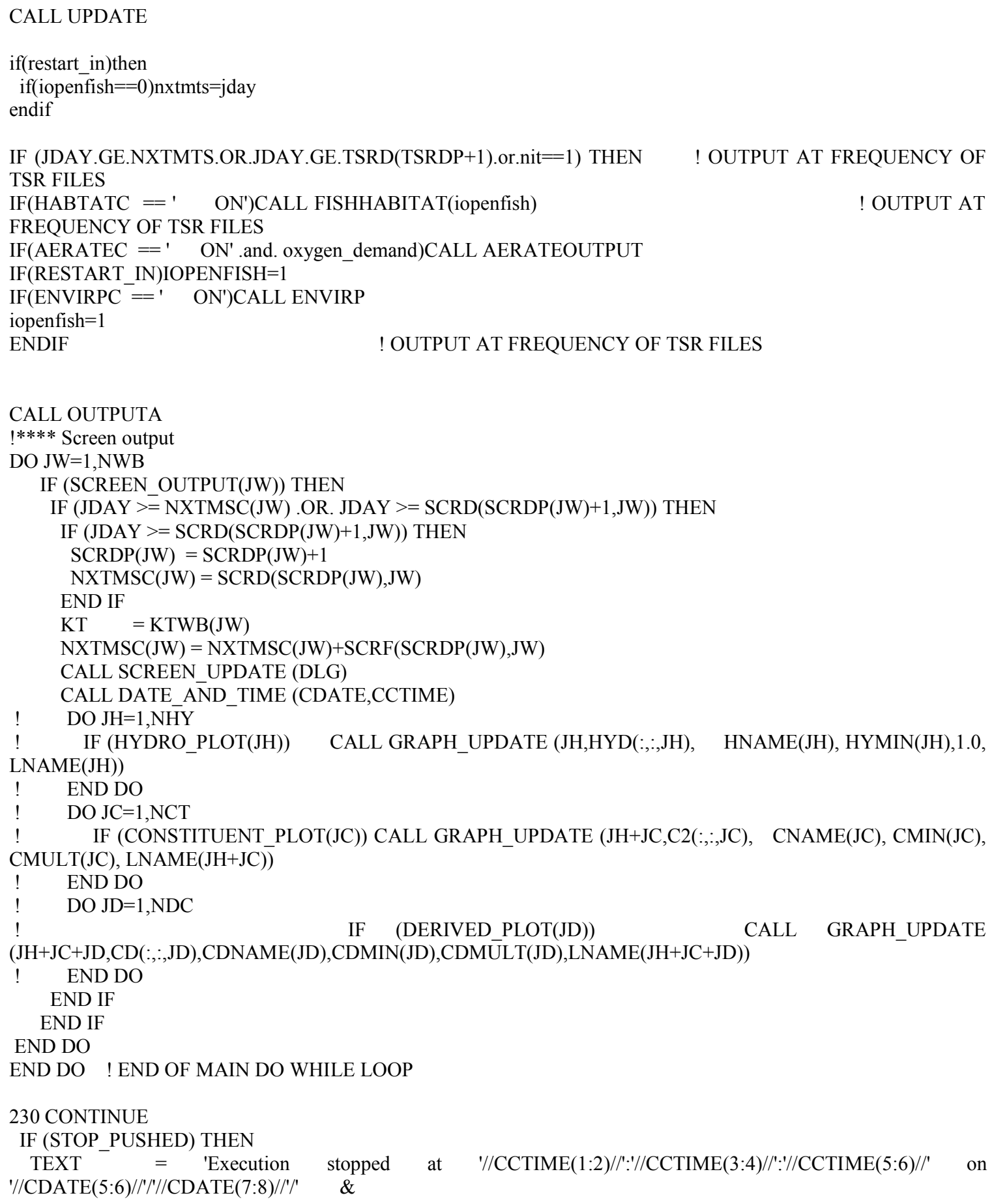




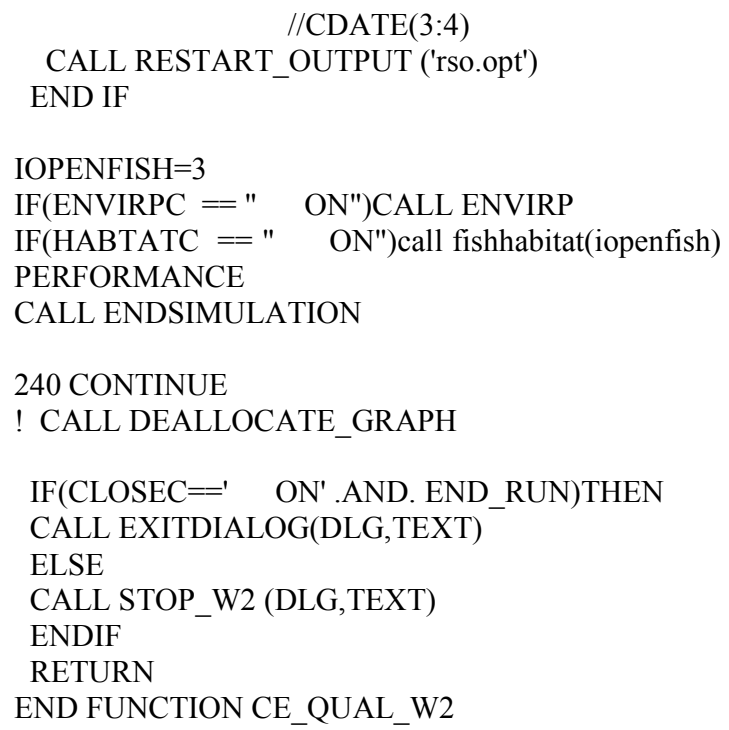




\section{init-u-elws.f90}

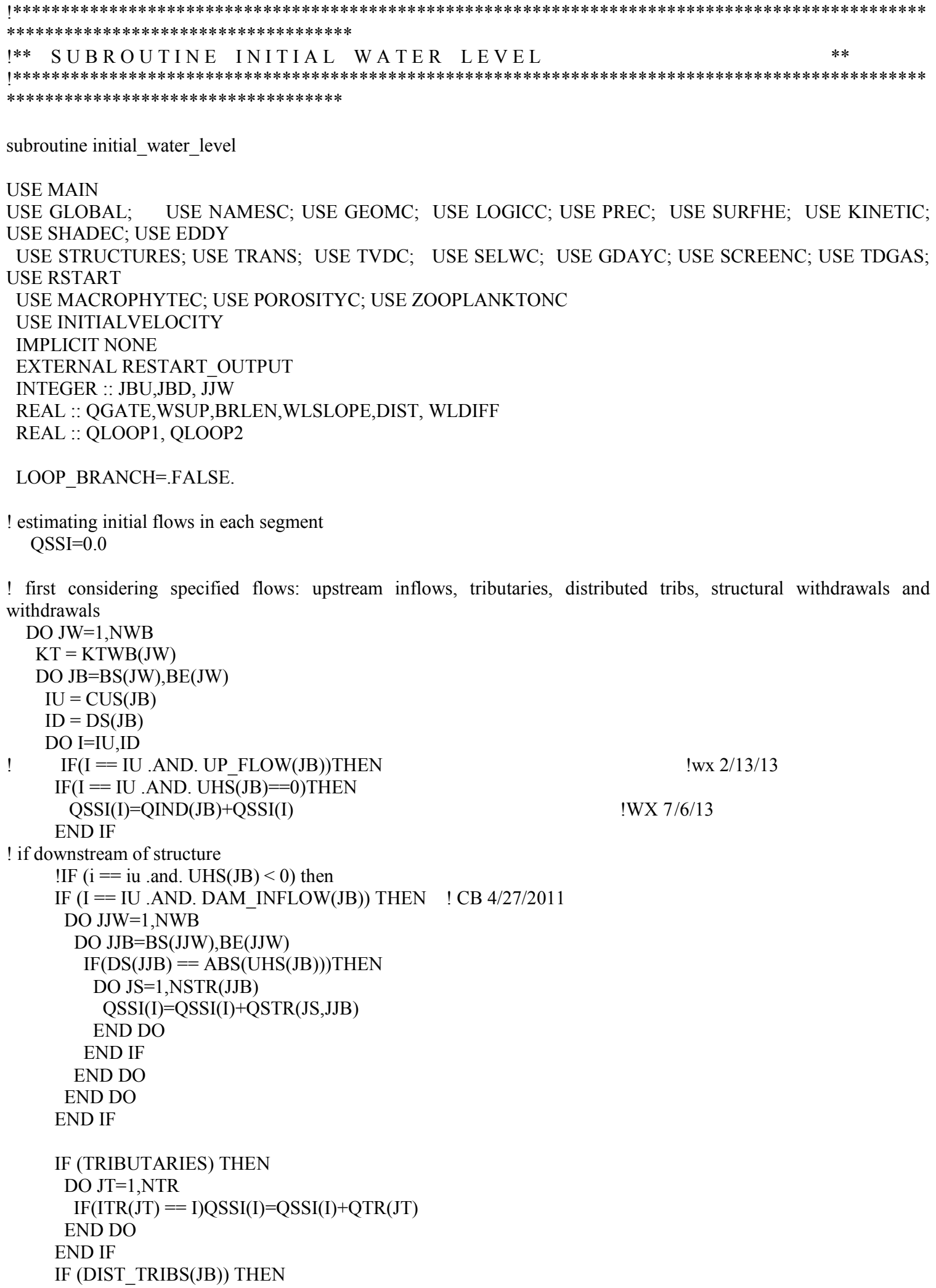


QSSI $(\mathrm{I})=$ QSSI(I)+QDTR(JB)/REAL(ID-IU+1) ！SINCE INITIAL WL UNKNOWN, DISTRIBUTING FLOW EVENLY BTW. SEGS.

END IF

IF (WITHDRAWALS) THEN

DO JWD=1,NWD

$\operatorname{IF}(\operatorname{IWD}(\mathrm{JWD})==\mathrm{I}) \mathrm{QSSI}(\mathrm{I})=\mathrm{QSSI}(\mathrm{I})-\mathrm{QWD}(\mathrm{JWD})$

END DO

END IF

$\mathrm{IF}(\mathrm{I}==\mathrm{ID}) \mathrm{THEN}$

DO JS $=1$, NSTR(JB)

QSSI $(\mathrm{I})=\mathrm{QSSI}(\mathrm{I})-\mathrm{QSTR}(\mathrm{JS}, \mathrm{JB})$

END DO

END IF

END DO

END DO

END DO

! INCLUDING FLOWS WITHIN BRANCH UPSTEAM OF SEGMENT

DO JW=1,NWB

$\mathrm{KT}=\mathrm{KTWB}(\mathrm{JW})$

$\mathrm{DO} \mathrm{JB}=\mathrm{BS}(\mathrm{JW}), \mathrm{BE}(\mathrm{JW})$

$\mathrm{IU}=\mathrm{CUS}(\mathrm{JB})$

$\mathrm{ID}=\mathrm{DS}(\mathrm{JB})$

DO I=IU+1,ID

QSSI $(\mathrm{I})=\mathrm{QSSI}(\mathrm{I})+\mathrm{QSSI}(\mathrm{I}-1)$

END DO

END DO

END DO

DO JW=1,NWB

$\mathrm{KT}=\mathrm{KTWB}(\mathrm{JW})$

$\mathrm{DO} \mathrm{JB}=\mathrm{BS}(\mathrm{JW}), \mathrm{BE}(\mathrm{JW})$

$\mathrm{IU}=\mathrm{CUS}(\mathrm{JB})$

$\mathrm{ID}=\mathrm{DS}(\mathrm{JB})$

DO I=IU,ID

! DETERMINING IF SEGMENT IS DOWNSTREAM INTERNAL HEAD BOUNDARY OF ANOTHER

*UPSTREAM* BRANCH, AND ADDING FLOW TO SEGMENT AND SEGMENTS DOWNSTREAM DO JJW=1,NWB

DO JJB $=\mathrm{BS}(\mathrm{JJW}), \mathrm{BE}(\mathrm{JJW})$

$\operatorname{IF}(\mathrm{DHS}(\mathrm{JJB})==\mathrm{I}) \mathrm{THEN}$

DO II $=$ I,ID

QSSI $(\mathrm{II})=\mathrm{QSSI}(\mathrm{II})+\mathrm{QSSI}(\mathrm{DS}(\mathrm{JJB}))$

END DO

END IF

END DO

END DO

! DETERMINING IF SEGMENT IS DOWNSTREAM OF SPILLWAY BELOW ANOTHER BRANCH

DO JS $=1$,NSP

IF(ESP(JS) < EL(2,I))THEN ! DISREGARDING IF CREST ABOVE GRID

$\mathrm{IF}(\mathrm{I}==\operatorname{IDSP}(\mathrm{JS})) \mathrm{THEN}$

DO II $=$ I,ID

QSSI(II) $=$ QSSI(II)+QSSI(IUSP(JS))

END DO

END IF

END IF

END DO

! DETERMINING IF SEGMENT IS DOWNSTREAM OF GATE BELOW ANOTHER BRANCH

DO JG $=1$, NGT

IF(EGT(JG) < EL(2,I))THEN ! DISREGARDING IF CREST ABOVE GRID

$\mathrm{IF}(\mathrm{I}==\mathrm{IDGT}(\mathrm{JG}))$ THEN 


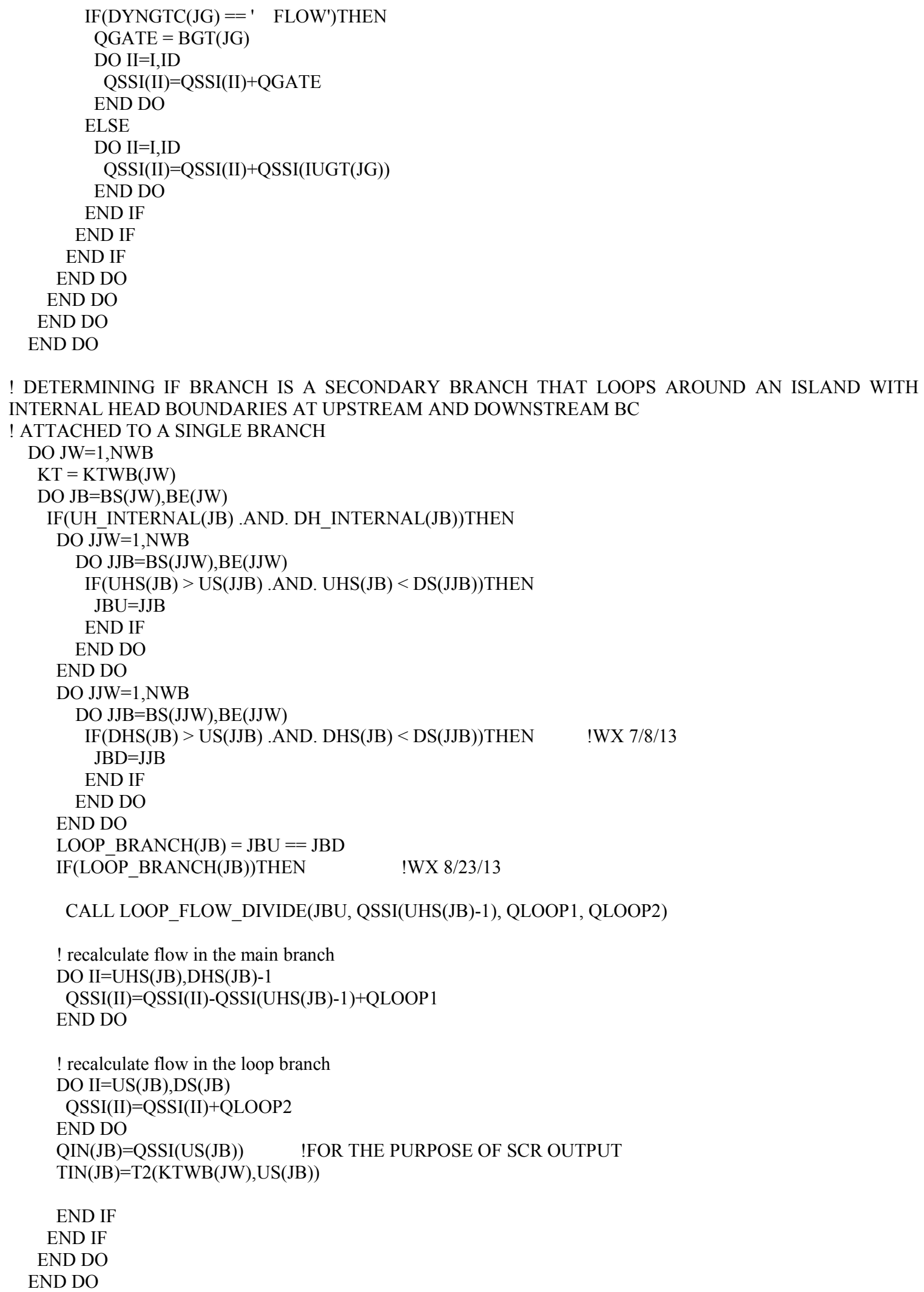




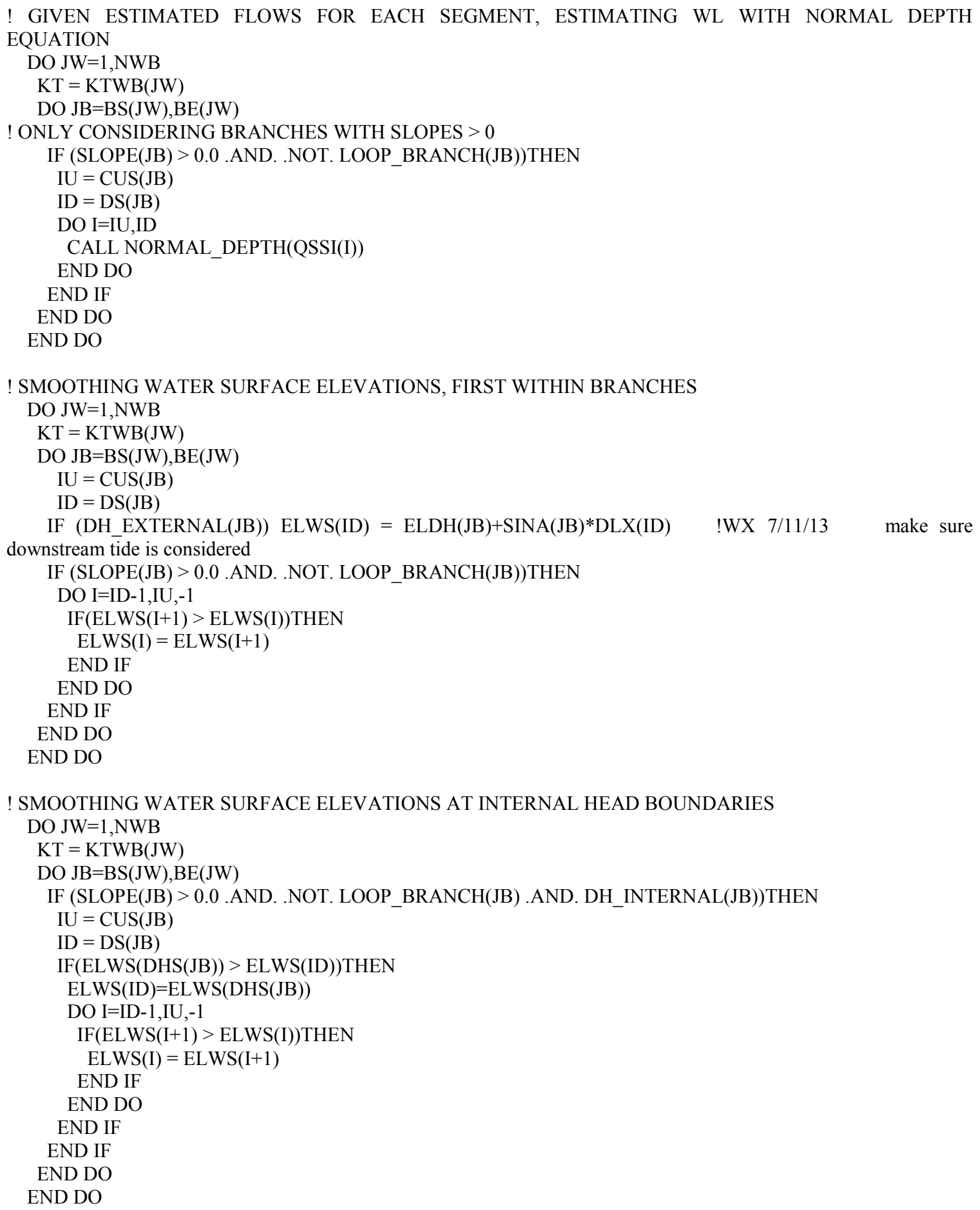

! IF SPILLWAY OR GATE AT DOWNSTREAM END OF BRANCH, MAKING SURE WATER LEVEL IS ABOVE CREST ELEVATION

DO JW $=1, \mathrm{NWB}$

$\mathrm{KT}=\mathrm{KTWB}(\mathrm{JW})$ 
DO JB=BS(JW),BE(JW)

! IF (SLOPE(JB) > 0.0.AND. .NOT. LOOP_BRANCH(JB).AND. NSTR(JB) ==0)THEN $\quad !$ wx 10/29/13

IF $($ SLOPE $(J B)>0.0$.AND. .NOT. LOOP_BRANCH(JB))THEN

$\mathrm{IU}=\mathrm{CUS}(\mathrm{JB})$

$\mathrm{ID}=\mathrm{DS}(\mathrm{JB})$

! SPILLWAYS

DO JS $=1$,NSP

IF(ESP(JS) < EL(2,ID))THEN ! DISREGARDING IF CREST ABOVE GRID

!WX $10 / 30 / 13$

$\operatorname{EL}(2, \mathrm{I})>>\operatorname{EL}(2, \mathrm{ID})$

IF(ID == IUSP(JS))THEN

WSUP $=\mathrm{ESP}(\mathrm{JS})+(\mathrm{QSSI}(\mathrm{ID}) / \mathrm{A} 1 \mathrm{SP}(\mathrm{JS}))^{* *}(1.0 / \mathrm{B} 1 \mathrm{SP}(\mathrm{JS})) \quad$ ! ESTIMATING UPSTREAM WS ELEV

IF(ELWS(ID) < WSUP)THEN

IF(IDSP(JS) .NE. 0)THEN ! CB 8/10/10

IF(ELWS(IDSP(JS)) > WSUP) WSUP = ELWS(IDSP(JS)) ! CHECKING TO SEE IF DOWNSTREAM

WS ELEVATION ISN'T ALREADY 'HIGH'

END IF ! CB 8/10/10

ELWS(ID)=WSUP $\quad$ !WX 10/30/13 CHENGED POSTION WITH THE LINE ABOVE

DO I=ID-1,IU,-1

IF(ELWS(I+1)> ELWS(I))THEN

$\operatorname{ELWS}(\mathrm{I})=\operatorname{ELWS}(\mathrm{I}+1)$

END IF

END DO

END IF

END IF

END IF

END DO

! GATES

DO JG=1,NGT GRID

IF(EGT(JG) < EL(2,I) .AND. DYNGTC(JG) .NE. ' FLOW')THEN ! DISREGARDING IF CREST ABOVE

$\operatorname{IF}(\mathrm{ID}==\operatorname{IUGT}(\mathrm{JG}))$ THEN

$\operatorname{IF}\left(\mathrm{DYNGTC}(\mathrm{JG})==\right.$ ' $\left.\quad \mathrm{B}^{\prime}\right)$ THEN

WSUP=EGT(JG)+(QSSI(ID)/(A1GT(JG)*BGT(JG)**G1GT(JG)))**(1.0/B1GT(JG))

END IF

$\operatorname{IF}\left(\mathrm{DYNGTC}(\mathrm{JG})=={ }^{\prime} \quad\right.$ ZGT')THEN

WSUP $=\mathrm{EGT}(\mathrm{JG})+(\mathrm{QSSI}(\mathrm{ID}) / \mathrm{A} 1 \mathrm{GT}(\mathrm{JG}))^{* *}(1.0 / \mathrm{B} 1 \mathrm{GT}(\mathrm{JG}))$

END IF

$\operatorname{IF}($ ELWS(ID) $<$ WSUP)THEN

$! \quad$ IF(ELWS(IDSP(JS)) $>$ WSUP) WSUP = ELWS(IDSP(JS)) ! CHECKING TO SEE IF DOWNSTREAM WS ELEVATION ISN'T ALREADY 'HIGH'

$! \quad$ IF(IDGT(JG) NE 0)THEN

! IF(ELWS(IDGT(JG)) > WSUP) WSUP $=$ ELWS(IDGT(JG)) $\quad$ !WX 08/20/13 UNLIKE A

SPILLWAY,ELEVATION UPSTREAM A GATE CAN BE LOWER THAN DOWNSTREAM

ELWS(ID) $=$ WSUP

END IF

DO I=ID-1,IU,-1

$\operatorname{IF}($ ELWS $(\mathrm{I}+1)>$ ELWS(I))THEN

$\operatorname{ELWS}(\mathrm{I})=\operatorname{ELWS}(\mathrm{I}+1)$

END IF

END DO

END IF

END IF

END IF

END DO

END IF

END DO

END DO

! SMOOTHING WATER LEVEL AROUND LOOP BRANCHES ～!\&ELWS(IU-1) ELWS(ID+1) !WX 4/11/13 DO JW=1,NWB 


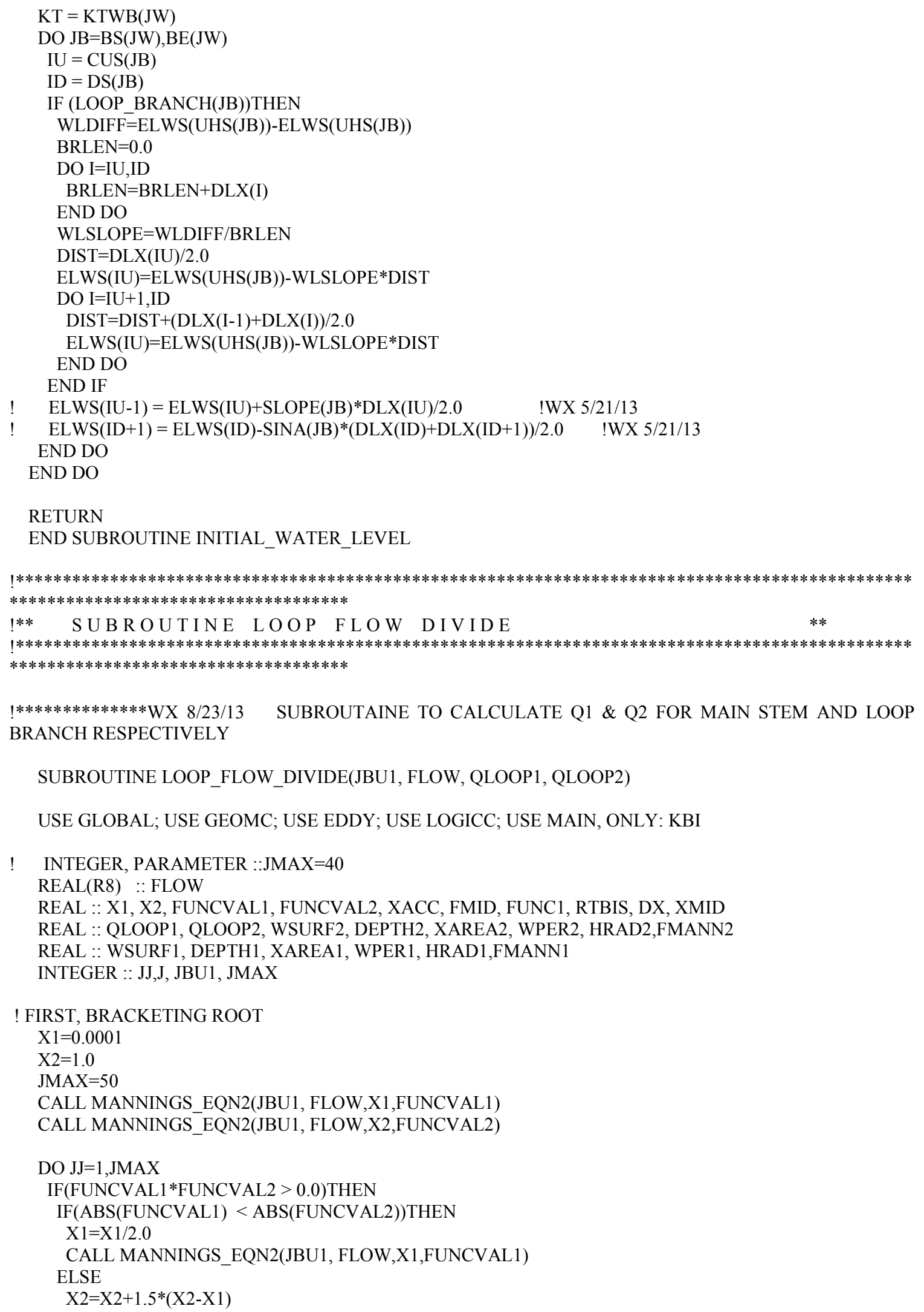




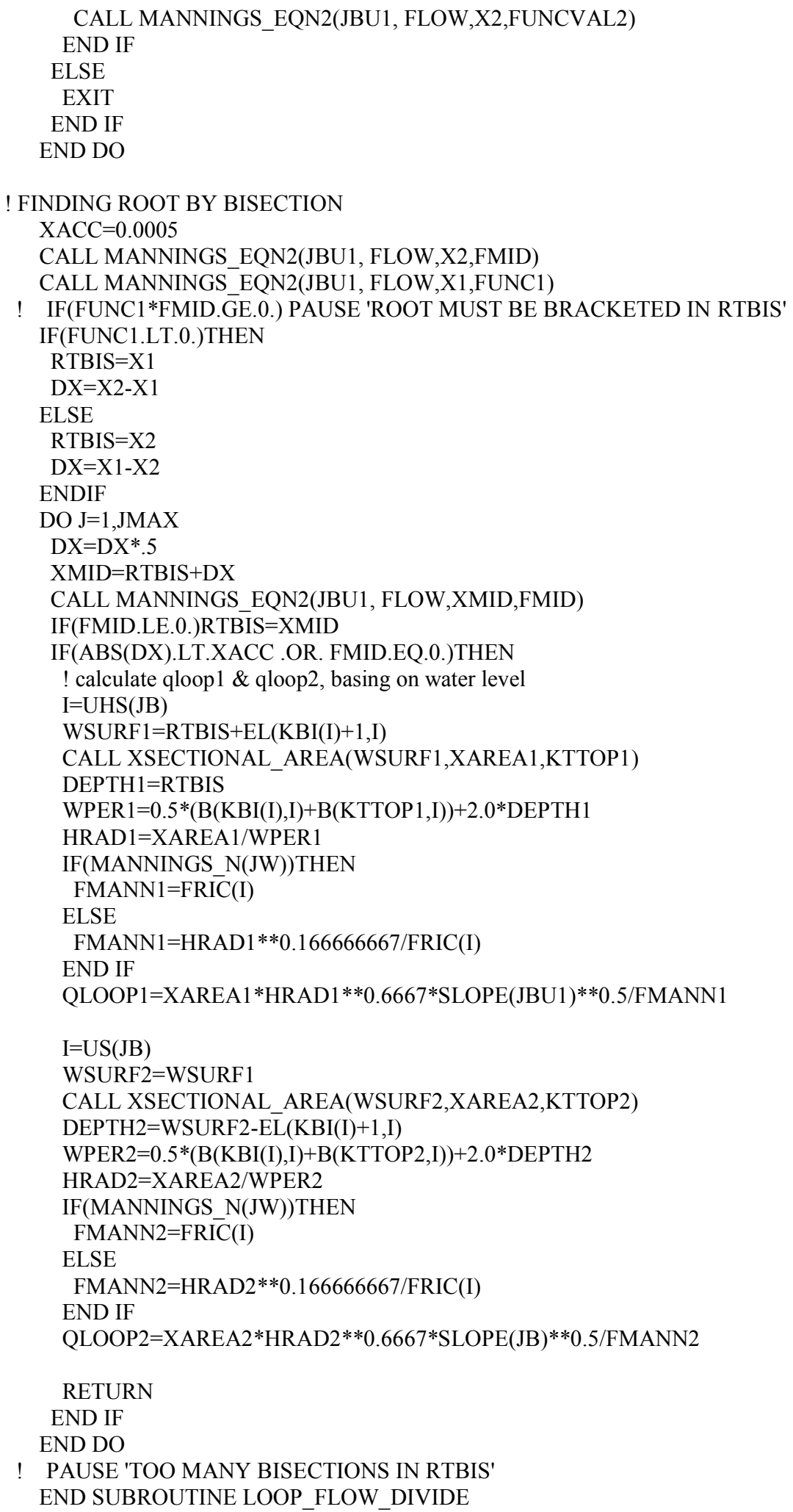




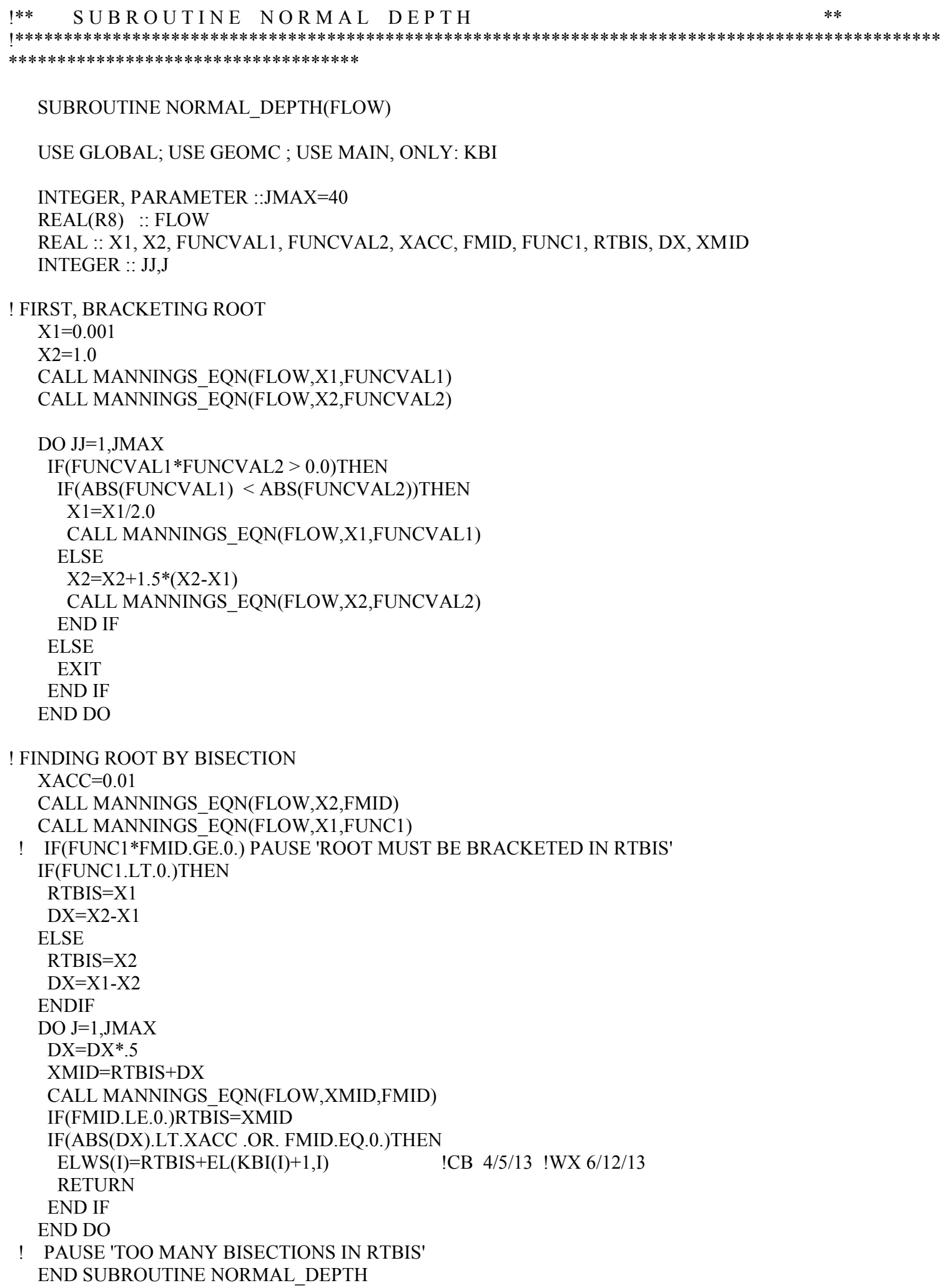




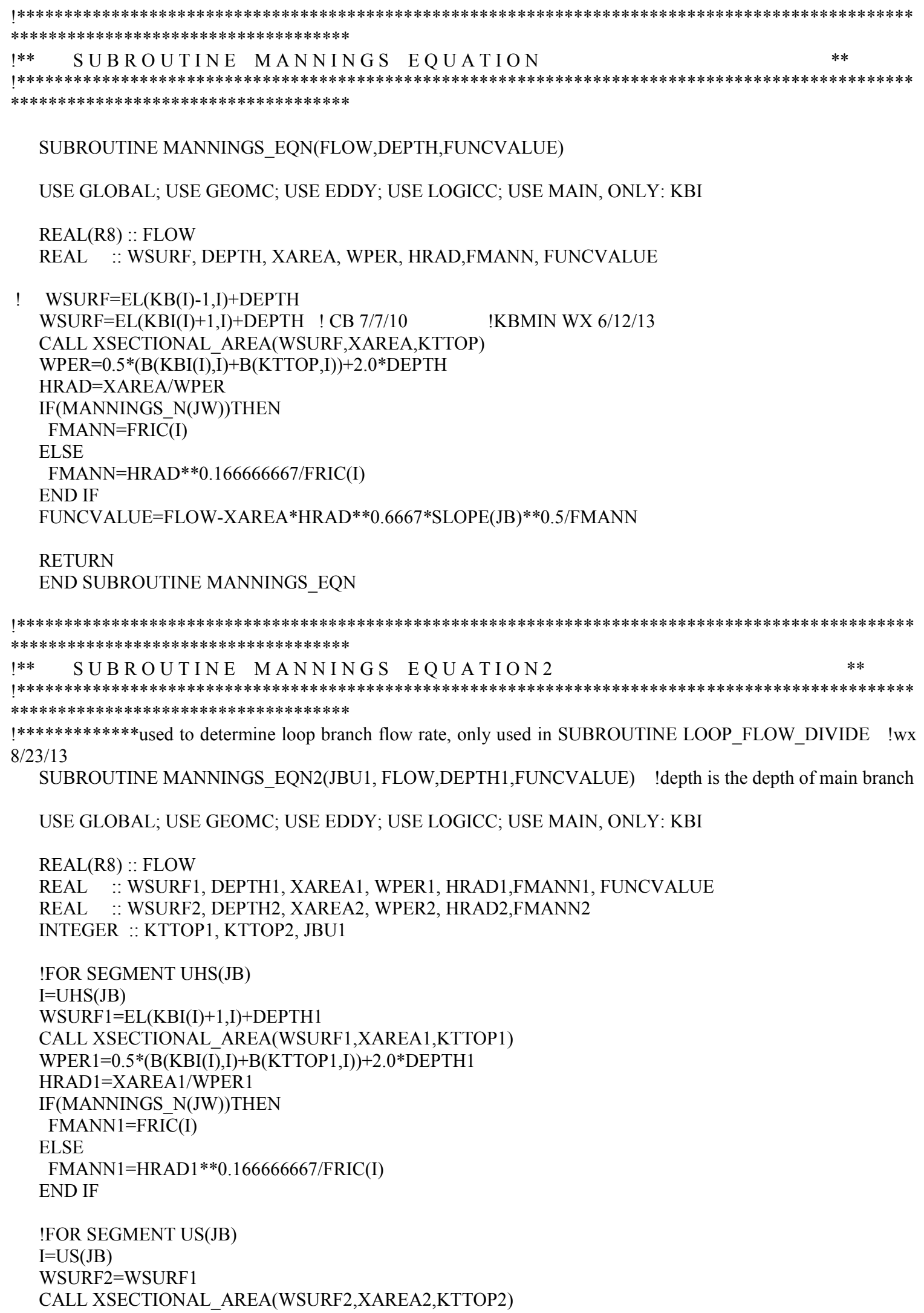




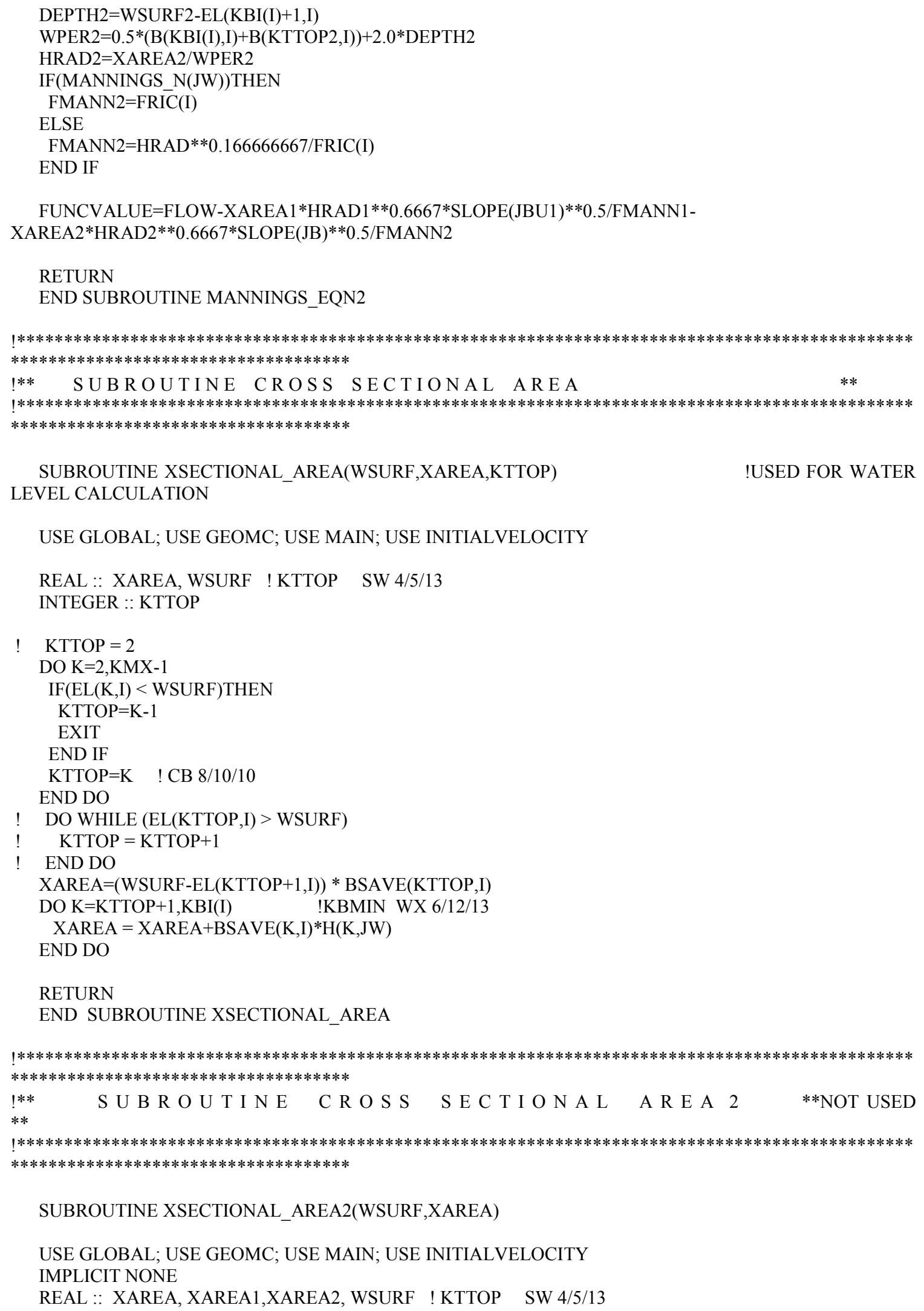




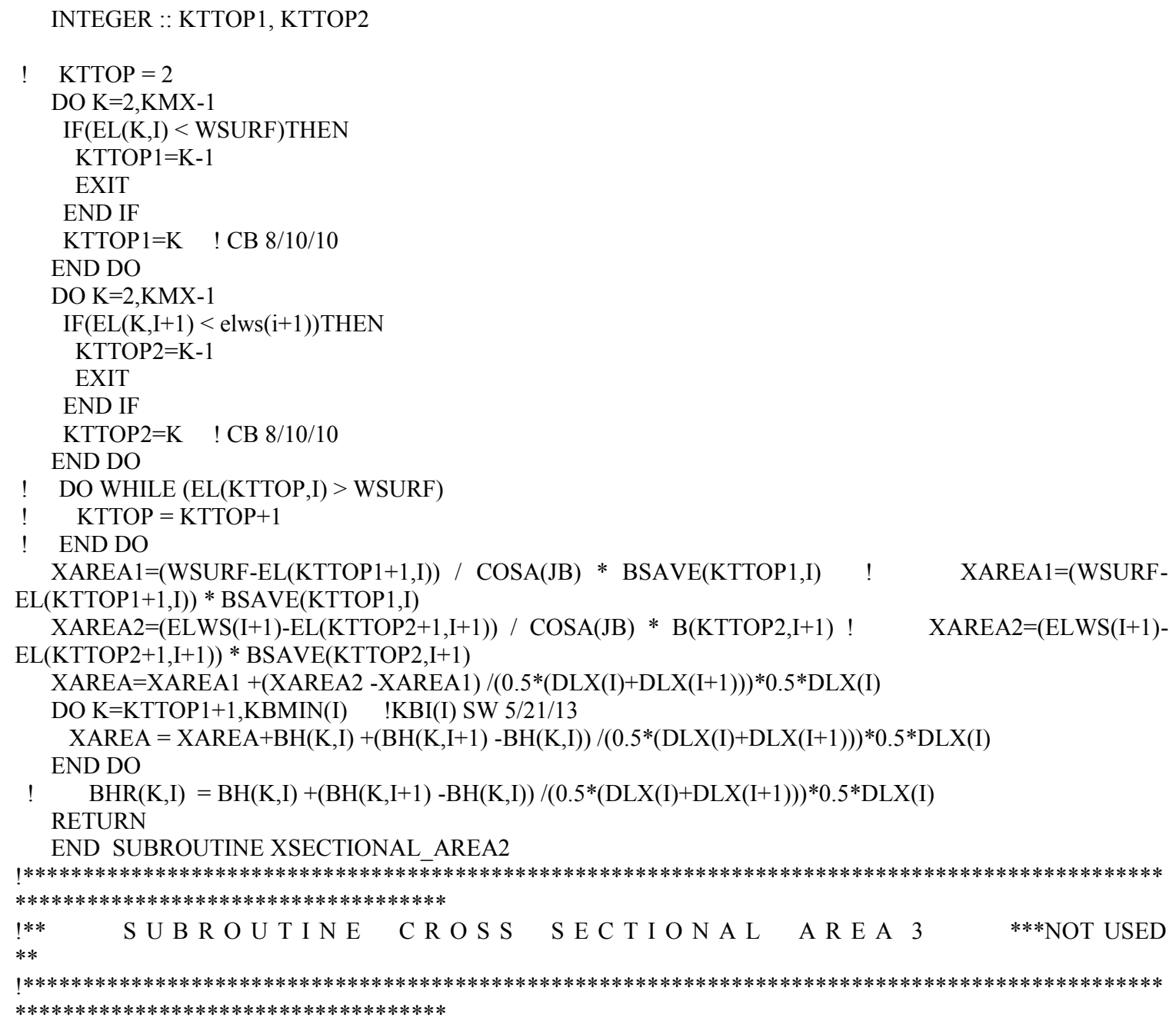




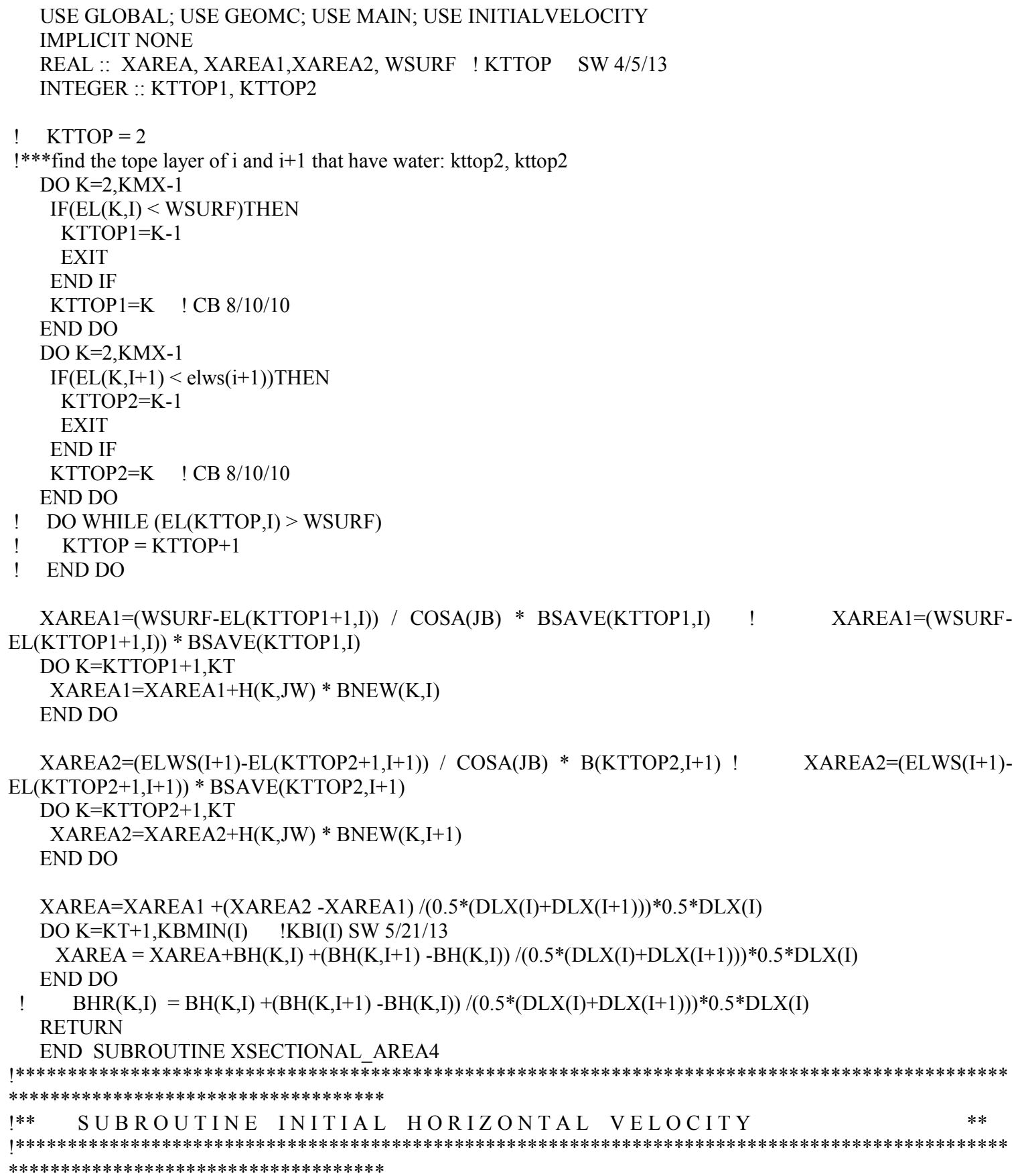




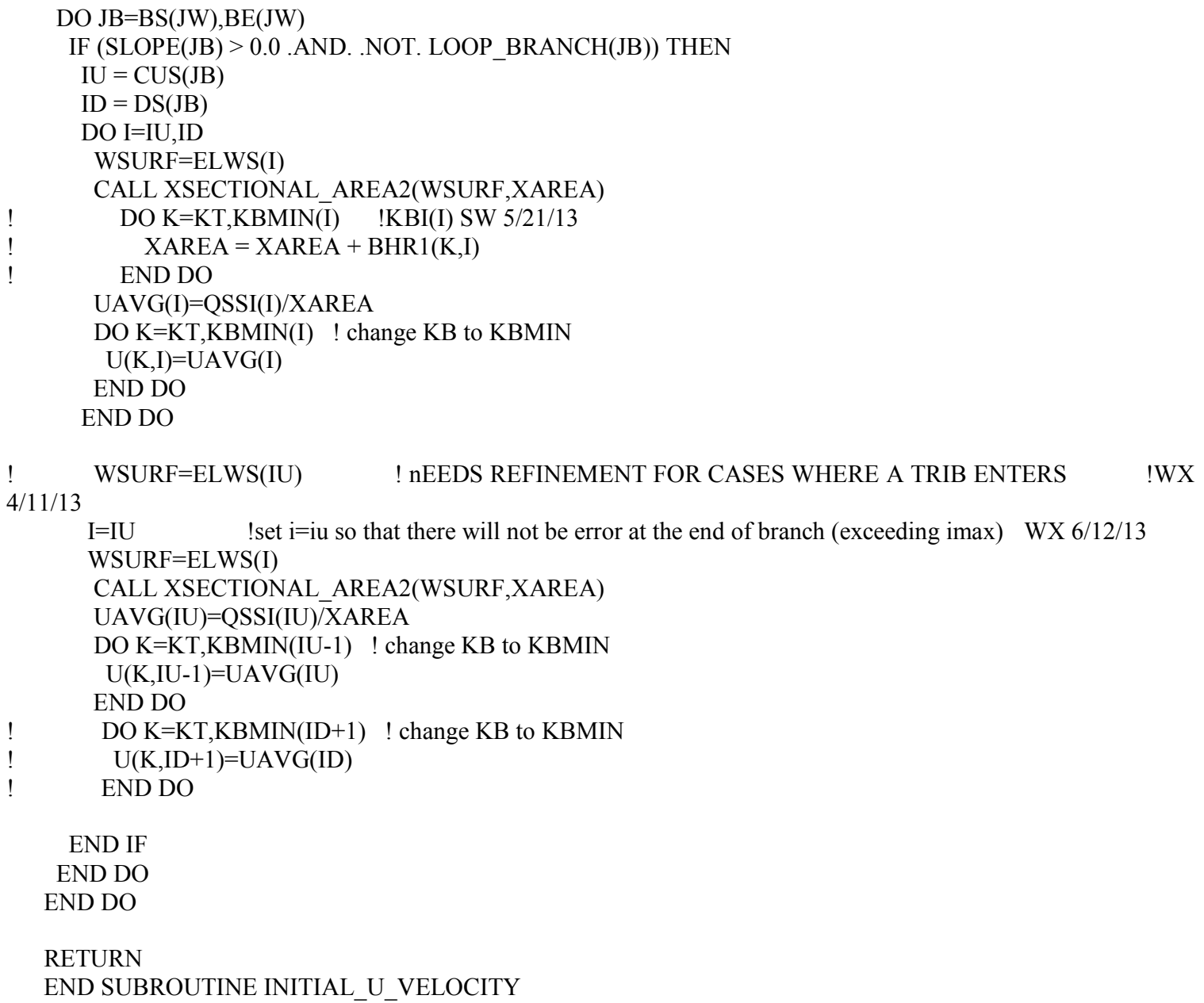




\section{hydroinout.F90}

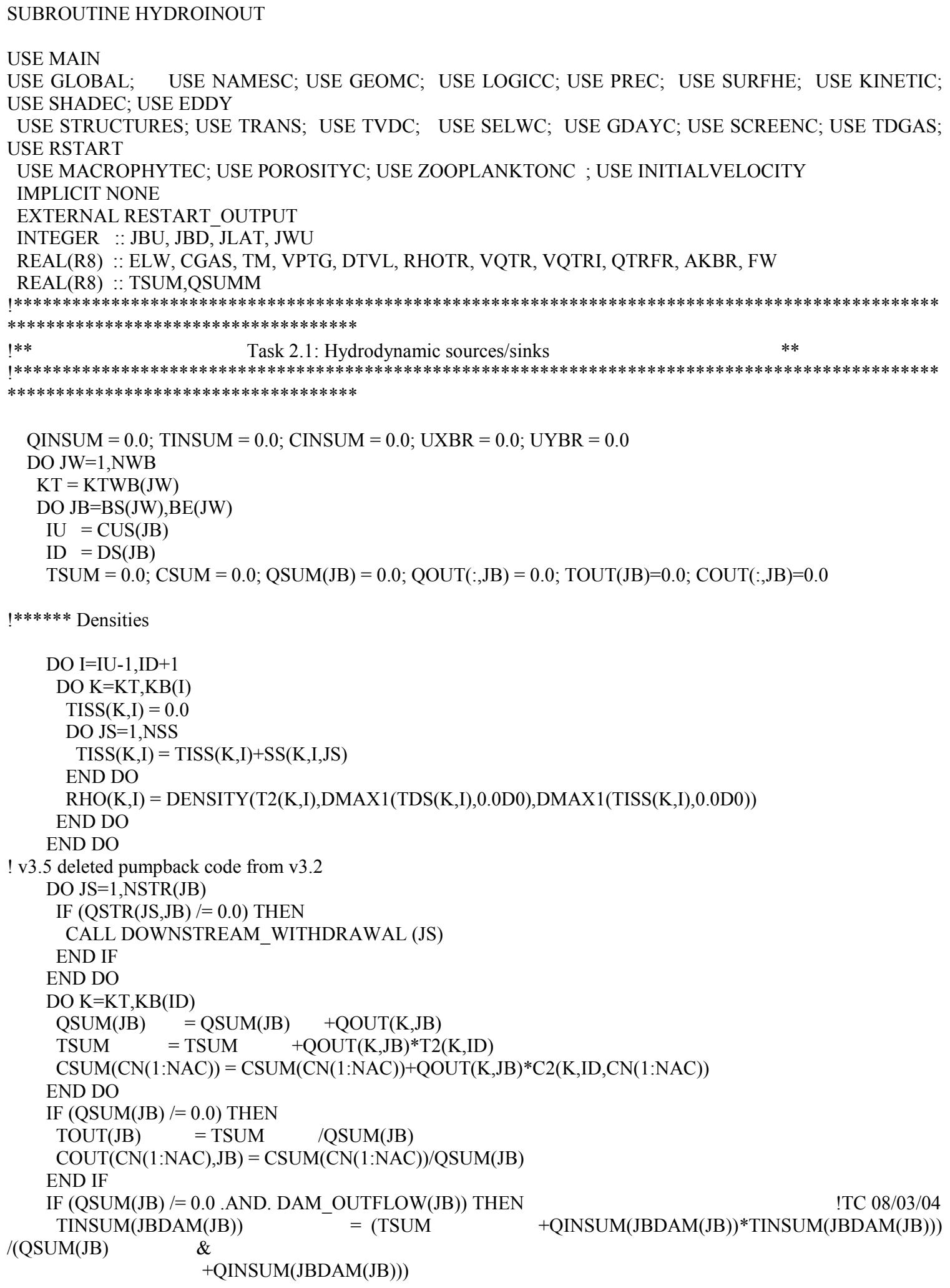




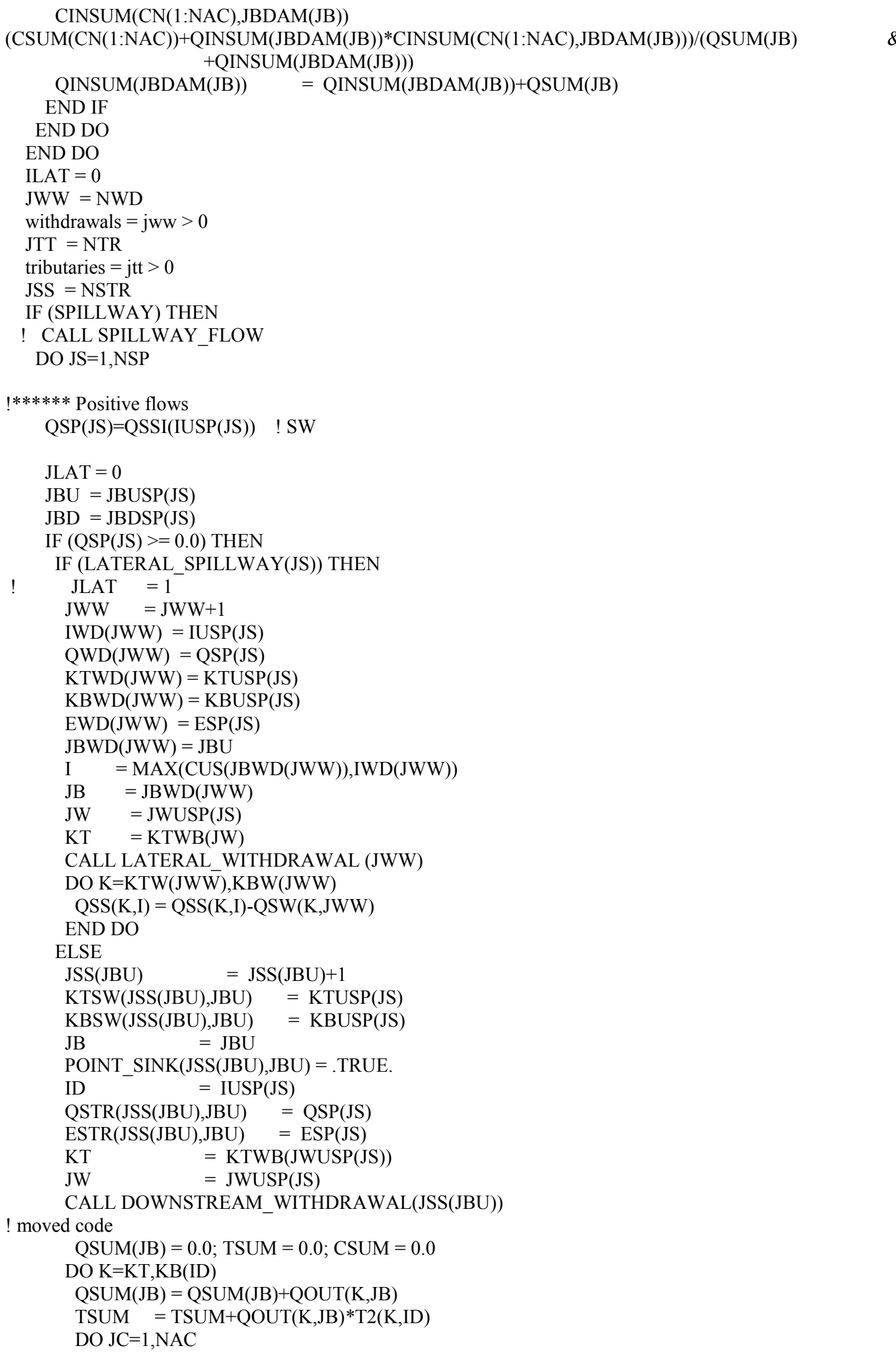




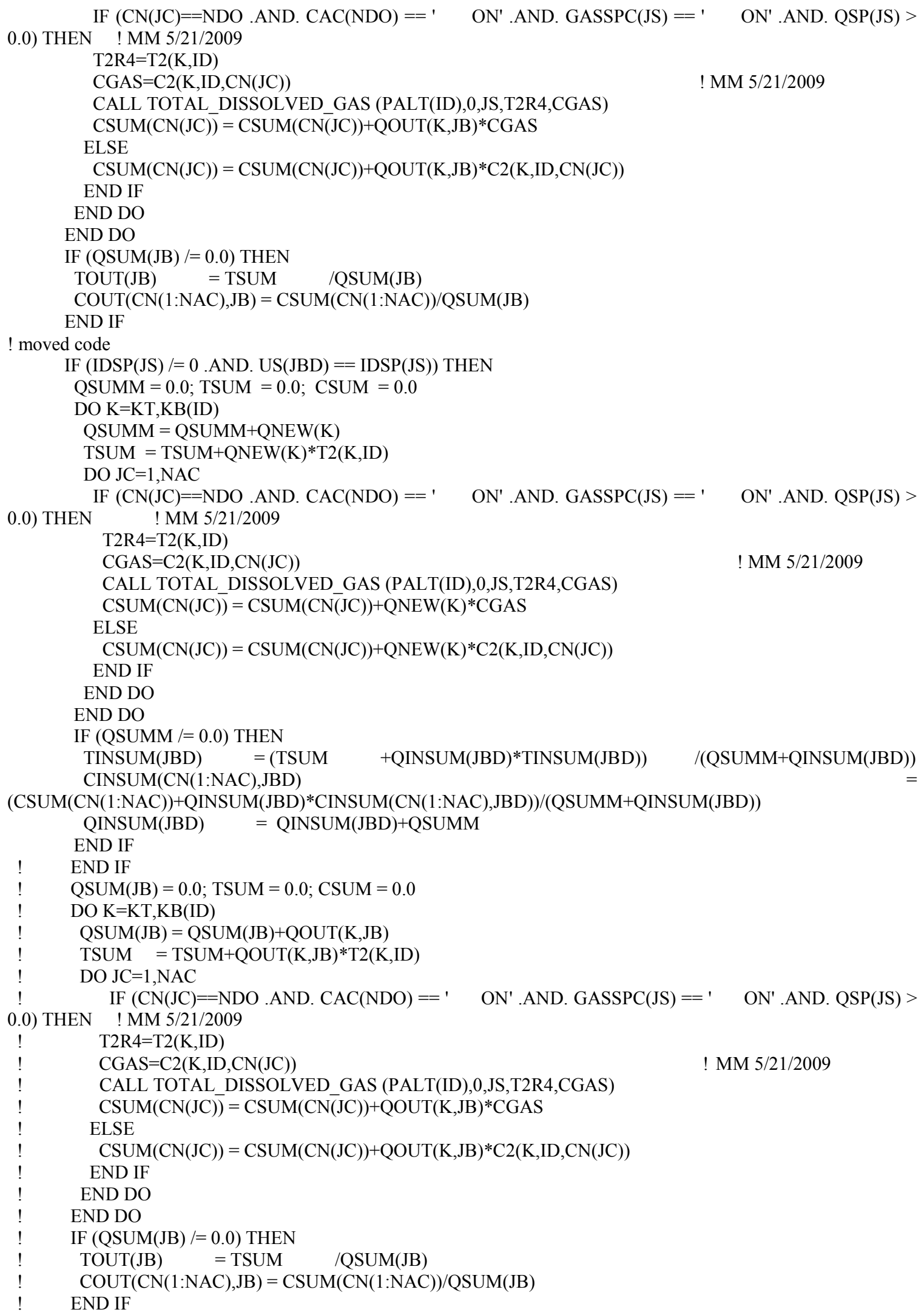




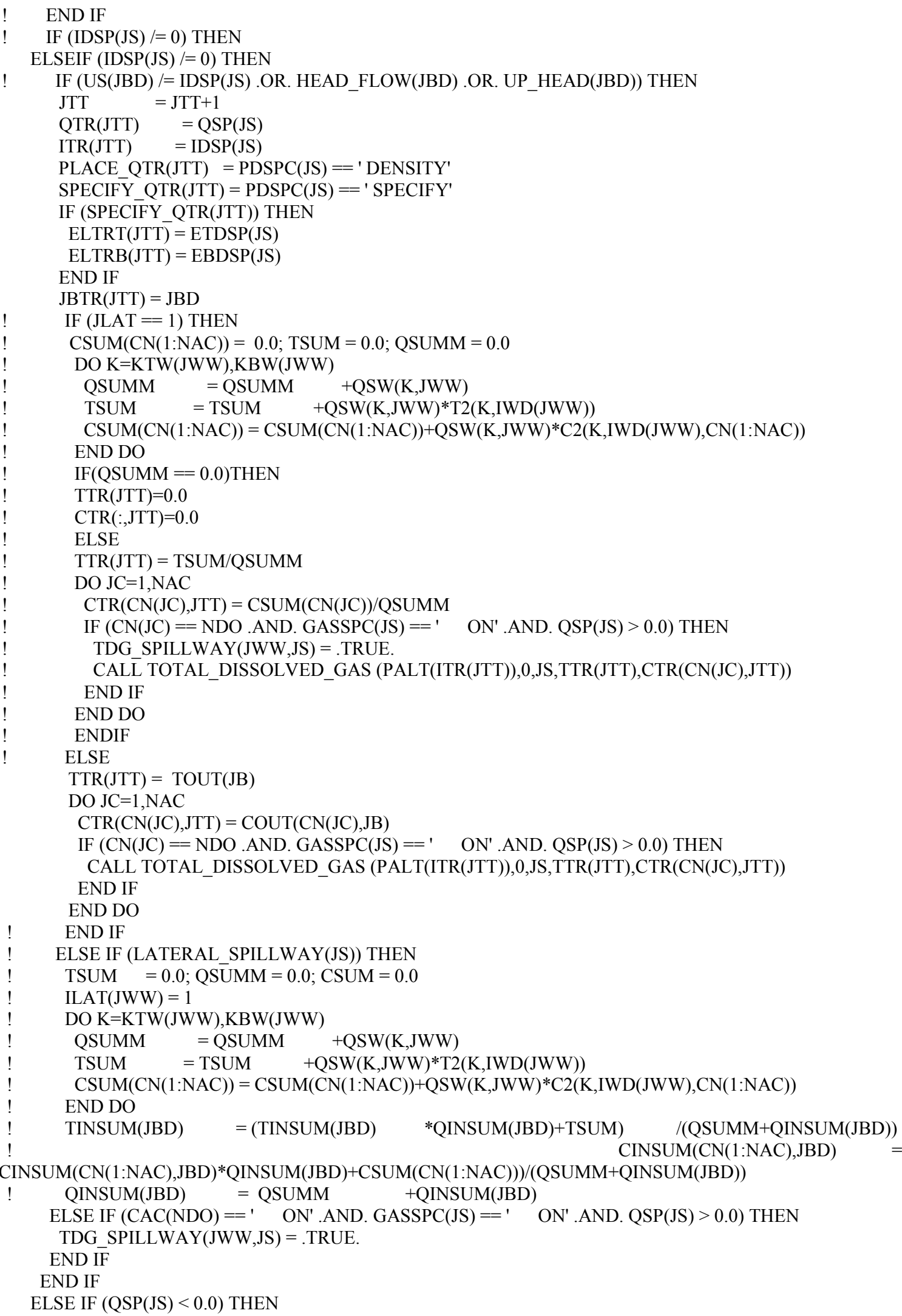




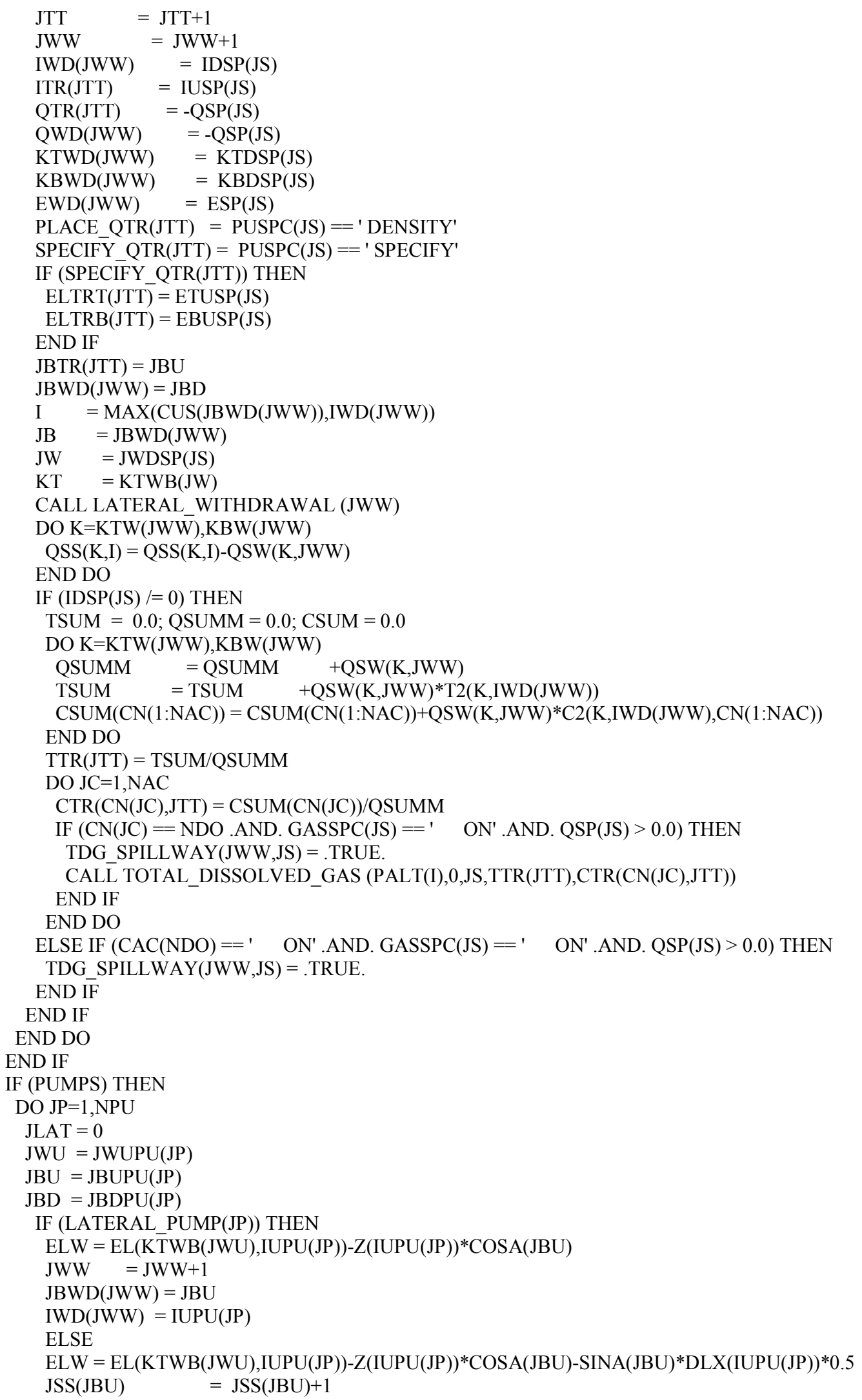




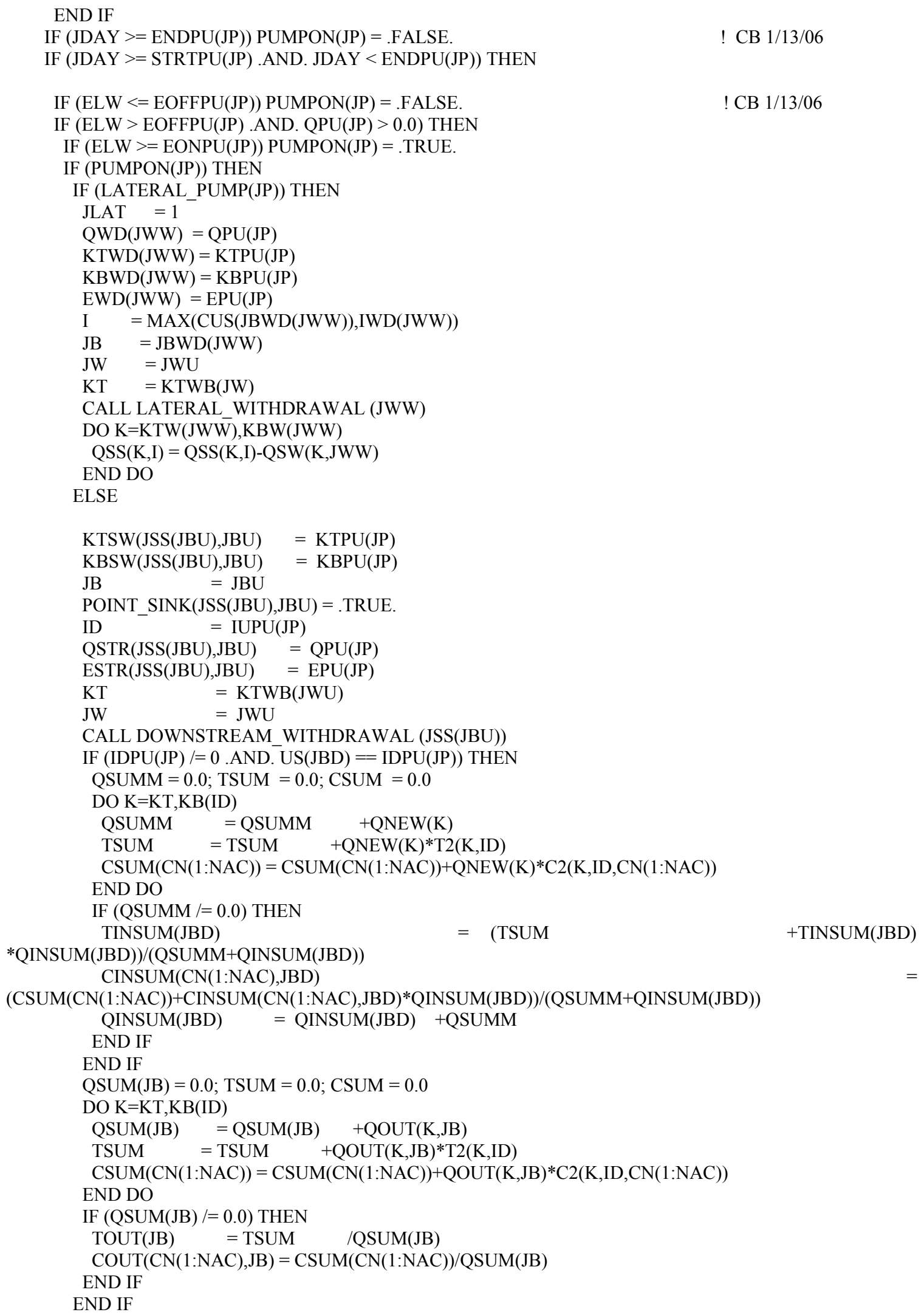




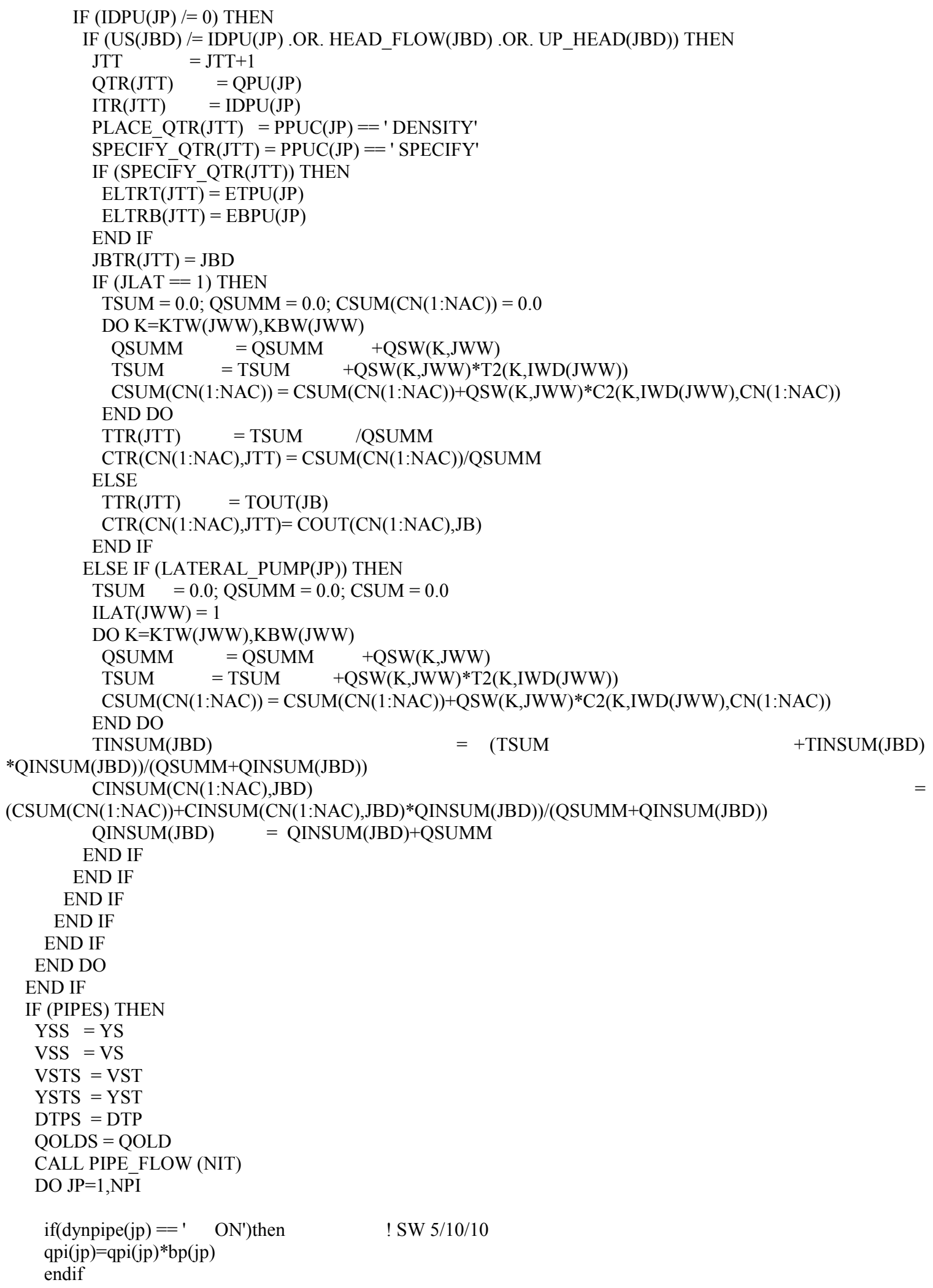




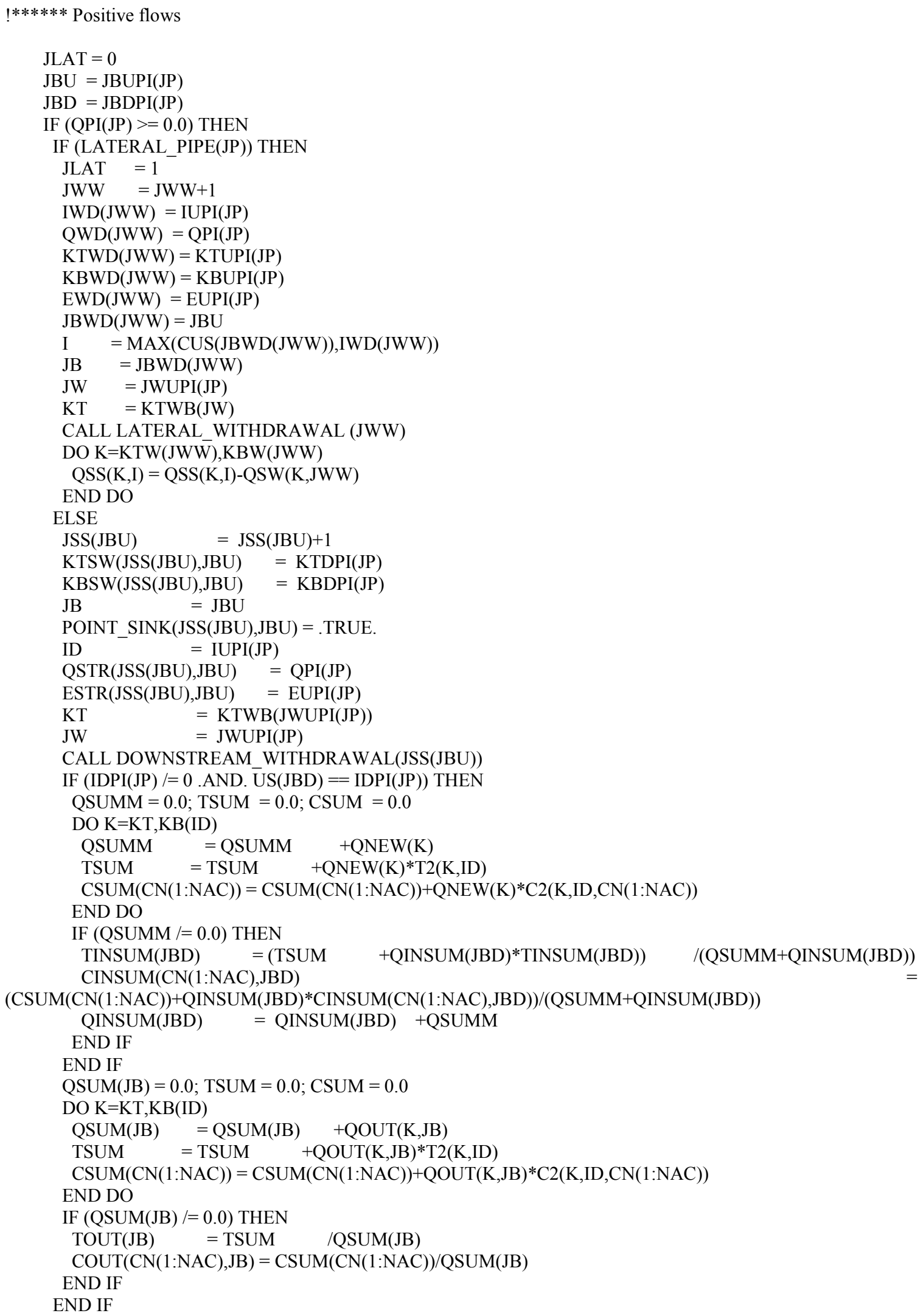




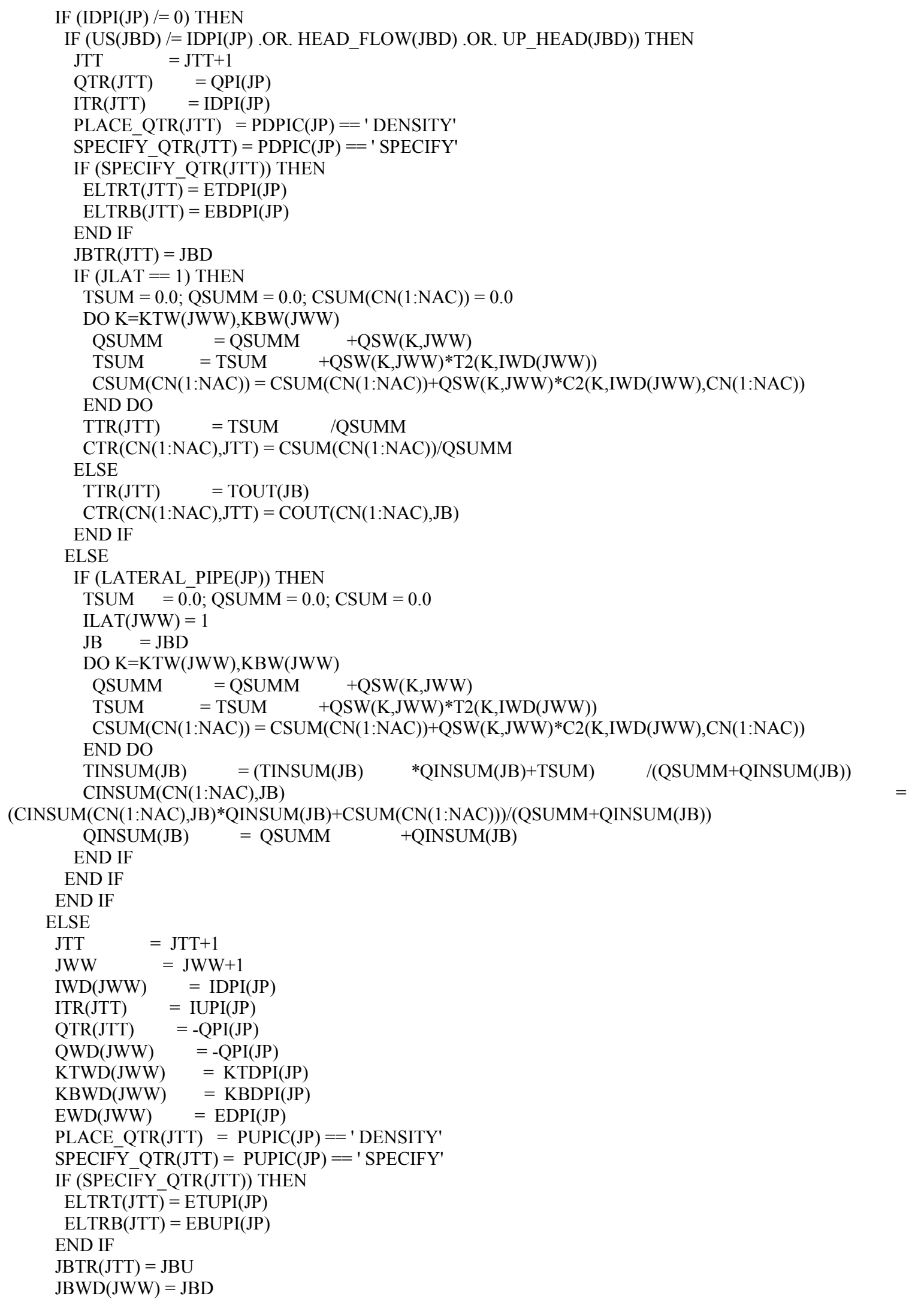




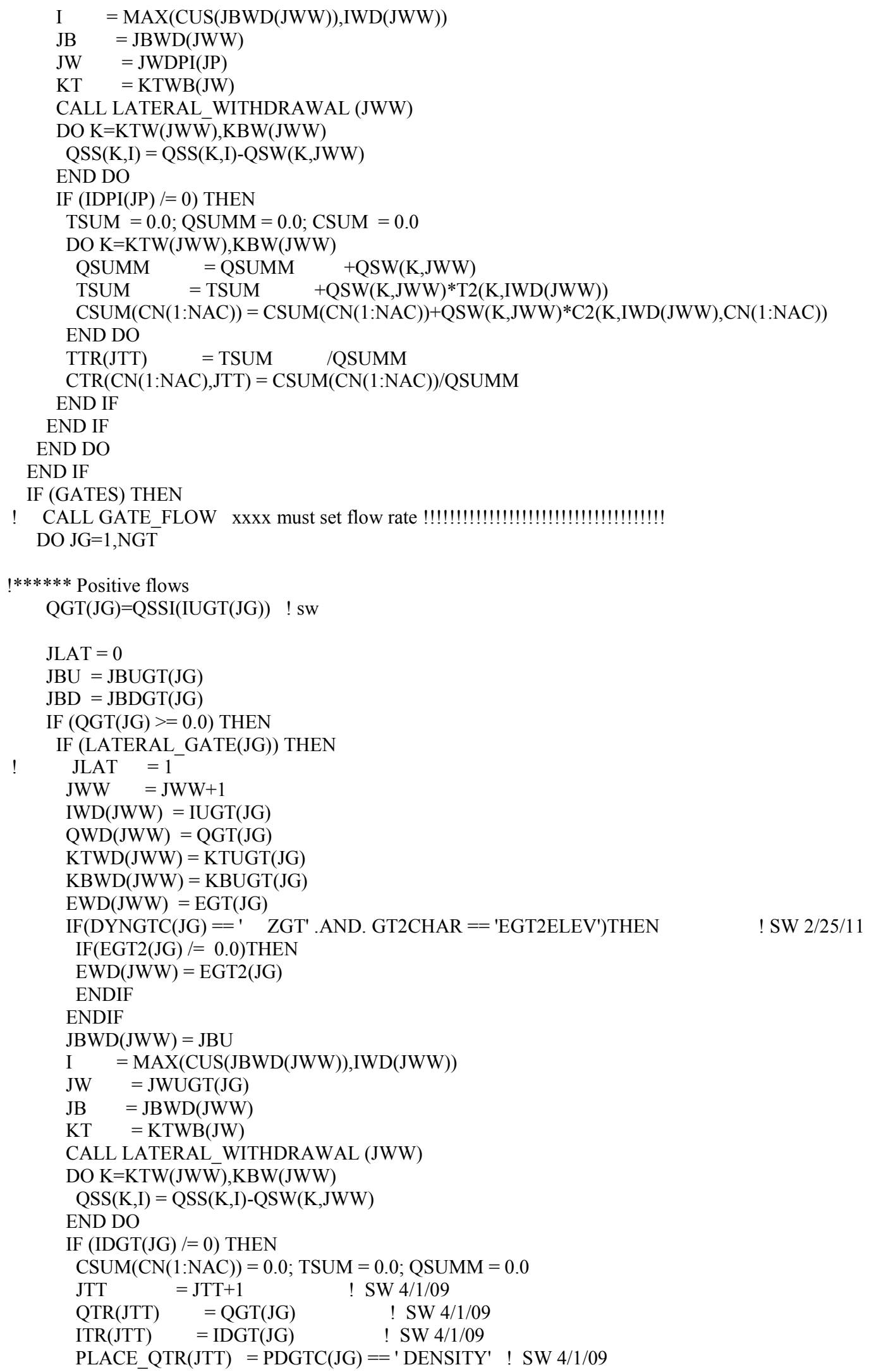




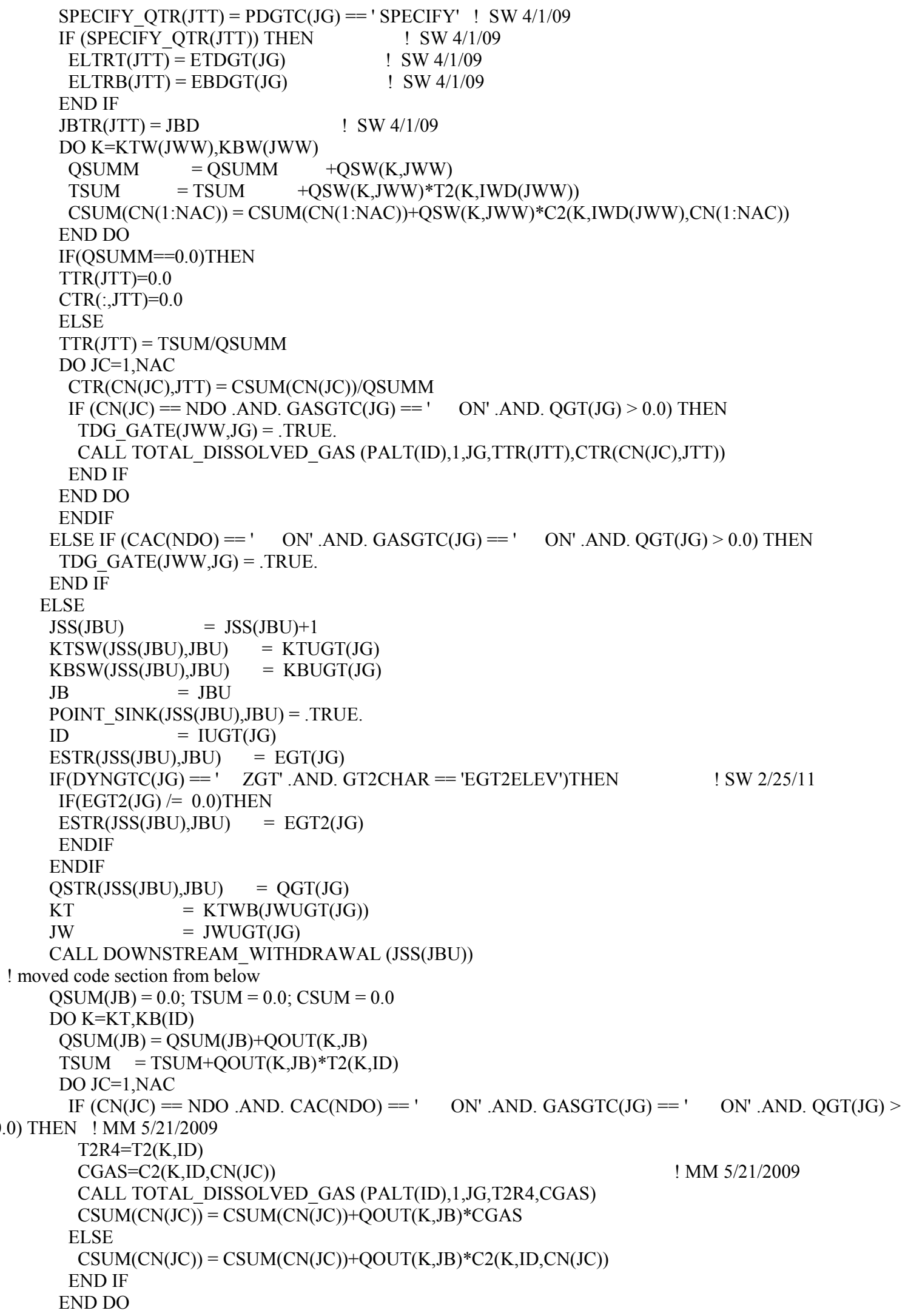




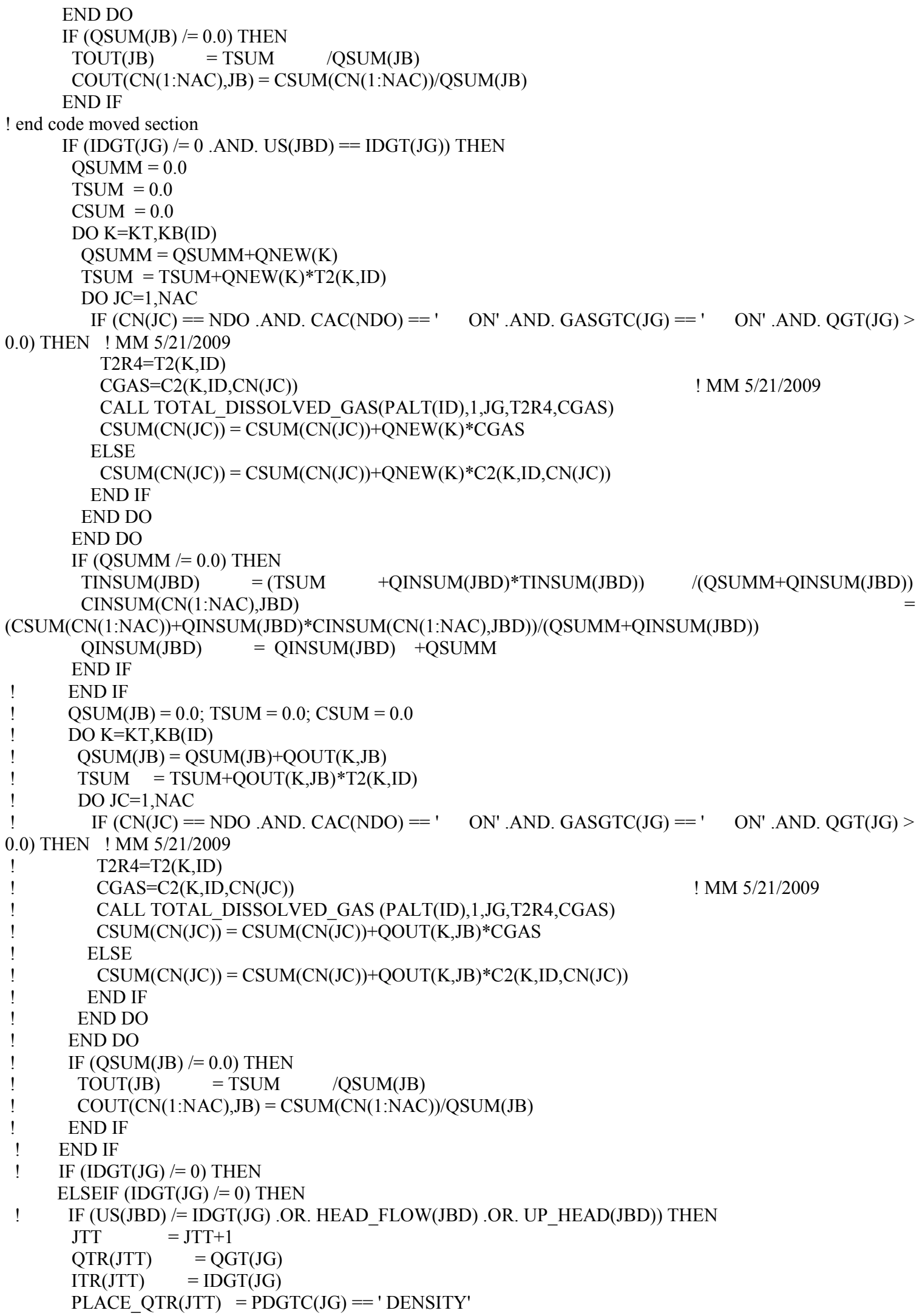




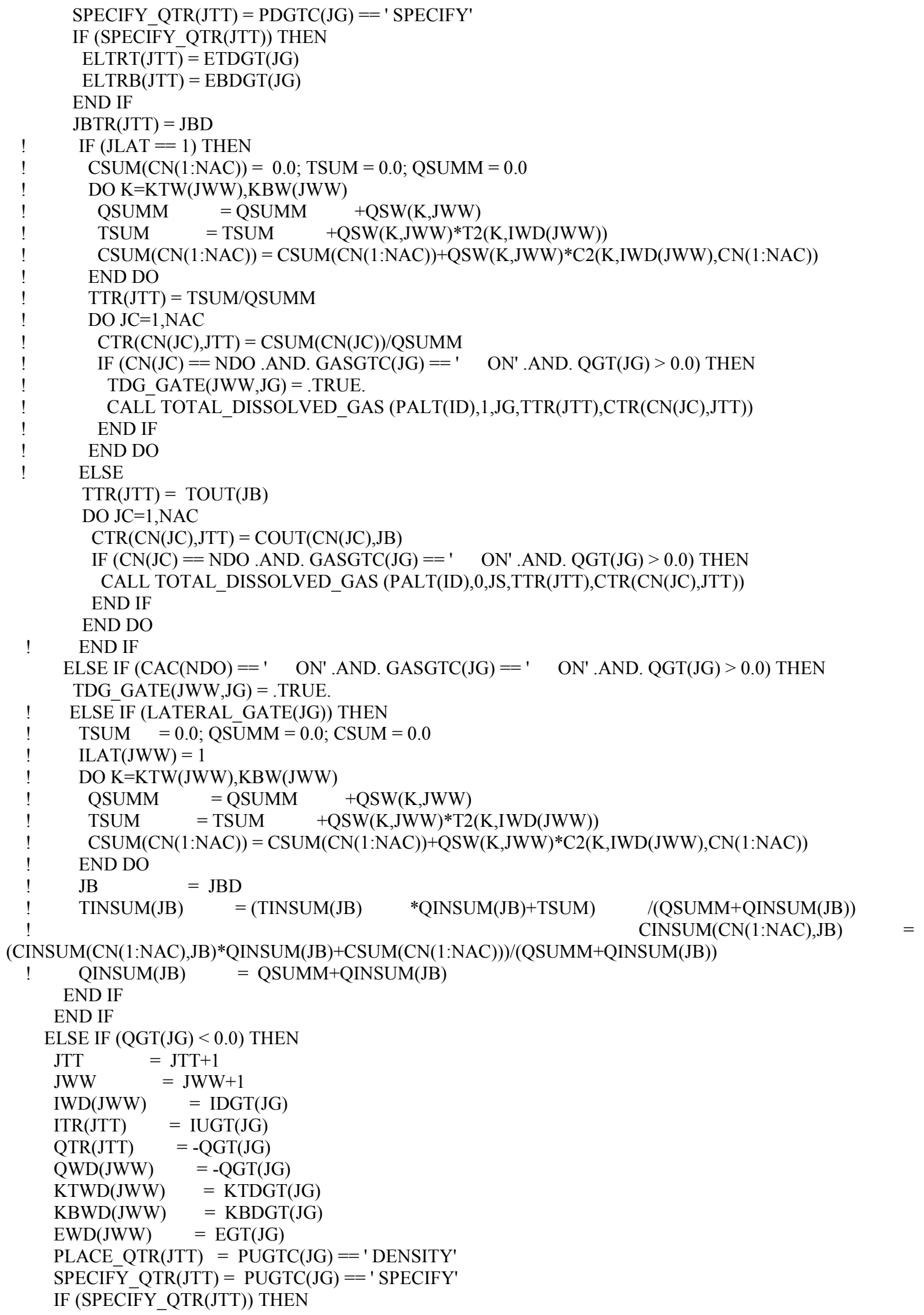




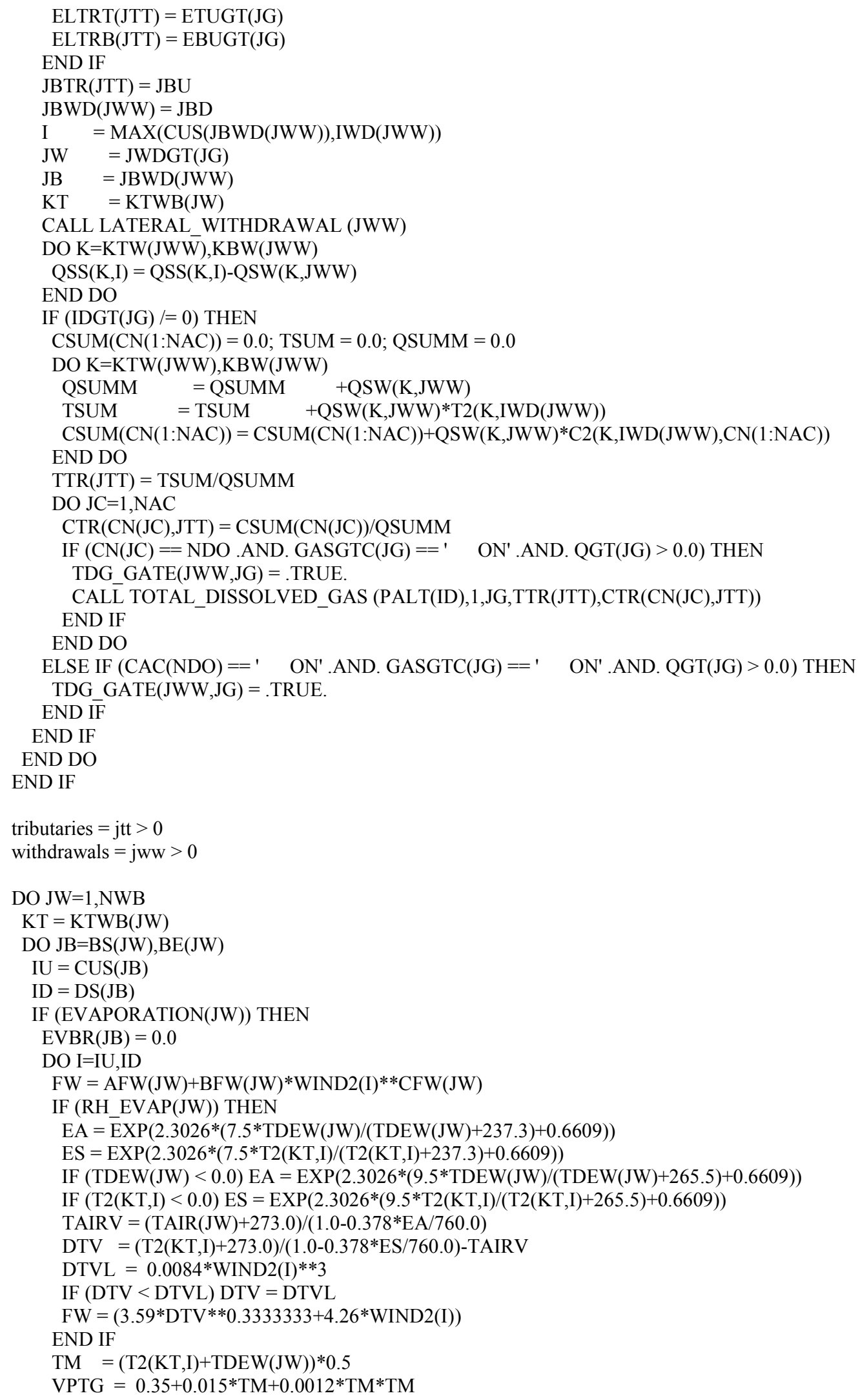




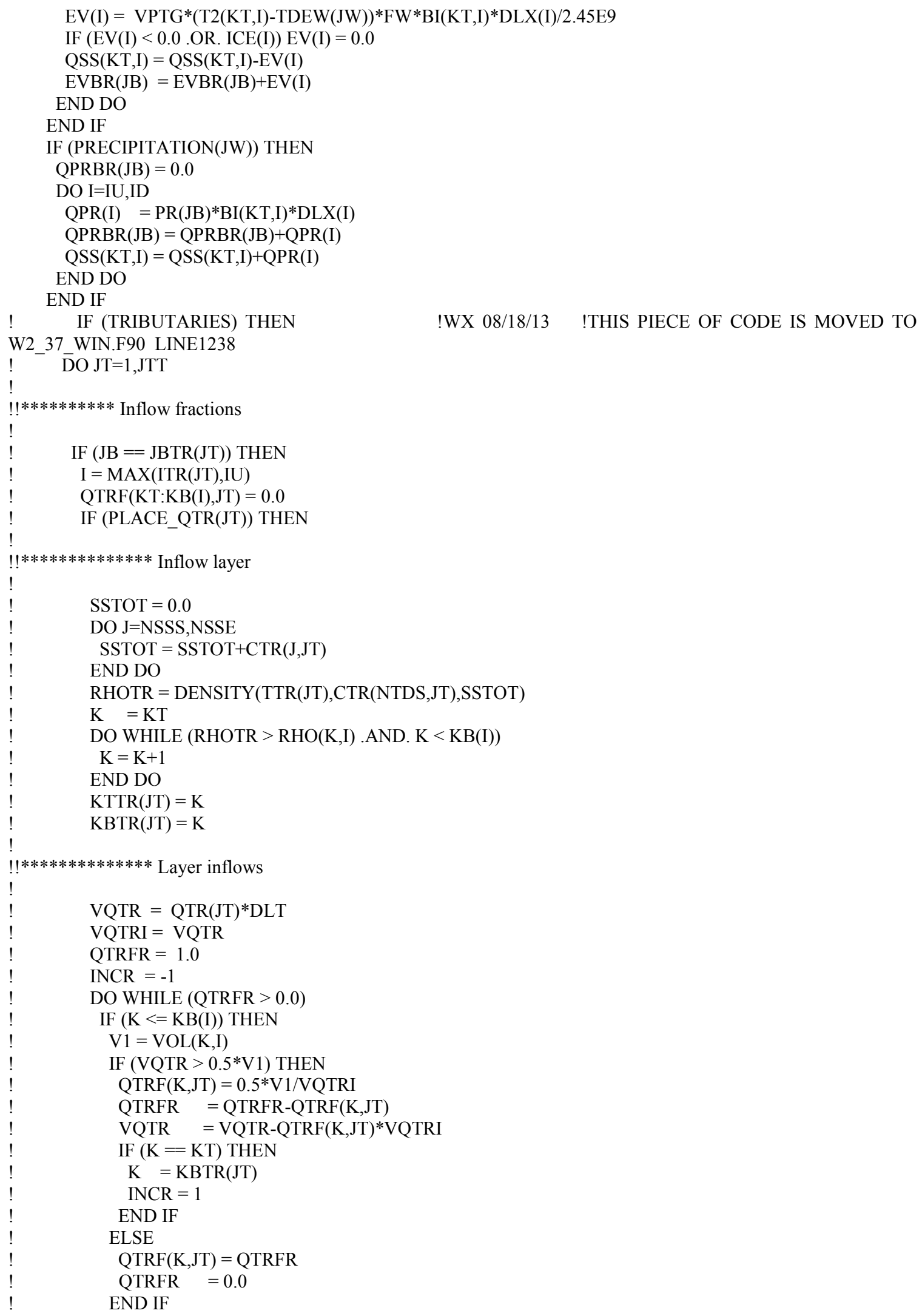




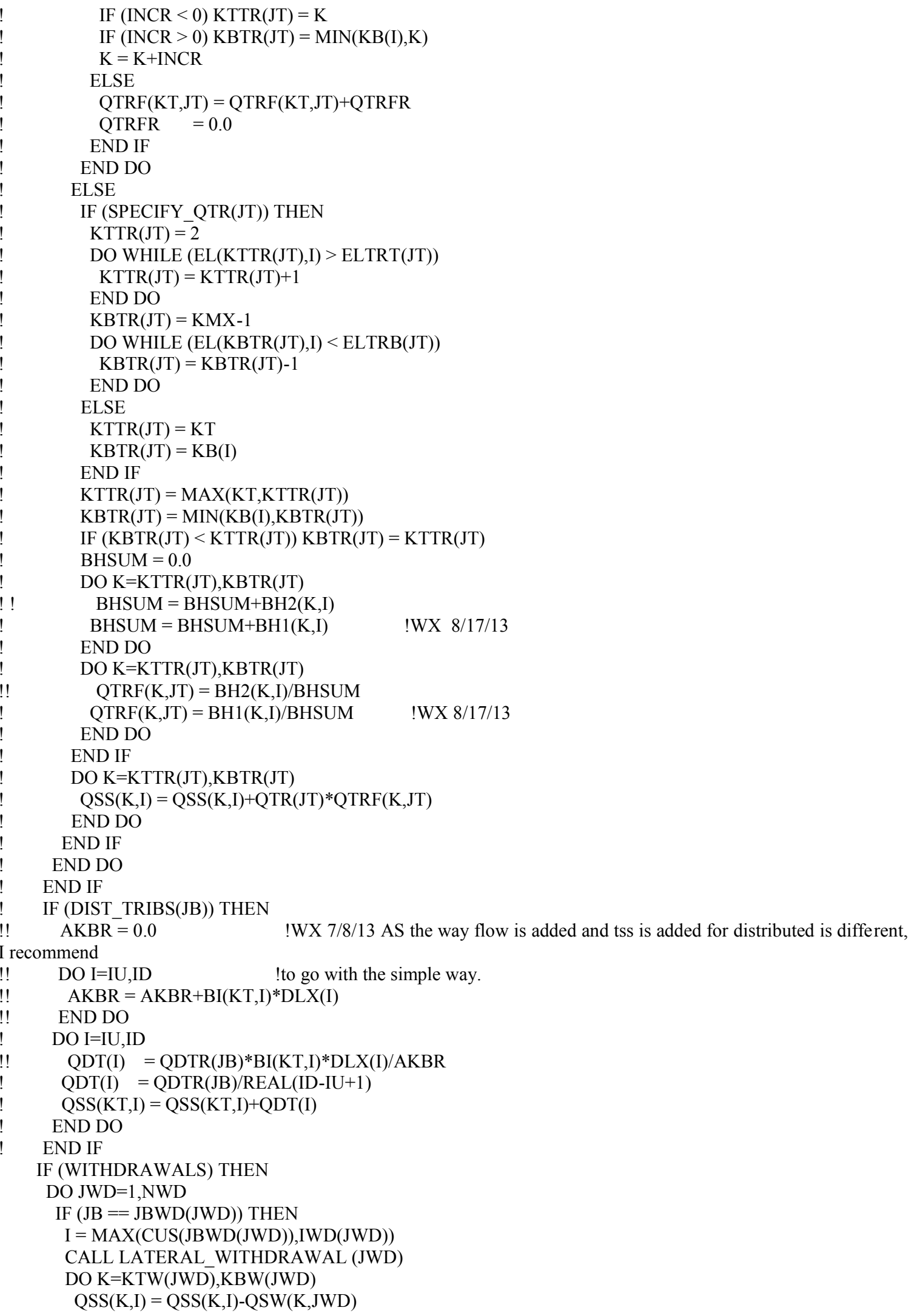




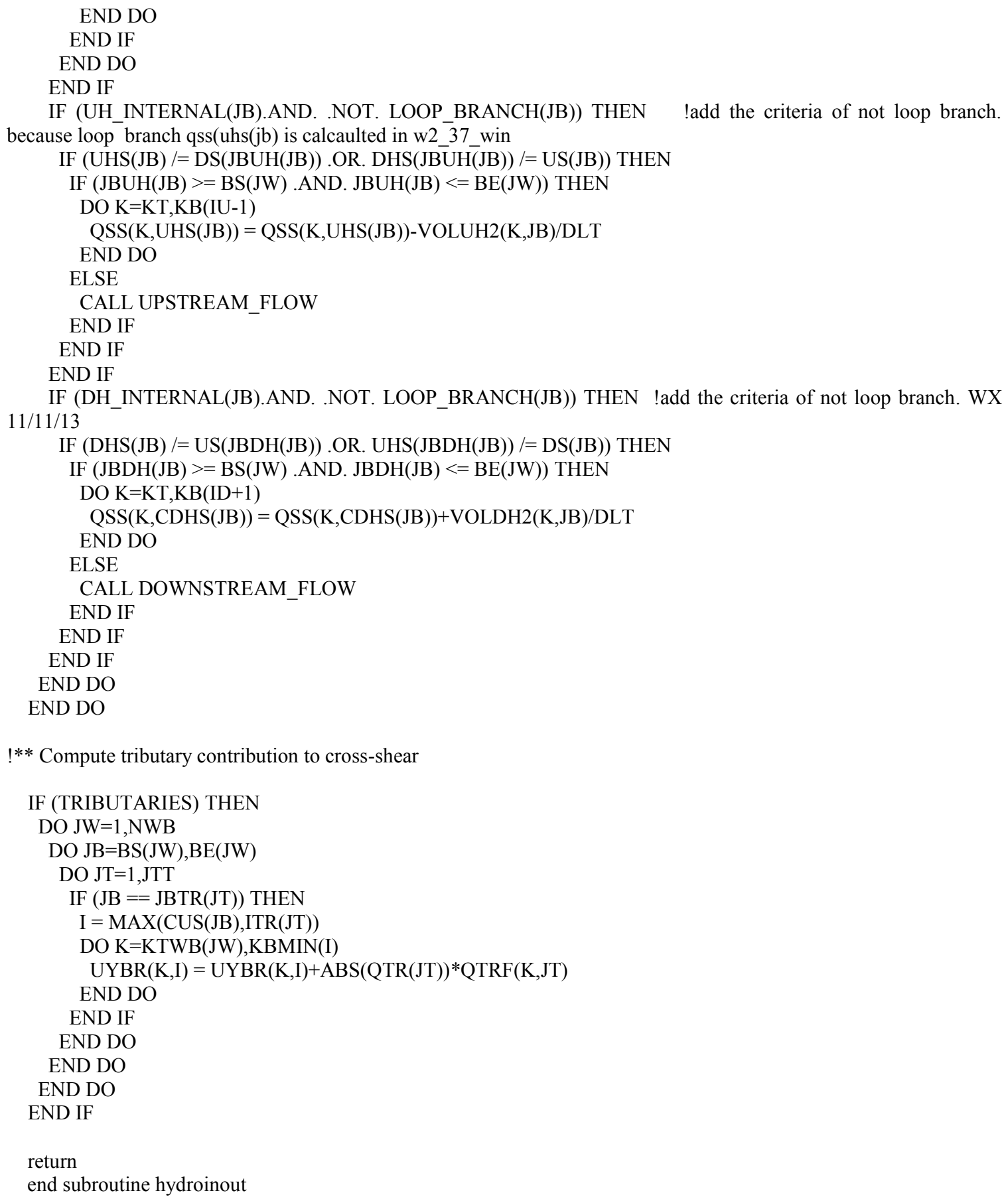




\section{temperature.F90}

subroutine temperature

USE MAIN

USE GLOBAL; USE NAMESC; USE GEOMC; USE LOGICC; USE PREC; USE SURFHE; USE KINETIC; USE SHADEC; USE EDDY

USE STRUCTURES; USE TRANS; USE TVDC; USE SELWC; USE GDAYC; USE SCREENC; USE TDGAS; USE RSTART

USE MACROPHYTEC; USE POROSITYC; USE ZOOPLANKTONC; USE INITIALVELOCITY, ONLY: QSSI

USE INITIALVELOCITY

IMPLICIT NONE

EXTERNAL RESTART_OUTPUT

REAL RN1

INTEGER ::JLOOP !WX 8/25/13

DO JW=1,NWB

$\mathrm{KT}=\mathrm{KTWB}(\mathrm{JW})$

IF (.NOT. NO_HEAT(JW)) THEN

IF (.NOT. READ_RADIATION(JW)) CALL SHORT_WAVE_RADIATION (JDAY)

IF (TERM BY TERM(JW))THEN ISW 1/25/05

IF(TAIR(JW).GE.5.0)THEN

RANLW $(J W)=5.31 \mathrm{D}-13 *(273.15 \mathrm{D} 0+\mathrm{TAIR}(\mathrm{JW})) * 6^{*}(1.0 \mathrm{D} 0+0.0017 \mathrm{D} 0 * \mathrm{CLOUD}(\mathrm{JW}) * * 2) * 0.97 \mathrm{D} 0$

ELSE

RANLW $(\mathrm{JW}) \quad=\quad 5.62 \mathrm{D}-8 *(273.15 \mathrm{D} 0+\mathrm{TAIR}(\mathrm{JW})) * 4 *(1 . \mathrm{D} 0-0.261 \mathrm{D} 0 * \mathrm{DEXP}(-7.77 \mathrm{D}-$

$4 * \mathrm{TAIR}(\mathrm{JW}) * * 2)) *(1.0 \mathrm{D} 0+0.0017 \mathrm{D} 0 * \mathrm{CLOUD}(\mathrm{JW}) * * 2) * 0.97 \mathrm{D} 0$ ENDIF

ENDIF

END IF

DO JB=BS(JW),BE(JW)

$\mathrm{IU}=\mathrm{CUS}(\mathrm{JB})$

$\mathrm{ID}=\mathrm{DS}(\mathrm{JB})$

!****** Heat exchange

IF (.NOT. NO HEAT(JW)) THEN

DO I=IU,ID

IF (DYNAMIC_SHADE(I)) CALL SHADING

$! * * * * * * * * * *$ Surface

IF (.NOT. ICE(I)) THEN

IF (TERM_BY_TERM(JW)) THEN

CALL SURFACE TERMS (T2(KT,I))

$\mathrm{RS}(\mathrm{I}) \quad=\mathrm{SRON}(\overline{\mathrm{JW}}) * \operatorname{SHADE}(\mathrm{I})$

$\mathrm{RN}(\mathrm{I})=\mathrm{RS}(\mathrm{I})+\mathrm{RANLW}(\mathrm{JW})-\mathrm{RB}(\mathrm{I})-\mathrm{RE}(\mathrm{I})-\mathrm{RC}(\mathrm{I})$

HEATEX $=\mathrm{RN}(\mathrm{I}) / \mathrm{RHOWCP} * \mathrm{BI}(\mathrm{KT}, \mathrm{I}) * \mathrm{DLX}(\mathrm{I})$

ELSE

CALL EQUILIBRIUM TEMPERATURE

HEATEX $=(\mathrm{ET}(\mathrm{I})-\mathrm{T} 2(\overline{\mathrm{K} T}, \mathrm{I})) * \operatorname{CSHE}(\mathrm{I}) * \mathrm{BI}(\mathrm{KT}, \mathrm{I}) * \mathrm{DLX}(\mathrm{I})$

END IF

$\mathrm{TSS}(\mathrm{KT}, \mathrm{I})=\mathrm{TSS}(\mathrm{KT}, \mathrm{I})+$ HEATEX

$\mathrm{TSSS}(\mathrm{JB})=\mathrm{TSSS}(\mathrm{JB})+$ HEATEX $*$ DLT

SROOUT $=(1.0 \mathrm{D} 0-\mathrm{BETA}(\mathrm{JW})) *(\operatorname{SRON}(\mathrm{JW}) * \mathrm{SHADE}(\mathrm{I}) / \mathrm{RHOWCP}) * \mathrm{BI}(\mathrm{KT}, \mathrm{I}) * \mathrm{DLX}(\mathrm{I}) * \operatorname{DEXP}(-$

GAMMA(KT,I)*DEPTHB(KT,I))

$\operatorname{TSS}(\mathrm{KT}, \mathrm{I})=\mathrm{TSS}(\mathrm{KT}, \mathrm{I})-\mathrm{SROOUT}$

$\mathrm{TSSS}(\mathrm{JB})=\mathrm{TSSS}(\mathrm{JB})-\mathrm{SROOUT} * \mathrm{DLT}$

$\mathrm{IF}(\mathrm{KT}==\mathrm{KB}(\mathrm{I})) \mathrm{THEN} \quad$ ! SW 4/18/07

SROSED $=$ SROOUT $*$ TSEDF $(J W)$ 


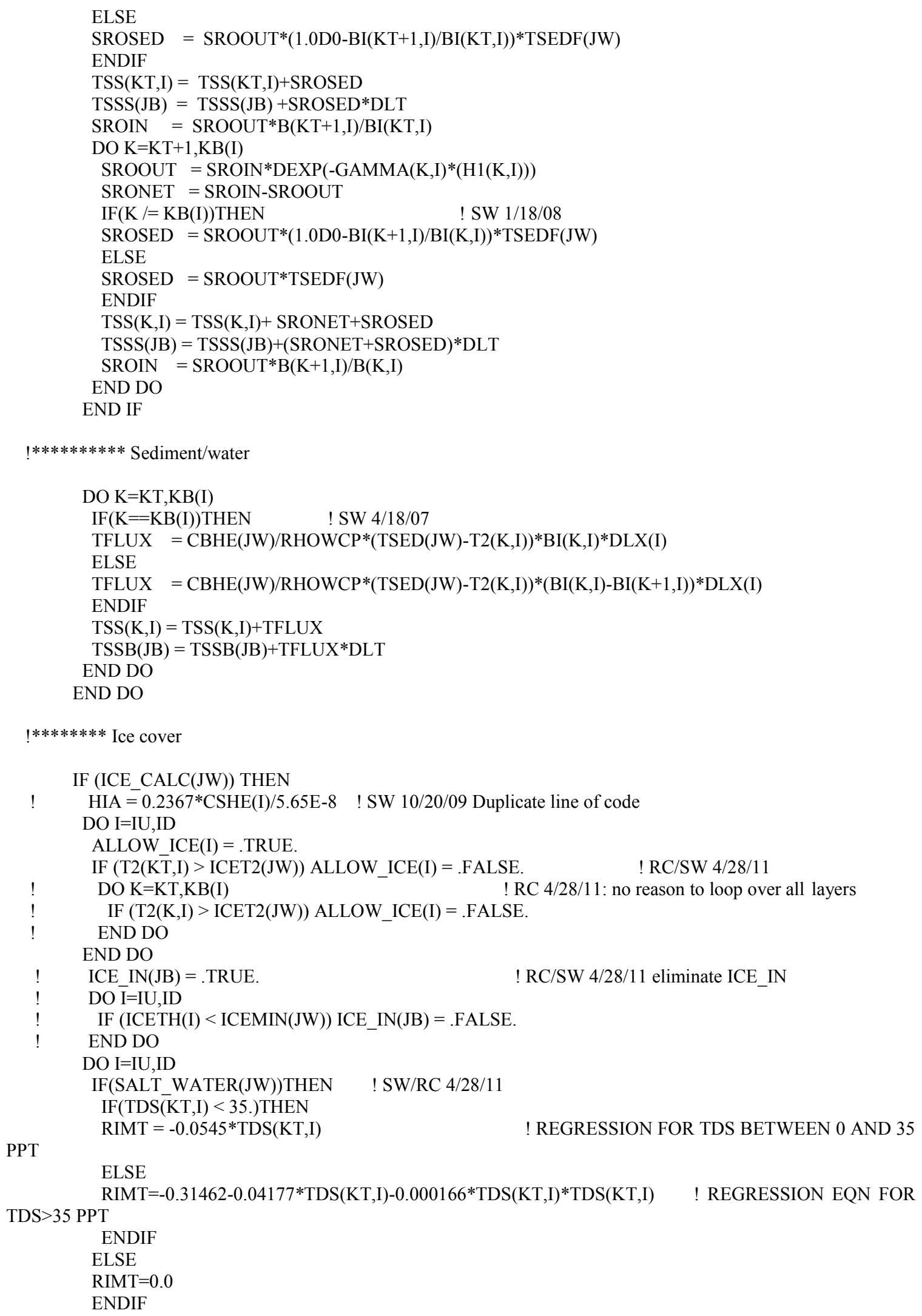




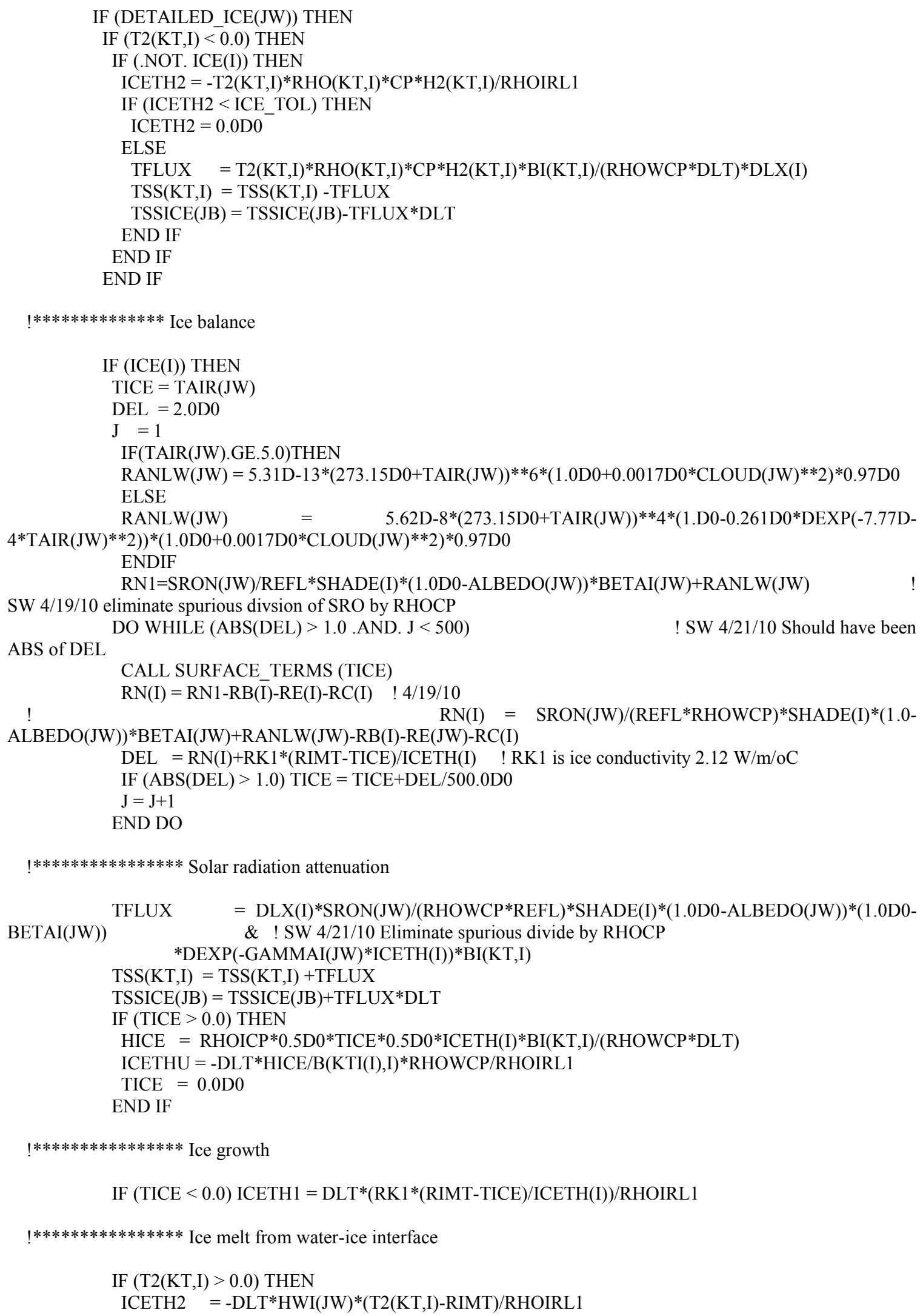




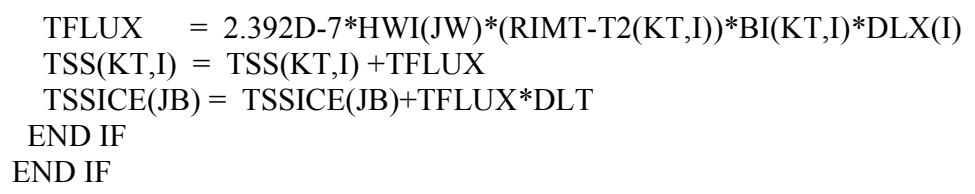




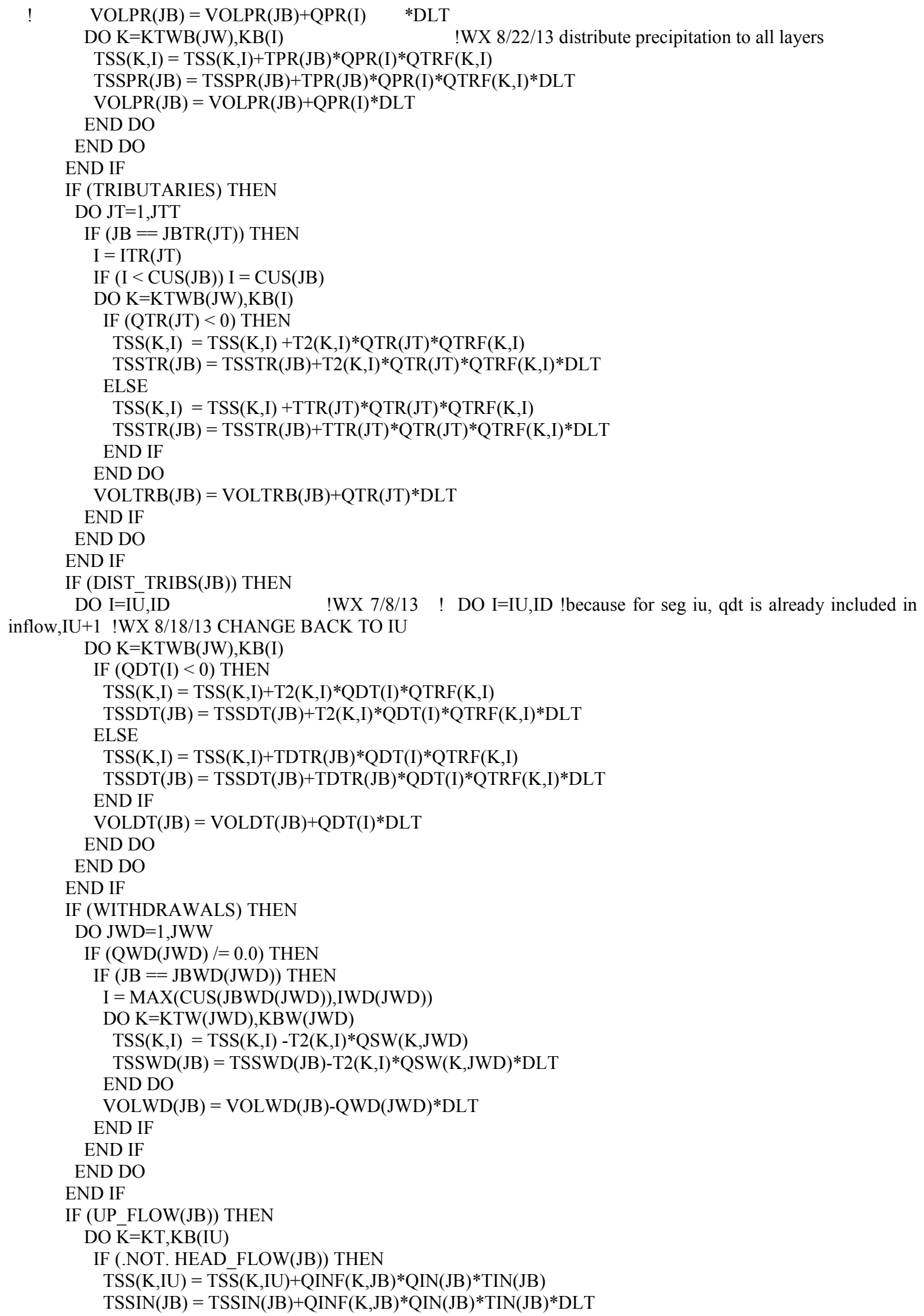




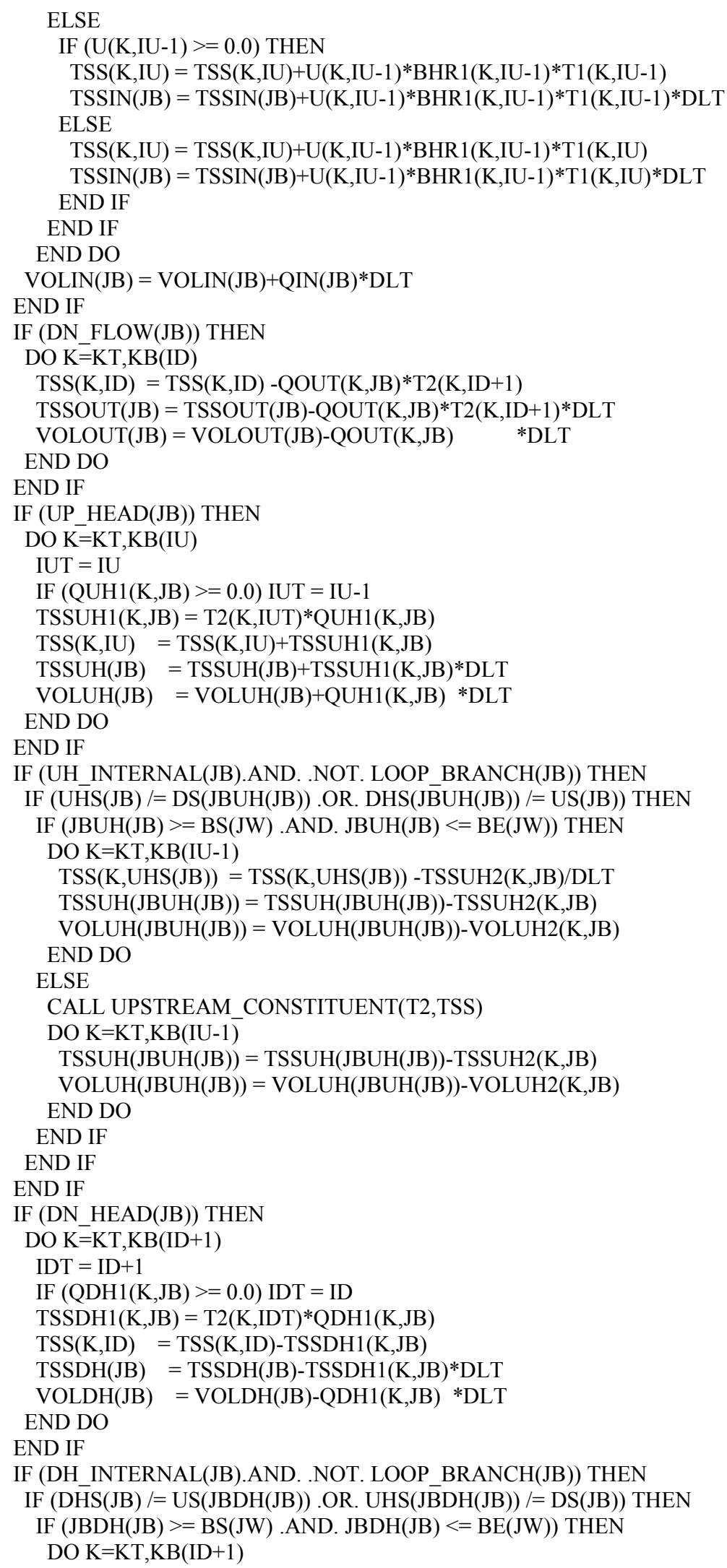




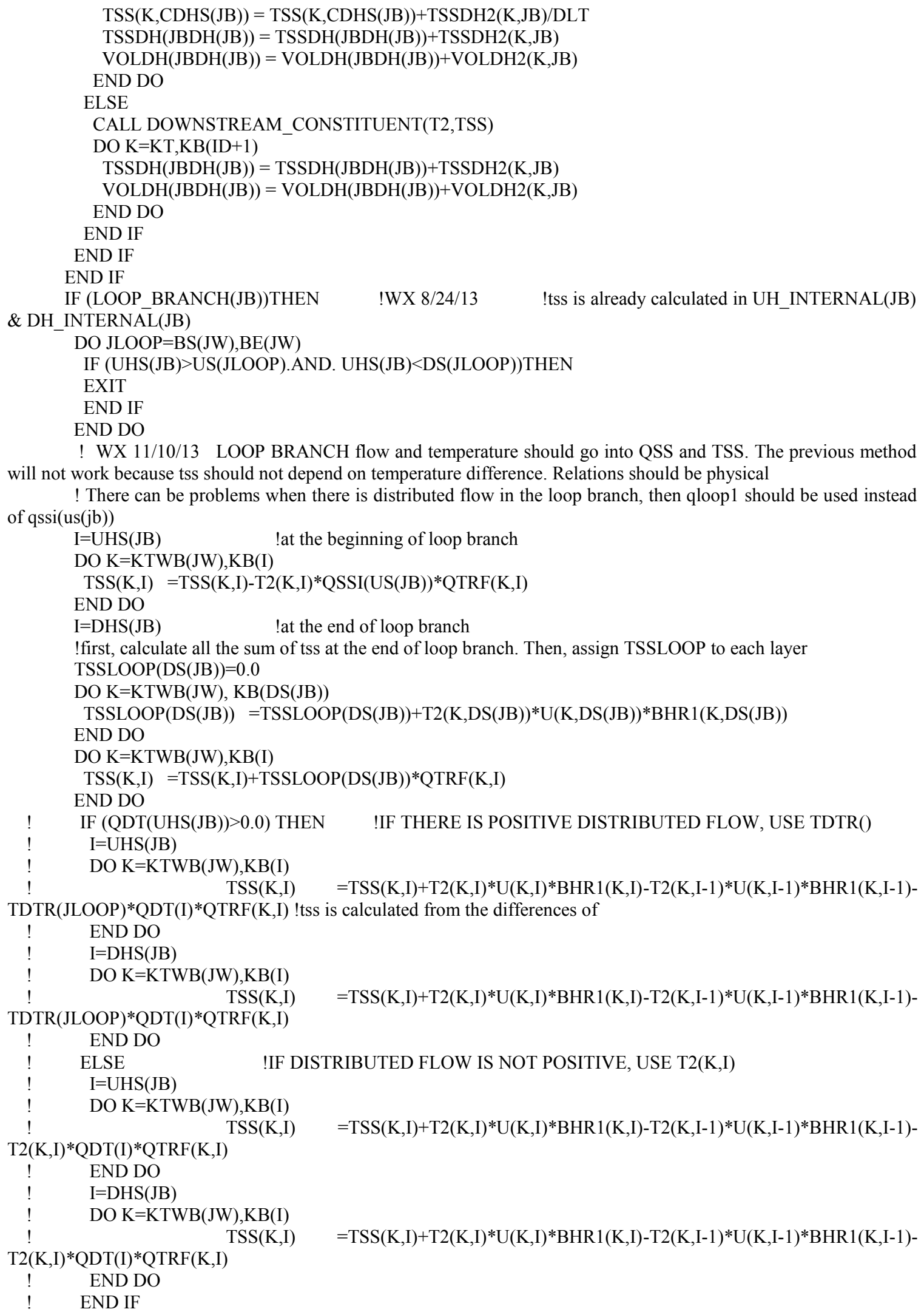




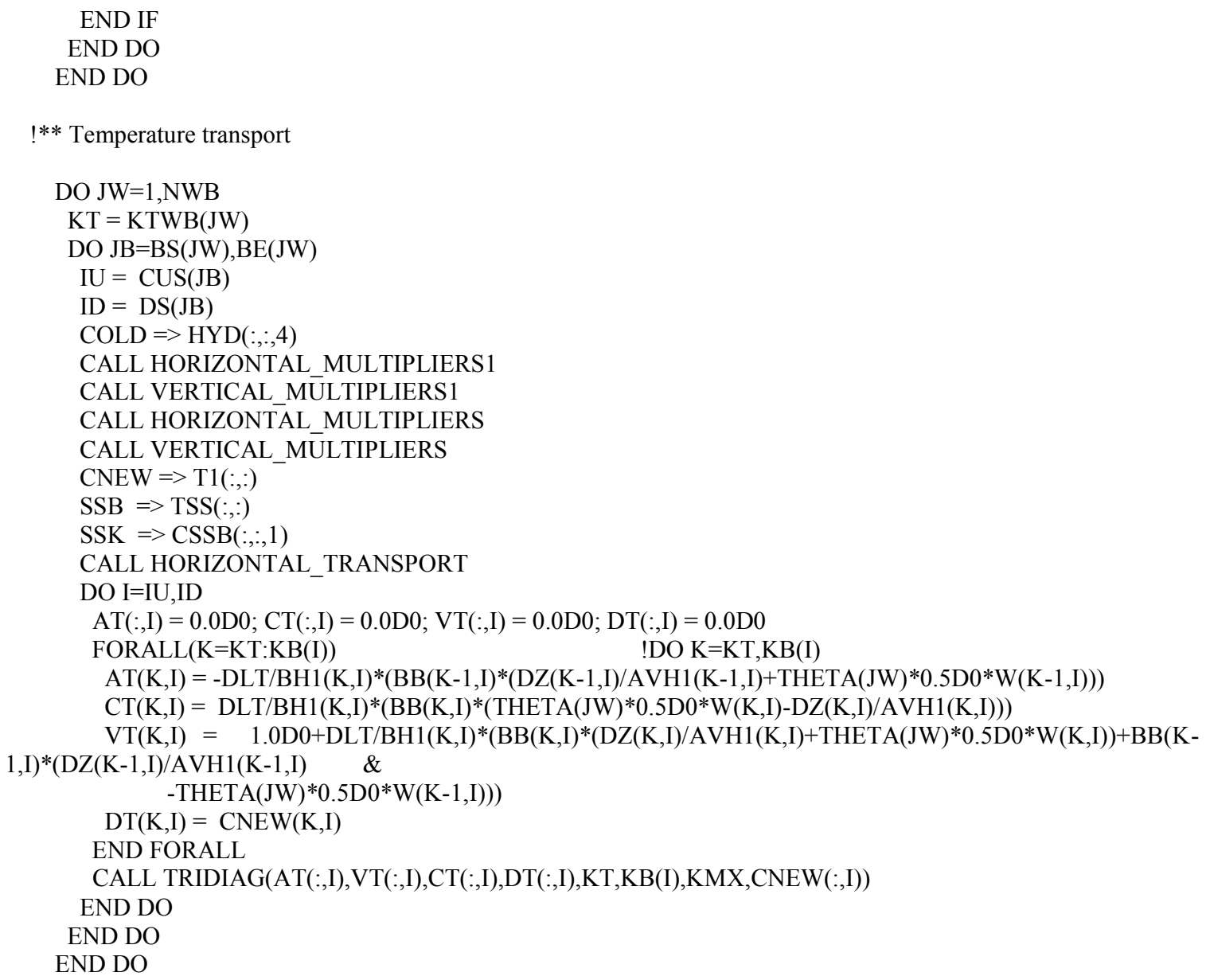

END SUBROUTINE TEMPERATURE 